










\section{EXPLANATION OF PLATE I.}

\section{[Figures 1 to 8 , inclusive, natural size.]}

Gypsy Moth, Porthetria dispar (L.).

Fig. I. Female with the wings spread.

2. Female with the wings folded.

3. Male with the wings spread.

4. Male with the wings folded.

5. Pupa.

6. Caterpillar.

7. Caterpillar. $\}$ Full grown.

8. Cluster of eggs on bark.

9. Several eggs enlarged.

Io. One egg greatly enlarged. 

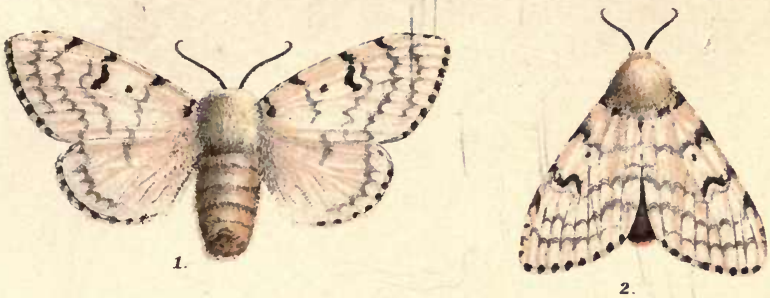

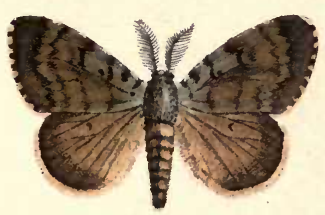

3.

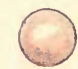

10.

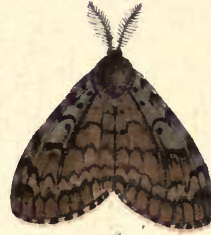

4.

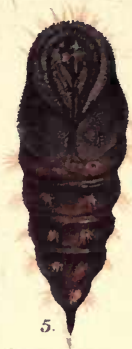

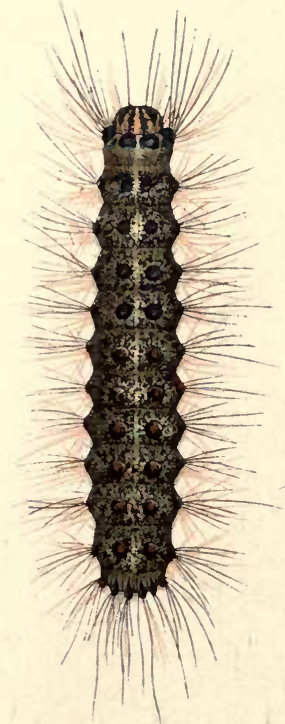

6.

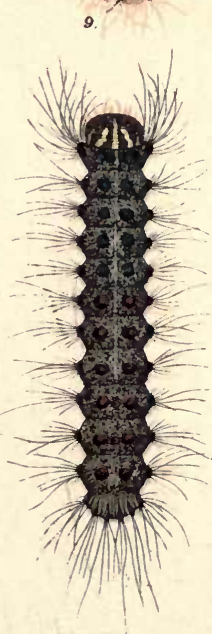

7.
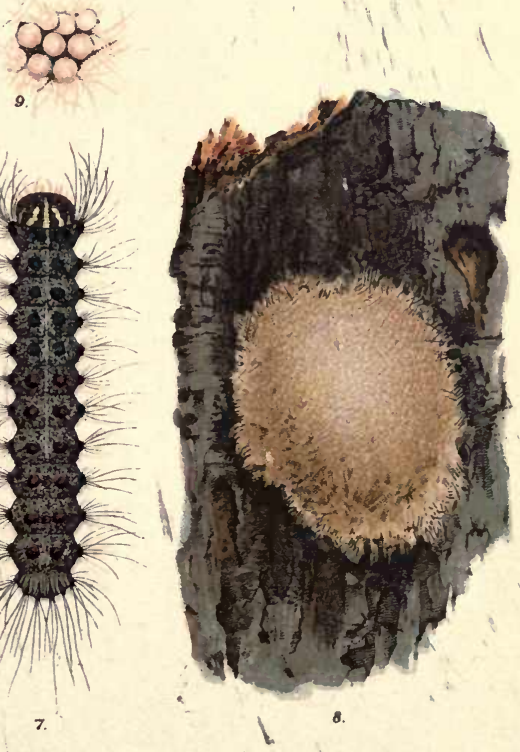

Drawn by Joseph Bridgham.

Geo.HWalker \& Ca,Boston. GYPSX MOTH 



\section{THE GYPSY MOTH.}

Porthetria dispar (Linn.).

\section{A Report of the Work}

OF DESTROY TNG THE INSECT IN THE COMMONWEALTH OF Massachusetts, TOGether with an ACcount

OF ITS HISTORY AND HABITS BOTH IN

Massachusetts and Europe.

BY

Edward H. Forbush,

Field Director in Charge of the Work of pestroying the Gypsy Moth, Ornithologist to the State Board of Agriculture, Former

President of the Worcester Natural

HISTORY SOCIETX, ETC.,

AND

Charles H. Fernatd, A.M., Ph.D.,

Professor of Zoölogy in the Massachusetts agricultural College, Entomologist to the State Boskd of Agriculture, ENTOMOLOGist to the HATCH EXPERI-

MENT STATION, ETC.

Publibhed UNDer the direction of the State BoArd of Agriculture BY AUTHORITY OF THE LEgISLATURE.

BOSTON :

WRIGHT \& POTTER PRINTING CO., STATE PRINTERS, 18 Post Office Square.

1896. 


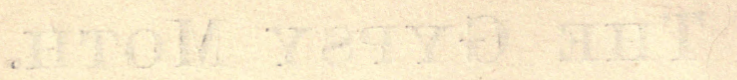




\section{LETTER OF SUBMITTAL.}

Boston, Jan. 1, 1896.

To the Massachusetts State Board of Agriculture.

Gentlemen : - We have the honor to submit herewith the report on the gypsy moth, which has been prepared under our direction, as authorized by chapter 71, Resolves of 1894 .

Respectfully,

E. W. WOOD,

AUGUSTUS PRATT,

F. W. SARGENT,

J. G. AVERY,

S. S. STETSON,

WM. R. SESSIONS,

Committee on the Gypsy Moth. 



\section{CONTENTS.}

Prepace,

The Gypsy Мотн, Porthetria dispar (L.).

Part I., E. H. Forbush.

The gypsy moth : its history in America, • • • • . • . . 3

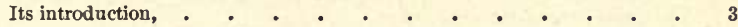

The nnnoticed increase of the moth, , . . . . . . . 4

Influences that at first retarded its increase, . . . . . . 5

The first destructive appearance of the moth, . . . . . . 7

The outbreak of 1889 , . . . . . . . . . . . 10

The swarming caterpillars become a serious nuisance, . . . 14

The destructiveness of the moth, . . . . . . . . . 23

How the people fought the moth, . . . . . . . . . 28

The matter brought to the attention of the public at large, . . . . 32

The commission of 1890 , . . . . . . . . 38

The work of 1891 , . . . . . . . . . . . . 45

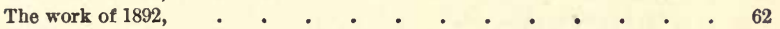

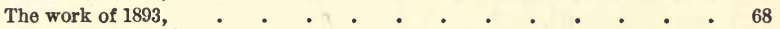

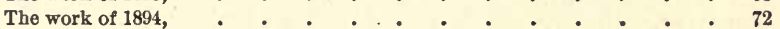

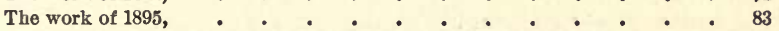

The number of men employed and work done, 1890 to 1894 inclusive, $\quad$. $\quad 89$

The increase and distribution of the gypsy moth, . . . . . . 94

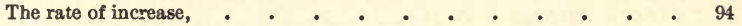

Distribution as affected by food supply and other natural causes, . $\quad 97$

The connection of distribution and population, . . . . . . 99

The distribution of the moth by man's agency, . . . . . . 100

A study of the methods and rontes of transportation,. . . . . 106

The effect of the work of extermination on the distribution of the gypsy moth, - • . . . . . . . . . • . 113

Methods used for destroying the gypsy moth, . . . . . . 117

The destruction of the eggs, . . . . . . . . . . 117

The destruction of the caterpillars, . . . . . . . . 126

Measures for destroying all forms of the moth, . . . . . 164

A summary of the methods most useful to the farmer, . . . . 194

The annual inspection, . • • . . . . . . . 196

Measures for the information of the public, . . . . . . . 198

Natural enemies of the gypsy moth, . . . . . . . . . 203

Insect-eating birds, . . . . . . . . . . . 203

Birds seen to feed upon the gypsy moth, . . . . . . . 207

The progress of extermination, . . . . . . . . . . 244

The Gypsx Mотн, Porthetria dispar (L.).

Part II., C. H. Fernald.

Scientific and common names, . . . . . . . . . . 255

Bibliography, . . . . . . . . . • . • . 257

Distribution in other countries, . . . . . . . . . 267

The gypsy moth in England, . . . . . . . . 268

Injuries in the old world, . . . . . . . . . 273

Methods of destroying the gypsy moth in Europe, . . . . . 284 


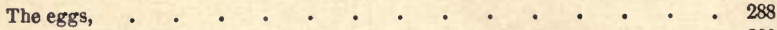

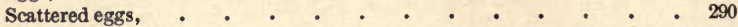

Date of hatching, . . . . . . . . . . . 294

A second brood, . . . . . . . . . . . . 295

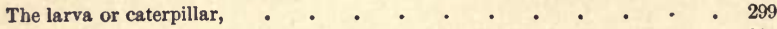

Feeding habits, . . . . . . . . . . . . 311

Process of pupation, ..$\quad$. . . . . . . . 332

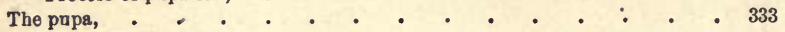

Papation in the field, . $. \quad . \quad . \quad . \quad . \quad . \quad$. $\quad$. 335

The imago, . . . . . . . . . . . . 336

Mating, . . . . . . . . . . . 342

Habits of flight, . . . . . . . . . . . . 344

The assembling of the gypsy moth, . . . . . . . . 345

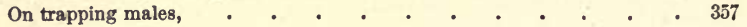

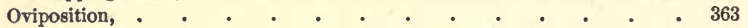

Parthenogenesis, . . . . . . . . . . . . 365

Internal anatomy, . - . . . . . . . . . 368

Natural enemies of the gypsy moth, . . . . . . . . . . 375

Hymenoptera, . . . . . . . . . . . . 375

Coleoptera, . . . . . . . . . . . . . 381

Diptera, . . . . . . . . . . . . . 385

Hemiptera, . . . . . . . . . . . . 392

Spiders, - $. \quad . \quad . \quad . \quad . \quad . \quad . \quad . \quad . \quad 404$

Insectivorons vertebrates, - . . . . . . . . . 404

Vegetable parasites, . . . . • . . . . . . 405

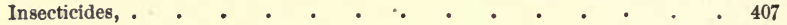

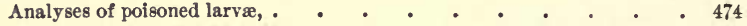

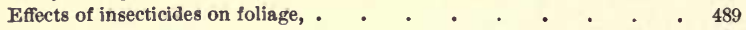

Analyses of insecticides, . $\quad$ - . . . . . . . . . 492

Leaf area of trees, . $\quad . \quad+\quad . \quad+\quad . \quad+\quad . \quad . \quad . \quad 4 \quad 494$

Appendices : -

Appendix A, report of a conference held at the rooms of the State Board of Agriculture, Boston, Mass., March 4, 1891, . . . . . . jii

Appendix B, revised rules and regulations adopted by the State Board of Agriculture, . • . • . • . . . . .

Appendix C, an extract from a description of Section 8, Medford, as it appears in the section book, showing the condition of that section and the work done in it in 1891, .

Appendix $\mathrm{D}$, reports of entomologists who visited the infested region in

Appendix E, reports of entomologists who visited the infested region in 1894; opinion of the United States entomologist, . . . . . . xliii

Appendix F, the dangers of arsenical poisoning resulting from spraying with insecticides, . . . . . . . . . . .

Appendix G, a list of correspondents and observers who have furnished information in regard to the gypsy moth in Massachnsetts, . . . Iviii 


\section{PREF A CE.}

This report is respectfully submitted for the benefit of the people of Massachusetts, especially those residing in the district infested by the gypsy moth, who have suffered from the injuries inflicted by the insect. The design of the report is to present, within the prescribed limits, as full a history as possible of what is known about the gypsy moth in Massachusetts; also to give a brief résumé of its history abroad. We have endeavored to present most fully those features of the subject which are most important from a practical and economic standpoint. That clause in chapter 71 of the Resolves of 1894 which authorizes the preparation for printing "of the scientific facts ascertained" has been kept in view, and much matter of a more or less scientific or technical nature, which has come under our notice in connection with the field work or while making the investigations and experiments with which we have been charged, has been recorded in this volume. The investigations of the life history and habits of many of those forms of animal life which exert controlling influences upon the gypsy moth have not yet proceeded far enough to allow the results to be fully chronicled. A summary of the results of some of the most important experiments is given, and, where observations have been made by a sufficient number of individuals to warrant the drawing of conclusions, such conclusions have been recorded. A further study of the parasites and enemies of the gypsy moth is in progress.

Part I. of this volume records such of the most impor- 
tant results attained by the State Board of Agriculture in the work of exterminating the gypsy moth as could be included within the limits of the space allowed to the report. Part II., besides giving the bibliography of the moth and instances of its injuries in Europe, deals especially with the "scientific facts ascertained," and chronicles many of the more important experiments made with a view of finding means to check the ravages of the insect and secure its extermination.

The authors are well aware of many shortcomings in the work. They have labored under the disadvantage of residing in different parts of the State, and therefore have not had opportunity to consult together and compare notes as often as was desirable. All responsibility for error in either part will be assumed individually by the author to whom that part is accredited. Other duties which were imperative in their demands upon our capacity for labor have at times prevented that painstaking revision which such work requires. Much valuable information has necessarily been excluded for lack of space. It was impossible, for instance, to quote fully from accounts of injuries committed by the moth in Europe. For the same reason, one hundred and forty-six statements in regard to the ravages of the moth, from residents of the infested district in Massachusetts, have been omitted. Extracts from some of them are given, however, in Part I. Most of that portion of Part I. which is devoted to spraying was prepared in 1894, and cannot be considered as up to date, as spraying has not been one of the chief methods employed in the field work of the last two years.

The Appendices relate largely to the views expressed by certain eminent entomologists in regard to the work of extermination. Appendix F, on the dangers attendant on 
arsenical poisoning by spraying, was written by Mr. Forbush.

The drawings for the insect plates were made by Mr. Joseph Bridgham, Miss Ella M. Palmer and Mr. J. H. Emerton. The drawings of appliances and tools were made by Mr. C. A. King. Messrs. A. H. Kirkland, R. A. Cooley and C. P. Lounsbury made the drawings for the anatomical plates. Most of the other drawings were made by $\mathrm{Mr}$. Kirkland.

We are under obligations to the Boston Woven Hose and Rubber Company, W. \& B. Douglass, Gould Manufacturing Company, A. H. Nixon and John J. MeGowen for cuts of spraying apparatus; also to Estes \& Lauriat for three cuts from “ Coues' Key to North American Birds," Little, Brown \& Company for three euts from Baird, Brewer and Ridgway's "North American Birds," and J. B. Lippincott for two cuts from " Birds About Us," by Dr. C. C. Abbott.

It only remains to perform the pleasant duty of acknowledging the many favors which have been bestowed upon us by those who have assisted in the preparation of this work. Acknowledgments are due to the scores of foreign correspondents, both eminent naturalists and government officials, who have furnished information, and also to residents of the infested district, who have given useful information, and whose names appear in Appendix G. In our bibliographical researches we have been most courteously and ably assisted by the officials of the Boston Public Library and those of the libraries of Harvard University, Museum of Comparative Zoölogy, Arnold Arboretum, Boston Society of Natural History, Boston Athenæum, Massachusetts Horticultural Society and Massachusetts Agricultural College. To Mr. Samuel Henshaw we are especially indebted for assistance in obtaining many references concerning the 
history of the gypsy moth in Europe; and to Dr. F. B. Stephenson, U. S. N., for the translation of Russian works. We are greatly indebted to Messrs. J. A. Farley and A. $H$. Kirkland for very valuable services in connection with the preparation of the report. Mr. Farley, who has made an exhaustive study of the distribution of the gypsy moth, has contributed the material for that portion of the paper on distribution which treats of the "methods and routes of transportation." While certain portions of Part II. are credited in the text to Mr. Kirkland, he has been of great assistance to the authors in many other ways. Messrs. F. H. Jones, F. A. Bates and C. W. Minott have rendered much aid in the way of criticism and suggestion. Lack of space forbids the mention by name of the scores and even hundreds of other intelligent observers, more or less permanently connected with the work, who have furnished useful notes.

The main credit for the production of this volume is due to the committee of the State Board of Agriculture, who have for five years conducted the work with the steadfast purpose of ridding the Commonwealth of the gypsy moth. They have recommended that the Legislature authorize the preparation and printing of the report. They have conferred upon us the honor of preparing the volume, and our thanks are due to them for endorsement of our plans and for their constant and consistent support.

THE AUTHORS. 


\section{THE GYPSY MOTH.}

Porthetria dispar (L.).

$$
\text { PART I. }
$$

ㅍ. 포. FOR円US포. 




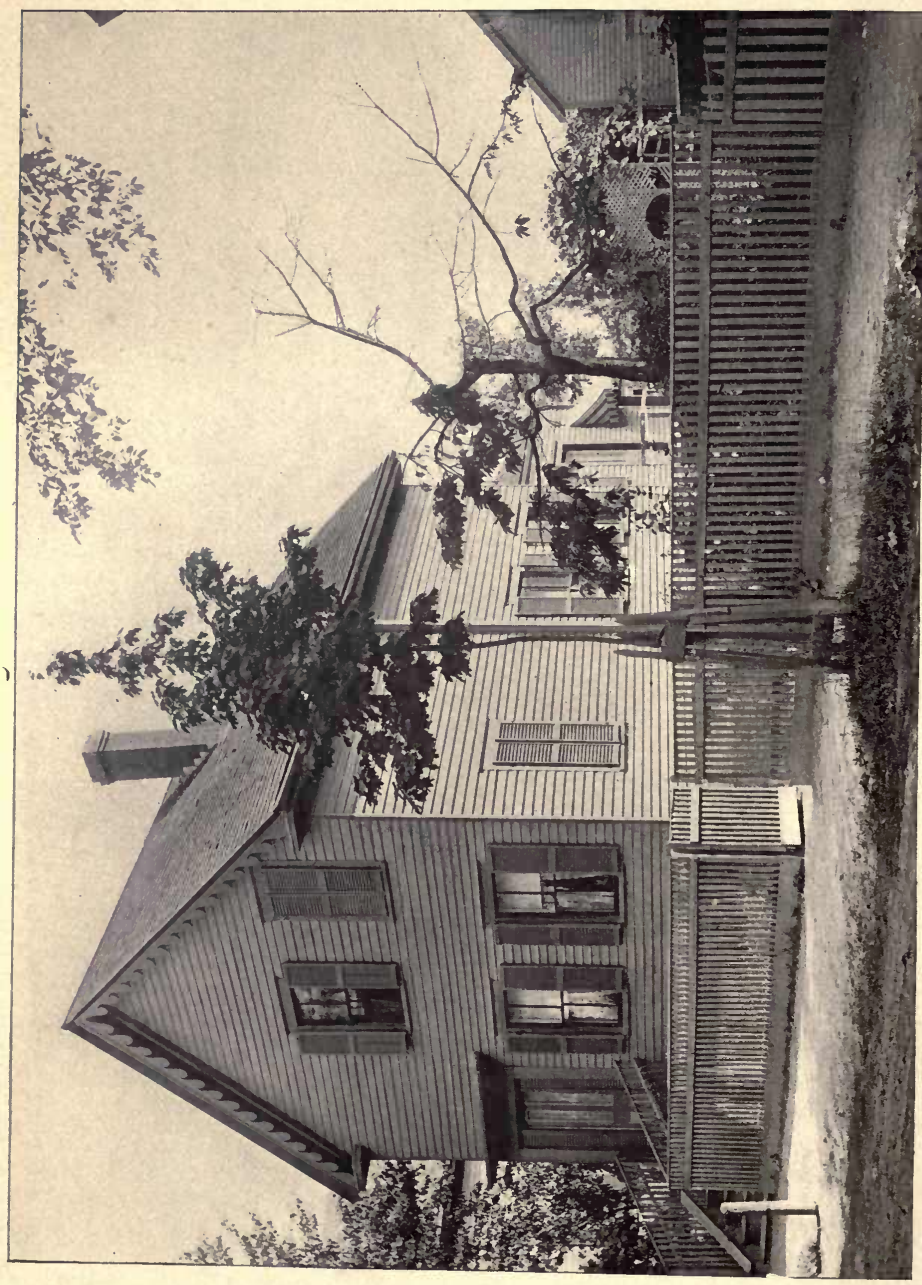

용

on

I

เุ

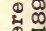

व

G

ठั้

ఫ

년 둥

7

잉

30

वै द्व

ชี क

เै

$\Phi 0$

党敌

요

70

मे

运

- 4

N 0

$\circ:$

द

iᄋ

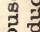

ㅇ․

$+$

명

D

芩

है क

(

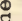

है

$\exists$

田

E

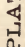




\section{THE GYPSY MOTH.}

ITS HISTORY IN AMERICA.

\section{ITs Introduction.}

The gypsy moth(Porthetria dispar)a pest of European countries, was introduced into America in 1868 or 1869 by Leopold Trouvelot, a French artist, naturalist and astronomer of note. Prof. C. V. Riley, then State entomologist of Missouri, recorded the occurrence in 1870 in these words : "Only a year ago the larva of a certain owlet moth ( $H y$ pogymna dispar) which is a great pest in Europe both to fruit trees and forest trees, was accidentally introduced by a Massachusetts entomologist into New England, where it is spreading with great rapidity." *

Though Professor Riley did not then mention Trouvelot or Medford, the facts were evidently well known to him, as twenty years later he wrote in "Insect Life" as follows: "This conspicuous insect, although not recorded in any of our check lists of North American Lepidoptera, has undoubtedly been present in a restricted locality in Massachusetts for about twenty years. It was imported by Mr. L. Trouvelot in the course of his experiments with silk-worms, recorded in the early volumes of the 'American Naturalist,' and certain of the moths escaping, he announced the fact publicly, and we mentioned it in the second volume of the 'American Entomologist,' page 111 (1870), and in our 'Second Report on the Insects of Missouri,' page 10." †

In a Bulletin of the Hatch Experiment Station, published in November,' 1889, Prof. C. H. Fernald wrote: "Mr. Samuel Henshaw and Dr. Hagen(of Cambridge have both informed me that the entomologist who introduced this 
insect was Mr. L. Trouvelot, now living in Paris, but at that time living near Glenwood, Medford, where he attempted some experiments in raising silk from our native silk-worms, and also introduced European species for the same purpose. Dr. Hagen told me that he distinctly remembered hearing Mr. Trouvelot tell how they escaped from him after he had imported them."

Prof. N. S. Shaler of Harvard University, who knew Mr. Trouvelot, has also stated to the writer that he remembers hearing Mr. Trouvelot speak of the importation and escape. Thus we have evidence from eminent scientific authorities that settles beyond doubt the approximate time and the place of introduction of this insect, and who was responsible for it. During his sojourn in Medford Mr. Trouvelot lived in a house (now known as No. 27 Myrtle Street) near Glenwood station on the Medford branch of the Boston \& Maine Railroad. It is said by people who lived in the vicinity in 1869 that he imported some insects' eggs about that time, some of which were blown out of a window of the room in which they were kept, and that he was much disturbed on being unable to find them. Others state that the insects escaped in the larval form. Probably the insect was imported in the egg. Its escape seems to have been accidental, and Trouvelot, being aware of the dangerous character of the pest, and finding his efforts for its eradication futile, gave public notice of the fact that the moth had escaped from his custody.

\section{The Unnoticed Increase of the Moth.}

The historian is considerably embarrassed by lack of evidence in regard to the increase and spread of the moth during the first ten years. No one except Trouvelot is known to have observed it during any portion of that time. For most of the evidence of its spread and ravages during the decade from 1879 to 1889 we must depend on the testimony of residents of Medford and Malden. Much information bearing on the subject has been obtained during the past three years, letters and carefully revised statements having been received from a large number of people in these cities.

For several years after the moth escaped, it attracted no attention in Medford. People who witnessed in 1889 the 
first extensive outbreak of the moth in Medford, and thus became acquainted with its voracity and reproductive powers, were unable to understand how so destructive a creature could have existed unnoticed for twenty years. But the moth was not unnoticed after the first ten years, although its identity remained unknown and its spreading attracted no attention outside the locality where it was first introduced. Within twelve years from the time of its introduction it had become a serious nuisance to those living in and near the Trouvelot house; but they then supposed the caterpillar to be a native. Its lack of conspicuous markings, which to the common eye would distinguish it from other species, and its habits of concealment and nightfeeding will explain its unheeded distribution. Within twenty years it had spread into thirty townships and gained a foothold in each without attracting public attention. Of these facts we have the most convincing proofs.

\section{INFLUENCES THAT AT FIRST RETARDED ITS INCREASE.}

A study of the growth of many isolated moth colonics which have been found existing under conditions similar to those influencing the Trouvelot colony, gives abundant proof that the growth of such swarms for the first few years is exceedingly slow.

The experiments made have not yet shown conclusively how much the enforced and continuous inbreeding which results from isolation affects the vitality of the species. Field observations show that in some cases isolated colonies have come very near extinction in the first years of their existence, while others have died out. During the eight or ten years following its introduction, the moth, while becoming acclimated, battled against the many influences which served at first to hold it in check. A consideration of the operation of these influences will go far toward explaining its apparently slow increase during the first few years. It must be considered that the nevi-comer had much to contend against. It had to encounter :-

1. A new and changeable climate. How potent were climatic influences in controlling the increase of the species? Such influences may have been felt for years. If the moth 
was introduced from France, our harsher climate may have destroyed many of the smaller caterpillars before they had attained strength enough to resist exposure to its sudden changes. A warm period early in the season, followed by a cold storm or severe frost, sometimes destroys many of the young caterpillars. They are first hatched by the unseasonable warmth, and then killed by the cold immediately following.

2. Isolation, with all its attendant perils. The isolation of the species and its small numbers rendered it peculiarly sensitive to the attacks of new enemies which surrounded it. Parasitic and predaceous insects were no doubt plentiful then, as they are to-day. The topography of the locality and the vegetation of the neighborhood were such as to render it specially attractive as a breeding ground for insecteating birds. Myrtle Street was then flanked by gardens and orchards, and nearly surrounded by woodland and bushy pasture. Not far to the east is a small swamp and stream, and the whole locality lies near the marshy banks of the Mystic River. Many of the birds which frequent such places feed on the gypsy moth in one or more of its forms wherever it is found. It is related in Samuels's "Birds of New England," published in 1870, that Mr. Trouvelot, who was then engaged in rearing silk-worms, placed two thousand of them on a small oak in front of his house, and that in a few days they were all eaten by robins and catbirds. He had a large area of woodland fenced in and covered with netting to protect his silk-worms. The birds came from all quarters to feed on the worms, breaking through the netting, so that he was obliged to shoot them in defence of his " infant industry." Mr. Trouvelot, in describing his work on the American silk-worm (Telea polyphemus), says that it is probable that ninety-five out of a hundred worms become the prey of birds. $\dagger$

At that time the cuckoos, blue-jays, orioles, vireos, catbirds, bluebirds and warblers which are known to feed upon the caterpillars were also abundant in that locality during the season when the caterpillars were feeding. The inroads

- Birds of New England, page 156. + American Naturalist, Vol. I., page 89. 
made at first by birds alone on the comparatively small number of caterpillars would have been sufficient to hold them in check. Fly-catchers secure many of the moths also; other birds destroy the pupæ. The restraining influence exerted by birds and predaceous insects would be greater in proportion when the moths were comparatively few.

3. Forest or brush fires. The locality in which the moth was first liberated was favorable for its unnoticed increase and spread, as there were many forest trees and a dense undergrowth in the vicinity, which afforded it a liberal food supply. Undoubtedly it was somewhat checked in this waste land during the first few years by fires, which frequently occurred in the woodland near the Trouvelot house. Such fires destroy some eggs of the moth which are deposited near the ground, and are also very destructive in the spring to the young larvæ. Mr. John Crowley, formerly one of the selectmen of Medford, speaks of these fires as follows:-

Glenwood, twenty-one years ago, was a thinly settled district and consisted largely of brush land. There were brush fires there every year. 'The fire department was called out twice in one year because dwellings were in danger. I think the frequent brush fires held the moth in check for many years, and will explain why they were so slow in making their appearance in the orchard and shade trees of other sections.

\section{The First Destructive Appearance of the Moth.}

After the first ten or twelve years following their introduction the moths increased so rapidly that the larvæ did considerable damage in the immediate vicinity of $\mathrm{Mr}$. Trouvelot's house, according to testimony of people in the neighborhood. During the first few years of their abundance the insects spread along Myrtle Street and into the woodland and swamp at the south, across the railroad, but did not for some years become numerous or destructive north of the street.

That the moth did not increase faster and spread more rapidly to other parts of Medford is largely due to the efforts of certain residents of Myrtle Street, who for ten or twelve years persistently fought the pest on their own property. 
That their efforts were finally without avail is true, but it might have been otherwise had the moths not remained unmolested in the woodland near by, from which, whenever food became insufficient, they sallied out and overwhelmed the near gardens and orchards.

Mr. William Taylor, No. 19 Myrtle Street, speaking of the years from 1879 to 1889 , said : -

In the fall of 1879 I moved to 27 Myrtle Street, where Mr. Trouvelot, who brought the gypsy moth to this country, formerly lived. In the following spring I found the shed in the rear of his house swarming with caterpillars. I knew that Mr. Trouvelot had been experimenting with silk-worms, but I did not know that the swarms of caterpillars in the shed came from the gypsy moth. The caterpillars were such a nuisance in and around the shed that I got permission to sell it, and it was taken to Mr. Harmon's on Spring Street. This will explain how the moth was carried into that section, and why the woods there became so badly infested. I fought the caterpillars of the gypsy moth for ten years before the State did anything. In their season I used to gather them literally by the quart before going to work in the morning.

Mr. and Mrs. William Belcher, well-known residents cf - Glenwood, still residing at No. 29 Myrtle Street, have had the best of opportunities to observe the increase of the insect in that vicinity. Mrs. Belcher writes as follows :-

Mr. Trouvelot, who is said to have introduced the gypsy moth into this country, was a next-door neighbor of ours. The caterpillars troubled us for six or eight years before they attained to their greatest destructireness. This was in 1889. They were all over the outside of the house, as well as the trees. All the foliage was eaten off our trees, the apples being attacked first and the pears next.

Mrs. J. W. Flinn of Malden, who lived in Glenwood near Mr. Trouvelot's house during a part of this decade, says :-

We moved to Myrtle Street, Medford, in 1882, and that year the gypsy-moth caterpillars were very troublesome in our yard and in those of our immediate neighbors. At that time they were confined to our part of Myrtle Street, but they soon spread in all directions. The caterpillars were over everything in our yard and 


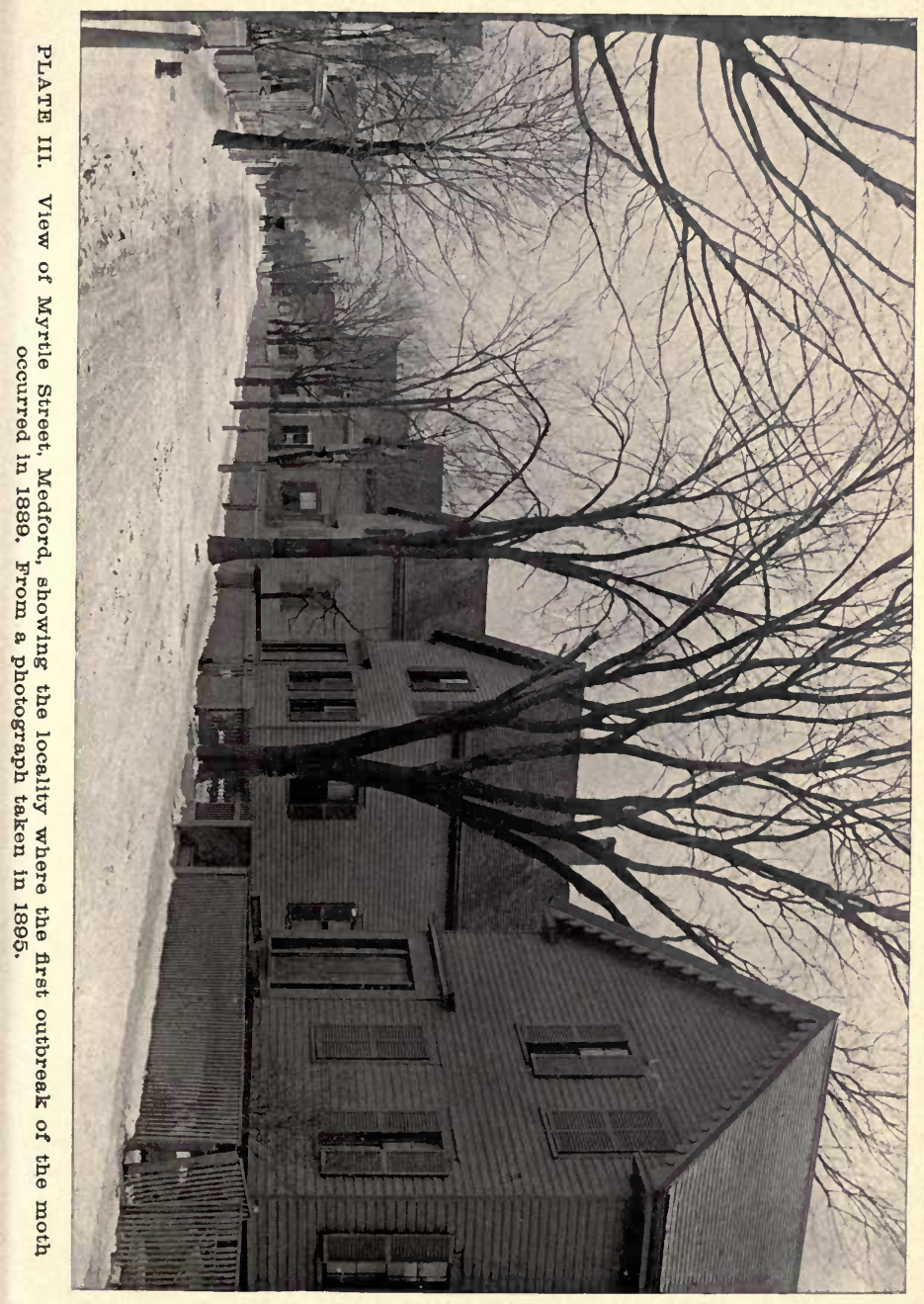



stripped all our fruit trees, taking the apple trees first and then the pears. There was a beautiful maple on the street in front of the next house, and all its leaves were eaten by the caterpillars. They got from the ground upon the house and blackened the front of it. . . The caterpillars would get into the house in spite of every precaution, and we would even find them upon the clothing hanging in the closets. We destroyed a great many caterpillars by burning, but their numbers did not seem to be lessened in the least. Other neighbors did not fight the caterpillars as we did, and so our efforts were in a measure rendered abortive. I think perhaps that if an organized effort had been made at that time to destroy the caterpillars they might have been stamped out. We lived on Myrtle Street for four years, and every year had the same plague.

It should be noted that the Flinn family moved from Myrtle Street in 1886, having suffered from the pest from 1882 until that time, which was three years before it became generally prevalent. Although the moths were so numerous near the Trouvelot house from 1880 to 1885 , they did not become a serious pest farther down the street until about 1886. We quote Mrs. M. F. Fenton:-

In 1886 we lived at No. 10 Myrtle Street, and that summer we could not take any enjoyment out of doors. The caterpillars were very thick. We destroyed very many of them, but it seemed impossible to diminish their numbers. They seemed to be multiplying steadily. A mere shake of a tree would bring them down on one in showers. They strip trees very quickly.

Mr. D. W. Daly, No. 5 Myrtle Street, makes the following statement :-

I moved here in 1884 , and the next year got quite a crop of apples. I have three apple trees and a crab apple. In 1886 the gypsy-moth caterpillars appeared for the first time in any considerable numbers in my yard. Nobody knew what they were. There were more of them farther down the street. In 1887 they came in droves, and before June 17 they had my trees stripped as clean as in December. After stripping the apple trees, they stripped a Sheldon pear tree as clean as the others. From 1887 to 1890 , inclusive, I got no fruit. The caterpillars worked some little havoc on the lilacs. I was more fortunate than some others, whose trees were killed. I spent much time in killing eaterpillars. I used to 
sweep them off the side of the house and get dustpanfuls of them. At night time we could hear the caterpillars eating in the trees and their excrement dropping to the ground. In the morning the walk would be covered with the latter. I inked my trees in 1888 and kept them out of the trees to some extent, but not wholly, for some of them blew into the trees, and they also got into them from the house. In $1887 \mathrm{I}$ used to sweep them off in solid masses from the tree trunks. They used to get on the washing and stain it. Two of my apple trees since that time have never been the same as regards fruit-bearing qualities. I do not think I saw six caterpillars all last summer.

\section{The Outbreak of 1889.}

During the years from 1869 to 1889 , while the original colony. of the moths was increasing and extending its territory at Glenwood, stragglers therefrom were constantly scattering abroad to form new colonies. Later these joined with the parent swarm in forming the multitude which spread over the town. No particular attention was paid, during these years, to the moths which appeared here and there, for it must be borne in mind that the identity of the insect had been lost, and it was not generally known that there was a new insect in the land. The introduction of dispar by Trouvelot was forgotten or unknown, and wherever shade or fruit trees were defoliated, the damage was placed to the account of such old and well-known pests as the canker-worm or the tent caterpillar.

Gen. S. C. Lawrence, the first mayor of Meaford, who lives on Rural Avenue, a mile and a half to the west of Myrtle Street, testifying in 1893 at the hearing before the legislative committee on Finance, said : -

I helped fight it [the moth] for years before the appointment of the commission, not knowing really what it was.

Mr. John Stetson, living a mile to the west of Myrtle Street, who in 1889 sent specimens of the insect to the Hatch Experiment Station at Amherst for identification, said : -

I discovered them in 1888 on a quince bush. I noticed one day that the leaves were all off from this bush. I examined it, and found there were worms there clustered on the limbs. 


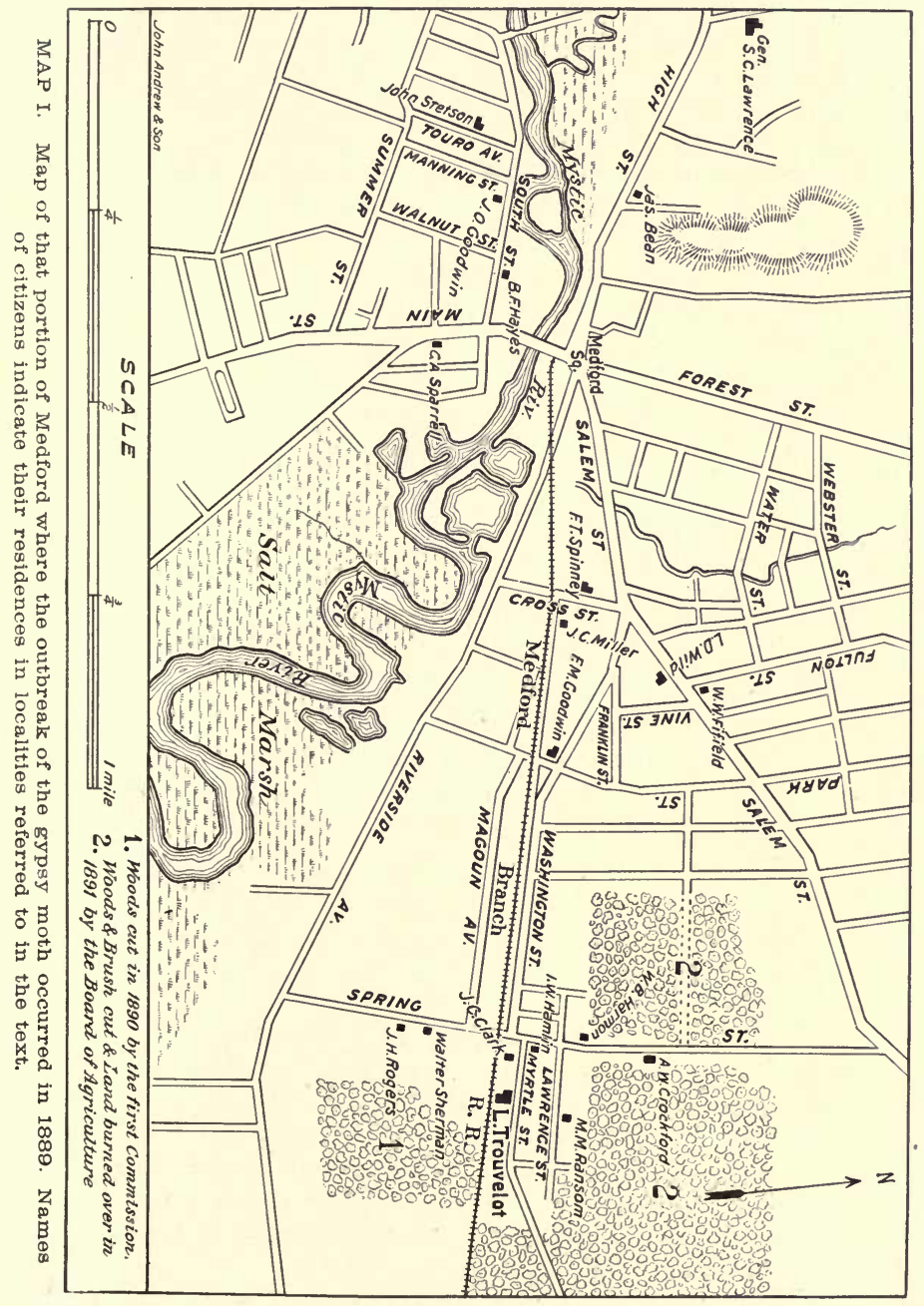



At last a season arrived, that of 1889 , when the moths became so abundant in Glenwood and in some other parts of Medford, and the consequent destruction of foliage so complete, that the food supply gave out. Armies of " worms" suddenly appeared in localities where they had never before been noticed, and seemed about to destroy every green thing. The growing caterpillars which had devoured the foliage in the wooded land around Glenwood, being checked on the south by the salt marsh, moved east, west and north. They reinforced those in the yards and orchards along Myrtle Street, where most of the foliage had already been destroyed. The supply of food there being at once exhausted, the caterpillars marched from yard to yard and from tree to tree, their numbers constantly augmented by those they met, which in quick succession were also forced by lack of food to join the hurrying host. Their enforced movements from tree to tree, from yard to yard, and from one street to another, in search of food, in the summer of 1889 , are well described by the inhabitants. It will be seen that there was no general migration in any one direction. The movements were local, and were directed mostly from those points where the foliage had been entirely destroyed toward others where some still remained. Such migrations had before been noticed in Glenwood whenever the foliage had been nearly all devoured. Said Mrs. Belcher :-

My sister cried out one day, "They [the caterpillars] are marching up the street." I went to the front door, and sure enough, the street was black with them, coming across from my neighbor's, Mrs. Clifford's, and heading straight for our yard. They had stripped her trees, but our trees at that time were only partially eaten.

Mrs. R. Tuttle, 22 Myrtle Street, writes :-

As fast as we gathered them, others would take their places. They seemed to come just like a flock of sheep.

Mrs. I. W. Hamlin, corner Myrtle and Spring streets, said :-

Our yard was overrun with caterpillars. ... When they got their growth these caterpillars were bigger than your little finger, 
and would crawl very fast. It seemed as if they could go from here to Park Street in half an hour.

Park Street, by reason of its nearness to Glenwood, soon became infested by the moth. Mr. F. M. Goodwin, living at the corner of Park and Washington streets, testifies interestingly to this :-

Some years ago I saw the eggs of the gypsy moth plastered thickly on the bark of a willow tree on Spring Street. A great many millers were laying their eggs there. The moths later worked towards Park Street, and my neighbor's apple trees across the street were stripped clean, leaving the young apples hanging on the bare limbs. They crossed from this yard to mine, and I killed pecks of them. . . The caterpillars came into my yard by night. I killed what I could during the day, and the next morning I would find them as thick as ever.

While the moths were thus travelling to the west from Glenwood towards Medford Square, others were moving in all directions from places where they had become established in former years. They appeared in great numbers on Cross Street, at the residence of Mr. F. T. Spinney, Medford's postmaster, and crossed to the east side of the street. Their movements there are recorded in the words of people whose trees and gardens suffered. Said Mrs. Spinney :-

I lived on Cross Street in 1889. In June of that year I was out of town for three days. When I went away the trees in our yard were in splendid condition, and there was not a sign of insect devastation upon them. When I returned there was scarcely a leaf upon the trees. The gypsy-moth caterpillars were over everything.

Three other residents of this neighborhood speak as follows : -

In 1889 the caterpillars of the gypsy moth appeared at Spinney's place on Cross Street, and after stripping the trees there started across the street. It was about five o'clock one evening that they started across in a great flock, and they left a plain path across the road. They struck into the first apple tree in our yard, and the next morning I took four quarts of caterpillars off of one limb. (D. M. Richardson, then living at $8 \frac{1}{2}$ Cross Street.) 



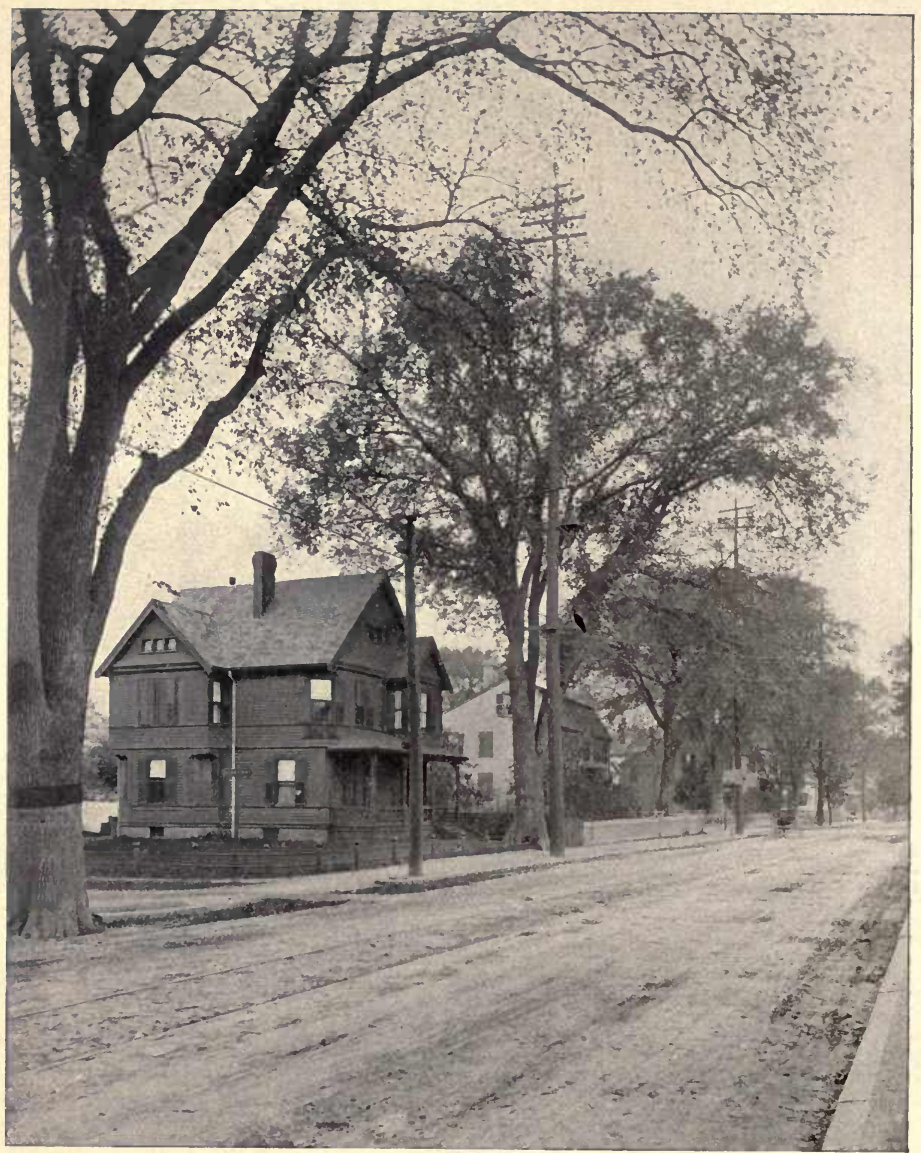

PLATE IV. View of Salem Street, near corner of Fulton Street, Medford, showing elm trees which were defollated in 1889 by the gypsy moth. From a photograph taken in October, 1895. 
The caterpillars would travel on the fences in droves, and we could not go out of doors without getting them all over us. . . . When the caterpillars had cleaned out Mrs. Spinney's trees, they started across the street in droves for the orchards on the other side, and the next morning you could see the path which they had made across the street. (Mrs. W. H. Snowdon, 7 Cross Street.)

At this time (summer of 1889) they were crossing from Mr. Spinney's by multitudes into yards on the other side of the street. It seemed but a few hours after they left Mr. Spinney's before they were all through my trees. They came literally in droves, and seemed to have a method in their movements. (J. C. Miller, 3 Lauriat Place.)

Another outbreak occurred on Vine Street, one-half mile from the Trouvelot house. This colony extended north across Salem Street to Fulton Street. Miss Helen T. Wild, 63 Salem Street, writes :-

In 1889 the apple-trees in our neighborhood were attacked and stripped by the gypsy-moth caterpillars. They fed on the apple trees until there was nothing more to eat, and then started for the elms on the street. In the morning following the night when they finished the apple trees they were to be seen crossing the fence in swarms in the direction of the large street elms. They were crawling fast, and were plainly heading for the elms.

Mrs. George Fifield of Fulton Street, Medford, first noticed the caterpillars at the corner of Fulton and Salem streets. They were then travelling in lines along the sidewalk. Several of these lines converged upon a large elm at the corner of the street, and a constant stream of larvæ was ascending the trunk. A day or two later all the trees in the neighborhood were stripped, and in going toward Glenwood she found the same condition everywhere.

Mr. J. O. Goodwin, writing in the Medford "Mercury" in 1890 , describes the movements of the caterpillars in his neighborhood on South Street :-

After devastating my neighbor's trees, they marched in myriads for my premises, fairly covering the fences, houses, out-buildings, grass land, currant bushes and concrete driveways with their trooping battalions.... The number of worms cultivated on the three 
or four worthless trees on the premises adjacent to my own is astonishing; numbers fail to convey an adequate idea. The earth seemed to be corered with them.

In June, 1889, there were similar local outbreaks over a tract extending as far as West Medford, two miles to the westward, and to Edgeworth in Malden, a mile to the east.

\section{The Swarmixg Caterpillars become a Serious Nuisance.}

The number of caterpillars that swarmed over certain sections of the town during the latter part of June and most of July, 1889, is almost beyond belief. Prominent citizens have testified that the "worms" were so numerous that one could slide on the crushed bodies on the sidewalks; and that they crowded each other off the trees and gathered in masses on the ground, fences and houses, entering windows, destroying flowering plants in the houses, and even appearing in the chambers at night. The huge, hairy, full-grown caterpillars were constantly dropping upon people on the sidewalks beneath the trees, while the smaller larvæ, hanging by invisible threads, were swept into the eyes and upon the faces and necks of passers. The myriads that were crushed under foot on the sidewalks of the village gave the streets a filthy and unclean appearance. Ladies passing along certain streets could hardly avoid having their clothing soiled, and were obliged to shake the caterpillars from their skirts. Clothes hanging upon the line were stained by the larvæ which dropped or blew upon them from trees or buildings. In the warm, still summer nights a sickening odor arose from the masses of caterpillars and pupæ in the woods and orchards, and a constant shower of excrement fell from the trees. The presence of this horde of gypsy-moth larvæ had become a serious nuisance, and was fast assuming the aspect of a plague. The condition of affairs at this time is best shown by the following extracts from statements of residents :-

The caterpillars were worst in 1887,1888 and 1889 . In the summer of those years a good portion of my time was occupied in fighting the pest. The two large elms in front of our house were full of caterpillars, and had not a perfect leaf. In the night-time the noise of the worms eating in the trecs sounded like two sticks 
grating against each other. In the months of July and August I have gone out in the morning and raked up from under the elms a pile of leaves three or four feet high. These leaves had been cut off by the caterpillars, and usually there was a worm on the under-side of every leaf. I would pour kerosene over the mass and set it on fire, and the squirming of the caterpillars would cause it to rise up as if it had life of its own. The caterpillars used to cover the basement and clapboards of the house as high as the window sill. They lay in a solid black mass. I would scrape them off into an old dish-pan holding about ten quarts. When it was two-thirds full $I$ poured kerosene over the mass of worms and set them on fire. I used to do this a number of times a day. It was sickening work. I have used in burning caterpillars five gallons of kerosene in three days. I have seen my fence black with the small caterpillars when they first hatched out in the spring. I used to kill them on the fence by pouring scalding water on them. The caterpillars used to be very thick in the grass, and there would be one under every fallen leaf. On certain occasions callers have had to wait at the front door until I could sweep the caterpillars off the steps so that they could come in without getting the worms on their clothing. (Mrs. Thomas F. Mayo, 25 Myrtle Street.)

On the morning of the fourth of July, 1889, my domestic and myself went around the whole of our fence and gathered ten or twelve quarts of caterpillars. A little while afterwards they appeared to be just as thick as ever on the fence. On another occasion we gathered two quarts of eggs and caterpillars from the fence on one side of the yard only. . . . It is not easy to give outsiders an idea of how bad the caterpillars were. If the State had not done something, I honestly think we should have had to move away from here. For several summers the women folks on our street made a regular business of killing eaterpillars. We got fairly worn out catching them. I have seen Mrs. Mayo, across the way, sweep the caterpillars up in the gutter in great piles and burn them. . . A Another of our neighbors had the whole front of her house practically covered with caterpillars. One could hardly go out-doors without getting caterpillars on the clothing. You could see them travelling about. When they were thickest we did not pretend to go out the front door at all. We had the front doorsteps torn up, and found underneath a good many nests. There were thousands of eggs and caterpillars under the underpinning of the houses. In 1889 they got into our cellar, and we had it whitewashed. When the caterpillars were very small they would get all over the washing when it was hung out. There were no 
trees very near, but they would spin down from somewhere.

(Mrs. R. Tuttle.)

In the summer of 1889 , while living on Park Street, Medford, we were literally overrun with the gypsy-moth caterpillars. That summer we could have got the caterpillars out of the holes in the trees by pecks. After the caterpillars ate all the leaves off the trees, they went down into the grass, where they swarmed. When the plague was the worst that summer, I do not exaggerate when I say that there was not a place on the outside of the house where you could put your hand without touching caterpillars. They crawled all over the roof and upon the fence and the plank walks. We crushed them under foot on the walks. We went as little as possible out of the side door which was on the side of the house next to the apple trees, because the caterpillars clustered so thickly on that side of the house. The front door was not quite so bad. We always tapped the screen doors when we opened them, and the monstrous great creatures would fall down, but in a minute or two would crawl up the side of the house again. When the caterpillars were the thickest on the trees, we could plainly hear the noise of their nibbling at night when all was still. It sounded like the pattering of very fine rain-drops. If we walked under the trees we got nothing less than a shower bath of caterpillars. We had a hammock hung between the trees that summer, but we' could not use it at all. The caterpillars spun down from the trees by hundreds, even when they were of a large size. We had tarred paper around the trees, but they crawled up the trunks in masses and went right over the paper. The bodies of those that got stuck in the printers' ink served as a bridge for their brethren. The caterpillars were so thick on the trees that they were stuck together like cold macaroni. A little later in the season we saw literally thousands of moths fluttering in the back yard. In the fall the nests were stuck all over the street trees. (J. P. Dill, then living on Park Street.)

No one who did not see the caterpillars at that time can form any idea of what a pest they were. They got into the strawberry bed (although they did not eat the leaves), and I used to go out with a dustpan and brush and sweep them up by the panful. It seemed to us absolutely necessary to go out daily and make an effort to at least lessen their numbers. We killed many with boiling hot water, and would then dig a bole and bury them, so as to prevent a stench. Mr. Belcher was poisoned by them. While killing them upon the trees they would get upon his neck and blister and poison it. It was impossible to stay long in the garden, for they would crawl all over one. We fought them for two or 
three years before the commission took hold. When they hatched out in the spring our fence would be one living mass. My sister and myself blistered the paint all off the fence with the scalding water that we poured on. When they were small it was almost impossible to keep them off one's person. It is a fact that we have scraped a quart of eggs at a time off the trees. We did the best we could to keep them down, but we could not get them all, for many would hide away and lay their eggs. (Mrs. William Belcher.)

In 1889 the walks, trees and fences in my yard and the sides of the house were covered with caterpillars. I used to sweep them off with a broom and burn them with kerosene, and in half an hour they would be just as bad as ever. There were literally pecks of them. There was not a leaf on my trees. Back of the house and across the railroad track was a large, tract of young-growth oaks and maples. They were all stripped. The caterpillars did not leave a leaf. The trunks and branches were covered with their cocoons. The cocoons hung in bunches as big as a pint dipper. The stench in this place was very bad. (Mrs. S. J. Follansbee, 35 Myrtle Street.)

When the caterpillars were small they would spin down on their threads and blow out into the street or even entirely across it. The caterpillars were a dirty pest. You could hardly go out of doors or sit down anywhere without getting them orer you. Trees were either completely stripped so that not a green thing was to be seen on them, or else were eaten so that the skeletons of the leaves only remained. The caterpillars were very numerous on a large tree behind my house. I have scraped them off by the quart on the fence and shed adjoining the tree. They clustered as thickly as bees swarm. Before caterpillar time we used to see bodies of trees plastered all over with their egg clusters. They were so thick on certain trees that they reminded me of shells at the sea-shore. (J. H. Rogers, 17 Spring Street.)

I lived on Spring Street when the caterpillars were thickest there. The place simply teemed with them, and I used to fairly dread going down the street to the station. It was like running a gantlet. I used to turn up my coat collar and run down the middle of the street. One morning, in particular, I remember that I was completely covered with caterpillars inside my coat as well as out. The street trees were completely stripped down to the bark. . . . The worst place on Spring Street was at the houses of Messrs. Plunket and Harmon. The fronts of these honses were black with caterpillars, and the sidewalks were a sickening sight, covered as they were with the crushed bodies of the pest. (Sylvester Lacy, 9 Daisy Street.) 
They [the caterpillars] were so numerous that when they clustered on the trunks they would lap over each other. A neighbor gathered in one day in my yard a peck of caterpillars, and poured kerosene over them and set the mass on fire, but many nevertheless walked away from the burning mass. . . I I used to scoop them off the sides of the house and the tree trunks with a dustpan. ... Their eating in the trees sounded just like a breeze. Many got into the house, and we could not open the windows. I found them in the kitchen and in the bedrooms. I used to find them in the beds when I turned down the blankets. (Mrs. Spinney.)

In the summer of 1889 the gypsy-moth caterpillars attracted universal attention in Medford. They spread very fast over the town. I believe there were enough that summer to have cansed the destruction of all the green leaves in town by the following year, had their spread not been checked. During the summer the caterpillars were found in great numbers on South Street and in the eastern section of the town. Myrtle, Park and Pleasant streets and Magoun Avenue were overrun with the pests. Nobody knew what these caterpillars were until they had been identified in Amberst. They clustered on the bark of the Sonth Street elms in multitudes. From the ground clear to the tops of the trees they lay thickly in the rough bark. (Ex-Selectman John Crowley.)

The caterpillars were everywhere. They would get under the doorsteps and on the window-sills and even into the house. We found them under tables and even under the pillows. The windows could not be opened unless guarded by a screen. . . . When the caterpillars were full grown they would herd in great patches on the trunks. I have seen the end of Mrs. Spinney's house so black with caterpillars that you could hardly have told what color the paint was. In moth time $I$ have seen the moths (it almost seemed by the bushel) crawling and fluttering around the bases of the trees. (Mrs. Snowdon.)

In 1889 the trees on South Street were full of caterpillars. People did not know what they were at first. The four large street elms in front of my house were covered with them. ... The sidewalk under one elm was covered with caterpillars which had dropped off. They were so thick on the tree that they had apparently crowded each other off. The front railing of $\mathrm{Mr}$. Archibald's house on South Street looked as if it was covered with mud, the caterpillars were so thick on it. (F. E. Foster, 20 South Street.)

I remember being at Judge Hayes's, South Street, one evening in the summer of 1889. Mrs. Hayes came in and said that she "never saw such a sight" in her life as the caterpillars presented. 
We went out and found the fence rails literally covered with caterpillars. You could not set your foot down on the walks without crushing the worms. We took shingles and scraped quantities off the trunks of the big street elms. People used to scrape them off into piles and then burn them with kerosene. (Ex-Selectman W. C. Craig.)

The caterpillars covered one side of my house so thickly that you could not have told what kind of paint was on it. It was impossible to keep them entirely out of the honse. The women had to shake their clothing when they went into the house. People used to come from other parts of Medford to Myrtle Street just to see the ravages of the insect. (J. C. Clark, 11 Myrtle Street.)

The caterpillars were so thick in the trees that you could bear them eating. They would get on the fences, until they made them fairly black. They would crawl upon and into the houses. They would get inside somehow, and it was a common thing to see them crawling on the table, and we have even found them on the beds. They would get under steps, stones, and into old stove-pipes, old cans, boxes, in short, any place which afforded a shelter. They crawled into the cellar windows. They were so thick on the street trees that people would walk out in the middle of the street, where there were fewer dropping down. It is no exaggeration to say that I have raked quarts of caterpillars off a tree. . . I I have seen them crawling in great numbers on the rails of the Medford branch track. After a train had gone along, the rails would be all green with their crushed bodies. (William Taylor.)

In the old days, when the caterpillars were so bad, the houses and fences were blackened with them. We used to sweep them off into a basin of kerosene. As you went up and down the street you would see no foliage except on pear trees. If you carried a sunshade down the street, the caterpillars would get all over it. (Miss R. A. McCarty, 26 Myrtle Street.)

I recollect one elm tree in particular on Park Street which stood against the fence. There was an inked band around the tree, and about two quarts of gypsy-moth caterpillars had collected below the band. Some of the caterpillars had got over the band, and they had spun threads which served as ladders by which the others were crossing. (F. M. Goodwin.)

We could not sit under the Porter apple tree, the caterpillars were so thick on it. They swarmed on the ground at the foot of the Baldwin. We poured boiling water on them. The fence was one mass of caterpillars, and they lay thickly under the clapboards and gutters. Our apple trees were stripped two years in succession. (Mrs. John Benson, 3 Cross Street.) 
About four to five P.M. they [the moths] flew about in thousands. Later in the season (1889) their eggs could be seen in clusters on the stone walls, fences, buildings and trees in great numbers, of ten nearly covering such objects. (James Bean, High Street.)

Nothing too bad can be said of the caterpillars. If you sat down anywhere you would crush caterpillars. If the washing was hung out under trees infested with them, they would get on and stain the clean clothes. They were all over the sidewalks, and would drop down upon one from the trees. (Miss R. M. Angelbeek, 24 Myrtle Street.)

In 1888 and 1889 the gypsy-moth caterpillars were a terrible pest on Cotting Street and in that neighborhood. In a neighbor's yard [Mr. Rugg's] they brushed off of one apple tree at one time fourteen quarts of caterpillars. (Almon Black, 10 Cotting Street.)

The elm trees in our yard were badly eaten by the gypsy-moth caterpillars. The ribs of the leaves alone were left. In the afternoon, when the sun got low, the caterpillars in the trees would get into the sun, and you could see the long line of them stretching away up the tree trunk. (Miss A.B.Bockman,21 Franklin Street.)

The willows at the corner of Magoun Avenue were completely stripped for two years in succession. The moths were so thick at one time under the willows that $I$ have collected them by the handful and fed them to my hens. (Walter Sherman, 23 Spring Street.)

In the evening we could hear the caterpillars eating in the trees. It sounded like the clipping of scissors. We kept the caterpillars down in our yard as much as possible, but it was discouraging to see them coming straight across the street in droves to our yard. They almost seemed to have a concerted plan of action. (Mrs. M. M. Ransom, 18 Lawrence Street.)

The trees of our next-door neighbor, Mr. Randall, suffered very much. The caterpillars got into his evergreens, and were so thick that they made them look black. (Mrs. Hamlin.)

In 1889 the brush lot at the corner of Lawrence and Spring streets swarmed with gypsy-moth caterpillars, and the young oaks were all stripped bare. Our bouse stood next to the brush lot. The caterpillars got upon the outside in great numbers, and we also found many inside. (J. G. Wheeler, Daisy Street.)

The outside of my stable was literally black with caterpillars at the time when the gypsy moth was the thickest in this section. It was a disgusting sight. (R. Gibson, 5 Lawrence Street.)

The year before the State began fighting the gypsy moth, I visited an acre of brush land in Glenwood, where the nests of the moth were laid by the hundred on stumps, bush stalks and other objects. This was in the fall of 1889. (J. Sherman, 76 Riverside Avenue.) 
The caterpillars were thickest in Glenwood, where in places they were like a carpet on the ground. Since the State took hold of the matter the trees have been in good condition, and excellent work has been done. (G. C. Russell, 11 Washington Street.)

The caterpillars were a sickening sight when they were at their thickest. They used to make a living path, as it were, from the ground up into a tree. (Richard Pierce, foreman of the Sparrell estate, No. 90 Main Street.)

We did what we could in our neighborhood to fight the caterpillars, but they were so thick that one hated to go out of doors or on the street. We could plainly hear them at night eating in the trees. (Miss Helen T. Wild.)

Many a time I have swept the caterpillars off by the dustpanful from the underpinnings of the house. (Mrs. E. M. Russell, then living on Cross Street.)

In 1889 our apple, pear and crab-apple trees were all stripped by the gypsy-moth caterpillars. They either bore no fruit or else bore so late that the frost destroyed it. When the caterpillars were small we could see them in the daytime spinning down from the trees. At night you could not dodge them, and they would get into your neck and eyes. (F. H. Haushalter, 42 Myrtle Street.)

A few years ago the caterpillars were terrible in Glenwood. You could not go down Myrtle Street without getting your shoulders covered. ... We spent hours killing caterpillars, but there seemed to be two to every one we killed. (A. P. Perry, Myrtle Street.)

I believe that, had the State taken no action in this matter, they would have increased to such an extent that they would have bred a pestilence in our country. They soon grew to the size of your finger, and the stench that arises from them when they are in large quantities is nauseating. (W. W. Fifield of Medford, before the legislative committee on Agriculture, Feb. 27, 1894.)

Before public measures were taken in the matter, the foliage was completely stripped from all the trees in the eastern part of our town, presenting an awful picture of devastation, and promising in a short time to kill every tree and shrub and all vegetation in any region visited by the creatures; which shows how inadequate individual effort was to cope with the subject. (J. O. Goodwin, Medford.)

People who wished to avoid the plague by removing to other towns or localities are said to have had some difficulty in disposing of their homes on account of the desolate appear- 
ance of the surroundings and the disgusting presence of the caterpillars.

The bad condition of this section as regards the gypsy-moth plague was detrimental to real-estate valuations. (Mrs. Mayo.)

The gypsy-moth plague hurt property in this section. Our house was advertised for sale, and when people came to look at the property they were apt to inquire why the leaves of the trees in the neighborhood were so badly eaten. When we told them it was the work of caterpillars, they would say that they would not live in such a locality. (Mrs. Flinn.)

The condition of the Edgeworth district of Malden in 1889 was similar to that of Glenwood. Space permits but a few statements of residents :-

The first year that the caterpillars were very bad was in 1889 . They took the leaves off the trees so that they were as bare as in midwinter. We could not sit out on the lawn a minute, for the caterpillars would be all over one. My son used to climb a shade tree in front of the house and shake the caterpillars off. We would put a sheet underneath, and they would come down in showers. The top of the fence was covered so thickly with caterpillars that you could not put a pin between them. The apple trees in the yard next to ours were stripped. The ribs of the leaves were left. and they looked ghastly. They leafed out again in June, but they bore no fruit. We used to gather the caterpillars in a dustpan and put them in a pail. When the pail was full we would dump them out and burn them with kerosene. Our next-door neighbor, Mrs. Cahill, used to devote much time to killing the caterpillars. She would sweep them off the fence with a broom and burn them. We would see them in droves on the ground coming and going. (Mrs. John Dowd, 194 West Street.)

In 1889 we were overrun with eaterpillars. We did not know what to make of them. During that summer I could not use my front door, they were so thick around it. They were as thick as leaves. We had four apple trees, and they were stripped entirely bare. A second growth of leaves came out, but we got no fruit. For three years there was not an apple nor even a blossom on the trees. We could not have endured the plague, had the State not done something. (Mrs. Daniel Kelly, 209 West Street.)

In 1889 the caterpillars were very bad. Every leaf was taken off my sycamore tree. I nsed to go out with a hoe and scrape the caterpillars off the trunk. If I sat out on my steps after dark 
I could hear them eating in the tree. My other trees were also badly eaten. (Mrs. Margaret Cronin, corner of Oakland and Sheridan streets.)

The trees in the lower part of Edgeworth were badly eaten by the gypsy-moth caterpillars in 1889. They were thick on Oakland and Malden streets and the Common. (T. J. Neville, Pearl Street.)

In 1889 we had as many caterpillars as anybody. You could take a knife and scrape them off the trees. (Mrs. Margaret Connell, 97 Malden Street.)

\section{The Destructiveness of the Мoth.}

The caterpillars devoured the foliage of nearly all species of trees and plants in the worst infested region. During the years when the moth was most abundant, the destruction of or injury to fruit, shade and forest trees and fruit and garden crops was of course greatest. The destruction of trees was greatest in those localities where the moth had been longest abundant, for, though the smaller plants were often killed in one season as were also the less hardy trees, those trees which were lusty and vigorous would frequently withstand defoliation for two or three successive years before they finally gave up their hold on life. Thus the trees and gardens of residents of Glenwood suffered more in these respects than those of people in other parts of Medford.

\section{Trees Killed.}

In some cases where shade trees near dwellings were attacked they became such a nuisance as a harboring place for the caterpillars that they were cut down while still alive, as the only practical means of abating the nuisance. Fruit trees, however, were generally allowed to stand, and a fight was made to save them, which was in some cases successful, but in others all efforts to check the ravages of the moth and save the trees were futile. They finally died, were cut down and the stumps rooted up.

The statements following are given in the words of people whose trees suffered :-

We had three apple trees, four pear trees, one plum tree and one mountain ash killed by the gypsy-moth caterpillars. These trees 
were stripped of their foliage in the summer of 1887 . They began to leaf out again late in the season, but were immediately stripped. The apple trees also put forth a few blossoms at this time. The following year they did not leaf out at all. They all died, and we cut them down. The apple trees were good-sized trees. One was a spice greening, another a Porter and a third an August sweeting. We also cut down a little locust tree which was badly eaten by the caterpillars, and the limbs of which died. The caterpillars swarmed in a tall Norway spruce in our back yard. They ate every bit of foliage on this tree, so that we had to cut all the limbs off. Nothing but the pole of this tree remains in our yard to-day. This tree was so full of caterpillars that when I shook a limb with a rake they would fall off in a shower and blacken the ground. There were so many of them that it sounded like pebbles falling. In addition to the trees, our currant bushes were stripped by the pest. (Mrs. Mayo, next-door neighbor of Trouvelot's.)

The moths ruined me as regards fruit. They were worst in 1889. Their ravages caused me to lose five nice apple trees, two cherry trees, one pear tree and five plum trees. . . I I had a crabapple tree that blossomed very full that spring, but the caterpillar's covered it, and it died. One of the apple trees which the caterpillars killed was a beautiful Hubbardston. Some years I would get four barrels off of it to put away. All you will see of it today in my yard is the stump, over which we train nasturtiums. The spring following the ravages of the moth these trees leafed out a little, but not much, and finally died. (J. C. Clark.)

In 1889 we lost three apple trees because of the caterpillars. They were stripped clean, and then leafed out and bloomed again in September. The next spring they leafed out a little, but did not bear, and finally died. (L. M. Clifford.)

In another yard two large apple trees were stripped by the caterpillars, and died. The way this was brought about was as follows: the caterpillars stripped the trees early in the season, and, as they continued their ravages for nearly the whole summer, the trees had no chance to recover. The next year the trees would leaf out and be stripped again, and so on, until, unable longer to withstand such treatment, they died. (Almon Black.)

Our next-door neighbor, Mrs. Kelly, had a fine Baldwin apple tree which the caterpillars stripped clean. They kept it stripped. One year it blossomed twice. It leafed out and blossomed and was stripped, and then leafed out and blossomed and was stripped again. Finally it would leaf out and blossom once, perhaps, and then it would leaf out but not blossom, and last year only one branch leafed out. The tree is nearly dead. This tree stood very 


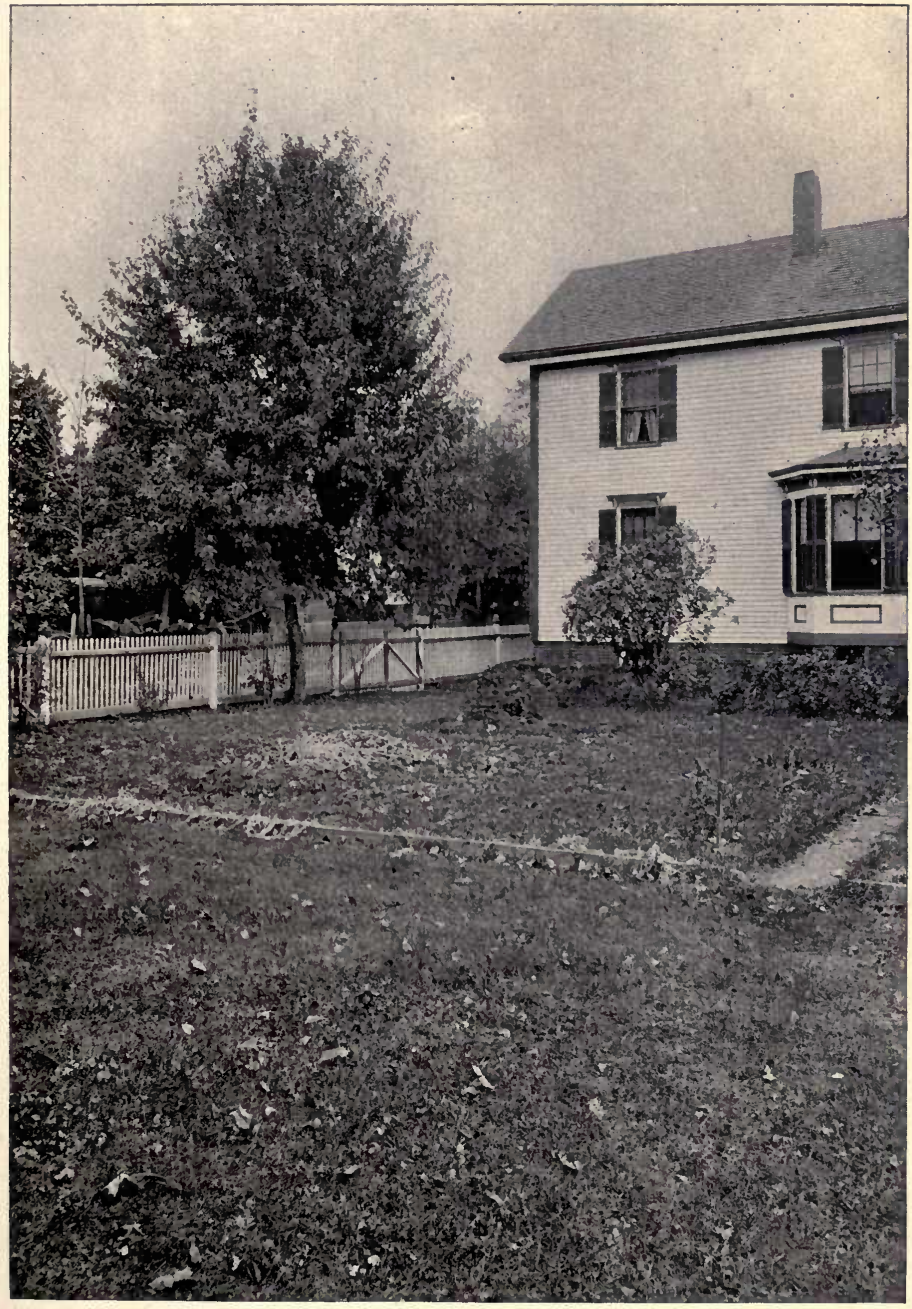

PLATE V. Residence of J. C. Clark, No. 11 Myrtle Street, Medford. The picture shows a portion of the yard formerly occupied by fruit trees killed in 1889 by the gypsy moth. 

near our window, and as we ate supper in the early evening we could distinctly hear the caterpillars chewing among the leaves. In the night-time I have frequently heard their "chip-chipchipping" out in the shade trees on the street. In a yard adjoining ours there is another apple tree which is more than half dead because of the ravages of the caterpillars. It. used to bear splendid Baldwins, but last year there were not more than a dozen apples on the tree. The caterpillars used to strip it twice a year up to two years ago, when their numbers were greatly reduced. For two years in succession the caterpillars stripped two maple trees in front of our house. They ate all of the leaf except the ribs. We had two shade trees cut down which were in a dying condition because of the ravages of the caterpillars. This was some five or six years ago. On Otis Street also we had two trees which we cut down because the caterpillars ate them so badly. In Mrs. Kelly's yard there was a large balm of Gilead tree which was cut down because it was nothing more or less than a breeding place for the gypsy moth. The tree was a sight. The trunk and limbs were black with caterpillars. The tree stood close by Mrs. Kelly's house, and you can still see the discoloration under the eaves where the caterpillars clustered so thickly. Mrs. Meach, across the way, had a weeping willow cut down. (Mrs. 'Tuttle.)

One of our sweet-apple trees died from the effects of the stripping by the caterpillars. The branches died one by one, but we let it stand one year, hoping that it would revive, but it did not. Onr four Baldwin apple trees bore good crops until the caterpillars attacked them. By June you would not see a leaf on them, and they would remain in that leafless condition all summer. In the fall of 1892 we got our first crop of apples in seven years. (Miss R. A. McCarty.)

A young maple which had been set out on the street in front of our house was stripped by the caterpillars and died. . . A young peach tree died, apparently because it was stripped by the caterpillars. (Mrs. Flinn.)

Two oaks on the street in front of our house were entirely stripped. The next year they did not leaf out, and were cut down. (J. W. Harlow, 58 Spring Street.)

We cut down two cherry trees in our own yard because there were so many eggs, cocoons, etc., in the seams and holes. (Mrs. Snowdon.)

I cut down three tall poplars in front of No. 19, where I now live, because they were so badly infested. I also cut down an apple tree because it attracted so many caterpillars and was so badly eaten. (William Taylor.) 
I had several balm of Gilead trees cut down because they were so badly eaten by the caterpillars. (Walter Sherman.)

Our four apple trees which we eut down because of the pest yielded the year before eleven or twelve barrels of fine Baldwin apples. (J. P. Dill.)

An apple tree was stripped twice, and we had no fruit. The caterpillars so nearly killed the tree that it has since that time borne very little. (Miss C. E. Camp, 28 Myrtle Street.)

\section{Fruit, Garden Crops and Flowering Plants Destroyed.}

The caterpillars destroyed not only the foliage of trees, but also fruit and vegetables. The long period of feeding made it possible for the larvæ to secure a great variety of food. When the supply of leaves in the trees fell short (and oftentimes before) they attacked the gardens. Little was spared but the horse-chestnut trees and the grass in the fields, though even these were eaten to some extent. There was evidently some choice exhibited; for instance, pear trees were not so badly injured as the apple, but eventually most forms of vegetable life in the caterpillars' path were either injured or entirely destroyed.

When fruit trees were stripped of their leaves, the immature fruit either failed to develop or dropped from the tree. In some cases the fruit itself was partially eaten by the voracious caterpillars. The destruction of berries was often as complete. Many vegetables were ruined. Flower gardens were destroyed, and even greenhouses were invaded and rose bushes and other flowering plants eaten. Our space permits but a portion of the evidence of such devastations in Medford :-

They [the caterpillars] ate nearly everything green in the yard, killing my rose bushes and doing much damage to the vegetables. (Mrs. Belcher.)

I had quite a little vegetable garden, which was nearly ruined by the caterpillars. They destroyed the cucumbers and ate the tops of the tomatoes. They also destroyed some flowering plants. (Wm. B. Harmon, 5 Spring Street.)

They [the caterpillars] even nibbled the young green pears, and I lost a good many in that way. My large cherry tree, which usually bears two bushels, was stripped clean for two years running, and I got no fruit. The caterpillars ate all the young tomato vines 


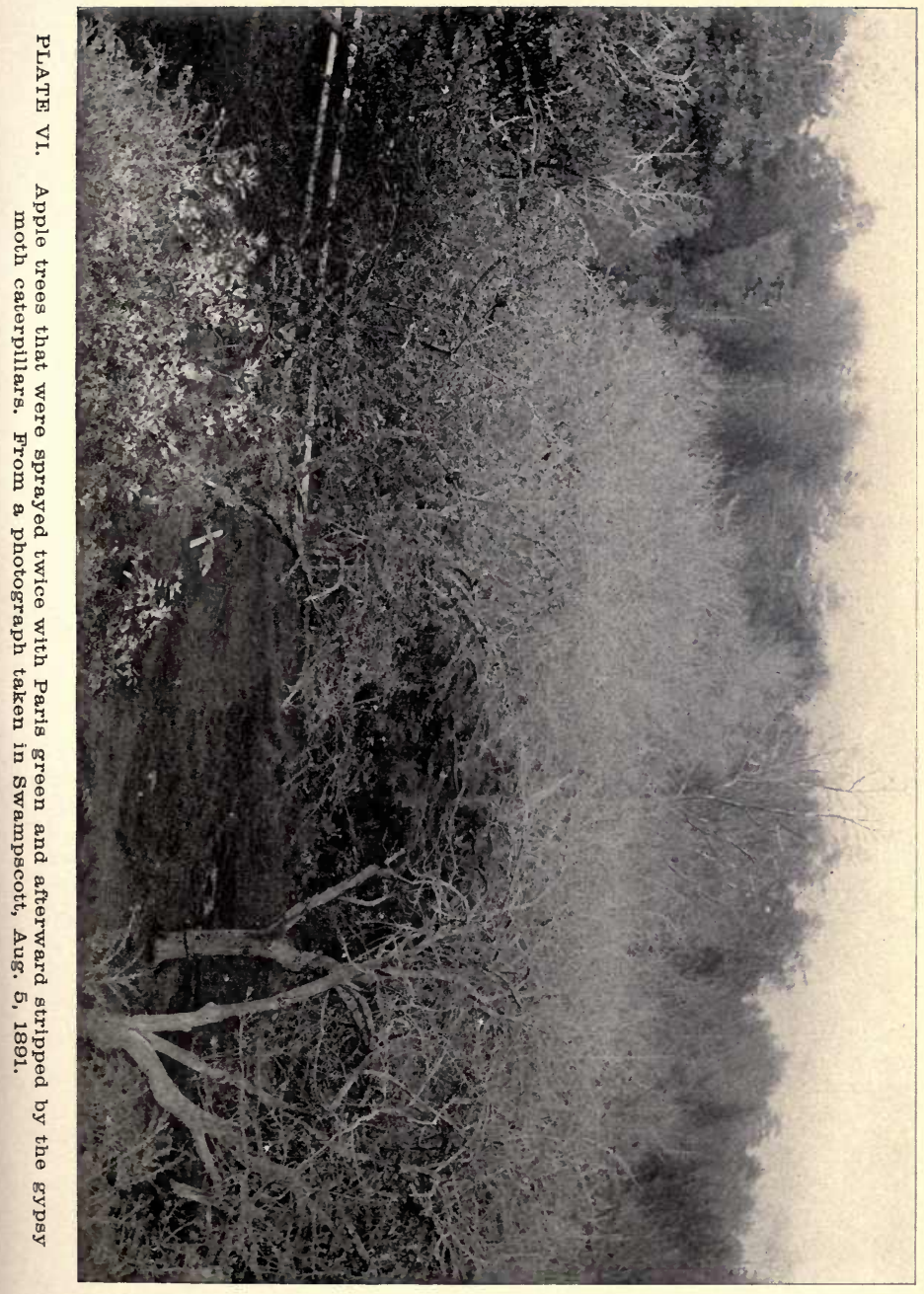



and injured my rose bushes. . . . For three years previous to 1891 my Baldwin apple tree bore no fruit on account of the ravages of the moth. It was stripped every year. (Mrs. Follansbee.)

At my place on Woburn Street I had a small bed of spinach and dandelions which the caterpillars completely destroyed. My tomatoes suffered a like fate. (Ex-Selectman Craig.)

In $1889 \mathrm{I}$ had twenty-seven hundred young carnation pinks set out of doors, and the biggest part of them were destroyed by the caterpillars. This was in June. They were eaten off close to the ground. In 1890 the gypsy moth appeared in my greenhouses, and the foliage of the bushes in one rose house was completely eaten up. (A. W. Crockford, 81 Spring Street.)

It was almost impossible to have plants or green things of any sort. The caterpillars would eat anything that they could get hold of. The rose bushes were stripped. My mother plants yearly beans, peas, etc., but that year we did not get much from them. The parsley also was almost all eaten. (Miss R. M. Angelbeek.)

The rose bushes were completely stripped, all the leaves and blossoms being lost. Despite the utmost efforts of two of us, it was impossible to keep the rose bushes free of caterpillars. They were very fond of the deutzias in the garden, and completely ruined them. (Mrs. Ransom.)

They seemed particularly destructive to the Porter apple tree. The apples very largely fell off, and the inside of those that remained on the tree was not fit to eat. . . The caterpillars ate the leaves of a white rose bush and a syringa in our yard, and the latter died from the effects of the stripping. (Mrs. Benson.)

Our regetable garden was practically ruined by them, peas, beans, corn, etc., being eaten. The garden of our next-door neighbor, Mr. Camp, suffered a like fate. . . O Our raspberry bushes were also stripped of their leaves. We lived later on Lawrence Street, and here also the caterpillars were troublesome. An umbrella bush in the yard was killed by them. (Mrs. Flinn.)

My usual apple crop was from fifty to one hundred barrels yearly; but the second year of the caterpillar plague I did not get more than forty barrels. The third year I do not think I got more than thirty barrels. (D. M. Richardson.)

After they had eaten the foliage of trees, the caterpillars would devour almost any green thing. (J. N. French, 7 Lawrence Street.)

They were the most ravenous worms I ever saw. They would eat almost everything, taking the apples and the elms first. (John Cotton, 16 Cotting Street.) 
The caterpillars ate almost everything, feeding on small fruits and shrubbery as well as the trees. (Almon Black.)

Our blackberry and raspberry bushes were badly eaten, and we got but little fruit from them that summer [1890]. (J.W. Harlow.)

After eating the foliage of the trees, the caterpillars would attack the vegetables. (J. G. Wheeler.)

The caterpillars even ate the grape-vine to some extent. (William Taylor.)

\section{How the People fought the Moth.}

No doubt the citizens of Medford did all that the people of any community would have done individually in fighting the pest. Many of them owned their homes, and gave much attention to the care of their grounds. Each householder had a small lot of land, and most of them had gardens or small orchards to protect from insect ravages. There were many people in a given area each of whom had an interest in protecting his own small portion of that area. Many of these people spent most of their leisure time during the summer months in fighting the eaterpillars, killing great numbers of them. The number thus killed on Myrtle, Spring, Washington, Park and Cross streets during a summer must have checked considerably the increase of the moth. Many people banded the trunks of their trees with tarred paper, to which they applied tree ink as a protection against the migrating worms. This was a partial success, if the bands were carefully watehed and the caterpillars which gathered below them killed in time to prevent their crossing the bands by mere force of numbers. A considerable part of the fruit crop was saved in some orchards in this way, the tree ink having the effect of turning many caterpillars away from banded trees to those left unbanded. Yet, in spite of all checks, the moths on Myrtle Street increased and spread so as in time to overwhelm the town. It is known that people there fought them with fire, water and coal oil from five to eight years before they became prevalent in other parts' of Medford.

Extracts from statements graphieally describing the methods used are given herewith :- 
Many citizens scraped off all the caterpillars that they could, and killed them. The caterpillars were scraped off in masses as high up as a man could reach. Some people burned them off by means of a rag soaked in kerosene and tied to a pole. (ExSelectman Crowley.)

At the time when the gypsy-moth caterpillars were thickest in this neighborhood I used to spend all my leisure time fighting them, and then failed to keep them down. . . We used to take a can with a little kerosene in the bottom and pick the caterpillars off into it and later bury them in the ground. In a half-hour I have picked a canful off one apple tree. (Mrs. Ransom.)

The caterpillars were of an enormous size, and would lie in clusters on the tree trunks. We used to scrape them off into a pail. (Mrs. Charles A. Lawrence, then living at 10 Cotting Street.)

We used to destroy the caterpillars on the fences by pouring scalding water on them. We burned with kerosene those in the trees. We would go out several times a day and kill them. We also used to scrape them off into cans. (Mrs. A. H. Plummer, 14 Lawrence Street.)

We spent hours killing caterpillars on them [street elms]. We would get two quarts off at a time. They were very large. They got into every crevice and under every piece of bark. Our neighbor across the way, Mrs. Turner, used to go out with a pail of hot water and poke the caterpillars into it with a stick. My son used to tie a rag soaked in kerosene around a pole and set it on fire and singe them.off the trunks of the trees. (F. E. Foster.)

I put a piece of stout paper about a foot wide around the tree at my place for the gypsy-moth larvæ to go under. I visited it a number of days later and found the trunk of the tree under the paper to be entirely covered with the insects. There were hundreds of them. A neighbor, Mr. Dutton, tried a similar experiment with a strip of carpet, with like results. (James Bean.)

We used to take lighted candles and run them along under the fence rails and scorch the eggs there. (Miss R. M. Angelbeek.)

I had charge of this estate [Sparrell estate, Main Street], and I killed a great many caterpillars by brushing them off the trees with a broom and crushing them. After brushing them off the trees, I would wait half an hour and then there would be just as many again on the trees. I could have gathered a half-bushel of caterpillars every evening through their season. (Richard Pierce.)

I used to burn them in the trees with torches. . . . We killed them on fences with boiling water. (Mrs. Spinney.)

We used to sweep them off into a dustpan and burn them, but in a short time they would be as thick as ever on the tree again. . . . 
The next spring (1890) I found the apple trees in my own yard were pretty well infested with nests. I had my hired man scrape them all off with a putty knife. We collected them in a dish and burned them up in the furnace, where they snapped and crackled. (J. E. Wellington, Wellington.)

I fought the caterpillars in my own yard by placing cloths in the crotches and around the trunks of the trees. The caterpillars collected in great numbers under the cloths, and were then easily destroyed. (S. F. Weston, 11 Fountain Street.)

We had both the steps and the fence split up and burned, so as to deprive the pest of its harboring places. I have frequently gathered half a coal-hodful of caterpillars from the fence within a short space of time. In twenty minutes they seemed to be just as thick as ever. We burned many pecks of them in all. (William B. Harmon.)

In the evening, after the men had come home from work, you could see fires in all the yards, where they were burning caterpillars. (Mrs. Fenton.)

For four or five years I fought the gypsy-moth caterpillars, as did my neighbors, but could not keep them down. . . . By putting tarred paper around the trees and keeping the printers' ink fresh, I succeeded in a measure in keeping the caterpillars out of the trees. One tree which was very full of caterpillars I sprinkled with the garden hose and knocked the pests out of it. The tarred paper kept them from crawling up again, and they would collect in a mass below the band. (J. N. French.)

When the caterpillars were very small the fences were black with them. We used to kill them on the fences by taking teakettles and walking along beside the rail and pouring boiling water on the vermin. . . . We would scrape them from the tree trunks with hoes and burn them with kerosene. We used to build little fires at the base of a tree and collect the eggs and burn them. (Mrs. Snowdon.)

The greenhouse was full of them [caterpillars]. The warmth caused them to hatch out early. I destroyed most of them by picking off the leaves and burning them, and also by spraying with an emulsion of whale-oil soap, kerosene and ammonia. (A. W. Crockford.)

For six weeks a great deal of our time was deroted to killing these caterpillars. ... We would go out in our yard time after time during the day and gather the caterpillars in dishes. Time and again $I$ have stayed out in the yard for two hours at a time, catching caterpillars; but in half an hour afterwards they seemed to be just as thick again.

(Mrs. Hamlin.) 



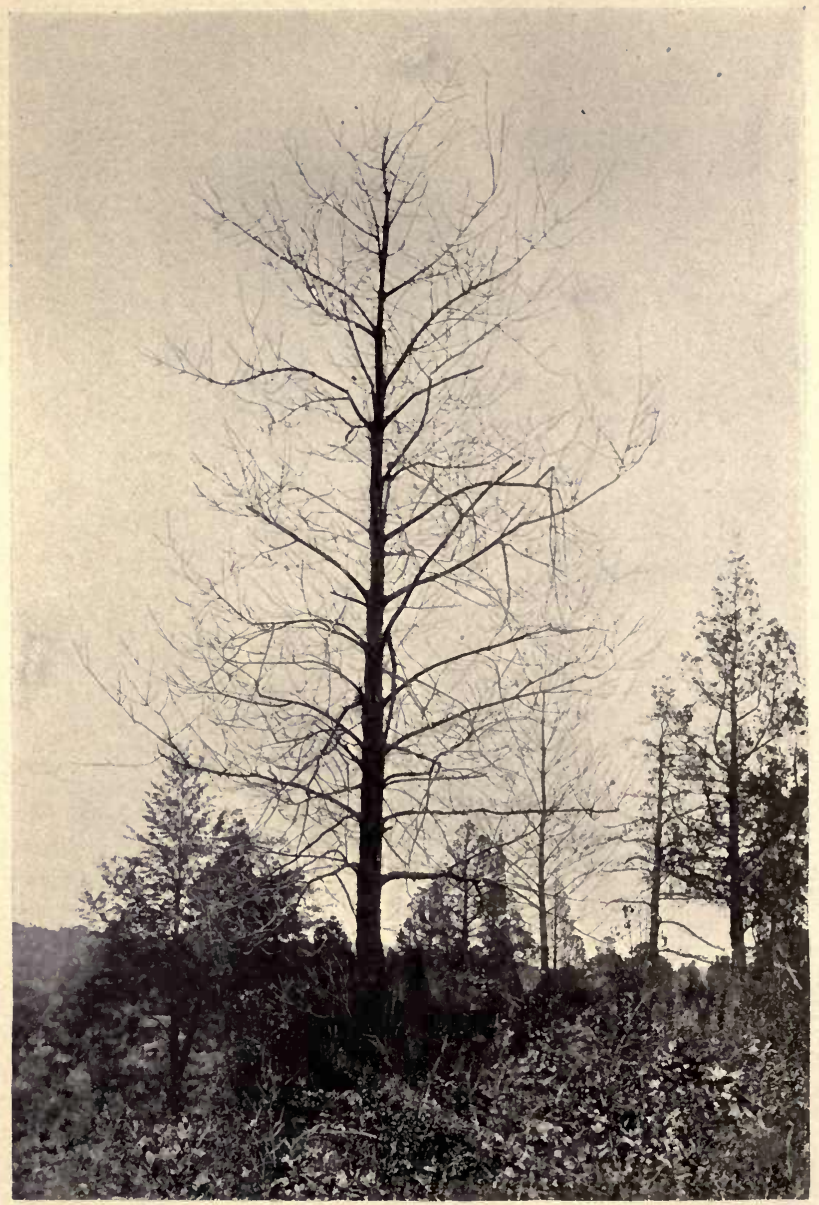

PLATE VII. Cherry, red cedar and yellow pine trees attacked by the gypsy moth. From a photograph taken in Medford. 
During the summer of which I speak (1889) my currant bushes were also attacked. They were covered with caterpillars, but I saved them by sprinkling them twice a day with a solution of soapsuds and kerosene. (J. C. Clark.)

\section{The Moth multiplies on Neglected Lands.}

Though there were many people who did their utmost to destroy the moths, there were others who made little effort in that direction. There was waste land which no one cared for, and in such places the moth increased apace, until the advances of the ravenous larvæ could no longer be stayed by individual effort : -

I think, if every one had taken hold and fought the moths in the beginuing, they might have been stamped out right in the place where they originated. The trouble was that some people would not do anything. Some people on the street were tenants only, and therefore took little or no interest in the condition of their yards. I remember the case of one house which was vacant during one summer. The caterpillars in that yard were a sight. Another neighbor, not owning his house, and not intending to stay there, was overrun in a like manner. (William Taylor.)

Other residents make similar statements : -

A house near by being unoccupied, the caterpillars in the garden there had full swing, there being no one to fight them. This yard was a recruiting place for the whole neighborhood. No sooner would we get our own yard comparatively free than a lot more would crawl around on the fence from the other yard. (Mrs. Plummer.)

One difficulty in fighting the caterpillars used to be that now and then a neighbor would not do anything to keep them down on his own land. As a consequence, the caterpillars, after stripping. this man's trees and getting about three-quarters grown, would migrate into the other yards and be even more destructive, their voracity increasing with their size. (J. N. French.)

The only way I suffered was because my neighbors were negligent. The caterpillars blew over on to my trees. . . . I saw them coming from my neighbor's premises on a concrete walk extending along where my fruit trees grow. The walk was literally covered with these worms when they were about the size of your little finger, so that it appeared like a carpet. (J. O. Goodwin, before the legislative committee on Agriculture, Feb. 27, 1894.) 
There were some people on Cross Street who used to do nothing in the way of fighting the caterpillars, and for that reason the work of individuals failed to cope with the pest. (Mrs. Spinney.)

\section{The Pluague brodght to the Attention of the Public} at LaRge.

Messrs. John Stetson, W. C. Craig, J. O. Goodwin and Dr. Pearl Martin, all of Medford, were among the first to call public attention to the ravages of the moth. Mr. Stetson first noticed the larvæ of the moth in 1888 at his place on South Street, nearly a mile from the Trouvelot house. In June, 1889, when they began to defoliate the trees in his neighborhood, he took a specimen for identification to Hon. Wm. R. Sessions, secretary of the State Board of Agriculture. Mr. Sessions, being unable to identify it, advised sending specimens to the Hatch Experiment Station at Amherst. This was done, and the caterpillars were received at the station June 27. Professor Fernald, the entomologist of the station, was absent at that time in Europe, and no one at the station immediately recognized the species. After a thorough search through American entomological literature, the conclusion was reached that the insect was foreign. Recourse was then had to European works in the library of the entomologist, and after a slight search through the authorities, Mrs. Fernald and her son, Dr. H. T. Fernald, identified the caterpillars as those of Ocneria dispar, known in England as the "gypsy moth," in Germany as the "sponge spinner" or stem caterpillar, and in France as "le zigzag." Mr. Stetson was notified of the identification, and information regarding the outbreak was immediately sent to Professor Fernald. Later he observed in Germany the ravages of this insect, and consulted with European entomologists in regard to the matter. All these authorities regarded the gypsy moth as a scrious pest, and the opinion was expressed that it would become far more destructive than the potato beetle, by reason of the number of its food plants."

In the mean time the people of Medford were becoming alarmed.

- See Bulletin of the Hatch Experiment Station, November, 1889. 
The Medford "Mercury" of June 28, 1889, contains this item :- -

The army-worm has struck Glenwood and Park Street gardens, stripping trees of their foliage.

About this time Mr. Craig, then one of the selectmen of Medford, became interested in the outbreak. The condition of the trees and gardens so alarmed him that he immediately brought the matter to the attention of the town officials. He writes :-

In 1889 I was connected with the town government of Medford. Coming out one day on the train from Boston, I noticed that the trees in Glenwood had the appearance of having been burned. I made a remark to the effect that the trees had been burned, when a lady said, "That is the work of the army-worm." In company with Mr. J. O. Goodwin I investigated the matter, and found that the insects which were preying on the trees were not army-worms. Being a selectman, I conferred with the other members of the Board, but we had nothing to do with the trees on the streets or in the orchards of the town. Mr. Goodwin and myself waited on the road commissioners and asked them to expend some money in stopping the ravages of the pests, which were the gypsy-moth caterpillars. The commissioners at that time had no money which they could expend for such a purpose, but were in full sympathy with the movement and did all they could to further it. I saw ex-Senator Boynton, General Lawrence, J. Henry Norcross and other leading eitizens in regard to the matter, and it was agreed that some action must be taken. . . . It was the sentiment that the road commissioners should do what they could to stop the ravages of the caterpillars.

The alarming condition of the shade trees was considered sufficient cause for immediate action. At a meeting of the road commissioners on July 1 , it was decided (pending action by the town authorities) to put fresh ink on the bands of the trees on the streets where the caterpillars were most numerous. These trees, in common with other street trees in the town, had been banded earlier in the year as a guard against the ravages of the canker-worm. The inking of the tree bands was done the next day, and at night "it was found 
that thousands of the pests were bunched beneath the printers' ink" (Medford “Mercury," July 5).

Though this protection of the trees had the effect of alleviating the injury to those protected, it hastened the diffusion of the caterpillars and drove them to other plants and to other localities where trees were not banded, thus extending the area of the injury until it included most of the trees in the eastern part of the town. There were some localities, however, that escaped the general devastation. At a town meeting held on July 15 it was voted, on petition of the road commissioners, to appropriate the sum of three hundred dollars for the care of shade trees. This appropriation of three hundred dollars was in addition to the usual appropriation of five hundred dollars for the care of shade trees made earlier in the year. It was expended under the direction of Dr. Pearl Martin, one of the road commissioners. A number of men were employed in scraping off the egg clusters of the gypsy moth from shade trees, chiefly on Park and Salem streets, where the trees were badly infested. The eggs were burned with kerosene. In addition to the work done by the town, much effort and money were expended by citizens in the endeavor to free their premises of the moth.

Professor Fernald, having meantime returned from Europe, visited Medford and viewed the infested district. Later, in company with Hon. Wm. R. Sessions, secretary of the State Board of Agriculture, he visited and inspected Medford again. These two gentlemen waited on Chairman Wadleigh of the Board of Selectmen, and urged that the selectmen take action to petition the General Court for legislation authorizing the State Board of Agriculture to exterminate the caterpillars. This course was approved by the selectmen at their next meeting, October 25 ; but, as the Legislature was not then in session, no immediate action was taken. In November an illustrated bulletin on the gypsy moth was issued by Professor Fernald at the Hatch Experiment Station. By authority of the State Board of Agriculture and with the co-operation of the Massachusetts Society for Promoting Agriculture, an edition of forty-five thousand copies was printed, and mailed to tax-payers in Medford and vicinity. The bulletin was printed in full in the Medford "Mercury" on December 6. 
The task of destroying the eggs, which had been delegated to the Medford road commissioners, was far greater than had been anticipated, and the money appropriated was soon expended, while only a small part of the eggs had been destroyed. While the work was in progress Dr. Martin saw that the moths were so numerous and so widely distributed that the town authorities could not cope with them. At a meeting of the selectmen, December 10, he appeared in behalf of the road commissioners and advised applying to the Legislature for State aid. The Board voted that the clerk should communicate with Secretary Sessions of the State Board of Agriculture " in relation to measures to be taken to place this matter properly before the next Legislature."

At the next meeting of the selectmen, December 17 , a communication was received from the Hatch Experiment Station, advising that the Legislature be petitioned for an appropriation to exterminate the moth. The clerk, reporting in regard to his interview with Secretary Sessions, recommended that petitions in favor of such an appropriation be circulated in Medford and vicinity for presentation to the Legislature. Messrs. Wadleigh and Lawrence were appointed a committee to draw up such petitions. Mr. Lawrence was also appointed a committee to confer with Secretary Sessions in regard to preparing a bill to be presented to the Legislature.

In December, Prof. H. H. Goodell, president of the Massachusetts Agricultural College, wrote to Governor-elect Brackett, urging that measures should be taken by the incoming Legislature to provide for the extermination of the gypsy moth.

In his message to the Legislature of 1890 Governor Brackett said : -

A new enemy is at present threatening the agriculture, not only of our own State, but of the whole country. It is the gypsy moth, said to attack almost every variety of tree, as well as the farm and garden crops. The pest is spreading with great rapidity, and, if its eradication is to be attempted, immediate measures are of the utmost importance. 
A petition for legislation for the extermination of the gypsy moth was presented to the Legislature by the selectmen of Medford, Jan. 15, 1890. Other towns joined in the movement. On January 21, the selectmen of Arlington presented a petition. Soon after, petitions were presented by the boards of selectmen of Everett, Winchester, Stoneham and Wakefield, and by city officials of Malden and Somerville. A petition was presented from the State Board of Agriculture, headed by President Groodell of the Agricultural College; also one from the Essex County Agricultural Society. The Massachusetts Horticultural Society took an active part in the movement, petitioning the Legislature as follows:-

The Massachusetts Horticultural Society, recognizing the dangers threatening the agricultural interests of the State by the sudden appearance in the town of Medford of a dangerous insect pest, petitions the Legislature, in support of the petition of the citizens of Medford and adjacent towns, for State aid in stamping it out.

The joint standing committee on Agriculture of the Massachusetts Legislature visited Medford early in 1890, and saw the masses of egg clusters on the trees. ${ }^{*}$ Public interest having in the mean time been aroused, an act appropriating twenty-five thousand dollars "for the extermination of the Ocneria dispar or gypsy moth" was passed. $\dagger$ This was accomplished mainly through the influence and untiring efforts of Mr. J. Henry Norcross of Medford, then a member of the House of Representatives, aided by hearty co-operation of Representatives from the neighboring towns. The act was approved March 14, 1890, and is here given in full :-

[ChAPTER 95.]

An Act to provide against depredations by the insect known AS THE OCNERIA DISPAR OR GYPSY MOTH.

Be it enacted, etc., as follows :

Section 1. The governor by and with the consent of the council is hereby authorized to appoint a commission of not exceeding three suitable and discreet persons, whose duty it shall be to pro-

" "The walls and almost every tree were almost wholly covered with nests." (Ex-Senator Low, before the legislative committee on Agriculture, Feb. 27, 1894.)

+ Dispar has now been referred to the genus Porthetria. 
vide and carry into execution all possible and reasonable measures to prevent the spreading and to secure the extermination of the ocneria dispar or gypsy moth in this Commonwealth; and to this end said commission shall have full authority to provide itself with all necessary material and appliances and to employ such competent persons as it shall deem needful; and shall also have the right in the execution of the purposes of this act to enter upon the lands of any person.

SECr. 2. The owner of any land so entered upon, who shall suffer damage by such entry and acts done thereon by said commission or under its direction, may recover the same of the city or town in which the lands so claimed to have been damaged are situate, by action of contract; but any benefits received by such entry and the acts done on such lands in the execution of the purposes of this act shall be determined by the court or jury before whom such action is heard, and the amount thereof shall be applied in reduction of said damages; and the Commonwealth shall refund to said city or town one-half of the amount of the damages recovered.

SECT. 3. Said commission shall have full authority to make from time to time such rules and regulations in furtherance of the: purposes of this act as it shall deem needful; which rules and regulations shall be published in one or more newspapers published in the county of Suffolk, and copies of such rules and regulations shall be posted in at least three public places in each city or town in which said ocneria dispar or gypsy moth shall be found by such commission to exist, and a copy thereof shall be filed with the city or town clerk of each city or town. Any person who shall knowingly violate any of the provisions thereof shall be punished for each violation by a fine not exceeding twenty-five dollars.

SECr. 4. Said commission shall keep a record of its transactions and a full account of all its expenditures, in such form and manner as shall be prescribed by the governor and council, and shall also make return thereof to the governor and council at such time or times and in such form as shall be directed by the governor and council. The expenses incurred under this act shall be paid by the Commonwealth, except claims for damages by the entry upon the lands of any person and acts done thereon by said commission or by its direction, which shall be paid as provided in section two of this act.

SECT. 5. The governor and council shall establish the rate of compensation of the commissioners appointed under this act, and the governor may terminate their commissions at his pleasure.

SECr. 6. Any person who shall purposely resist or obstruct said commissioners or any person or persons under their employ, 
while engaged in the execution of the purposes of this act, shall be punished by a fine not exceeding twenty-fire dollars for each offence.

SECT. 7. It shall be unlawful for any person to knowingly bring the insect known as the ocneria dispar or gypsy moth, or its nests or eggs, within this Commonwealth; or for any person knowingly to transport said insect, or its nests or eggs, from any town or city to another town or city within this Commonwealth, except while engaged in and for the purposes of destroying them. Any person who shall offend against the provisions of this section of this act shall be punished by a fine not exceeding two hundred dollars or by imprisonment in the house of correction not exceeding sixty days, or by both said fine and imprisonment.

Sect. 8. To carry out the provisions of this act a sum not exceeding twenty-five thousand dollars may be expended.

SECT. 9. This act shall take effect upon its passage. [Approved March 14, 1890.

\section{The Comyission of 1890.}

In accordance with the provisions of the act of March 14, Governor Brackett appointed a salaried commission, consisting of Warren W. Rawson of Arlington, then a prominent member of the State Board of Agriculture, Dr. Pearl Martin of Medford and J. Howard Bradley of Malden.

The commission organized in Medford, March 22, with the choice of Mr. Rawson as chairman and Mr. Bradley as secretary and general superintendent. The records show that in April, Mr. Samuel Henshaw of the Boston Society of Natural History was appointed entomologist to the commission. Headquarters were established in Medford, and meetings of the commission were held almost daily untll the last of July and several times per month during the rest of the year.

The commission began its labors by a partial inspection of the known infested district, for the purpose of discovering and marking the infested trees, shrubs and other objects. The infested trees were marked with a red tag. The moth was soon found in many localities outside the restricted district to which it was at first supposed to be confined. This district did not exceed one-half mile in width and one and one-half miles in length. The inspection of 1890 justified 



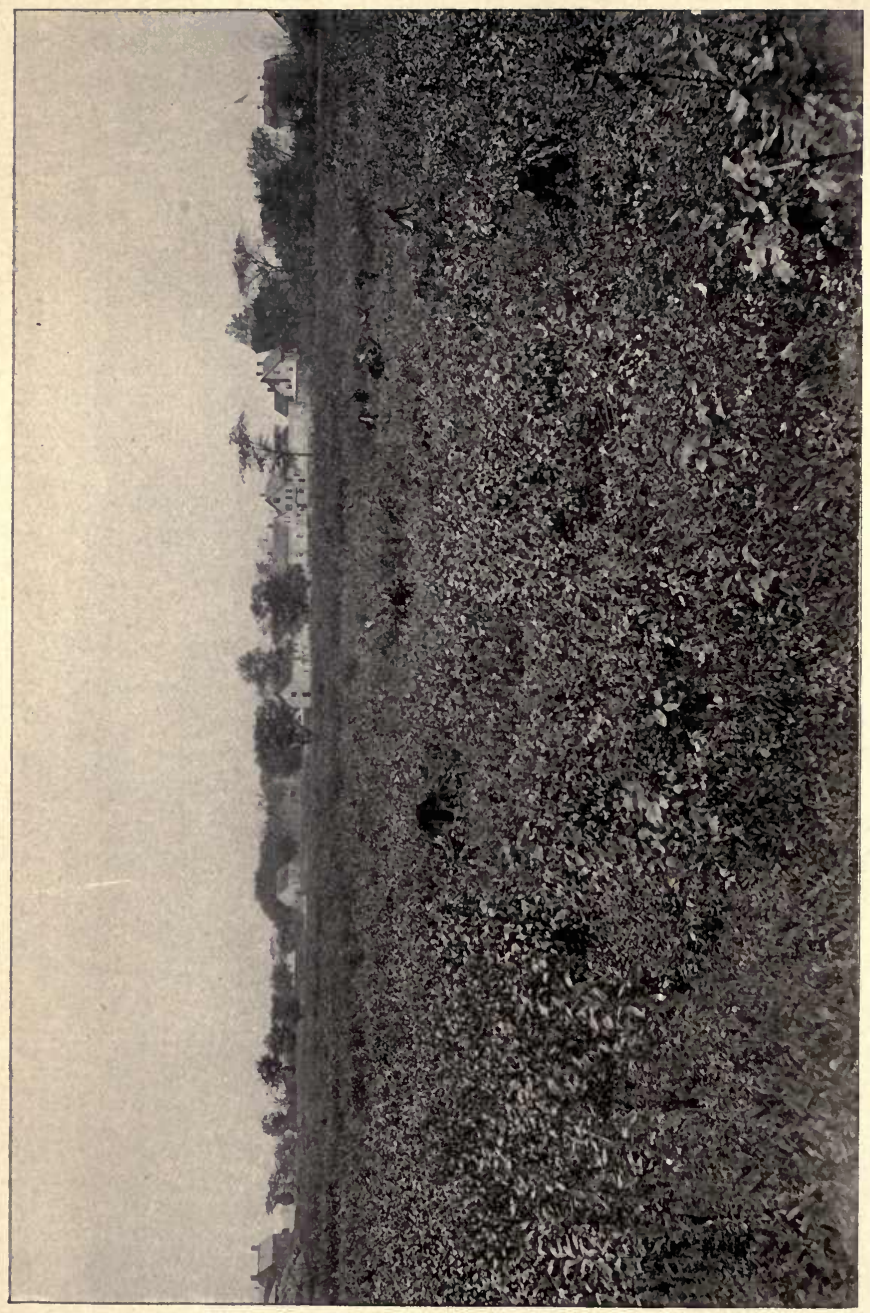


the commissioners in the assumption that fifty square miles of territory were then more or less infested.

It soon became apparent that the appropriation of twentyfive thousand dollars would be entirely insufficient for the needs of the season's work, chief of which was the expensive item of spraying. On May 9, in a communication addressed to Governor Brackett, the commission reported having found the infested territory "some sixteen times as large as first represented," and asked for an additional appropriation of twenty-five thousand dollars. This appropriation was made by the Legislature and approved June 3, 1890. The force of employees was increased as the season advanced, and reached its maximum strength in June, eighty-nine men being employed from June 16 to 28 .

During the month of April many eggs of the moth were scraped from the trees and destroyed by the employees of the commission. Early in May the spraying of infested trees and foliage with Paris green was begun and continued until about the middle of July. This was the principal work of the summer. Fifteen teams were in use, and spraying was done in Medford, Malden, Arlington, Chelsea and Everett. The greatest amount of spraying was done in the Glenwood and Wellington sections of Medford and the Edgeworth district of Malden.

Another feature of the season's work was the guarding of highways leading out of Medford and Malden, with the view to preventing the further dissemination of the moth by means of vehicles. About a dozen special policemen were employed in this duty from early in June until the last of July. They were on duty twelve hours in the day. Caterpillars of the moth were found on many vehicles going out of the infested district.

Large kerosene torches were used during the summer to burn the clustering caterpillars. Considerable cutting and burning of infested trees and bushes was also done, the chief work of this sort being in the badly infested woodland north and south of the railroad at Glenwood. About twenty acres of ground were thus cleared.

In September and October a few men were engaged in scraping eggs from the trees in Medford, Malden, Somerville, 
Arlington, Everett, Cambridge and Chelsea. In November the force was slightly increased, and an inspection was made of certain parts of the infested territory. The cavities of some trees along the highways were closed with cement. On December 6 all men in the employ of the commission were discharged, and the field work of 1890 closed.

The Abundance and Destructiveness of the Moth in 1890.

Referring to the work of 1890 and the numbers of the moth, Mr. E. J. Cadey, an ex-employee of the commission, said :-

At the time when the commission first started I saw the eggs of the moth on trees in such numbers that the trees had a spongy appearance, and the men who gathered them used large-sized pails, holding about a peck. Some days we filled these pails twice and occasionally three times. Especially was this the case at the Wellington willows, in Glenwood, where the moths originated. The walls of an old shed were one yellow mass of eggs. Early in the summer, previous to the spraying season, on sixteen acres of woodland and brush on land of Mr. Pinkert near the Boston \& Maine Railroad, there was not a green leaf to be seen. We afterwards cut these sixteen acres. There were five or six willows on the corner of Spring and Magoun streets that were so thickly covered with pupæ that the bark could not be seen. In $1890 \mathrm{I}$ do not think there was a whole leaf in Medford, and the people complained of a very disagreeable stench.

Mr. William Enwright, who was also employed by the commission in 1890 , writes : -

I was sent to Glenwood to the brick yards. Here I found the bricks completely covered with the caterpillars. Nearly opposite here, on Lawrence Street, there was an old barn literally covered inside and out with nests and caterpillars. Trees were completely stripped. The streets and sidewalks were so covered that it was almost impossible to step without crushing some of the caterpillars. In the fall of the first year, when we were cleaning the nests from the rubbish, we used shovels to shovel them into cans. You could not walk in the woodland without being covered with caterpillars. In $1890 \mathrm{Mr}$. Bradley drove his horse through the woods, and the horse's mane and tail were covered with caterpillars. 
Mr. G. T. Pierce, who was employed in 1890, writes:-

When I was working at Dr. Newton's place on Highland Arenue, Somerville, on seventeen or eighteen apple trees you could not find a leaf that had enough left of it to call it a leaf. Most of them were only a stub of the midrib. In a large bunch of willows at Wellington, which the old commission cut down almost the first thing they did, the trunks were literally covered with egg clusters from the ground up, so that I doubt if you could find many places where you could put your hand on the surface of the tree without covering one or more nests.

Mr. C. S. Mixter, an ex-employee, testined as follows : -

In one place in Chelsea the nests were so thick in 1890 that you could not put your finger down without striking a nest. We scraped the nests off. We had several panfuls.

Despite the great destruction of the moth by the commission during the work of 1890 , the ravages of the creature in Medford were still serious. Although the injury wrought was not as widespread as in 1889 , the stripping of trees and the consequent loss of fruit crops still continued. On Spring Street, in 1890 , the moths appear to have been at their worst. Mr. W. B. Harmon, of No. 55 Spring Street, says :-

In the summer of 1890 the caterpillars destroyed all our fruit. They attacked and stripped the apple trees first, and then turned their attention to the pear trees, which they also stripped. The young fruit was entirely ruined, and we had nothing that fall. The trees in places were actually black with the caterpillars. They would collect in great bunches, and we would sweep them off with a broom. . . We could not step ont of doors, either upon the grass or the walk, without crushing the caterpillars under foot. Over our front door the house was black with them. We would clean them off every morning, but in an hour it would be black again. People could not come in that way. It is no exaggeration to say that there were pecks of the caterpillars under the doorsteps and on the fence. . . The next lot to ours was a vacant brush lot. It actually swarmed with caterpillars, and they came from there into our yard by thousands. 
Other residents of the neighborhood give similar testi. mony :-

In 1890 we lived on Spring Street, and that year the caterpillars seemed to be at their worst. You could not go along the street after dark without getting them all over you. (Mrs. Fenton.)

Four years ago (1890) I saw the gypsy-moth caterpillars by the thousand on the Sherman lot on Spring Street. I never saw such a sight. Their eggs were as thick on the big willows as spawn in a fish. (A. W. Crockford.)

In 1889 the washing on our clothes reel seemed to have a dingy appearance, and I found tiny black worms on the clothes. These would blow over from the Myrtle Street yard adjoining. They were young gypsy-moth caterpillars, although at that time I did not know what they were. The next year they appeared in our yard by swarms. The board walks were completely corered with them. It was impossible to walk without crushing them under foot. On going out of doors they would get on one's clothing. Our trees and other green things were stripped twice and leafed out twice. The foliage of everything that was set out in our yard was riddled; the woodbine alone escaped. We became discouraged, and let things go. The grape-vine suffered. One morning Mr. Merrill picked caterpillars for an hour and a half off one rose bush. The trunk of the umbrella tree in the yard was completely hidden by the mass of caterpillars stuck together. I scraped the caterpillars off into a tin can, but in a short time they were just as thick again on the trunk. Some of our small fruit trees which were stripped at that time have not done much since. In that year (1890) if you went down the street with a sun umbrella, the caterpillars would drop down on it just like rain. (Mrs. E. E. Merrill, Lawrence Street.)

In 1890 the street trees were badly injured by the gypsy-moth caterpillars. At night in the lindens in front of the house there was a noise like the gentle falling of rain. This was the noise of the caterpillars eating the leaves. (Mrs. Plummer.)

In 1890 the whole place was full of gypsy-moth caterpillars. I think I seraped off balf a peck of caterpillars from the sills of the house and from under the porch and from off the trees. (E. Loeffler, Lawrence Street.)

The caterpillars did much damage in the Cross Street neighborhood. Says Mr. J. C. Miller :-

The next year (1890) all the orchards in this section were completely ravaged, and there was no fruit. The caterpillars simply 
swarmed. I destroyed thousands of them by burning them with rags soaked in kerosene. I spent many hours in destroying them, but without making any perceptible difference in their numbers. They were over everything, and even got into the cellars. Some of my apple trees overhang my shop. In the evening when the caterpillars were liveliest the noise of their droppings falling on the shingles sounded like a steady shower. The gutter was brimful and running over with the droppings.

\section{Other sections of the town were afflicted in like manner :-}

In 1890 the apple trees on Fulton Street, Allen Court and Fountain Street were more or less stripped by the gypsy-moth caterpillars. Some of the apple trees were wholly denuded of their foliage, and the crops in some cases were lost. In some cases the limbs of the apple trees were killed by the ravages of the caterpillars. Even pear trees were sometimes badly eaten, and cherries also suffered. The leaves were completely destroyed on a little German willow in my yard. Rose bushes were very badly eaten. (S. F. Weston.)

The large elm in front of my house was full of caterpillars in 1890. The leares were riddled and many were cut off. We would sweep up daily these bits and fragments of leaves which fell from the tree, but the next day the ground beneath would be littered with them again. This elm stands in front of the piazza, and many caterpillars came from the tree upon the house. They were so thick that we could not sit out on the piazza at all that summer. When we opened the front door they would string down all over one. The caterpillars at one time were so thick on a fence on Salem Street that I could have run my hand along the top rail and scooped them up. In this same year a maple tree standing in front of my house on Allen Court was badly eaten by the caterpillars. You could hear them eating up in the tree. (Mrs. P. N. Ryder, Salem Street.)

The gypsy-moth caterpillars were very numerous in 1890 on the Sparrell estate, No. 90 Main Street. . . As evening came on you would see them everywhere on the ground heading for the trees. I have heard the noise of their feeding after dark. They kept coming into my yard from the yards of other people who paid less attention to destroying them. The leares of the trees were just as if they had been scorched. One tree did not bear for several years. (Richard Pierce.)

In $1890 \mathrm{I}$ saw the caterpillars clustering in a mass on the body of an elm tree on South Street. I destroyed a great many of these by burning. (John Hutchins, 16 South Street.) 
Four years ago (1890) in the yards on the north side of Cotting Street the gypsy-moth caterpillars stripped the trees bare of their leaves. (John Cotton.)

In $1890 \mathrm{I}$ fought the pest. They came on to my place in millions in April. The top of my fence rail would be covered with gypsy-moth caterpillars about as small as ants. . . . I would take a brush broom and fight them perhaps an hour and a half. I would destroy them in the morning, and at noon would find as many more and clean them every one from my premises. At night I went through the same operation. I destroyed undoubtedly millions. (W. W. Fifield, before the legislative joint standing committee on Agriculture.)

\section{Residents of Edgeworth make similar statements :-}

The caterpillars were very thick on the house in 1890 . When I went out of my side door I had to take a broom and brush them off the platform. I killed quarts that summer. At the next house they were just as bad. I swept them off above the door again and again, and they seemed to be back again as thick as ever in five minutes. An apple tree back of the house looked as if the leares had all been burned. A few blossoms would come out and then wither away. I saw the gypsy-moth men burn the caterpillars by the pailful. (Mrs. B. Wallace, West Street, Edgeworth.)

In 1890 they were also plentiful, although not as thick as in 1889. I got few if any apples in either year. The caterpillars were larger than your little finger. They would lie thickly together on the trunks of the trees. In the erening they were so thick that they would drop down on the steps from above the door. (William McLaughlin, 107 Oakland Street.) 



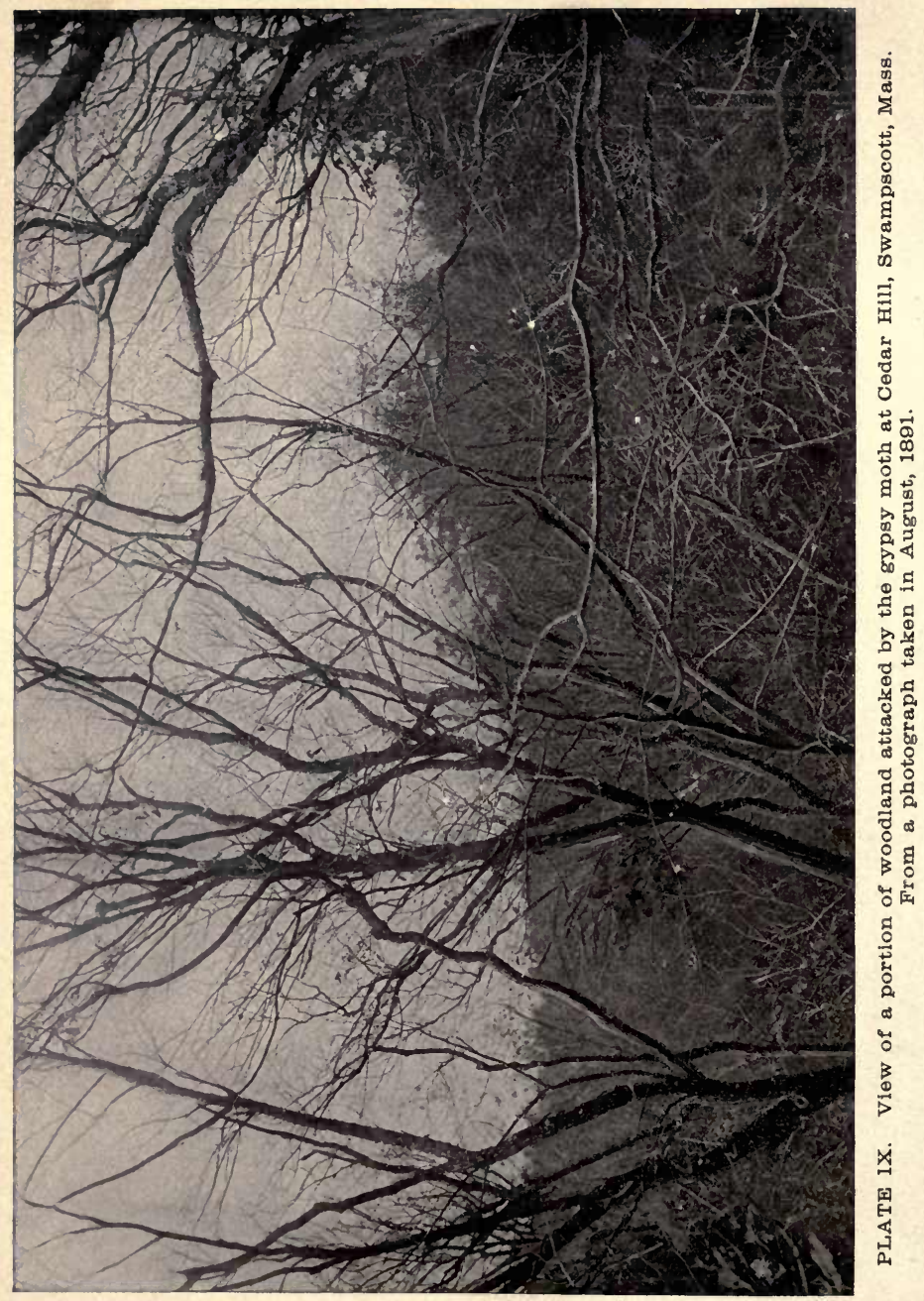




\section{THE WORK OF 1891.}

\section{Appointment of the Second Commission.}

Governor Russell, having removed on Feb. 15, 1891, the salaried commission for the extermination of the gypsy moth, appointed another commission which organized as follows: Prof. N. S. Shaler of Harvard University, chairman, Francis H. Appleton of Peabody, secretary, both members of the State Board of Agriculture, and Hon. Wm. R. Sessions, secretary of that Board. These gentlemen served without remuneration, accepting office with the understanding that legislation would be asked for with reference to placing the work under the control of the State Board of Agriculture, where they believed it properly belonged. The new commissioners, having received information of their appointment by the governor, lost no time in obtaining information from the best authorities in regard to the possibility of exterminating the moth and the best methods of procedure. They received their commission on March 4, and the same day held a conference at the office of the State Board of Agriculture, with several eminent entomologists. Many prominent men from the towns in the region infested by the gypsy moth were also invited to attend. Among those present were Professor Riley, entomologist of the United States Department of Agriculture, Professor Fernald, entomologist of the Hatch Experiment Station and of the Board of Agriculture, Mr. Samuel Scudder of Cambridge, Mayor Wiggin of Malden, Chairman L. S. Gould of the selectmen of Melrose, Selectman W. C. Craig of Medford and W. A. Pierce of Arlington. The prevailing opinion of the entomologists was that recourse must be had to spraying with some of the arsenites in order to bring about the extermination of the moth. (See Appendix A for a report of the conference.)

\section{Preliminary Arrangements.}

On March 12 the commissioners invited the members of the first commission to a consultation at the office of the State Board of Agriculture. Ex-Commissioners Rawson and 
Bradley met with the commissioners. They gave the commission such information as they possessed in regard to the habits of the moth, the methods used in controlling it and preventing its spread, its distribution and the extent of territory infested by it. They also outlined on a map the territory known by them to be infested by the moth. (See map.) The " director of field work" who was appointed on that day was present and consulted with the commissioners in regard to taking immediate steps for the eradication of the moth.

In view of the conflicting opinions expressed in regard to the effectiveness of spraying as a means of extermination, it was decided to organize at once a force of men, and to destroy as many of the eggs of the gypsy moth as possible before the time for hatching arrived. The director took the train at once for Amherst, and visited the Hatch Experiment Station, where two days were spent in consultation with the entomologist, Prof. C. H. Fernald, and in examining insecticide appliances and the literature germane to the subject.

It had been proposed by the commissioners that the director secure the services of some of the students or graduates of the Massachusetts Agricultural College as assistants. Through the good offices of Professor Fernald and Dr. H. H. Goodell, president of the college, in advising the students, several young men were induced to engage in the work of extermination. Some of these students had studied economic entomology under the guidance of the entomologist, and were especially fitted for the work in hand. From that time Professor Fernald's advice and assistance were always freely sought by the committee and director, and as freely given. All plans made were submitted to him for approval, and were only perfected after a careful consideration of his recommendations. The students who had been engaged were released in a few days from their college engagements, and on March 19 nine of them reported at the office of the State Board of Agriculture and received instructions. In the mean time the office and storehouse, which had been used by the first commission, had been opened, an inventory of property taken, and a hasty inspection made of the infested region by the director, in company with Ex-Commissioner Bradley. A few experienced men had also been employed. 


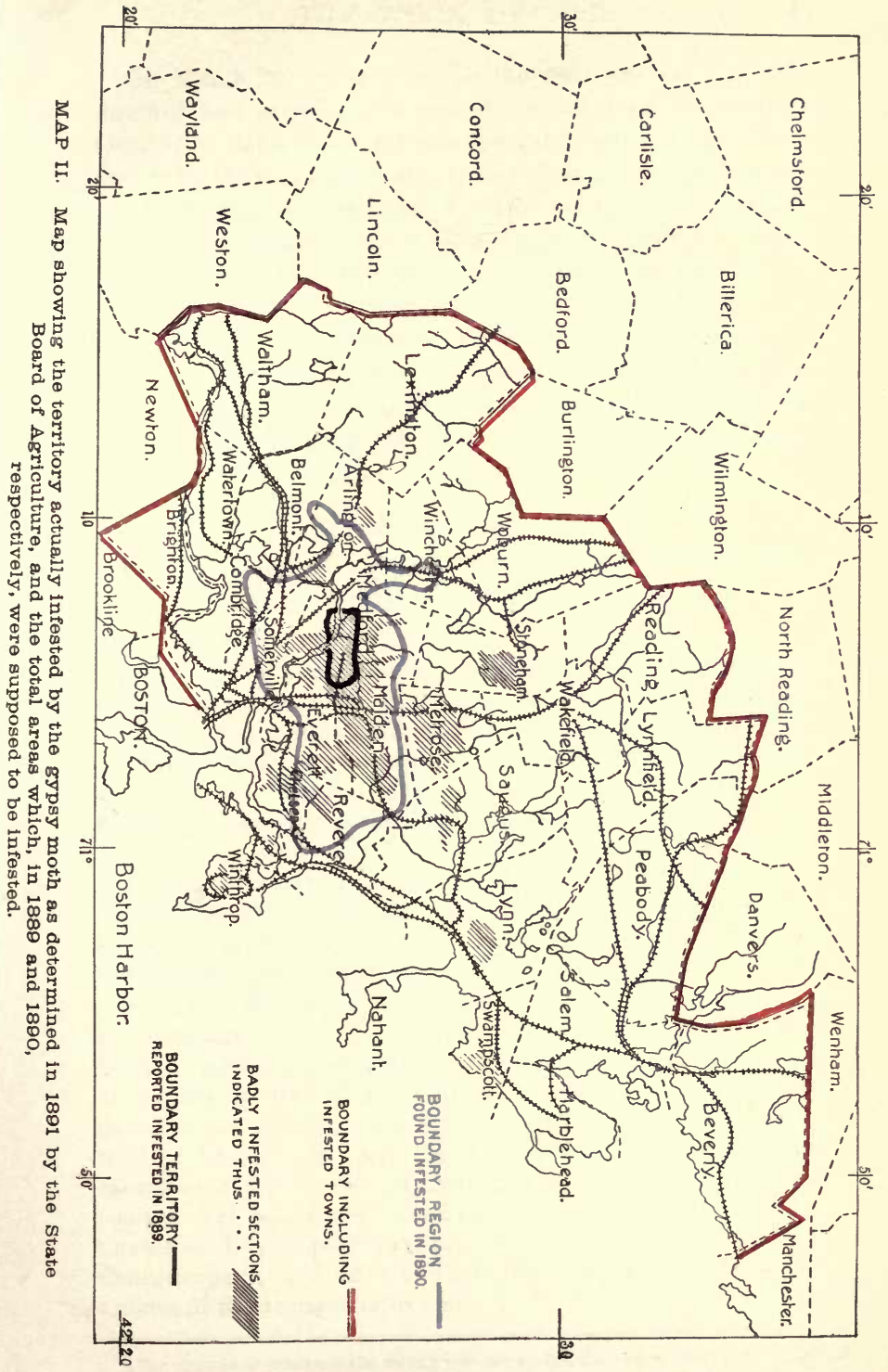



On March 20 actual work in the field was begun. The director and sixteen men visited the farm of Mr. Gilman Osgood in Belmont, which was the only locality in that town known by the first commission to be infested. It was then supposed that this was an isolated moth colony, and an attempt was made to stamp it out by gathering the eggs.* During the day, however, other colonies were found in Belmont.

\section{The Work delegated to the Board of Agriculture.}

The commission of 1891 was superseded after a few weeks by the State Board of Agriculture, the act (chapter 210, Acts of 1891) placing the work in the hands of the Board being approved April 17. The act follows :-

[ACTS OP 1891, CHAPTER 210.]

AN ACT to PRovide AGAINST DEPREDations BY THE INSECT KNOWN AS THE OCNERIA DISPAR OR GYPSY MOTH.

Be it enacted, etc., as follows :

Section 1. The state board of agriculture is hereby authorized, empowered and directed to provide and carry into execution all reasonable measures to prevent the spreading and to secure the extermination of the ocneria dispar or gypsy moth in this Commonwealth; and to this end said board shall have full authority to provide all necessary material and appliances, and to employ such competent persons, servants and agents as it shall from time to time deem necessary in the carrying out the purposes of this act; and said board shall also have the right itself or by any persons, servants or agents employed by it under the provisions of this act to enter upon the lands of any person.

SECT. 2. The owner of any land so entered upon, who shall suffer damage by such entry and acts done thereon by said state board of agriculture or under its direction, may recover the same of the city or town in which the lands so claimed to have been damaged are situate, by action of contract; but any benefits received by such entry and the acts done on such lands in the execution of the purposes of this act shall be determined by the court or jury before whom such action is heard, and the amount thereof shall be applied in reduction of said damages; and the Commonwealth shall refund to said city or town one-half of the amount of the damages recovered.

* The attempt to eradicate the colony was not at that time snccessfal, bnt was accomplished later. The moths were found that season in many localities in Belmont. 
SECT. 3. Said state board of agriculture shall have full authority to make from time to time such rules and regulations in furtherance of the purposes of this act as it shall deem needful, which rules and regulations shall be published in one or more newspapers published in the county of Suffolk; and copies of such rules and regulations shall be posted in at least three public places in each city or town in which said ocneria dispar or gypsy moth shall be found by said board to exist and a copy thereof shall be filed with the city clerk of each such city and with the town clerk of each such town; and any person who shall knowingly violate any of the provisions thereof shall be punished for each violation by a fine not exceeding twenty-five dollars.

Sест. 4. Said state board of agriculture shall keep a record of its transactions and a full account of all its expenditures under this act, and shall by its chairman or secretary make report thereof, with such recommendations and suggestions as said board shall deem necessary, on or before the fourth Wednesday in January, to the general court.

SECr. 5. Said state board of agriculture shall establish the rate of compensation of any persons, servants or agents employed by it under this act.

SECT. 6. Any person who shall purposely resist or obstruct said state board of agriculture, or any persons, servants or agents employed by it under the provisions of this act, while engaged in the execution of the purposes of this act, shall be punished by a fine not exceeding twenty-five dollars for each offence.

SEcr. 7. It shall be unlawful for any person knowingly to bring the insect known as the ocneria dispar or gypsy moth, or its nests or eggs, within this Commonwealth; or for any person knowingly to transport said insect, or its nests or eggs, from any town or city to another town or city within this Commonwealth. Any person who shall offend against the provisions of this section shall be punished by a fine not exceeding two hundred dollars or by imprisonment in the house of correction not exceeding sixty days, or by both such fine and imprisonment.

Sест. 8. The said state board of agriculture may exercise all the duties and powers herein conferred upon said board, by and through its secretary and such members of said board as it may designate and appoint to have in charge, in conjunction with its secretary, the execution of the purposes of this act.

SECT. 9. All moneys heretofore appropriated or authorized to be expended under the provisions of chapters ninety-five and one hundred and fifty-seven of the acts of the year eighteen hundred and ninety or by any other act, and not heretofore expended, are 
hereby appropriated and authorized to be expended by the said board in carrying out the purposes of this act.

SECT. 10. All the property acquired and records kept under the provisions of said chapter ninety-five of the acts of the year eighteen hundred and ninety shall be delivered into the custody of said board, and said board is authorized to take, receive and use the same for the purposes of this act.

SEcr. 11. Chapter ninety-five of the acts of the year eighteen hundred and ninety is hereby repealed, but all claims for damages under said chapter ninety-five for entry upon and acts done on the lands of any person may be prosecuted, as therein provided, against the city or town wherein the lands entered upon are situate, and the damages shall be ascertained and one-half of the amount thereof recovered against any city or town shall be refunded to such city or town as provided in said chapter ninety-five. [Approved April 17, 1891.

A special meeting of the Board of Agriculture was held on April 28, and Messrs. Sessions, Shaler and Appleton were appointed a committee in accordance with the provisions of section 8 of the act.

This committee organized on May 19, with the choice of Mr. Sessions as chairman and secretary. The committee continued the work which it had begun as a commission, confirming the appointment of the field director, and directed that the work being done in the field should be continued. A code of rules and regulations for the public was adopted. (See Appendix B.) At the time of appointment of the second commission there remained unexpended of the appropriation of 1890 the sum of $\$ 24,460.68$. On May 19 $\$ 11,003.22$ only remained. On June 30 an additional appropriation of $\$ 50,000$ was made by the Legislature.

\section{Mapping the Infested Region.}

In apportioning the territory to different inspectors, it was found necessary to make a hasty survey of the field and to plat it on maps of the towns known to be infested and those contiguous to them. These maps were divided into sections of such size as could be conveniently carried by the men engaged in field work. For convenience these sections were so drawn as to be bounded by town lines, streets and 
railways, or by natural bounds, such as streams and lakes. Each map was accompanied by a written description of the boundaries of the section which it represented. The work was done, under the supervision of the director, by Mr. J. O. Goodwin of Medford, an experienced engineer, well acquainted with the topography of the region. It was intended so to divide the region that each inspector or foreman could be held responsible for a certain tract or section with definite and well-marked boundaries. Each section in each town was numbered. Each inspector, on entering the field, was required to run the boundaries of the section allotted to him, and mark the section number prominently with white paint on fixed objects at each angle of the boundary. To avoid any possible confusion of lines, each inspector was also required to "blaze" or mark the line with white paint wherever it was not otherwise easily distinguishable. When this system was extended into the towns farthest from the infested centre, it was not found necessary to divide such towns into sections on account of the comparatively small number of moth colonies found in them. They were treated, therefore, as sections, and an inspector with a gang of men was placed in charge of each. If, however, it was found, on close inspection, that a town that had not been "sectioned" was badly infested, and would require several gangs of men, it was then "sectioned." Each inspector was required occasionally to sketch maps; also to locate and mark infested localities on section maps, and to make such additions to the maps as were from time to time necessitated by the construction of new streets or railways in the infested towns.

\section{Organization and Instruction of the Field Force.}

Whenever suitable men could be found they were added to the force. Some of the most capable men of the force of 1890 were re-employed. Others, whose previous experience in field study in entomology or kindred sciences had fitted them for careful observation, were engaged and trained to act as inspectors.

When field operations were commenced the eggs of the moth were the only living form of the pest. The men were taught how to recognize and destroy them, and to 
distinguish them from those of native moths. They were taught to observe all evidences of the presence of the gypsy moth, and were requested to secure by personal observation as the season advanced all possible information in regard to its habits. When the inspectors had gained sufficient knowledge to enable them properly to instruct others, laborers were employed, and each inspector was put in charge of a few men, over whom he was given full authority with instructions to recommend the discharge of any man who proved inefficient or untrustworthy. Each inspector was given a short time in which to instruct his men by engaging them in practical work in the worst-infested portions of Malden and Medford. Then a section (indicated by a map) was allotted him, with instructions to inspect it and destroy the eggs therein. When eggs were found on a tree or other object, certain characters were marked upon it with white paint, and the locality was designated on the map.

As the season advanced and the extent of the region occupied by the moth became known, it was found necessary to employ two hundred and fifty men, and distribute them over this region. It became evident that it was impossible for one man to keep the entire field under supervision. Six superintendents were then selected from among the most efficient of the inspectors. Each of these was required to supervise the work in several towns. When spraying began, one man was placed in charge of tools and supplies, including spraying apparatus and teams. A code of rules and regulations was prepared and printed early in the season, and copies were distributed among the employees. (See Appendix B.)

\section{Daily Reports and Records.}

Each inspector was instructed to make out daily a written report of the work done by himself and men, and to incorporate in these reports his observations on the habits of the moth and its parasites, notes on its distribution and all useful information acquired by him in regard to the moth or methods of eradicating it. In these reports the number of trees, buildings, fences, walls, hedges and other objects inspected daily was recorded; the number of each on which the moth was found; the number of each form of the moth 
found and destroyed by hand on each estate; the number of trees cut or treated by banding, burlapping, cementing or scraping; and the number of acres of brush or woodland burned over. Mention was also made of any work left unfinished for the time being, or thought to be necessary later. Whenever the moths were found in a locality not before known to be infested, the inspector was required to sketch on the day's report a map of the locality, marking the colony in a manner prescribed and in such a way that it could be found at once by one not familiar with the place.

The name of the inspector appears on each of his daily reports, together with the names of his men. The number of hours per day that each man works is also recorded on the report. The reports are filed, and by them it is possible to determine which inspector and men are responsible for any work done at any point on a given day in any year, and to fix the responsibility should any omission of duty or any misdemeanor occur on the part of the employees. An account with each infested estate is kept in the office in books known as "section books."

The section books in which the records of field work are kept now number seventy-eight, of one hundred pages each. On the first page of each book the bounds and a general description of the section are given, and the work done in it and the results attained for the year are recorded on the succeeding pages. There is also a "blue print" map marked in such a way as to designate each infested locality. (See Appendix C.) It is possible by consulting these books to learn how much work has been done on each infested estate, how many units of each form of the moth have been killed by hand, and whether the moth has been eradicated from that locality or not. There is thus kept a complete record of the progress made.

\section{The Spring Inspection.}

An inspection of the infested region was begun in March, with a view of determining its extent. This inspection commenced in Medford and Malden near the centre of the region, and extended to the surrounding towns as the organization of the force was perfected and its size increased. Each 
inspector was first sent with his squad to inspect a section in one of the towns then known to be infested. He was instructed to inspect the entire territory within the boundaries of the section, and destroy all the eggs found therein.

It was at once seen that the moth was most numerous along the thoroughfares. A few of the most expert men were sent into the towns nearest Malden and Medford to examine the roadsides and mark any colonies found. These men speedily found the moth in Lexington, Winchester, Wakefield, Melrose, Revere and Saugus, thus greatly adding to the knowledge of the extent of the infested region. Work was hurried forward in all these towns. The eggs were cut or scraped from the trees with knives, gathered into cans and burned with oil in small stoves made for the purpose. Rubbish and undergrowth containing eggs were also destroyed by fire. As much more territory was found infested than was at first estimated, it was found impossible to secure and train men enough to make a thorough search of the entire region and destroy all the eggs before hatching time. As it was necessary to determine as soon as possible how far the moth had become disseminated, a portion of the work in Malden and Medford was given up, and the men who had been engaged in destroying eggs there were sent into the outlying towns. For this reason, when the eggs began hatching a considerable area yet remained in a few of the inner towns where the eggs had not been destroyed. Many eggs which had been scattered about, both by the work of the first commission in the fall of 1890 and by the work in the spring of 1891, hatched, and caterpillars began to appear in large numbers over a wide area. When work was begun the time remaining for this inspection and egg killing did not exceed six weeks, as the eggs begin hatching before May 1. Yet in that short time the moths had been found far beyond the utmost limits of the region previously known as infested.

The Condition in which the Infested Region was found in 1891.

When work was begun by the second commission the eggs of the moth were found in great numbers upon the trees in 
certain localities in which little work had been done in the fall of 1890 by the first commission. In some of these places the bark of the trees was so covered with egg clusters that it presented a yellowish appearance. This was the case only in parts of Medford and at a few points in Malden. Wherever the first commission had worked the previous autumn, few egg clusters were found on the trees. It was decided, however, to make a thorough search of all localities wherever it was practicable. With this in view, the base boards of fences were taken off, plank walks raised, the steps of houses torn up and cellars and buildings entered. In such places the eggs of the moth were found concealed in great numbers. In some cases quarts of eggs were taken out from beneath piazzas or flights of steps. Many eggs were also found in some cellars. As the inspection progressed, $\mathfrak{d}$ few badly infested localities were found in other towns and many eggs were destroyed. In most of these towns the moths had not been colonized long enough to become numerous, but were found in isolated colonies along the roads. Such inspections as were made of woodlands revealed in most cases comparatively few colonies, most of them small and isolated.

A careful estimate has been made from the daily reports of inspectors, which shows the number of egg clusters destroyed during the first six weeks of 1891 to be 757,760. The number of eggs contained in these clusters would probably be from three to five hundred millions.

\section{The Enforcement of Police Regulations.}

When in May the caterpillars were seen to be dropping by their threads from the trees upon passing teams and vehicles, it was deemed necessary to do something to check their distribution in this nanner. The method (used by the commission of 1890) of guarding the roads leading out of the worst-infested district was tried. The police were required to inspect all horses and vehicles going out of the infested district, record all facts regarding their destination, and destroy any caterpillars found upon them. They were also required to enforce the regulations of the department in regard to the hauling of hay or manure without covers, and 
other matters relating to team traffic. The police outposts were inspected by Professor Shaler of the committee in charge of the work, by the director and by the superintendents, and it was soon seen that the method was impracticable. A perfect cordon could not be maintained, and the results obtained were not proportionate to the expense incurred. At the end of two weeks the plan was abandoned. In the mean time some good had been done by destroying caterpillars found on vehicles, and by gaining a knowledge of the destination of the teaming between badly infested localities and towns outside of the known infested district. This knowledge was utilized in the fall inspection.

\section{Spraying.}

In April the director's office was removed to Malden, at a point near the centre of the infested region and having better railway communications with the surrounding towns. More commodious rooms were here secured, and experimenting with insecticides was begun. Most economic entomologists concurred in recommending spraying with arsenical poisons for killıng all leaf-eating larvæ. Following such advice, experiments with arsenites were begun. An early supply of gypsy-moth larvæ was obtained by artificial hatching, and the experimental work was continued during the spring and summer, the experiments with Paris green giving the best results. In the laboratory it was found that young caterpillars, fed upon plants to which this poison had been properly applied, died within a few days. In later experiments it was noticed that a considerable proportion of the larger caterpillars survived. In the experimental work in the laboratory; no injury to the foliage was observed when a mixture of one pound of this poison to one hundred and fifty gallons of water was used. Glucose was also added to retain the poison upon the leaves.

When it became evident that Paris green was the most effective of the arsenites, preparations were made for its use on an extensive scale. In the first part of May teamsters were employed, and twenty spraying outfits were put upon the road in Medford. The number of men and teams was soon found to be insufficient. Ten additional spraying out- 
fits were purchased, and the capacity of each was doubled by improved appliances. Each outfit with the accompanying squad of men was under the immediate charge of an inspector. When the apparatus had been tested and the men had gained the skill necessary for its intelligent use, the entire force 'was sent to the periphery of the region then known to be occupied by the moth and ordered to work toward the centre. The infested area was thus sprayed until the middle of July. At that date numbers of caterpillars were fully grown and had stopped feeding; some had pupated and others were wandering from tree to tree. Other means were then used for the destruction of both caterpillars and pupre.

Considerable opposition to the use of Paris green for spraying was manifested by many people living in the infested towns. A mass meeting of opponents of the spraying was held in Medford. One citizen, who attempted to cut the hose attached to one of the spraying tanks, and threatened with violence the employees of the Board who had entered upon his land, was arrested and fined. Others neutralized the effects of the spraying by turning the garden hose upon trees and shrubs that had been sprayed, and washing off the solution. The opposition to the spraying affected the results of the work unfavorably to a considerable extent. In June a bulletin of information was issued by the State Board of Agriculture, containing quotations from Professor Riley and other economic entomologists as to the lack of danger to man or beast attending the use of Paris green. This bulletin was distributed freely among the people of the district, but it failed to allay the popular prejudice against the spraying.

During the spraying season Professor Riley and Mr. Samuel Henshaw (at that time an entomological agent of the United States Department of Agriculture) visited the district and inspected and criticised the operations in the field.

It became evident before the close of the season that the spraying, while reducing the numbers of the moth, could not be relied upon as a means of extermination, for many caterpillars survived its effects. In June, when the caterpillars had reached the fourth molt and begun to cluster in 


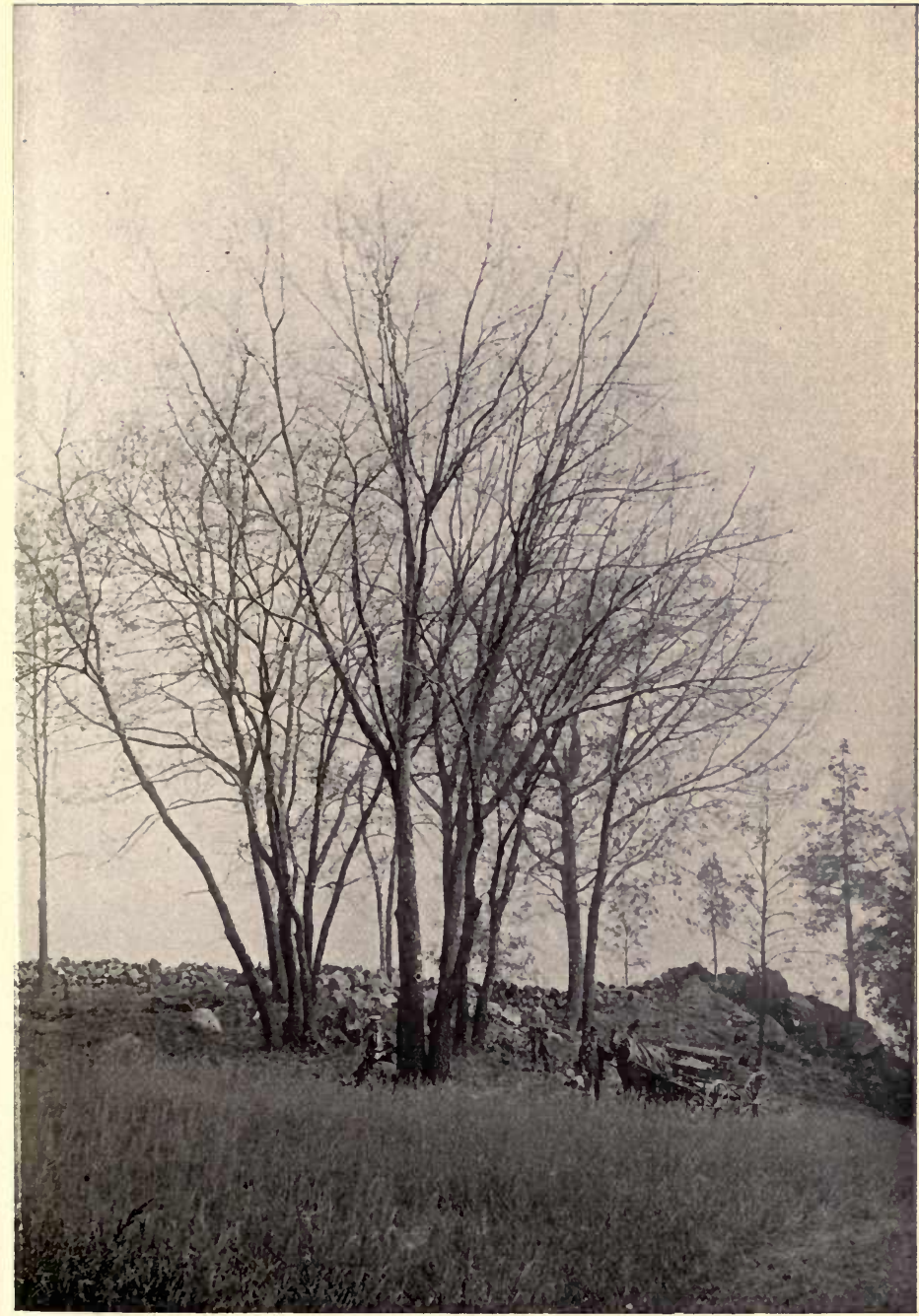

PLATE X. Trees stripped by caterplllars of the gypsy moth, Arlington, Mass. From a photograph taken July 9, 1891. 

cavities of the tree trunks and in other hiding places, they were destroyed by spraying with insecticides which killed them by contact. The arsenites have no effect when used in this way. Burlap bands were also placed about the trees to serve as artificial hiding places for the caterpillars, and many were destroyed beneath the bands. This method was so successful that it was generally adopted, and more than sixty-eight thousand trees were banded during the season.

\section{Entomological Work.}

On June 18 Prof. Charles H. Fernald was appointed entomological adviser to the committee. Arrangements were made by which he could give a portion of his time to the work, and one of his assistants, Mr. E. P. Felt, was employed in making observations and experiments. Professor Fernald critically examined the field work, reported thereon, and made frequent subsequent visits of inspection to the infested territory, directing the experiments and giving advice concerning the work in the field. At his suggestion the inspectors were directed to watch for parasites of the moth in its various stages. Several parasites were discovered. All dead pupre found during the season in the central towns were collected and preserved, in order that the parasites preying upon them might be obtained. The dead pupæ found in the outer towns of the infested territory were left on the trees, that the parasites might escape from them and continue their work. The inspectors were encouraged in their observations on the habits and life history of the moth. The feeding habits were made the subject of especially careful observation, and all the information thus gained was recorded and tabulated for future use.

Numbers and Destructiveness of the Moth in the Summer of 1891.

Though a great number of eggs had been burned in the spring, and thousands of caterpillars had been killed by spraying, burning, burlapping and other means, they were still so numerous in the summer of 1891 that some damage was done in certain localities. A few trees in some orchards in Malden and Medford were almost defoliated. 
In one case in Medford three apple trees which had been sprayed were only saved from defoliation by the use of contact insecticides. Two bushels of dead larvæ and pupæ were gathered from the ground beneath these trees. The injury was most severe wherever a locality had been overlooked in the spring inspection, and numerous eggs thereby allowed to hatch. Early in June a colony of moths was found in a small grove of trees in Arlington. Although the trees were sprayed twice with a mixture of Paris green and water (two pounds to one hundred and fifty gallons), the foliage was entirely destroyed, and the caterpillars then spread in all directions through the fields, eating the grass as they went. In spite of all that was done to stay them, many reached the woodland one-eighth of a mile away. Others, having defoliated the trees, clustered in masses on the trunks and branches and about and upon the rocks beneath. These were finally destroyed by fire. After the larvæ upon the trees and undergrowth had been destroyed, the stones beneath the trees were overhauled and pupæ were gathered at the rate of about eleven hundred per hour per man. There were similar but less destructive outbreaks in other parts of Arlington, and in Winchester, Chelsea and Melrose, but the one of greatest magnitude occurred in Swampscott. This was beyond the range of the spring inspection, and the colony was found in July by an inspector who had been sent out to search that region for caterpillars. It was situated on a hillside near Humphrey Street. There were several trees infested in a yard and others in a small orchard on a hillside in the rear. Back of the orchard was a pasture somewhat overgrown with trees and shrubs. On the east and extending over the highest point of the hill there was woodland composed of a great variety of trees, both deciduous and coniferous. Beginning at the edge of the orchard a dense undergrowth or jungle of creeping vines and bushes extended into the woodland.

When this colony was first found the caterpillars had begun eating the foliage of nearly all species of trees and plants in the immediate vicinity of the house and outbuildings, and were fast spreading into the woodland and pasture. A gang of men was sent to the spot with a spraying tank 


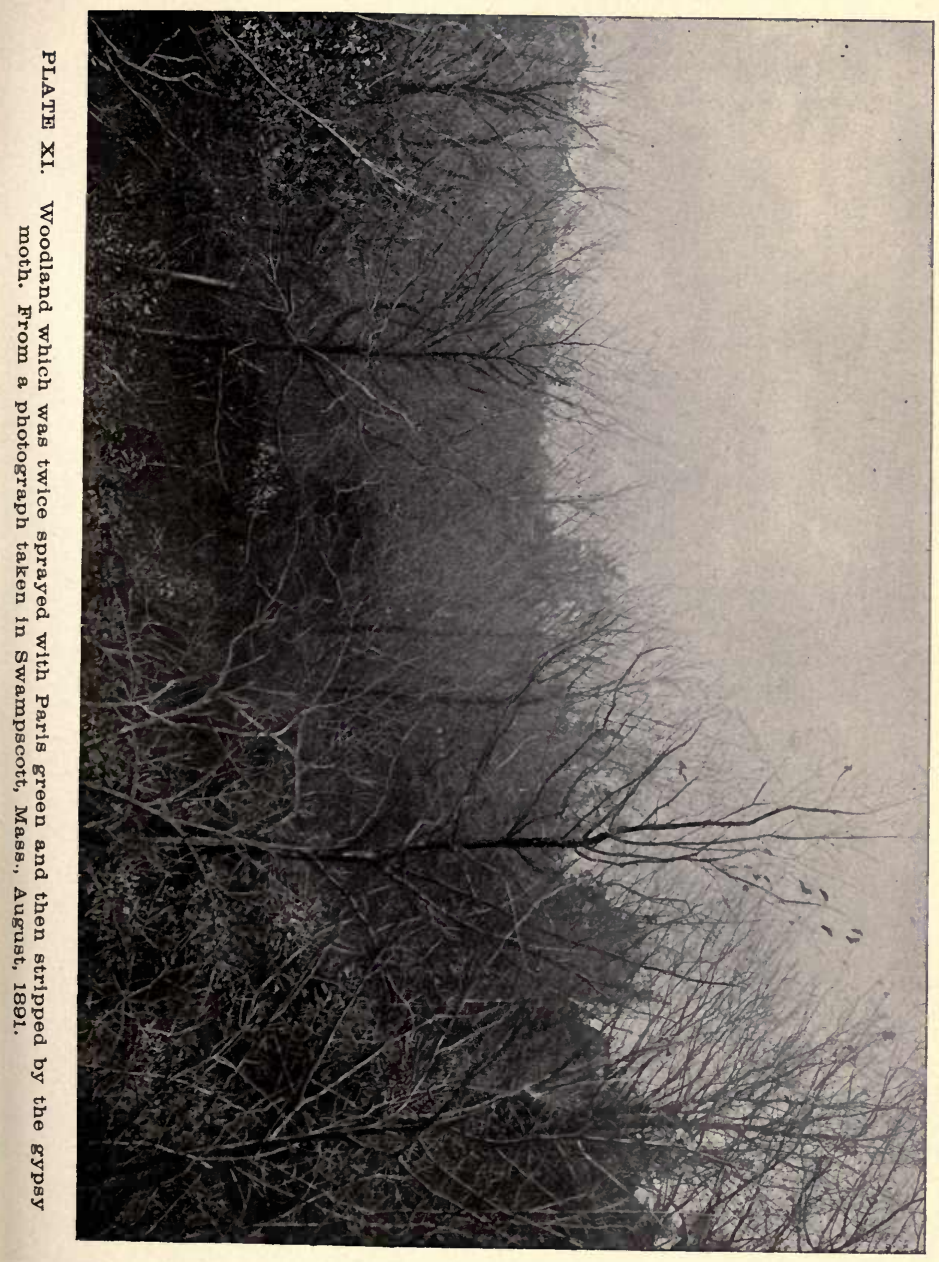



which was set on a hill near by. Water was drawn by a hose from a near hydrant, and the trees, shrubbery and vegetation in the whole neighborhood were sprayed heavily with Paris green. As this did not appear to check the ravages of the larvæ, the locality was resprayed at once. Within a few days of the time of the last spraying nearly every green leaf on several acres was eaten by the caterpillars. This destruction continued incessantly, and the injury spread in all directions. Six gangs of men were despatched at once with orders to surround the infested locality and work from the outside to the centre, and burn with an oil spray all undergrowth and everything on which the larvæ could feed, destroying at the same time with the fire all the caterpillars possible. This treatment effectually checked their diffusion, thereby preventing further injury. The pupæ were raked off the worst-infested trunks and burned or otherwise destroyed.

Mr. C. R. Drew of Medford, writing of the numbers of the moth in 1891 at his place, says :-

There seemed to be almost millions of gypsy-moth caterpillars in 1891 at the corner of Fountain and Salem streets, where I then lived. They very nearly destroyed a blue pearmain apple tree. It bore no fruit that year. This tree blossomed out in the spring, but when it began to leaf out the caterpillars attacked it and every vestige of green clisappeared. It looked as if fire had run through the tree. Several sweet-apple trees were also badly eaten. You could hear the noise of the caterpillars eating in the trees at dusk. They were so thick that you could scrape them off anywhere. They crawled all over the concrete, and we crushed them as we walked. We had seats on the grass under the trees, but we could not sit there because the caterpillars dropped down so thickly. It was possible daily to gather a half water-bucketful of them, but the next day they would be just as bad.

Mr. L. B. Sanderson, an employee of the Board, reports : -

At Mr. Drew's yard we got one day twenty-two quarts of caterpillars.

Such cases, however, were exceptional, for the greater portion of moths in the worst-infested places were destroyed 
by the agents of the Board of Agriculture before serious injury had been done.

\section{Fall Inspection and Egg Gathering.}

In September, when the moths had laid their eggs, the force of men was reduced. The most expert employees were retained, and these were engaged in destroying eggs in the worst-infested districts of Malden and Medford, until, by practice, they had become efficient in this sort of work. As soon as the leaves had fallen from deciduous trees, the men were sent into the towns and cities beyond the region which the moth was known to occupy, and the inspection, which had been interrupted in the spring by the growing leaves, was continued. An inspector was assigned to each town, and instructed to inspect that town hastily, and if moths were found there to proceed immediately to the next, and so on until a wide belt of territory around the infested region had been inspected in which no moths could be found. Eighteen towns and three cities outside of the known infested region were thus inspected in November and December. The moths were found in each of the cities and in four of the towns, and it was reported to the Legislature that whereas in the spring the moths had been supposed to be confined to a few towns, they were now known to be in thirty townships, as follows: Arlington, Belmont, Beverly, Brighton (Ward 25, Boston), Cambridge, Charlestown (Wards 3, 4 and 5, Boston), Chelsea, East Boston (Wards 1 and 2, Boston), Everett, Lexington, Lynn, Lynnfield, Malden, Marblehead, Medford, Melrose, Peabody, Reading, Revere, Salem, Swampseott, Saugus, Somerville, Stoneham, Waltham, Wakefield, Watertown, Winchester, Winthrop and Woburn.

\section{Results of the Work.}

During the season of 1891 the work carried on was effective, inasmuch as it destroyed all the large colonies of the moth, and protected the fruit and shade trees of the State from further injury. The spraying and other treatment of the trees redoubled the fruit crop of the district. The measures used disposed of the annual increase of the moth, and reduced the numbers originally found by about ninety per cent. 
The inspection of 1891 gave a closely approximate idea of the size of the region infested by the moth, as it has not since been found in any numbers or to any distance outside of the boundaries then laid down. As the work was necessarily hurried in order to complete it by Jan. 1, 1892, so that the size of the infested region might be reported to the Legislature, many small colonies were overlooked. Thus, though the approximate area of the infested region was determined, its condition was not thoroughly known at the close of 1891. It was seen early in the season that the appropriation made would not be sufficient to exterminate the moth in one year, but it was thought that $\$ 75,000$ was all that could be used to advantage until such time as the exact area and condition of the infested region could be ascertained. 


\section{THE WORK OF 1892 .}

On the first of January, 1892, there remained of the appropriation of 1891 the sum of $\$ 5,213.13$. This could have been used to good advantage before January 1, but it was thought to be of more importance to retain it, so that the most expert men might be kept at work until such time as another appropriation would become available. The nucleus of an organization was thus maintained during the winter. Early in January, 1892, when the Legislature convened, the State Board of Agriculture by its secretary made a report recommending an appropriation of $\$ 75,000$ for the year. Though the money available in $1891 \mathrm{had}$ proved insufficient to maintain as large a force as was needed to obtain the best results, the committee deemed it unwise to recommend more than $\$ 75,000$ for the work of 1892 . The experience of 1891 had determined that spraying with arsenical insecticides (the method which had been most strongly recommended by the best authorities) was a failure as a means of extermination. The experimental work of the first year had not resulted in providing a better insecticide, and further experiments were necessary. Again, much difficulty had been experienced in securing efficient and trustworthy men. It was evident that a large portion of another season must be occupied in selecting and training a body of men which could be used in organizing a larger force.

Although the moths had been found scattered over a region of two hundred square miles, there was considerable doubt as to whether the extent of the infested area had yet been determined. Though the outlook was not altogether encouraging, nine-tenths of the moths in the region found infested had been destroyed, and there was no immediate danger from them so long as they were kept under control. The committee were confident that the moths could be controlled and their numbers at the same time still further reduced with the amount of money recommended, while in the mean time experimental work could be carried on to determine the policy for the future. 
Only forty of the most efficient men had been retained from the field force of 1891 , and by reason of delay in granting the appropriation, the committee were obliged to discharge them all. Some of the most capable of these men soon obtained employment elsewhere, and this loss reduced the efficiency of the working force. Very little work was accomplished during the month of February. Finally, on March 1 , an act authorizing an appropriation of $\$ 75,000$ was passed by the Legislature. This made it possible to make arrangements to resume field work, although unseasonable snow-storms still further delayed the spring inspection. The old method of scraping the eggs from the trees and burning them was discarded, and the eggs were left on the trees and treated with acids or creosote. The scattering of eggs was thus avoided.

The experimental work of 1891 resulted in the trial in the field in 1892 of several new insecticides. None of them, however, proved generally effective, although bromine and chlorine were useful in destroying eggs in hollow trees.

Professor. Fernald had recommended in December, 1891, " that the nests of the gypsy moth hereafter gathered be preserved in such a way that the eggs of parasites that may have been laid in such eggs of the gypsy moth be allowed an opportunity to develop into the perfect insect." This plan was put into operation early in 1892 in the towns of Malden and Medford. All the eggs gathered were taken to a central point in each town, and were there kept in a closed case until all were hatched. As only a single specimen of an egg parasite was obtained in this way, the plan was abandoned.

Owing to the lateness of the appropriation, which caused delay in examining and employing men, and the unseasonable weather, it was impossible before hatching time to make a thorough inspection of the infested region, but an attempt was made to destroy all egg clusters found along the roads. This was done to prevent the spreading of the caterpillars. This method was intended to take the place of police outposts on the roads. It was a preventive measure, for, if the eggs were removed from the trees, there would be no caterpillars to spin or drop down upon the passing vehicles and 
teams. It was in this manner that the moths had been distributed in former years. Wherever large trees near highways had been cleared of eggs, they were banded with tree ink or with "Raupenleim" ("insect lime") to prevent the caterpillars ascending them from the ground. This was intended to keep the moth out of such trees for the season. Very little spraying was done during 1892. Two spraying outfits were kept busy for a short time, and were sent from place to place wherever the caterpillars appeared in considerable numbers. The trees in such localities were sprayed when the caterpillars were small, and many of the latter were killed. This served to lessen the dissemination. The method of burlapping trees was used in place of spraying, and was extensively employed over most of the infested region. The force of employees, numbering two hundred and thirty-four during the spring inspection, was afterwards reduced, but was again increased during the inspection of burlaps. The appropriation was not sufficient, however, to provide enough men to thoroughly examine the burlaps. Notwithstanding this disadvantage, burlapping and hand-killing during the summer disposed of nine-tenths of the gypsy moths in the places known to be infested, and in many localities they were exterminated by this work alone.

During the fall inspection an attempt was made to search the country thoroughly, but again the lack of money was felt, and it was found necessary soon after the first of September to discharge a large proportion of the force. Only about forty of the most expert men could be retained. It was impossible with this number of men to make a thorough examination of the entire infested region. A great deal of effort was devoted to determining whether the moth had spread farther than had been reported in 1891. A considerable proportion of the later expenditure of the year was thus used in the towns immediately surrounding the infested region. But the moth was not discovered in any other towns in 1892 .

The infested region was so well covered by the distribution of the force that no scrious outbreak of the moth occurred in 1892. Enough had now been learned of the condition of the infested territory to convince the committee 

that larger appropriations were needed. They believed that they had now learned by experience how to eradicate the moth. A large number of colonies had already been exterminated, and it had been proved that the moths could be exterminated wherever they were found. The committee in its annual report to the Board recommended that an appropriation of $\$ 165,000$ be granted for the work of 1893 . The report was accepted by the Board, and presented to the Legislature of 1893. The report begins as follows:-

In presenting the report of the gypsy moth department of the State Board of Agriculture, in accordance with the provisions of chapter 210 , Acts of 1891 , the committee desires to call attention to the fact that this effort to exterminate the Ocneria dispar is the first attempt on a large scale ever made in this Commonwealth to destroy a species of insect, consequently there was no trustworthy experience to guide the work. As it was an imported insect, its habits and peculiarities in this country had to be ascertained before the most effective methods of destruction could be determined.

Much of the work that has been done may be considered as in a measure experimental. As we have become more familiar with the extent of the territory invaded by the moth, the magnitude of the task has become more apparent. When the Legislature made the first appropriation, it was supposed that the moth occupied but a small part of one town. Careful inquiry has shown that it infests thirty cities and towns. From our observations we have no doubt that it was in nearly every one of these localities in 1890 , when the campaign of extermination was commenced.*

During the year much had been done toward inspecting the towns on the borders of the infested district. Of this, the committee reports :-

Much effort, involving a large expenditure, has been devoted to the inspection of territory outside the infested limit. Numerous letters have been received from different parts of the State and from adjoining States, to the effect that supposed gypsy moths had been found. These notices have in all cases led to an inspection of the suspected locality. The towns just outside those

* Report of the State Board of Agriculture on the Extermination of the Gypsy Moth, Jannary, 1893, page 5. 
infested have also received some attention, but in no case has the gypsy moth been found outside of the limits reported last year.*

Such expert men as could be spared from other work had been detailed to examine as much as possible of the large wooded region in the infested territory, so that its condition might be reported on as fully as possible to the Legislature. The woodland was found to be more or less infested, but its exact condition could not be determined, owing to a lack of money and trained men. On what was known of its condition, the committee based their recommendation for a larger appropriation, setting forth their plans in regard to it in the following words:-

We desire to present to the Legislature the state of the problem and various plans for solving it, with an estimate of the cost of each class of work for the next year. There are large areas of woodland in the infested towns. There are points in these forested districts known to be infested. There are probably other points where colonies have been established, and possibly many such. The dense growth of the underbrush in this woodland, and the thick carpet of dead leaves on the ground, make perfect inspection almost impossible. There are about four hundred acres of this woodland, which will, if it is allowed to remain, continue to be an uncertain element in our problem.

If the timber could be felled and burned on the ground during the winter and early spring, and the ground carefully burned over twice during the summer, that element would be eliminated. We estimate the cost of this work at $\$ 125$ per acre, or a total of $\$ 50,000$; but we are confronted with the fact that most of the forest is situated in Medford, Malden, Arlington, Melrose, Winchester and Stoneham, and that much of it is valued for prospective parks. Its destruction would be considered a calamity by the inhabitants of these places.

We believe that with sufficient means, and in several years' time, these forest lands can be cleared of moths without destroying the timber. To accomplish it all the underbiush and all the decayed and worthless trees must be cut and destroyed by fire, the ground burned over, and the whole carefully inspected at least twice each year. Burlaps must be placed wherever the moth appears or has been found previous to the clearing up. The latter

* Report of the State Board of Agriculture on the Extermination of the Gypsy Moth, January, 1893, page 6. 
plan will in the aggregate cost more than the former, but, as the work need not necessarily be all done at once, and as it could be done in connection with the other work of the department, utilizing the time of the men in the winter and early spring, it may be the best plan to pursue.*

The committee had undertaken to secure as full information as possible in regard to European experience with the gypsy moth and the methods used in Europe to combat it, as well as the probabilities regarding its future in this country and the destruction which would be caused by it if it were allowed to spread unchecked except by individual effort. The information thus gained was tersely embodied in the report to the Legislature, as a warning to show what might be expected in the future. Tables of damage done to crops in the United States by insects were presented in the field director's report. The entomologist, who had at first grave doubts of the possibility of complete extermination, stated in his report that he had been led to believe that such a thing was really possible, provided the work were continued for several years with sufficient appropriations to keep the entire territory under careful supervision. The State Board of Agriculture, approving the action of its committee, urged that the appropriation recommended be granted, and that every effort be made at once to rid the State of the pest.

* Report of the State Board of Agriculiure on the Extermination of the Gypsy Noth, January, 1893, page 7. 


\section{THE WORK OF 1893.}

Pursuant to the recommendation of the State Board of Agriculture, the joint standing committee on agriculture of the Legislature of 1893 reported a resolve appropriating $\$ 165,000$ for the extermination of the gypsy moth. While this resolve was before the committee on finance, the committee on the extermination of the gypsy moth roted "to suggest to the committee on finance that they advise the appointment of a committee of three or five of the Legislature to investigate the work of the committee of the Board of Agriculture during the year 1893, and make such a report to the next Legislature as in their judgment seems wise." No such committee was appointed. Members of the Board of Agriculture appeared before the committee on finance to advocate the appropriation of $\$ 165,000$.' Expert entomologists and many citizens of the infested district also appeared or sent communications, advising that every possible effort be made to exterminate the moth, and that the Board of Agriculture be given the full appropriation. But the finance committee reported in favor of reducing the amount to $\$ 100,000$.

There was considerable delay in granting this appropriation, and, as the money remaining from 1892 was nearly exhausted, it became necessary to suspend all field work. While the work was thus suspended and the committee was awaiting an appropriation, as in 1892 , several of the most experienced men obtained other situations. This loss reduced the efficiency of the force. By reason of the delay several weeks of the best working time of the year passed unutilized. On April 12 an appropriation of $\$ 100,000$ was made by the Legislature. A resolve was also sent to Congress by the Legislature, asking for $\$ 100,000$ additional to continue the work. This resolve got no further than the committee room, and was never entertained by Congress.

As soon as the appropriation became available, field work was again commenced. The force of men was inereased as fast as was compatible with their proper examination and training. 
The short time remaining before egg-hatching time was utilized in destroying eggs in the worst-infested towns, and searching for them in the outer and less-infested towns. The trees in infested localities were banded with burlaps. During the summer the burlaps in the outer towns were visited daily, and the trees were occasionally examined, both by the regular men and by special inspectors. By this means the moth was almost completely eradicated from such towns, and in some of these towns no eggs were found during the autumn. Owing to the insufficiency of the appropriation and the consequent lack of men, the burlaps in the central towns were not as often visited. As the effectiveness of this method depends on daily visits to the bands, the results here were not as satisfactory as in the outer towns, but the moths were held in check and somewhat reduced in numbers.

During the summer an experiment in trapping the male moths was tried, with a view of determining whether the number of fertile egggs would be decreased thereby. Experiments with insecticides during the season proved the usefulness of a new insecticide, - arsenate of lead. Raupenleim was used to a considerable extent in 1893 , as it was during 1892 , but was not found so effective, perhaps by reason of its inferior quality.

In May the committee voted to request Professor Fernald to invite six of the most prominent entomologists in the adjoining States to visit the infested region and critically examine the field and office work, and report the results of their observations. Prof. Clarence M. Weed, D.Sc., of the New Hampshire State College, Dr. A. S. Packard of Brown University, Dr. J. A. Lintner, State entomologist of New York, Professor John B. Smith of Rutgers College, State entomologist of New Jersey, and Dr. H. T. Fernald, professor of zoölogy at the Pennsylvania State College, visited the territory in the summer, examined and criticised the work, and reported upon it. Their reports will be found in Appendix D. The recommendations of these entomologists were carefully considered by Professor Fernald and the director, who reported to the committee that the suggestions made should be carried out as far as practicable. 
With the increased force provided by the larger appropriation, it was possible to accomplish in 1893 much more than had been done in former years. Every effort was made to determine how far the moth had spread, and whether it had passed beyond the limits of the region known to be infested in 1891. Careful inspection was made of a large number of towns on the border line of the infested region, which resulted in small colonies being found in three places just outside the line drawn in 1891. It was evident that these colonies had been in existence for several years, even before the work of extermination was begun. One other colony was found at Franklin Park in Boston. This had evidently been growing for at least four or five years. Efforts were made to exterminate the moth from the outer belt of towns of the infested region. These efforts were so successful that at the end of the year no form of the moth was found in any of the following towns: Beverly, Brighton, Burlington, Charlestown, Danvers, Lynnfield, Marblehead, Reading, Waltham and Watertown.

During the season more than eight hundred colonies of the moth had been exterminated. But a detailed search of certain portions of the woodland in the infested region, which had been suspeeted but had not been known before to be infested, revealed small colonies seattered here and there, indicating that while a large proportion of the force had been concentrated upon the outer towns with a view to exterminating the moth there, the problem had been inereasing from within by the spreading of the moths into the woodlands in the interior towns.

The Board of Agriculture in its annual report on the gypsy-moth work to the Legislature again advised that everything possible be done to exterminate the moth, and recommended that $\$ 165,000$ be appropriated for the work of the ensuing year. The magnitude of the work and the possibility of destruction to the forests were stated, and the plans for dealing with the moth in the woodland were described. Statements from citizens were given showing the destruction of trees and garden plants which had been accomplished by the moth in Massachusetts during the years before the State began the work of extermination. 
It was shown in the report that the region occupied by the moth had been considerably reduced by the work already done, and the belief of the committee was stated that with the appropriation asked for still more could be accomplished toward reducing the infested area. The report described the probable condition of the parks, woodlands and farms of the State should the moth be allowed to go on unchecked. Every effort was made to place fully before the Legislature the necessity of continuing the work with a view to extermination. 


\section{THE WORK OF 1894 .}

Remembering the experience of former years, and considering the likelihood of similar delay on the part of the Legislature and a consequent embarrassment of the work, the committee had laid their plans for 1893 so as to retain a considerable portion of that year's appropriation with which to begin the season of 1894 . On Jan. 1, 1894, $\$ 29,744.69$ of that appropriation remained unexpended. This was retained in order that the most expert men of the force of 1893 could be employed until such a time as the Legislature should make another appropriation. There were eighty-three men at work on January 1.

Early in the year, Prof. N. S. Shaler, who had been a member of the committee from its organization in 1891 and who had been most active and prominent in the work, was obliged to resign from the Board of Agriculture on account of the pressure of other duties. Since his resignation, however, he has kindly given his advice and assistance whenever called upon.

On January 16, an order was presented to the Legislature by Representative Bullock of Fall River, which was afterwards adopted. This appears below, together with the answer made to it by the Board of Agrieulture :-

Ordered, That the State Board of Agriculture be instructed to report in writing to the General Court, on or before the first day of February next, the following facts and estimates relative to the work of exterminating the gypsy moth:-

1. The amount appropriated and amount expended annually for such purpose since the work began.

2. The amount per year which, in the estimation of said Board, it will be necessary to expend upon such work during the next ten years.

3. Whether, in the estimation of said Board, it will be neeessary to continue the work of extermination for an indefinite period.

4. If it will not be necessary to continue said work for an indefinite period, what is the probable limit of time during which it will be necessary to continue said work, and what will be the probable necessary expenditure therefor, in the aggregate, after the expiration of ten years from date. 


\section{REPLY BY THE BOARD.}

To the Senate and House of Representatives of the Commonwealth of Massachusetts.

In response to an order of the Legislature under date of Jan. 15, 1894, the State Board of Agriculture, by its gypsy moth committee, presents the following "facts and estimates relative to the work of exterminating the gypsy moth." The amounts of appropriations and expenditures have been reported in the several annual reports of the committee, and a summary of the same appears in the report of the work of 1893 , now in the hands of the Legislature. The original bills and pay-rolls, showing the details of all expenditures, may be found in the office of the State Auditor in the State House.

The following is a condensed account of the appropriations made and the amounts expended annually :-

\section{ApPropriations.}

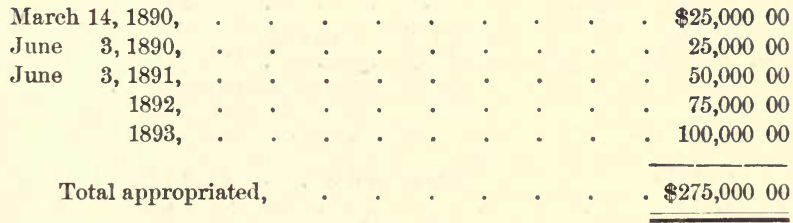

Expended in 1890 hy Finst Commission.

Salary of commissioners, . . . . . $\$ 3,11827$

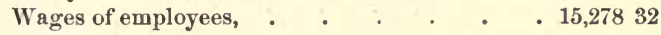

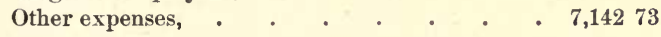

Total expended in $1890, . \quad$ • $\quad$ • . . . . . $\$ 25,53932$

\section{ExPEnded in 1891 by Second Commission.}

Balance of salaries due members of first commission, . $\quad . \quad$. $\$ 63095$

Salary of director, one and one-half months, . . . . . . 30000 Wages of employees, . . . . 10,14797 Other expenses, including travelling expenses, teaming, rent, supplies and tools, . . . . . . 2,378 54 
Amonts brought forward, . . . . $\quad$. $\$ 13,45746 \quad \$ 25,53932$

Expended IN 1891 by the State Board of Agriculture.

Expenses of committee in charge of the work, . . . . . . . $\$ 12153$

Director's salary, seven and one-half months, . . . . . . 1,500 00

Advising entomologist's salary and expenses, . . . . . . 28084

Wages of employees, . . . . . $\quad .41,09686$

Other expenses, including trarelling expenses, teaming, rent, supplies and tools, . . . . . . . . 12,79086

Total expended in 1891, 55,79009 69,24755

Expended in 1892 by the State BoA Rd of Agricultcre.

Expenses of the committee in charge of the work, $\$ \$ 13049$ Director's salary, . . . . . . . 2,40000 Advising entomologist's salary and expenses, . 52560

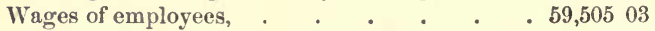
Other expenses, including travelling expenses, teaming, rent, supplies and tools, . . . 11,979 84

Exi'ended in 1893 by tile State Board of Agriculture. Expenses of eommittee in charge of the work, . \$11028 Director's salary, . . . . . . 2,400 00 Advising entomologist's salary and expenses, . $\quad 73016$ Wages of employees, . . . . . . 59,03965 Other expenses, including travelling expenses, teaming, rent, supplies and tools, . . . 13,647 39

Total expended to Jan. 1, 1894,

The estimates called for must, from the nature of the attending circumstances, be only opinions. The plans for the work of 1893 , for which an appropriation of $\$ 165,000$ was asked, contemplated a careful tree to tree search of all the forest land within the infested territory. This search would have cost a very large sum; but as only sixty per cent. of the sum asked was appropriated, this, with much other work planned for the central district, was necessarily postponed. It was decided that the work of extermination in the outer infested towns and the inspection of the territory surrounding them still further out was most necessary and would contribute most toward extermination. Were the uncer- 
tainties which confront us in the condition of these forest lands eliminated, our opinions would more nearly approximate to the character of estimates made by experts when all the conditions of a problem are known.

In 1893 considerable progress toward extermination was made. Ten towns were apparently cleared, comprising more than one-third of the territory originally infested. In 1894, with the appropriation asked for $(\$ 165,000)$, the committee ought to be able to bring into the same category Swampscott, Salem, Peabody, Wakefield, Woburn, Lexington, Winthrop and Franklin Park. This would leave Belmont, Arlington, Cambridge, Chelsea, East Boston, Everett, Lynn, Malden, Medford, Melrose, Revere, Saugus, Somerville, Stoneham and Winchester still infested. Several of these towns should be very nearly or quite cleared in 1894. But we have, in our estimates, left them with the list of probably uncleared. If, in $1895, \$ 150,000$ is appropriated, the work of that year should clear all towns but Arlington, Chelsea, Everett, Malden, Medford, Melrose, Revere, Sangus and Somerville. The moth in these towns should then be brought to the verge of extermination so that, with an appropriation of $\$ 100,000$, the work of 1896 would be quite likely to bring them very near to the condition of the cleared towns. During all this time a large amount of this money must be expended in closely inspecting the towns supposed to be cleared. In 1897 an appropriation of $\$ 50,000$ would be necessary to provide for the completion of the work in the last-mentioned towns and for the necessary careful reinspection of the whole territory. We think this appropriation would also provide means to stamp out any possible remains of colonies supposed to be exterminated that might be found by the careful reinspection. For the five succeeding years we believe that an average annual appropriation of $\$ 25,000$ would be necessary to continue the careful inspection of the whole territory and provide the means to deal with any colonies that may possibly have been overlooked. While it is our opinion that it is quite possible to exterminate the moth if large appropriations, such as have been mentioned, are granted for the next few years, we believe it also probable that should an appropriation of only $\$ 50,000$ per year be granted the work would have to be continued indefinitely, as a very large proportion of such an appropriation would necessarily be expended in watching the outside territory and taking measures to prevent the spreading of the insect.

Another method of estimating the probable future cost of extermination would be to multiply the average cost of extermination per estate in the towns already cleared by the number of estates 
still infested. We estimate the number of estates still infested at eight thousand. Our records show that the average cost of extermination, per estate, in the towns cleared has been $\$ 41.10$. At the same rate, the cost of exterminating the moth from eight thousand estates would be $\$ 328,800$. This statement is made on the assumption that the estates yet infested are now in no worse condition than were those which had been cleared. This computation does not include the large sum which must necessarily be expended in inspecting territory already cleared, that outside which must be watched, and the cost of reinspection for several years of these eight thousand estates after extermination is believed to have been accomplished.

In the opinion of the committee the above-mentioned estimates afford the closest approximation to a forecast that can well be made. It is proper, however, to state that the questions asked by the Legislature cannot be answered with certainty.

Respectfully submitted,

Per order of the Gypsy Moth Committee

of the State Board of Agriculture,

JAN. 29, 1894.

Wm. R. Sessions, Chairman.

At the annual meeting of the Board of Agriculture on February 8 , new by-laws were adopted, aflecting a reorganization of the Board. The committee in charge of the gypsymoth work was thereafter known as the "committee on the gypsy moth, insects and birds," and its number was increased to six.

The following is the article under which this committee acts : -

It shall be charged with the duties of the gypsy moth committee, as provided for in chapter 210 of the Acts of 1891. All matters relating to birds and insects shall be referred to this committee, who shall report to the Board from time to time.

The following members of the Board were elected to serve upon this committee: E. W. Wood of Newton, Chairman, Wm. R. Sessions of Hampden, Francis H. Appleton of Peabody, Wm. H. Bowker of Boston, F. W. Sargent of Amesbury, and Augustus Pratt of North Middleborough. 
In the mean time the recommendation of the Board for an appropriation of $\$ 165,000$ for the work of the year had been considered by the legislative committees. The joint standing committee on agriculture had unanimously endorsed the recommendation and had reported a bill to the House providing for an appropriation of $\$ 165,000$. The committee on the gypsy moth, insects and birds, together with many citizens from the infested district, appeared before the committee on expenditures and urged that the full amount of the appropriation be granted. But the latter committee, disregarding the recommendation of the committee on agriculture, reported a bill recommending an appropriation of $\$ 100,000$. The committee on the gypsy moth, insects and birds also urged that a committee of the Legislature, consisting of three or five, be appointed to fully investigate the gypsy-moth work during the season and report to the next Legislature. This was not done.

When it became known later that the Legislature had not approved the recommendation of the committee, and that only $\$ 100,000$ had been appropriated, Mr. Francis H. Appleton, one of the original members of the committee, tendered to the Board of Agriculture his resignation as a member of the committee. The reasons given by Mr. Appleton were that inasmuch as the committee had plainly stated that a certain sum must be available in order to do all possible toward extermination in one year, and as the committee was required by law to use "all possible and reasonable measures" to secure the extermination of the moth, and as with the $\$ 100$,000 the committee could do no more, in his opinion, than to continue the suppression of the moth, he felt it incumbent upon him to resign rather than to attempt a task which he believed impossible to accomplish with a less sum than had been recommended.

As the committee had been elected by the Board and delegated to this work, and as the Board would have no meeting during the spring or summer, the other members of the committee considered it their duty to do all that was possible with the appropriation made, and report the result to the Board at its next annual meeting with such recommendations as should at that time seem best. 
On June 19 the executive committee of the State Board of Agriculture petitioned for an additional appropriation of $\$ 65,000$, but the petition was referred by the Legislature to the next General Court.

The work of destroying the eggs of the moth had been carried on, whenever the weather permitted, in January, February, March and April. During these months the Legislature had been considering the advisability of making the appropriation recommended by the committee in charge of the work. On March 6 the committee held a joint meeting with the Metropolitan Park Commission. Arrangements were made so that the work of the Board of Agriculture in the Middlesex Fells might not conflict with the plans of the Park Commission. The public forest reservation controlled by the Park Commission and situated in Malden, Medford, Melrose, Stoneham and Winchester, includes most of the Middlesex Fells.

On May 1, the appropriation of 1893 having been expended, all field work was discontinued. Nothing was done in the field from that time until May 23, when the Legislature appropriated $\$ 100,000$. More than three weeks of the best working time of the season were thus lost. Those portions of the infested region in which it had been planned to destroy the eggs or young caterpillars were left entirely unguarded and the caterpillars hatched and scattered over the surrounding country. Thus the delay of the appropriation made the work far more costly. Trained and experienced employees were obliged to seek positions elsewhere, and the indirect loss and delay occasioned were as detrimental to the work as the loss of time when the men were laid off. "This enforced suspension of the work was most unfortunate, occurring as it did when the men were destroying the egg-clusters at the rate of thousands per day. Before work was resumed the remaining eggs had hatched and the larvæ had scattered. Had the work not been thus interrupted, it would have been possible in many places to destroy these young larva en masse by means of burning." *

- Fourth Report of the Board of Agriculture on the work of Extermination of the Gypsy Moth, January, 1995. 
As soon as possible after the appropriation was available all those experienced and trustworthy men who could be reached were re-employed. The trees were burlapped and all haste made to prepare the infested trees for the summer work. In many places the caterpillars appeared in large numbers and it required the work of the entire season to hold them in check.

The hatching and seattering of the caterpillars, which the delay of the appropriation allowed, necessitated the burlapping of a greater number of trees and the employment of a larger force for the summer. There were 624,673 trees burlapped during the summer and 265 men were of necessity employed to attend the burlaps. The result was the destruction at a great expense of a great number of caterpillars, many of which would not have existed had the appropriation been made at an earlier date. A large part of the appropriation having been used in burlapping trees and killing caterpillars during the summer, it became necessary to discharge a large part of the force at the end of the burlapping season on August 25. Thirty-three men were then discharged and others were discharged in September, so that by October 1 only 133 men remained. This force was entirely insufficient to inspect thoroughly the 220 square miles in the known.infested region, to say nothing of the belt of territory outside of it which the committee believed ought to be inspected. The men were kept at work during every day when it was possible to work to advantage, and everything was done that could be done with the small force remaining to inspect the outer towns of the infested region. It was found necessary again to neglect the central towns to a certain extent that the outer towns might be inspected as thoroughly as possible and that the moth's spreading might be prevented.

In June Dr. George H. Perkins of the University of Vermont, entomologist of the Vermont State Agricultural Experiment Station, visited the infested region upon invitation of the committee and inspected the work. In July Prof. F. L. Harvey, botanist and entomologist of the Experiment Station at the Maine State College, Prof. J. Henry Comstock of Cornell University, formerly United States entomologist, and Mr. L. O. Howard, entomologist of the United States 
Department of Agriculture, examined the infested region and inspected the work. These gentlemen gave the committee the benefit of their criticism and advice in the field, and Professors Perkins, Harvey and Comstock made written reports to the committee. (See Appendix E.)

Mr. Howard, later, in his annual address before the sixth annual meeting of the Association of Economic Entomologists, of which he was president, gave his impressions and opinions of the work. (See Appendix E.)

During the summer the experiment in trapping male moths was tried on a larger scale than in 1893. While many moths were destroyed, the results as a whole were not successful enough to warrant the adoption of the method in field work. Arsenate of lead (first experimented with in 1893) was used in spraying to a limited extent during the spring. While more effective than Paris green, it was determined that it could not be depended upon to exterminate.

The fall inspection in Boston revealed the presence of moths in three sections of the city not before known to be infested-Roxbury, Dorchester and the city proper. One colony was found in each section. Two of them had been established evidently for several years, but the demands of the work elsewhere had hitherto prevented an inspection of this large territory.

The inspection of towns which had been apparently cleared in 1893 revealed a ficw egg-clusters or other forms of the moth in all of them. A careful search of a portion of the unexplored wooded region revealed a number of small colonies in the Lynnfield woods. With this exception very few moths were found in any of these towns. The discovery of the moths in these towns emphasized the necessity of keeping them under surveillance for a few years after they had been apparently cleared and as long as there were moths in any of the adjacent towns.

The discovery of the moths in the Lynnficld woods verified the prediction which the committee made in 1893, of the probability of the moth's existence in the wooded region, and showed the necessity of a sufficient appropriation to thoroughly search the woodland. The committee in its report 
to the Legislature stated the condition of the infested region as follows: -

In ten of the outer towns the moth has been apparently exterminated; in five more it has been very nearly exterminated. More than a thousand well-marked moth colonies have been stamped out of existence. In all of the infested towns such sections as have been worked over year after year by the employees of the State Board of Agriculture are now nearly cleared of the moth, and the general condition of the inhabited and cultivated lands is better than ever before. Against this favorable condition of such portions of these towns we must place the fact which has been revealed by the inspection of the past season, - that the woodlands in many of the towns are much more generally infested than has been hitherto supposed. Scattered colonies of the moth are known in the woods of Lexington, Winchester, Arlington, Belmont, Stoneham, Medford, Wakefield, Melrose, Malden, Lynnfield, Sangus, Revere, Swampscott, Lynn and Salem.

This condition of the forested lands is due to the fact that there has not been money enough to provide for destruction of these colonies whenever found. It has been impossible, with the means at our command, to make a thorough search of all this woodland; but during the past season special efforts have been made to inspect it so far as was possible under the circumstances, and enough is now known to justify the presumption that colonies of the moth are scattered through the woods from Lexington to the sea. Though many of the colonies found have apparently had their origin within two or three years, many others originated at least ten years since. The woodland which is thus more or less infested probably covers fifty square miles of the central and north-central portions of the infested district.

In the attempt to exterminate the gypsy moth it was early ascertained that the species was spread over a region many times greater than that which was at first known to be infested, and that it was not confined to lands under cultivation, but had penetrated to some extent into the woodlands. These discoveries made it certain that extermination would be extremely difficult, requiring years for accomplishment even under the most favorable conditions. The best methods known and used at first were not effectual in securing extermination, and the methods which later proved effective were so expensive that they could not be carried out over so large an area without larger appropriations than those which have been granted.

Although the extent of the infested region, the existence of the 
moths in the woods and the great expense of exterminative methods have been all repeatedly presented to the Legislature in the annual reports of this Board, the amount appropriated for each of the past two years has been only about two-thirds of that recommended by the Board as absolutely necessary to do all that could be done to advantage under the circumstances.

The law requires the Board "to use all reasonable measures to prevent the spreading and to secure the extermination" of the moth. The Board has apparently been successful in preventing the spread of the moth and has considerably lessened the area known to be infested. It has never had an appropriation sufficiently large to do all that might have been done in one year toward the extermination of the moth. If the work is to be carried on under the present statute, and the policy of extermination is to be continued, we believe that two hundred thousand dollars should be appropriated for the work of the coming year.

The committee believes that the work of extermination should be continued, but is also firmly of the opinion that, if the Legislature is unwilling to appropriate the sum necessary for an aggressive campaign for extermination, the law should be changed so that the Board of Agriculture shall be required to conduct the work only along the line of preventing the spread of the gypsy moth. The committee further believes that, if the Legislature is unwilling to provide sufficient funds for restricting the spread of the gypsy moth and holding it in check, the work should be discontinued entirely. The committee is not in favor of appropriating inadequate funds for the work in hand. It seems unjust to require the extermination of the pest while providing inadequate means for the purpose. The Board of Agriculture has recommended for each of the past two years an appropriation of one hundred and sixty-five thousand dollars, believing that sum was absolutely required for the successful prosecution of the work. The Legislature has appropriated only one hundred thousand dollars, or about sixty per cent. of the sum asked for each of these years.*

- Fourth Report of the State Board of Agriculture on the work of Extermination of the Gypsy Moth, January, 1895. 



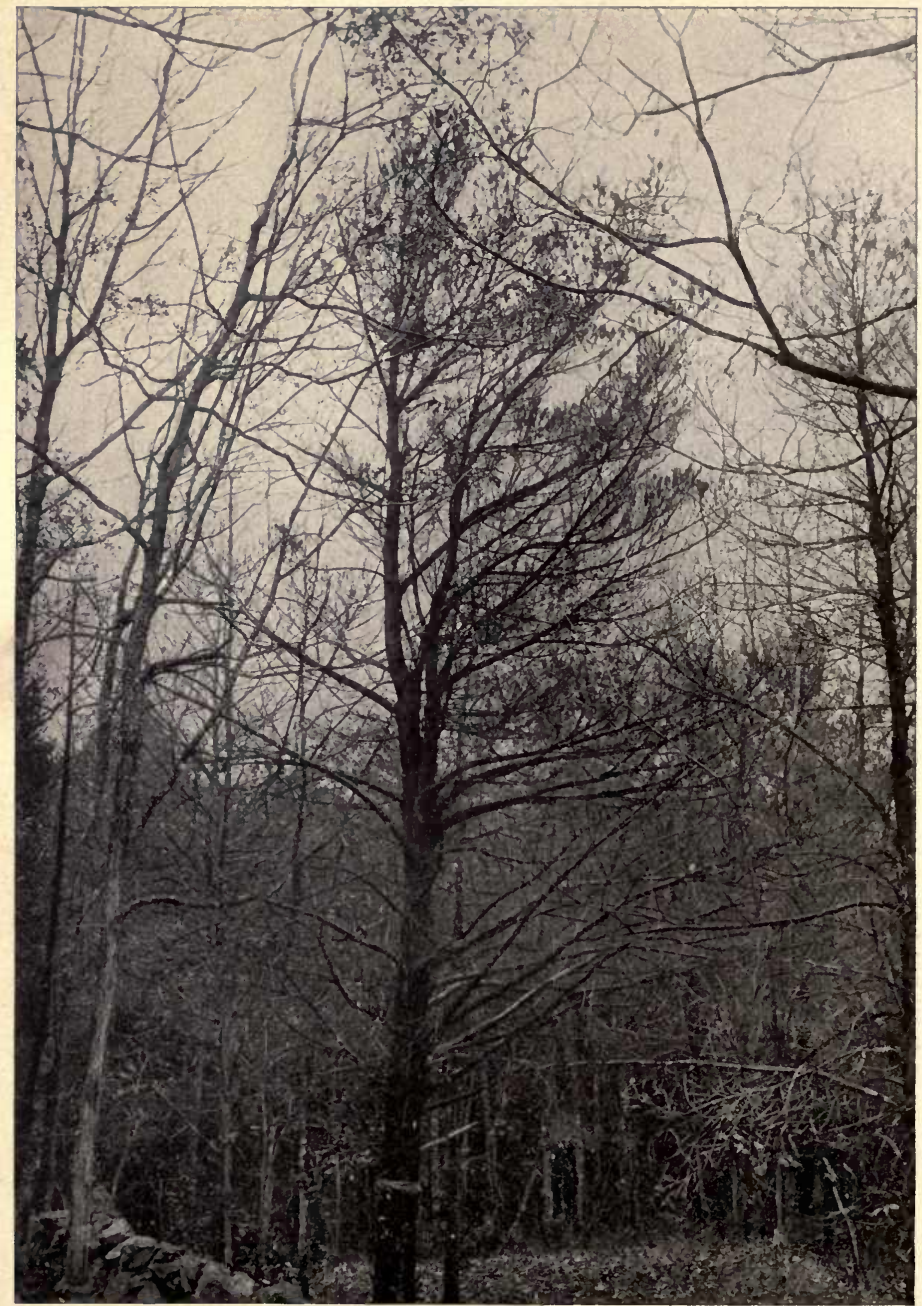

PLATE XIII. Oak and pine woods attacked by the gypsy moth. From a photograph taken in Lexington, July 11, 1895. 


\section{THE WORK OF 1895 .}

The Legislature of 1894 had adopted a resolve requesting the senators and representatives from Massachusetts in the Congress of the United States to urge upon Congress the necessity of prompt and vigorous action to exterminate the gypsy moth, and to use their influence to secure from Congress an appropriation of one hundred thousand dollars to assist this Commonwealth in defraying the necessary expenses of the work.

The Board of Agriculture was notified by the agricultural committee of the United States Senate that a hearing would be given on Friday, Jan. 4, 1895, upon the resolve presented by the Massachusetts Legislature. A committee consisting of Francis H. Appleton, vice-president, and Wm. R. Sessions, secretary, of the Board of Agriculture, accompanied by the director of field work, appeared on January 5 before the Senate committee on agriculture, and also before the committee on agriculture of the United States House of Representatives, at a special hearing upon a resolution introduced into Congress by Hon. William Cogswell, which provided for the appropriation asked for by the resolution of the Massachusetts Legislature. The committee also presented the matter to Hon. J. Sterling Morton, secretary of the United States Department of Agriculture. Later, a resolve appropriating forty thousand dollars for the extermination of the gypsy moth passed the United States Senate but was defeated in a conference committee chosen from both houses.

At the annual meeting of the Board of Agriculture, Feb. $6,1895, \mathrm{Mr}$. Wm. H. Bowker, a member of the committee on the gypsy moth, insects and birds, retired from the Board, his term having expired on that day. Mr. Bowker had been a prominent member of the Board, and its reorganization was the outcome of his suggestions. The two vacancies in the membership of the committee, left by the resignation in 1894 of Mr. Appleton and the retirement of Mr. Bowker, 
were filled by the election of Messrs. John G. Avery of Spencer and S. S. Stetson of Lakeville.

The report of the Board of Agriculture, containing a recommendation for an appropriation of two hundred thousand dollars, was presented to the legislative committee on agriculture immediately after its organization in January. Some opposition to the appropriation developed in the committee, and the time and attention of the members were occupied for some weeks with other important measures. This committee held public hearings during the week beginning February 11, at which hundreds of citizens from the infested towns were present. The preponderance of sentiment was in favor of granting the appropriation asked for. On March 21 the committee finally acted upon the matter, and reported a resolve calling for an appropriation of one hundred and fifty thousand dollars. Although this amount was looked upon by the Board of Agriculture as entirely inadequate, there appeared to be fully as much danger to the work by delay in making the appropriation as by reduction of its size. The committee on the gypsy moth, insects and birds therefore endeavored to urge upon the General Court the immediate passage of the bill as reported by the committee on agriculture. But it was not until May 17 that the appropriation of one hundred and fifty thousand dollars finally became available. Early in the year the appropriation of 1894 was nearly exhausted and on February 6 the field force was discharged. The work of destroying the eggs of the moth, which should have been carried on during the spring in those portions of the infested towns not wholly cleared of them in the fall, was thereby brought to an end. Thus the experience of 1894 was repeated, but the amount of working time (three months) lost in 1895 , owing to the lateness of the appropriation, was much greater than in the previous year. The discontinuance of the field work in 1895 was especially disastrous because occurring in an early spring which later developments showed was particularly favorable for the moths' increase. The great multiplication of the numbers of the moth which occurred during this favorable season, their scattering abroad and the consequent injury to trees by their feeding, might have been prevented by destroying the eggs in the spring. 



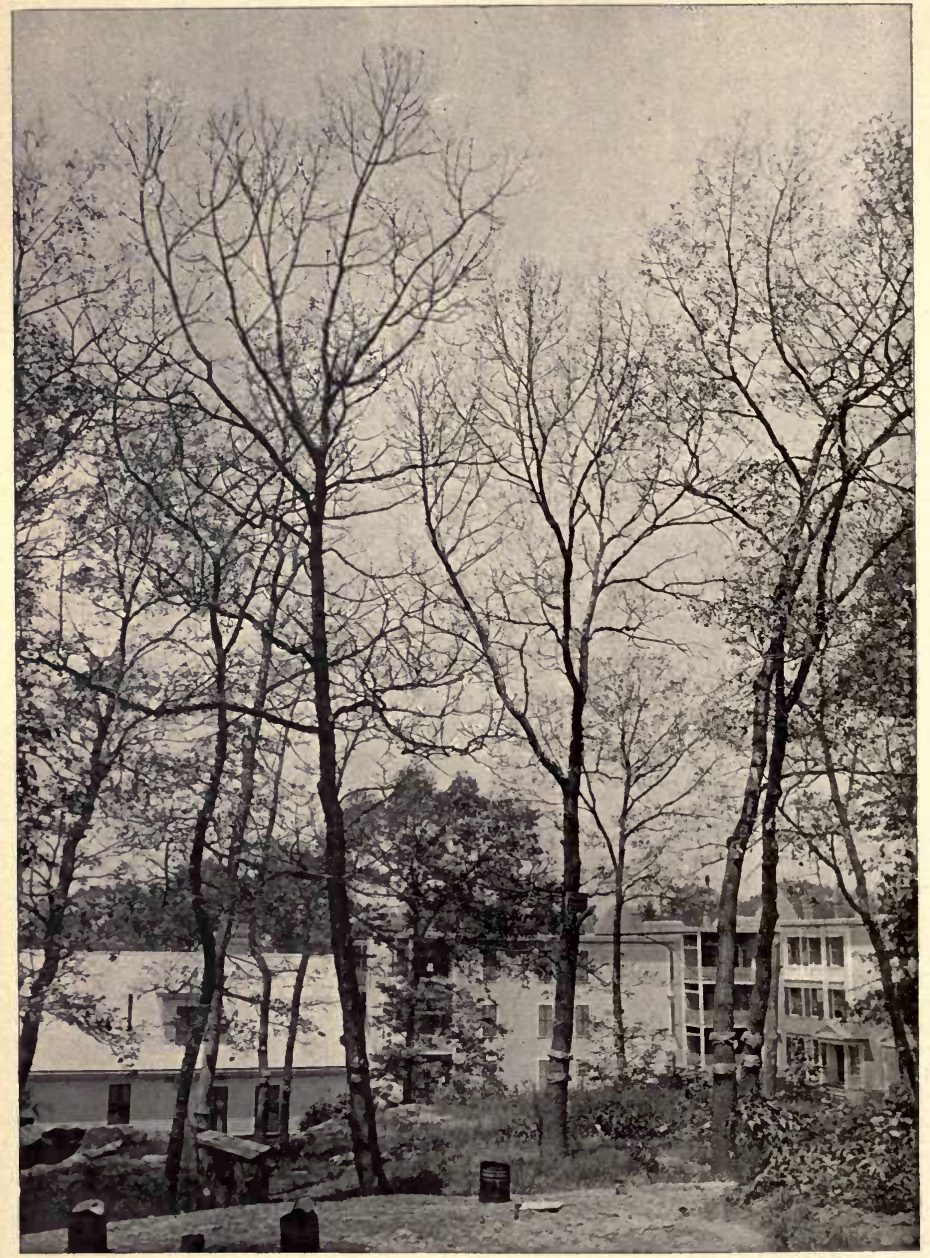

PLATE XIV. Oak trees stripped by caterpillars of the gypsy moth, Sargent Street, Dorchester. (Ward 16, Boston.) From a photograph taken July 24, 1895. 
When it became evident that there would be considerable delay in legislation, the committee authorized the director to employ as a nucleus of an organization such experienced men as were willing to wait for their pay until such time as the Legislature should make an appropriation. The office force was employed; the records were closed up; examinations of applicants for positions on the force were begun; arrangements were made for the purchase of supplies; and other preliminaries, providing for the early employment of a full force of men, were arranged. When the appropriation became available, it was too late in the season to accomplish much by the destruction of eggs, for most of them had hatched. As the men were put at work, those who were inexperienced were given a week or more of training in clearing up infested woodlands and cutting and burning brush. They were then organized into burlapping gangs and employed in placing burlap bands around the trees in infested localities.

It was found necessary to increase the force as rapidly as the careful selection and examination of men allowed, for the caterpillars of the moth were appearing numerously wherever the egg-clusters had not been destroyed. As the season advanced the great increase in the numbers of the moth was noticeable. More men than were ever before employed in the work were engaged to meet the emergency. On July 20 three hundred and fifty men were at work, and even with this force it was not possible to prevent occasional injury to foliage in certain places. A swarm of caterpillars appeared in one locality in Dorchester, within a few rods of the point where the inspection of the winter previous had ceased on account of snow. Many of the trees in an oak grove were defoliated before the presence of the caterpillars was discovered. Immediate steps were taken to destroy them and in a short time some eighteen bushels of caterpillars were killed in this locality.

Various points in the woods of Lexington and Woburn were found to be swarming with the caterpillars of the gypsy moth. Here they defoliated several acres of woodland. Later in the season similar colonies were discovered in the woods of Medford, one being situated in the southern por- 
tion of the metropolitan park reservation known as the Middlesex Fells. Others were found in the Saugus woods. In some of the localities where the moth appeared in numbers in the woods the injury extended over from one to three acres, leaving the trees as bare as in winter.

Wherever the forest was defoliated in this manner the infested trees presented from a distance the appearance of having been killed by fire. These reddish patches on the hillsides stood out strongly in contrast with the green of the summer foliage by which they were surrounded. On entering one of these infested spots during the time when the caterpillars were feeding, one was immediately struck by the rustling sound caused by their movements and the falling of their droppings and the bits of foliage which they were continually cutting from the leaves. A little later in the season, during the warmer part of the day, the male moths fluttered in swarms about the trees while the white females were scattered over the trunks and branches of trees and upon the dry leaves on the ground.

Nearly all species of trees and most herbaceous plants in this badly infested woodland were stripped by the caterpillars. In some places they ate the foliage of the pines, both young and old. Some of these trees appear now to be dying. But on account of the unusually rapid development of the moths this season, their consequent maturing and cessation of feeding, the trees were not continually stripped throughout the summer; therefore the deciduous trees began to throw out new foliage late in July and early in August, when the female moths were laying their eggs. This rapid development of the moths during the past season appears to be unprecedented in this country so far as can be ascertained. As the probable result, a second brood of the moths appeared in one locality in Woburn. Young caterpillars were found leaving the egg-clusters in the first weeks of September. As the summer waned, many localities in the woods were found where the egg-clusters of the moth were quite numerous, bidding fair, if not destroyed, to produce a brood of caterpillars during 1896 which may prove even more destructive than those of the present season.

This condition of affairs fulfilled the predictions which the 


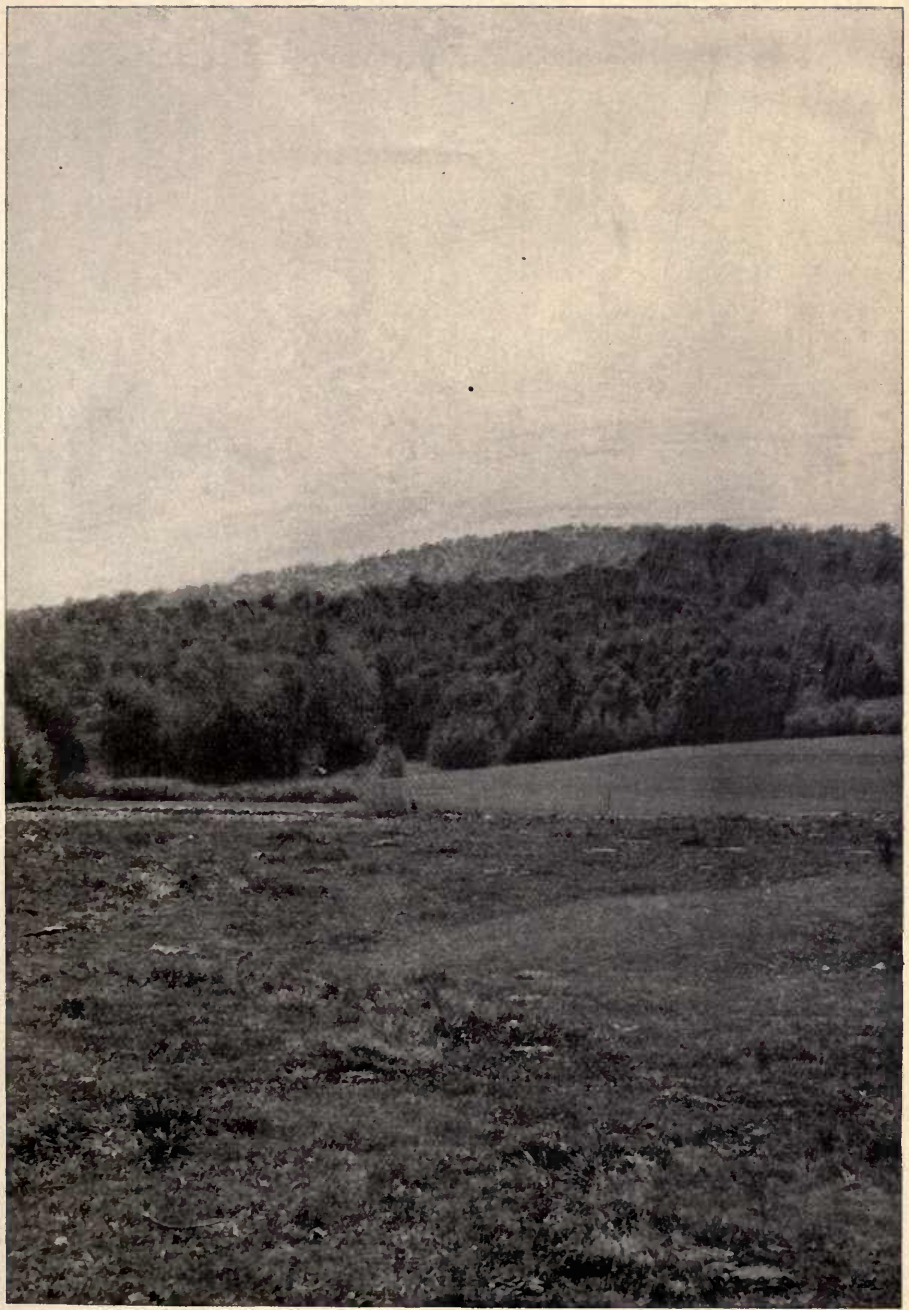

PLATE XV. Woodland colony of the gypsy moth as seen at a distance of one-third of a mile. The light area in the woods in the background shows the appearance of a defoliated tract as compared with the surrounding uninfested trees. From a photograph taken in Woburn, July 19, 1895. 
committee made to the Legislature in former years, namely, that the moths were distributed generally through the woodland in the inner towns of the infested region, and demonstrated that they might prove a serious danger to wooded parks and forests. Experts were sent into the woods to examine them as thoroughly as was possible during the summer. They discovered that a large portion of the Middlesex Fells was more or less infested by the moth. At least one thousand acres of this reservation now appear to be in this condition. In Saugus a tract of about the same size appears to be similarly affected, and another even larger, situated in Woburn, Lexington and Arlington, is also more or less infested. There are at least three thousand acres of woodland in the foregoing towns that are now known to be infested by the gypsy moth. This condition had been suspected, but the appropriation had never been sufficient to watch the cultivated lands and highways and also to care for the forested region.

Throughout the season of 1895 , as in previous seasons, experiments on insecticides were conducted in the field and observations were made on the habits of the moth and its enemies. A small building was erected in the Malden woods for use as an experiment station, and to facilitate the breeding of parasites and predaceous insects to be used for experimental purposes. In all probability the results obtained from observations and experiments in 1895 are more valuable than those of former years. The experiments and their results are treated of in the report of the entomologist.

In some localities, where the moths were numerous upon valuable ornamental shrubs or trees, the foliage was sprayed with arsenate of lead. Where it was used at a strength of thirty pounds to one hundred and fifty gallons of water all the caterpillars appeared to be destroyed.

During the season fire was used with good effect in many cases to check the ravages of the caterpillars in waste land.

At the time of going to press little can be said of the results of the work of 1895 . It may be predicted, however, that considering the phenomenal increase of the moths in those sections where egg killing was not done in the spring because of the delay of the appropriation, and considering 
also the large number of men employed later, the results of the season's work will show a greater number of the different forms of the moth destroyed than at any time since 1891.

We have long feared that unless appropriations sufficient for complete eradication were granted, some favorable season might give the moths a sudden impetus which would cause them to increase beyond immediate control. Such an emergency has arisen, and in the centres of population, in cultivated lands and along the highways, it has been fully met. It is true that in the woodland where the greatest infestation occurred some injury was done for a time by the moths, but, in such places, they are now under control, and with vigorous measures they may be entirely exterminated from these localities within two or three years. Yet there is a large wooded region in the north-central towns which never has been thoroughly cared for and never can be unless larger appropriations are made. In many portions of this woodland the moths are doubtless steadily increasing in numbers, and all that has been done or can be done there, with the means thus far furnished by the Commonwealth, is to check them whenever they appear in such numbers as to threaten serious injury to the trees.

The results of the work of 1895 will be presented in the next annual report to the Legislature. 



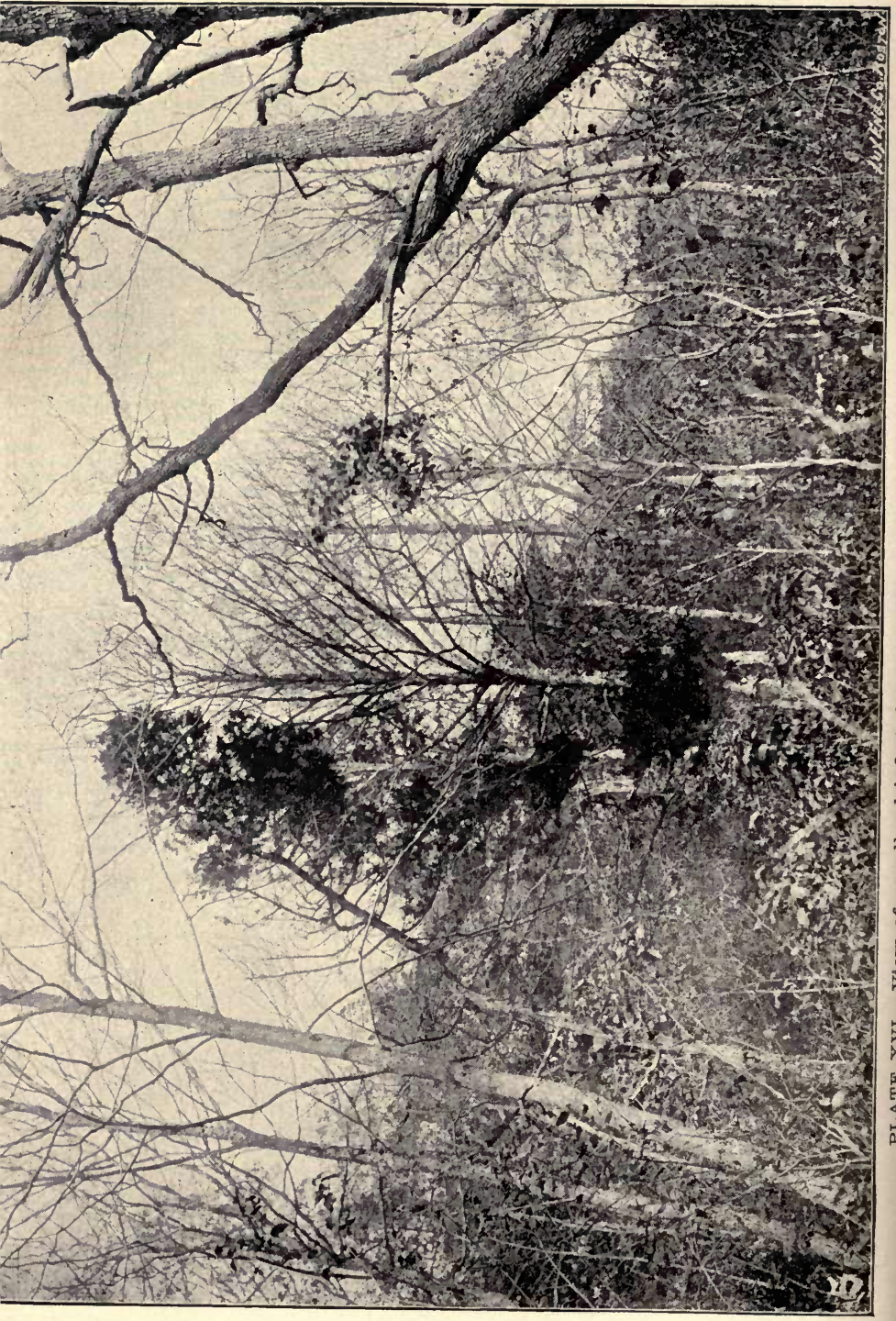




\section{The Number of Men employed and Work DONE, 1890 TO 1894 InCLUSIVE.}

In order to give an opportunity for comparing the number of employees and the amount of work done each year we give tables taken from the pay-rolls of 1890 and the reports of the years 1891 to 1894 inclusive :-

1890 .

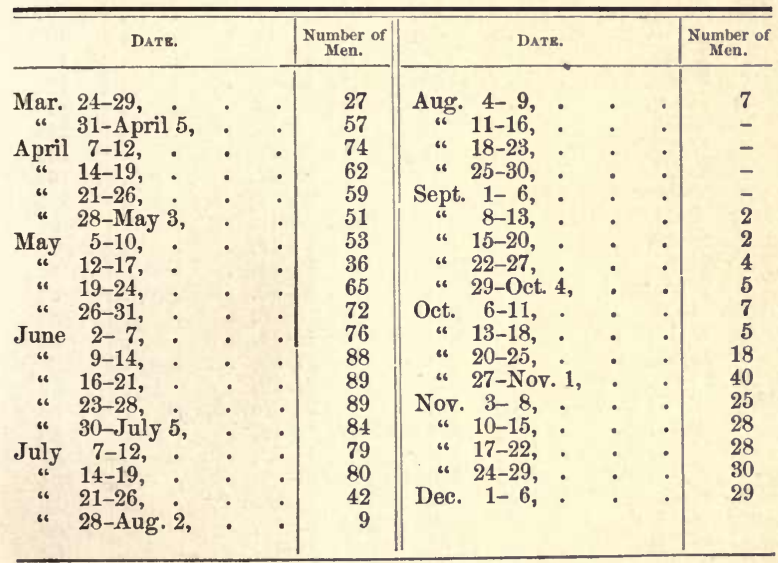

1891 .

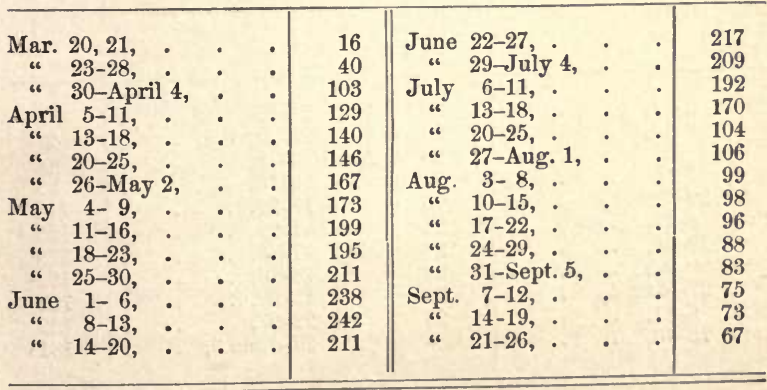


1891 - Concluded.

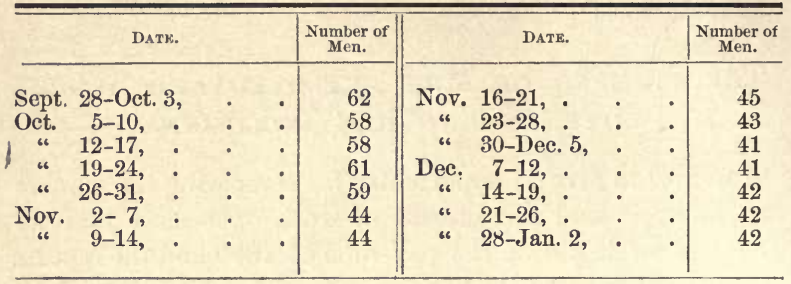

1892 .

\begin{tabular}{|c|c|c|c|c|c|c|c|c|c|c|c|}
\hline Jan. & 4- 9 & . & - & . & 46 & July & 4-9, & - & - & - & 95 \\
\hline " & 11-16, & . & . & & 46 & “" & $11-16$ & . & - & & 102 \\
\hline 66 & 18-23, & . & ( & & 47 & " & 18-23, & . & - & . & 120 \\
\hline “ & 25-30, & . & • & & 48 & “ & 25-30, & . & . & - & 120 \\
\hline Feb. & $1-6$ & . & - & & 48 & Aug. & $1-6$ & . & - & - & 126 \\
\hline " & 8-13, & - & - & & 48 & & $8-13$ & . & . & . & 129 \\
\hline " & $15-20$ & . & . & & 31 & " & $15-20$ & - & • & . & 122 \\
\hline " & $22-27$ & . & . & & 68 & “ & 22-27, & . & & . & 107 \\
\hline “ & 29-Mar. & 5 & - & & 88 & “ & 29-Sep & t. 3 , & . & . & 107 \\
\hline Mar. & 7-12, & . & . & . & 111 & Sept. & 5-10, & . & • & . & 97 \\
\hline “ & 14-19, & . & - & • & 127 & “ & 12-17, & . & . & . & 95 \\
\hline “ & $21-26$ & & & & 141 & " & 19-24, & . & . & . & 37 \\
\hline “ & 28-April & 12, & . & & 191 & " & $26-30$ & . & - & . & 33 \\
\hline April & $4-9$ & . & • & - & 219 & Oct. & $3-8$ & . & 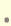 & . & 38 \\
\hline "، & 11-16, & . & & t & 234 & “ & 10-15, & . & . & . & 36 \\
\hline "“ & 18-23, & . & - & • & 233 & “ & 17-22, & . & • & - & 37 \\
\hline " & 25-30, & - & & • & 230 & “ & 24-29, & . & • & - & 37 \\
\hline May & $2-7$ & . & & $\cdot$ & 232 & " & 31-Nov & .5 & . & • & 38 \\
\hline " & 9-14, & . & & & 183 & Nov. & 7-12, & . & . & • & 38 \\
\hline “ & 16-21, & - & & - & 140 & 66 & 14-19, & - & - & . & 37 \\
\hline " & 23-28, & . & & - & 140 & “" & 21-26, & . & - & - & 34 \\
\hline “ & 30-June & 4 & 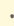 & - & 91 & "6 & 28-Dec & 3 & • & - & 36 \\
\hline June & 6-11, & . & & , & 90 & Dec. & 5-10, & • & . & - & 36 \\
\hline “ & 13-18, & . & & & 87 & “ & 12-17, & - & & • & 35 \\
\hline “ & 20-25, & . & & • & 89 & " & 19-24, & . & & - & 34 \\
\hline " & 27-July & 2, & & - & 93 & " & 26-31, & - & - & - & 33 \\
\hline
\end{tabular}

1893 .

\begin{tabular}{|c|c|c|c|c|c|c|c|}
\hline $\begin{array}{c}\text { Jan. } \\
\text { “ } \\
\text { “ } \\
\text { Feb. } \\
\text { " } \\
\text { "“ } \\
\text { Mar. }\end{array}$ & $\begin{array}{c}2-7, \\
9-14, \\
16-21, \\
23-28, \\
29-\mathrm{Feb} . \\
6-11, \\
13-18, \\
20-25 \\
27-\mathrm{Mar} . \\
6-11, \\
13-18\end{array}$ & $\begin{array}{l}\dot{ } \\
\dot{4} \\
\dot{ } \\
\dot{4} \\
\dot{4}\end{array}$ & $\begin{array}{l}: \\
: \\
:\end{array}$ & $\begin{array}{l}30 \\
28 \\
28 \\
27 \\
25 \\
24 \\
24 \\
22 \\
25 \\
25 \\
-\end{array}$ & 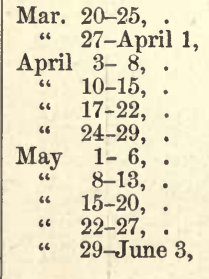 & $\begin{array}{l}\dot{:} \\
\dot{:} \\
\dot{:} \\
\dot{ } \\
\dot{.}\end{array}$ & $\begin{array}{r}8 \\
27 \\
44 \\
93 \\
115 \\
125 \\
128 \\
132 \\
132 \\
132 \\
131\end{array}$ \\
\hline
\end{tabular}


1893 - Concluded.

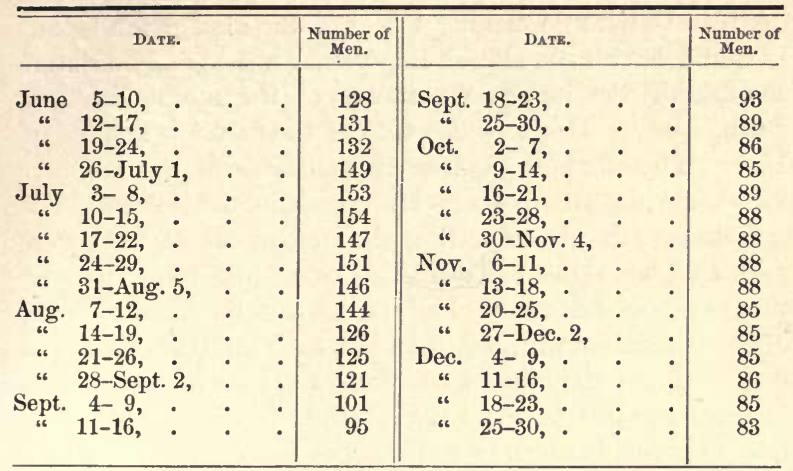

1884

\begin{tabular}{|c|c|c|c|c|c|c|c|c|c|c|}
\hline Jan. & $1-6$, & . & - & - & 82 & June & $25-30$, . & - & . & 261 \\
\hline ". & $8-13$ & . & - & . & 86 & July & $2-7$, & 。 & . & 265 \\
\hline “ & $15-20$ & . & . & . & 85 & 6 & $9-14$ & . & . & 270 \\
\hline “ & $22-27$ & . & . & . & 86 & $" 6$ & $16-21$, & . & . & 265 \\
\hline$"$ & 29-Feb. & 3 , & • & & 83 & “ & 23-28, . & . & - & 270 \\
\hline Feb. & 5-10, & . & - & • & 82 & 6 & 30-Aug. 4, & • & - & 261 \\
\hline$" 6$ & $12-13$ & . & . & • & 82 & Aug. & $6-11$, & . & . & 266 \\
\hline "6 & 14-17, & - & - & . & 23 & "6 & 13-18, . & . & . & 260 \\
\hline " & 19-24, & . & . & . & 81 & “ & $20-25$, & . & . & 216 \\
\hline “ & 26-Mar. & 3 , & - & & 81 & 66 & 27-Sept. 1, & . & - & 15 \\
\hline Mar. & $5-10$ & 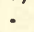 & • & • & 82 & Sept. & $3-8$, & • & . & 16 \\
\hline " & 12-17, & . & . & & 84 & 6 & $10-15$, . & • & . & 147 \\
\hline " & 19-24, & . & . & & 85 & “ & $17-22$, & . & - & 148 \\
\hline "6 & $26-31$, & . & • & & 91 & “ & $24-29$, . & . & • & 133 \\
\hline April & $2-7$ & . & $\bullet$ & - & 95 & Oct. & $1-6$, & . & . & 133 \\
\hline "6 & $9-14$ & . & - & & 121 & “6 & $8-13$, . & - & • & 131 \\
\hline " & $16-21$, & . & & & 157 & " & 15-20, . & . & - & 123 \\
\hline “6 & 23-28, & . & & & 159 & “ & $22-27$, . & & - & 125 \\
\hline " & 30-May & 1, & & & 156 & “ & 29-Nov. 3, & . & & 128 \\
\hline May & $2-9$ & . & - & • & 15 & Nov. & $5-10$ & . & . & 128 \\
\hline “ & 10-12, & - & & & 164 & 6 & $12-17$ & - & • & 133 \\
\hline " & 14-19, & . & & & 173 & "6 & 19-24, . & . & . & 133 \\
\hline “6 & $21-26$ & . & & • & 213 & “6 & 26-Dec. 1 , & . & . & 132 \\
\hline “ & 28-June & 2 , & & & $228^{\circ}$ & Dec. & $3-8$ & . & . & 132 \\
\hline June & 4-9, & . & . & • & 230 & “ & $10-15$, & . & . & 134 \\
\hline “ & $11-16$, & . & & & 229 & " & $17-22$ & - & . & 135 \\
\hline " & 18-23, & . & - & - & 225 & " & $24-29$, & . & . & 132 \\
\hline
\end{tabular}

Summary of Work done during Four Years.

During the year 1890 no account of the number of different forms of the moth destroyed was kept by the first 
commission, and the reports of the work are not in a form that can be used in making tables of the kind given below. It would have been almost impossible to keep any accurate account of the immense numbers of the moth destroyed during 1890. This was also true of the first few months of 1891. Therefore no figures or estimates of the numbers killed during those years are given in the tables. The egg-clusters destroyed during the first weeks of 1891 were estimated at eight cart-loads. During the latter part of that year a systematic account was kept of the number of the different forms of the moth found on each infested estate, and from that and the other accounts of the season, a somewhat incomplete table of the work of 1891 has been made. A fuller account is given of the work of the succeeding years. Yet even this summary cannot be considered as complete, for the tables pertain mainly to the hand work done annually, and only such figures are given as from their nature can be accurately recorded. Obviously no account could be kept of the number of moths destroyed by spraying, fire and other wholesale measures.

It will be seen that though a larger number of men was employed in 1893 and 1894 than in 1892, fewer trees were found infested in the later years, although the number of the different forms of the moth killed by hand was larger. This may be chiefly accounted for by the extension of the work into woodlands in the inner towns, where the moths had increased unmolested. In badly infested places in the woods the number of moths per tree was very great. Many caterpillars, pupæ and egg-clusters were destroyed in bushes and young growth. This greatly swelled the sum total of forms of the moth destroyed. The larger appropriation of 1894 made this woodland work possible.

\begin{tabular}{|c|c|c|c|c|}
\hline & 1891. & 1892. & 1893. & 1894. \\
\hline $\begin{array}{l}\text { Trees (fruit, shade and forest) :- } \\
\text { Inspected, } \\
\text { Found to be infested with caterpillars, } \\
\text { pupæ, moths or eggs, } \\
\text { Cleared of eggs, } \\
\text { Cemented, } \\
\text { Banded (insect lime or tree ink), }\end{array}$ & $\begin{array}{r}213,828 \\
212,432 \\
19,296 \\
12,000\end{array}$ & $\begin{array}{r}108,428 \\
99,989 \\
12,172 \\
21,251\end{array}$ & $\begin{array}{r}44,716 \\
2,068 \\
4,583 \\
19,453\end{array}$ & $\begin{array}{r}48,752 \\
2,176 \\
7,844 \\
-\end{array}$ \\
\hline
\end{tabular}




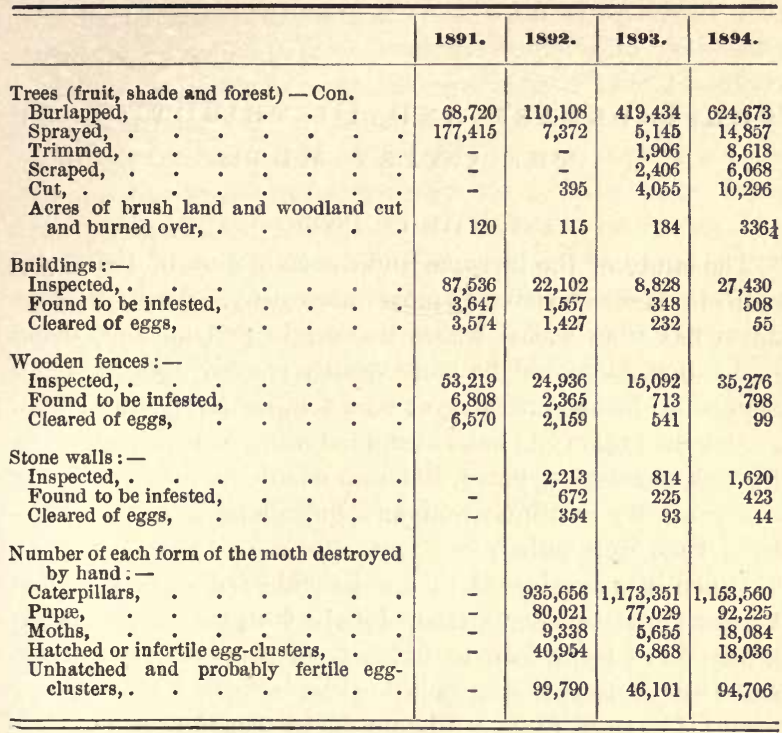




\section{The InOREASe and Distribution of THE GrPST Mотн.}

\section{The Rate of Increase.}

The study of the increase and dissemination of the gypsy moth in Massachusetts is most interesting. Perhaps there never has been a case where the origin and advance of an insect invasion could be more readily traced. As the moth appears to be confined as yet to a comparatively small area, and as the region has been examined more or less thoroughly for five successive years, the opportunities offered for the study of the multiplication and distribution of the insect have been unequalled.

When it is considered that the number of eggs deposited by the female averages from 450 to 600 , that 1,000 caterpillars have been seen to hatch from a single egg-cluster, and that at least one egg-cluster has been found containing over 1,400 eggs, there can be no doubt that the reproductive powers of the moth are enormous. Mr. A. H. Kirkland has made calculations which show that in eight years the unrestricted increase of a single pair of gypsy moths would be sufficient to devour all vegetation in the United States. This, of course, could never occur in nature, and is mentioned here merely to give an idea of the reproductive capacity of the insect.

It seems remarkable at first sight that an insect of such reproductive powers, which had been in existeuce in the State for twenty years, unrestrained by any organized effort on the part of man, did not spread over a greater territory than thirty townships, or about two hundred and twenty square miles. Some of the causes which at first checked its increase and limited its diffusion in Medford have already been set forth (pages 5-7). Most of the checks which at first served to prevent the excessive multiplication of the gypsy moth in Medford operate effectively to-day wherever the species is isolated. True, it has now become acclimated. But any small isolated moth colony still suffers greatly from the attacks 
of its natural enemies and from the struggle with other adverse influences which encompass it. The normal rate of increase in such isolated colonies as are found to-day in the outer towns of the infested district is seen to be small. The annual increase can be readily ascertained by noting the relative number of egg-clusters laid in successive years, the unhatched or latest clusters being easily distinguished from the hatched or "old" clusters, and the age of these latter, whether one, two, three or more years, being indicated by their state of preservation. The ratio of the average annual increase of ten such colonies was found to be 6.42 , - that is, six or seven egg-clusters on an average may be found in the second season to one of the first season.

Though even at this rate of increase the progeny of a single pair of moths would be numerically enormous within twenty years, ${ }^{*}$ yet for the first few years, under normal conditions, the increase of a small and isolated moth colony is not great enough to work any serious or extended injury. The great army of moths does not advance rapidly by the skirmish line, as it were, but only by the main body, for a great increase and rapid spread to a distance can only occur where the moths have become so numerous over a considerable area as to have nearly reached the limit of their food supply.

\section{Conditions favoring Rapid Increase.}

When any colony under average normal conditions has grown to a considerable size and then receives an added impetus from exceptionally favorable conditions, its power of multiplication and its expansive energy are greatly augmented and its annual increase rises above all calculations. $\dagger$ Under such influences hundreds of egg-clusters will appear in the fall where few were to be seen in the spring, and thousands are found where scores only were known before. It is probable that the season of 1889 was particularly favor-

\footnotetext{
* At this ratio the number of egg-clnsters produced in the twentieth year wonld be $14,148,179,507,899,404$.

t The increase of these large colonies seems to be limited only by the supply of food. Whenever food becomes scarce many of the moths are less prolific. The larvæ which do not find snfficient food either die or develop early, and the female moths lay fewer eggs than those which transform from well-nourished caterpillars.
} 
able for the moths' increase. The season of 1894 and that of 1895 appear also to have furnished conditions especially favorable for an abnormal multiplication of the insect.

The operation of the causes of these sudden outbreaks is not fully understood. It is evident, however, that the warm, pleasant spring weather of the past two years (1894 and 1895) hastened the development of the caterpillars, thereby shortening their term of life. The length of life of the caterpillar varies from six to twelve weeks. During cold, rainy weather the caterpillars eat little and grow slowly. During warm, dry weather they consume much more food and grow with great rapidity. In the unusually warm spring and early summer of 1895 many of the caterpillars moulted a less number of times than usual, and their length of life did not exceed six or seven weeks. Under these conditions they proved more quickly injurious to foliage than in a more normal season, and were more completely destructive within any given area in which their numbers were great. And they were not so long exposed to the attacks of their enemies. While it may be true that the parasitic enemies of the moth will also develop rapidly under conditions that hasten the growth of their host, birds and other vertebrate enemies will secure fewer of the moths in six or seven weeks than in ten or twelve. This would probably be true of many predaceous insects. It is believed that dry weather is unfavorable for vegetable parasites of insects, but to what extent the caterpillars are affected by them in a humid season it is impossible to say.

The past two years have been "canker worm years" in the infested region. Many of the birds which habitually feed on the caterpillars of the gypsy moth have been largely occupied during May and the early part of June in catching canker worms, which they scem to prefer, turning their attention to the gypsy-moth caterpillars in the latter part of June and July, when the canker worms have disappeared. The birds, therefore, have not been as useful in checking the increase of the gypsy moth as in years when the canker worms were less numerous.

A few of the restraining influences which have been less active than usual during the past two years have been men- 



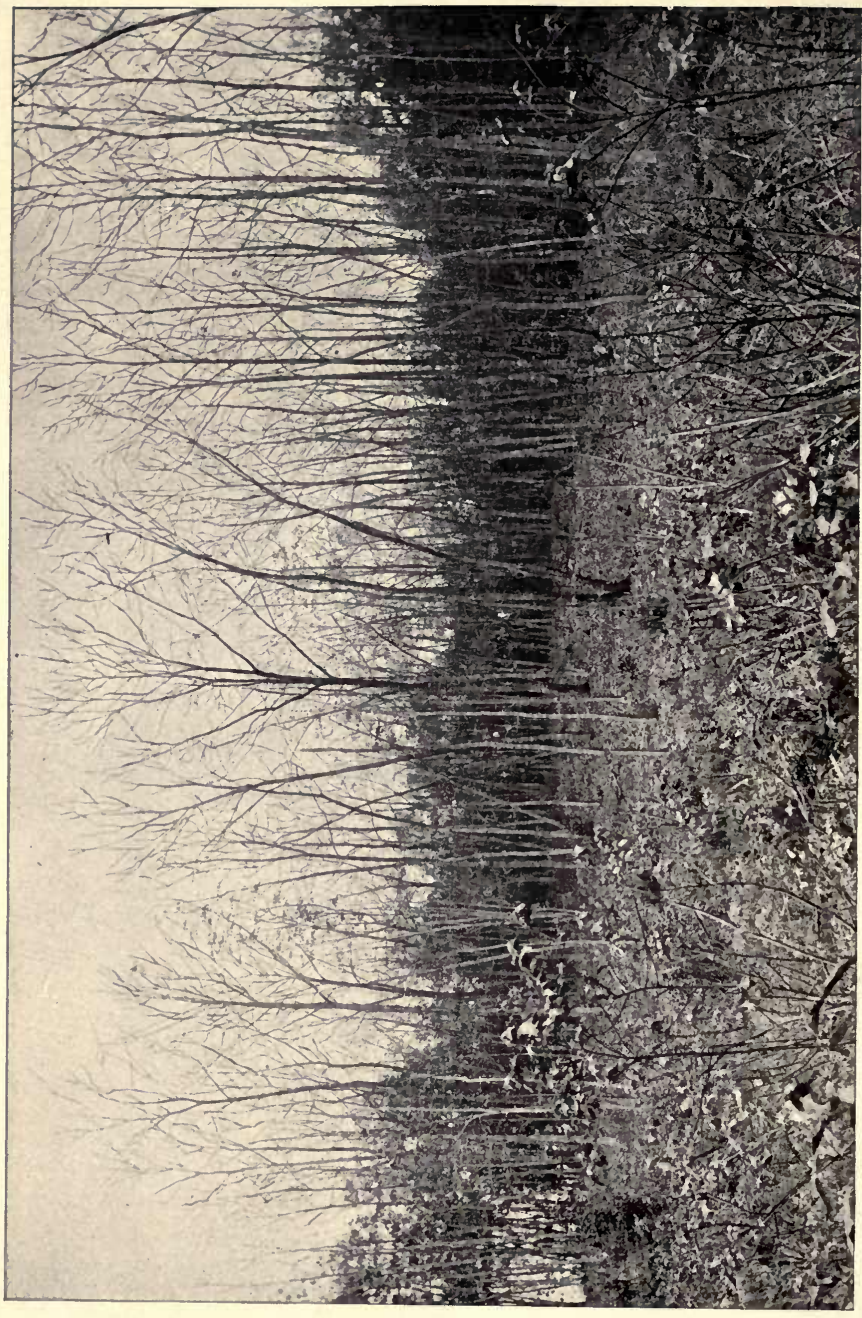



జ

मृ. ळ

क से

4 है

\& 25

$\stackrel{0}{=}$

$\Rightarrow 1$

क्ष

+

ه

4

क

म م

T)

?

क्ष

$+\infty$

ర్ర

(1) 岳

요 19

$+40$

$\infty$ 동

孚

of

잉 뭉

ने क्षे

द्न

ळ

'ㄷㅇㅇ

용

B 용

or

\%

品

$\Phi$ 웅

究

वै

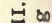

5

45

闵

봉

4

송 
tioned, and possibly many others have escaped observation, but those given may serve in a measure to explain the unusual increase of the moth. It is during such seasons that its destructiveness is most apparent. It is then that the groves and forests are stripped of their leaves, and whole rows of trees in orchards and along highways appear to have been stripped in a single night.

Distribution as aFFected by Food Supply and other Natural Causes.

If the number of gypsy-moth larvæ in a given territory is small and their food supply is large, they do not usually spread of their own volition to any appreciable extent. So long as the supply of food is abundant and accessible the caterpillars usually remain on or near it, and will move only when disturbed or dislodged from the trees or other plants on which they feed. In such cases they will reascend the same tree or crawl to near-by vegetation. When a tree is overcrowded with eaterpillars, and by reason of their voracity food becomes scarce, they will crawl rapidly in all directions in search of it, and thus they spread out from a common centre over a limited area. Wherever the moth is introduced it has the advantage of such species as the canker worms (Paleacrita vernata and Anisopteryx pometaria) and the tent caterpillar (Clisiocampa americana), which are confined to a few kinds of food plants. Because of the great number of its food plants it is capable of subsisting in almost any locality whereto it may migrate or be transported. Its spreading is, therefore, more general and its distribution less localized than that of the canker worms. But as the female moth does not fly, the species is limited in its powers of migration, and though the larger caterpillars are very restless, their movements show little method except when food becomes scarce. It has been seen that isolated colonies of the moth in woodlands not frequented by men do not often spread to, a considerable extent until the caterpillars have increased in numbers so as to destroy all the foliage in the originally infested localities. They then migrate in search of food, and when this movement is once begun they some- 
times scatter to a considerable distance. Though this is the rule there are some exceptions. In some localities, presumably where the larvæ are persecuted by many enemies, they are found scattered abroad over a considerable area even when food is abundant.

The moths are sometimes distributed by birds. Many birds feed upon the caterpillars, and in some cases they have been known to drop them alive while carrying them to their young. As the larvæ are very hardy and are likely to survive rough treatment, they may be scattered somewhat in this way. Some of the distribution in woodlands may be thus accounted for. The smaller larvæ may even be occasionally carried a short distance on the feathers of a bird. The caterpillars are also occasionally transported by the wind. As they hang by threads from the trees they are sometimes swept off by sudden gusts of wind and carried to a distance of perhaps a hundred yards. As the moths are found distributed along running streams, it is probable that caterpillars and imagoes are occasionally swept down stream, and that now and then an egg-cluster is carried away on a floating piece of bark or dead twig or branch. Pieces of driftwood with eggs upon them have been found on the banks of streams and on the shores of islands in ponds. Egg-clusters thus exposed to the action of water have been known to hatch. The moth has been distributed in the same way along tide-water streams and even to trees and bushes growing on spots above the level of tide-water in salt marsh. Wherever the insect is numerous the eggs are sometimes laid on the leaves of the trees. They are frequently laid on dead leaves on the ground. In either case the leaves may be afterwards blown to some distance by the autumnal winds. Egg-clusters may be broken during gales by the branches of a tree beating against each other or the trunk, and the scattered eggs will then be blown away by the wind. Other ways in which distribution might happen will occur to those familiar with the subject. But the peculiar distribution of the moth over a region more than two hundred square miles in extent cannot be accounted for either by the movements of the caterpillars or by any of the foregoing causes, for there are well-marked isolated colonies 



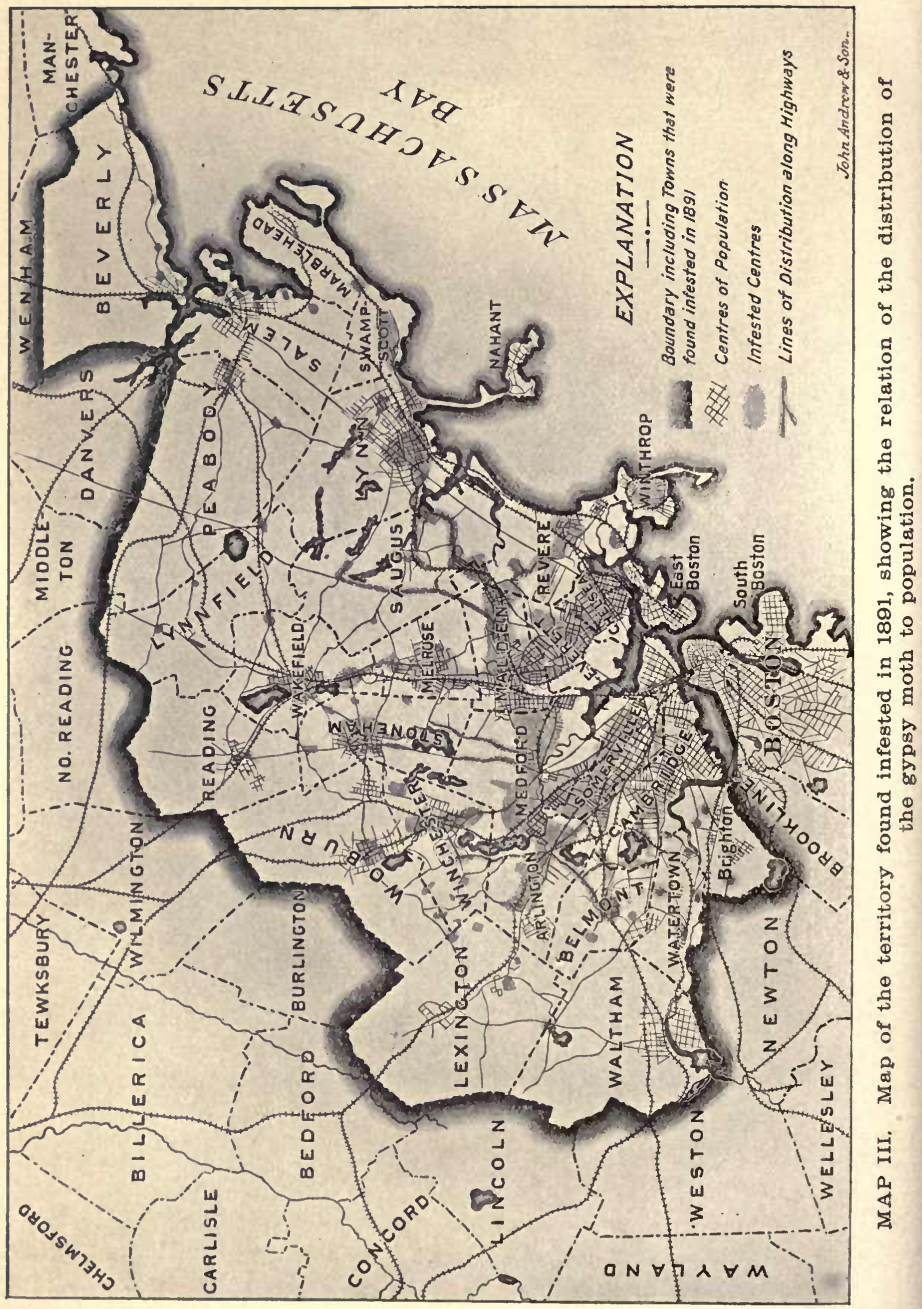


at a distance of a mile or more from other infested localities. When the action of the regulative influences which at first checked the increase of the moth and the limitation of its powers of locomotion are considered, it seems improbable that the moths could have spread over thirty townships in less than twenty years unless transported by some human agency.

\section{The Connection of Distribution and Population.}

The study of the infested territory made in 1891 showed that the most densely infested areas were very nearly coincident with the centres of population. In other words, the moth colonies were larger and more numerous in or near thickly populated districts. (See map IV.) It was noted that as the inspection receded from Medford, where the moth was first introduced, the towns were less and less infested. When, in this inspection, the centre of a town next adjoining Medford was reached many moths were found. As the centre was passed they grew less numerous until few, if any, appeared along the highways. Such trees as were found infested were generally near farm-houses and other residences. On approaching the next town the moths were again found in considerable numbers, although not as numerously as in the first town. After the second town was passed none were found upon the country roads leading farther out. This led to the hope that there were no moths in the region beyond. But an inspection of the next town revealed a few, while in the towns beyond none were found.

Outside of Medford the moths were most numerous in portions of the cities lying nearest to that town, such as Malden, Chelsea, Somerville and Cambridge. Next, the larger towns, as Melrose, Arlington, Belmont and Winchester, and the more distant cities, Lynn and Salem, were most infested. Comparatively few moths were found in the more spareely settled towns, like Lynnfield, Reading and Lexington. This distribution of the moth along the roads and over populated districts led to the assumption that man was accountable for its diffusion as well as its introduction. 
The Distribution of the Moth by Man's Agency.

The distribution of the moth by man, and the means by which it was accomplished, will be better understood if a description of the territory comprised by the infested towns and cities is first given.

This region extends along the coast of Massachusetts Bay from Boston harbor to the Beverly shore. North of Boston a considerable portion of the land surface next to the shore consists of salt marsh, penetrated here and there by tidal streams like the Mystic and Saugus rivers. Nahant and Marblehead Neck are bold, rocky peninsulas extending out into the sea. The Salem "Great pastures," lying not far from the sea, consist of rolling pasture land covered to some extent with a scrubby growth of red cedars and the characteristic barberry and other wild shrubs of the locality.

A long beach extends along the outer border of the salt marsh from the Saugus River to the shores of Beachmont, and is known locally as Crescent or Revere Beach. It is a popular summer resort. High bluffs front the sea on the Winthrop peninsula, and beyond them to the south is a strip of gravelly shore called Winthrop Beach. A tide of summer travel ebbs and flows along all these shores.

Back from the shore in the valley of the Mystic River an open and quite level country extends from the salt marsh through Medford and Arlington to the Mystic lakes, where the river has its source. The Charles River valley through Cambridge, Watertown and Waltham consists of a beautiful open country. A range of rocky hills traverses the northcentral portion of the infested district and extending northerly and easterly from Lexington reaches the sea at Marblehead. At the Marblehead shore these hills are almost treeless, but in Swampscott and through Lynn, Saugus, Melrose, Malden, Medford, Stoneham, Winchester, Arlington and Lexington they are more or less clothed with trees. This rocky, wooded region is of no great agricultural value. Portions of it have been reserved for public parks by the towns and municipalities. A large tract situated in Malden, Medford, Winchester and Stoneham has been taken by the State as a public forest reservation. This region, which is known as the Middle- 
sex Fells, contains some of the finest natural scenery in the eastern part of the State. These rocky hills, crowned with a growth of pines, cedars, oaks and other characteristic trees, intersected by running streams with here and there miniature cascades and occasional reedy fens, together form a succession of delightfully picturesque scenes of rugged beauty. Woodlands interspersed with open spaces, freshwater meadows, towns, villages and farming lands extend to the northern and western boundaries of the infested region. Nearly all of the southern portion of this region is occupied by Boston and its adjacent cities.

The situation of the towns and cities of the infested region, and their relative positions, may be seen by reference to the map. A large proportion of the population of Massachusetts is contained within this district.* Boston and the cities in its immediate vicinity lie in or near the Charles and Mystic valleys. It will be seen that Somerville, Cambridge, Chelsea, Malden, Medford, Everett and Waltham are all cities lying in the immediate neighborhood of Boston. Along the shore to the north-east are Lynn, Salem and Beverly. Woburn is the only city in the north-western part of the district.

The following cities and towns are comprised within the territory which is or has been infested: Arlington, Belmont, Beverly, Boston, Burlington, Cambridge, Chelsea, Danvers, Everett, Lexington, Lynn, Lynnfield, Malden, Marblehead, Medford, Melrose, Nahant, Peabody, Reading, Revere, Salem, Saugus, Somerville, Stoneham, Swampscott, Wakefield, Waltham, Watertown, Winchester, Winthrop and Woburn.

The larger portion of the region infested by the gypsy moth lies north of Boston. Boston's avenues of communication to the north and east and in part to the west run through it. The main lines of the eastern and western divisions of the Boston \& Maine Railroad pass through the infested district but east of its centre. Several branch lines lead to or through different parts of the district. Two lines run from Boston to Medford, - the Medford branch, ending in

* By the State census taken in 1895 (first count) the population of the cities and towns of the district infested by the gypsy moth is 963,159 . 
the centre of the town, and the main line of the southern division of the Boston \& Maine Railroad, passing through Somerville and West Medford. The old turnpike roads from Boston to Salem, Newburyport, Lawrence and Lowell all pass through the infested region. The roads which pass through this region from Boston lead outward toward the north, north-east and west.

The continual and immense traffic between Boston and towns to the northward, coming and going through the badly infested region, together with that in and out of the region itself, has resulted in spreading the moth to many of these outer towns. This has been brought about chiefly by means of the transportation of caterpillars on vehicles. In the spring of 1889 , and in other years when the moths were in greatest abundance in Malden and Medford, the young caterpillars, when disturbed by wind or by any object striking the branches, hung in great numbers by their silken threads from the trees in a manner similar to that habitual with the common canker worms. While suspended in this way above the street they were often struck by passing vehicles upon which they dropped, remaining either until a stopping place was reached or until shaken off along the roadside.* Regular teaming, daily or at stated intervals to or from a badly infested spot during the time when the caterpillars were very numerous on wayside trees, would finally result in transporting numbers of them to certain localities where the wagons stopped. A market gardener's wagon going regularly through the infested region to Boston and return, and passing under infested trees along the way, would be very likely to carry caterpillars into the yard at the end of the route. If a single pair of the caterpillars thus transported survived and passed through their transformations, and the resulting pair of moths mated, the seed for a colony might be planted. Even if one female caterpillar survived and transformed into a moth, and there were a similarly surviving male moth in the neighborhood, under favorable conditions the latter might be attracted to the former

* All forms of the moth have been found on wagons standing nnder trees. The caterpillars frequently crawl for shelter under the bodies of standing vehicles. 
and fertile eggs result. There were many ways in which the regular traffic with towns round about was kept up to or through the infested region. Florists and nurserymen were constantly sending plants to all parts of the region and to Boston. Truck farmers' teams hauled loads of produce to Boston and returned with loads of manure. Expressmen made their regular trips; butchers, bakers, peddlers and milkmen daily went their rounds, and the premises of many of these people who were constantly driving about the infested region or through it became infested. During the summer there was much carriage driving through the infested district, especially along the North Shore, and this also served to distribute the moth to some extent. In addition to the transportation of the moth in its various forms by means of vehicles there were other means of distribution more strictly local. The caterpillars were carried about to some extent on the clothing of pedestrians and on the backs of cattle, goats, dogs and other animals.

While the spread of the moth has been mainly due to the transportation of the caterpillars, the eggs of the creature were also carried about in various ways. Wood was cut from infested trees and carried with eggs upon it from one town to another. Packing cases and barrels left under infested trees are sometimes selected by the female moth as receptacles in which to deposit her eggs. Barrels and cases which had been exposed to such infestation were not only shipped about through the infested region but were sometimes sent to a considerable distance outside. If an eggcluster laid on an article thus shipped escaped destruction en route, there would be danger of the seed of a new colony being planted at the article's place of destination.

\section{Instances of Distribution by Man.}

It was learned in 1891 that the area occupied by the moth was practically included within the boundaries of thirty townships. Since that time it has been found outside of this boundary in a few isolated cases only, each of which was accounted for by the existence of driving or teaming from the infested district. The moth had reached these places during the few years previous to 1891 , when it was most 
abundant in Medford. These years of its greatest abundance were also the years of its greatest diffusion, for during the period when it was most numerous on trees, about buildings and along highways, many more caterpillars were carried out on vehicles from the worst infested localities than at any time before or since. From the small size and general appearance of most of the colonies found in 1891 at a distance from Medford, it was apparent that they had originated but two or three seasons previous to that time. On further inspection it became evident that the moth had become widely distributed in 1888,1889 and 1890 over the region occupied by it in 1891 .

Most of this diffusion to a distance from Malden and Medford was accounted for by teaming and driving to and from the district originally infested. Therefore, it may be termed the primary distribution, as it was caused by transportation direct from the towns first infested. Here and there, however, large colonies were found that must have been growing for eight or ten years. These colonies, if on or near highways, had already become centres of infestation from which the moths had been distributed widely, not only along the roads leading out of the infested locality but also back toward the originally infested centre by means of vehicles bound toward Boston. This spreading from these colonies may be called a secondary diffusion. Of this there are some interesting examples. From the large colony in Swampscott (see page 58) the moths were not only distributed on to Marblehead but they were also taken back into Lynn. The Lynn residence of the owner of the place where the Swampscott colony was situated was found in 1892 to have been recently infested, and it was learned that the owner had been accustomed to drive frequently to the Swampscott place and leave his horse and buggy in the yard under the infested trees.

Early in 1891 a colony was found in North Cambridge in the yard of Muller Brothers' tannery. As thirty-five thousand egg-clusters were taken there the colony must have originated several years previous to 1891 . Dead horses were frequently carted from Malden and Medford to the Muller place, where there were at that time facilities for making such use of these 
remains as was compatible with their character, age and general utility. It is probable that the moths were originally carried there on the wagons which were used for this dolorous traffic. The Cambridge almshouse was situated a few rods in the rear of the tunnery. The city swill was hauled from all parts of Cambridge to this almshouse and was then distributed for miles around to farmers and others who kept hogs. These swill-takers' wagons in going and coming were obliged to pass under the branches of some badly infested trees that overhang the street. A tide-water stream ran through the tannery yard. An inspection revealed that the trees along the stream for many rods were infested. Here was a secondary centre of distribution of the first magnitude. Persistent efforts were made to stamp out this colony. When this had been done the locality was carefully watehed. As the country roundabout was inspected the moths were found scattered all over neighboring portions of Cambridge, Somerville and Arlington. In 1893 a list of the persons to whose places swill had been teamed was secured from Capt. M. L. Eldridge, superintendent of the almshouse. This comprised the names of nearly three hundred people residing in the following towns: Arlington, Bedford, Belmont, Brighton, Burlington, Cambridge, Carlisle, Concord, Lexington, Lincoln, Medford, Somerville, Waltham, Watertown, Weston, Winchester and Woburn. The places of more than fifty people in the list have since been found to be infested. The results of the investigation did not indicate that in all cases they had become infested by the carriage of swill, for it was seen that some places to which swill had been hauled during the months when the caterpillars were numerous upon trees were not infested, while others to which swill had been hauled in the winter only were infested. Yet it seems probable from all the data obtained from inquiry in these localities that more than half the infested places had received infestation from the hauling of swill from the almshouse.

Localities in the infested district that are much visited on account of their historical associations are usually found infested, and if cleared of the moth are likely to become reinfested. Many eminent men have been buried in Mount Auburn Cemetery, which lies partly in Cambridge and partly 
in Watertown. This cemetery is often thronged with visitors from far and near. It was well cleared of the moths in 1892 and 1893 , but in 1895 the caterpillars appeared again in such quantities near the graves of the poets Lowell and Longfellow that much effort was required on the part of the workmen employed by the Board to prevent serious injury to the trees in the cemetery. Though Charlestown was cleared of the moths in the first three years of the work, they were found in $\mathbf{1 8 9 5}$ at Monument Square. These grounds about Bunker Hill monument are much frequented. Many people coming from other parts of the infested region have visited the monument within a year. The carnival in Charlestown on the 17 th of June, a time when the caterpillars are most numerous, draws thousands of people from the region round about to the vicinity of the monument.

\section{A Study of the Methods and Routes of Trans- PORTATION.}

In 1891 hasty inspection of the infested region finally revealed its apparent extent. This inspection was carried on until, in 1893, a wide belt around the region had been examined. The question whether the moths had been transported to any distance beyond this belt in sufficient numbers to continue the existence of the species and thus form other centres of distribution remained unsolved. It was not possible under the appropriations made to extend the search over the entire Commonwealth. As it was evident that the moth was distributed principally by man, a study was made first of the nature and direction of the traffic and travel which had caused the dissemination of the moth through the region known to be infested; next a study was made of such similar traffic as extended to a distance from the infested region and which, therefore, might expose other localities to infestation.

In studying methods of transportation special attention was paid to the steady and constant traffic back and forth between points within and without the heart of the infested district. Information was also secured as to the character, routes and destination of outward freight shipments by road and rail, and of the vast miscellaneous traffic and pleasure driving 
over the road. Inquiries were first made in the inner and worst infested towns. Supplementary and additional information was gathered later outside the infested district in those localities known to have had more or less communication with the "danger tract" of the infested region during the greatest prevalence of the moth. This "danger tract" was the heart of the infested region (Medford and Malden) because the swarming numbers of the caterpillars there had made possible their frequent transportation by vehicles to other points. At first there was not so much danger of such transportation from anywhere else in the infested district because of the comparative scarcity of the moths in other localities and the usual small size of their colonies. This study shed a flood of light upon the manner of the distribution of the moths in the territory originally infested from Medford, and explained the existence of many colonies in woods and other retired places. It also indicated the places which had been most exposed to infestation in the territory lying beyond the known limits of the moth's spread.

The investigation of the transportation of the moth was confined mainly to the traffic and communication to the north, east and west of Medford. The great bulk of all driving over the road and the still greater proportion of "dangerous" or constant traffic was to the north and west and along the North Shore to the north-east, and consequently the moth had been diffused farther in those directions. There is little constant and direct teaming traffic to any other southern point than Boston, and the latter place, by reason of the small number of trees in its business sections, was a comparatively safe point for the reception of such traffic.

In the inquiry in regard to the traffic over the road, all information possible was obtained concerning the routes of expressmen and movers, market-gardeners, farmers, milk, hay and wood dealers, swill-takers, butchers, peddlers and junk men. Local boards of health and milk inspectors in and around Boston furnished information by means of which those engaged in the milk business and in swill taking were located and their routes ascertained. Much information was secured in regard to the great market-gardeners' traffic over the road between Boston and towns within the infested district 
or to the north and west of it. Information was sought in regard to excursions and picnics to the groves situated on all sides of the worst infested district. Much knowledge was obtained in regard to the grounds used by church and Sunday school picnic parties from Malden, Medford, Revere, Somerville, Cambridge, Arlington, Melrose, Lynn and Everett. Places of great public resort, like militia and camp-meeting grounds, were also noted and were later examined. Facts bearing upon the hauling of wood to or through the infested district were carefully gathered. Inquiries were made of expressmen and movers in regard to the destination of families which had moved from badly infested localities, and as to the large amount of summer moving and teaming along the North Shore, and the amount of teaming over the road weekly, monthly or yearly between the infested district and centres of traffic like Lawrence and Lowell. The matters of shipments of nursery stock and greenhouse plants over the road and of towns visited and routes taken by peddlers and junk dealers were also investigated. A vast amount of facts bearing on the subject of miscellaneous driving was also obtained. The inquiry was not entirely confined to the heart of the infested district but was extended to less infested places like Lynn and Salem. The scope of the whole investigation quickly broadened. Clues obtained within the infested district were followed out, and this led to much additional inquiry in many towns to the north-east, north and west of the infested region. Every possible fact and item bearing upon the subject of communication with the moth-region were obtained. It was not difficult in country towns to learn who were the regular and who the occasional visitors to or from the infested district and what was the nature of their business. The lines of travel were also easily learned. In cities like Lawrence and Lowell which, although farther away, were in a sense exposed because of their being centres of population, lists were obtained of teamsters and movers who went more or less frequently to the district to the south and the character of their business was learned. These local teamsters as a rule made their return trips empty handed, and thus the danger of moth transportation, except by the vehicle itself, was avoided. 
The investigation and the subsequent inspection based thereon revealed the important fact that the most dangerous traffic was that going only a short distance from the centre of the infested district. A large proportion of this did not even go out of the district, and nearly all the remainder went but little farther. The proof of this is ample. The most dangerous traffic is the steady and constant traffic back and forth between the same points which, by its regularity, makes possible the occasional transportation of caterpillars to the same locality. This regular traffic includes the trips of market-gardeners, farmers, milkmen, swill-takers and others living in the outer towns of the infested district or in the towns next beyond, who go daily or weekly in and out of the heart of the infested district or through it to Boston and return. Nearly all of the foregoing classes of people live comparatively near the heart of the infested district. None of them live very far away. In a word, in proportion as the distance from the heart of the infested district increased, the regularity and frequency of traffic to and fro decreased, and in the same ratio the danger of moth transportations and consequent possible establishment of new colonies diminished. The work of four years has proved that new colonies at a distance from the infested centre have owed their origin and rise, not to a single transportation of the moth but to various cases of the sort which have been made possible by steady communication over the road between two points. Even pleasure driving, when constant and frequent between an infested locality and one outside, has been responsible for the establishment of a new colony.

In the study of traffic and driving of all sorts over the road, the question of routes became of the utmost importance. The vast aggregate amount of wheeling by its very existence caused the roadsides of all main highways and the neighborhoods of hotels, village stores, blacksmith shops and watering troughs to become more or less exposed, the danger, of course, decreasing as the distance increased from the infested district. There were two reasons for this: first, the great bulk of all wheeling, miscellaneous as well as regular, did not go to a great distance; second, the ma- 
jority of larvæ transported on vehicles are undoubtedly shaken or brushed off before many miles are traversed.

The possible danger attaching to freight shipments by rail from Malden and Medford was investigated by an examination of "freight forwarded" books at the various stations. The examination of these books revealed the origin, character and destination of shipments since 1880. The origin and character of shipments immediately revealed the danger, if any, attaching to them. To illustrate: Manufactures and household goods, constituting the bulk of shipments, coming as they do from in-doors, are practically safe shipments ; while articles which have been exposed out of doors, such as empty boxes, nursery stock, bricks, stones, scrap iron or builder's' materials, may, if coming from an infested locality, be dangerous shipments. In this connection the matter of date of shipment was important. Some articles, by reason of their place of origin, might be dangerous shipments only during the larval season; others, only during the months when the eggs aro the only living form of the moth. Finally, the examination of the freight books revealed the receivers of goods (whether in or out of the infested district).

The danger of moth transportation on freight sent by rail was shown by the investigation to be very slight. The proportion of shipments which on account of their character or frequency might be considered as dangerous was extremely small.* The destination of these being known, it was possible to do supplementary work in the nature of inquiry and inspection at these points of destination. In most cases such work was done.

The matter of shipments of bricks from Medford deserves special mention in this connection both because of its intrinsic importance and as an illustration of the methods of inquiry pursued. The premises of the Anderson Pressed Brick Company were in the past badly infested. Shipments of brick had been made to many points outside the infested territory. Most cases were investigated and an inspection made at the places to which the brick had been shipped. In this work the agents of the Board visited a number of towns

- This is equally true of freight shipments over the highway. 
widely scattered over the State. Although the danger of the transportation of the moth in the egg form had appeared serious, no trace of the insect was anywhere found.*

In addition to the freight shipments, another danger of moth transportation lay in the possibility of the cars themselves earrying some form of the moth. This might happen in case a car had stood for some time on a siding near infested trees or other objects. Two instances are recorded where egg-clusters have been found on freight cars standing on sidings. This led to an inquiry into the condition of railroad sidings,' whether treeless or not, and if the latter, whether infested or not. It was obvious that if moths were transported by cars and new colonies started, these would be found along the lines of railroad, probably at sidings and stations. This later led to the inspection, as a measure of precaution, of the lines of railroad running north and west out of the infested district, the eastern and western divisions of the Boston \& Maine road being followed out as far as Portland, Me., the southern division as far as Concord,N.H., and the Fitchburg road as far as Fitchburg. In the matter of possible danger of moth transportation by cars, the shipment of wood to the Bay State Brick Company in Medford deserves mention. The premises of this brick company are infested. Thousands of cords of wood are shipped there yearly from New Hampshire points, and the same platform cars were in the past often sent back and forth again and again. A certain amount of danger had unquestionably attached to this species of traffic. The places of shipment in New Hampshire were consequently visited and the sidings in their neighborhood carefully examined, but no trace of the moth was found. In this work additional information was secured whenever possible as to any communication between outside points and the infested region. This inspection of suspected localities outside the State was rendered necessary in connection with the policy of extermination, which proceeded on the theory that the moth was confined to a limited area in the State of Massachusetts.

* The danger of transportation of eggs was lessened by the fact that the finest bricks, the only ones sent to a distance, were cleaned before being shipped. 
At the height of the caterpillar plague in Medford, it is said that it was almost impossible for people going through the streets leading to the Glenwood station of the Medford branch railroad to avoid carrying caterpillars which dropped down upon their clothing from the wayside trees. (See the statement of Mr. Sylvester Lacy on page 17.) As the railroad ran only from Medford to Boston, there was not as much danger of the caterpillars being transported to a distance by means of the luggage and clothing of passengers as there would have been had the railroad passed through Medford to other parts of the State or to other States. Nevertheless, during 1888, 1889 and 1890 very many caterpillars undoubtedly were carried in this way not only to Boston but to other parts of the State. Even in 1891 caterpillars were thus frequently carried. An agent of the Board of Agriculture stated to the writer that in 1891 he took a gypsy-moth caterpillar from the cloak of a lady standing in front of the ticket office in the western division station of the Boston \& Maine Railroad in Boston. The lady had come from Medford and had just bought a ticket for Northampton, a city in the Connecticut valley. Had the caterpillar not been removed from her cloak, it might have been carried a long distance, or if left upon the cars it might have escaped observation, dropping off eventually at some point along the road. If such cases have frequently occurred the question at once arises, why have not moth colonies been formed far and wide? While at first sight it would seem probable that they have been thus formed, yet upon consideration it is seen that the carriage of caterpillars in this way to a distance is not necessarily dangerous." The farther a caterpillar is carried from others of its kind the less becomes the probability of its reproduction. The female moth does not fly. With favoring winds in open country the male can find the female, by means of his sensory organs, at a distance of about half a mile. The change of cars which was necessary in Boston, and the radiation of the railroads to the north, east, south and west, served to decrease the chances of propagation, for the farther a caterpillar was carried from Boston the greater became the distance which separated it, not only from the infested region, but from other lines of 
railroad leading out of Boston on which other caterpillars might be carried out. Thus, though many caterpillars might be accidentally carried to a long distance outside the infested region, there was very little probability that any number of such individuals would be dropped within half a mile of each other. Furthermore, the chances that isolated caterpillars would complete their transformations and emerge as perfect insects are very small. Therefore, there would be hardly a possibility of a colony being started by the accidental transportation of caterpillars to a distance unless it should be proved that parthenogenesis (the reproduction of the species by the virgin female) occurs. ${ }^{*}$ If, however, the moths should at any time become abnormally numerous on the line of an extended railway, their chances of accidental distribution by regular and constant travel would greatly increase and a wide dissemination would almost certainly follow. So far, notwithstanding the unhindered carriage of caterpillars in this way on the Medford branch railroad for several years previous to 1892 , no evidence of the moths' existence at a distance from the infested towns has ever been found along the lines of other railroads.

\section{The Effect of the Work of Extermination on the Distribution of the Moth.}

While the work of destroying the gypsy moth has much reduced the numbers of the moths and the extent of territory occupied by them, it has been necessary to exercise great care to avoid accidental distribution of the caterpillars by the workmen.

The work of spraying is responsible for some slight local scattering of the caterpillars. When the branches of a tree are disturbed by the sprayers, many of the caterpillars spin down and either fall to the ground or are carried about upon the clothing of the workmen or others passing beneath the tree. Unless great care is taken they may be carried from place to place on the spraying team. Those falling to the ground

\footnotetext{
* Observations so far made in this country have not revealed a case of parthenogenesis in this species, but, on the contrary, many instances have shown isolation to result in extermination. A few European instances of parthenogenesis have been recorded.
} 
frequently crawl to other trees, and if later these trees are sprayed many of the caterpillars crawl still farther. It is almost impossible to aroid scattering the moths when spraying is resorted to, which makes it necessary to spray all vegetation near an infested spot, that the scattering caterpillars may find poisoned food.

As the work of burlapping has progressed since 1891 the proportion of caterpillars seeking the shelter of the burlap appears to have diminished. Many either remain in the tops of trees or seek out places near the ground in which to secrete themsclves. There also seems to be a tendency to scatter farther and farther from the infested localities. These habits may have been induced by the frequent disturbing of the caterpillars in the work of burlapping, or here may be another illustration of the survival of the fittest. When the caterpillars are very young and while the workmen are placing the burlap bands about the trees they are likely to dislodge some of the caterpillars which, falling upon their clothing, may be carried about from place to place. To lessen the risk of such carriage the workmen in summer are dressed in a uniform suit of a light color so that any dark object falling upon them may contrast strongly with their clothing. The men are also cautioned to examine carefully each other's clothing when leaving an infested place. Notwithstanding this precaution it is possible that a few localities from which the moths have been entirely exterminated have become reinfested in this way, for occasionally a place in which no form of the moth has been found for a year or two becomes again infested. In such cases from one to three or four caterpillars have been found during the season, not a sufficient number to indicate that eggs had been laid there in the previous season.

\section{The Distribution Restricted and Changed.}

As far as the work of extermination has proceeded it has radically changed the distribution of the moth. It is often the case that the most persistent and thorough work will not exterminate the moths from a locality in one year. It is necessary to search a locality for several years in order to be assured that the moths are all destroyed and no seed is 



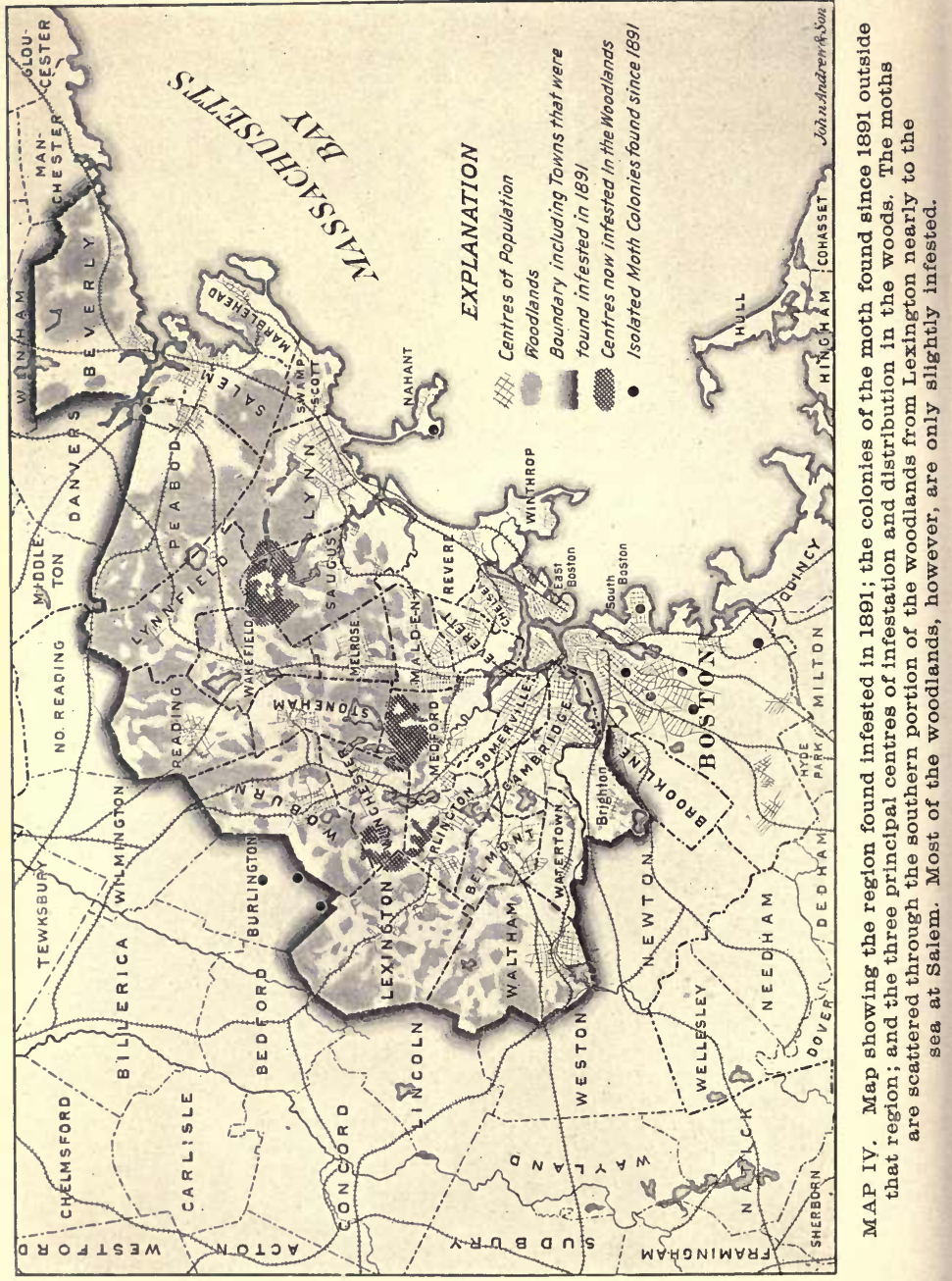


left. But we have now sufficient data for the belief that the moths found in most colonies in the outer towns in 1891, 1892 and 1893 have been exterminated. In this way the outward spread of the moth to new territory has been restricted. It has been necessary, as a part of the policy pursued in preventing the spreading of the moth towards towns outside the boundary of the infested region, to search carefully the borders of highways and streets in towns and cities, as it was from cultivated grounds in populous towns and by highways leading from the towns that the moths were mostly distributed. As the moths in the woods spread slowly, and were less liable to transportation outside the infested region than those in the residential and business sections, work was concentrated upon these districts to the neglect of the woodland. As has already been stated, the centres of distribution in 1891 coincided with the centres of population, and in the attempt to clear these centres and prevent injury to valuable trees and plants the larger part of each appropriation was used. From what was learned yearly by the woodland searchers it was believed that the moths were increasing and spreading in the woods. The committee in charge of the work stated this belief year after year to the legislative committees and strongly urged in their reports to the Legislature that more money be appropriated. for the inspection of the woodlands and the destruction of the moths within their borders. Sufficient appropriations not being forthcoming the result of the neglect of the woodland is now shown in the present distribution of the moth. The normal diffusion from centres coinciding with the centres of population has given place to a much slower dissemination from centres situated in the woodlands of the north-central infested towns. Though much work has been done in these woodlands it has been from necessity superficial and has merely resulted in partially holding the moths in check. In some localities where the woods were not searched the increase and spread have been unimpeded because the colonies were not known.

In the report of the work of the year 1894, made by the Board of Agriculture to the Legislature, it was stated as probable that the moths were scattered through the woods from Lexington to the sea. That this probability has be- 
come a certainty is shown by the developments of the season of 1895. As has before been stated, there are in this region three centres of infestation of at least a thousand acres each. (See page 87.) These centres are included in a belt of woodland a mile in width, which is all more or less infested, reaching with some interruptions from East Lexington to Salem, a distance of about eighteen miles.

As compared with 1889 the moths in open and cultivated lands are now much reduced in numbers in the worst infested sections and are elsewhere extinct or comparatively rare. On the other hand, in the belt of woodland north of the centre of the infested region they occupy more ground than in 1889, and the number of badly infested places is greater. 



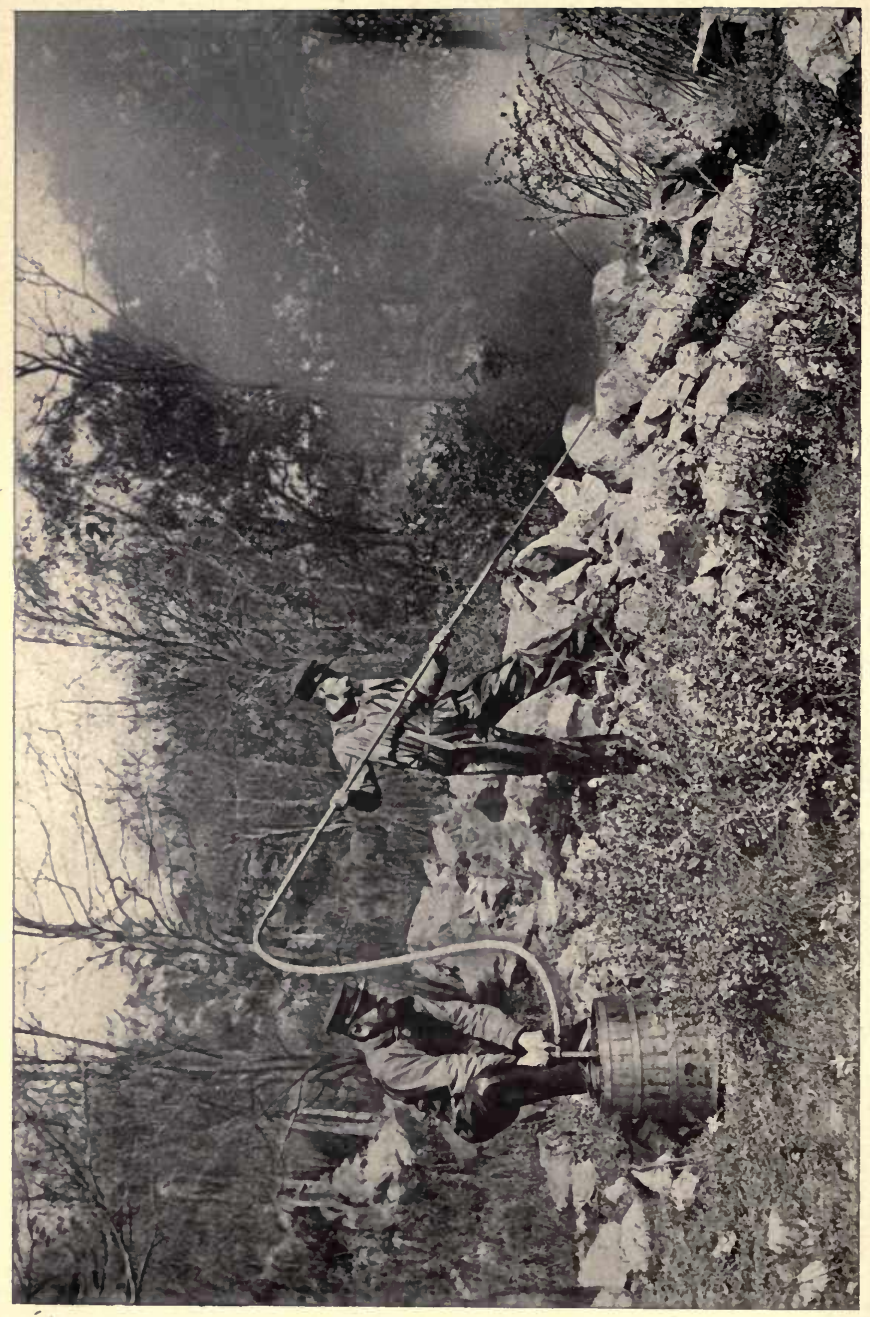

\&્木

马ึ?

ดี ลี

용ㅇㅇ

$\exists$.

ळः

क्त

응

क 운

돈

뎐

व

as

2.

of 9

-

면

4. 응

क ㅇ

bo 2

(1)

연 묭

sot

ב]

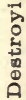

岁 
METHODS USED FOR DESTROYING THE Gysy Mотн.

\section{The Destruction of the Eggs.}

As the egg-clusters of the gypsy moth are of a conspicuous color and may be found upon trees and other objects during at least eight months of the year, the possibility of stopping the moth's increase by destroying great numbers of caterpillars in embryo becomes apparent. In each buff egg-cluster temptingly displayed upon the tree trunks during the fall, winter and spring there are from three hundred to fourteen hundred potential caterpillars. Destroy the egg-cluster and apparently you have disposed of the coming brood. You have prevented the hatching of the eggs and the consequent spreading of the caterpillars which otherwise would have scattered abroad, feeding upon nearly all kinds of trees, shrubs and garden plants. Obviously it is safer, easier and less expensive to destroy the egg-cluster in which the brood is united and stationary than to find and destroy the caterpillars after they have hatched and scattered. The destruction of eggs may not always secure extermination, as the female imago sometimes scatters fertile eggs upon the ground, and concealed egg-clusters may sometimes be overlooked. Yet persistent and thorough egg-destruction in the autumn, winter and spring may be relied upon to so reduce the number of the moths that they will do comparatively little injury in the ensuing summer. Egg-killing is recommended by many European authors as the first and chief method of preventing the ravages of the moth.

Bechstein wrote in 1804: "The clusters of eggs can be looked for from the last of September or October to March, upon the trunks of trees, walls, hedges and fences, and may be crushed or knocked off into a pot and burned by kindling a fire upon them."*

Canon Schmidberger, who wrote the papers on "Insects

" “Vollstandige Naturgeschichte der schadlichen Forstinsekten," Leipzic, 1804, page $3 \% 2$. 
Injurious to Fruit Trees" for Vincent Kollar's work, published at Vienna, Austria, says: "With respect to destroying these insects, the first thing that is necessary is to find out the egg-masses and destroy them." *

This method is quite generally employed in European countries where the gypsy moth is plentiful. We have conducted a considerable foreign correspondence to determine what methods are now in use in European countries to check the ravages of the moth. Under date of Aug. 29, 1895, Dr. Antonio Augusto Carvalho Monteiro writes from Lisbon, Portugal: "We generally endeavor to kill the larvæ at about the end of June, or to destroy the cottony dises which enclose the eggs during autumn, by scraping the trunks of the trees, the walls, ete., and then crushing or burning them, or sometimes even covering them with a thick layer of coal tar by means of brushes."

Professor Henry of the School of Forestry at Nancy, France, writes under date of July 27, 1895: "The best thing to do is to kill the heavy female wherever it is met with, and especially to coat the egg-clusters, generally very easily seen, with a thick coat of tar by means of a brush at the end of a pole."

Prof. N. Nasonov writes from Warsaw University Museum of Zoölogy in Russia, Aug. 7, 1895, stating that the first method used is scraping the bark from the trees after the deposit of the eggs.

Prof. Max. Fingerling writes from Leipzic, Germany, on Aug. 9, 1895: "The best method of holding the insects in check is by destroying their eggs. In this particular case nature has provided a means in the easily recognizable eggclusters."

When in 1891 the people of the infested region were consulted by the agents of the second commission for the extermination of the gypsy moth, it was found that there existed among them a strong prejudice against spraying, and also a belief that it was not effective with the gypsy moth. Gathering the eggs was believed by those who had fought the moth in Medford to be the most effective method of destruction

" "A Treatise on Injurious Insects," by Vincent Kollar, English translation by J. and M. Loudon, London, 1840, page 202. 
then in use. Egg-killing was begun by the commissioners, who, fearing that spraying might not prove effective, determined to leave no stone unturned, but to give all promising methods a thorough trial.

\section{Burning the Eggs.}

Professor Fernald had recommended in 1889 that the eggs of the moth be scraped from the trees and burned. This was the most effectual method of egg-killing pursued by the first commission. During the spring of 1891 it was used by the second commission and later by the employees of the State Board of Agriculture. The eggs were seraped off or cut away from the objects upon which they rested, placed in tin cans and burned in stoves or brush fires. A fierce heat is required to ensure their destruction. When exposed to such heat they finally burst with a snapping like a bunch of miniature fire-crackers or the cracking of corn in a popper. Whenever the eggs were very numerous in undergrowth or waste land, fire was run through the dead leaves and debris as an experiment; but this method seemed to have little effect, as the heat was not sufficiently intense. The hairy covering of the egg-clusters seems to possess remarkable non-conductive properties, rendering the eggs almost impervious for a time to sudden intense heat. Even with the hottest fire that can be applied to the egg-clusters, some minutes are required to destroy them utterly. A running brush fire merely scorched the outside of the cluster, killing perhaps a few of the eggs in the external layer, but leaving the majority uninjured. Experiments were next made with crude petroleum, by spraying it over the ground and vegetation by means of watering pots and then igniting it. The fire thus made was fieree enongh to destroy the small undergrowth and the upper layer of leaves, together with most of the eggs, but such egg-clusters as remained under roots or rocks were not injured. Considerable oil was wasted by soaking into the ground, and the remainder did not give the degree of heat which is obtained by atomizing. Experiments were then made with a view of perfecting a burning machine which would ineinerate all undergrowth in a given tract. The first experiments were not entirely successful, 
as the machines were either too cumbersome or could not be used on rough or uneven ground. It was found necessary to provide an apparatus which would distribute the oil in a spray, as when thus thrown in fine particles in the air and ignited, it formed an extremely hot gas flame and was consumed to the best advantage. For economy's sake such an apparatus must be light enough to be carried and operated by two men, as wagons could not be driven over much of the ground upon which this work was done. Experiments were made with the cyclone nozzle. (Plate XXVII., Fig. 2.) An oil spray from this nozzle when ignited was found to give a very hot and effective flame. Crude oil was first

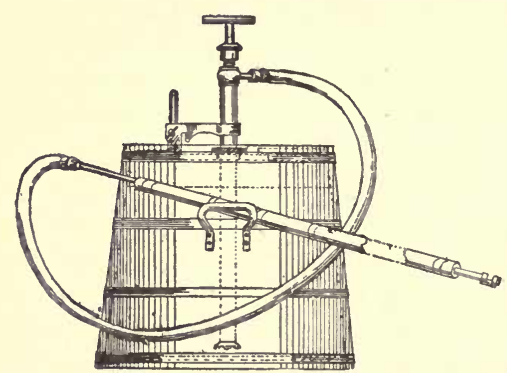

Fig. 1. The cyclone burner. used as a burning fluid, but as it is very objectionable on account of its rank odor, "paraffine gas" oil was substituted later. This oil has less odor and burns to better advantage, but is somewhat more expensive. A fifteen-gallon tank

which could be readily carried about by two men was provided. On such a tank a Johnson pump with a fine strainer placed over the suction pipe was mounted, and a short hose of the kind made for the delivery of oil was attached. Ordinary rubber hose is worthless for such a purpose, as it is soon destroyed by the corrosive action of the oil, and in the mean time the disintegrated particles frequently clog the nozzle.* A pole, consisting of an iron pipe twelve feet long, braced by being surrounded by wood for three-fourths of its length, was coupled to the hose. (See Fig. 1.) No solder could be used in the fittings of the pipe or nozzle,

* The best "oil hose" that can be obtained will soon become corroded, clogging the nozzle. If an " automatic clearing nozzle" could be devised which would withstand the heat, much time might be saved which is now necessarily used in clearing the nozzle. 
as the fierce heat of the flame would fuse it. The wooden cylinder into which the pipe was thrust was one and onefourth inches in diameter. The wood, being a non-conductor of heat, was of great convenience in handling the pole. The end of the pipe was fitted with a cyclone nozzle. The aperture of this nozzle is very small, hence the value of the strainer before mentioned, which prevents the entrance of foreign substances with the oil and a consequent clogging of the nozzle. The two men handling this apparatus filled the tank with oil and then carried it to the spot where the burning was to be done. One man then operated the pump while the other handled the pole and nozzle. As soon as the pump was started a fine spray of oil was thrown into the air and ignited by a match. By means of the pole the resulting fierce flame was carried among the undergrowth and over the ground, destroying every living thing in its path. When this work was carefully done, no eggs escaped except such as were hidden in ledges or holes in the ground. An attempt was made also with this apparatus to destroy eggs which had been deposited in stone walls. (See Plate XVIII.) Though this was partially successful in so far as the fire reached and destroyed most of the eggs, those which were deposited under the lower stones of the wall were unharmed, even though in many cases the stones were cracked and broken by the heat. As it sometimes became necessary to use this apparatus in burning out walls near growing crops, a sheet-iron screen was set up between the flame and the growing vegetables to protect them from the heat, being moved along the wall as the work progressed. Burning was thus done without any resultant injury to the gardens. This machine, which has been christened the "cyclone burner," would be most useful in checking invasions of crawling pests like the army worm.

Fire was also used in hollow trees, the eggs hidden within them being destroyed by burning out the decayed wood. If this is judiciously done, there will be no injury to the tree. Unless great care is used, however, to extinguish the flame in time, there is much danger of destroying apple trees in this way. Cherry, oak and willow trees have rarely been injured by burning out cavities; indeed, some old trees appear to 
have been benefited by such burning, as they have shown a better growth during the season following. Oil is poured in at the top of the hollow, and a sufficient aperture made at the bottom to ensure a good draft. The oil is then lighted, and the draft in the funnel thus made fans the flame until the decayed wood has been consumed. This should be done only in the winter, when the sap is dormant, and the fire should be extinguished before it has done serious injury to the live wood. This treatment is unnecessary in cavities so accessible that the eggs and dead wood may be removed by other means.

The naphtha burner, an instrument commonly used by painters and plumbers, was used in 1891 as a substitute for the scraping of eggs from trees and rocks, which sometimes resulted in their being scattered. This burner is supplied with an air pump, and furnishes an air-blast flame of an extremely fierce heat. If this flame is applied directly to the egg-cluster, it will reduce it to ashes on the tree, although occasionally eggs exposed to such great heat will burst, possibly scattering others. The burner should be used only on the trunks of large trees having thick bark, or in such cavities in trees or rocks as cannot be reached by other methods.

\section{Killing the Eggs with Chemicals.}

Early in the work of 1891 it was seen to be impossible to detach the egg-masses from their various places of deposit without occasionally seattering and losing some of the eggs. Experiments made during the following winter proved that eggs scattered and exposed to the vicissitudes of the season were not all destroyed by frost or snow, but that about twothirds of them hatched in the spring. It was seen that it would be wiser and safer to destroy the eggs without removal, and experiments were made with that end in view. The most successful method at first used was the application of acids which in combination destroyed the eggs. The apparatus was designed and the method invented by Mr. F. C. Moulton, a chemist employed in the gypsy-moth work. The apparatus (Fig. 2) was composed of a small tin case holding two bottles, each of them having a rubber stopper with two glass tubes, each of which projected into the bottle as 
well as out at the top of the cork, where it was bent at a right angle. One of the tubes in each bottle was drawn down to a point with a small aperture, and served as a discharge pipe. The other was connected with a rubber tube having a mouth-piece of glass. One of the bottles held a mixture of phenol or carbolic acid and turpentine (fifty per cent. of each); the other, chemically pure nitric acid. By blowing into the mouth-piece of the bottle containing the carbolic acid mixture, a jet of this acid was thrown upon the egg-mass. This carbolic acid at once penetrated the cluster and in all probability destroyed the life of the eggs. To render the destruction of all the eggs an abso-

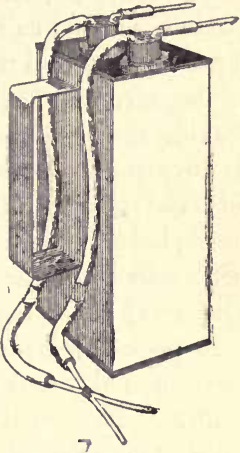

FiG. 2. Acid apparatus. Iute certainty, a jet of nitric acid from the other bottle was then thrown in the same manner upon the mass. While nitric acid of itself will not penetrate the egg-clusters, it is alone sufficient to kill the eggs if they are divested of their hairy covering and immersed in it. The two acids in combination reacted and produced an extreme heat and corrosion, and a few applications entirely destroyed the egg-cluster.

While this apparatus was being used in the field, experiments were made to find some simpler method of destroying the eggs. Although the acids were effective, they were expensive and there was some danger of injuring the men using them. Clothes, ropes, tools and apparatus were also injured by the fumes of acids which were kept with them in the tool boxes. The experiments finally resulted in the choice for use in the field of a cheap creosote oil manufactured by the Carolina Oil and Creosote Company, Wilmington, N. C. This oil was recommended for trial by Prof. N. S. Shaler. It requires neither preparation nor complex apparatus, but can be drawn from the barrel into cans and applied with a brush. If a cluster is thoroughly soaked with this liquid, it penetrates and kills all the eggs, and is very effective except in the coldest weather, when it may sometimes thicken. It may then be made more penetrative by being mixed with 
carbolic acid and turpentine, as follows: creosote oil, fifty per cent. ; carbolic acid, twenty per cent. ; spirits of turpentine, twenty per cent.; coal tar, ten per cent. The coal tar is always added to color the egg-clusters, so that those which have been treated may be distinguished. The creosote itself is not strongly colored, and often fades after application, leaving the egg-clusters of their original color. Tar is used in preference to ordinary pigments because it mixes well with the creosote, and does not settle to the bottom of the can but is held in suspension. Almost any mixture of sufficient penetrative qualities and containing considerable carbolic acid will kill the eggs.

A pocket receptacle has been devised for convenience in carrying paint and creosote and applying them to infested objects. This consists of a tin can or box (Figs. 3 and 4), in which two tubes are fastened. One of these tubes contains creosote and the other white paint. Each of these tubes is stopped at the mouth by a cork through which the handle of a small paint brush is thrust. The space inside the can and about the tubes is packed with cotton waste (Fig. 4), which receives all drippings from the tubes. Paint and creosote can be carried thus in the pocket with little danger to the clothing.

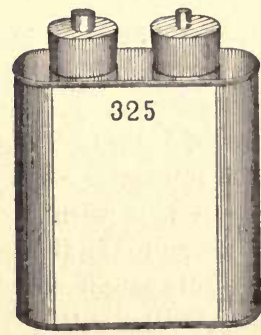

Fie. 3. Paint and creosote can.*

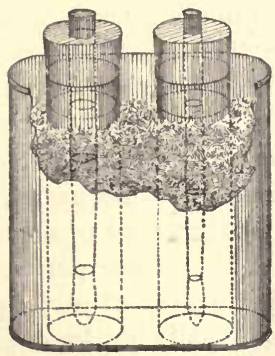

Fra. 4. A sectional vlew, showing manner of packlng.

When a tree or other object is found infested, it is marked with paint to indicate the fact. The egg-clusters are then treated with the creosote. In woodland in outer towns each

* Every tool issued to workmen in the field has its number stamped npon it. 


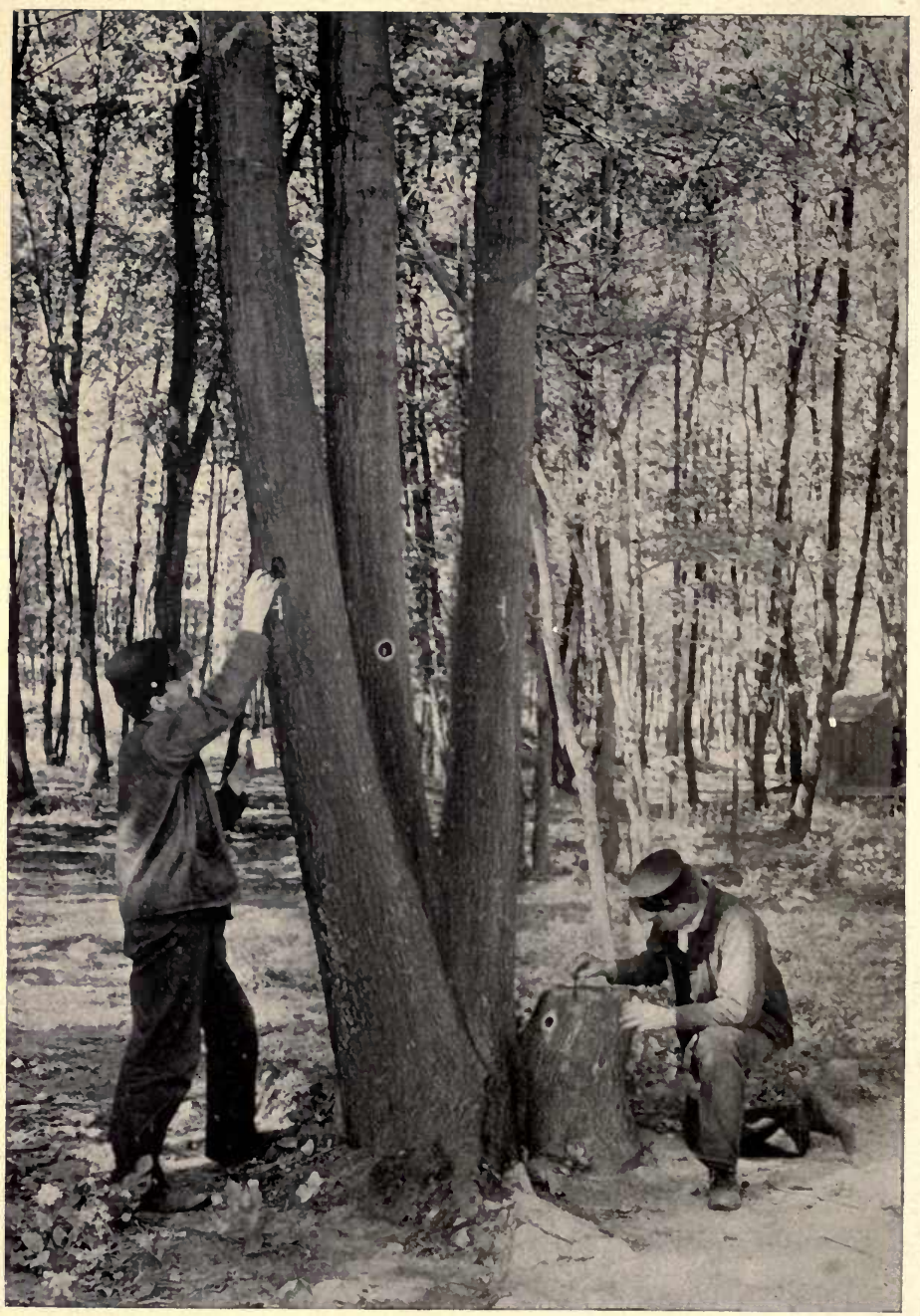

PLATE XIX. Treating egg-clusters with creosote. 
egg-cluster when treated is surrounded with a ring of white paint to prominently mark its location. (see Plate XIX.).

The most recent preventive method used in Europe is the covering of the eggs with a coat of tar or with raupenleim, a substance much used to prevent caterpillars from ascending trees. Though these substances, as well as varnish, have been used here experimentally with some success, the use of creosote oil is much to be preferred, as it penetrates the eggs at once and destroys their life, while the other substances merely prevent the larvæ from emerging, provided the covering remains intact.

\section{Destroying the Eggs by Gases.}

Experiments were made to find some agent other than fire that would destroy the eggs in hollow trees. A little bromine or chlorine poured into the hollow of a tree, branch or stump will destroy all animal life within the hollow if the cavity can be thoroughly sealed or closed.

\section{Implements used in the Search for the Eggs.}

Each inspector is provided with a small binocular glass of opera size, which he carries in a leather case suspended by a strap from his shoulder. By means of this he is able while on the ground to distinguish the eggs of the gypsy moth from those of other insects when attached to the higher limbs of large trees. This glass is useful in dark or cloudy weather, as well as in the morning or evening twilight of the short winter days. Its use often renders tree climbing unnecessary, and thus much time is saved. Each man is provided with a pocket mirror so constructed that the glass, if broken, can be quickly and cheaply replaced (Fig. 5). This is extremely useful in many ways during the search for eggs. Whenever the lower rail of a board or picket fence is so near the ground that its under side cannot be seen, a mirror placed at a slight angle underneath will reflect the whole lower surface for several feet, and show any egg-clusters which may be deposited there.

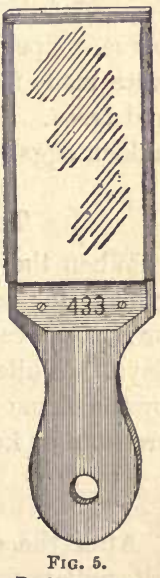

Pocket mirror. 
Mirrors are also useful in reflecting sunlight into the holes and cavities of trees and rocks, so as to determine whether or not the eggs are hidden within these recesses. Occasionally hollows in the under surfaces of high limbs are inspected from the ground by the combined use of the opera and hand glasses, the hand glass throwing the light into the hollow, and the opera glass enabling the inspector to determine its contents.

During the spring of 1891 the egg-clusters, being then very numerous, were found in almost every conceivable situation. They were deposited on the under surface of steps, under piazzas, floors, beneath the baseboards of fences, in hollow fence posts, in sheds, out-buildings, cisterns, conductors, ventilators, basements, cellars, chimneys and many other places both within and without dwellings. Their numbers in many such places were so great that it was deemed unsafe to allow them to hatch, lest the caterpillars should prove very destructive before their ravages could be stayed.

Boards were therefore removed

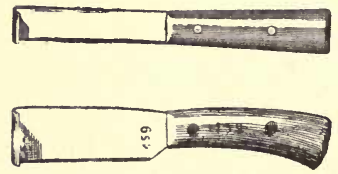

FiG. 6. Cleaning knives.

from fences, steps and buildings, and this work required the use of such implements as crow-bars, pinch-bars and hammers. Dark lanterns were frequently required in cellars, under piazzas and in barns. Special knives with blades bent at different angles were made for removing the eggs from the recesses of fences and trees. With the aid of such implements most of the hidden eggs were found and destroyed.

\section{The Destruction of Caterpilizars.}

When the larvæ first emerge from the eggs, they usually remain for several hours on the outside of the egg-cluster, or if the weather becomes cold or stormy, for two or three days. While in this position they may be quickly destroyed by the flame of a naphtha burner or by an application of creosote or kerosene.

\section{Banding Trees.}

After the eggs on trees have been destroyed, the young caterpillars which hatch elsewhere may be kept from ascend- 



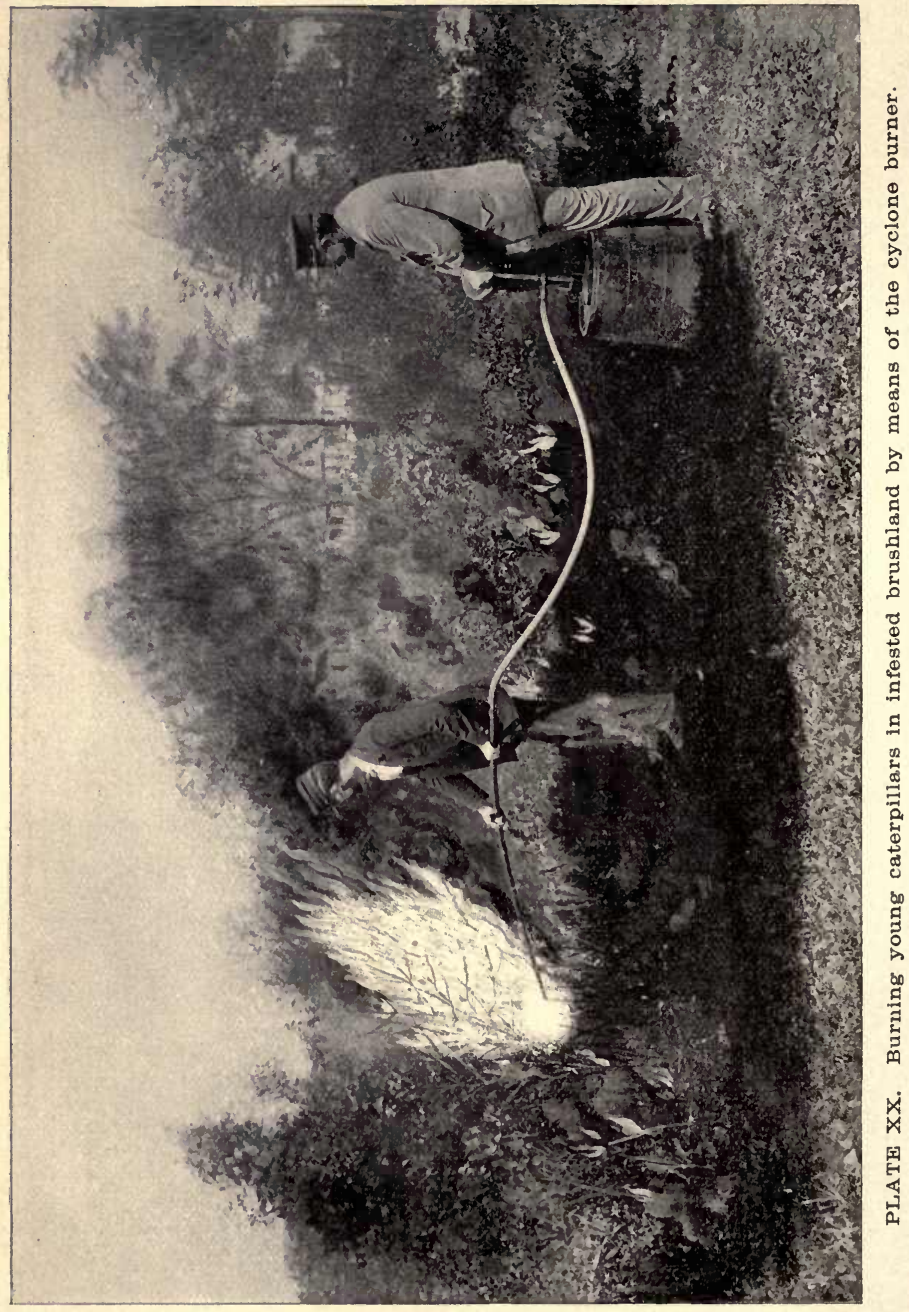


ing the trees by encircling the trunks with some appliance or substance which the larræ eannot eross." The protection of large trees by banding is most important as their size favors the distribution of the moth, rendering it both diffcult and expensive to care for them.

Such trees are often situated near buildings, lumber piles, ledges, accumulations of loose rock or other objects which offer many hiding places to the caterpillars and other forms of the gypsy moth. Occasionally sheds or hencoops are built about the trunks of trees. When such places of shelter as are not readily accessible to the workmen are thus offered to the moth, the caterpillars must be prevented from ascending the trees, and either destroyed by starvation or driven to other quarters. Where there is no other vegetation near, this may be accomplished by banding the trees in the early spring. If there is no other food in the vicinity, the young caterpillars prevented from ascending the trees will starve. If there are other trees within crawling distance which are so located and environed as to have no shelter about them inaccessible to man, the migration of the caterpillars thither will facilitate their destruction by the workmen. In woodlands, if the eggs upon the trees are destroyed and the trees well banded previous to the hatching of eggs, which may have been overlooked on the ground, and all vegetation on the ground is killed by means of the cyclone burner soon after the caterpillars appear, extermination will result. The method of burning caterpillars in infested brush is shown in Plate XX.

Bands are most useful for these purposes when put on just before the young caterpillars appear. They will then be fresh and sticky when the young larvæ are weak and unable to crawl far if deprived of the sustaining and strengthening nourishment which they eagerly seek. Before the hatching of the eggs in 1891 and 1892 many of the large street trees in Malden and Medford and some in Somerville were banded with strips of tarred paper. This work was first undertaken in Medford. It was proposed by the selectmen of that town as a means of protecting the trees from the gypsy moth and

\footnotetext{
- In 1891 bands of loose cotton batting were experimented with for this purpose,
} but they did not prevent the larger caterpillars from ascending the trees. 
the canker-worm, and a part of the expense was borne by the town. The bark of the tree was first scraped or planed at a height of about six feet from the ground, so that a reasonably smooth surface about six inches wide was formed extending around the trunk. A band of cotton waste was then placed on the smooth surface about the trunk, and a band of tarred paper about the cotton. A cord about the paper drew it closely to the cotton waste, which was thus pressed firmly against the tree. This waste was placed beneath the paper to prevent the newly hatched caterpillars (which can pass through very minute crevices) from crawling

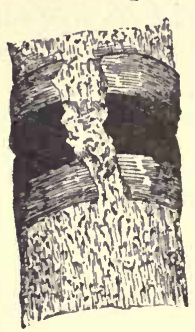

Fig. 7. Tarred paper band.

under it and so on up the tree. The tarred paper was then covered with a mixture consisting of three parts tree ink, one part pine tar and one part petroleum (residuum oil). The cotton waste prevented this mixture from penetrating to the bark of the tree. Fig. 7 shows the band about the tree with the string removed and a piece torn away to show the cotton packing. The black band represents that part of the paper which was covered with the mixture.

Tacks and staples were used where necessary to draw the paper and string closely to the tree.

It was necessary at first to apply several coats of the mixture, so that the tarred paper might become so well saturated that it would not absorb subsequent applications. When this was effected, an application was made at least twice a week for the rest of the season where trees on dusty streets were banded, but it was not required so often (except in very hot, dry weather) in orchards or woodland. As a result of the banding, most of the caterpillars were kept out of trees along the streets, and therefore there was little danger of their being distributed along the highways in such numbers as in former years. In badly infested localities this method can only be effective when the eggs on the trees have been destroyed and a large part of the egg-clusters in the vicinity gathered. Otherwise, the massing caterpillars will bridge the tarred paper with their bodies and on this bridge others will cross, or else the young caterpillars will be borne on the 
wind from the branches of one tree to those of another, rendering all precautions useless.

In banding, all poles, dead trees and other objects which in any way communicate with banded trees must be removed or banded. Where the limbs of trees touch houses, fences, rocks or the earth, they must be so trimmed as to prevent such contact. Unless all such means of communication are cut off, banding will not produce the desired effect. Much discrimination must be used in banding trees in cultivated lands, lest the caterpillars be driven from trees and scattered abroad among shrubbery, weeds or garden crops, where they cannot be so readily dealt with.

\section{Raupenleim Bands.}

In 1891 Mr. B. F. Fernow, chief of the Division of Forrestry of the United States Department of Agriculture, recommended that "raupenleim" or " insect lime," a German preparation for the protection of trees, be used in this work. ${ }^{*}$ A sample was ordered, but it arrived too late in the season to be experimented with that year. In 1892 experiments were made, and later thirteen and one-half tons of the "leim" were ordered and used in banding 40,704 trees during that season and the next. The raupenleim used in 1892 was very effectual, but much of the importation of 1893 was apparently inferior in quality to that used the previous year, and the results obtained were anything but gratifying. If results similar to those of 1892 can be secured, this material will be of great value for use in this country against such insects as the canker-worms, which pupate in the ground and whose female imagoes are wingless.

Raupenleim was used in the gypsy-moth work to take the place of the tarred paper bands. The advantages obtained from its use are that when of a good quality and properly placed upon the tree, it will remain soft and viscid for several months, and during that time will prevent the ascent of nearly all larvæ and also wingless female imagoes. The sub-

- Ranpenleim, translated literally, would read "caterpillar glue." According to Webster, lime (a viscons snbstance) is akin to the German word "leim." It is used here in connection with the word insect in much the same sense as it is used in connection with bird as "bird-lime." 
stance has been used abroad, especially in Germany, for several years past. The government forestry authorities of Bavaria employ it to prevent the ascent of the nun moth. This insect in 1890 devastated the German forests to such an extent that " three thousand men were employed to check its ravages, and in one instance it was necessary to cut and burn a strip of timber four miles broad by five miles long to prevent further devastation." *

It was ascertained by experiment that the application of this insect lime did not injure the trees, nor has any injury been observed to trees where it has been used in this country. Though the death of three or four young trees has been reported and credited to the injury caused by liming, it is possible that the primary injury was caused by too deep scraping of the bark. In such a case the oil contained in the lime might penetrate the liber and cambium of the inner bark and eventually destroy the life of the tree. There is no necessity for scraping a smooth-barked tree. Though over 40,000 trees have been banded in the work in Massachusetts, these are the only cases where injury is believed to have resulted. This agrees with the experience of the foresters in Germany. $\dagger$ 1892.

"Dr. R. Hartig in “Forstlich - naturwissenchaftliche Zeitschrift," Jannary,

+ "The excellent resnlts of the lime-rings for the prevention of larvæ ascending the stem and feeding on the foliage of our forest trees has been proven during the past ten years. Not content with this, however, - for it became our duty to see if the lime itself did not injure the tree, - we examined the different layers of the bark, and can confidently assert that no harm to the most tender trees has been done by liming them.

"We firmly believe that the man who scrapes the bark off the trees can do more harm in one hour than he conld by ringing trees with lime the rest of the year; and we would therefore recommend for the work, men who know the difference between the inner and outer bark of trees infested, and especially warn them to be careful of smooth-barked trees, from which they have to remove only such mosses and lichens as are found on them. On the trees - Dr. R. Hartig says - that were limed twentyfive years ago no bad resnlts have been observed. In fact, on the part of the tree where the ring was laid on, the growth of wood was larger than either above or below, which he ascribes to the action of the lime on the outer bark, softening it somewhat and giving freer circulation of the sap in the inner bark.

"Only in instances where the bark was scraped to the quick has the lime penetrated, and therefore ail harm must be ascribed to the scraping knife and not to the lime.

"There is, therefore, no occasion for alarm as regards the ringing of trees with insect lime to preserve them from the ravages of insects of all kinds." - (Translated from " Forstlich - naturwissenchaftliche Zeitschrift," July 7, 1892.) 
A variety of machines have been devised in Europe for applying raupenleim to the trees. One of these, the " Eichhorn machine" (Fig. 8*), was imported by the Board and was used to some extent. It consists of a triangular wooden box with two handles, one of which is hinged and acts as a lever. At the apex of the box is an aperture of the size desired for applying the lime to the trunk of the tree. This receptacle being first filled with lime, a handle is grasped in each hand of the workman,

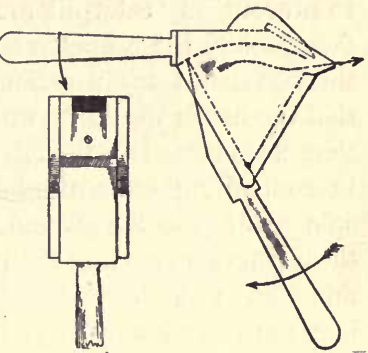

FIG. 8. The Elchhorn machine. who, by pressure brought to bear on both handles, forces the contents through the opening. In the mean time the machine is passed around the trunk, and a band of lime adheres to the bark. This machine can be used to advantage where the rings are put on at a height of three or four feet from the ground; but where it is necessary to place them at a height of six feet or more, as on street trees, great strength is required to force the lime out, and the use of the machine is not practicable. In the machine as imported the aperture through which the lime passed was about one-fourth of an inch in width and one and one-half inches in length. It was found by experiment that the lime remained viscid for a longer time and was more effective in stopping the ascent of the gypsy-moth caterpillars if the band was made wider than the length of this opening, and of greatest thickness on the lower edge; consequently the opening of each machine was enlarged to such dimensions as to deposit a band on the tree about one-half inch in thickness on the lower edge and two and one-half inches in width. The lime could be so put on by trowels or spades made for the purpose that the lower edge of the band projected more than half an inch from the bark. If this lower edge was made even thicker than this, and shaped at an acute angle, the oil, which gradually tried out from the surface of the band when exposed to the sun- 
light, would trickle down to the edge and hang there, forming an impassable obstacle to the caterpillars. The intent of the lime bands used in the work on the gypsy moth was to prevent any caterpillars from ascending the trees. If a few reached the branches and remained in the trees, passed through their transformations and laid their eggs, it is obvious that the bands would be worthless for the purpose for which they were intended, though even then they might be useful in controlling certain other caterpillars which frequently spin or drop to the ground, as they would prevent most of them from reascending the tree. But in a case where extermination is sought, and destruction of all gypsy caterpillars is a consequent necessity, it is imperative to prevent their ascending large trees. Quite frequently the bands were injured or displaced in some way by people or animals brushing against them, and often leaves or twigs from the trees dropped and stuck upon the bands, forming bridges over which the caterpillars could climb. To lessen the chances of their reaching the branches, two or even three bands were sometimes put upon the same trunk, one above the other. ${ }^{*}$ The same thing has been done in Germany during great invasions of the nun moth (Liparis monacha), and for this purpose a machine has been devised for applying insect lime at a greater height on trees than could be otherwise reached by hand from the ground.

The Hochleim machine (Plate XXI., Fig. 1) $\dagger$ is a tin cylinder attached to a long pole. A top that acts as a plunger is fitted to the cylinder and may be depressed by pulling on a cord that is fastened to a strong spiral spring. This spring is connected with iron wires which are attached to the upper part of the machine. When this is depressed, the lime is forced out at the bottom of the machine through a round hole bored in a brush which is fastened to one side, as scen in the figure. The lime, which must necessarily be of a more or less liquid consistency, is applied around the trunk of the

- This would not be ordinarily necessary in protecting trees against attacks of native caterpillars.

+ Figures of the implements and machines appearing on plates XXI. and XXII. have been previously published, together with others, in "Die Nonne," by Dr. H. Nitsche, Ed. Holzel's Verlag, Vienna, 1892. 

PLATE XXI.

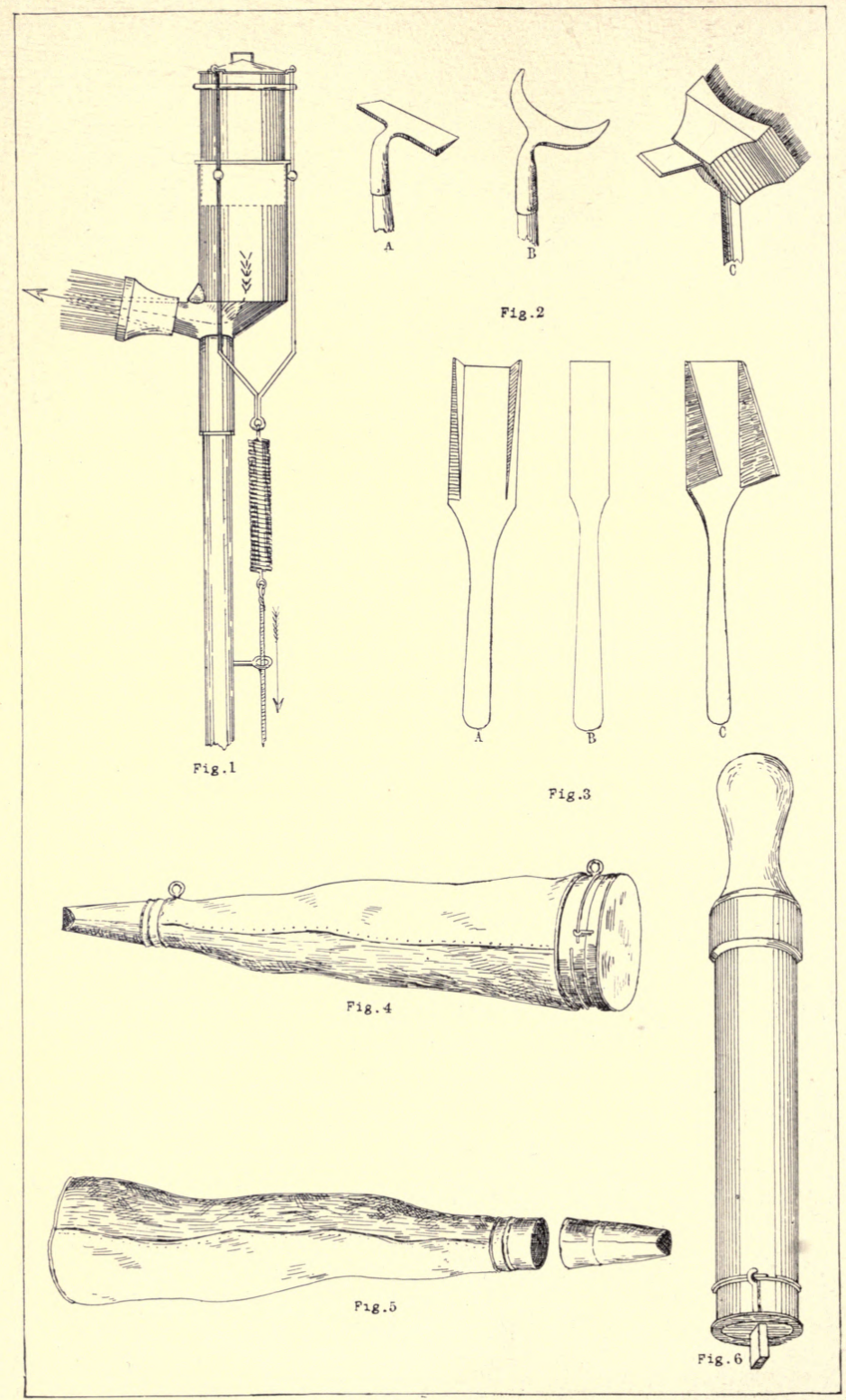



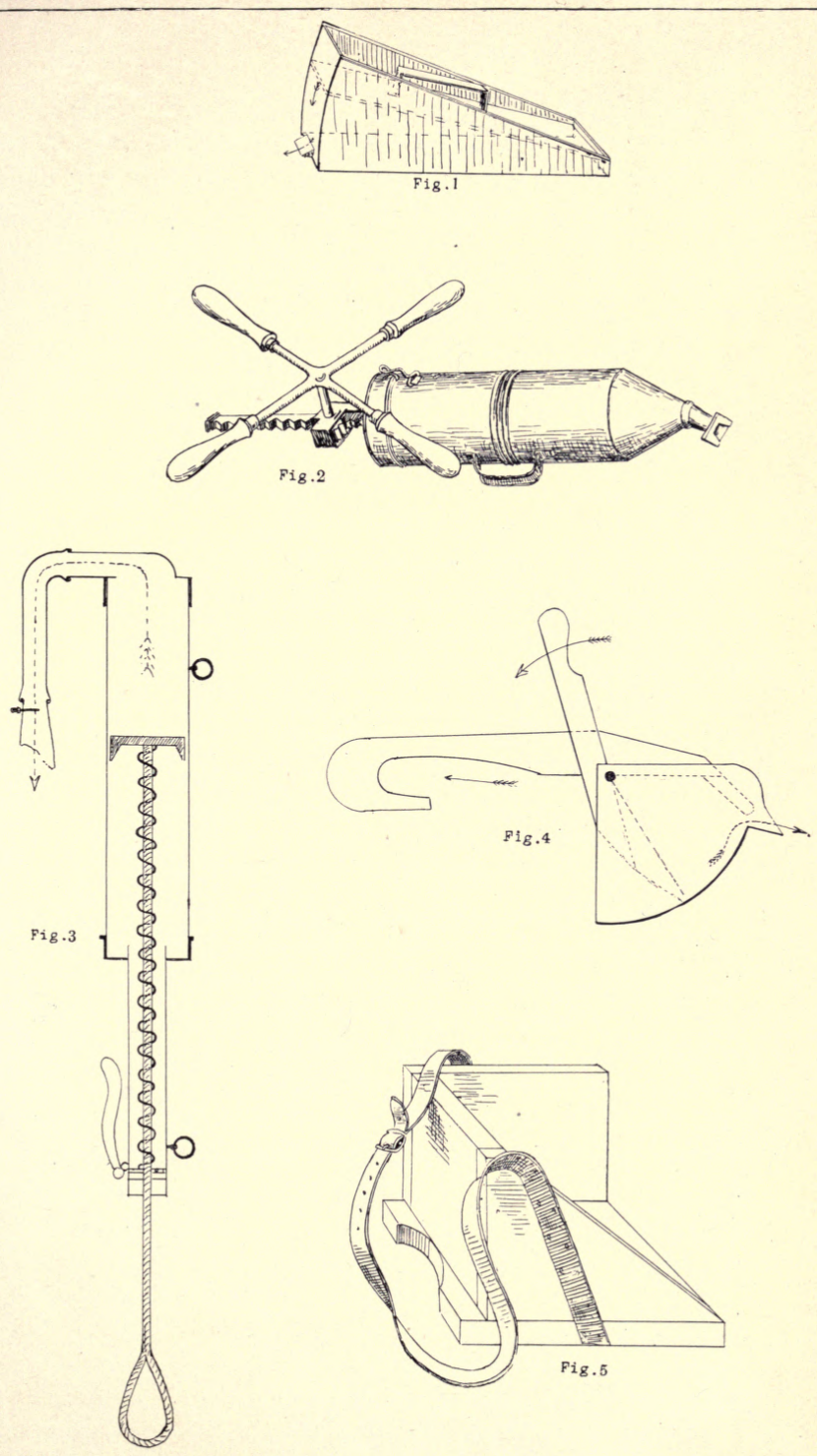

tree with the brush. The tools (Plate XXI., Fig. 2, $a, b, c$ ) are also attached to poles, and are used for scraping and smoothing the bark at a height. Tool $c$ has a scraper upon one side and a stiff brush upon the other. The lime hose (Plate XXI., Fig. 4) is an elongated cone-shaped bag made from some thick fabric. It has a mouth-piece at the small end for the outlet of the lime, while on the large end is attached a tin ring or cover, by means of which the bag may be filled and closed. This apparatus is carried by a strap or band passing over the right shoulder, and the lime is squeezed out by forward pressure of the right hand. It is inexpensive, easily carried and durable; still, it cannot be entirely satisfactory, as the oil with which the lime is mixed will gradually work through the fabric and soil the clothing of the workman.

The Eck lime hose is illustrated also (Plate XXI., Fig. 5), but, as the filling is done at the smaller end, requiring an expensive apparatus for forcing the lime in, it would hardly seem a desirable machine, although its cost in Germany is small (1 mark, about 25 cents). A very simple machine is a large tin cylinder (Plate XXI., Fig. 6) with a piston, the handle of which is pushed in by the man using it, who in this way drives the lime through the tin mouth-piece. This mouth-piece can be removed and others of different sizes can be substituted, according to the thickness and shape of the lime ring desired.

The Seitz lime machine (Plate XXII., Fig. 2) is a large tin apparatus holding about two and one-half quarts. The cover is fastened with a "bayonet" lock. The piston, which is geared, is worked back and forth by a geared wheel or cog fastened to the cover, and turned by a handle. This larger apparatus, rather heavy when filled, is carried crosswise in front of the workman, who turns the handle with his right hand.

The Hauenstein lime machine (Plate XXU., Fig. 3) is operated on the same principle as the last, except that the piston is driven forward by spring-power. The tin mouthpiece is connected with the main body of the machine by a piece of hemp hose, which is movable. The spring is drawn by the aid of a wire rope with a loop at its end. The workman sets his foot in the loop, draws the machine upward and so draws the spring, which is arrested by a snap latch. The 
machine is then filled. When in use the spring is released from the latch. Like the other machines, this machine is carried by a harness or carrying band.

A simple utensil (Plate XXII., Fig. 1) is like the "Eichhorn" machine, a lime "squeezer," and consists of a wedgeshaped box, one side of which is movable and may be pressed into the opening formed by the four stationary walls of its other sides. Spades or trowels (Plate XXI., Fig. 3, $a, b, c$ ) are often used to apply the lime and shape the bands where the work is done by hand. Where a number of men are at work, a lime hod (Plate XXII., Fig. 5) is also used. This hod is carried by one man, who keeps several cthers supplied with the lime.

There are some disadvantages in the use of insect lime. It is not cleanly, as under a hot sun more or less running oil exudes, especially on smooth-barked trees. Unless placed at a considerable height from the ground, cattle and horses frequently rub against it, plastering their coats in a very disagreeable manner. Complaints have been occasionally received that pet cats returning from excursions up the tree trunks have "tracked" the insect lime over their owners" carpets. Notwithstanding all care that has been used in the application of the material, certain spring overcoats and fine shawls have been ruined when the owners of these garments carelessly leaned against trees which had been banded. The insect lime does not adhere well to trees when they are wet, and occasionally heavy showers will cause it to drop off in lumps. These lumps when trod upon adhere to the shoes and are sometimes a source of considerable annoyance to housekeepers. Such accidents may be avoided by applying the lime when the trees are dry, and by forming the band with its upper edge bevelled toward the tree so as to shed water. It is then not likely to be displaced by rains.

If the lime is used on trees standing on lawns, it is likely to prove a source of unpleasantness. Some complaints in regard to this have been received from owners of lawns and croquet grounds. Such objections to its use will apply, however, to any material of the kind, and are not to be avoided as the lime is ordinarily used. It is sometimes recommended to place a band of stiff paper about the tree, turn up the 
lower edge in such a way as to form a trough and then apply the lime upon this. If this band of paper is placed at a considerable height, it may prevent many of the disagreeable accidents which otherwise frequently happen. Thus far we have had no experience in applying the lime in this manner.

\section{Other Uses for Insect Lime.}

Dr. John B. Smith, entomologist of the New Jersey Experiment Station, in a paper read by him as president of the Association of Official Economic Entomologists at a meeting of that society held Aug. 27, 1895, in connection with the meeting at Springfield of the American Association for the Advancement of Science, gave the results of his experiments with raupenleim and a similar material, "dendrolene.” * Dendrolene was invented by Prof. F. L. Nason of New Brunswick, who, at the request of Dr. Smith, experimented with a view of obtaining a material of home manufacture possessing the insecticide and protective properties of the raupenleim. According to Dr. Smith, raupenleim and dendrolene are both crude petroleum products, though the raupenleim has some admixture of a substance resembling tar in color and odor; but in both cases the base is, or seems to be, a very crude or impure vaseline, which has the appearance of the base of such lubricating mixtures as wheel-grease. Dr. Smith has used both substances on trees to prevent both the entrance and the emergence of certain tree borers. So far he has seen no injury to the tree resulting from the use of either material, even when large areas of bark were covered. While the raupenleim seemed more effective against borers, the dendrolene remained soft longer, making, as Dr. Smith says, "a perfect barrier against insects attempting to cross it." He also says that "such materials may be employed against scale insects on comparatively small trees where they cover only the trunks and larger branches, and where even a thin coating applied with a brush early in the season before the eggs have hatched or before reproduction has begun in the case of the viviparous species, will absolutely prevent the emergence of young. The appli-

- See Bulletin of Experiment Station, New Jersey Agricnltural College, No. 111, Sept. 16, 1895. 
cation of a coating on the trunks of peach trees made early in the season will prevent oviposition by the adult of the peach tree borer." But it may be questioned how far this covering the bark with such a material can be carried without eventually injuring the tree. Our experiments go to prove that raupenleim will asually prevent the ascent of the female canker-worm moth. It is quite probable, however, that after wet or cold weather, some of the moths may cross the band before the warmth of the sun has rendered it viscid, as the lime hardens somewhat in such weather and does not again become soft until affected by the sun's warmth. Climbing cutworms and many other caterpillars have been caught on the bands. Most insects, however, seem to prefer to turn back rather than attempt to cross. The larger gypsymoth caterpillars will cross when the bands have become somewhat hardened by rain or cool weather, but the smaller caterpillars seldom crawl over the bands. The raupenleim was therefore very useful for banding trees which had been cleared of the moth, providing the young caterpillars could be destroyed by fire or other means before they attained sufficient size and strength to cross the lime. The bands are useful also in preventing the ascent of such common pests as the tent caterpillar and tussock moth after trees have been cleared of the caterpillars or eggs of these species.* Dr. Smith says that as a protection against mice and hares, "dendrolene will serve an entire season when put on one-fourth of an inch thick or more." As much cannot be said of the raupen-

- The application of bands of insect lime appears to prevent the common tent caterpillars from crawling either up or down trees. A wild cherry tree which contained a great number of these caterpillars was banded with insect lime. When the caterpillars had devoured all the foliage upon the tree they crawled down the trunk to the band and there remained clustering npon the trank within two feet of the upper edge of the band, where they died, apparently of starvation. This wonld indicate that by banding worthless trees infested by this insect it might be prevented from migrating to other trees, and compelled to perish from lack of suitable food. Yet no instance of this kind has been observed with any other insect, and no record was kept of the number of caterplllars originally on the tree, so it is impossible to tell how many may have escaped. It is not safe to base any conclusions on a single observation of this sort. It is given here merely to show the necessity of further observation and experiment with insect lime, which can probably be used in many ways as a preventive to insect attacks or an insecticide application.

The application of the insect lime to egg-clnsters has already been mentioned (page 125), but it has been superseded in Massachusetts by more economical and effective measures (page 123). 



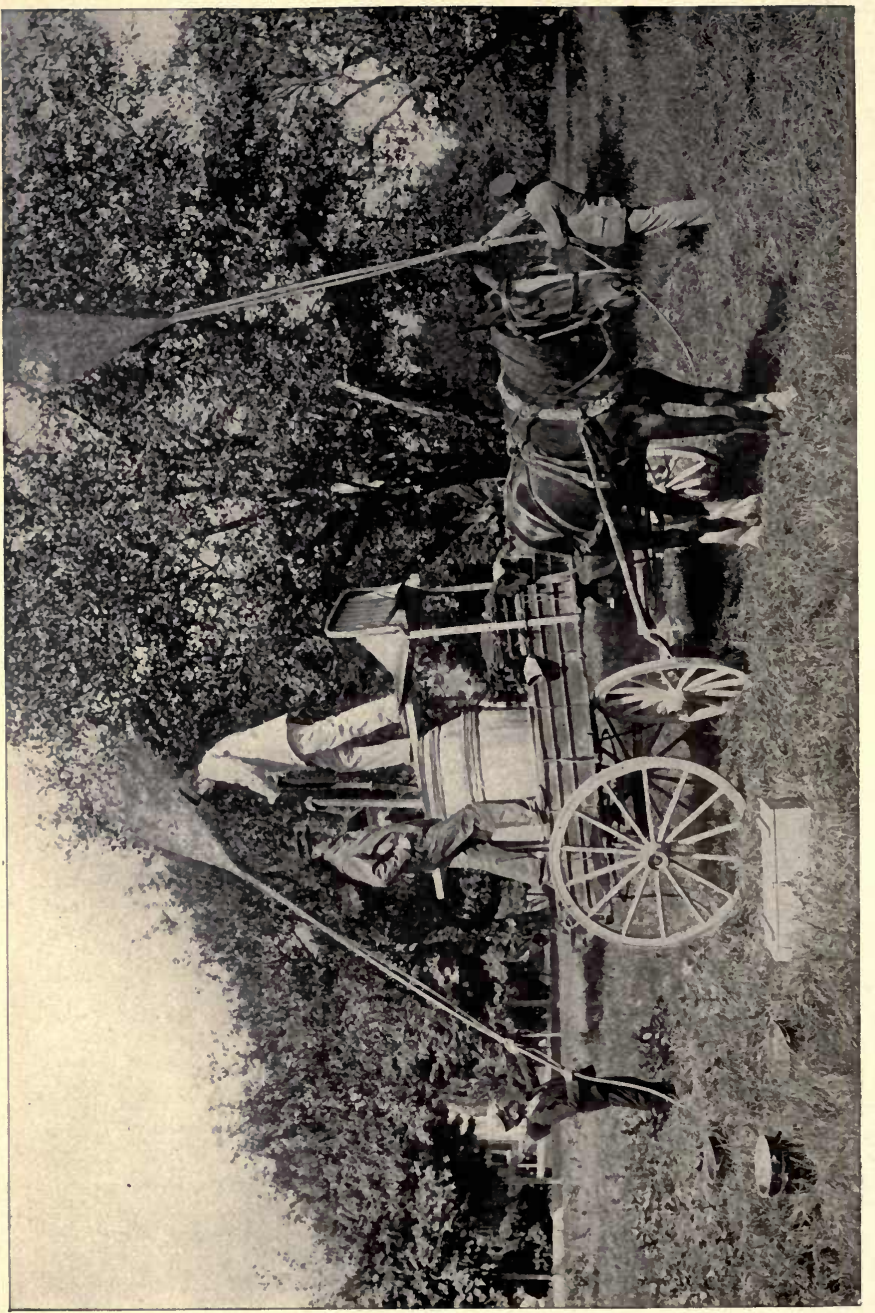

变 
leim used for the gypsy-moth work, although the best of it remained in good condition from one to three months; yet in some cases it became necessary to make two or three applications during a season. During windy weather bands upon dusty streets require frequent attention and occasional renewal. Dr. Smith says that in no case has he ever observed any injurious effect of dendrolene upon the trees.

Dendrolene is supplied by Prof. F. L. Nason, New Brunswick, N. J. Insect lime can be obtained of the Bowker Fertilizer Company, Boston, Mass., and of Wm. Menzel \& Son, New York.

\section{Spraying with Paris Green.}

When the second commission began work in the spring of 1891 , it was learned that the efficacy of Paris green as an insecticide for the gypsy moth was doubted by many people in Medford. Experiments were therefore immediately begun to determine whether spraying with Paris green would kill the caterpillars. In April young caterpillars were hatched by artificial means in the office of the commission and fed upon leaves which had been carefully sprayed with a solution consisting of one pound of Paris green to one hundred and fifty gallons of water. Not only was the ordinary Paris green experimented with, but samples of finely bolted poison were secured. The experiments showed that the use of either quality of Paris green caused death. It was noticed, however, that the caterpillars which ate the leaves sprayed with the pulverized poison died soon after beginning to feed, or within twenty-four hours; while those which ate of the leaves sprayed with the ordinary Paris green lived for several days, very few dying within twenty-four hours. The majority lived three or four days and some even a longer time. Samples of both the pulverized and ordinary Paris green were analyzed and the analyses gave substantially the same amount of arsenic in each. From this it would appear that both were equally poisonous. Why they were not equally effective has not been fully determined. But as the ordinary Paris green was made up of fine crystals which were more or less insoluble, while a larger proportion of the finely powdered Paris green was apparently soluble in water, the 
latter would be more quickly dissolved in the digestive fluids of the caterpillars. This subject, however, needs more scientific investigation, as the experiments made were too limited in scope to allow any conclusions to be based on the results. As it was found later that neither brand of Paris green gave as satisfactory results in the field as had been obtained in-doors, and as the use of this arsenite was finally given up, the subject of the comparative efficiency of the pulverized and the ordinary Paris green was not further investigated.

The results obtained by in-door experiments with the pulverized Paris green led to experiments on a larger scale in the field and accordingly a ton of this poison was purchased. Early in May spraying in the field was begun (see page 55). Most of the sprayers were supplied with the fine Paris green, which, though not proving as efficacious as in the laboratory, nevertheless killed many of the smaller caterpillars. As the spraying continued it was observed that a considerable proportion of the caterpillars of middle age were also destroyed. Sometimes, though rarely, persistent spraying appeared to destroy most of the larger caterpillars. By this time it had been determined by experiments in the laboratory that Paris green would not kill all the larger larvæ; yet as it had given better results than any other insecticide, it was thought best to continue its use at varying proportions in the field, and the poison was used at a strength of from one to four pounds to one hundred and fifty gallons of water. As a rule the spraying did not seriously burn the foliage when a solution was used consisting of one pound of Paris green to one hundred and fifty gallons of water; but with larger proportions of poison the foliage was considerably burned. The injury developed so rapidly that within a short time the leaves were all killed and the surviving larvæ were obliged to go elsewhere to feed. Therefore, a strong Paris green mixture had little better effect than a weak one. Lime was then used with the Paris green with a view of neutralizing the burning but considerable injury to the foliage still continued.

Though even when three or four pounds of the Paris green were used to a tank of water, many of the larger feeding 
caterpillars survived. Yet a difference in the effect of the spraying on the caterpillars was noticed. Occasionally in badly infested places so many of the caterpillars died within two or three days after the spraying that the people living on the infested estates were obliged for the sake of cleanliness to sweep up the dead from the walks and burn them. The unevenness in the effect of the spraying at once aroused suspicion that it might be caused by improper mixing or application of the insecticide. Although some inefficiency on the part of inexperienced sprayers was expected, a great difference in the effect of the insecticide was observed even when the poison was most thoroughly and carefully mixed and uniformly applied.

Every effort was made during the spraying season to determine why the results of spraying were not uniform and satisfactory. The feeding caterpillars were watched day and night by many observers. The spraying was most carefully superintended and the conclusion finally arrived at was that under ordinary conditions spraying with Paris green for the gypsy moth was ineffective and unsatisfactory.*

* In a few cases, where spraying was done just after a storm, an unusual mortality among the caterpillars was noticed during the next few days. At first it was thought that this result was due to the poison being more effective at such times, on account of its better retention on the foliage. It was known, also, that the caterpillars sought shelter and ate but little during rains, but that they fed ravenously during the warm, clear weather that frequently follows a storm. It was believed that the unusual amount of poisoned food taken at such a time, when the system was weakened by fasting, might have been sufficient to cause a greater mortality than nsual. It was soon noted that the poison appeared to produce the same effect occasionally in dry weather or after light rains. This seemed to disprcve the first hypothesis advanced, and raised the question whether the larvæ, which sometimes succumbed in such numbers, were not first weakened by disease or other causes.

In some cases the accuracy of the observations was doubted. It is difficult to make accurate observations on the results of such work done in the field. For instance, it is almost impossible to determine the proportion of larvæ killed by spraying. When they disappear immediately after spraying, there is no certainty as to whether the spraying alone is responsible for their disappearance, or whether they have not been carried off by birds or predaceous insects, or have not crawled to other localities or to more congenial food. In some places, where the dead larvæ fell to the ground in considerable numbers, most of them were immediately carried away by ants or other scavengers, which left few behind to tell of the results of the spraying. Correct conclusions cannot be drawn where there is such liability of error, unless observations recorded by many careful individuals and extending over a considerable period of time agree in the main. As no extended spraying with Paris green was done after 1891, the opportunity passed for an exhaustive study of the effect of meteorological or other conditions on the results of spraying. The cause of the apparent differences in the results of carefully conducted spraying with Paris green for the gypsy moth is a question which deserves further investigation. 
It is interesting to note that while many of the gypsy caterpillars were apparently uninjured by the spraying, the canker-worms and tent caterpillars were almost exterminated, and the tussock moths (Orgyia leucostigma) disappeared. The trees of the infested region were never in better condition than at the end of the spraying season of 1891, and the fruit crop was larger than it had been for many years. Though this cannot all be credited to the spraying, the contrast between sprayed and unsprayed trees was often very marked, the sprayed trees bearing more and finer fruit.

During the spraying season thirty heavy spraying outfits were worked back and forth between the outer part of the infested region and its centre. Fifteen towns were thus covered. There were also a dozen light fifteen-gallon hand tanks which were sent into the outer towns. They were carried in wagons, two men being assigned to each wagon. The tanks and pumps used were the same as are used with the cyclone burner (Fig. 1, page 120). The men with the light outfits went to the outlying orchards and residences, where a few trees were infested. They filled their tanks at brooks or wells and carried them by hand to such infested spots as were not accessible by a team, sprayed the trees in the vicinity, reloaded the tanks upon the wagons and drove to the next infested place. In this way the isolated colonies in the outer towns were covered by the sprayers. The large tanks mounted upon wagons and handled by from four to six men were used mainly in towns where water service was available and were filled from hydrants or stand-pipes. The order was given to spray everything green within two hundred feet of an infested plant or tree. An adherence to this regulation caused the spraying of all vegetation in the worst infested towns.

No extended spraying with Paris green has been done since 1891. While spraying with Paris green cannot be considered a successful method of extermination, it destroyed a considerable proportion of the number of very young caterpillars wherever it was done efficiently and in season. It thus checked the multiplication and assisted in preventing the spreading of the species. Though it failed to accomplish the end sought, it was certainly the most effectual method known at that time of disposing of the young caterpillars. 
In looking back over an experience of five years we are unable to see how any better method of destroying the young larvæ could have been devised from the knowledge of insecticides then possessed.

\section{Spraying with London Purple.}

London purple was used both in-doors and in the field in the season of 1891 but the results of the experiments with it were not as satisfactory as those reached with Paris green. While it was quite as effective as Paris green in destroying larvæ, it injured the foliage more. London purple is more finely powdered and lighter than Paris green and requires less stirring. It also has the advantage of cheapness. The great objections to its use are its partial solubility in water, which causes burning of the leaves, and the unevenness of the effects produced by it. While one sample may give fairly satisfactory results, the next may not only burn the foliage badly but even the young fruit on fruit trees. According to Professor Bailey the arsenic in London purple is in the form of arsenite of calcium, which in some samples is about seventytwo per cent. of the whole compound. Over fifty per cent. of this arsenite or nearly forty per cent. of the London purple is quickly soluble in water. ${ }^{*}$ The analysis of leaves injured by Paris green shows no arsenic in the texture of the leaf; but when leaves injured by London purple are analyzed, arsenic is found in their texture. This shows the penetrative powers of the latter poison. The London purple was used in the field to some extent, but the conclusion arrived at was that while, as it is ordinarily used, one might be justified in experimenting with it upon his own premises, its use in public work on the premises of others was unwarrantable.

\section{Spraying with Arsenate of Lead.}

Although nearly all poisons known to us which can be used as insecticides have been experimented with during the past five years in the hope that something would be found which would prove fatal to the gypsy moth, only one which is more effective than Paris green has been discovered. This

\footnotetext{
* See "Experiences in Spraying Plants" by Prof. L. H. Bailey, Report Agricultural Experiment Station, Ithaca, N. Y., Bulletin 18, 1890, page 98.
} 
is arsenate of lead, a poison slower in its action than the other, but which has three distinct advantages: (1) It can be used at any desired strength without serious injury to the foliage; (2) It is visible wherever used, as it forms a whitish coating on the leaves ; (3) It has adhesive qualities, given it, probably, by the acetate of lead, and therefore remains on the leaves for a much longer period than Paris green. When sufficient glucose was added to a strong mixture of arsenate of lead, it withstood rainstorms and remained on the foliage during an entire season.

When in 1891 it became evident that the arsenites would not accomplish the desired result, other means of destroying dispar were sought. Yet it could be hardly credited that the larva was indifferent to the action of arsenical poisons as ordinarily used, and the experiments of 1891 were duplicated during the season of 1892 . They were performed by Professor Fernald and his assistants, but the results of these experiments confirmed those of 1891 .

When it was seen that the known arsenites could not be used at the requisite strength for killing gypsy-moth caterpillars without serious injury to the foliage, Mr. F. C. Moulton, one of the inspectors employed in the field, who was also a chemist graduated from the State College of Agriculture and Mechanic Arts, Orono, Me., was detailed to make experiments to determine what portion of the compound produced the caustic effect upon the foliage. The results of the experiments confirmed the conclusions of previous experimenters that the soluble arsenic burned the foliage. It was obvious that if a form of arsenic entirely and quickly soluble in water could be precipitated, it would become insoluble and obviate the burning.

In the winter of 1892-93, at a hearing before the legislative joint standing committee on agriculture, a bill for the destruction of caterpillars within the State was considered. At this hearing Mr. Andrew H. Ward proposed the use of arsenate of soda as an insecticide. At the hearing we obtained from Mr. Ward the particulars in regard to the price of arsenate of soda and where it could be procured.

Upon consultation with Professor Fernald (who had also been previously asked by Mr. Ward to try the insecticide 
properties of arsenate of soda), he advised experimenting with it. A sample was procured and was found to be entirely soluble in water. When used it burned the foliage to a greater extent than the other arsenical poisons. Mr. Moulton was detailed to find some material which would precipitate the arsenate of soda in water and thus obviate the burning. He proposed acetate of lead and after several experiments the desired result was obtained and the proportions were fixed. The effect of the mixture of acetate of lead with arsenate of soda in water is to throw down the arsenate of lead in a fine precipitate which is held well in suspension by the water and is therefore more evenly distributed than Paris green.

While the complete insolubility of arsenate of lead is an advantage as far as its effects on the plants are concerned, it is less effective on the insect than Paris green when used in equal quantities. Though the action of arsenate of lead is slower than that of Paris green and London purple, this may be partially accounted for by the smaller proportion of arsenic in the composition. Caterpillars poisoned with arsenate of lead have quite a different appearance from those poisoned with Paris green. Inflammation and the shedding of hair appear to be symptoms of poisoning by arsenate of lead. As it is slow in its action, it is well to apply it early in the life of the caterpillar or in great strength.

The experience with arsenate of lead is in some respects analogous to that with Paris green. While in-doors there is no difficulty in destroying caterpillars with small quantities of the poison, the effects obtained out-doors are not so satisfactory. Indeed, it is only when applied at a strength of from twenty-five to thirty pounds to one hundred and fifty gallons of water that it appears to do exterminative work. This, to some extent, may be due to the difference in the material. The arsenate of lead used in the laboratory was furnished in the form of a fine dry precipitate. In the field the two poisons were furnished in a cruder state. They were added to the water and precipitation took place in the tank. The preparation was much less expensive when made in this way but was not as finely powdered. Indeed, it required considerable stirring in warm or hot water to dissolve the 
lead sufficiently for it to pass through the strainers of the pump. When arsenate of lead has been applied in proportions of from twenty-five to thirty pounds to one hundred and fifty gallons of water, occasional burning has been noticed. This was due to the fact that the lead was not thoroughly dissolved, for in such cases there was a lack instead of an excess of acetate of lead in the mixture as it came from the nozzle. When applied in this strength it is a question whether it is safe to use it in pastures where cattle are feeding or near where poultry are quartered.

It is evident that spraying with arsenate of lead should be used as an exterminative method only in exceptional cases where there is no danger to animals and where more drastic measures, such as fire, cannot be used. While it will undoubtedly be useful with many other insects, we would not recommend that implicit reliance be placed upon it unless used early in the season and at a strength of at least three pounds to one hundred and fifty gallons of water. However, it will probably not be necessary to use it at this strength for all leaf-eating insects though some may require a greater strength. Many experimenters have made trials of this material since the formula was first published in the annual report of the State Board of Agriculture in 1894, but we are not aware that it has yet come into general use in practical out-door work. Professor Fernald's experiments with arsenate of lead on the tent caterpillar indicate that it would be effective with this species in the field when used at a strength of one pound to one hundred and fifty gallons of water. It has given good results when used by him at the same strength for the Colorado potato beetle (Doryphora decemlineata, Say). Larger quantities have been required for some other insects.

At first sight it would seem that if it were necessary to use three pounds of arsenate of lead to one hundred and fifty gallons of water, the expense would be prohibitory. Yet it should be borne in mind that when mixed with glucose and properly applied to dry foliage, much of the solution will remain throughout most, or all, of the feeding season. Its application is not, therefore, as expensive as that of poisons which have to be applied three or more times during the season. 
By making a strong application early, the expense of the labor of making the later applications is done away with. Experiments being made by entomologists in different parts of the country will soon indicate the degree of usefulness of this arsenate in destroying different species of native and introduced leaf-eating insects. Practical use in the field later will determine its value as a general insecticide.

In the field work of the Board of Agriculture the formula of arsenate of lead most used was sodic arsenate, 29.93 per cent., plumbic acetate, 70.07 per cent. Two quarts of glucose were generally added to 150 gallons of water to give better adhesive qualities.

Professor Fernald directs that arsenate of lead can be prepared in the proportion of eleven ounces of acetate of lead and four ounces of arsenate of soda in water.

Apparatus used for Spraying Large Shade and Forest Trees.

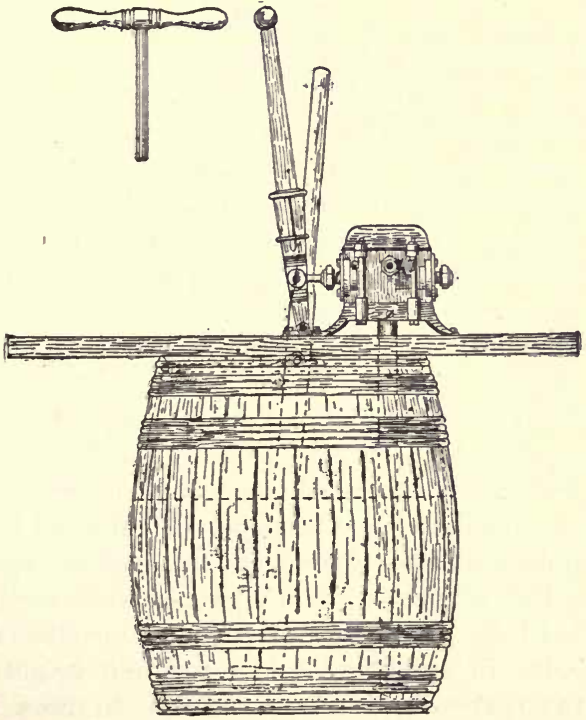

Fig. 9. Spraying tank.

The heavy spraying outfits used by the first commission in 1890 were again put in service by the State Board of 
Agriculture in 1891, but were so improved and modified by labor-saving attachments as to render them doubly effective. For each of these outfits a tank or hogshead holding one hundred and sixty gallons (Fig. 9) is provided, bearing on its upper end a plank foot-board six feet long and one foot wide. A double-acting Douglass or Gould force-pump (see Plate XXV., Fig. 1, and Plate XXVI., Fig. 2) is mounted near the middle of the foot-board. Either of these pumps when well manned furnishes sufficient force for all kinds of spraying with several nozzles at once. The suction pipe of the pump descends into the tank at the side and reaches to within two inches of the bottom, where it is terminated by a fine wire gauze strainer made from No. 32 wire, woven forty or fifty meshes to the inch, which serves to exclude all foreign substances which may clog the pump or nozzle. The diameter of the strainer should not be less than twice that of the suction pipe. In the head of the tank is inserted a stirrer made from two pieces of two-inch spruce scantling, one six feet and the other two feet in length, the two being joined at right angles at the lower end of the longer piece. When placed in the tank the long arm is hinged on a bolt or rod at the opening in the head of the hogshead while the short arm swings just clear of the bottom. This lever projects above the top of the tank. By moving it back and forth the liquid is thoroughly agitated. The pump is operated by means of a powerful lever or brake worked by one or two men, according to the amount of pressure needed. It is connected by means of a Y coupling with two lines of hose upon which from two to six nozzles can be used. The men when pumping stand on the foot-board already mentioned. The whole apparatus is lashed on a wagon or cart and transported from place to place as required. When in use one man operates each line of hose, the driver of the team usually does the stirring, while the whole work of spraying is directed by an inspector. With this apparatus there is no difficulty in spraying at any required height. Two men on the brakes furnish force sufficient to throw a good spray from a Gem nozzle when held ninety feet from the ground. 
Thorough and constant stirring is the prime requisite for obtaining satisfactory and uniform results in spraying, as the arsenical compounds used do not enter into true solution with water, but having greater specific gravity remain in suspension only. For this reason the particles of the poison have a constant tendency to settle to the bottom of the tank. Therefore the strength of the solution varies according to the amount of agitation given it. Hence the necessity of a continuous stirring of the contents of the spraying tank even when the pump is not being used, as while it is being taken from one tree to another. Even with continuous stirring the liquid issuing from the nozzle when the tank was nearly emptied usually contained more poison than that taken from a full tank or one half full. In most spraying machines the liquid is agitated only when the pump is in motion and the insecticide settles when the pump is not in use. It then becomes necessary to scrape the bottom of the tank and stir vigorously.

Several kinds of hose were used in spraying. The halfinch, rubber-lined, cotton-covered Eureka hose was found to be most convenient for the heavy apparatus on account of its light weight. For light machines, where only one small nozzle is used to each line of hose, quarter-inch rubber tubing is large enough. Each spraying gang was supplied with eight pieces of hose, each fifty feet in length, which were used in two lines of two hundred feet each. These were sometimes united to form a single line so as to spray places which, from their locality, could not be reached otherwise. In general use, however, the two lines of hose were used simultaneously. A "shut off" was coupled on each line of hose near the pump and also at the nozzle.

Not the least important part of the spraying apparatus is the nozzle. The desirable qualities of a nozzle for spraying large trees are that it shall throw voluminous jets of spray to a distance of eight or ten feet, clear itself readily, and be easily adjusted to varying distances, thus enabling the workmen to work rapidly. A series of tests was made with thirty-three different kinds of nozzles. The Lowell and Gem nozzles were found to be most effective. Both of these noz- 
zles are operated on the same principle and both have been much used in the gypsy-moth work. A good climber using the Gem nozzle can spray large trees both thoroughly and rapidly.

When it is impossible to reach the ends of branches with a fine spray, a turn of the nozzle will cause a heavier spray to be thrown to a distance of ten or twelve feet. If necessity requires, this can be reduced to a stream which can be forced upward for thirty feet, where it will break into drops; but when the foliage can be reached with a spray, the use of the stream should not be permitted, as such work does not give the best results.

There are some objections to the use of these nozzles. They waste more or less of the liquid and do not distribute it so finely as some other nozzles. They also may tempt the workman to avoid climbing by substituting the stream for the spray where the branches are not easily accessible, thus impairing the efficiency of the spraying. Yet if the operations are superintended by competent men, this may be guarded against and the work done far more rapidly than with nonadjustable nozzles throwing a finer spray.

The Lowell nozzle (Plate XXIV., Fig. 2) consists essentially of two brass tubes placed one within the other. The inner tube at its posterior end bears a coupling by means of which it is connected with the hose, while the anterior end terminates in a tapering point at the base of which on opposite sides are two openings which allow the fluid to escape into the chamber between the tubes. The cone-shaped point of the inner tube tapers for about two-thirds of its length, at which point its diameter is abruptly enlarged and then tapers again at an increased angle to its apex. On the outside of the inner tube is a coarse screw thread which moves on a blunt screw inserted through the side of the outer tube and by this arrangement the latter is moved forward and backward. This outer tube, which is slightly shorter than the inner one, closes on the latter at the posterior end by means of a band of packing held in place by a movable nut. At its anterior end it is widened to form a bell-shaped opening which at the centre closes tightly around the tapering point of the inner tube. When in use the outer tube is slid forward by 
Plate XXIV.

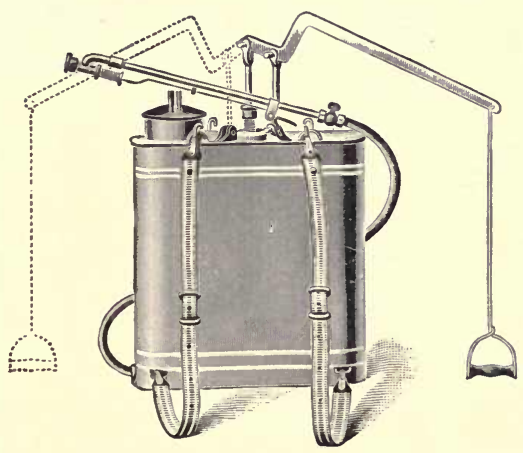

Fig. I.

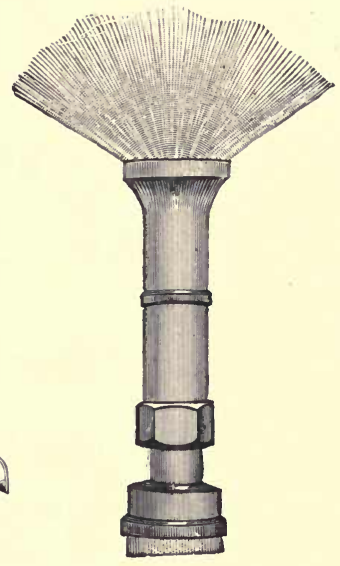

Fig. 2.

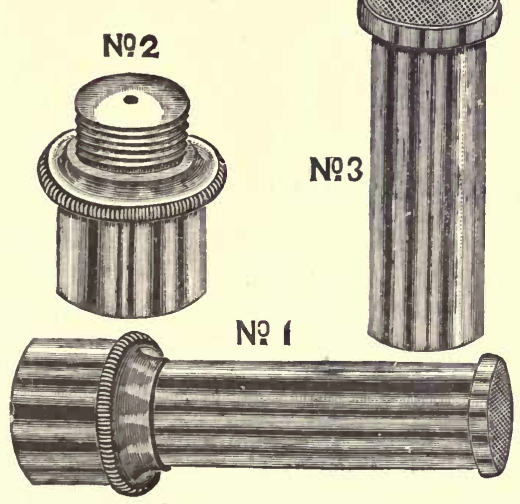

Fig. 3.

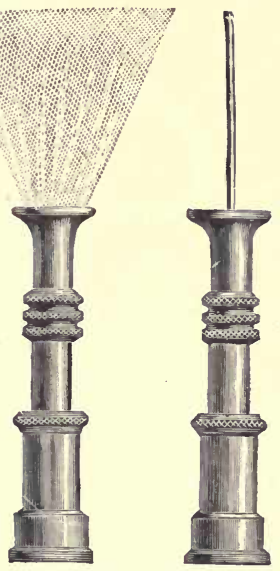

Fig. 4. 
Plate XXV.

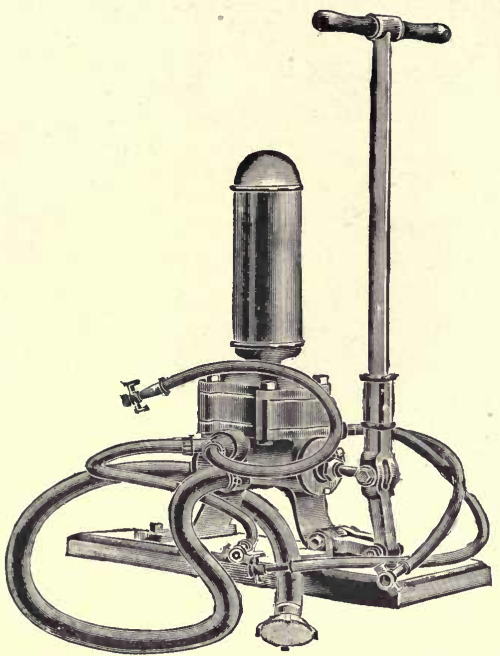

Fig. I.

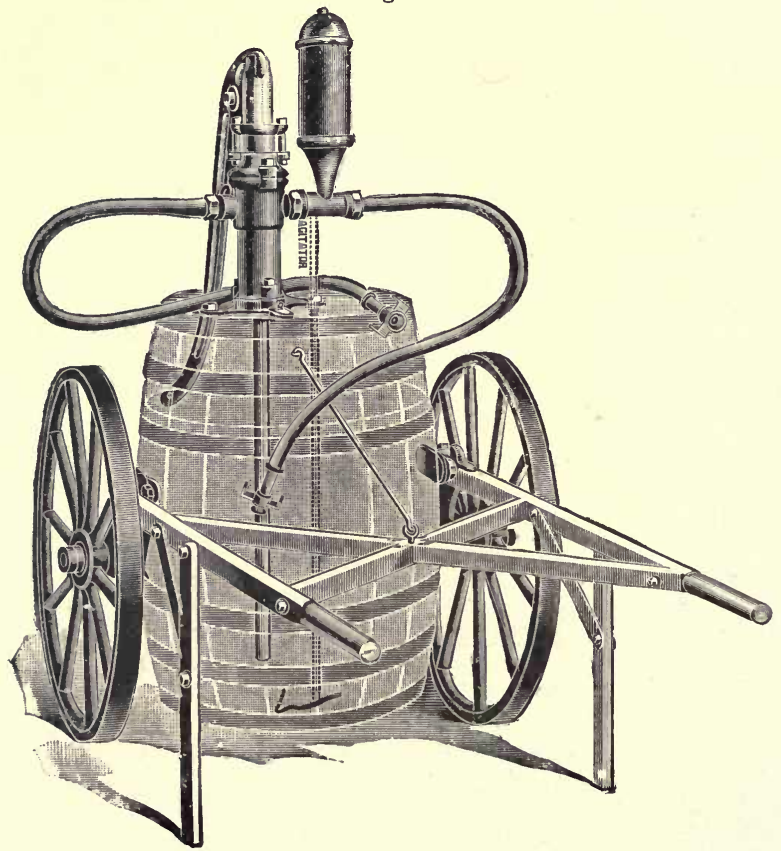

Fig. 2. 


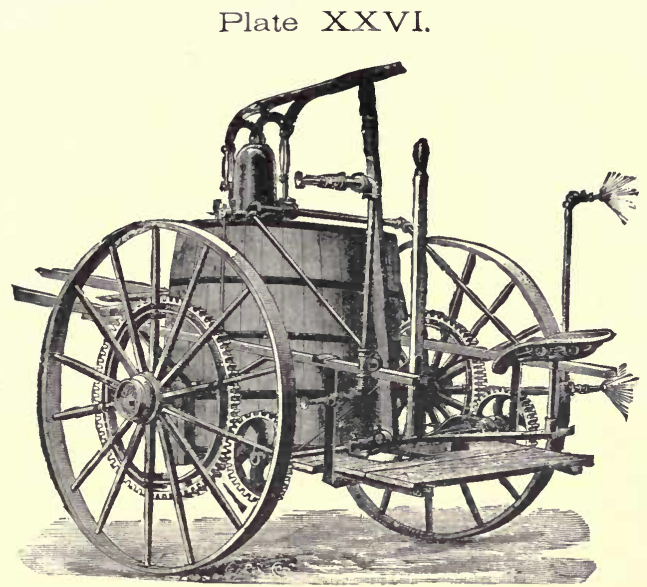

Fig. I.

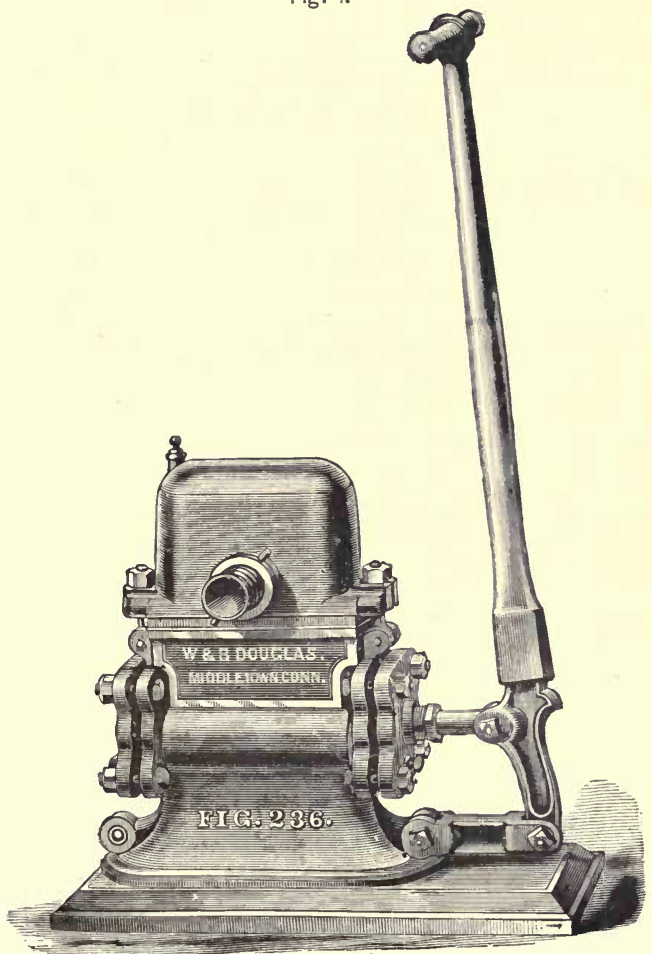

Fig. 2. 
Plate XXVII.

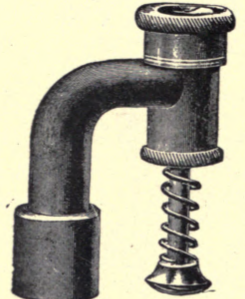

Fig, I.

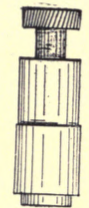

Fig. 5.
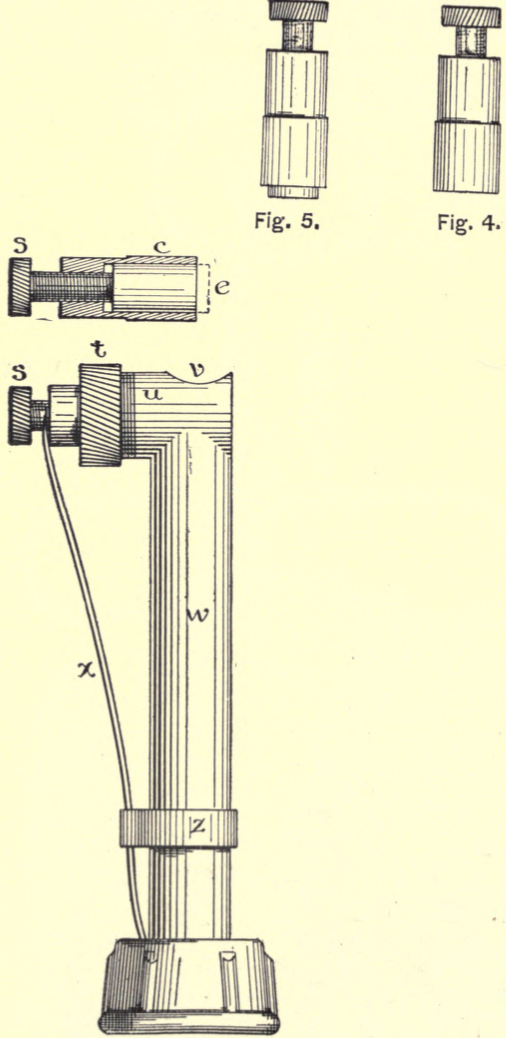

Fig. 4.

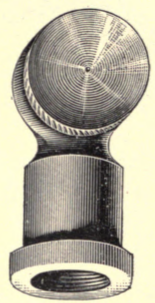

Fig. 2.
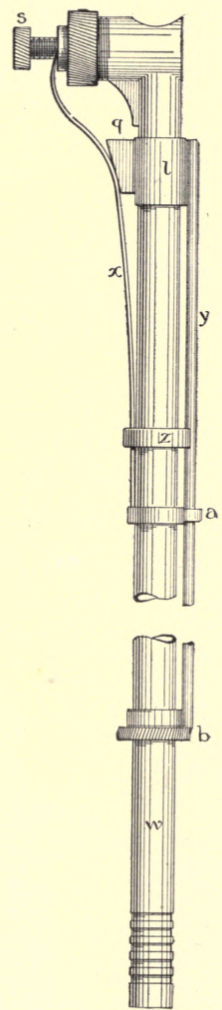

Fig. 6. 
a rotary motion on the screw bearing of the inner tube, and the spraying solution is forced out through the circular space thus opened between the point of the inner tube and the inner surface of the outer tube, which surround it. $\mathrm{By}$ turning the outer tube the density of the spray and the distance to which it can be thrown are regulated.

The Gem nozzle (Plate XXIV., Fig. 4) is made on the same principle as the Lowell. In using these nozzles a strong pressure is required to insure a fine spray.

For spraying orchard trees and shade trees of ordinary size, light hand ladders were found to be very serviceable. But when the tops of tall street elms were sprayed, extension ladders, thirty, forty or even sixty feet in length, were necessary. A heavy extension ladder sixty-five feet in length, such as is used by firemen, was purchased for the latter purpose. This ladder could be readily and skilfully handled by six men with the aid of blocks and tackle. The small hand ladders were carried on the spraying wagons and the larger ones by hand or upon wagons, hand-carts or wheels, as was most convenient. Ladders mounted permanently upon wheels could not be used to advantage on account of the uneven nature of the ground where much of the spraying was done. Ladders twenty to twenty-five fect in height with braces so made that they could be set up like step-ladders were used at first, but they were unwieldy and it was soon seen that more effective work could be done by using light ladders and climbing into the trees themselves. In climbing fruit and shade trees care must be taken not to injure the branches.

Machinery for Spraying Orchard Trees and Garden Plants.

Although in spraying small gardens and orchards any good tank or pump may be used, the heavy and more cumbersome outfits are not necessary. A small portable tank and pump which can be taken about by the operator, either attached to his person or upon a wheelbarrow, will suffice for all the spraying required in small estates.

For spraying garden plants and small fruit trees the "knapsack pump," which is fastened on the shoulders, has been otten recommended for use in small gardens and 
orchards. The Gould handy knapsack spraying pump (Plate XXIV., Fig. 1) has been used experimentally in the gypsy-moth work and gives fairly good results. These knapsack sprayers, however, are inconvenient when spraying is required on a large scale as they do not carry sufficient liquid.

The hand tank and pump used with the cyclone burner (page 120, Fig. 1) has been found very useful in spraying small orchards. With the pole attachment most of the trees can be sprayed from the ground. This tank may be carried and operated by two men.

Gould's barrel sprayer is shown in Plate XXV., Fig. 2. It has been very useful in our experimental work, and could no doubt be used to advantage in spraying small orchards, gardens and field crops. It has the advantage of being movable without the aid of a horse. Its wide tires can be run over ground where it would not be possible for a horse to go without doing injury.

In spraying in gardens where tender and valuable plants are grown or in orchards containing choice varieties of fruit trees, it is most essential that the liquid be thoroughly stirred, and especially that the spray be distributed evenly and in a fine mist, otherwise injury to the plant may result. Spraying may be done with the crudest implements. Cornbrooms and whitewash brushes have been used with good effect in some eases, but for uniformly good results we have seen nothing better than some of the modifications of the cyclone nozzle (Plate XXVII., Fig. 2). This nozzle was originally brought to public notice by Professor Riley, then chief of the United States Entomological Commission. When used in its original form, it throws a finer and more even spray than any nozzle which has come to our notice, yet it has faults which preclude its use except in very limited fields. It sprays very slowly and is frequently clogged by the coarser particles of the insecticide or by foreign substances, the perforation through which the liquid passes out in spray being very small. It is then necessary to remove the cap and clear the nozzle: Therefore much time is consumed in its use. When first tried experimentally at Medford it was found that an hour was required to spray 
thoroughly a large apple tree. Still the cyclone nozzle has been used to some advantage against the gypsy moth by uniting four nozzles in one (Fig. 10 ) and slightly enlarging their apertures. The nozzles radiate somewhat so that the spray from the four covers a much larger field than that from only one. The amount of the spray thrown in a given time, as well as the area of the foliage covered, is more than quadrupled. Yet clogging occurs more

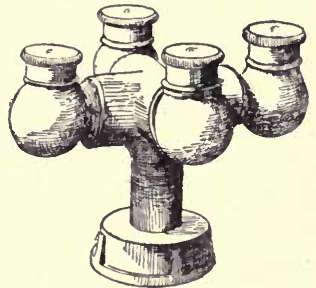

FIG. 10. Quadraple cyclone nozzle. frequently on account of the greater number of nozzles.

The Vermorel modification of the cyclone nozzle (Plate XXIII., Fig. 1) is an improvement on the original invention. It throws more liquid than the cyclone but gives a fine, even spray which, because of its fineness, cannot be projected to a distance. This spray will drift on the wind, however, so that spraying can be done for some distance to the leeward of the operator. Though this nozzle uses less of the spraying fluid than the Gem or Lowell nozzles, it uses more than the cyclone and therefore will spray more rapidly than the latter. It distributes the spray more finely and evenly than the Gem or Lowell nozzles and gives better satisfaction in spraying small trees or shrubbery. Experiments indicate that in the number of caterpillars killed, there is a slight difference in favor of the Vermorel nozzle over the nozzles previously mentioned. Spraying may be done more rapidly by attaching two or more nozzles to the same hose by means of the $Y$ coupling (Fig. 11).

The Vermorel nozzle consists of a short brass tube bent at right angles, having a coupling at one end by means of which it is attached to the hose and at the other

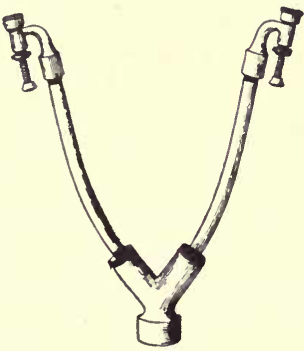

Fia. 11. Y nozzle. end entering at right angles a small cylinder, which is divided by a transverse partition into two chambers. 
orchards. The Gould handy knapsack spraying pump (Plate XXIV., Fig. 1) has been used experimentally in the gypsy-moth work and gives fairly good results. These knapsack sprayers, however, are inconvenient when spraying is required on a large scale as they do not carry sufficient liquid.

The hand tank and pump used with the cyclone burner (page 120, Fig. 1) has been found very useful in spraying small orchards. With the pole attachment most of the trees can be sprayed from the ground. This tank may be carried and operated by two men.

Gould's barrel sprayer is shown in Plate XXV., Fig. 2. It has been very useful in our experimental work, and could no doubt be used to advantage in spraying small orchards, gardens and field crops. It has the advantage of being movable without the aid of a horse. Its wide tires can be run over ground where it would not be possible for a horse to go without doing injury.

In spraying in gardens where tender and valuable plants are grown or in orchards containing choice varieties of fruit trees, it is most essential that the liquid be thoroughly stirred, and especially that the spray be distributed evenly and in a fine mist, otherwise injury to the plant may result. Spraying may be done with the crudest implements. Cornbrooms and whitewash brushes have been used with good effect in some cases, but for uniformly good results we have seen nothing better than some of the modifications of the cyclone nozzle (Plate XXVII., Fig. 2). This nozzle was originally brought to public notice by Professor Riley, then chief of the United States Entomological Commission. When used in its original form, it throws a finer and more even spray than any nozzle which has come to our notice, yet it has faults which preclude its use except in very limited fields. It sprays very slowly and is frequently clogged by the coarser particles of the insecticide or by foreign substances, the perforation through which the liquid passes out in spray being very small. It is then necessary to remove the cap and clear the nozzle: Therefore much time is consumed in its use. When first tried experimentally at Medford it was found that an hour was required to spray 
thoroughly a large apple tree. Still the cyclone nozzle has been used to some advantage against the gypsy moth by uniting four nozzles in one (Fig. 10) and slightly enlarging their apertures. The nozzles radiate somewhat so that the spray from the four covers a much larger field than that from only one. The amount of the spray thrown in a given time, as well as the area of the foliage covered, is more than quadrupled. Yet clogging occurs more

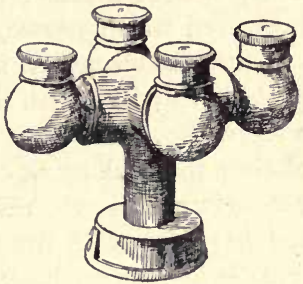

Fia. 10. Quadruple cyclone nozzle. frequently on account of the greater number of nozzles.

The Vermorel modification of the cyclone nozzle (Plate XXIII., Fig. 1) is an improvement on the original invention. It throws more liquid than the cyclone but gives a fine, even spray which, because of its fineness, cannot be projected to a distance. This spray will drift on the wind, however, so that spraying can be done for some distance to the leeward of the operator. Though this nozzle uses less of the spraying fluid than the Gem or Lowell nozzles, it uses more than the cyclone and therefore will spray more rapidly than the latter. It distributes the spray more finely and evenly than the Gem or Lowell nozzles and gives better satisfaction in spraying small trees or shrubbery. Experiments indicate that in the number of caterpillars killed, there is a slight difference in favor of the Vermorel nozzle over the nozzles previously mentioned. Spraying may be done more rapidly by attaching two or more nozzles to the same hose by means of the $\mathrm{Y}$ coupling (Fig. 11).

The Vermorel nozzle consists of a short brass tube bent at right angles, having a coupling at one end by means of which it is attached to the hose and at the other

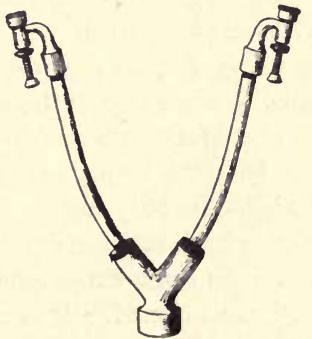

Fig. 11. Y nozzle. end entering at right angles a small cylinder, which is divided by a transverse partition into two chambers. 
out climbing. The extension nozzles ordinarily made, being but five or six feet in length, are not particularly useful for this purpose, but may be used to advantage when the workman stands on a tirm step-ladder. In the work on the gypsy moth a light wooden pole twelve feet in length was used in orchard spraying. The nozzle and hose were attached to this pole by means of snap hooks, or the nozzle was secured to the end of the pole by means of a cap provided for the purpose. In using this pole the workman carried the lower end in a socket attached to a belt around the waist.

\section{Power Spraying Machines for Orchards and Field Crops.}

Several horse-power spraying machines have been produced with the intent of saving time, labor and money to the user. In using such of these machines as we have seen, it is necessary to keep the horse moving in order to work the pump by horse power, and it is difficult to get sufficient power without driving too fast to give time for thoroughly spraying the trees in passing. Therefore in spraying trees the pump must be operated by hand. These machines are valuable in spraying potatoes and other crops grown on the ground.

The "giant, automatic power sprayer" (Plate XXVI., Fig. 1) has been adopted for use in the gypsy-moth work, but as yet has not been thoroughly tested in the field. It consists of a sixty-gallon oak tank suspended between two wheels with wide tires. The diameter of the wheel is three and one-half feet. The frame is strongly made to enable the operator to use the machine upon rough ground. Endless sprocket gears attached to the wheels communicate the power to the handle of the pump by means of a shaft. The gearing may be thrown out of action in an instant to prevent waste when it is not desired to operate the sprayer. The pump can be disconnected from the horse-power machinery and operated by hand in spraying large trees. This sprayer in operation is shown in Plate XXVIII. Several steam spraying machines have been invented, but we have had no experience in their use. 


\section{The Care of Spraying Machinery.}

The operations of spraying are frequently more or less delayed by minor accidents or imperfect working of parts of the machinery. The action of the insecticide mixtures corrodes certain parts and the pumps require constant attention to keep them in good working order. Unless their construction is understood by either the workmen or the man in charge, considerable delay and loss of time are occasioned by sending the pumps away for repairs or awaiting the services of experts called in to remedy the difficulty. Yet most of the trouble may be easily and quickly remedied if the men using the apparatus have a sufficient knowledge of the different parts of the pump to take out those that work imperfectly, repair and replace them. Most of the delays in the field are caused by either a clogging of the strainer in the tank, some obstruction in the valves or the wearing of the packing of the piston in the cylinder.

Before the spraying apparatus is sent into the field in the spring, it should be thoroughly overhauled and tested. While the spraying is in progress, each of the spraying gangs should be furnished with a tool box containing wrenches, tools, packing and other materials which are useful in taking apart the pumps and making repairs. Mr. E. C. Ware, who superintended the spraying teams in 1891 , gives the following information and directions in regard to the care of pumps in the field:-

If a pump fails to throw a stream, it is well to put some clean water in at the top, as it is quite often the case that the valves are made or lined with leather, which, in drying, has become hard or warped out of shape. If the pump is an old one and the valves are of leather, it may require new valves before it can be made to work. If the pump still fails to operate satisfactorily, examine the strainer to see whether it has become clogged, as the trouble with the pump can be quite often found at the bottom of the strainer. If the pump has not been used for a day or two, the strainer may have become corroded. Sediment from the material used for spraying will sometimes dry on the meshes of the strainer so as to prevent the passing of the liquid through the pump. 
When Paris green, lime, arsenate of lead or similar compositions are used with glucose or other adhesive constituents, and the pump is not thoroughly cleaned after using, trouble with the valves may be expected. When the trouble cannot be found at the strainer, it is well to clean the valves thoroughly, being careful to put them back in their original positions, seeing that the packing is clean and in place before putting the screws back or screwing any nuts down. In tightening the nuts or screws, put them down until they come to an easy bearing all around; after which go over them again and settle them down tightly. In case the pump should be a heavy one having a piston working through packing, and the liquid escapes around the piston, loosen the large nut and take out the ring which will be found pressed in by the nut. If the packing which will probably be found there is hafd and dry, it will be well to replace it with some hemp packing such as is used by steam fitters (or if this is not at hand, with cotton wicking), saturating it with heavy oil or tallow mixed with a liberal supply of black lead (graphite). Soak the packing thoroughly and wind it loosely about the piston, pushing it in the mean time toward the pump until you have about as much wound on as the ring will push in without preventing the nut from catching. Then screw the nut up as far as it will go without preventing the pump from working easily. It is not well to screw it up too tightly at first, but to turn it a little at a time, just enough to keep the pump from leaking.

In connecting hose to pumps, it will be found necessary to use rubber washers at dll connections to prevent leakage when couplings are screwed together. Wherever the castings or other parts of the pump are broken by accident, much time may be saved if duplicate parts are kept ready for such an emergency. Before the pumps are stored at the end of the spraying season, they should be taken apart and carefully cleaned and oiled.

\section{When to Spray for the Gypsy Moth.}

Spraying should be done early in the season, as soon as the leaves are well grown, for at that time there is least risk of injury to the foliage. The insecticide also will be 
more effective if applied soon after the caterpillars hatch. As the young gypsy-moth caterpillars hatch at intervals from the latter part of April until the middle of June, and as the leaves are constantly growing during the early part of the season, thereby offering daily more fresh unpoisoned surface upon which the caterpillars may feed, it may be necessary to spray once or twice more in May or June. Spraying with the best insecticides known (arsenate of lead excepted), if done late in the season, has little effect on the gypsy-moth caterpillars where they are numerous, as they will strip all foliage from the trees before being seriously affected by the poison. The uselessness of such spraying is shown by the illustrations in plates IX., XI. and XVI. The caterpillars thus destroyed the foliage in the Swampscott woods early in August, after the trees had been sprayed twice with Paris green.*

It is well not to spray fruit trees when in blossom. If sprayed at all at that time, the work should be done with a nozzle throwing a fine, mist-like spray. A coarser spray is likely to injure the blossoms, as well as to wash off the pollen. There is danger also of poisoning bees. Prof. F. M. Webster, entomologist of the Ohio experiment station, has experimented by spraying apple trees in full bloom and giving bees access under natural conditions to the sprayed blossoms. Many of the bees which visited the trees died suddenly, as well as the young larvæ of a brood from uncapped cells. Arsenic was found in the contents of the abdomen as well as on the external parts. The bees all gave evidence of having died from the effects of arsenic which could only have been introduced from without the hive. If the pollen is washed off the blossoms by the spraying and the bees which distribute pollen are killed by the poison, the spraying of fruit trees when in blossom will affect their fruitfulness.

Spraying should not be done during showers or after showers before the leaves dry, or when a heavy dew is on the foliage. When spraying is done during showers,

\footnotetext{
* Many of the failures that have been recorded in spraying for other insects may be traced to the fact that the work was done too late, and not until after the injury was so serious that the spraying could not stop it in time to save the foliage.
} 
much of the poison will be washed off or gather in spots. If the trees are sprayed in dry weather or at a time in the day when the leaves are dry, the poison adheres to the leaves as it falls and is thus most effective.

\section{How to Spray for the Gypsy Moth.}

In many cases spraying for insect pests is a failure. Where tender plants and choice fruit trees are sprayed, more harm than good is often done. This is not to be attributed, however, to the method, but to either poor machinery or to ignorance or carelessness in the use of insecticides. When spraying is thoroughly and carefully done according to the rules given by the best authorities, it will almost always give good results with most leaf-eating insects. Yet, as has been shown, the most careful spraying with the best insecticides may fail to check the gypsy moth. If spraying is done when the caterpillars are young and feeding mostly on the lower surface of the leaves, it will be most effective. Use not less than fifteen pounds of arsenate of lead and two quarts of glucose to one hundred and fifty gallons of water. Be sure that the acetate of lead is dissolved in water (warm if need be) before it enters the tank. Stir the mixture constantly and spray evenly and thoroughly with a fine spray. If this does not kill, double the dose.

Spray fruit trees to as high a point as possible from the ground by the use of a long pole or extension with any nozzle which will throw a very fine spray, spraying always in such a way as to reach the under side of the leaves.

On tall shade or forest trees spraying may be best accomplished by the use of a ladder. A nozzle which will throw a coarse spray to a distance, like the Gem, Lowell, Nixon or MeGowen, may be used. Often the lower limbs may be sprayed from the ground by means of a pole. The pole cannot be so well handled in the tree, and the workman can spray best by climbing up the main trunks and branches and spraying from below as he climbs. If the spraying is done later in the season, particular attention must be paid to the ends of the branches and to the tops of the trees, for many of the larger caterpillars crawl to the very tips of the branches and to the tops of the trees to feed. 


\section{Injury to Plants caused by Spraying.}

The strong prejudice against the use of Paris green for spraying which was met with in Medford in 1891 was partly caused by the belief that both trees and garden plants would be injured or killed thereby. This belief was shared by many people and was largely based upon the results of the work of the first commission, as observed in 1890. Many individuals who had experimented with London purple and Paris green in an attempt to protect their trees had succeeded only in destroying the foliage. It is true that the foliage of many trees was injured in 1890 , and that to a less extent this occurred in the work of 1891 . Yet much of the apparent injury was effected by other causes than spraying. In the investigation of complaints that the foliage of trees had been burned, it was found that in some cases the injured trees had not been sprayed. In at least one case the supposed burning was caused by the effect of a late frost. A blight upon fruit trees early in the season closely resembled, upon superficial examination, the appearance produced by arsenical burning. Later in the season, during the drier portion of the summer, many leaves on trees, which had not been sprayed, turned yellow and fell, presenting much the same appearance as was observed on fo'iage which had been burned by spraying. Many reports were received that trees had been killed by spraying, but in most of these cases it was not clearly proved that death was not due to some other cause. Still there is evidence that some young trees were either killed by spraying or were so weakened by burning or defoliation resulting from spraying that they succumbed to the heat of the summer. Such a result is unusual, however. An apple tree which was sprayed in 1890 with the contents of fifteen tanks of the Paris green mixture, each tank containing a pound of Paris green, was not permanently injured. It is said that many young and tender plants in gardens were not only seriously injured but actually killed by spraying; yet where this happened it was probably due to some ignorance or carelessness in the use of the insecticide. Some species of trees are more susceptible than others to the effects of the poison. The foliage of plum 
trees and especially that of peach trees is often destroyed by an application which will not injure the apple or many other species. There appears to be a difference among varieties of trees of the same species in their susceptibility to poison, and some individuals of the same variety seem more susceptible to injury than others. This is also true of shrubs and garden plants.

\section{Causes of the Burning Effect.}

We have already stated that the burning of foliage by arsenites appears to be caused by the soluble arsenic in the insecticide; yet it is known that poisons like Paris green, which are comparatively insoluble in water, will burn the foliage under natural conditions if applied in great strength. This seems to indicate that the arsenic on the leaf is dissolved more or less by dews and rains, the dehydrating effects of the sun's rays, a moist atmosphere or the exhalations from the leaf, or by all combined. We have noted that although experiments with arsenites performed in a dry atmosphere in the laboratory produced no burning effect, the same strength of material burned badly out of doors. Professor Fernald's experiments in the insectary indicate that Paris green burns more in warm damp weather than in cool dry weather.* The larger the amount of arsenic deposited on the leaf the greater will be the amount eventually dissolved, and the greater the burning effect. If the liquid is distributed evenly in minute drops over the leaf, there is less danger of burning than if it is distributed in large drops, or if the tree is so copiously showered as to cause the arsenic to settle and accumulate in spots upon the leaf. Wherever such accumulations occur, the burning is the more serious and the injury spreads from the burned spots. Therefore, there will be the least burning from a fine spray, lightly and evenly distributed.

\section{How to prevent Burning the Foliage.}

What should be done and what avoided to prevent or lessen the burning of the foliage may be summarized as follows:- 
1. Avoid the use of London purple.

2. If Paris green is used, keep the spraying liquid constantly and thoroughly agitated.

3. Use only a very fine spray and distribute it lightly. This applies especially to tender plants and valuable fruit trees where burning may mean serious loss.

4. Do not let the spraying liquid stand in the tank but use it as soon as mixed.

5. Spray early in the season when the injury to leaves will be least.

6. If Paris green does not give good results, use arsenate of lead, which will not burn if properly mixed and applied.

Reports of Injury to Man and Animals by Spraying.

The prejudice against spraying in Medford and other towns was intensified by the belief that there was danger of fatal poisoning to man and animals. When the spraying was in progress, sensational reports were circulated. Statements were made in the daily press that a man had died from the effects of chewing leaves taken from trees sprayed in Medford, and that a child had been fatally poisoned by eating bread and butter on which some of the spray had fallen from the trees. On this at least one newspaper editor advised his readers to shoot at sight the workmen employed in spraying. It was reported that there was great danger from eating sprayed fruit. Several quarts of cherries which had been taken from sprayed trees and preserved in jars were analyzed, and no trace of arsenic was found. Yet even before they were analyzed, it was reported that they had been sent to Amherst and that arsenic enough had been found on them to kill a dozen people. A large portion of the cherries on these trees were stolen by boys or given away, yet no immediate mortality occurred among the juveniles of the neighborhood. It was frequently reported that people had been badly poisoned by having a spray thrown in their faces. It is possible that this statement had some slight foundation in fact. While in eating fruit there is little danger of the consumption of sufficient poison to have any appreciable effect on the system, there is a certain amount of danger from the absorption or inhalation of arsenic, and great care should 
be always exercised in its use. About ten per cent. of the men employed in spraying suffered more or less from arsenical poisoning. Some appeared to be much more susceptible to its effects than others. This subject is more fully treated in Appendix F, where instances of the ill effects produced by the careless use of arsenic are given. Numerous sensational tales were promulgated in regard to the effect produced on animals by eating grass or foliage poisoned with Paris green. That there is no danger of serious results to the larger domestic animals from ordinary spraying has been proved by Prof. A. J. Cook's experiments.* He fed to his horse and to sheep grass on which the poison had been allowed to drop copiously from sprayed trees. We have frequently fed a horse in the same way without any apparent harm to the animal. A Medford milkman was accustomed to take as a gift the grass which people feared to use, it having been cut on lawns where the trees had been sprayed. This grass formed the principal food of his cows during the summer and they showed no ill effects. At one farm in Somerville, where the trees were liberally sprayed, three cows suddenly died. A suit was threatened, but on account of lack of evidence it never came into court. $\dagger$ Several flocks of fowls were stricken with sudden mortality immediately after the trees which hung over hen yards had been sprayed. Fowls show a great susceptibility to arsenical poisons. It is a question, however, whether the fowls were killed by eating poisoned caterpillars or grass on which the spraying liquid fell, or whether they did not die from some epidemic disease. The matter was not fully investigated. One instance was noted where a hen died just as the workmen walked into the yard to begin spraying. The owner was immediately notified so that the impression might be avoided that it was killed by Paris green.

- Bulletin No. 53, Agricultural College of Michigan Experiment Station, Angust, 1889.

+ Cows have fed withont apparent Injury on grass under trees which have been twice sprayed with arsenate of lead at a strength of fifteen ponnds to one hundred and fifty gallons of water.

† If wild birds are likely to be destroyed by eating poisoned vegetation or poisoned insects, the benefits derived from spraying must be largely disconnted, as birds are most useful as insect destroyers. 


\section{Spraying with Contact Insecticides.}

When it was seen that spraying the foliage with Paris green had little effect on the larger gypsy-moth caterpillars, experiments were made with insecticides which were intended to kill by contact. This was done to find a means of disposing of the masses of caterpillars which did not seem to be much affected by the use of Paris green and which clustered on many trees where fire could not be used. Contact insecticides, when of a strength sufficient to kill the gypsymoth caterpillars, are likely to cause injury when used on the foliage. Therefore they can only be used to advantage as a last resort where the caterpillars have stripped trees or where they are clustered in such numbers on the trunks as to make it less expensive to spray with an insecticide than to kill them by hand.

Kerosene emulsion was first tried. A strong emulsion gave fairly good results but its preparation in the field was not economical. The only way in which it could be made to give satisfactory results was to mix it at a central point and distribute it to the different towns. When it was made in the field the men did not get uniform results.

Fish oil and whale oil soap gave better satisfaction when used as follows:-

Take one pound of whale oil soap and slice into thin, small pieces. Place the pieces of soap in a pail and add about a gallon of boiling or nearly boiling water; then stir until the soap is dissolved; dilute at the rate of one pound of soap to twenty gallons of water. This formula was prepared by Mr. E. P. Felt.

Solutions made from soap powders also proved effective. The following formula was prepared by Supt. F. H. Jones :-

Place one pound of "Gold Dust" in a pail; add one gallon of lukewarm (not hot) water; stir briskly until the powder is dissolved; then add three gallons of cold water; stir well.

Where the larvæ and pupæ are clustered together on the trunks of trees and in stone walls or other sheltered places, they should be well drenched with the solution. The hand tank (Fig. 1, page 120) and Gem nozzle were found useful 
in spraying with contact insecticides. A tree in Swampscott, the trunk of which was covered with caterpillars, was sprayed, killing nearly all at one spraying. Excellent results were obtained wherever the liquid was carefully mixed and applied. It is poor economy, however, to use contact insecticides except where the larvæ are very numerous, for elsewhere they may be more rapidly and cheaply killed by hand, either by burlapping the trees or by other methods.

While the use of soap powders upon the gypsy moth has some advantages, it is not to be recommended except in the most extreme cases and with the exercise of great care and judgment.

\section{Measures for Destroying all Forms of the Moth.}

The methods thus far described have each been intended for the destruction of a particular form of the moth. The methods hereinafter described are intended to facilitate or secure the destruction of all forms of the moth, and have been used with a view to preventing the creature's spread and securing its extermination. It has sometimes become necessary to destroy all vegetation in an infested spot in order to prevent the moth's rapid spread and wide dissemination. For this purpose fire and the axe have been resorted to.

\section{Cutting and Burning.}

As an exterminative method for use in wooded tracts, the felling of trees and their destruction, together with that of all other vegetation, by means of fire has no equal in point of expedition and economy. This can only be done advantageously, however, on lands where the timber is of little value, as the damage caused and expense incurred by treating valuable woodland in this way would be great. This method is expedient only where a badly infested spot is found in woods not otherwise infested and where by vigorous and immediate exterminative methods the pest may be stamped out. When a colony of this kind is discovered, the trees may be felled to best advantage in the fall or early winter. At the same time the undergrowth can be cut close to the ground and burned together with the tree-brush, or it may be left to dry 
a rotary motion on the screw bearing of the inner tube, and the spraying solution is forced out through the circular space thus opened between the point of the inner tube and the inner surface of the outer tube, which surround it. By turning the outer tube the density of the spray and the distance to which it can be thrown are regulated.

The Gem nozzle (Plate XXIV., Fig. 4) is made on the same principle as the Lowell. In using these nozzles a strong pressure is required to insure a fine spray.

For spraying orchard trees and shade trees of ordinary size, light hand ladders were found to be very serviceable. But when the tops of tall street elms were sprayed, extension ladders, thirty, forty or even sixty feet in length, were necessary. A heavy extension ladder sixty-five feet in length, such as is used by firemen, was purchased for the latter purpose. This ladder could be readily and skilfully handled by six men with the aid of blocks and tackle. The small hand ladders were carried on the spraying wagons and the larger ones by hand or upon wagons, hand-carts or wheels, as was most convenient. Ladders mounted permanently upon wheels could not be used to advantage on account of the uneven nature of the ground where much of the spraying. was done. Ladders twenty to twenty-five fect in height with braces so made that they could be set up like step-ladders were used at first, but they were unwieldy and it was soon seen that more effective work could be done by using light ladders and climbing into the trees themselves. In climbing fruit and shade trees care must be taken not to injure the branches.

Machinery for Spraying Orchard Trees and Garden Plants.

Although in spraying small gardens and orchards any good tank or pump may be used, the heavy and more cumbersome outfits are not necessary. A small portable tank and pump which can be taken about by the operator, either attached to his person or upon a wheelbarrow, will suffice for all the spraying required in small estates.

For spraying garden plants and small fruit trees the " knapsack pump," which is fastened on the shoulders, has been otten recommended for use in small gardens and 


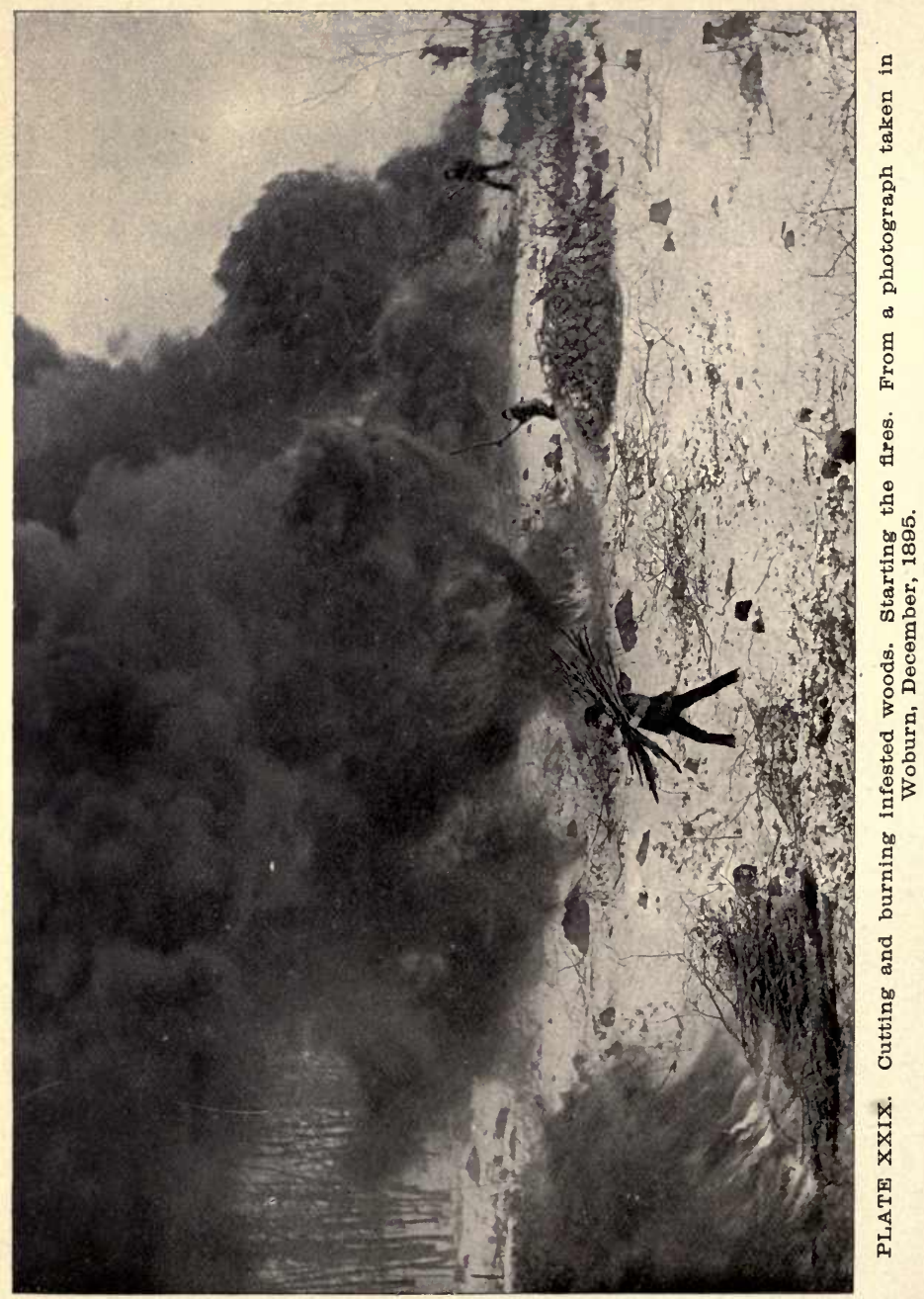


where it falls and burned later with the wood by means of a running fire. Fire will dispose of the eggs upon the trees and undergrowth, yet many will remain among the dried leaves on the ground. In order to secure the destruction of the caterpillars which hatch from these, the territory cleared should be thoroughly burned over in the spring with the cyclone burner. This should be done shortly after the young caterpillars hatch. The eutting and burning should extend for several hundred feet beyond the utmost confines of the infested spot. The immediate effect of this treatment will be to destroy all vegetation above ground, and as a consequence any young caterpillars not reached by the flames will starve. From the stumps of deciduous trees cut down, sprouts will in time spring up. The burning will not kill the roots and a new growth of trees will finally develop. There will be no sprouts from the older coniferous trees, as they do not renew their growth in this way, but are replaced by deciduous trees. The burning is not entirely without beneficial effect on the land. The ashes resulting from the combustion of wood and dry leaves stimulate the growth of such roots as are buried in the ground or beneath the leaves and which send forth shoots under the influence of sun and rain. Within a few months the entire burned area will be covered with a growth of young plants and trees.

A locality in Woburn where timber land is being cleared in this way is shown in our illustration (Plate XXIX.). The appearance of this woodland when attacked by the gypsy moth may be seen by referring to Plate XVII. The owner was willing that the ground should be cleared in order to secure relief from the pest. The trees were first cut down and the wood cut in eight-foot lengths and the brush piled and burned, leaving the land ready for the final burning with the cyclone burner in the spring.

Valuable woodlands generally infested have been treated by clearing away the undergrowth so as to leave nothing on the ground for the insects to feed upon. In this work great care must be taken to avoid injuring the trees by making too hot a fire about their trunks. It is better to rake away the dead leaves and undergrowth from the bases of the trees and burn them than to risk girdling the trees by running a hot 
fire close to their trunks. They may then be banded with insect lime so that the caterpillars may find nothing on which to feed, or they may be burlapped and the caterpillars caught under the burlaps. This method will not injure the growing timber, and if a cleared grove is desired the timber may be thinned by cutting away the least valuable trees. This will render the later treatment less expensive.

In 1891 nearly all the trees were felled on a tract of more than one hundred acres near Myrtle Street, Medford, where the moths were first introduced. (See Plate XXX.) The undergrowth was then burned by a running fire. The extermination of the moths at that place was not then attempted, but the work was done as an experiment in preventing their increase and spread from a badly infested locality. As such it was a success. A fire run through dry leaves and undergrowth before the middle of May will destroy the greater portion of the young larvæ if done when they are small, and when the dry vegetation burns with a quick heat.

When worthless and badly infested trees are found in orchards or elsewhere, the most effectual and economical method is to cut and burn them. Such trees are usually full of holes, cracks and cavities, and in such hiding places all forms of the moth are found in numbers. They can be immediately disposed of by burning the trees, thereby obviating the necessity of further search and treatment.

There is much waste land covered with undergrowth and scrubby trees in the infested region. It receives no care from its owners, being held, not for its productive value, but for speculative purposes. Fire often runs over such land, killing the bushes and young pines and injuring the larger growth so that it is comparatively worthless. Such land can be cut over with little or no loss to the owner; indeed, clearing may often enhance its value. It is not well to cut the growth during the spring months, when the caterpillars are upon it, as they will be disturbed by such work and scattered in all directions. It is much better to cut over such land in the fall, and burn the brush as it is cut or let it lie on the ground until it is well dried and then run fire through it, destroying as many of the eggs of the gypsy moth as possible. Then when the larva hatch in the spring, 


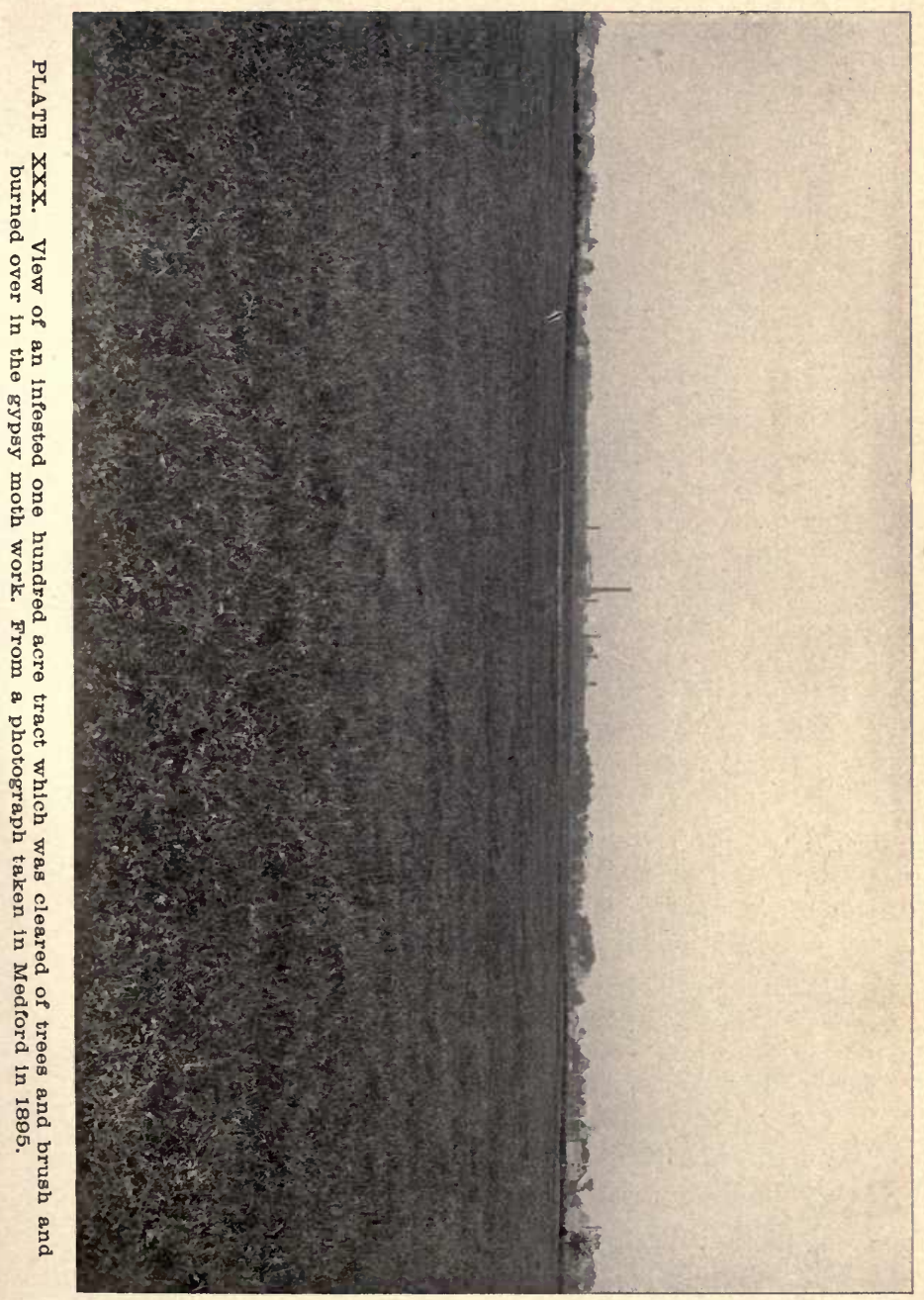



there will be nothing for them to climb upon, and they may be all destroyed by burning the ground over with a cyclone burner. (See Plate XX.) If it is desired to prevent a new growth of brush, the ground should be burned over in August while the sap is in the plants, and again in the following spring. After such treatment the plants will not so readily sprout and a frequent repetition of the burning will result in killing their roots.

\section{Burlapping.}

Early in the summer of 1891 burlap or bagging was first used by the employees of the State Board of Agriculture as a means of assembling the gypsy-moth caterpillars so that they might be readily found and destroyed. It was noticed that before the caterpillars had attained balf their growth, they daily left the leaves on which they had fed during the night and clustered in sheltered places, such as cavities in the trunks of trees or the under sides of branches or other natural objects. They began thus swarming in the second week in June. As they grew larger the tendency to seek shelter during the day became more and more noticeable. They often wandered in search of shelter, leaving trees which did not offer secure hiding-places and retiring to rubbish heaps, stone walls and other places of refuge to pass the day. It was seen that whenever old garments, cloth or paper were thrown in the forks or wound around the trunks or branches of infested trees, the shelter of such materials was sought by the larva during the heat of the day. The bulky nests of the English sparrow also served them as hiding-places.

The conclusion having been reached at this time that spraying with Paris green was only partially successful in destroying the caterpillars, other means of destruction were sought. Experiments were made to find an inexpensive yet durable shelter which would prove attractive to the caterpillars, and which could be readily examined by the men, thus serving in a measure the purpose of a trap. A cheap eight-ounce burlap was found to be the best material for this purpose. A large quantity of baled burlap was purchased and cut into strips about twelve inches wide. These 
strips were made into rolls which the workmen carried surspended from the shoulder. Each man was provided with a sheath knife. When a tree was to be "burlapped," the end of a roll was passed around the trunk at a height of four or five feet from the ground, and enough cut off to encircle the tree and lap sufficiently at the ends to allow for shrinkage. (See Plate XXXI.) The burlap was held in place by twine tied around both tree and cloth. (See Fig. 12, a.) The upper half of the burlap was turned down over the twine, so that it hung like a tablecloth suspended from a clothes line, and made a band of double thickness around the tree. (See Fig. 12, b.) Although the edges hung loosely, the centre was bound quite securely to the

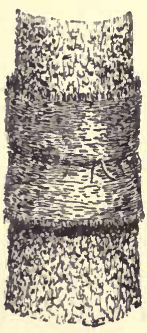

$a$.

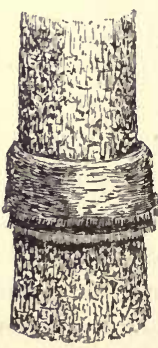

b.

FIG. 12. Manner of applylng the burlap. trunk of the tree. If the trunk and branches offered no better hiding-places to the caterpillars, most of those on a tree would crawl down, morning after morning, and seek the shelter of the burlap, remaining there during the greater part of the day. When thus assembled, they were killed by the employees of the Board, who daily went their rounds from tree to tree, raising each half of the burlap separately and cutting or crushing the caterpillars beneath. Most of the larvæ are found on the bark behind the burlap, but some are taken between the folds. When, in the search for larvæ, the burlap is examined for the first time, it is left turned up against the tree. At the second examination it is turned down. It is turned up at the next visit, down at the next and so on. By following this plan any band that has been missed will attract attention. Experience indicates that the number of caterpillars taken is not materially affected, whether the band is left up or down; yet for general use it should be turned down, as it sheds rain better and presents a neater appearance.

Where the caterpillars are massed, they may be quickly crushed by a wisp of straw or a wad of old cloth. Where 




PLATE XXXI. Putting on the burlap. 
few are found, they may be cut in two by the knife and brushed off the tree. Care must be taken not to crush them with the bare hand, as their hairs when brought forcibly in contact with the skin sometimes cause an irritation much like that produced by nettles.

The burlap band in no way prevents the caterpillars from ascending or descending the tree, neither does it entrap those which it shelters. But it was soon seen that most of the caterpillars which descended the tree remained under the burlap during the day, and that others which were restlessly roaming about on the ground often ascended the tree to the same shelter. Still others, fully grown and ready to pupate, retired to the cover of the burlap to undergo their last transformations, and the female moths emerging would often deposit their eggs upon or beneath it.

The larvæ seek the burlap in greatest numbers during very hot weather, when they usually come down the trees in the early morning hours, go under the burlap and remain there during the heat of the day. The greater number keep on the shady side of the tree, moving with the sun so as to avoid its direct rays. A few leave the burlap during the day, but most of them remain until evening. Observations made on a small apple tree showed that an average of sixty-six per cent. of the larvæ on the tree gathered daily under the burlap. This habit is illustrated by Plate XXXII.

The following quotation from the notes of Mr. W. L. Tower, one of the inspectors engaged in the gypsy-moth work, indicates that the antipathy the larger larvæ have for sunlight is not uniformly shared by the younger or smaller individuals : -

The small larvæ on the tree were less restless and were disposed to remain longer in the sun than were the older ones. Some of the smaller ones would remain all day in the sun on the upper side of a branch, and in one or two cases when placed in a shady place on the tree returned to their first position in the sunsline.

The burlap band to be effective must entirely encircle the trunk, and its edges must hang loosely. If under the influence of sun and rain it shrinks too closely to the tree, the larvæ may not be able to crawl beneath it. This may be 
obviated by cutting the burlap once or twice from its edges nearly to the twine on the side of the tree opposite the lapped ends. This will facilitate the entrance of the larvæ, as they can easily push their way under the loose corners. If a large cord is used to bind the burlap to the tree, there will be more room left under the upper half of the burlap when it is turned down. When the larvæ are very numerous, the burlap may be tacked on and pleats taken in it, to afford more room for the larvæ to pass beneath. On large trees, where the trunk is of irregular conformation, tacks will be sometimes required to hold the burlap to the tree.

To those familiar with the habits of the moth, other devices which might serve a sinilar purpose will occur. Old tin cans or wisps of hay or straw may be placed in the forks of branches or near the roots of trees or beneath hedges to attract the caterpillars, which may be then disposed of by fire. Old blankets hung on fences or walls near infested trees will collect great numbers of caterpillars.

When caterpillars were found to be plentiful in shrubhery, stakes with pieces of burlap attached were frequently driven into the ground in the midst of the bushes. This made an attractive shelter for the caterpillars, and many were assembled and destroyed. Burlap was often left in the forks of branches or thrown over rubbish or stone heaps in badly infested localities. If it was repeatedly examined, many caterpillars were found and destroyed. It was early noted that not all the caterpillars would come down firom the larger trees, such as street elms, but that some of them would remain in the upper part of the tree. In such cases burlaps were banded about the trunk or branches at a height of twenty or twenty-five feet from the ground. An examination of these burlaps necessitated the use of a ladder, but the results often justified the time and labor expended.

The only considerable expense required by the burlapping method is that of labor. To secure the best results the bands must be examined each day so long as any form of the moth can be found beneath them. Old cloth will answer the purpose equally as well as burlap.

There are no valid objections which can be urged to the use of burlap. There seems to be no injury to the tree 


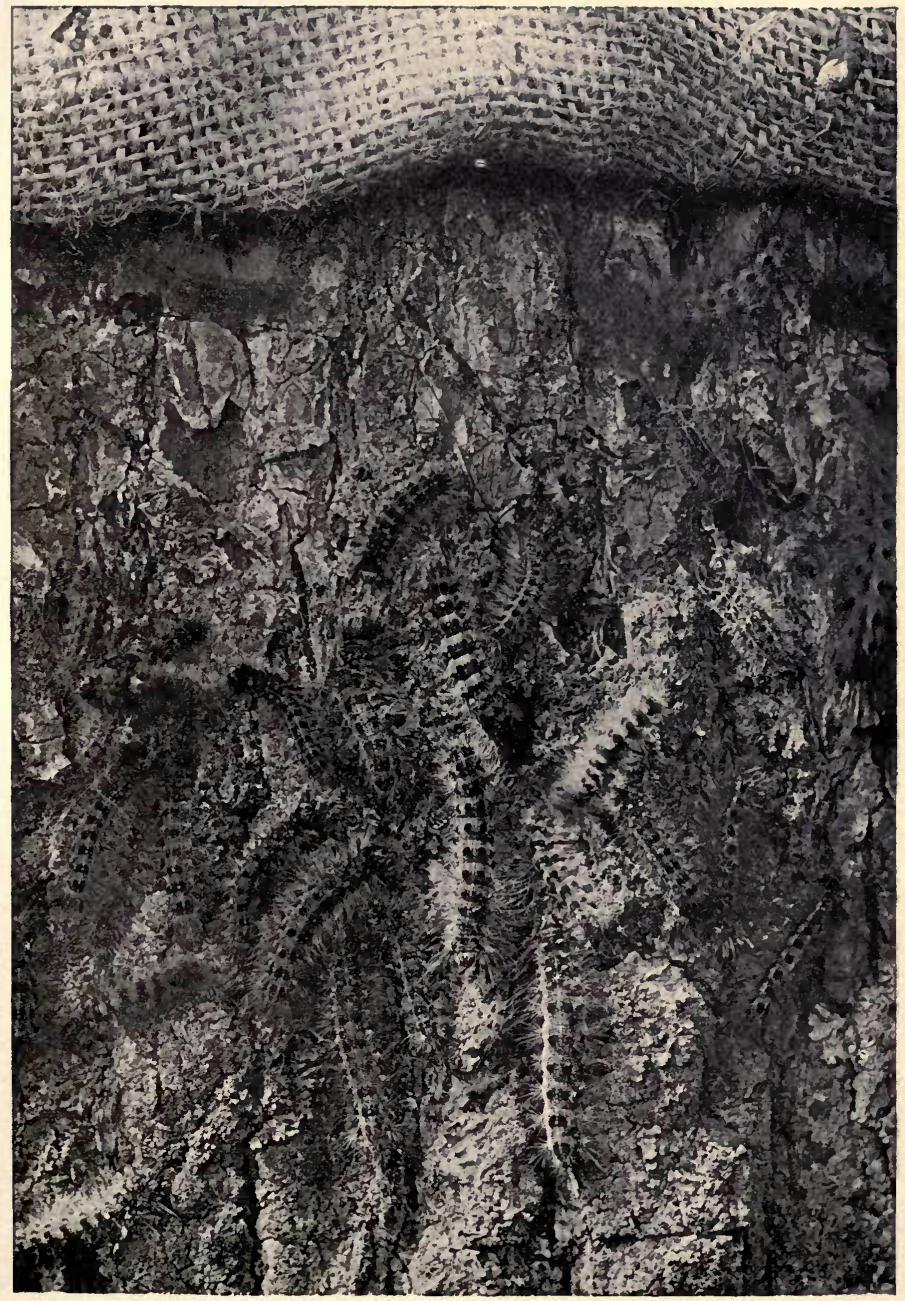

PLATE XXXII. Section of burlap band raised, showing gypsy moth caterpllars that had gathered beneath it on the trunk of an eim tree. 
from its use, although if it is not visited often and watched carefully, other insects injurious to trees will use it as a hiding-place. In the fall the larvæ of the codling moth (Carpocapsa pomonella, Linn.) will crawl under the burlap and gnaw away the bark while preparing a place to pupate; but if the burlap is watched and all injurious insects found beneath it destroyed, its use will prove of great benefit to the tree. Should it be applied to very young fruit trees (which is seldom necessary, as a cloth thrown in a fork of the tree may be used in such cases), there may be some little danger that the cord, if large, will shrink too tightly and crease the bark of the growing tree.

Though the use of the burlap for the destruction of the gypsy moth grew out of observation and experiment by the employees of the State Board of Agriculture, later research in the literature of economic entomology showed that similar devices had been used in the past for other insects.

Dr. Harris, in his report on the injurious insects of Massachusetts (first published in 1841), writes as follows of the use of bands for attracting the larvæ of the codling moth:-

Mr. Burrelle says that if any old cloth is wound around or hung in the crotches of the trees the apple worms will conceal themselves therein; and by these means thousands of them may be obtained and destroyed.*

Kollar wrote of the use of the same method in Europe :-

The following mode of destroying the insects injurious to fruit trees, communicated to me by M. Scheffer of Modling, is so simple and yet so efficacious that I cannot do better than to lay it before my readers. M. Scheffer lays loosely rolled-up pieces of old cloth or blotting-paper in the forks of his trees. The caterpillars eat during the night and while the dew is on the leaves in the morning; but they seek protection from the heat of the day, and crecp into these rolls for that purpose. Thus it is only in the middle of the day that these rolls should be examined, and the caterpillars concealed in them destroyed. $\dagger$

* "A treatise on some of the insects injurious to vegetation," by T. W. Harris, M.D., page 487. See also "New England Farmer," first series, Vol. 18, page 398.

+ "Practical Entomologist," Vol. 1, page 83. 
As Kollar resided in Austria, where the gypsy moth was sometimes injuriously abundant, it is probable that this crude means of assembling the caterpillars was used in destroying this species with others.

A few people in Medford who had observed the habits of the gypsy moth had also used similar bandages with good effect prior to 1891. (See statements of James Bean, page 29 , and S. F. Weston, page 30 , of this report.)

The burlap bands are used most successfully on trees that are well kept and in good condition, with sound and smooth trunks and branches. If the trees were originally in such condition or were first properly prepared for the work, the moths were eradicated from many localities by the burlapping method alone. When trees with decaying branches, hollow trunks and rough or loose bark became infested, the caterpillars often preferred the shelter offered by such cavities and inequalities to that provided by the burlap. Many of them would not come down the tree to the burlap until the cavities were filled or covered, the dead branches cut away and the loose outer bark removed by scraping. It was necessary also to remove rubbish, weeds and brush from the ground about the trees.

There are, therefore, four auxiliary processes (all beneficial to trees or grounds) which must be resorted to to ensure the greatest measure of success in the use of burlap. They are: judicious pruning or trimming of trees; treating and filling cavities; removing loose bark; removing and destroying rubbish, undergrowth and weeds.

\section{Pruning Infested Trees.}

To any one who has critically examined any considerable number of orchard or wayside trees in this Commonwealth, the insertion here of an exhaustive treatise on the pruning and care of trees would seem of great utility. This, however, is not the function of this volume. It is our purpose to cousider here only: (1) the proper removal of dead, de. caying or broken branches, which, if allowed to remain, offer hiding-places for the gypsy moth and other injurious insects ; (2) the removal of clusters of small shoots or suckers, which, growing thickly on the trunks or larger branches, offer shel- 
ter to the gypsy-moth caterpillars, which, by remaining in such hiding-places instead of going to the burlap, may escape destruction. At least seventy-five per cent. of the older orchards in the region infested by the gypsy moth have been either ruined or greatly injured by their owners' neglect or improper pruning or by both. Thousands of trees have been killed by having large limbs chopped or sawn off or otherwise mutilated in such a manner that the exposed and unprotected stubs have died and communicated decay to the hearts of the trees. This condition of so many trees, by furnishing numberless places of shelter for the moth, adds greatly to the labor of extermination.

Dangers of Bad Pruning. - One of the most fruitful causes of hollows in trees in which the caterpillars may hide is the neglect of the simplest precautions in the amputation of large limbs. Wherever we go in the country, orchard trees may be seen with trunks disfigured by unsightly protuberances and yawning cavities. Yet projecting dead stumps such as have assisted in bringing the trees to this condition are periodically left by the hand of the bungling pruner, who will continue in this course until he has completed the ruin already begun. Such trees are monuments to the ignorance or negligence of those who have had them in charge. Intelligent, capable men, careful of their other material interests, continue year after year to "butcher" their trees in this outrageous manner, as their fathers did before them, even though the results of such work are conștantly before their eyes.

The growth of many orchard trees has been badly directed. They have been pruned " up into the air," so that their long, tall, slender limbs have been unable to withstand the fury of the gale or support the loads of ice which form on them during winter storms. Weakened as such trees are by decay, the action of the wind has sent their greatest branches crashing down in ruin. The ice storm of Nov. 5, 1894, which visited the eastern part of this Commonwealth, destroyed hundreds of apple trees by breaking down most of their large branches; yet we have not seen a sound, vigorous, well-nourished and properly pruned tree that was materially injured by that storm. Neither was it always the older trees which succumbed, for some of the oldest, having had good 
care and therefore not being weakened by the almost universal decay, upheld their loads, survived the storm's fury and were not seriously injured.

It is far better never to prune at all than to prune in an unscientific manner. Native forest and fruit trees never pruned by the hand of man grow to maturity in better condition than those in many orchards. In the forest, trees are pruned by nature. As they grow upward, the dense shade formed by their tops kills the lower branches by depriving them of the sunlight. These branches decaying drop off or are torn away by the wind. Little or no damage to the resinous coniferous trees results from this process. As the branches usually break off close to the trunk, and the wood is so filled with resin as to exclude water and parasitic fungi, the wounds heal readily and the trunk remains perfect. More injury is likely to follow to deciduous trees from this operation, especially when the branches are large, yet wounds caused by broken branches are often healed. The breaking is most likely to take place during the winter storms, when there is less danger of injury to the trunk and bark. Yet serious injury is often done and the weaker trees are frequently killed or their shape is ruined by this process of natural pruning. Such pruning as is required for the purposes of the gypsy-moth work will assist in forming healthy growth rather than retard it.

That many apple trees are in ruins before they are fifty years old is almost entirely due to neglect or the ruinous policy pursued in their handling. Such trees well cared for might continue to bear fruitfully for a century.* A knowledge of vegetable physiology and the practical application to tree culture of its laws is greatly needed by those who have the care of trees. A knowledge of the causes of diseases of trees and the means of their prevention is also essential to the farmer, orchardist and forester.

It is the function of roots to fix the plant in the soil and to absorb from it water and the soluble organic and inorganic crude material which is needed for growth and development. It is now believed by botanists that this fluid, which we will

- Apple trees in an orchard planted in Medford hy Gov. John Brooks soon after the Revolutionary War have borne fruit within a few years. 
call crude sap, charged with material for the upbuilding of the tree, is absorbed from the soil by the roots and is forced upward, flowing through the trunk and branches to the leaves, where it is elaborated by the evaporation of water and the absorption of carbonic acid gas from the air. It then finds its way throughout the whole tree, even to the roots, passing through the soft bast cells of the inner bark just outside the cambium layer, forming, as it goes, the new wood and bark.

It may be stated as a general rule that there can be no perfect circulation of the sap and no long-continued growth of new wood or bark on any branch or stump which supports no leaves. It would appear, then, that roots, trunk and branches have no inherent power of themselves to continue growth and extension, but must depend upon the action of the leaves to furnish that elaborated nutriment without which their continued growth and development is impossible.* If the new wood is formed by the sap in its descent from the leaves, it evidently follows that if the projecting stump of an amputated branch is left without leaves so placed as to draw the sap to its farthest extremity, there to be elaborated and returned, it must die. $\dagger$

Effect of Bad Pruning. - The cut, Fig. 13 , represents a stump left on a street tree by the workmen employed in pruning trees under the direction of the city forester of one of our Massachusetts cities. Around such an unprotected stump the rain and other atmospheric influences soon begin the

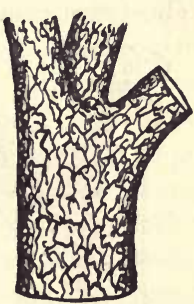

Fig. 13. Stnmp of a branch left by bad pruning. work of decay between the bark and the wood. The cambium layer, lacking circulation, dries up; insects enter;

\footnotetext{
* It is well known that the roots will for a time perform their functions withont the assistance of the leaves, and that growth of different parts of the tree occurs at a time when there are no leaves npon it. But this growth is made by the absorption of water by the roots and by the nse of reserve material. If a tree is continually deprived of its leaves until its reserve material is exhansted, it will die.

+ It is well known that there are some exceptions to this rule. Certain vigorons trees will push out shoots from latent buds near the end of the amputated branch, and leaves are formed, which by their functions enable the tree to cover the wound. Willow trunks and branches deprived of their leaves and left npon the ground have thrown out foliage and roots and grown into vigorous trees.
} 
the bark becomes loosened, warping away from the wood and finally falling off. This condition, so familiar to observing people, may be seen by reference to Fig. 14, which represents an extreme case. Nevertheless, in pruning, such stumps are commonly (we might say usually) left, not only by farmers and orchardists, but also by the employees of city street departments and park commissions

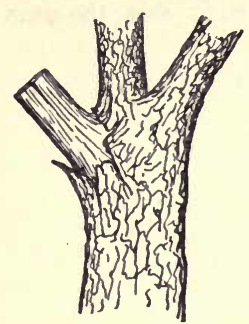

Fig. 14. The stump dies back, Injuring the trunk. and even by the workmen employed in public forest reservations. The stump left exposed to sun, rain and the action of the frost cracks. Water enters and decay sets in which gradually extends through the wood cells down into the trunk. Therefore each stump left projecting eventually produces decay in that part of the tree with which it conneets. Fig. 15 shows a short section of the trunk of a tree on which such a stump has been left. The stump shown at the right indicates the remarkable effort made on the part of the tree to cover the wound;

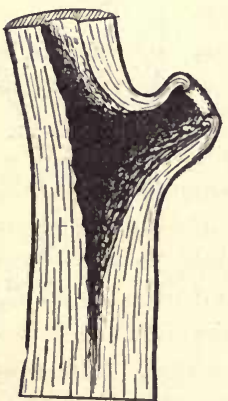

Fig. 15. A trunk rulned by bad pruning.

yet in the course of years the wood has been eaten away by rot and the wound has never healed. Decay has entered the heart of the tree and is fast destroying it. Had the branch been cut even with the surface of the trunk and the wound properly treated, it might have been covered with new growth of wood, and decay might have been prevented.

Wounds on vigorous trees caused by the removal of small branches in this manner sometimes heal over because of the small size of the branches and the comparative shortness of the stumps. But as the stump often decays before the wound heals, injury to the tree results, and in any case an awkward protuberance is formed on the trunk. From such misshapen parts shoots or suckers usually spring. Another section of a trunk is here shown. 
(Fig. 16.) The wound has neurly healed, yet decay has set in and an unsightly excrescence has been formed on the trunk of the tree in the effort of healing. If the wound is well covered by the new growth of wood before injury has been done by the rot, the progress of decay is stopped. In order to heal readily, a wound caused by the removal of a branch should be so made that the sap on its way to the roots may come in contact with the entire edge of the wound without deviating from a direct course.

The Proper Method. - Evidently, then, no portion of the amputated branch should be left, but the cut should be made close to and perfectly even with the outline of the

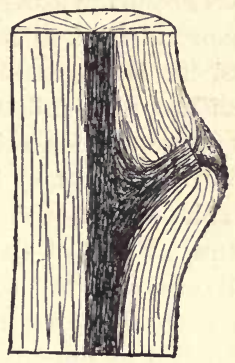

FIe. 16. Excrescence caused by bad pruning. trunk or limb from which the branch is removed, without regard to the size of the wound thus made. When this is done, the elaborated sap flows over the wound from the edges, forming callus first at the top and sides, and gradually covers it with healthy, straight-grained wood. The wound is thus healed over and the decay of the trunk is prevented. This healing is gradual and may require years for accomplishment, especially if the limb removed is large and the tree old and not vigorous. The annual wood-ring being thickest on a young tree, wounds made on such a tree will heal more quickly than on an old tree. Wounds made near the top of a growing tree heal more readily than those near the base, for the reason that the annual wood-ring is thickest at the top. If the wound is left exposed to the sun and wind during the time required for healing, its surface invites decay. To prevent this we must protect the wound at once by applying shellac or coal tar to its entire surface. The use of grafting wax or other thick coatings for such a purpose is not recommended, as they are likely to be cracked or pushed off by the growth of the new hark and thus leave the wood comparatively unprotected. A solution of shellac and alcohol, such as is commonly used by painters, is an excellent wood preservative, as it closes the wound, prevents 
the exudation of crude sap, commonly called "bleeding," and is not open to the objection which applies to grafting wax. Paint is often used. Thick mineral paint mixed with linseed oil has given satisfactory results at the Massachusetts Agricultural College at Amherst, and is recommended by Prof. S. T. Maynard. Coal tar has been long used in Europe as the best substance known for this purpose. It needs no preparation aside from an occasional warming in cold weather, and may be readily applied with a painter's brush. This substance will not injure the wood, but, on the contrary, is one of the most perfect wood preservatives known. If pruning is done with discretion at the right season, the trunk being not already decayed, and if the tar is applied at once on the removal of the branch, the wood will remain sound, and, except in the case of very old and feeble trees, the new growth will in time cover the wound. Decay may be prevented or delayed even in old trees by such treatment. Coal tar should be used with some caution on cherry and plum trees, as it may injure the tree if applied to the bark. Wounds on the maple and eln, which often "bleed," may need more than one application of coal tar to stop the "bleeding." In such cases the first coat of tar should be well rubbed off before the second application.

The two most essential rules in regard to removing limbs are followed in the pruning done in the gypsy-moth work. Although known and practised in this country at the beginning of the present century, they have been ignored by most American writers on tree pruning. Yet Wm. Coxe of Burlington, N. J., wrote in 1817 :-

In cutting off a branch, it should be done as close as possible, never leaving a stump, for the bark cannot grow over it, and disease in the wood will inevitably follow. If the wound produced by the separation be very large, corer it with tar or thick paint.*

The principles of pruning were ably set forth in 1861 by De Courval, as practised with perfect success for more than forty years in the forest of his vast estate of Pinon (Aisne), 
France. Later in 1864 the Baron Des Cars published an able treatise, describing a thorough, practical system of forest-tree pruning, based on the principles laid down by De Courval. The American edition of this work (translated from the seventh French edition) with an introduction by Dr. Chas. S. Sargent, professor of arboriculture in Harvard University, is the most comprehensive work on this subject that has ever appeared in the English language.* The publication of the American edition of this work was made possible by the trustees of the Massachusetts Society for the Promotion of Agriculture, an old and honored association, which has done much for the improvement of agriculture in this Commonwealth. The book should be in the hands of every person who has the care of trees.

Season for Pruning. - Writers on horticulture differ as to the best season for pruning. Each urges the advantages of pruning at certain seasons to increase wood growth or the development of fruit. Objections are frequently made to pruning in the winter, on account of real or supposed danger to the tree from exposing large wounds to the extreme cold. Similar objections are sometimes urged to pruning in the early spring and late fall, when the newly cut surfaces are exposed to the influence of sudden and severe frosts. It is frequently said by orchardists that if a tree is pruned in the spring, when the sap is flowing copiously, and the crude sap is allowed to flow down from the wound, it will poison the bark below and produce decay of the trunk of the tree.

Such examinations as we have been able to make of the results of spring pruning indicate that the injury is due to entirely different causes, viz., the crushing of the bark and consequent killing of the cambium layer at the base of the wound or the separation of the bark from the trunk. Such injuries are likely to occur unless great care is used in pruning. The danger of a separation of the bark from the trunk below the wound and the consequent running of the crude sap into the cavity thus formed is always greatest during the

* "A treatise on pruning forest and ornamental trees," by A. Des Cars, translated from the seventh French edition, with an introduction by Dr. Chas. S. Sargent. Boston, 1884. 
time of the year when the bark peels most readily. In explanation of this, we cannot do better than to quote Prof. R. Hartig of the University of Munich, whose pathological work is a model of thoroughness and scientific accuracy :-

At the time when the cambium is active, it is quite impossible to prevent the cortex being loosened, the friction of the saw being sufficient to account for it. But the main cause is to be traced to the fact that, in order to prevent the cortex being torn off, a cut is first of all made underneath, and during the sinking of the branch the lower edge of the wound is subjected to severe pressure. The cortex of the lower edge of the wound forms a pivot round which the sinking branch turns, and, although the effects may not be immediately visible, still, the crushing and tearing at that point kills the cambium for an inch or two from the edge of the wound. Of course in such a case the new growth - namely, the callus - is not formed at the edge of the wound, but at a considerable distance from it, where it is covered by the cortex. The result is that the cortex, which was originally in intimate contact with the wood, becomes detached, so that a cavity is formed beneath the wound between the wood and the dead tissues. This cavity acts like a gutter to catch the rain-water that flows over the surface of the wound, as well as all the organisms that it may contain. This forms a specially suitable place for the germination of the spores or parasitic fungi, and it is from here that water containing the soluble products of decomposition finds its way by means of the medullary rays into the interior of the wood. This cavity is a gutter in every sense of the term, and at the same time the point of attack for fungi. Even although the surface of the wound may have been coated with tar immediately after pruning, this spot remains unprotected, and indeed it is only formed after the cortex has been separated from the wood by the advancing callus. It is in fact the Achilles' heel of the branch wound. In pruning, the main object must be to prevent its formation; but this is possible only if pruning be confined to autumn and winter, when growth is at a stand-still, and when the cortex is less liable to be detached from the wood. If one also takes the precaution to support the branch during sawing, and at the moment of separation to push it elear of the wound, danger is reduced to the minimum.*

* “The Diseases of Trees," by Prof. R. Hartig, pages 255-257. English edition by Dr. H. Marshall Ward, London, 1894. 
An examination of injurious results of spring and summer pruning indicates that the injury sometimes extends downward and serious harm is done.

There is a danger from the running of sap which occurs when pruning is done in spring or summer, aside from any possible harm resulting from the drain on the vitality of the tree. Warmth and dampness are particularly favorable for the germination of parasitic fungi and the progress of decay. Though decay may occur without the presence of these organisms, its progress is more rapid when they are present. Therefore, wounds which are constantly kept wet in warm weather by the flow of crude sap are most likely to decay.

There are reasons also why pruning in summer is likely to be weakening to the tree :-

If the term, winter pruning, is given to any removal of shoots during the resting period of a woody plant, we may say generally that winter pruning is strengthening, while summer pruning is weakening.

If any portion of the shoot system is taken away after it has passed through one summer, the structure and activity of the root system - that is, its power of absorption and of forcing up water - is such that it can nourish all the branches. At the beginning of the next period of activity, by cutting away some branches the water-consuming area is diminished. The same amount of pressure has therefore a reduced field of action, and consequently the effect on the remaining branches must be increased.

By pruning in the summer we remove soft shoots with only recently developed leaves. The latter have yet their chief work to perform ; for at the commencement they are developed at the cost of the reserve material which is stored up in the branch, then comes a period at which the young leaf requires all the substance it assimilates from without for its own growth, and only after its full development does it begin to work for the benefit of the branch. If, therefore, a soft shoot is taken away, the older portions of the branch are robbed of the materials which were used in the unfolding of the leaves, without receiving anything in return from the leaves they have developed. This causes, therefore, a loss to the general economy of the plant; but, with the 
increased productiveness of our cultivated plants, such a slight weakening may be overlooked, if any other special advantage is gained.*

Tarring the wounds gives the most satisfactory result when pruning is done late in the autumn or in winter, for it is then that the tar is best absorbed by the surface of the wound. When branches are cut off in spring or summer, the tar fails to penetrate the surface of the wound because of the flowing sap, and its thin superficial layer does not prevent the cut from drying later. In drying, cracks are formed, into which water and the spores of fungi may gain entrance. For this reason it is often necessary to apply two or more coats of tar to the wound.

Having considered some of the objections to removing limbs in summer, it is plain that the late winter is the most favorable time for such pruning as is here advocated. There is then less exposure to extreme cold to be considered. It is known that certain trees have a considerable flow of sap in winter. It is said that the Indians were accustomed to draw the sap from the sugar maples in November, when good sap days frequently occur. $\dagger$ It may be better to prune such trees in the spring or summer. The results of pruning native deciduous and coniferous trees at different seasons of the year have never been fully observed with scientific accuracy, and there is much to be learned.

Removal of Dead or Broken Branches. - Dead branches may be removed at any time of the year, if proper precautions are taken to avoid injuring the bark or trunk of the tree in the operation. If these branches are left upon the tree until they decay and drop off or are torn away by the winds, the bark loosens and forms a harboring place for the gypsy moth and certain other insects, which hide beneath it and oviposit there. Their eggs being out of sight, they hibernate in comparative safety until the following spring, when the larva hatch and attack the foliage, thus weakening the tree. If dead branches are not removed, they are some-

\footnotetext{
" "A popular treatise on the physlology of plants," by Dr. Paul Sorauer. English edition by Prof. F. E. Weiss, pages 137, 138.

+ "The Circulation of Sap in Plants," by W. S. Clark. Annual Report of the Massachusetts State Board of Agriculture, 1873-74, page 162.
} 
times broken off by the wind, leaving a long stump projecting from the tree. The ragged surface of the break offers perfect conditions for the beginning of decay, and the seams of the stump communicate it rapidly to the trunk. Fig. 17 shows a section of a tree trunk bearing the broken stump of a dead branch. The tree, being vigorous, has pushed forward callus on the branch and partially covered it with new wood and bark. This attempt at healing might have been successful had the branch been broken close to the tree; but in this case the effort of the tree to heal the wound was of no avail. The neglect

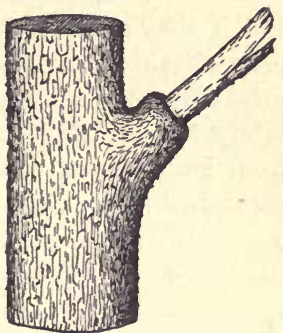

Fig.17. Decaying branch left on the trunk of tree.

to remove these dead branches is often indirectly the cause of cavities in tree trunks. When living branches are broken by the wind, heavy loads of 'fruit or other causes, the stumps should be removed. Such ragged and broken snags ofler points of attachment for parasitic fungi; and if the break occurs in summer, when the sap is flowing, the conditions are particularly favorable for the propagation of these fungi, and the extension of wound rot.

The decay of a tree trunk resulting from improper pruning and the neglect to remove broken branches is shown in Fig. 18. Such rotting away of the wood of the tree as is shown here will not occur immediately, but is the result which will inevitably, in the course of years, follow such a policy. If pruning is begun on the young fruit tree by nipping off buds and directing shoots so as to form a symmetrical head, and is carried on with good judgment as the tree grows, there will be no need of the amputation of large limbs, except such as are broken by accident or die from other causes.

Amputations of the large lower branches of shade trees are often necessary in pruning

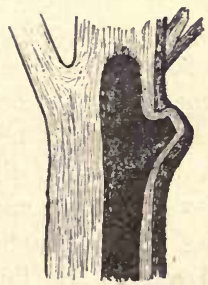

Fra. 18. Bectional view of a trunk, showing the result of neglect and bad pruning. for beauty and utility. In orchards bad pruning often necessitates later the removal of large, decaying hollow limbs, lest 
they break down and split off a portion of the trunk, which in such case is frequently hollow. The removal of such limbs in time may prevent injury to the trunk. These amputations when necessary are merely a question of surgery; and if they are performed at the right season and in the proper manner, and the wound is properly treated, there is little danger of injury to an otherwise sound tree. Where injury to such a tree results from the process, it is usually from ignorance of correct methods or carelessness in their use. Still, it is well to bear in mind that when a surgical operation is to be performed, the result depends not only on the skill of the operator but also on the age and vigor of the subject.

The death of old decaying trees is sometimes hastened by the amputation of large and hollow branches. The shock caused by the removal of several large branches, together with the reduction of leaf surface, which makes it difficult for the tree to heal the wounds, will often kill such trees.* The proper method for treating the cavities of such trees will be spoken of later.

Removing Large Limbs. - In this process great caution must be exercised: (1) not to injure the tree by the unnecessary removal of too many large branches in one season; (2) to avoid injury of the tree by the breaking down or falling of the branch; (3) to guard against accidents to workmen. The old rule for removing large branches was to cut the stump across its diameter near its base, never making a cut larger than the diameter of the branch. This practice has already been shown to be pernicious, as the tree has great difficulty in covering the lower part of the wound with a new growth of bark. Where a large limb is removed in this manner, the lower part of the stump never becomes entirely covered, and finally decays. In sawing off a branch the first cut should never be made from above, as the limb is likely to split and tear away from the trunk. The result of such an accident as is shown in

* If an old tree with sound trunk whose branches appear to be dying is " headed down" by the removal of most or all of its large branches, it may revive, throw out shoots and form a smaller and more vigorous head. 
Fig. 19 may prove very serious to a tree. Whenever it is necessary to amputate a large or long branch, a cut should be made from the under side of the branch, at a distance of two or three feet from the trunk, and should extend half way through its diameter, as in Fig. 20, line $\mathrm{A}$; another cut, $\mathrm{B}$, should then be made farther out, extending down into the branch until it falls. The first cut will prevent the limb from breaking Fia. 19. Limb breaking down and splitting off and the bark from tear-

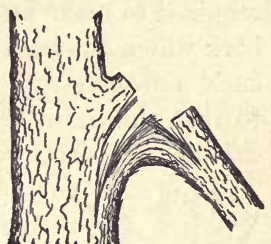
ing down on the tree. The stump may then be removed close to the trunk on the line C, cutting first from below, and supporting the stump so that crushing or tearing of

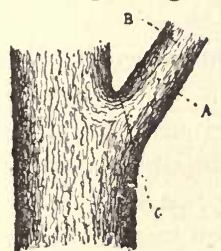
the bark may again be avoided. This method will prevent injury to the tree and guard against serious accidents which sometimes occur when the limb is first cut too close to the tree. . In such cases the outer end of the branch striking the ground has sometimes caused the inner Fia. 20. The proper method end to rebound and strike or throw down of removing a large limb. the workman. Whatever method is employed, the wound should be made perfectly smooth and even with the outline of the trunk by cutting or planing its surface, which should then be immediately covered with coal tar.* On fruit trees, however, it is well never to remove a large excrescence or shoulder (such as is sometimes formed at the base of a limb) if the wood is sound, but to cut the limb at its junction with the shoulder.

Large wounds are often made in the tree trunk by the teeth of horses, the breaking down of large limbs or in other accidental ways. When such an acci-

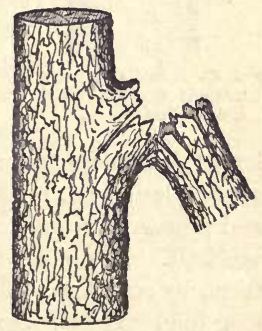

FiG. 21. A trunk injured by the breaking of a large limb. dent occurs as is shown in Fig. 21, it should receive imme-

* If the roughened snrface left by a saw-cut is smoothed, it lessens the danger of decay; and if the edges of the wound are trimmed down to the outline of the tree, the wound is more readily covered by the occluding callus. 
diate attention. It is necessary to cut away the stump which is left and to remove as much of the wood as will be required to make an even surface; also to cut away all the bark which has been loosened below the wound. Otherwise such a wound will in time present an appearance similar to that shown in Fig. 22, and the injury may continue to extend. If such wounds are not immediately treated and

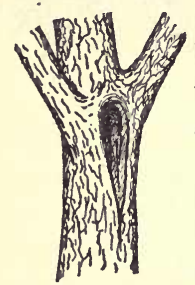

Fic. 22. A cavity caused by the tearlng away of a large limb. scribed is shown in Fig. 23. Decay has been stopped, and the new bark and wood have entirely covered the edges of the wound, leaving the tree in a healthy condi-

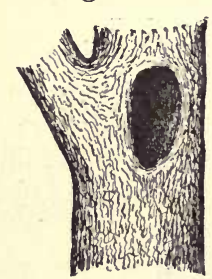

Fra. 23. A cavity properly treated; decay arrested and healing begun. tion. The directions given by Des Cars for the use of coal tar on trees are so admirably stated that we give an extract from them : -

Coal tar has remarkable preservative properties, and may be used with equal advantage on living and dead wood. A single application without penetrating deeper than ordinary paint forms an impervious coating to the wood cells, which would without such covering, under external influences, soon become channels of decay. This simple application, then, produces a sort of instantaneous canterization, and preserves from decay wounds caused either in pruning or by accident. The odor of coal tar drives away insects, or prevents them, by complete adherence to the wood, from injuring it. After long and expensive experiments the director of the parks of the city of Paris finally, in 1863, adopted coal tar in preference to other preparations used for covering tree wounds, as may be seen in all the principal streets of the capital. . .

One coat of coal tar is sufficient for wounds of ordinary size; but when they are exceptionally large, a second coat may after a few years be well applied. In warm countries, like the south 
of France, the great heat of summer renders coal tar so liquid that it is impossible to properly treat wounds made at that season. In such cases another coat should be applied during the following winter.*

Removing Shoots and Suckers. - Many street trees, especially elms, which have suffered from the effects of bad pruning, send forth shoots or suckers from many points of the trunk. These shoots are believed to be detrimental rather than beneficial to the tree, impairing the development of its top and larger branches. So long as suckers are allowed to remain, many of the gypsy-moth caterpillars will seek shelter among them during the day in preference to going to the burlap. If suckers are carefully removed, no injury to the tree will result.

Treating Hollow Trees. - When the trunks and larger limbs of trees are riddled with holes caused by neglect or bad pruning, another mode of treatment becomes necessary. Thousands of gypsy caterpillars which feed upon the foliage at night will retire through the holes to the interior of the hollow trunks and branches, where they secrete themselves during the day, emerging at night to continue their destructive work under cover of the darkness. The closing of such cavities by filling, covering or sealing them is an important auxiliary to the other means of extermination. It prevents the caterpillars from hiding and the moths from ovipositing within the hollow trunks and branches, and drives them to the burlap for shelter. If the holes are carefully covered in the winter, many egg are enclosed within. When they hatch in the spring, the young caterpillars are prevented from leaving their hiding-places and are thus buried alive, as it were, in the tree trunks. This work must be very thoroughly done to prevent the escape of the minute, newly hatched caterpillars.

During the work of the first gypsy moth commission many holes were filled with hydraulic cement. If the hole was large, it was packed with stones and a coating of cement put on the face of this filling at the mouth of the hole. If the hole treated was in a large and otherwise sound trunk, 
the cement, provided it was properly mixed and applied, remained intact for years. Small holes surrounded by sound wood were also filled to advantage in this manner. The cement may be held effectively if laid on a strong iron wire netting nailed across and just within the mouth of the hole. Whenever cement is used on growing trees, it should be

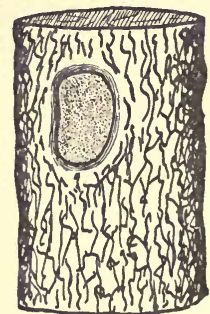

Fig. 24. Cemented cavity.

faced up within the growth of new bark and wood, so that the latter may grow over and hold it tightly. (See Fig. 24.) When the callus has already formed on the edge of the cavity, it should be cut away. This cutting will stimulate new growth, and if the cement is properly faced up within the mouth of the cavity, the callus will eventually cover it. If the hole is so filled that the cement laps over the edge upon the bark, it is likely to prove worse than useless, as the growing bark beneath the cement will throw it off from the tree, leaving a space as a hiding-place for the caterpillars. Hard cement must be carefully applied by an experienced man, otherwise it is likely to prove worthless, and by crumbling and cracking leave the cavity in a worse condition than before.

This cement cannot be used during the colder months of the year, as the action of the frost may canse it to crack. Neither can it be used effectively to stop cracks or cavities, the sides of which may be moved independently of each other by the action of the wind on the branches. Experiments in closing such cavities with plaster of Paris, mineral

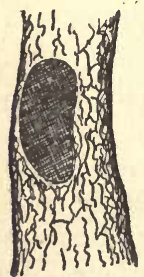

Fig. 25. Burlapped cavity. wool, Purcell's elastic cement, Webster's elastic cement, Portland cement and Roslindale cement were made in the winter of 1891-92. None of these materials gave satisfactory results. Tarred burlap or canvas has been used for this purpose with some success. If three thicknesses of burlap are closely and strongly tacked over the opening to a hollow in a tree trunk and afterward thoroughly soaked with coal tar (Fig. 25) the covering will remain intact and impervious to the weather for several years. Oiled cloth will also 



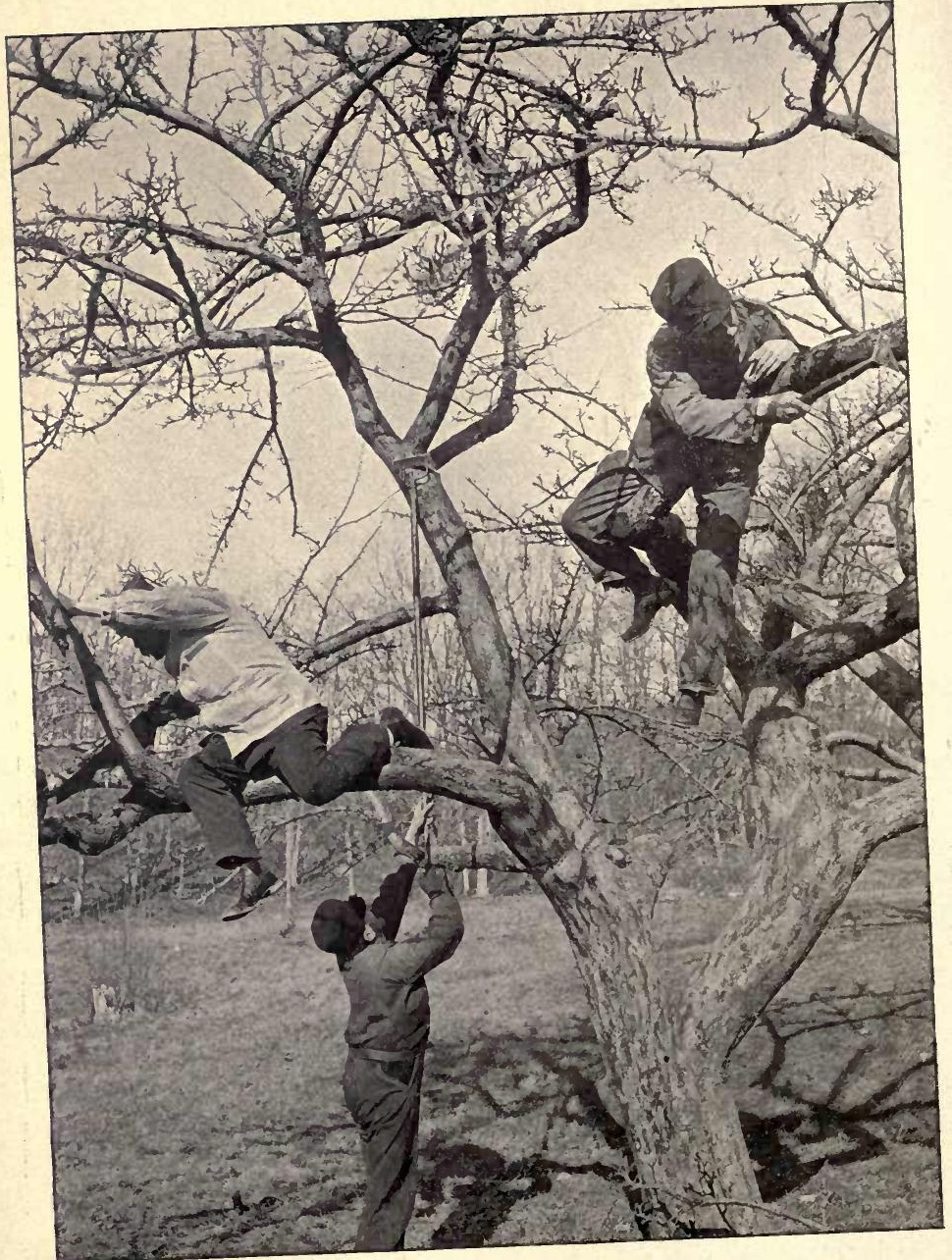

PLATE XXXIII. Pruning and scraping trees. 
answer the same purpose. These fabrics are not materially affected by the movements of the tree, and if well tarred are not often bored through by insects, as the tar is repugnant to them.

In many cases such cavities as are exposed by the sawing off of large hollow stumps of broken branches may be covered to advantage with tin or zinc, which must be tacked closely over the cavity and afterwards painted or tarred. 26.) If these coverings are applied in the winter, it may be necessary to use in connection with them some such substance as the insect lime, in order to prevent the escape of the young caterpillars in the spring. This substance may be smeared around the edge of the tin or burlap in such a manner as to close every crevice communicating with the cavity. It has also been used to stop small holes in trees, and will answer the Tinned cavity. purpose temporarily, but it must be occasionally smoothed over, as it shrinks and cracks in a short time.

\section{Scraping Trees and Removing Loosened Bark.}

Scraping the loose outer bark from old trees facilitates the discovery of the eggs, larvæ and pupæ of the gypsy moth. Such scraping leaves the surface of the trunk and larger branches in a comparatively smooth condition, and deprives the caterpillars of their places of refuge, causing them to crawl down and seek shelter under the burlaps.

If in dealing with fruit trees the loose bark only is scraped off and burned, the main object is accomplished. Such scraping benefits orchard trees by the removal of mosses and lichens and the eggs and hibernating forms of injurious insects.

An implement modelled after the scuffle hoe is useful for this work. (Fig. 27.) Its blade being double-edged, it may be used with both the upward and downward motion, and by means of a long handle the trunk and branches of the fruit trees may be reached to a height of from twelve to eighteen feet from the ground. The ordinary "three-cornered" scraper is also much used. It is believed that this loose outer bark forms a protection to the tree from the cold of 
winter. Objections to its removal based on this belief are obviated by scraping in the spring before the opening of the leaves, when the tree no longer needs protection against the cold. If the loose bark of apple trees is scraped off about April 15 and caught upon cloths spread beneath the trees and the scrapings afterward burned, many injurious insects are likely to be destroyed.

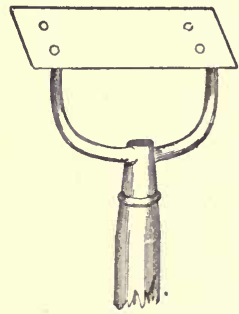

FiG. 27. Long handled scraper.

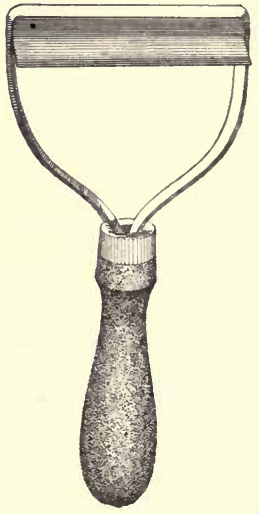

Fia. 28. Bark shave.

If we go further, and without cutting too deeply remove some of the outer bark, double benefit to the tree ensues.*

Its growth is stimulated, a great flow of crude sap occurs, a luxuriant growth of foliage is thrown out and an unusual supply of elaborated sap for the upbuilding of the tree is returned from the foliage and flows into the liber or inner lining of the bark, killing or driving away the bark borers (scolytidae). These beetles are among the most dangerous enemies of trees. For bark cutting a shave (Fig. 28) invented by Mr. G. W. McKee, one of the special inspectors employed by the Board, has been found very effective.

Dr. Packard says that perhaps the best method of preventing or stopping the work of bark beetles is that of a

* Elms which have had the onter bark removed in this manner in November have developed an unusually vigorous growth of dark green foliage in the ensuing sninmer. Trees treated in this manner have shown great vigor also in healing wounds on their trunks. 
Frenchman, M. Robert, as described in the "Gardener's Chronicle" and referred to by Miss Ormerod. He gives the quotation from Miss Ormerod as follows :-

The best remedy appears to be that adopted with great success in France by M. Robert, after careful observation of the circumstances which stopped the operations of the female beetle when gnawing her gallery for egg laying, or which disagreed with or destroyed the maggots, and is based in part on similar observations of the effect of flow of sap to those noticed in England by Dr. Chapman.

It appeared on examination that the grubs died if they were not well protected from the drying action of the air; on the other hand, if there was a very large amount of sap in the vegetable tissues that they fed on, this also killed them; and it was observed that when the female was boring through the bark if a flow of sap took place she abandoned the spot and went elsewhere. It was also noticed that the attack (that is, the boring of the galleries which separates much of the bark from the wood) is usually under thick old bark, such as that of old elm trunks, rather than under the thinner bark of the branches. Working on these observations, M. Robert had strips of about two inches wide cut out of the bark from the large boughs down the trunk to the ground, and it was found that where the young bark pressed forward to heal the wound and a vigorous flow of sap took place many of the maggots near it were killed, the bark which had not been entirely undermined was consolidated and the health of the tree was improved.

Working on from this, M. Robert tried the more extended treatment of paring off the outer bark, a practice much used in Normandy and sometimes in England for restoring vigor of growth to bark-bound apple trees, and noted by Andrew Knight as giving a great stimulus to vegetation. M. Robert had the whole of the rough outer bark removed from the elm (this may be done conveniently by a scraping knife shaped like a spoke shave). This operation caused a great flow of sap in the inner lining of the bark (the liber), and the grubs of the Scolytus beetle were found in almost all cases to perish shortly after. Whether this occurred from the altered sap disagreeing with them, or from the greater amount of moisture around them, or from the maggots being more exposed to atmospheric changes, or any other cause, was not ascertained, but the trees that were experimented on were cleared of the maggots. The treatment was applied on a large scale, and the barked trees were found, after examination by the commissioners of the institute at two different periods, to be in more 
vigorous health than the neighboring ones of which the bark was untouched. More than two thousand elms were thus treated.

This account is abridged from the leading article in the "Gar. dener's Chronicle and Agricultural Gazette" for April 29, 1848, and the method is well worth trying in our public and private parks. It is not expensive; the principle on which it acts as regards vegetable growth is a well-known one, and as regards insect health it is also well known that a sudden flow of the sap that they feed on, or a sudden increase of moisture around them, is very productive of unhealthfulness or of fatal diarrhœa to vegetable-feeding grubs.

A somewhat similar process was tried by the Botanic Society, in 1842 , on trees infested by the Scolytus destructor in the belt of elms encircling their garden in the Regents' Park, London. "It consists in divesting the tree of its rough outer bark, being careful at the infested parts to go deep enough to destroy the young larvæ, and dressing with the usual mixture of lime and cow dung." This operation was found very successful, and details with illustrations were given in a paper read in 1848 before the Botanic Society.*

No injury to trees which have been scraped in the course of the work on the gypsy moth has been observed, although this practice has been continued for three years and more than nine thousand trees have been scraped. Apple trees and elm trees treated in this way have shown an immediate increase of foliage area and growth, presenting a marked contrast to trees near by which have been left untreated. Whether a reaction will set in in future years remains to be seen. As yet no serious reactionary effect has been noted. Trees which have been scraped have exhibited remarkable vigor in healing wounds. In the gypsy-moth work large elms are fiequently met with which cannot be cleared of the moth without shaving off their outer bark. This bark often overgrows small cavities in the trunk in such a manner that hiding-places for the moth are formed which it is impossible to discover until the rougher portion of the outer bark has been removed. While that is being done, it is not difficult to expose these hiding-places and to destroy any form of the moth found within.

- Fifth report of the United States Entomological Commission, 1886-90, pages 31, 32. 


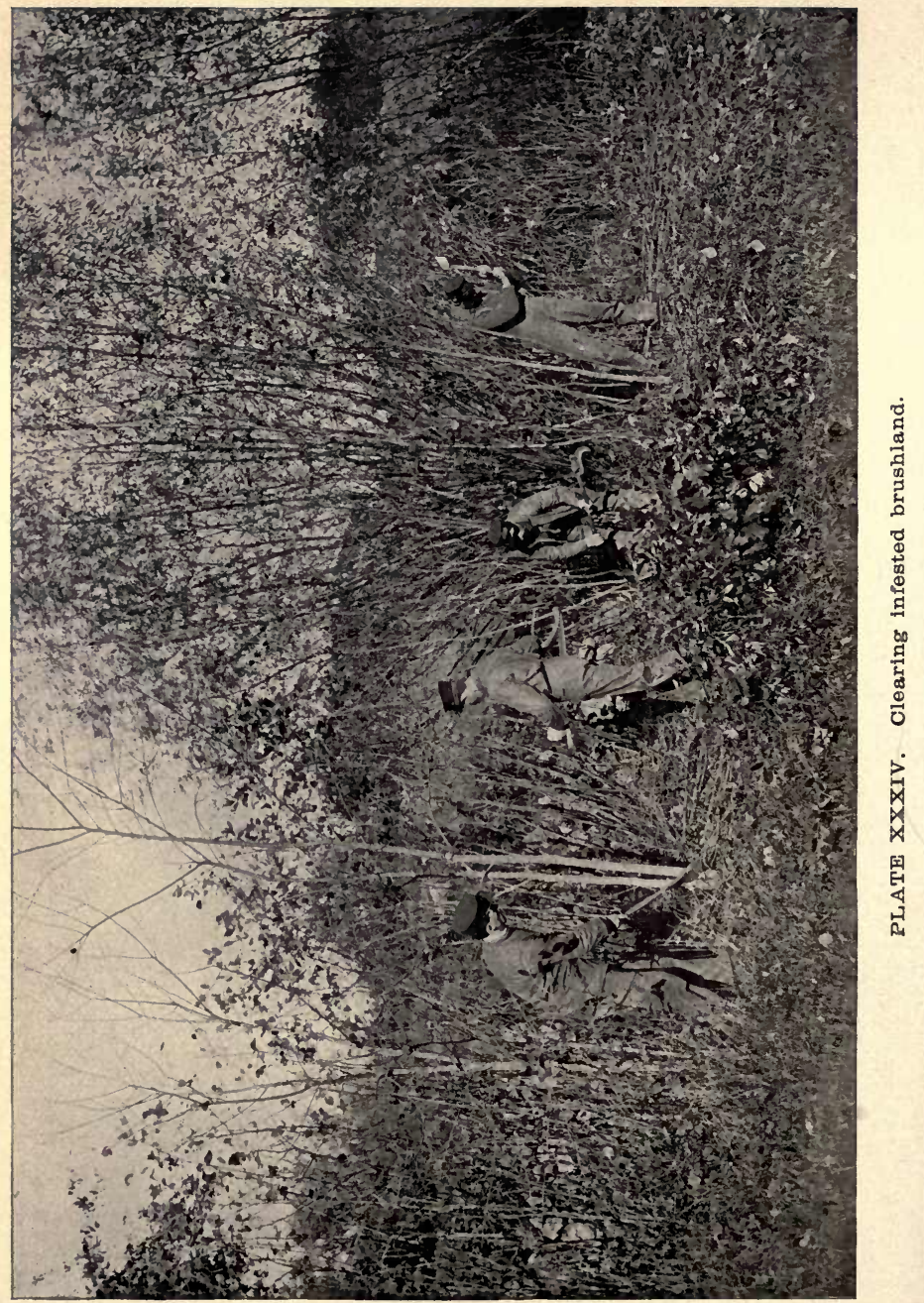




\section{The Destruction of Rubbish.}

The gypsy moth, like many other insects, shows a liking for a rubbish pile. Brush heaps, old stone walls and fences overgrown with bushes and vines, dumping grounds, old piles of lumber, tin cans, rags, paper and other débris all furnish many hiding-places for the caterpillars, retreats for pupating and places where the moth can deposit its eggs.

It is remarkable how many absolutely filthy rubbish heaps accumulate in the back yards of some tenement-houses. These deposits of rubbish are especially noticeable in certain districts of the larger towns and smaller cities. Not only are all sorts of waste material from all parts of the house from cellar to garret thrown into the back yard, but refuse from the kitchen is also frequently deposited there, together with a collection of empty but unclean cans, such as are originally used for "canned goods." Old shoes, broken bottles and earthen ware, cast-off articles of apparel, corn husks and the withered tops of regetables in all stages of decay, bones, fish heads, lobster and oyster shells are also common constituents of these rubbish piles. Such heaps of rubbish, often overgrown with weeds and bushes, would form an instructive spectacle for local boards of health.* Even the grounds of the wealthy are not always exempt from accumulations of rubbish, which may be found occasionally about the corners of back fences or in the rear of stables.

Amid such associations the gypsy moth delights to dwell. In the many places of shelter offered by such rubbish heaps the larvæ can safely hide during the day, sallying forth at dusk to destroy the foliage in the vicinity.

One of the first steps, then, toward exterminating the gypsy moth from any locality is to clear up the ground; burn rubbish, old lumber, wood, brush, rags and dead leaves; bury or melt up old tin cans; tear down or remove stone walls and old fences; and leave the premises as clean as possible. Cremation is a cleansing process; bonfires mark the progress of civilization. Such work will not only aid in

There has been much improvement in respect to the accumulation of rubbish in yards in our cities and large towns since the slight cholera scare of 1893. 
disposing of the moth but will remove harboring places for other insects and render the locality more healthful and wholesome. The agents of the Board of Agriculture have found it necessary to remove, burn or bury many of these accumulations of débris in order to secure the destruction of the moth.

\section{Destroying Pupce and Moths.}

As the eggs of the gypsy moth hatch in the months of April, May and June, the larvæ feed in the latter part of April and during the months of May, June, July and August. In July and August all forms of the moth may be found together in the same locality. Pupæ and moths are found upon the same trees, under the same burlaps and in the same rubbish heaps with the larvæ; therefore no special measures are taken to destroy these forms of the insect. They are searched for in all the hiding-places which shelter caterpillars, and are destroyed by the same means. The white female imagoes are especially noticeable when resting on the bark of trees. They may be found in July and August, and, as they do not fly, they may be readily captured.

\section{A Summary of the Methods most Useful to the FARMER.}

Unless sufficient appropriations are made to exterminate the gypsy moth or to hold it in check where it now is, its rapid increase and spread over this and other States will probably follow. In case of the permanent cessation of public exterminative or preventive work, the labor of holding the gypsy moth in check or of repressing its destructive outbreaks will devolve upon the citizen and especially upon the farmer.

In considering the methods most useful to the farmer for the destruction of the gypsy moth, it is well to inquire, first, what class of farming erops are most liable to injury by the pest. As the gypsy moth feeds by preference on trees, shrubs and foliaceous plants, those farmers who devote themselves entirely to dairying or grain raising will be likely to suffer least. Market-gardeners have less to fear from the gypsy 
moth than the general farmer or fruit grower. The well-todo market-gardener who raises little or no fruit has few trees on his land to care for ; his methods of cultivation are intensive, and he is obliged to employ a number of field hands in his business. He is therefore better able to protect his crops against the attacks of an insect like the gypsy moth than is the general farmer or the small farmer who has to depend largely on his own labor. There would be less danger to the interests of the agriculturist in thickly settled districts where market-gardening is carried on than in thinly settled sections where farms are larger and less highly cultivated, where much wood is grown and where there are many orchards. In such regions the waste and wooded land, where the moth might breed and where little could be done by the owners to check it, greatly exceed in area the cultivated land, where its ravages would do the greatest injury.

In considering, then, the means most useful to the farmer for controlling or exterminating the moth, we must choose those most readily available to the general farmer of moderate means.

Burning the eggs or killing them by means of creosote or other oils are the methods which can be used most effectually by most farmers. The work can be done during the late fall, winter and early spring, - a time of the year when most farmers are not overburdened with the labors and cares incidental to planting and harvesting. If this is thoroughly done in an orchard, there need be no fear of the fruit crop being destroyed in the ensuing summer by the gypsy moth unless the orchard is invaded from without by caterpillars which have bred in the woods or upon shade trees.

If shade trees are near the orchard, all the orchard trees cleared of eggs should be banded with insect lime or supplied with tree protectors, either of which will go far toward protecting them from the inroads of migrating caterpillars. But if there is a tract of badly infested woodland near the orchard, the bands will be of little use in protecting the trees against the invasion of the multitude of caterpillars. In such cases the most economical plan would be to cut down all the infested woods and burn over the ground. Few farmers can afford to attempt to keep the pest out of wood- 
land, as the cost of the labor would be more than the value of the wood. If precautionary measures have been neglected, and the caterpillars appear in swarms, they may strip the trees before arriving at an age when they will seek the burlap.

When small caterpillars are very numerous upon the trees, spraying with arsenate of lead at the rate of thirty pounds to one hundred and fifty gallons of water will destroy most of them. If arsenate of lead is not at hand, two or three good sprayings with Paris green in May will greatly lessen their numbers. The trees may be afterwards burlapped, and the caterpillars killed as they gather day by day under the burlaps. A small burning tank with a cyclone burner might be used to stay the march of an invading host of these caterpillars, and would check them anywhere. (See Plate XX.) The care of trees and the general cleanliness of grounds will do much toward rendering an orchard an unfit dwelling-place for the gypsy moth, and will facilitate the moth's destruction.

\section{The Anndal Inspection.}

The inspection and egg-killing in the infested district and the inspection in the towns in its vicinity during the late fall, winter and early spring are the chief means of preventing the dissemination of the moth, and the first and most important steps toward extermination. It is by examining the trunks and the lower surfaces of large limbs of trees during this search that most of the conspicuous egg-clusters are found. In this way most of the colonies of the moth have been discovered.* It is for the prosecution of this work that the most efficient and experienced men are retained. The inspection goes on through the winter months, except when interrupted by severe storms, deep snow or the exhaustion of the appropriation.

So long as there are moths in the district at present infested, just so long will there be danger of their distribution throughout that district and to adjacent towns; the danger

* Webster defines a colony (under the head of natural history) as a number of animals or plants living together beyond their usual range. In the gypsy-moth work the word "colony" has been applied to the moth when it has been found isolated from others of its kind by a belt of uninfested country. 
increasing or decreasing, according to the increase or reduction of the number of the moths, especially along highways or in cultivated lands and woodlands most frequented by man.

Each autumn, as soon as the foliage is well off the trees, the most experienced employees of the Board are organized into squads, which are set to work examining such territory within the infested towns as has not been recently inspected. Many colonies have thus been found by careful search within the region known in 1891 to be infested. Much time and money have been spent in this search, but money enough has not been provided in any year to make the search thorough and complete. To provide against the spread of the moth, more or less of this kind of work has been done each year in the towns outside of the infested region. In this outside search considerable time and money have been expended, and only a few small colonies of the moth have been found. These were all at a short distance outside the boundary of the region known in 1891 to be infested. Though this search does not at first sight appear to have furnished results proportionate to the expense incurred, yet, had the colonies not been found and stamped out of existence, any one of them might have increased and spread like the original Trouvelot colony.

As the prevention of the spread of the moth and its extermination are the objects contemplated by the statute authorizing the work, this search of towns adjacent to the infested region must continue so long as the region continues to be infested; otherwise, there can be no absolute assurance that the moths are not spreading beyond the limits of the region in which the work is carried on.

As the search extends farther away from the centre of the infested region, the territory to be examined becomes greater, increasing the expense, while the likelihood of its being infested diminishes. Therefore, in towns next outside those immediately adjacent to the infested region the search is confined to those places which experience has shown are most likely to become infested, mainly the villages and borders of highways. Especial attention is paid to all points which by reason of the character of the business of the resi- 
dents appear to have been particularly exposed to infestation.

Beyond these towns only the borders of railways, certain highways, the centres of villages and such estates as are believed to have been exposed to a possibility of infestation are inspected. A few cities which are centres of trade and travel form an exception to this rule. They have been more thoroughly inspected. The following cities and towns have been more or less thoroughly looked over. Some have been visited only once, but most of them have been inspected several times during the last five years. In none of them has any trace of the moth been found :-

\begin{tabular}{|c|c|c|}
\hline Bedford. & Ipswich. & North Andover. \\
\hline Boxford. & Lincoln. & Quincy. \\
\hline Billerica. & Lowell. & Rowley. \\
\hline Brookline. & Middleton. & Sudbury. \\
\hline Concord. & Manchester. & Topsfield. \\
\hline Dedham. & Milton. & Tewksbury. \\
\hline Essex. & Newton. & Wilmington. \\
\hline Georgetown. & Newbury. & Wayland. \\
\hline Gloucester. & Newburyport. & Weston. \\
\hline $\begin{array}{l}\text { Hamilton. } \\
\text { Hull. }\end{array}$ & North Reading. & Wenham. \\
\hline
\end{tabular}

\section{Measures for the Information of the Public.}

The Board of Agriculture has from the first believed that success in the work of preventing the spread and securing the extermination of the gypsy moth could not be hoped for without the intelligent co-operation of the public. Every effort, consistent with the letter and meaning of the statute under which the work has been carried on, has been made to diffuse information in regard to the identity and character of the pest and the laws enacted and regulations made for its destruction. The rules and regulations of the gypsy moth committee have been frequently advertised in the daily papers. Every facility has been offered to the daily and weekly press in regard to the publication of illustrated articles upon the gypsy moth. Cuts of the moth have been loaned many newspapers, and have had a wide circulation. Information has been frequently given to the agricultural press. 
The prejudice existing against the spraying and other features of the work, which was expressed in the local press in 1890, continued to find some expression in 1891. The papers, however, gave the work of the Board of Agriculture a wide publicity. We can do no less than acknowledge the spirit of fairness of the press of the State, and the willingness manifested to publish everything in regard to the work which would be of interest to the people. Yet false reports as to the appearance of the gypsy moth in various places at a distance from the infested region have been frequently and widely circulated. These appear to originate not with the newspapers themselves but with citizens who, believing that they have discovered the gypsy moth on their premises, cannot wait to notify the Board, but immediately rush into print and so give the alarm. In all such cases it has been found upon investigation that the injury noticed was caused by some other insect. Yet these local " scares" have assisted in arousing the interest of the people, and leading them to further investigation of the appearance and character of the moth.

Early in 1891 arrangements were made with an artist for drawings of the gypsy moth to be reproduced for illustration. A colored plate (Plate I. of this report) was prepared and printed in the first annual report of the State Board of Agriculture on the extermination of the gypsy moth. Ten thousand copies of this report were printed and distributed throughout the Commonwealth, especially in and near the infested district. Fifteen hundred extra copies of the plate were also printed, to be used in connection with other material and for posting in public places, such as post-offices, schools, libraries and museums. One hundred and fifty glass-covered cases, containing specimens of the different forms of the gypsy moth, preserved, mounted and labelled, were prepared for exhibition in the infested district, as well as for museums and other public places in the State. A bulletin of information was also prepared, and five hundred copies were printed in large type and framed. In the centre of each frame was placed one of the colored plates representing the different forms of the gypsy moth; a printed explanation accompanied the plate. These frames were placed in prominent positions in post-offices, mostly 
in eastern Massachusetts. A large frame containing in addition to the bulletin a photograph of the moth's ravages, and having a specimen case attached, was placed in the main postoffice of each city or town in the infested district.

In 1891 a bulletin of information in regard to spraying for the gypsy moth and other insects was printed in pamphlet form and distributed through the infested district. Some fifty thousand copies of the law of 1891, providing for the extermination of the gypsy moth, together with the rules and regulations under which the work is conducted, have been printed and distributed among the people of the infested district and in towns near by. The law and the rules and regulations were also printed in poster form and posted in many public places. Many placards containing certain sections of the law were also printed and posted. Each season from twenty thousand to twenty-five thousand copies of the annual report on the gypsy moth (each with a colored plate of the insect) have been printed for distribution, in addition to the nine hundred copies annually printed for the use of the Legislature. Circular letters, calling the attention of citizens to the threatening danger from the invasion of the moth, have been printed and sent with or without the reports to newspapers and citizens throughout the State. Lectures on the gypsy moth and the means of its extermination have been given by the secretary of the Board of Agriculture, the entomologist and the director. Other speakers have frequently spoken on the same subject at farmers' institutes and other meetings.

When the Massachusetts exhibit at the World's Columbian Exposition at Chicago was being prepared, the committee in charge requested the Board of Agriculture to prepare an exhibit for the exposition. This was done, and the exhibit occupied a central place in the Massachusetts building at the fair. It consisted of a glass case seven feet in height, containing a representation of an apple tree denuded of its leaves by the gypsy-moth caterpillars, and exhibiting on its trunk and branches all forms of the moth, together with many of the vertebrate and invertebrate enemies of the moth, including birds, fowls, predaceous beetles and parasites. Photographs showing the destructiveness of the moth were 
exhibited. A large amount of printed matter in regard to the moth was distributed at the fair.

In October, 1895, in response to a request recelved from the Massachusetts Charitable Mechanic Association, this exhibit was sent to the fair held in the Mechanics building, Boston, where it was exhibited together with another case containing sections of tree trunks and other objects on which the egg-clusters of the gypsy moth had been laid. There was also a collection of bromide enlargements of photographs, showing the moth as in nature, its ravages and the means of destroying it. At the request of L. O. Howard, entomologist of the United States Department of Agriculture, duplicates of some of these bromides were also sent to the Cotton States and International Exposition at Atlanta, Ga., where they were exhibited as a part of the entomological exhibit of the United States Department of Agriculture.

The measures taken to inform the public have succeeded in arousing public interest to such an extent that many citizens of the State immediately report to the Board any injurious insects which appear to them to be gypsy moths. Such reports are sometimes received from other States. Many false alarms of the moth's presence have been sent in, and all have been investigated. Reports of the appearance of insects which were wrongly supposed to be the gypsy moth have been received from the following places:-

Places from which False Alarms have been received.

\begin{tabular}{|c|c|c|}
\hline Massachusetts. & Brockton. & Georgetown. \\
\hline Acton. & Brookfield. & Gloucester. \\
\hline Andover. & Bourne. & Grafton. \\
\hline Ashburnham. & Chester. & Groton. \\
\hline Athol. & Concord. & Holden. \\
\hline Abington. & Charlton. & Hopedale. \\
\hline Amesbury. & Carlisle. & Haverbill. \\
\hline Auburn. & Clinton. & Holliston. \\
\hline Billerica. & Dedham. & Hyde Park. \\
\hline Berlin. & Duxbury. & Hingham. \\
\hline Braintree. & Easton. & Hudson. \\
\hline Bedford & Fall River. & Hull. \\
\hline Bolton. & Foxborough. & Ipswich. \\
\hline Boxford. & Fitchburg. & Lincoln. \\
\hline Brookline. & Framingham. & Lowell. \\
\hline Bridgewater. & Gill. & Lawrence. \\
\hline
\end{tabular}


Places from which False Alarms have been received - Concluded.

Massachusetts - Co
Marlborough.
Marshfield.
Merrimac.
Milford.
Methuen.
Manchester.
Maynard.
Milton.
Monson.
Newburyport.
Newton.
Needham.
Newbury.
Northbridge.
Norwood.
North Andover.
North Brookfield.
North Reading.
Pittsfield.
Pepperell.
Plymonth.
Princeton.
Quincy.
Randolph.
Rowley.
Rockport.

Rehoboth.

Scituate

Southborough.

Sterling.

Sutton.

Sudbury.

Springfield.

Templeton.

Tewksbury.

Townsend.

Tyngsborough.

Uxbridge.

Weymouth.

Wenham.

West Bridgewater.

Wilmington.

Weston.

Westborough.

West Newbury.

Wellesley.

Wayland.

Wrentham.

Worcester.

Rhode Island.
Providence.
Pawtucket.

Connecticut.

Fairfield.

Glastonbury.

Ridgefield.

Maine.

Cape Porpoise.

Sabbatus.

New Hampshire.

Barnstead.

Center Harbor

Haverhill.

Kensington.

Kingston

Lakeport.

Portsmouth.

Pratts.

Seabrook.

Iowa.

Fort Madison.

Vermont.

Green River.

In all cases the damage reported was caused by some other insect. The many reports thus received are gratifying, indicating as they do a public interest in the work, and a desire to aid as far as possible in stamping out the pest. The investigations in other States have been made mainly to prove or disprove the claim that the gypsy moth is confined in America to a limited district in Massachusetts. This is the theory on which the work of extermination has so far proceeded, and no proof has ever been given that it has been found outside of this district. 



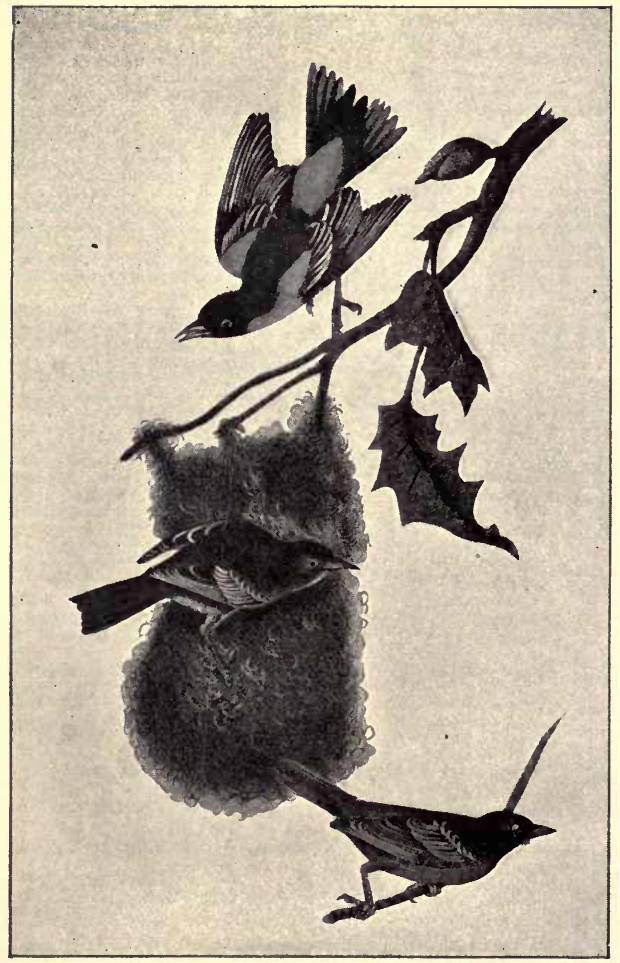

PLATE XXXV. Baltimore orioles and nest. 
Natural Enemies of the Gypsy Moth.

\section{InseCt-EATING Birds.}

Since the work of preventing the spreading and securing the extermination of the gypsy moth in Massachusetts was placed in the hands of the Board of Agriculture in 1891, particular attention has been paid to the natural enemies of the moth. All persons employed in the work have been instructed to watch for enemies or parasites, and keep a record of all observations made. In accordance with these instructions, voluminous notes now covering many hundred pages have been made. Many enemies of the moth have been studied both under natural conditions and in confinement. Search has been made through European literature for information in regard to the enemies of the moth abroad. Much information bearing upon the subject has also been obtained by foreign correspondence. In apportioning the preparation of the report on the natural enemies, the task of preparing a report on the birds was assigned to me. My colleague, Professor Fernald, will treat of the other enemies of the moth.

\section{The Usefulness of Birds as Insect Destroyers.}

The subject of birds versus insects is a most important one. The influence of birds on the agriculture of a country is incalculable. The protection or destruction of native birds and the introduction of foreign species are subjects worthy of the most thoughtful consideration of the agricultural department of any government.

Land birds fulfil their part in many ways in preserving the balance of nature, but chiefly by doing much toward holding in check the increase of the insect world, which, if unrestricted, would swarm over and devastate the earth.

Birds are among the most highly organized of vertebrate animals. In them we find the greatest activity and the highest temperature of the blood. To maintain this tem- 
perature and supply the tremendous waste of the tissues caused by this activity a great quantity of food is necessary. Excellent provision is made by nature for the rapid digestion and assimilation of a great amount of food. In August, 1895, two young crows were confined at the experiment station in Malden, and observations were made on their feeding habits. The time from the entrance of the food into the mouth to the first voiding of excreta containing remains of the food eaten was usually about one and one-half hours. It is probable that digestion is still more rapid in the smaller insect-eating birds. * The common titmouse or chickadee (Parus atricapillus) is one of the smaller birds of New England, yet the good accomplished by it in destroying the eggs of insects injurious to orchard and forest trees is almost beyond belief. I have given elsewhere an estimate, based on careful observations and dissections, that in twenty-five days one of these birds will destroy 138,750 eggs of the canker-worm moth (Anisopteryx pometaria). $\dagger$

Prof. Samuel Aughey, who fed confined plovers on insects, found that they would eat on an average 202 locusts and other large insects per day. $\ddagger$

Professor Treadwell fed to a young robin in twelve hours forty-one per cent. more than its own weight in worms. The same bird consumed nearly half its own weight of beef in a day. $\S$

At this rate a man would eat daily about seventy pounds of meat. Because of their enormous appetites, birds are most potent factors for good or ill. It is well known that crows and blackbirds destroy vast quantities of grain for a short season when they swarm upon the fields; but their services in destroying injurious insects are not generally recognized.

- According to Maynard the Indigestible remains of food are excreted by the cedarbird in one-half hour after eating. (See "Birds of Eastern North America," C. J. Maynard.)

+ Bulletin on "Birds as protectors of orchards," Massachusetts Crop Report, July, 1895, pnblished by the Massachusetts State Board of Agriculture.

† First report United States Entomological Commission, 1877, page 343.

\$ "Birds of New England," by E. A. Samuels, page 159. The paper on this subject was originally read by Professor Treadwell before the Boston Society of Natural History. 
The activity of birds, as shown in running, climbing trees, hopping or flying, together with their powers of vision, renders them particularly adapted for searching out, overtaking and destroying insects. Birds often assemble where insect outbreaks occur, and assist in checking great insect invasions.

In a search through agricultural, entomological and ornithological literature, we find many instances on record in both hemispheres where birds have been instrumental in saving crops or forests by destroying injurious insects. Samuels states that in 1847, as an immense forest in Pomerania was on the brink of being utterly ruined by caterpillars, it was suddenly and very unexpectedly saved by a flock of cuckoos, who established themselves in the place for a few weeks and thoroughly cleaned each tree.*

During the great locust invasions in the West the investigations of Professor Aughey, as published in the first report of the United States Entomological Commission, showed that birds were among the greatest enemies of locusts, and that in many instances when the farmers had given up the battle against the "grasshoppers," the crops were saved by the flocks of birds that descended upon the fields, destroying immense numbers of the feeding locusts. $\dagger$

Many instances are on record where a great increase of insect pests has followed the destruction of birds. George Kearly, in the "Entomologist's Weekly Intelligencer," speaks of an outbreak of insect pests in a park at Brussels, in which the gypsy moth was one of the chief offenders, having stripped well-nigh all the trees of their foliage. He says this great increase of insects followed soon after and was caused by the destruction of sparrows and other birds in the park, by order of the authorities. $\ddagger$ In a letter recently received from J. O. Clercy, secretary of the Society of Natural Sciences, Ekaterinburg, Russia, he states that the ravages of two species of cutworms and some ten species

\footnotetext{
* E. A. Samuels, in report of Massachusetts State Board of Agriculture, 1865-66, page 117.

† Report of the United States Entomological Commission, 1877, page 338.

† The “Entomologist’s Weekly Intelligencer," 1858, Vol. 4, page 192.
} 
of locusts contributed, together with the want of rain, to starve the inhabitants in that region in 1891 and 1892. One of the causes, he says, which permitted such a numerous propagation of insect pests was the almost complete destruction of birds, most of them having been killed and sent abroad by wagon loads for ladies' hats. A law for the protection of birds has now been enacted, and, says Clerey, " the poor little creatures are doing their best to reoccupy their old places in our woods and gardens. This reoccupation, however, does not go on as rapidly as did their destruction."

Many species of water birds, the gulls and terns especially, are useful as insect destroyers. In 1848 the crops of the Mormons in Utah were attacked by the Western cricket ( Anabrus simplex), which came down in great armies from the highlands about Salt Lake. These crickets had already destroyed a considerable portion of the crops, when great flocks of gulls appeared and ate the crickets. Hon. George Q. Cannon says: "Black crickets came down by millions and destroyed our grain crops; promising fields of wheat in the morning were by evening as smooth as a man's hand, - devoured by the crickets. Sea gulls came by hundreds and thousands, and, before the crops were entirely destroyed, these gulls devoured the insects so that our fields were entirely freed from them."*

This occurrence is well authenticated and testified to by many eye-witnesses. $\dagger$

While some ornithologists regard birds as by far the most important natural enemies of injurious insects, many entomologists believe that insect and vegetable parasites are more useful in this respect than birds; yet some of the most eminent economic entomologists, who have had occasion to observe the insect-eating habits of birds in connection with great outbreaks of insect pests, have been among the first to

" "Insect Life," Vol. 7, No. 3, page 275.

+ See the nineteenth annual report of the secretary of the Massachusetts Board of Agriculture, 1871, page 76; the report of the United States Commissioner of Agriculture, 1871, page 79; also the second report of the United States Entomological Commission for 1878 and 1879, relating to the Rocky Mountain locust, page 166, A. S. Packard, Jr. 
give public expression to their appreciation of the value of birds as destroyers of noxious insects. *

A study of the food of insect-eating birds leads to the belief that if in any way their numbers and efficiency can be augmented, an increase in agricultural products will be secured.

Birds seen to feed upon the Gypsy Moth.

Thirty-eight species of birds have been identified when feeding upon the gypsy moth in one or more of its forms. They are as follows:-

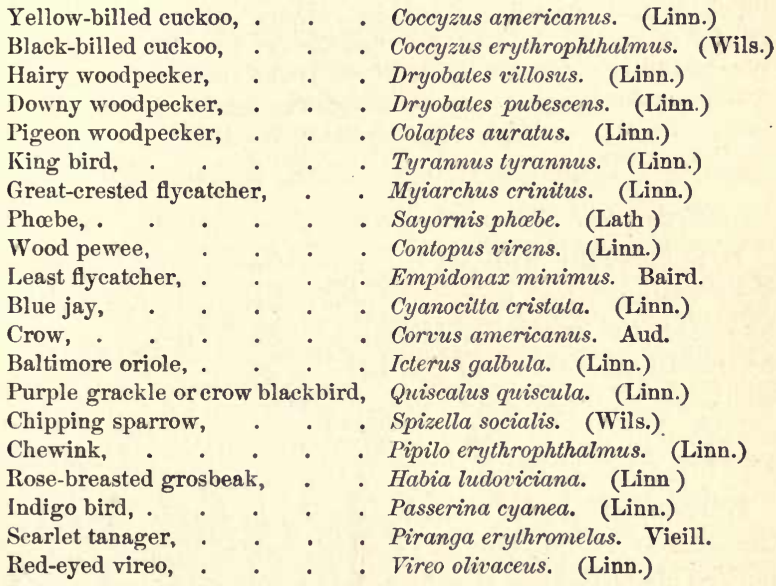

* Townend Glover, first entomologist of the United States Department of Agricultnre, wrote in 1871: "Insectivorous birds are the best allies of the farmer, and were they all destroyed there is little doubt that it would be almost impossible to raise certain crops." (Report of the United States Commissioner of Agriculture, 1871, page 71.)

He also wrote: "A knowledge of their nature and habits is of as mach importance to the farmer and fruit culturist as is the science of entomology." (Report of the United States Commissioner of Agriculture, 1865, page 36.)

Prof. C. V. Riley, late entomologist of the Department of Agriculture, has testified to the utility of birds as follows: "Few injurious insects can be well and fully considered without reference to their liability to be devonred by various natural enemies, and especially birds." (Report of the United States Commissioner of Agriculture, 1885, page 210.)

Prof. John B. Smith, State entomologist of New Jersey, in an address to the farmers of New Jersey, said: "Take care of yoúr natural friends! Among these the birds rank bighest." ("Insecticides, and how to apply them," seventeenth annual report of the New Jersey State Board of Agriculture, 1889-90, pages 294, 295.) 
Yellow-throated vireo,. . . Vireo flavifrons. Vieill.

White-eyed vireo, . . . Vireo noveboracensis. (Gmel.)

Black-and-white warbler, . . Mniotilta varia. (Linn.)

Yellow warbler, . . . . Dendroica astiva. (Gmel.)

Chestnut-sided warbler, . . Dendroica pensylvanica. (Linn.)

Black-throated green warbler, . Dendroica virens. (Gmel.)

Oven bird, . . . . . Seiurus aurocapillus. (Linn.)

Maryland yellow-throated war-

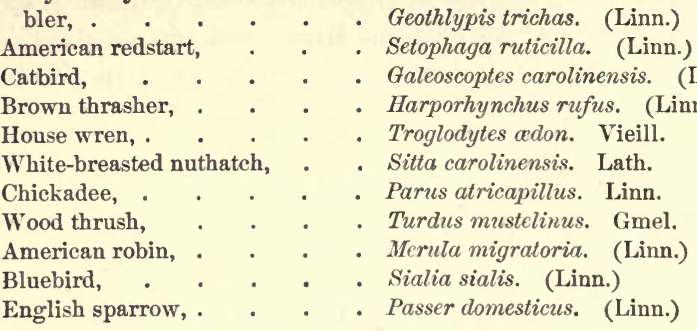

Birds which feed on the Larve, Pupce and Imagoes.

It is generally believed by entomologists (judging from their writings) that hairy caterpillars have a certain immunity from the attacks of birds. In Europe this appears to be true to some extent of the larvæ of the gypsy moth. A writer in the "Annales de l'Institut Horticole de Fromont" says that in twenty years of observation he has not seen a bird bring one of the caterpillars to its young.*

Keppen, writing of the gypsy moth in Russia, says that the cuckoo is the only bird which takes them. Grimm noticed about Saratov that birds had completely forsaken the places where the caterpillars were usually numerous. This is said to have taken place also in the district of Kirsanov in the province of Tambov. $\dagger$ Grimm thinks this is owing to

" "Annales de l'Institut Horticole de Fromont," Vol. 5, page 311, Paris, 1833.

+ This does not agree with the experience of the forest anthorities in Bavaria during the recent invasion occasioned by the sprnce moth or "nnn" (Liparis monasha), 1889-91. This insect is closely allied to the gypsy moth and was formerly placed in the same genus. The caterpillars are provided with hairs similar to those of the gypsy caterpillars. The flight of starlings collected in one locality alone was credibly estimated at 10,000, all bnsy feeding on the caterpillars, chrysalides and moths, not to mention enormons fights of titmice and finches similarly engaged. The attraction of starlings to such centres became so great that market-gardeners felt their absence serionsly in distant parts of the country.

" Protection of Woodlands," by Hermann Furst, English edition; translated by John Nisbet, 1893, page 126. 
the fact that the body of the caterpillar is covered with small hairs, which become detached, and, piercing somewhat the skin of persons and animals, cause great itching.*

I have found very little evidence in the writings of European authors that birds other than the cuckoo and the titmice destroy the larvæ of the gypsy moth, although several species are said to destroy the eggs. $\dagger$ In this country, however, the reverse appears to be true. Few birds seem to eat the eggs, while many attack all other forms of the moth. In the season of $1891 \mathrm{my}$ attention was first called to the fact that certain birds were devouring large numbers of the larvæ. The accuracy of the reports received was soon verified by my own observations. Several species of birds were seen busily engaged in eating the insects wherever they were numerous. The inspectors were directed to record all observations made on birds which were feeding on the caterpillars.

Unfortunately, there were at that time only eleven observers on the force who could accurately identify birds in the field. These men were also perfectly familiar with the different forms of the moth. The notes made by them indicated that thirteen species of birds were feeding on the moth in one or more of its forms. The observations begun in 1891 have been continued during a part of each succeeding summer. Although as a rule they have been made incidentally in connection with the work in the field, one or more men have been detailed at times to disprove or confirm reports that have been made, or to watch some particular species of bird, so that some points in regard to its value as a moth destroyer might be settled. Where the caterpillars are very numerous, they cluster in masses on trees. Certain birds habitually visit these swarms either to eat the caterpillars or to take them as food to their young. If the observer remained quietly at his post, he was able to view them at a distance of a few feet or yards. Each observer was

* Translated from "Injnrious Insects" by Theodore Keppen, 3d Vol., special part.

+ In a recent letter Dr. Ebermayer of Munich names starlings, crows, titmice and tree creepers among the enemies of the gypsy moth but does not say what form of the moth they destroy. 
supplied with an opera glass, by means of which he could determine at a greater distance whether or not the birds were feeding on the caterpillars of the gypsy moth. Few birds were shot and few dissections made as compared with the number of birds reported as feeding on the caterpillars. This might serve to discredit the accuracy of the observations, were they not made at close range, and when the caterpillars were large enough to be readily identified. No birds were shot except where it was absolutely necessary to determine whether it was the gypsy moth caterpillar or some other upon which they were feeding. No observations were accepted as conclusive unless the observer was known to be careful in his work and conservative in his statements, or unless ample corroborative evidence was obtained. While there is some possibility of error in field observations, there is also a possibility of error in stomach examinations. Digestion in birds is so rapid that it is impossible to specifically identify some portions of their insect food unless the bird is killed within a very few minutes after the insects are eaten. When birds are feeding on larvæ, a large proportion of the stomach contents is often unrecognizable.*

Birds do not always swallow hairy caterpillars whole. In many cases they tear them open, eating only some of the internal parts which are unrecognizable upon dissection of the stomach. Other birds appear to kill wantonly many caterpillars and moths. Woodpeckers, jays and chickadees have been seen to snap them up and then drop them to the ground, sometimes uninjured but often mortally hurt. Sparrows and other birds have been seen to kill many moths which they do not eat.

\section{The Most Useful Birds.}

The records of the observations made on birds comprise one hundred and fifty typewritten pages. A glance over these pages shows that the greater number of observations have been made on less than a dozen species, and indicates that these are probably the birds most useful in destroying

* Considering the possibility of error in records made from either observation or dissection, it would seem that one should be used as a supplement to and a check on the other. 
the gypsy moth. It cannot be stated with certainty which species is of most value in this respect, as the birds observed vary both in numbers and usefulness with the locality and season. From observations made eleven species are known to be very useful. In the apparent order of their usefulness they are: yellow-billed cuckoo, black-billed cuckoo, Baltimore oriole, catbird, chickadee, blue jay, chipping sparrow, robin, red-eyed vireo, yellow-throated vireo and crow.

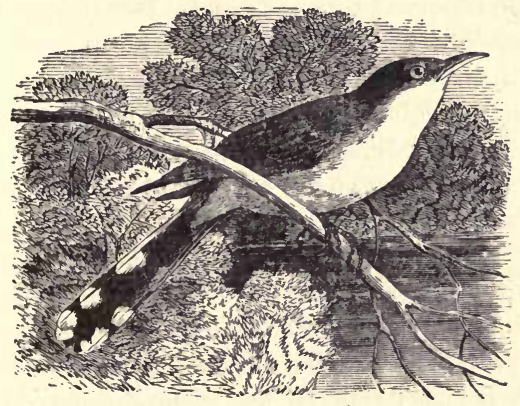

FIG. 29. Yellow-billed cuckoo.

The cuckoo is the only bird that I have found mentioned in European literature as feeding commonly on the larvæ of the gypsy moth. Altum says the cuckoo is efficient especially in local ravages of the moth. ${ }^{*}$ Appearances indicate that the cuckoos lead the rest of the American birds in destroying the gypsy moth. Yet it must be considered that as these cuckoos are comparatively large birds, seeking by preference the larger larvæ, their feeding is readily observed. As the larvæ are usually swallowed whole by the cuckoo, their remains are readily recognized in the dissected stomach. It is difficult to identify with certainty the smaller larvæ when they are eaten by small birds. If these small birds consume the smaller larvæ in numbers equal to those of the larger ones eaten by the cuckoo, they are more beneficial, as the destruction of the larva when young will prevent the injury they might do to vegetation before the cuckoo would be likely to attack them. 
Yellow-billed Cuckoo. - In 1891 yellow-billed cuckoos were observed in several of the worst infested localities, where they remained nearly all day, feeding on the gypsy larvæ or carrying them from time to time to their young. This habit of feeding on hairy larvæ seems to be quite constant with the cuckoos. They seem to prefer the gypsy larvæ even to the pupæ.

Mr. F. H. Mosher, an inspector in the employ of the Board, who observed this species in 1895, says that it will go to a bunch of pupæ and search for larvæ, pulling out the nolts or casts, and will take pupæ only when larvæ are not to be found. This was noticed in different individuals of this species and in different localities. Some of the cuckoos would take no pupæ at all, but would continue their search for larvæ until they found them.

That the yellow-billed cuckoos feed their young quite constantly on these larvie is evident from the observations made. The stomach of one young cuckoo when examined contained a number of partly digested larvæ and the heads of sixteen others. Ninety per cent. of the stomach contents consisted of these larval remains. When the young birds were able to fly, the parents would lead them to the worst infested spots and feed them frequently with caterpillars.

Mr. C. E. Bailey, an agent of the Board and a field ornithologist of much experience, says that the yellow-billed cuckoo is very fond of the gypsy larvæ, sometimes eating nine or ten full-grown ones in less than a half hour. He also states that he has observed that it eats more caterpillars than the black-billed cuckoo.

Black-billed Cuckoo. - The black-billed cuckoo is probably nearly if not quite as useful as its congener in destroying hairy caterpillars, and appears to be almost equally destructive to the gypsy moth larvæ. From personal observation, as well as from reports of the observations of others, I am led to believe that this bird does not feed as rapidly as the yellow-billed cuckoo, and spends more time in beating the caterpillars, perhaps for the purpose of killing them, or possibly to divest them of their hairs before eating them. In the end, however, the caterpillar is swallowed whole. Like the yellow-billed cuckoo, this species feeds the caterpillars to its young. 
Neither species of the cuckoo is very numerous in the infested region, but both are fairly common and both are attracted by the gypsy moth to badly infested orchards or to the edges of badly infested woodland. Five cuckoos have been seen at a time in an infested tree. In some infested places they may be found at times in considerable numbers, and the number of larvæ they destroy is astonishing. They frequently take larvæ from under the burlaps.

Baltimore Oriole. - The oriole, like the cuckoo, is a wellknown destroyer of the tent caterpillar (Clisiocampa Americana) and other hairy larvæ. Several observers have seen this bird taking gypsy larvæ from the burlaps. In 1894 in an orchard in Winchester four orioles were seen to follow along the rows of trees, flitting from burlap to burlap, and taking the larvæ from under the cloth. The birds would hang to the burlap while turning up the edges and running their bills beneath. The young orioles frequently enjoy a gypsy moth diet, and the adult birds have been seen day after day feeding their young with these insects.

Only three orioles' stomachs have been dissected. One contained four nearly full-grown gypsy moth larvæ, another two, and one was empty. These dissections probably did not fairly indicate the value of these birds as caterpillar destroyers, as the orioles have been seen to kill caterpillars of which they ate only a small portion.

Catbird. - Where the gypsy moth has penetrated into thickets, the catbird feeds on the larvæ, and, as the season advances, destroys many of the pupæ, taking both these forms of the moth to its young. That this habit is quite constant is evident, as the catbird was seen feeding on the larvæ in 1891, and almost daily through a considerable portion of the sum-

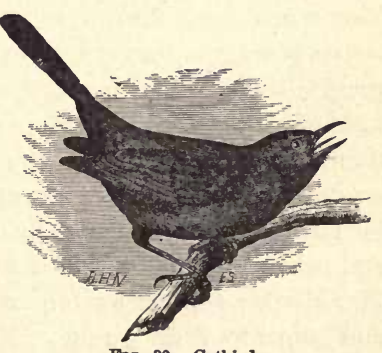

Frg. 30. Catbird. mer of 1895 by observers in several different towns. The catbird has been seen to take larvæ of all sizes to its young. It is one of the birds that frequent badly infested localities. 
Chickadee. - The chickadee, though a small bird, feeds quite constantly on the gypsy moth larvæ, "skinning" or

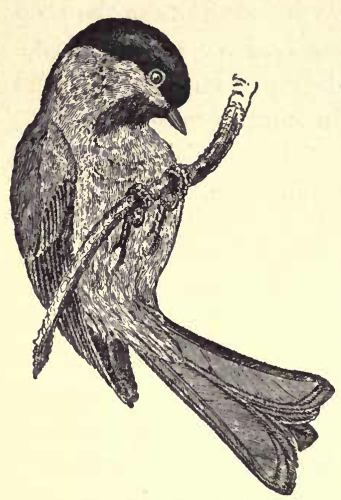

FIG. 31. Chickadee.

tearing to pieces the larger larvæ which it cannot swallow. On capturing a large specimen the bird usually stands on the caterpillar, striking it with its bill until the skin is torn open, when it proceeds to eat the vital parts. Sometimes the chickadee eats nearly all of a large larva. This bird is also fond of the pupæ, usually breaking them open and eating a small portion of the body tissues and juices. Chickadees have been seen to feed on the female moths.

Blue Jay. - In infested woodlands or in orchards near its favorite haunts the blue jay is most useful as a caterpillar hunter. Mr. M. J. Flood, formerly in the employ of the Board, who was stationed in 1891 at a badly infested locality in Arlington, where he watched the gypsy moth larvæ for forty-eight hours, reported that he saw hundreds of the larvæ picked up by this bird. During the day he saw sixteen blue jays eating the larvæ and pupæ, which he could see very distinctly as the birds held them in their bills. These birds are known to be regular visitors to badly infested trees, yet they are so wary that it is difficult to observe them closely. The prying nature of the blue jay stands it in good stead in searching out hidden larvæ. It pecks them from the erevices of the bark or from under the bark on dead limbs, and searehes every hole. It frequently visits burlaps on infested trees, thrusting its bill under the burlap and raising it enough to draw out the hidden larvæ beneath. Mr. Mosher reports having seen the blue jays feeding larvæ and pupæ to their young. The jays have been frequently seen carrying the larvæ in their beaks, probably with the intention of feeding them to their young. Sometimes they pinch or hammer the larvæ, killing them in wanton sport or 
maiming them and dropping them upon the ground. This habit of killing and dropping larvæ has been observed elsewhere.*

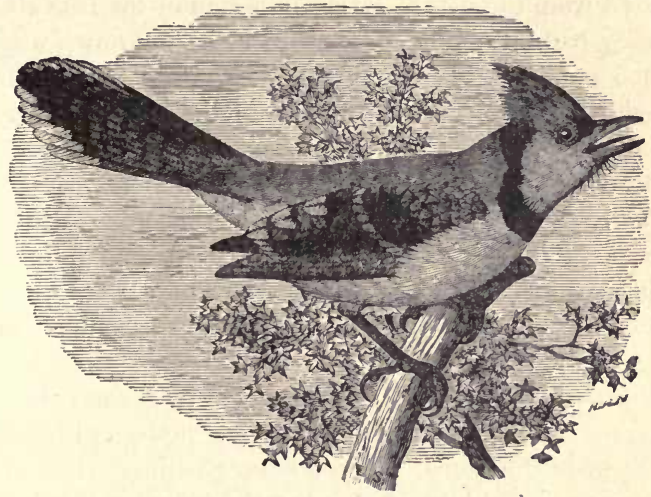

Fia. 32 Blue jay.

Chipping Sparrow. - Though the chipping sparrow does not rank high among insectivorous birds, and feeds largely upon seeds during certain seasons of the year, it nevertheless destroys very many insects, especially lepidopterous larvæ, which are injurious to trees and garden plants. It is often seen chasing flying gypsy moths. It appears to be fond of gypsy moth caterpillars, and I have frequently observed it in badly infested spots catching

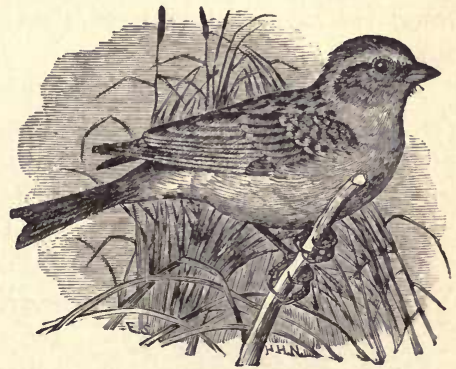

FIG. 33. Chipping aparrow. and killing large larvæ. A young chipping sparrow shot and dissected contained a nearly full-grown larva of the gypsy moth, which had been swallowed head first.

In 1891 Mr. E. P. Felt confined (for experimental pur-

* Dr. C. M. Weed in the Ninth Annnal Report of the Ohio Agricultural Experiment Station, 1890, p. Iv. 
poses) a number of gypsy moth caterpillars in nets on the branches of apple trees. It was found almost impossible to complete the experiments, as many of the caterpillars disappeared from the nets. An examination of the nets showed that they had been broken open in some unknown way. I watched one of the nets and saw a chipping sparrow break through the netting and secure one of the larger larvæ. As these birds were frequently seen about the nets, it is probable that they were responsible for the abduction of many larvæ which disappeared. Mr. Felt says in his notes that sixty per cent. of the larvæ used in the experiments were taken by birds which broke into the nets. There were very few of these larvæ in the vicinity, except those confined in the nets.

Robin. - The robin has been reported by several observers as feeding upon the larvæ of the gypsy moth, and by one as feeding upon the pupæ. One observer believes the robin to be the most useful bird of all; but the notes on this bird are lacking in detail. 'I can say nothing from personal observation in regard to its habits of feeding on the gypsy moth, except that it has been often seen feeding on the ground about apple trees frequented by the gypsy moth, or upon the lower branches of such trees, also in trees in badly infested woodland.

Red-eyed Vireo. - This bird has been seen by many observers to feed on the gypsy moth larvæ. It probably feeds its young quite regularly on the larvæ. The vireos are known

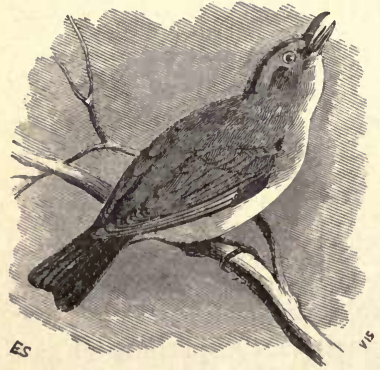

Fra. 34. Red-eyed vireo. to be caterpillar hunters, but are believed to prefer smoothskinned species. They, however, frequently break open the nests of the tent caterpillar to get at the hairy larvæ within. This bird usually places the gypsy moth larva on a limb, and pulling it to pieces eats the pieces separately; yet it has been seen often to eat the larva whole and also to feed it alive to the young birds. 
Yellow-throated Vireo. - Mr. C. E. Wood, an inspector in the employ of the Board, writes that he saw a yellowthroated vireo take a large larva, alight on a limb with it, and, placing one foot on it, peck its head off and give the body to a young full-fledged bird which was waiting to be fed. The young bird took the body of the larva, placed it on the limb under one foot, and, pecking off a few small pieces swallowed the rest whole. The yellow-throated vireo has been seen by several observers to catch and eat the larvæ, and is probably nearly as useful in this respect as the red-eyed vireo.

Crow. - The crows in the infested region are so shy that it is difficult to get near enough to them to observe carefully their feeding habits. It was not until 1895 that they were actually seen to feed upon the gypsy moth, though it had been noted that they sometimes frequented badly infested places. They had also been seen to take their young to infested localities, where they were apparently feeding them with the larvæ or pupæ. In the summer of 1895 the probability of their feeding upon the gypsy moth was made a certainty by the observations of Mr. Mosher, whose work in observing birds has been done with the most painstaking and patient care.

The prying, inquisitive habits of the family are well illustrated by the crow when searching for gypsy moth larvæ and pupæ. Dead bark is torn off from branches, clumps of bushes are penetrated, and rubbish on the ground is overhauled by the bird in its search for the insects. Mr. Mosher watched a crow which alighted within thirty feet of him on a branch above his head, and fed upon the gypsy larvæ without noticing his presence. By using an opera glass all the motions of the crow in searching for and capturing its prey were readily seen. The crows will alight upon the branches and search the under sides, where the gypsy moth caterpillars crawl or cluster. They are apparently quite fond of the pupæ, and will also eat the female moths. The young crows kept at the insectary were fed almost exclusively for two or three days upon these insects. Although they ate them at first with avidity, they soon refused them and would not touch them so long- as other food could be obtained; neither 
would they capture and eat the larvæ. When the first moths were placed in the cage, they caught and ate them eagerly. The larger crow ate eighty-three and the smaller thirty-three. On the second trial, crow number one ate fifty-eight moths and crow number two twenty-three, thus together destroying eighty-one. On the third trial they would have none of them. At first, the birds, being apparently quite hungry, devoured them whole. Later they rejected the thorax with the wings and other appendages, and took the soft abdomens only. The birds were at first so eager for the moths that they would snatch them from each other. A curious fact about their eating was that they swallowed the moths hind end first, while grasshoppers were always swallowed head first. It would appear from this limited experiment that the crows soon became tired of a gypsy moth diet. It is quite probable that unconfined crows would tire of the moth as food were no other food available. Yet from the frequency of the crow's visits to the infested spots, the size and capacity of the stomach, and the number of different forms of the moth eaten, it may be inferred that this species is quite useful in destroying the gypsy moth.

\section{Other Useful Birds.}

Bluebird. - In 1891 the bluebird was often seen feeding on the larvæ and pupæ of the gypsy moth, but this was not noticed in the ensuing years, and in 1895 no bluebirds were seen during the summer in the infested region. When bluebirds breed in or near an infested orchard, they will no doubt destroy many of these insects.

Warblers. - Although certain warblers have been seen occasionally to capture many of the gypsy caterpillars and moths, it is difficult to determine by observation or dissection how useful they are in this respect. Owing to their activity, and the small size of the larvæ usually taken by them, it is often impossible to learn the species or the number of insects which they eat. The great vernal flights of warblers through the infested region occur in May, at a time when the larvæ of the gypsy moth are very small, and are either feeding or resting upon or underneath the leaves. The birds migrating northward restlessly move from tree to tree, and 
accurate observation of their feeding habits is then difficult. As warblers glean much of their food from the twigs and foliage, it is highly probable that the mortality among the small caterpillars is partly caused by these birds.

Observations on the feeding of the warblers were made when the spring migrants had gone north and the summer residents were breeding. The warblers which breed in the infested districts do not appear to feed habitually on the gypsy moth. Both observations and dissections indicate that most of them prefer the small, smooth, geometrid larvæ. All of them appear to have a particular fondness for the cankerworms, and a few eat the tent caterpillar. Yet some of the observations made show that certain species of warblers destroy many of the larger gypsy caterpillars. These species also destroy moths, both male and female. Mr. Bailey saw a yellow warbler take two large gypsy moth larvæ, tear them open and eat out the body contents, leaving the skins upon the tree. He saw a black-and-white creeping warbler just from the nest capture and eat seventeen gypsy moth caterpillars. All of them were pecked open.

Mr. I. C. Green, a former employee of the Board, considers the redstart the most useful of all birds in destroying the gypsy moth, but does not give the details of his observations. This species has been seen by other observers to feed especially on the male moth, which it often captures in flight.

The oven bird is mentioned by several observers as feeding on larvæ and moths. The other warblers in the list have seldom been seen to take any form of the moth.

Sparrows. - Though the towhee bunting or chewink was not seen preying on the gypsy moth prior to 1895 , the observations of Mr. Mosher give ample proof of its usefulness in this respect, especially in woodland or in sproutland where it is a common bird. It eats readily all forms of the moth excepting the eggs, and this habit has been frequently observed. The rose-breasted grosbeak and indigo bird occasionally eat the larvæ.

Flycatchers. - All the flycatchers which breed in the district are given in the list of birds which destroy the moth. Though most of them kill a great many moths, they probably are not as useful as most other birds on the list, as they 
pursue mainly the quick-flying male moths. Experience in trapping male moths has shown that ordinarily their capture has little effect on the number of fertile egg-clusters in a badly infested spot. This is partly because most of the male moths find their mates close at hand, and so fertilize females before taking any extended flight; and partly because the male being polygamous, each one that escapes the birds may fertilize several females. Yet as very many of the males are caught by flycatchers, this may account for the scarcity of males and the number of infertile egg-clusters sometimes found in badly infested localities. As many males emerge before the females, and as the moth lives but a few days

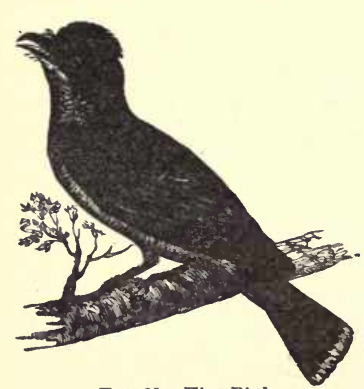

FIG. 35. King Bird. in the perfect form, most of the males usually die before the females all emerge, and males are comparatively scarce late in the season even in a badly infested locality. If at this time the flycatchers and their young frequent an infested locality, they still further reduce the number of surviving male moths. This scarcity of male moths late in the season, which is in part caused by the flycatchers and other birds, may prevent the fertilization at that time of many eggs. Yet the good done in this way by the flycatchers may be counteracted by their destruction of hymenopterous parasites of the moth. Of these parasites the ichneumon flies appear to be the most useful, yet even they have not proved at all effectual in reducing the numbers of the gypsy moth, even under the most favorable circumstances. Mr. Kirkland has seen a wood pewee dart down and eapture an ichneumon fly, apparently Theronia melanocephala. This fly sometimes attacks gypsy caterpillars, and has been frequently seen searching over trees infested by them. Occasionally a flycatcher will pick up a spinning larva as it hangs swaying in the wind by its thread from the tree, but there seems to be no reason to believe that this is a habit. Though the flycatchers confine their feeding on this insect mostly to the male moths, they 
frequently take females, and doubtless destroy many in the aggregate during a season. The king bird appears to be the most useful flycatcher in this respect, and has been seen to eat very many of the females. This bird may thus render efficient service to the farmer by preventing the deposit of many thousands of fertilized eggs. Its comparative value as a gypsy moth destroyer depends largely upon the number of female moths that it kills.

Woodpeckers. - Of these most useful birds the three resident species have all been seen feeding upon the caterpillars or pupæ of the moth.

The flicker has also been seen carrying caterpillars to its young. Mr. W. C. Colt, an inspector in the employ of the Board, says that he watched a female flicker take nearly fullgrown larvæ to its young. The bird made regular trips to its nest at intervals of from three to five minutes. The downy woodpecker was observed by Mr. Bailey to eat a few caterpillars, and to peck many others and afterward drop them from the tree to the ground.

From what is known of the habits of woodpeckers, it was expected that they would be found to feed on the gypsy moth pupæ. The downy and hairy woodpeckers are known to feed in winter to a greater or less extent on the hibernating pupæ of many insects. Yet the hairy woodpecker only has been observed to peck into the pupæ of the gypsy moth. This bird is not at all common in the district, but both old and young birds have been seen feeding upon the pupæ by Mr. Mosher.

There is much difference of opinion among observers as to the comparative usefulness of certain species of birds in destroying the gypsy moth. This is to be expected, as each is prone to regard his own observations as conclusive in respect to all the species which he observes. In drawing conclusions from observations on the food of birds a great deal must be allowed for their individual preferences and acquired tastes. For example: several observers report the red-eyed and yellow-throated vireos as feeding eagerly on gypsy moth caterpillars. Mr. Henry Shaw notes that in one infested locality the red-eyes appeared to be living on them, eating them constantly. Mr. C. E. Wood bas seen 
the yellow-throat go from burlap to burlap, drawing out the larvæ from beneath. Yet Mr. Bailey reports that he has seen individuals of these species search a tree over for hairless larvæ before they would eat one of the caterpillars of the gypsy moth, of which there were thousands on the tree. I do not question the correctness of any of these observations. Certain fowls or flocks of fowls in the infested region ate the caterpillars with avidity, while other individuals or flocks would not touch them. The same individual preference was noticed among toads.

It appears that the presence of a great number of hairless larvæ has the indirect effect of lessening the number of gypsy moth caterpillars destroyed by birds. When cankerworms are plentiful, the birds eat comparatively few of the hairy caterpillars until the canker-worms have disappeared. Although many gypsy moth caterpillars were eaten very early in the season of 1895 by the orioles, vireos and other birds, these caterpillars received very little attention later, when the growing canker-worms became more noticeable. Most of the birds then devoted their attention to the cankerworms. About June 10, when the canker-worms had mostly disappeared, the birds again attacked the gypsy moth larvæ and continued to fecd upon them for some time. Their appetites for these insects appeared finally to wane, having been apparently cloyed by an excessive diet of hairy caterpillars. It has been noticed that sometimes birds tire of a monotonous diet, and that they will even cease to feed for a time upon a favorite insect prey. This may partially account for the fact mentioned by Grimm, that the birds forsook the Russian forest which had been devastated by the gypsy moth. Yet this would not be a sufficient reason to account for a continued absence, as birds often return to feast again after a change of diet. But the lack of shade, water and green food, all of which together make a region unfit for the habitation of wood birds, may have driven them for a time from the devastated forest. In the infested district in Massachusetts forest birds will not remain constantly through the hot summer days in woodland which has been stripped by the gypsy moth, but will betake themselves to shaded glades and brooksides, making frequent sallies into the bare, infested woods to feed on the pest. 


\section{Birds attracted to Infested Localities.}

The attraction of birds to infested localities and the numbers of gypsy moths destroyed by them there may be best realized by visiting a badly infested spot at a season when all forms of the insect are to be found upon the trees. At such a time the birds which feed upon the moth may be observed to the best advantage. For this purpose one should rise before daybreak and be on the ground before sunrise, as many birds are in active pursuit of insects at that time.

Upon approaching at dawn a badly infested spot in woodland, the stroke of a flitting wing, the rustle of dead leaves, an occasional shower of scattering dewdrops, a chirp or alarm note heard here and there, all denote the presence of birds in the woods. Their forms are still hidden or only dimly visible in the uncertain, growing morning light. The infested spot has the appearance of an opening or clearing. We emerge in what appears to be a dead forest. The trees wear no foliage. The pines, oaks, birches, poplars and wild cherries are stripped and bare. The few leaves which still hang upon the young maples and walnuts only accentuate the general nakedness. There are sounds, not of the wind or storm, and yet akin to these, pervading the woods, - sounds as of dry leaves stirred by a rising breeze, mingled with those of the fine pattering raindrops of sudden showers. These are caused by the hosts of gypsy caterpillars which have devastated the woods. The sound of their feeding is in the air, their excreta rattle like raindrops on the dead leaves. As the rising sun throws level beams across the hillside, the tracery of the bare, interlacing branches and twigs is reproduced upon the barren upright rocks of a rugged ledge. There is little or no summer green, except the moss on the stones along the stream, and a few small shrubs which have not yet been wholly stripped. Upon the bare trees, especially those near the edges of the defoliated tract, hundreds of thousands of hairy caterpillars swarm. Many of them are now hurrying down the trunks and crawling away to places of concealment, seeking shelter from the sun's rays. Many more, having been travelling perhaps throughout the night 
in search of food, are still crawling in search of it, either on trees or upon the ground. Masses or swarms of caterpillars are clustered in every sheltered place; thousands are feeding on the leaves of trees near the borders of the desolated area. The pupæ hang in bunches under the limbs and in the crevices of the larger trees. Many female moths are just emerging from the chrysalides, and others are drying their wings. This is the appearance presented by a woodland colony of the gypsy moth on a July morning.

Seated here, somewhat screened by the remaining herbage on the borders of the stripped tract, we may observe the struggle for existence between the moth and other forms of life. From the harsh semi-conversational notes heard, first solemn and wary, then growing animated and cheerful, we judge that a crow is feeding its fledged young in the vicinity. Soon the crows are seen flying near. They alight about forty yards away by the brook, and the old bird, going to a clump of bushes, feeds her young time after time with something she takes from among the stems. With a glass we can see her take the larvæ and pupæ and put them into the open beaks of her eager young. The old bird now finds a female moth and passes it to one of the brood. Soon becoming alarmed by some morement on our part, they fly away to some pines, where in the high branches they resume their feeding. An examination of the bushes they have just left shows that the old crow has taken nearly all the larvæ, pupæ and moths from the clump, leaving only a few moult skins and spun threads to mark the recent existence of the moth there.

A family of chickadees now appear. Flitting about among the trees, they begin to eatch and eat the larvæ. One picks up a large caterpillar, places both feet upon it and eats out the viscera, leaving the head and skin. Another pecks a caterpillar into small pieces and apparently eats most of the pieces. Number one now flies some ten yaris with a large larva which it has just seized. Alighting on a convenient limb, the bird hammers its prey awhile and finally drops it, mutilated and dying, to the ground. Another bird tears a female moth in pieces, eating only the contents of the abdomen. All devote more or less time to killing the pupæ, eat- 
ing only a small portion of each. Thus with cheery chirp and call they flit about through the woods, killing and eating as they go. A red-eyed vireo alights on a branch within six feet of us, and, picking three half-grown larvæ from the leaves, swallows them head first and flies away towards the brook. Something is scratching in the leaves a few yards away. With the glass we can see four towhees scratching and digging like chickens. They are searching for the pupæ which they greedily eat. If a male moth flies low overhead, one of these birds will leap from the ground and capture it. They search about upon the ground and among the small shrubs and seize the newly emerged females, beating them on the ground and finally swallowing them. A lone cuckoo whose dismal notes we have just heard now comes down from a near-by tree, alights on a small sapling and proceeds to breakfast. It picks off fourteen caterpillars, one by one, hammers the larger ones a little and then swallows them whole. A family of brown thrushes is busy by the brook. With the glass one of them ean be plainly seen in the act of taking pupæ from the stem of one of the larger bushes. A family of five black-and-white creeping warblers come in sight. They run and climb about on the trunks and branches of the stripped trees, picking up the smaller larvæ of the gypsy moth and other insects, and now and then darting into the air after flying male moths or pecking at the females. These females they rarely eat and sometimes do not materially injure, though they knock many of them off the trees. One female which falls is snapped up by a towhee which springs from the ground to take it in the air. A single Baltimore oriole flies in, looks about as if out of its element, catches several larvæ and disappears in the direction of the highway. The harsh cries of the blue jays have been ringing for some time through the woods. One at a time, five jays pass among the trees. With the glass we can see two of them taking the large larvæ from a tree trunk. They fly with them to branches or to the ground, and eat them there. You can plainly see the jays as they take the caterpillars in their bills, but they are so shy that they will not remain long within our range of vision. Now the chickadees are back again. One of them takes twelve pupæ in 
succession, carries each one to a limb, pecks it open and drops it upon the ground.

As the sun grows warmer the number of male moths in zigzag flight increases. It is now six o'clock, and the snapping of bills heard on all sides tells us that the flycatchers are in the woods. Seven king birds are hunting the male moths. They catch scores of them, and occasionally they pick off a female or capture a falling larva. One of these birds comes in over the tree tops and hangs suspended on hovering wings. Suddenly dropping toward the earth, it picks up a fluttering female moth, and, flying to a limb, with a single snap of the bill divests the insect of both wings and swallows it. The bird then looks to right and left, flies from its perch, eatches a male moth in mid-air, returns to its perch, swallows the moth and calls cheerily to its mate. The other king birds are all busy in like manner. As they seem to have settled down to remain for some time, we will keep tally of such moths as we can actually see them take at close range. Several chipping sparrows now appear hopping about on the ground. Now and then one picks up a half-grown larva. They are pecking and eating the female moths. They also chase and capture a low-flying male moth. Two catbirds are searching the thicket along the brook. They are taking pupæ from the ground and dead leaves and also from the leaves and twigs of the low bushes, but we can see this only occasionally, as most of the time the birds are hidden from view. The crows went when the king birds came, but the flycatchers are still hawking about. As the reflected heat of the summer sun is radiated from the earth, the newly emerged male moths gain life and vigor from its warnth, and fly in large numbers through the woods. Three least flycatchers, two phœbes and several wood pewees are in sight and pursue the moths most of the time.

At half-past nine the king birds have disappeared. Our tally sheet shows that we have seen them take seventy-nine male and twenty-four female moths. They were watehed only a portion of the time, but were feeding quite constantly. It is safe to say that between 6.15 and 9.30 they have killed two hundred and fifty male moths. The number of females taken cannot be so readily estimated. 
One chipping sparrow has been seen to take five females; six least flycatchers, thirty-one males and nine females; two wood pewees, twenty-two males and seven females. These birds were most of the time at a considerable distance from the point of observation, and it was only now and then when they approached quite near that their actions could be distinctly seen. The phœbe appears to have taken male moths only. The towhees took eighteen moths, male and female, while on the ground. They then went into the trees, and while there moved on and were lost to view. A male yellow warbler appeared and was seen to eat a larva and a female moth. The oriole came again, taking four larvæ. Redstarts, creeping warblers and chickadees come and go, feeding on the moth, but it is impossible to follow them and also watch the other birds. It is now eleven o'clock. The birds have nearly all left the hot and barren land of the defoliated hillside, and are resting or feeding quietly in the shade among the leaves, where they cannot be so readily watched.

Let us now go to an infested orchard a mile away, where not all the trees have been stripped by the caterpillars. Here we find some species of birds represented that were seen in the morning in the woods, but the catbird, the towhee, the creepers, the redstart, the wood pewee and the crow are absent. Yet we find here the robin, bluebird, yellowthroated vireo, flicker and house wren, all of which feed more or less upon the moth. As the afternoon advances, seven black-billed and four yellow-billed cuckoos are seen feeding on the larvæ and pupæ. There are yellow warblers, chickadees, half a dozen orioles, several chipping sparrows and other birds in the orchard. The few infested orchard trees appear to be much better protected by birds than the woodland, and the moth has not made so much progress here.

In the waning summer afternoon we return to the woods, where, as the shadows lengthen, the birds again are busy. The king birds and other flycatchers and the chickadees are especially diligent. The king birds are now eating many of the female moths. A solitary scarlet tanager hammers a female moth upon a branch, shearing off its wings and then eating its abdomen. In the advancing shadows of the 
approaching night many sparrows are seen hopping along the ground, where they find their evening meal. Although the birds are quite silent and it is impossible to make out the species as they move among the shadows, the white female moths can be plainly seen as the birds pick them up in their bills. Some fifty birds are seen busily feeding on the moth as we walk through the stripped woodland once more before leaving for the night.*

\section{Birds which destroy the Various Forms of the Moth.}

The birds which have been found preying upon the gypsy moth may be classified as follows:-

Birds feeding on the larvæ - chickadee, downy woodpecker, wood thrush, yellow-billed cuckoo, black-billed cuckoo, yellow warbler, rose-breasted grosbeak, scarlet tanager, black-and-white creeping warbler, red-eyed vireo, chipping sparrow, oriole, blue jay, yellow-throated vireo, crow, catbird, black-throated green warbler, redstart, wood pewee, robin, English sparrow, least flycatcher, wren, Maryland yellow-throat, chestnut-sided warbler, brown thrush, purple grackle, oven bird, white-eyed vireo, bluebird, flicker.

Birds feeding on the pupæ-yellow-billed cuckoo, blackbilled cuckoo, chickadee, yellow-throated vireo, towhee, hairy woodpecker, scarlet tanager, crow, catbird, oriole, blue jay, phœbe, English sparrow, brown thrush, king bird, wood pewee, bluebird, yellow warbler.

Birds feeding on the male moths - king bird, chickadee, oriole, redstart, yellow warbler, towhee, wood pewee, yellowthroated vireo, red-eyed vireo, great-crested flycatcher, blackand-white creeping warbler, least flycatcher, phœbe, brown thrush, oven bird, English sparrow, chipping sparrow, bluebird, indigo bird.

Birds feeding on the female moths - king bird, chickadee, towhee, great-crested flycatcher, phœbe, black-and-white creeping warbler, red-eyed vireo, crow.

Birds which possibly eat the eggs - downy woodpecker, chickadee, white-breasted nuthatch, blue jay, English sparrow.

* This description of the feeding of birds upon the gypsy moth is taken from notes made in the field. 


\section{Do Birds feed on the Eggs of the Moth?}

The field agents employed in the gypsy moth work have often noticed egg-clusters of the moth which appeared to have been pecked open by birds. A large number of eggclusters in the woods presented this appearance. Occasionally a bird was seen apparently pecking or eating the eggs. A single species which would feed on the eggs during all the winter months would be far more useful than many feeding on the eaterpillars during the summer. The eggs are so minute that a bird feeding on them would destroy in one day more individuals of the species than another could in one hundred days by feeding on the large caterpillars. It could find these eggs for nine months of the year, whereas the caterpillars are to be found for less than five months. The destruction of the eggs also prevents all injury to vegetation by the eaterpillars, while if the eggs are allowed to hatch, the caterpillars may do considerable damage before they are killed.

Wishing to do all possible toward protecting and fostering egg-eating birds, I determined to learn by accurate observation and dissection whether any of our native birds were destroying any considerable number of the eggs. For this purpose Mr. Bailey was requested to watch birds during a part of the winter of 1894-95. He selected several stations for observation, one in an orchard and others in the woods of the Middlesex Fells. The stations in the woods were chosen because of the abundance of the egg-clusters of the gypsy moth in the vicinity of each. The station in the orchard was surrounded by a high board fence, built to prevent interference from without, and several hundred egg-clusters of the gypsy moth were exposed on a single, tree. At all these stations bait was hung upon the trees for the purpose of attracting birds. Pieces of beef bone, suet, waste meat and grain were used to attract the different species. Crows, jays, nuthatches, titmice, kinglets, woodpeckers and tree creepers soon found the bait and made frequent visits to the infested trees.

The birds soon became so accustomed to the presence of the observer that they would feed within a few feet of him. 
The chickadees became so tame that they would sometimes alight upon his hat or coat sleeve. They would come like a flock of chickens to be fed, and some would feed on limbs within three feet of his face. Occasionally one would even take food from his hand. In a short time chickadees, nuthatches, creepers and downy woodpeckers became so tame that their feeding habits could be closely watched. Then observations were begun. A downy woodpecker was seen to strike an egg-cluster, scattering the eggs over the snow; yet the bird did not eat any of them. On close examination it was seen that the eggs as well as some of the bark on which they rested had been removed by the bird to get at the larva of some insect which happened to lie under this bark. The birds which came to the bait on the infested trees were there many times each day for about three months, yet the eggs were seldom molested. During all this time, however, the birds were feeding daily on eggs and other hibernating forms of other injurious insects, of which they destroyed large numbers. Thirty-eight visits were made in one afternoon by birds to one tree on which were sixty-five gypsy egg-clusters. The birds all came within three or four feet of these eggs; two of them even perched on egg-clusters, but they did not eat or even notice the eggs. Whether the result would have been the same had there been no meat for them to feed on, we cannot say ; yet, as they were constantly destroying the eggs of other insects, and as they occasionally pecked the egg-clusters of the gypsy moth but did not eat the eggs, it is fair to assume that they will not do so unless perhaps ' when driven to it by extreme hunger. As from observations made on birds in confinement it seemed probable that the hairs with which the egg-clusters are covered were disagreeable to the birds, an experiment was made to see if they would eat the eggs when the hair was removed. For this purpose some hundreds of eggs denuded of hair were glued upon a twig or stick in close proximity to the meat. The birds attacked the bait as usual, but if they ate any of the eggs it was not observed, although a few were knocked or pecked off. They would not eat the eggs even when they were cleaned of hair and distributed over the meat. No birds were actually seen to eat any of the 
eggs. One hundred and ninety-one egg-clusters were put upon a tree to which from ten to thirty chickadees came daily. Only seventeen of these clusters were pecked open. In each case the bird was seen in the act. The eggs were pecked off or taken in the beak and dropped to the ground. A few blows would generally suffice to knock off most of the eggs. Ten birds which were pecking at the eggs were shot, but in no case were either the eggs or any portions of them found in the stomach or intestines.

The observations showed that the egg-clusters were sometimes pecked off by nuthatches, either in a search for hibernating larvæ or pupæ hidden beneath the clusters, or to secure the larvæ of predaceous insects which bore into the egg-clusters and feed upon the eggs. No bird has actually been proved to feed upon the eggs except the English sparrow. One of these birds which was kept in confinement ate a few of these eggs from time to time when deprived of other food, but did not appear to relish them. It appears that very little can be expected from our native birds in this respect, unless they acquire a taste for the eggs. Yet many egg-clusters have been found which appear to have been pecked open or eaten by birds. The cause of this appearance was sought, and it was seen that squirrels and woodpeckers when climbing about on the trunks and branches of trees frequently tore off the eggs in running or climbing over them, so that they presented much the same appearance as those actually pecked into by birds. The gray and red squirrels were seen in the act, as well as several species of birds. Chickadees have frequently been seen by men employed in the woods to peck these egg-clusters, and several observations seemed to indicate that birds were feeding on them. The woodpeckers occasionally knocked them off the trees. Considering the prying, thieving nature of the jays, it is quite probable that they may peck into the egg-clusters and eat the eggs. Though the eggs are so tough that the smaller titmice might have difficulty in breaking their shells, the more powerful beak of the jay would easily accomplish this.

In Europe, woodpeckers, creepers and titmice are said to perform great service by eating the eggs of the gypsy moth. 
Altum says that in the year 1848 endless numbers of the larvæ of the gypsy moth had eaten every leaf from the trees of Count Wodzicki. In the fall all the trunks and branches were covered with the egg-clusters. Having recognized the uselessness of the attempt to remove them by hand, he finally gave up all his endeavors, and prepared to see his beautiful trees die. Toward winter numerous flocks of titmice and wrens came daily to the trees. The egg-clusters disappeared. In the spring twenty pairs of titmice nested in the place, and the caterpillar plague was noticeably reduced. In the year 1850 the birds had so cleared his trees that he saw them during the entire summer in their most beautiful verdure.*

Reaumur says that the larvæ of the gypsy moth were very numerous in 1826 on the lines of the Allee Verte at Brussels. Many of the trees were stripped, and if one-half the eggs which were deposited that year had hatched, scarcely a leaf would have been left the next season, either there or in the park, where the eggs were numerous also; yet two months afterward hardly one was to be seen. This destruction of the eggs he attributes to titmice, tree creepers and other small birds. $\uparrow$

\section{The Introduction of European Birds.}

If it is true that these European birds are so very useful in this respect, the comparative immunity of many European regions from the attacks of the gypsy moth may be due in a measure to their efforts. If such be the case, their introduction into Massachusetts may well be thoughtfully considered. If introduced into a new country these feathered egg hunters might thrive and multiply exceedingly, and if the eggs of the gypsy moth are to them a familiar food, they would probably seek these eggs here in preference to the unfamiliar insect eggs which they would find. Such birds might in this way prove as useful as a small army of men. Yet what compensation would they exact for this service?

* "Forstzoologie," Vol. II., page 324, 1880.

+ "An Introduction to Entomology," by Kirby and Spence, Philadelphia, 1846, page 152. 
When the introduction of any bird or other animal from a foreign country is proposed, great care should be exercised to study thoroughly all phases of the subject. Often, when such importations have been made without careful scientific investigation, they have proved very expensive mistakes. The importation of the rabbit into Australia, the mongoose into Jamaica, and the sparrow into America and Australia, are familiar examples. The English sparrow was introduced here for the express purpose of suppressing such native pests as the larvæ of the canker-worm moths. If previous to its introduction its habits had been carefully studied in Europe by a competent man appointed for the purpose by the United States government, its introduction might have been prevented. This exotic species, the value of which is doubted in its native home, was brought here to perform a task which native American species might have accomplished much better had they been protected and encouraged in our parks as the sparrow was.

There are in Europe at least six different species of titmice. All of them are found in some of the countries where dispar is native. They are all recognized as eminently beneficial, and are regarded by foresters, entomologists and ornithologists as among the most useful species in controlling noxious insects. Could they be successfully introduced here, they might do a vast amount of good not only in destroying the eggs of the gypsy moth but the larvæ also, as well as the eggs of many other injurious insects. It is difficult to imagine that any harm could come from the introduction of these insectivorous birds, unless they should change their habits in some way or drive out our native species, especially the black-cap titmouse or chickadee, and fail to eat the females and eggs of the canker-worm moths which the chickadee devours in such quantities.* If that should happen, it would indeed be a catastrophe, as the chickadee is one of the most useful of all our native birds.

No importation of birds should be blindly attempted. An

* The great titmouse (Parus major) has been known to attack other birds and break open their skulls, eating their brains. Some species of European titmice are believed to do some injury to plantations of young trees by destroying buds or leaves. 
exhaustive study of their food habits should first be made in their native home, and all the possibilities of their introduction should be well considered.

\section{The English Sparrow and the Gypsy Moth.}

The English sparrow has been seen to feed on all forms of the gypsy moth; yet this bird in its relations to dispar is injurious rather than beneficial to man. That its name appears so frequently in the records of observations is due to the fact that it has been for years the most common bird in villages and cities of the infested region, and that it is known to many observers who would be unable to identify most other birds.

The sparrow was introduced into Beston Common in 1868. It is recorded that in 1871 it had reached Somerville, and in 1873 Lynn and Cambridge. It undoubtedly appeared in Medford about the same time, as Somerville adjoins both Medford and Cambridge, while Lynn is some ten miles east of Boston.*

While it is no doubt true that native birds were a great factor in holding the moth in check during the first eight or ten years of its existence in this country when its numbers were few, it is equally true that the rapid distribution and increasing numbers of the English sparrow later from 1875 to $\mathbf{1 8 8 5}$ in the region infested resulted in driving out many native birds. The bluebirds, wrens, house swallows and martins were the first to leave, for as the sparrows multiplied they took by force the bird houses and cavities formerly occupied by these birds, compelling them to seek nesting-places elsewhere. As the sparrows further multiplied, their quarrelsome disposition impelled them to attack and drive away other birds found around their nesting-places. What they could not do singly they accomplished by force of numbers, until comparatively few native birds were able to breed in the immediate vicinity of the towns and villages. It is undoubtedly true that the sparrow did something toward compensat-

* See “The English sparrow in America," United States Department of Agriculture, 1889, page 21. I am informed by Mr. Walter Wright of Medford that his father, Elizur Wright, liberated several pairs of sparrows in Medford about that time. 
ing for this exile of insect-eating birds by destroying some of the smaller gypsy caterpillars and occasionally killing some moths or even eating a few moth eggs; but it was noticeable that wherever the sparrow was most plentiful in the infested region, there also the gypsy moth became most numerous. This was due partly to a distribution of both species along the same highways and partly to the indirect protection extended by the sparrow to the moth in driving away the latter's enemies among native birds. The caterpillars used the bird boxes occupied by the sparrows as a place of retreat, and the female moths deposited their eggs in these boxes. Sparrows and caterpillars formed a sort of happy family in the bird houses, which swarmed with both birds and insects. By driving the native birds away the sparrow became in a measure responsible for the phenomenal increase of the gypsy moth in numbers and its consequent destructiveness in Medford. The increase of some other injurious insects has been noticed wherever the sparrow has become so plentiful as to banish native birds. ${ }^{*}$ The trees in Boston and some of the towns in its vicinity have often suffered injury from invasions of the Orgyia leucostigma, or white-marked tussock moth, caused indirectly by this sparrow. The sparrow, having driven away the native birds, fails to make good their loss by destroying the hairy caterpillars.

The ravages of leaf-feeding beetles (Chrysomela scalaris) have also become noticeable upon elm trees in localities most frequented by the sparrow. The imported elm-leaf beetle (Galeruca xanthomelcena) has also been most injurious in cities where the sparrow is abundant.

\section{The Distribution of the Moth by Birds.}

The dissemination of the moth in woodlands seems to indicate that it is distributed more or less by birds. This theory is substantiated by our observations. Isolated colonies of the moth are sometimes found in the vicinity of the nests of the larger land birds, such as crows, jays and robins. Occasionally birds flying to their nests with food for their

"Second report on the "Injurious and other insects of the State of New York," by J. A. Linter, Albany, 1885, pages 80-82. 
young drop caterpillars or other insects. We have a few instances on record where the gypsy moth caterpillars have been dropped in this way, and in one case at least the caterpillar was not materially injured.

Inspector Sanderson saw a wood thrush take a large caterpillar from a tree and fly off with it. The caterpillar wriggled in the bird's bill and finally fell when the bird had flown a few yards. The bird did not come back for it.

On July 6, 1895, Mr. Bailey saw a blue jay flying over the woods in Saugus. It was flying about thirty yards from the earth, and appeared to be making quite a long flight. As it came near him he observed that it was carrying something in its beak, and he immediately shot at it with his revolver, not with the intention of killing the bird, but to make it drop what it was carrying. It dropped a large gypsy moth caterpillar, very nearly full grown. Mr. Bailey picked up the caterpillar, which appeared to be uninjured. He had watched the bird's flight for some distance, and thought it came about half a mile. The bird continued its flight northward, carrying the remainder of the food in its bill. Mr. Bailey kept and fed the larva, which pupated on July 12. A female moth emerged from the pupa on July 29, apparently in fine health.

It is not an uncommon occurrence for birds when suddenly frightened to drop food, and when carrying several larvæ in the beak at once, the one nearest the end of the beak would be the one most likely to be dropped and also the one least liable to injury by the beak. Birds sometimes carry insects.a short distance without any apparent purpose. Mr. Bailey saw a chickadee take seven larvæ from a tree and fly away with them, dropping them ten feet or more from the tree. Three of these larvæ were not injured. He also saw a least flycatcher carry away three female moths, only one of which it ate. One was dropped at a distance of twenty-five yards from the tree from which it was taken.

There is another way in which the caterpillars may be distributed by birds. They are often hatched in holes of trees and in bird houses frequented by birds, especially by the English sparrow. When first hatched in such places, they are likely to spin down on their threads, and bird houses 
and hollow trees have been found in which these spinning caterpillars were very numerous. The caterpillars may become attached to the feathers of birds which pass to and fro, and in this way may be carried short distances. Yet the danger of distribution by the accidental dropping of caterpillars by birds in flight does not appear to be so great as that resulting from the dropping of caterpillars at the nest. It occasionally happens that hairy caterpillars wriggle out of the mouths of the young birds and are dropped into or below the nests.

Mr. Bailey saw an oriole take to its young a caterpillar so large that the latter could not eat it. The young bird placed its foot upon the caterpillar, and drawing backward ejected and dropped it upon the ground. The old birds occasionally dropped food at the nest. Mr. Bailey watched a pair of chickadees bringing food to their young. They appeared to fly about half a mile to an orchard infested with the cankerworm, returning to the nest about once in twelve minutes with food. These birds dropped a few of the canker-worms just outside the nest. A new colony of moths was discovered in Cambridge not far from a badly infested locality. The appearance of the colony indicated that it was started by crows, as the larvæ were scattered all about in the vicinity of the crows' nest. If several caterpillars of the same species are dropped in this way, there is a strong probability of a colony being formed in the vicinity of the nest. A bird may overlook a few caterpillars near its nest, preferring to go where caterpillars are plentiful rather than to search for them where they are scarce. It is probable, then, that the bird which is most useful in destroying caterpillars and which feeds the largest number to its young will be the most likely to aid in the distribution of the moth. The danger of distribution would probably be greater in the case of the larger species of birds, were it not that a caterpillar seized in the bill of a crow would be more likely to be seriously injured than one taken in the bill of a small bird. The danger of distribution to distances of much more than half a mile by birds in this way does not seem to be great.

Mr. Bailey watched a catbird taking food to her young. She flew back and forth about four times an hour. He 
could see her go and come for at least a thousand yards. She flew about twenty-five yards from the earth, going straight from the locality in which her nest was situated to the locality from which she procured the food. Other small birds have been known to fly an equal distance to secure food for their young.

The distribution of caterpillars by birds goes to prove the rule that nature does not usually work for the extermination of species. While the birds are very useful as assistants in the work of extermination by destroying the gypsy moths, they hinder the work to some extent by distributing the larvæ and the female moths.

No appreciable distribution of caterpillars by birds will occur, however, except when caterpillars are present in large numbers, for then only will birds go to a distance to secure caterpillars as food for their young. Probably no other form of dissemination of caterpillars by birds will materially extend the moth's distribution even under the most favorable conditions. Wherever the caterpillars are present in large numbers in a settled country, they will be carried much farther and scattered abroad more widely by man and domestic animals than by birds. In woodlands remote from civilization, birds might be the principal factor in diffusing the moth to a short distance from badly infested spots, but the distribution of the moth in such places is not of so much moment as in cultivated and settled regions. If the moth were allowed to increase and spread over the whole State, we may infer that all possible distribution by birds would be of little importance as compared with the good they would do in checking the increase of the moth.

In towns where the moths are few and where most of them have been already destroyed, and especially in small isolated colonies, birds are very useful allies in the work of extermination. In such localities they take the caterpillars only when they come in their way, and rarely carry them to their young unless the nests are quite near the infested spot. Undoubtedly in many such cases birds have contributed as much toward the extermination of the moth as have the men employed in the work of extermination. Where the caterpillars are few, therefore, birds render efficient assistance in 
the work of extermination. As this work progresses, birds become more and more useful as destroyers of the moth and less dangerous as disseminators of the insect.

There appears to be little if any danger of the distribution of fertile female gypsy moths by birds, for, though birds have frequently been seen to carry the female moths a few feet or yards, the observations of five years have not afforded an instance of their carriage to a greater distance. The perfect moths are to be found only in midsummer and later, a time when all of the larger and most of the smaller birds have no young in the nest.

It is not probable that the birds distribute the eggs of the moth to any appreciable extent, though they undoubtedly scatter them somewhat by pecking egg-clusters from the trees. As it was known that many of the scattered eggs hatch, when denuded of their hairy covering, it seemed important to determine whether birds would break the egg shells in feeding on the eggs, and whether unbroken eggs would pass through the digestive tract of a bird without injury to the shell and hatch if left exposed under natural conditions. Birds might thus distribute the moth as widely as they are known to distribute certain plants by scattering undigested seeds. A confined sparrow was fed upon the eggs of the moth, and it was found that most of them were broken by the bird's bill, or in the process of digestion; yet some were passed entire. A similar experiment was made with the crow. As the crows would not eat the eggs of the moth unless disguised in food more to their taste, these eggs were inserted in the bodies of grasshoppers and other large insects, and while thus covered were swallowed by the crows. A small proportion of these eggs were passed with the shell unbroken, but the life of the eggs appears to have been destroyed, as they are now drying up. This indicates that there is no danger of a distribution of living eggs to a distance by egg-eating birds.

Although, as has been shown, certain species of birds undoubtedly assist in the distribution of the moth by carrying the caterpillars about, birds do much to prevent distribution not only by reducing the numbers of the eaterpillars, but by capturing male moths in search of isolated females, 
thereby preventing the fertilization of scattered females and the establishment of new colonies of the moth. Under the most favorable circumstances in open country and with favoring wind and weather the male will occasionally find a female at a distance of half a mile. It is probable that in orchards or woodlands the scent of the female does not travel so far. In any case a male flying some distance to a female would wander about a good deal before finding its mate. In the mean time it must run the gauntlet of the flycatchers, sparrows, warblers and all the birds which so frequently capture flying males. It is to these birds a shining mark, and, although its flight is swift and eccentric, they readily follow and easily capture it. When flying low in the open land male moths are often pursued and captured by sparrows. They may also be captured by swallows, but this has never been observed. Experiments made in trapping male moths by attracting them to females have often failed because of the number of these moths captured by birds. Birds will sometimes capture every male moth before it reaches the trap. Therefore certain species do much in this way to compensate for the injury which they or others may do in distributing the moth.

\section{Birds versus Useful Insects.}

In their destruction of gypsy moths birds sometimes destroy parasites of these insects. The parasites within the caterpillars and pupæ are eaten together with their hosts. Yet the immediate destruction of caterpillars by birds is of more importance to man than the lingering death which is caused by the parasite. The larvæ of hymenopterous parasites feed almost exclusively on the fatty portions of the insects which they attack, thus allowing them to live, feed and grow, and do as much damage to vegetation as if they were not parasitized. When the caterpillar has finished feeding, or later when it has pupated, the parasite, having eaten the greater portion of the fatty substance, eats out the vitals, thus killing its host. The bird, on the contrary, snaps up the caterpillar at once, thus preventing further injury to the tree. The question then arises, would the parasite unhindered be more effectual in checking the rav- 
ages of its host than the bird? It is possible that, should predaceous birds, insects and other enemies be insufficient in holding the moth in check, the conditions in the course of years, after great damage had been done, would be so favorable for the multiplication of insect parasites that they might check for a time the ravages of the moth. Experience in many countries shows that, where other enemies of a pest fail to hold it in check, insect parasites, starvation and epidemic diseases sometimes put an end for the time being to the plague. In addition to the destruction of parasites, together with the host, some ichneumons and tachinid flies are captured in the imago form by the flycatchers. Birds also destroy some of the predaceous insects. This is especially true of robins, jays and crows. Yet Professor Forbes has shown that the destruction of such insects by birds is not necessarily an evil.* The bugs which appear to be most useful in the destruction of the moth are believed to have some immunity from the attacks of birds by reason of their pungent secretions. Crows, however, destroy certain of these bugs.

\section{Conclusions.}

Our present knowledge of birds as enemies of the gypsy moth in Massachusetts points to the following conclusions :-

At least a dozen species are very useful in this respect; probably twenty-five others are more or less useful, when the moths become very numerous, or when other species of insects which these birds prefer are scarce.

Birds destroy larger numbers of the gypsy caterpillars when the canker-worms or other hairless larvæ are scarce than when they are plentiful.

Although birds gather in localities infested by the moth for the purpose of feeding on the caterpillars, they do not flock to such infested localities in such numbers as they do to regions infested by migrating locusts or by hairless caterpillars.

Birds are particularly useful in preventing the increase of small colonies of the moth, and in this respect are allies to

* Bulletin No. 3, Illinois State Laboratory Natural History, November, 1880, page 83. 
man in the work of extermination. A few cases are noted in which such colonies appear to have bcen exterminated by birds. They are also useful ' in checking the increase of the moth in large colonies.

More species of birds are found attacking the moth in orchards than in woodlands, though woodland birds often visit orchards situated near their usual haunts, and orchard birds visit badly infested colonies in woodlands.

While birds are very useful in restraining local ravages of the moth, it is probable that should the moth be allowed to spread over the whole State, its increase would so outrun the numbers of birds that they would have no appreciable effect in checking its most serious outbreaks.

The injury done by birds in distributing the moth and destroying parasites and other useful insects appears to be of little importance when compared with the good they do in destroying the moth.

If laws for the protection of birds were enforced, and if birds were fostered, encouraged and protected generally by citizens, there is no doubt that their efficiency as insect destroyers could be greatly increased. The most important service that could be rendered by birds in the case of the gypsy moth would be the destruction of the eggs. This service, supplemented by that of destroying the other forms of the moth in summer, would be of very material benefit. As no American birds appear to eat the eggs to any extent, it would be well to investigate thoroughly the habits of European egg-eating species, with a view to their introduction into Massachusetts, if this should be found desirable.

\section{The Protection of Birds.}

It is quite evident that by pursuing a policy for the protection of birds, the number of birds in the region infested by the gypsy moth and their efficiency as insect police could be greatly increased. While the present laws for the protection of insectivorous birds are wise in the main, no adequate provision is made for their enforcement, and they are consequently a dead letter to certain classes of people. A great many birds are killed and many nests broken up by boys. In the fall the country swarms with gunners. 
Thousands of birds are killed for the milliners. The camps of Italians, where employees engaged in public works are quartered, furnish many of these gunners. These men will shoot birds of any kind, anywhere and on any man's premises. Everything that wears feathers is considered by them as fair game.

The appointment of officers to enforce the bird laws might assist much in bird protection. Children in the public schools should be taught the usefulness of birds, and it should be generally considered a crime to destroy insect-eating birds. The farmer might as well allow men to steal his fruit and grain as to shoot the insect-eating birds on his premises. The number of birds destroyed by cats is astonishing. I have known a single cat to break up the nests of six pairs of birds in a day, destroying all the young and one of the old birds. Many wild and vagabond cats roam the woods and orchards and destroy thousands of birds. Outside the cities cats probably do enough injury by killing birds to much more than counterbalance all the benefit derived from them in the way of destroying rats and mice. A few traps properly attended by a bright boy will do more towards clearing a place of rats and mice than half a dozen average cats.

The number of such birds as nest in boxes or hollow trees can be increased by putting up boxes in which they may breed, and protecting them as far as possible from the English sparrow and other enemies. If evergreen hedges and patches of shrubbery are provided as retreats for birds to which they can fly when pursued by hawks, and if plenty of wild and cultivated fruit is grown in the vicinity, such a locality will be much frequented by birds.

Birds may be attracted to infested localities in the winter or summer by supplying them with food and safe nestingplaces. A people who protect and foster insectivorous birds cannot fail to add materially to the prosperity of agriculture. 


\section{The Progress of Extermination.}

The extermination of the gypsy moth was begun by the Commonwealth under a misapprehension of the facts. When the first great outbreak of the pest was brought to the attention of the Legislature in 1890, it was believed that the moth was confined to cultivated lands in the town of Medford. This infested district was not supposed to exceed one-half mile in width and one and one-half miles in length. The difficulty and expense of extermination were consequently underestimated. An appropriation was made for the purpose of exterminating the moth in this small tract and preventing its spread to other parts of the State. In the attempt to exterminate the moth, the experience of the first year showed that the insect was not confined to Medford, and the commission of 1890 reported that fifty square miles were more or less infested. The experience of the second year proved that the moth was distributed over an area of over two hundred square miles, not only in cultivated lands but in waste and wood lands as well. The magnitude of the task undertaken by the Commonwealth then became apparent.

\section{Circumstances favoring Extermination.}

There are certain circumstances connected with the habitat of the moth, which, taken together with known facts in its life history, encourage the attempt to secure its extermination.

Limited Area Occupied. - The experience of five years confirms the belief that the moth is confined to a limited area on and near the coast line.

Favorable Location. - The infested region is bounded on the east and south-east by the ocean, which prevents the spread of the moth in those directions. . Much of the territory along the coast consists of salt marsh, in which the gypsy moth cannot live.

The infested region is in the most populous portion of 
the State; therefore the extermination of the moth directly interests a large number of people. This fact assures the intelligent co-operation of many individuals.

The original centre of infestation in the district was situated on a short line of railroad ending in Boston, and thus the danger of distribution by rail. was not great.

The Infested Area has been reduced. - As a result of the work of extermination, the region now occupied by the gypsy moth is considerably less than that occupied by it five years ago, when the work was begun.

Slow Spreading. - The female moth does not fly. On this fact rests the principal hope of preventing the spread of the insect, and finally securing its extermination. Could the female moth fly, as does the male, the species would probably have been distributed long since over all eastern Massachusetts and adjacent parts of New England, if not farther. The moth occupied twenty years from the time of its introduction in spreading over the territory infested by it in 1891.

The Moth hibernates in the Egg. - It remains in that form during most of the fall, the winter and early spring. The eggs are conspicuous, and an opportunity is thus given for inspecting the territory and discovering the colonies of the moth during the fall and winter months, while the trees are leafless and the insect is doing no damage. It is more feasible to exterminate an insect pest which may be attacked in the winter, when it is stationary for a fixed period, than to exterminate a species that can be reached only during the summer months, at which time its distribution is being effected.

\section{Obstacles to Extermination.}

Though there are many encouraging circumstances in connection with the problem, there are also serious obstacles to success.

Enormous Reproductive Capacity of the Moth. - Its wonderful reproductive powers and its remarkable tenacity of life provide for a rapid increase and redistribution in an infested locality in the inspection of which a few moths may have been overlooked. 
Many Food Plants. - Where the moth is abundant, it is found on nearly all plants of economic value. In inspecting a region in search of the moth it is necessary to examine all species of trees. It is therefore much more difficult and expensive to locate all the colonies than it would be were the insects confined to a few food plants.

Other Obstacles. - The infested region being densely populated, the danger of local distribution and reinfestation by man and animals constantly passing and repassing infested centres is much greater than it would be were the district thinly populated.

No one method can be depended upon for exterminating the moth. Nature often defeats an attempt to exterminate by a single process at a particular season of the year. The most approved methods applied singly frequently fail. Exterminative work must proceed day after day throughout the year, to insure success. Though every effort was made in 1891 to extorminate the moth from the region most infested, the inspection of 1892 gave abundant evidence of the impossibility of extermination in one year's time. In 1891 the destruction of the eggs was depended upon for extermination. Yet caterpillars were found in 1892, even in those parts of the infested territory where the work had been most carefully done, and where the greater part of the eggs had been destroyed. Many of these came from eggs which had been scattered on the ground in the previous fall and winter before the work of destroying the clusters was begun. Eggs are sometimes thus scattered by the wind and rain, by people picking fruit or pruning or cutting trees, by birds and animals, or by various other causes. The female moth occasionally drops a few eggs upon the ground or in crevices of the bark, where they will escape the most thorough search. Spraying, as ordinarily done, will destroy only a small portion of the caterpillars. Bands of insect lime and other tree protectors merely prevent most of the caterpillars from ascending trees which have been first cleared of eggs. If thus kept out of trees, they will betake themselves to other plants. While the burlap bands afford a means of disposing of most of the caterpillars, there can be no certainty of taking them all by this method. 



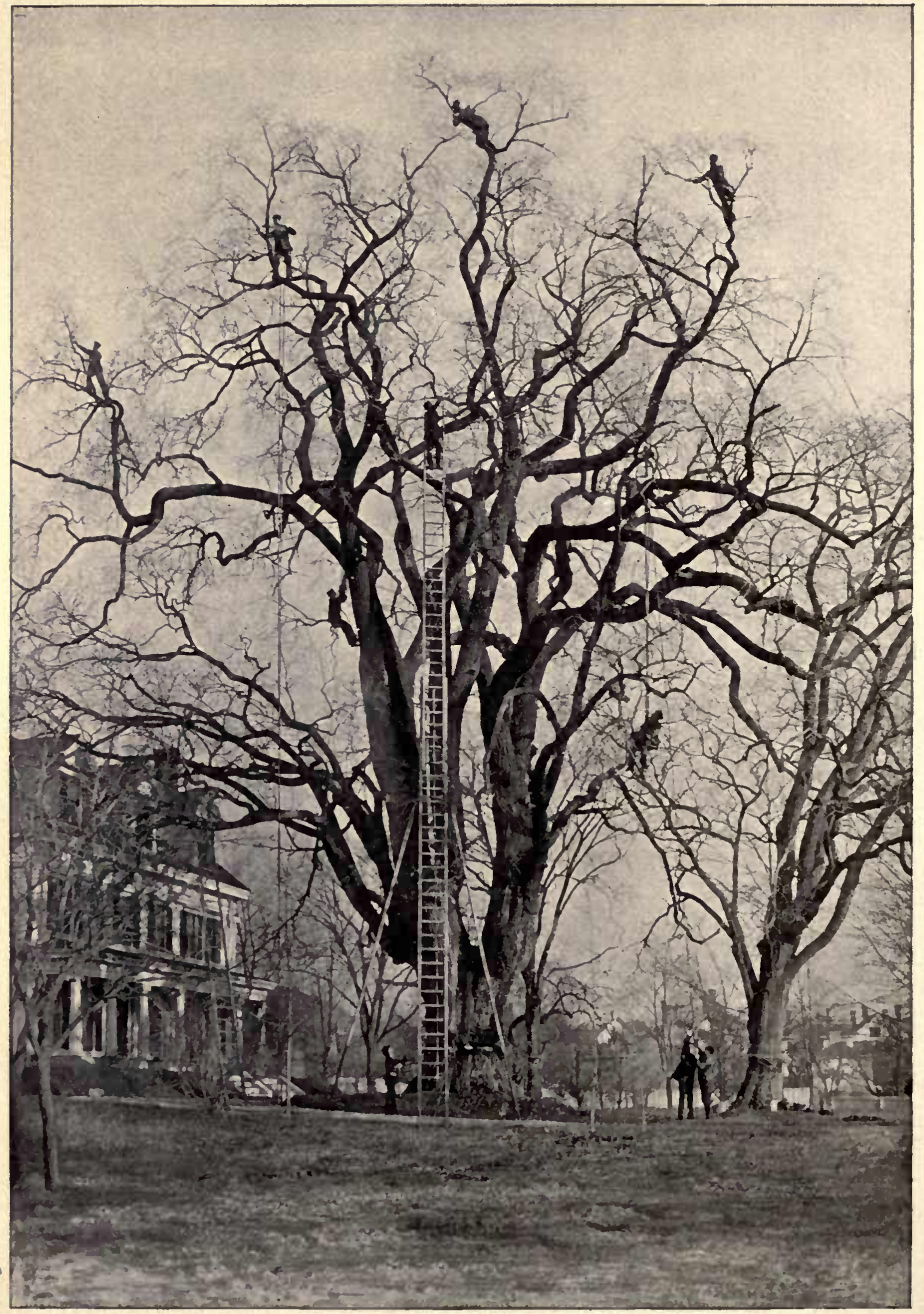

PLATE XXXVI. Men at work on the Dexter elm, Malden. From a photograph. 


\section{The Success of Local Extermination.}

The work of extermination was begun on the principle that, if the moths could be exterminated from one tree, they could be eradicated from any number of trees, providing the same kind of work that cleared the first tree could be carried on simultaneously over a large area. It was soon found that the moth could be cleared from trees of ordinary size by honest, thorough, intelligent labor. Yet many doubters asserted that it was impossible to clear the larger trees. Medford, being one of the oldest towns in the State, had many very large elms. This was also true of Malden. It was believed by some of the residents that it would be impossible to clear the moths from these trees except by the aid of a balloon. The largest tree in the infested region was selected for trial of the possibility of extermination. This tree is situated on the property of the Messrs. Dexter of Malden, and stands in front of the old Dexter mansion. The tree has been owned by this family for more than two hundred years. If not the largest tree in the State, it is one of the largest.* Early in 1891 an attempt was made to clear the moths from the tree, and a gang of four men, who had had some experience, went to work upon it to destroy the eggs of the moth. After working for several days upon the tree they reported it cleared. Another gang of men was put at work upon the tree, and six hundred additional egg-clusters were discovered. Notwithstanding this, caterpillars appeared in the spring upon the tree. It was then sprayed thoroughly, an extension ladder sixty-five feet in length being used, together with several additional ladders placed in various parts of the tree. Later in the season all the holes in the limbs were covered or filled, and the few egg-clusters found were treated with ereosote oil. In 1892 the tree was banded with tarred paper, which was kept constantly moist with a mixture of tree ink, tar and oil. A few eaterpillars were found, however, on the tree, having hatched probably from scattered eggs left in the

* The Dexter elm has the following dimensions: circumference at base, 29 feet; circumference six feet from ground, 21 feet; height, 110 feet; spread from northeast to south-west, 104 feet. Some of the branches of the tree are 3 feet in diameter. 
crevices of the bark. In 1893 no caterpillars appeared, and no form of the moth has been found since 1892 upon the tree. In the inspections of the tree every care has been taken to go over it thoroughly, from its highest branches to the base of the trunk. The dead limbs have been removed and holes have been covered, but no other work has been necessary at the regular inspections. Plate XXXVI. shows men at work in the inspection of the tree.

The extermination of the moth from many orchards was accomplished without much difficulty. Plate XXXVI. shows apple trees which were seriously injured during the season of 1891 by the gypsy moth. They were cleared of the moths and so treated that in 1892 they regained a large part of their foliage(Plate XXXVII.). They have borne very little fruit, however, since 1891.

Having learned that it was possible to clear the moth from any tree, it remained to be proved whether the creature could be cleared from orchards or entire estates. Although in 1891 many estates appeared to have been cleared, there was still some doubt that the moths were exterminated from them. But the estates were examined again and again in succeeding years, and no moths were found except in a very few instances. The number of infested estates from which the moths had been cleared increased annually. Not only were estates cleared, but infested localities consisting of many estates were entirely freed from the moth.

More than a thousand colonies in the infested region, some of them covering many estates, have been entirely cleared of the moth and have remained clear, until it has become an established fact that wherever the moths are found in open and cultivated lands, they can be exterminated. The difficulty of exterminating the moth in woodland has been found to be much greater. Yet, despite all obstacles, some of which at first seemed insurmountable, the moths have been cleared from certain infested localities in the woods. The destruction of all vegetation by fire will accomplish extermination in woodlands. But much of this infested woodland is retained by the Commonwealth for park purposes, and the destruction of the trees is out of the question, however much 



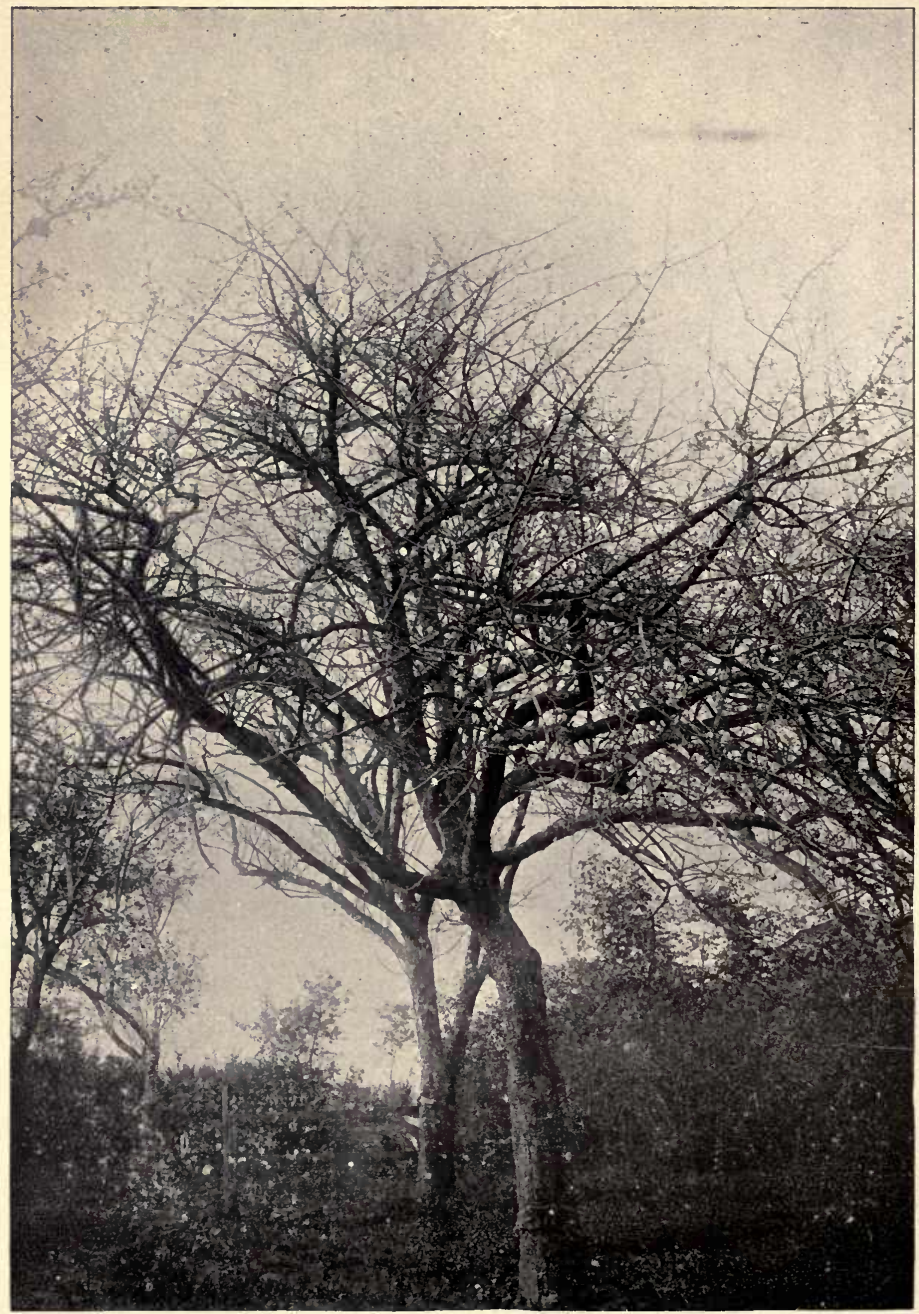

PLATE XXXVII. Apple trees stripped by caterpillars of the gypsy moth, Swampscott. From a photograph taken Aug. 5, 1891. 


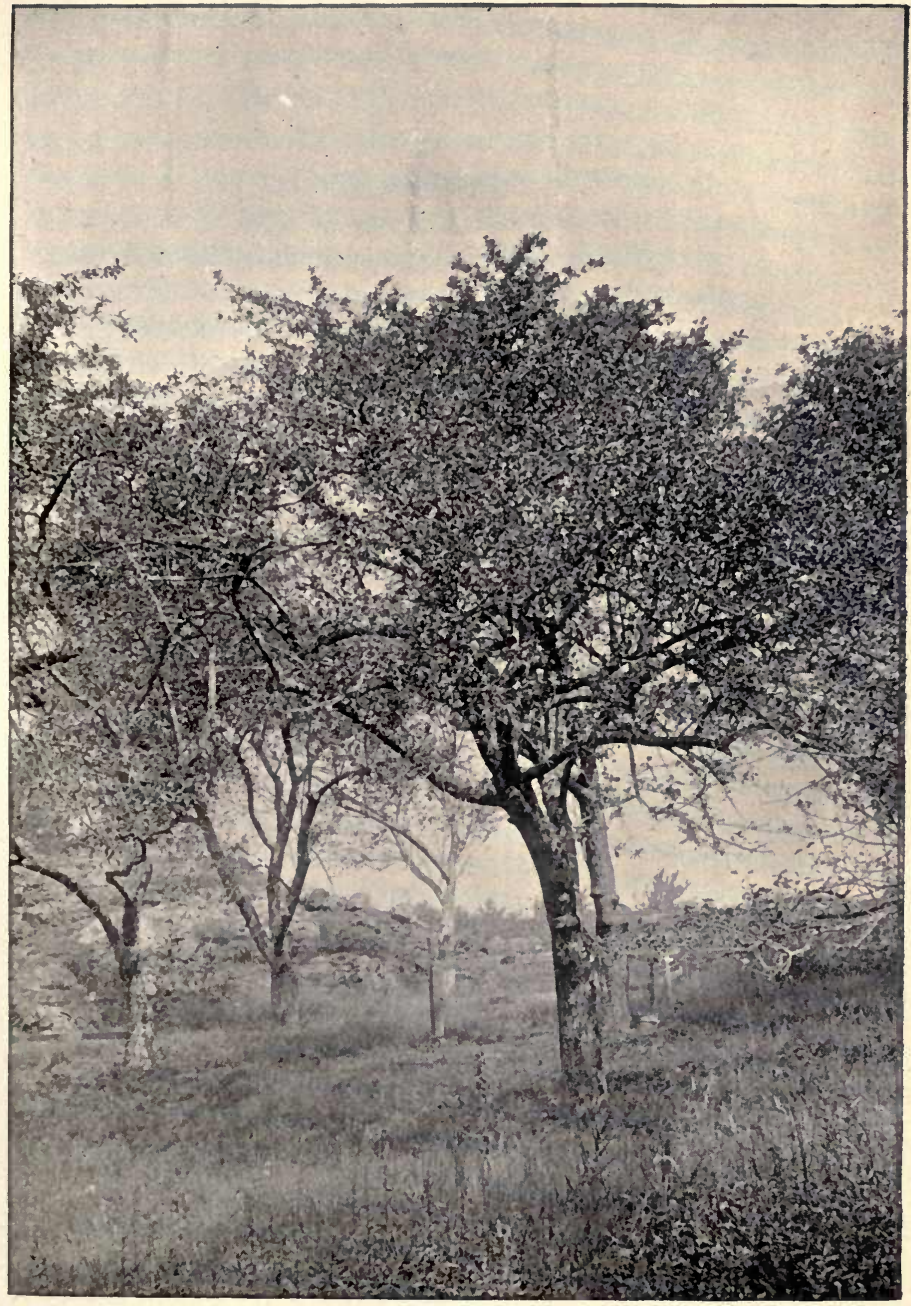

PLATE XXXVIII. View of the same trees in Swampscott a year later, after the moths had been cleared from the locality by the agents of the Board of Agriculture. From a photograph taken in July, 1892. 

the exigencies of the case might seem to warrant such a course. Therefore burlapping, banding, spraying and other means, less expeditious and in the end more expensive than fire, have been resorted to. These means call for larger appropriations than have yet been made, and without such appropriations, promptly granted, the extermination of the moth can never be accomplished. Though a continual advance in the work of extermination has been made annually in the outer towns of the infested district, though some of them appear quite and others nearly cleared of the moth, there is a section of woodland in the inner towns which is probably in a worse condition than it was in in 1891.

\section{Larger Appropriations Needed.}

While the agents of the Board have been engaged in preventing the spreading of the moth and prosecuting the work of extermination in the outer towns of the infested region, they have been unable to do much more with the means provided than to check the moth's annual increase in the central towns. This partial policy, the inevitable consequence of the inadequate appropriations, has necessitated in the inner towns an annual repetition of the work and expense without any considerable advance towards extermination in those towns. As a result, while extermination has been successful over large areas, principally in the outer towns, the moths have increased in the comparatively neglected woodland in the central towns. The Board is required by law to do all possible toward preventing the spread and securing the extermination of the gypsy moth in this Commonwealth. All possible with the means at hand has been undertaken. All the evidence obtainable goes to show that the spread of the moth into territory outside the region infested in 1891 has been prevented, and that extermination has been accomplished both locally and over a considerable area, greatly reducing the infested territory. Our only hope of preventing the spreading of the moth lies in doing everything possible to exterminate it. Therefore, whatever imperils the success of extermination, renders the prevention of the moth's dissemination less certain. The expense of extermination has been greatly augmented and success retarded and gravely 
imperilled by inadequate resources and repeated delays in making the annual appropriations. Unless ample appropriations are promptly granted, failure is certain.

To continue the past policy of inadequate and belated appropriations may result sooner or later in the escape of the moth from the territory to which it is at present confined and its final distribution over the whole country. In such a case it might injure the agricultural interests beyond calculation. If the gypsy moth should be allowed to spread over the United States, the average farmer would be powerless, under the conditions prevailing in this country, to protect his orchard, woodland or garden against the ravages of this insect. Whatever affects the prosperity of the farmer affects the prosperity of the whole people. Knowing as we do that the moth feeds on nearly all forest and orchard trees and garden plants, knowing also the injury done in Europe within the past century by this insect, having learned by experience the greatly increased destructiveness of European insects when introduced here, and considering the annual damage now done to agriculture by insects in this country (estimated by an eminent authority at three hundred and eighty million dollars), we can but view with alarm the possibility of the spread of this insect over the United States.

There is no doubt in the minds of those acquainted with the facts that the gypsy moth can be held in check where it now is and that it can be exterminated if sufficient resources can be secured and vigorous measures taken. It would seem, then, that the general government should seize the opportunity now presented to stamp out the pest which Massachusetts undertook to exterminate as soon as it was publicly known that it was within her borders, reducing its numbers and the area of its dissemination by local extermination and thus far holding it in check. The policy of control or extermination of insect pests by governmental commissions, which has been so successful in certain European countries, might be applied to advantage in this case by the government of the United States. There are those who believe that neither the State nor nation should appropriate money for the extermination of this insect, but that land owners should be left to protect their own property from its ravages. According to Professor 
Fernald, this would prove to be the worst possible policy, as after the moths had spread over the State, the expense to land owners would be enormous as compared with the expense of the work as carried on by the State in the present restricted territory. He makes the following comparison in his report on the work of 1895 , made to the gypsy moth committee of the State Board of Agriculture :-

"The value of the taxable property in this State is $\$ 2,429,832,966$, and an appropriation of $\$ 200,000$ is a tax of less than one-twelfth of a mill on a dollar. A man having taxable property to the amount of $\$ 5,000$ would have to pay a tax of only 41 cents and 6 mills. This beggarly sum of money would make but a small show in the work of clearing the gypsy moth caterpillars from an infested $\$ 5,000$ farm, while in the uninfested parts of the State the land owners would be paying an exceedingly small premium to the State to insure them against the ravages of the gypsy moth. This premium on a $\$ 1,000$ farm would be $8 \frac{1}{3}$ cents, and for fifty years it would amount to only $\$ 4.16 \frac{2}{3}$. This protection would extend not only to farmers and owners of forest lands, but also to residents in villages and cities who own lands with trees and shrubs on them, and to vegetation wherever grown within the limits of our Commonwealth."

The expense of this work, if undertaken by the United States government, would be infinitesimal to the individual citizen and would be an economical insurance against the ravages of the moth on his property and that of his posterity. 



\section{THE GYPSY MOTH.}

Porthetria dispar (L.).

\section{PART II.}

C. 포. 표Nㄷ․ 



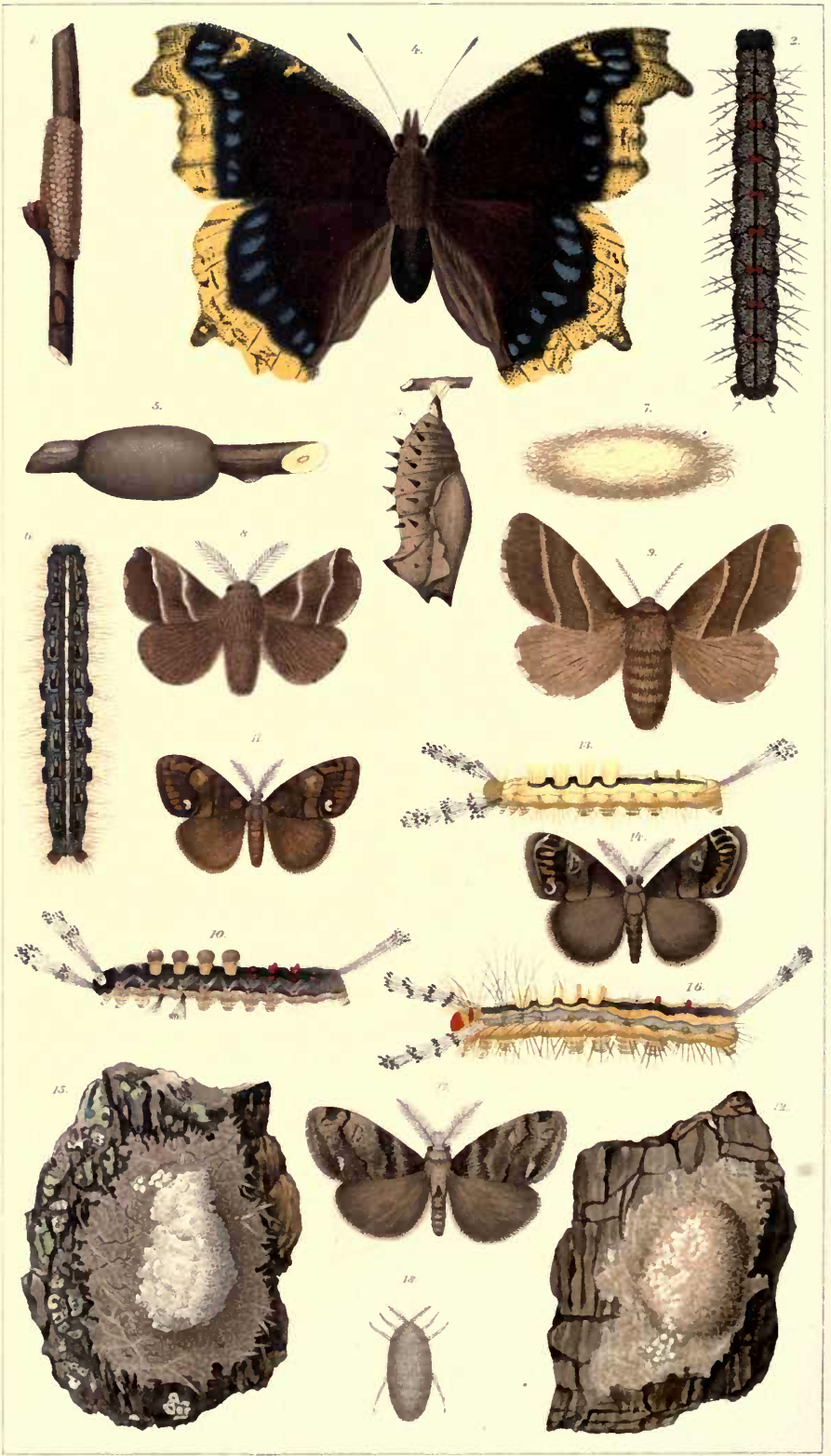




\section{Explanation of Plate 39.}

Drawn in colors by Ella M. PAlmer.

It has seemed desirable to present colored figures of the following insects since in some of their forms they are the ones most commonly mistaken for the gypsy moth.

I. Eggs of Euvanessa antiopa (Linn.) (Vanessa butterfly).

2. Caterpillar of Euvanessa antiopa.

3. Chrysalis " " "

4. Imago " " "

5. Egg-cluster of Clisiocampa americana Harr. (tent caterpillar).

6. Caterpillar of Clisiocampa americana.

7. Cocoon " " 66

8. Male imago of "6 6

9. Female imago of " "

10. Caterpillar of Orgyia antiqua (Linn.).

I . Male imago " " "

12. Egg-cluster of Orgyia definita Pack.

13. Caterpillar " " 6

14. Male imago " " "

15. Egg-cluster of Orgyia leucostigma (S. and A.) (the white marked tussock moth).

I6. Caterpillar of Orgyia leucostigma.

17. Male imago of " "

18. Female imago of " " 



\title{
THE GYPSY MOTH.
}

\author{
Porthetria dispar (L.).
}

This species was first described by Linnæus, in 1758, in the tenth edition of his " Systema Naturæ," Vol. I, page 501, under the name of Phaloena (Bombyx) dispar, the specific name being given because of the marked difference or disparity between the sexes. In 1801, Schrank, in his "Fauna Boica," placed this species under his genus Laria; but this generic name had been previously used by Scopoli in the beetles, and thus, being preoccupied, could not properly be used for the moths. In 1810, Ochsenheimer, in the third volume of his "Schmetterlinge von Europa," established the genus Liparis and put dispar under it; but Liparis is also preoccupied, and cannot be used. Hübner, in his "Verzeichniss bekannter Schmetterlinge," page 160, published about 1822, placed dispar in his genus Porthetria with three exotic species, and therefore dispar, being the only European species, has been taken as the type. In the same work, page 158, Hübner established the genus Ocneria with rubea Fab. as the type, but Staudinger and some others, believing that rubea and dispar should be in the same genus, placed them with their allies under Ocneria.

In 1829, Stephens, in his "Illustrations of British Entomology," Haustellata, Vol. II, page 55, established the genus Hypogymna and placed dispar under it. He also proposed this name in his catalogue the same year. In accordance with the laws of priority, almost universally accepted by zoölogists, it is necessary to adopt the oldest tenable generic name which is not preoccupied; and therefore Hübner's genus Porthetria, with dispar as the type, was given by Kirby in his recent "Catalogue of Lepidoptera Heterocera," and has been adopted by Comstock and Dyar in this country. 
The question whether dispar shall remain under the genus Ocneria depends on whether it has the same generic characters as rubea. If it has, then it should remain with rubea, otherwise it should be placed under the genus Porthetria. To settle this question to my own satisfaction, I sent to Europe and obtained specimens of Ocneria rubea, and, after a critical study of the structure, I am convinced that the two insects are not congeneric, and must be placed under different genera. On showing the insects to Prof. J. B. Smith, he agreed with me in my conclusions, and in a letter from Prof. A. R. Grote of Bremen, Germany, I learned that he had independently reached the same conclusion. I therefore feel obliged to adopt the name Porthetria dispar, given by Hübner over seventy year's ago. In all our previous publications, however, the name Ocneria dispar has been used, following Staudinger's catalogue.

\section{Common Names.}

The following are some of the common names which have been given to this insect in different European countries. We have adopted the common name "gypsy moth," because it is the one most frequently used in England, and has already come into very general use in this country. This name was first given to it, so far as I can learn, by Wilkes, in 1741; and Humphreys, in his "British Moths," says that "the popular name of the gypsy was no doubt suggested by the brown, tanned kind of color of the male."

SCHw Ammspinner : Fungus-spinner. The egg-cluster resembles a small tree fungus.

Drсккорг : Thick-head. The head of the caterpillar is unusually large.

Rosenspinner: Rose-spinner. They feed on rose bushes.

Apricosenspinner : Apricot-spinner.

STAMMPHALENE : Stem-moth. The moths rest on the trunks of trees.

Grosskopr : Great-head.

BaUmRaUPE: Tree-caterpillar.

ScHWAMMrAUPE : Fungus-caterplllar.

Grosse Schwammraupe: Great fungus-caterpillar.

Scuшамммотте: Fungus-moth.

Stammraupe: Stem-caterpillar.

GrosskopFspLNNER : Great-head spinner. 
UNGleicher SpinNer: Dissimllar spinner. The sexes are very unlike.

UNGLEICH NACHFALTER: Dissimilar nocturnal-moth.

ZWEIFACH : Two-fold.

GrosskopfBar : Great-bead bear.

DICKKOPFIGER BAR: Thick-headed bear.

LE BOMвYX DISSEMbLabLE: The dissimilar bombyx.

Le BомвyX Disparate: The dissimilar bombyx.

LA Spongieuse: The spongy (moth).

la Chenille commune: The common caterpillar.

LE ZiG-ZAG.

The Gypsy Moth.

The Brown ARches.

\section{Literature on the Gypsy Moth.}

All the works in this list have been examined except those marked with an asterisk.

Goedart, Histoire des Insectes, vol. I, pp. 118, 142, pl. 63, 1662.

Merian, Erucarum Ortus, etc., part I, pl. 18-31, 1679.

Merian, Erucarum Ortus, etc., part II, pl. 19, 1683.

*Blankaart, Schauplatz der Raupen, p. 25, pl. 6, figs. A-C, 1690.

Frisch, Beschreib. von Ins., vol. I, p. 14, pl. 3, figs. 1-9, 1720.

Frisch, Beschreib. von Ins., suppl., vol. XIII, p. 28, 1722.

Merian, Erucarum Ortus, follo edition, pl. 183, 1730.

La chenille a oreilles, Reaumur, Memolres, vol. I, p. 110, pl. 3, flgs. 1, $3-5$; p. 19 , pl. 4 , figs. $1-4,6-8$; p. 352 , pl. 22 , figs. $5,6,8-10$; p. 359 , pl. 24 , figs. $1-4$; p. 609 , pl. 45 , figs. $1-13$; p. 614 , pl. 46 , figs. $1-7$, 1734.

La chenille à oreilles, Reaumur, Memoires, vol. II, p. 63, pl. 1, flgs. 11-15; p. 433 , pl. 34 , flg. 3,1736 .

*The Gipsey Moth, Wilkes, Twelve New Designs of English Butterflies, $1741-42$.

Roesel, Insecten Belüstigung, part I, p. 17, pl. 3, figs. 1-7, 1746.

Schreber, Samml., vol. XIII, p. 153, 1750.

Baumraupe, Schaeffer, J. C., Nachricht von elner Raupe, etc., 1752.

Phalaena (Bombyx) dispar, Linn. Syst. Naturae, ed. 10, vol. I, p. 501, 1758.

Schaefter, J. C., Der Wunderbare Eulenzwitter, etc., 1761.

*Poda, Insecta Musei Graecensis, p. 86, 1761.

Phalaena Dispar, Scopoli, Ent. Carniolica, p. 197, 1763.

Le Zigzag, Geoff., Hist. Abrégée dẹs Ins., vol. II, p. 112, No. 14, 1764.

*Gronovius, Zoophylacium, vol. II, p. 208, 1764.

Schaeffer, J. C., Abh. von Ins., vol. II, p. 315, pl. 1, flgs. 1-8, 1764.

Schaeffer, J. C., Icon. Ins. Ratisb., part I, vol. I, pl. 28, figs. 3-6, 1766.

Phalaena (Bombyx) dispar, Linn. Syst. Nat., ed. 12, vol. I, p. 821, 1766.

*Bombyx Dlspar, Hufnagel, Berl. Mag., vol. II, p. 406, pl. 3, No. 16, 1766.

*Bombyx Dispar, Hufnagel, Berl. Mag , vol. III, p. 8, No. 2, 1767.

Merian, Hist. Generale des Ins. d'Eur, ed. 3, vol. II, p. 5, pl. 18, 1771.

Bombyx dispar, Wilkes, English Moths and Butterfles, pl. 42, 1773. 
Phalaena dispar, Gleditsch, Forstwiss., vol. I, p. 310; vol. II, pp. 45, 81, $227,739,1775$.

The Gipsy, Harris, Aurelian's Pocket Companion, pp. 29, 30, 1775.

Phalaena dispar, Christmann, Onomatologia Nat. Hist., vol. VI, p. 350, 1775 .

Bombyx dispar, Fab., Syst. Ent., p. 570, No. 49, 1775.

Phalaena dispar, Fuessl., Verz. Schwelz. Ins., p. 35, No. 660, 1775.

Bombyx Dispar, Denls and Schiffermïller, Syst. Verz. Schm., p. 52, No. 6, 1776.

Grosskopf, Mueller, O. F., Zool. Dan. Prod., p. 665, pl. 16, figs. 2-11, 1776. Phalaena dispar, Mader, Raupenkalender, p. 99, No. 282, 1777.

Plialaena dispar, Fischer, J. B., Natur. gesch. von Livland, p. 151, 1778. Phalaena dispar, Fuessl., Mag. für Liebhaber der Ent., vol. II, p. 286, 1778.

Phalaena Bombyx dispar, De Geer, Abhl. Gesch. der Ins., vol. II, p. 293, 1778.

Phalaena Bombyx dispar, Goeze, Ent. Beit. Ritter, part III, vol. II, p. $331,1779$.

Phalaena dispar, Leske, Anfangs. Handb. Nat. Gesch., p.460, No. 8, 1779.

Eichen und Ulmraupe, Glazer, Abhl. von schädl. Raupen, p. 39, 1780.

Phalaena dispar, Rimrod, Naturforscher, vol. XVI, p. 130, 1781.

Bombyx dispar, Fab., Species Insectorum, vol. II, p. 183, 1781.

Bombyx dispar, Lang, Verz., p. 86, No. 661-664, 1782.

Phalaena Bombyx Dlspar, Esper, Schmett., vol. III, p. 197, pl. 38, figs. $1-6,1782$.

*Bombyx Dispar, Martin, Vade-Mecum, Pom. Trees, No. 44, 1785.

Le zigzag, Ernst, Pap. d'Europe, vol. IV, p. 106, pl. 138, fig. 186, $a-g, 1785$.

Phalaena dispar, Bock, Versuch. Nat. Gesch., etc., vol. V, pp. 29-32, 1785.

*Fourc., Entomologia Parisiensis, p. 261, No. 14, 1785.

Bombyx dispar, Fab., Mantissa Insectorum, vol. II, p. 117, 1787.

Borowski, Naturgeschlchte Theirreichs., vol. VII, p. 97, 1786.

Borowskl, Naturgeschichte Theirreichs., vol. VIII, p. 77, 1787.

*De Villers, Ent. Linnaei, vol. II, p. 144, 1789.

Bombyx dispar, Vieweg, Tab. Verzeichniss, vol. I, p. 54, 1789.

Bombyx dispar, Lodi, Opuscol. scelt., vol. XII, p. 183, 1789.

Bombyx Dispar, Borkh., Eur. Schm., vol. III, p. 312, No. 118, 1790.

Bombyx disparate, Oliv. Ency. Meth., vol. III, p. 59, 1790.

Rossi, Fauna Etrusca, vol. II, p. 170, 1790.

Phalaena Bombyx Dispar, Preyssler, Verz. bömischer Insecten, p. 41, 1790.

Sepp, Nederlandische Insecten, vol. III, p. 5, pl. 2, 3, 1791 (?).

Phalaena Bombyx Dispar, Schwarz, Raupenkalender, pp. 60, 224, 377, 1791.

Phalaena Bombyx dispar,' Brahm, Ins. Kal. II, p. 517, No. 378 ; p. 739, No. 24,1791 .

*Hennert, Raupenfrass und Windbruch, 1791.

Bombyx dispar, Borkh., Rhein. Mag., vol. I, p. 334, 1791-94.

Bombyx dispar, Fab., Ent. Syst., vol. III, part I, p. 437, 1793.

Phalaena Bombyx Dispar, Pezolds, Mittel die uns Schäd., etc., vol. II, fig. $8,1794$.

- Bombyx dispar, Panzer, Fauna Germ., vol. II, pp. 22, 23, 1794.

Phalaena Dispar, Berk., Synop. Nat. Hist., Gr. Brit. and Ire., vol. I, p. 136, 1795. 
Phalaena Dispar, Don., Nat. Hist. Br. Ins., vol. V, p. 67, pl. 163 (Gipsey Moth). 1796.

Bombyx Dispar, Hub., Samml. Bomb., p. 121, pl. 19, figs. 75 male, 76 female, 1800 (?).

Bombyx Dispar, Illiger's edition, Wien Verz., vol. I, p. 75, 1801.

Laria dispar, Schrank, Faun. Bolca, vol. II, part 1, p. 256; part 2, p. 151, 1801-02.

var. (?) a, Bombyx disparina, von Mueller, Fauna Silesiaca, part III, vol. I, 1802 .

*Phalaena Bombyx dispar, Stewart, Elements of Nat. Hist., vol. II, p. 150, 1802.

Bombyx disparus, Haworth, Lep. Brit., p. 88, 1803.

Phalaena dispar, Blumenbach, Manuel d'Histoire Nat., vol. I, p. 465, 1803.

Stammphalane, Goeze, Naturgeschichte der Europais., vol. IX, p. 569, 1803.

Phalaena Bombyx Dispar, Bechsteln, Forstlnseckten, p. 369, pl. 6, fig. 1, $a-e, 1804$.

Bombyx dispar, Panzer, Syst. Nomen., p. 40, 1804.

Bombyx dispar, Latreille, Hist. Nat. des Crust et Ins., vol. XIV, p. 185, 1805.

Bombyx Dispar, Linn., Syst. Nat., Turton edition, vol. III, p. $20 \pi, 1806$. Bombyx Dispar, Hüb., Ges. Europ. Schm., pl. 37, fig. 2, a, b, c, 1806-18.

Liparis Dispar, Ochs., Schm. Eur., vol. III, p. 195, 1810.

Phalaena Dispar, Blumenbach, Abbild. Nat. Hist. Gegenstand, p. 370, 1810.

Bombyx disparate, Latreille, Crustaces, Arach. et Ins., pl. 8, flg. 2, 1810.

Laria Dispar, Leach, New Edinburgh Ency., Article Entomology, p. 721, 1815.

Phalaena Dispar, Salisbury, Hints to Propr. of Orchards, p. 67, pl. 1, figs. $10,11,1816$.

Sericaria dispar, Latreille, Le Regne Animal, vol. II, p. 269; Atlas, pl. 152, 1817.

Bombyx disparate, Latreille, Le Regne Animal, vol. III, p. 568, 1817.

Liparis Dispar, Zincken, Germar's Mag. der Ent., vol. III, p. 431, 1818.

Liparis dispar, Samouelle, Ent. Com., p. 246 (Gipsey Moth), 1819.

Liparis Dispar, Godart, Hist. Nat., vol. IV, p. 256, pl. 25, figs. 1, 2, 1822.

Porthetria Dispar, Hüib., Verz. bek. Schmett., p. 160, 1822 (?).

Bombyce disparate, Dumeril, Considerat. General., pl. 45, fig. 3, 1823.

*Laria dispar, Meig., Handb. für Schm., p. 122, pl. 47, 1827.

Hypogymna dispar, Daudville, Ann. Soc. d'Hort. Paris, vol. III, p. 98, 1828.

Hypogymna dispar, Daudville, Ann. Soc. d'Hort. Paris, vol. V, pp. 204, $324,1829$.

Bombyx dispar, J. M., Gardener's Mag., vol. V, p. 204, 1829.

Hypogymna dispar, Steph., Ill. Br. Ent. Haust., vol. II, p. 56, 1829.

*Liparis dispar, Klug., Verhandl. de Gesell, Naturf. Freunde, pp. 363, 369, pl. 1, flg. 20, 1829.

Hypogymna dispar, Steph., Cat. Ins. Haust., p. 50, 1829.

Hypogymna dispar, Rennle, Libr. of Entert. Knowl., vol. II, pp. 79-82, 1830.

Sericaria dispar, Latreille, Animal Kingdom, vol. IV, p. 201, 1831.

Liparis dispar, Bdv., Coll. Icon. et Hist. des Chenilles d'Eur., pl. IX, figs. $3,4,1832$. 
Bombyx dispar, Brown, Book of Butterfiles, vol. I, p. 52, 1832.

*Llparis dispar, Dup. et Guen., Icon. de l'Hist. Nat. Chenilles, vol. II, pl. 8, figs. 2-6, 1832.

Liparis dispar, Godart, Icon. des Chenilles, les Bombycltes, pl. 8, 1832.

*Hypogymna dispar, Rennie, Conspectus of Butterflies and Moths, p. 39, 1832.

Phalaena Bombyx dispar, Anon., Ann. de l'Inst. Hort. Fromont, vol. V, p. $311,1833$.

Liparis dispar, Silb., Revue Entomologique, ser. I, vol. I, p. 80, 1833.

Liparis Dispar, Bouché, Nat. Gesch. der Ins., Lleberung I, p. 106, 1834.

Liparis dispar, Burm., Manual of Entomology, p. 313, 1836.

Hypogymna dispar, Duncan, Naturalist's Library, vol. IV, p. 206, 1836.

Liparis dispar, Lacordaire, Manual of Entomology, p. 312, 1836.

Bombyx dispar, Sepp, title-page, vol. V, aberr. male, 1836.

Liparis dispar, De Selys, Cat. Lep. de la Belg., p. 28, 1837.

Liparis dispar, Krause, Arbeit. Schles. Gesell. f. vaterl. Kultur, p. 110, 1837.

Liparis dispar, Boie, Naturhistorisk Tidskrift, vol. I, p. 522, 1837.

Liparis dlspar, Audouin, Naturhistorisk Tidskrift, vol. II, p. 304, 1838.

Liparis dispar, Lacordaire, Intro. a l'Entomologie, vol. II, pp. 371, 383, 1838.

*Bombyce disparate, Debia, Rec. Agr. Soc. Dept., p. 156, pl. 1, 1838.

Hypogymna dispar, Curt., Br. Ent., vol. XVI, p. 767 (Gypsy Moth), 1839.

Bombyce disparate, Lamarck, Animaux sans Vertebres, vol. III, p. 77, 1839.

Bombyx dispar, Dejean, Anu. Soc. Ent. France, vol. VIII, p. 41, 1839.

Bombyx dispar, Reichenbacka, Galerya, Obr. Zwler. Hist. Nat., vol. II, p. $302,1839$.

Bombyx (Liparis) dispar, Nordl., Stett. Ent. Zeit., vol. I, p. 266, 1840.

Bombyx (Liparis) dispar, Kollar, Inj. Ins., English ed., p. 26, 1840.

Phalaena Bombyx dispar, Ratz., Forst. Ins., vol. II, p. 111, pl. 5, figs. $1 \mathrm{~F}, 1 \mathrm{~F}^{\prime}, 1 \mathrm{~K}, 1 \mathrm{~L}, 1 \mathrm{C}, 1840$.

Liparis dispar, Schultze, Stett. Ent. Zeit., vol. I, p. 49, 1840.

Iypogyinna dispar, Westw , Int. to Modern Classif. Ins., p. 384, 1840.

Bombyx dispar, Fonscol., Mem. de l'Acad. de Scl. Agr. Arts, etc., vol. V, p. 85,1840 .

Llparis Dlspar, Hering, Stett. Ent. Zeit., vol. III, p. 9, 1842.

Liparis dispar, Joly, Revue Zoologie, vol. V, p. 115, 1842.

Porthetria dispar, Humphrey and Westw., Br. Moths and their Transf., vol. I, p. 17, figs. 1-3, 1843.

Liparis Dispar, Duponchel, Cat. Methodique, p. 68, 1844.

Liparls Dispar, Eversmann, Fauna Lep. Volgo-Ural, p. 142, 1844.

Liparls Dispar, Herrich-Schaeffer, Eur. Schm., vol. II, p. 135, 1845.

Liparis dispar, Vilia, Memoria deg Insetti carnivori, p. 59, 1845.

Liparis dispar, Ratz., Stett. Ent. Zeit., vol. VII, p. 37, 1846.

Liparis dispar, Bellier, Ann. Soc. Ent. France, vol. XVI, p. 98, 1847.

Bombyx dispar, Johnson, Dict. of Modern Gardening, p. 92, 1847.

Bombyx dispar, Nordl., Stett. Ent. Zeit., vol. IX, p. 266, 1848.

Liparis dlspar, Belller, Bull. Soc. Ent. France, ser. II, vol. VII, p. 173, pl. $6,1849$.

Liparis dlspar, Guen., Hlst. Nat. Nocturnes, vol. II, pl. 8, fig. 2, $a, b, 1849$.

Liparis dispar, Bellier, Bull. Soc. Ent. France, ser. II, vol. X, p. 73, 1852.

Liparis dispar, Filippi, Stett. Ent. Zeit., vol. XIII, p. 263, 1852. 
Llparis Dispar, Speyer, Stett. Ent. Zeit., vol. XIII, p. 318, 1852.

Lymantrla dispar, Walk., Cat. Lep. Het., part IV, p. 872, 1855.

Bombyx dispar, Sepp, title-page, vol. VIII, aberr. male, 1855-60.

Liparis dispar, DeSelys (?), Ann. Soc. Ent. Belg., vol. I, p. 52, 1857.

Hypogymna dispar, Stainton, Manual, vol. I, p. 130, 1857.

Iypogymna Dispar, Humphrey, Gen. Br. Moths, p. 27, pl. 10, figs. 1-10, 1858.

Ocneria dispar, Speyer, Die Geograph. Verbreit. Schm., part I, p. 401, 1858.

Hypogymna Dispar, Kearley, Ent. Weekly Intelligencer, vol. IV, p. 192, 1858.

Rosenspinner, Hermann, Der Raupen und Schmetterlingsjäger, p. 81, 1859 .

Liparis dispar, Hagen, Stett. Ent. Zeit., vol. XXI, p. 34, 1860.

Liparls dlspar, Leunls, Zoologie, p. 543, 1860.

Hypogymna dispar, Batty, Ent. Weekly Intelligencer, vol. VIII, p. 141, 1860.

Hypogymna dispar, Stanley, Ent. Weekly Intelligencer, vol. VIII, p. 187, 1860.

Schwammspinner, Pueschl., Kurzgefasste Forst. Ency., Leipzic, pp. 186, 298, 1860.

Liparis dispar, Mulder, Tijdschrift voor Ent., ser. I, vol. II, p. 2, 1860.

Liparis dispar, Goreau, Ins. Nuis. aux Arbres Fruitiers, p. 89, 1861.

Liparis dispar, Hagen, Stett. Ent. Zeit., vol. XXII, p. 59, 1861.

Liparis Dispar, Rathke, Stett. Ent. Zelt., vol. XXII, p. 238, 1861.

Bombyx dispar, Siebold, Stett. Ent. Zeit., vol. XXII, p. 443, 1861.

Liparis dispar, Döbner, Zool., vol. II, p. 345, 1862.

Ocneria dispar, Speyer, Die Geog. Verbreit. Schm., part II, p. 287, Nachtrage, 1862.

Liparis dispar, Keller, Stett. Ent. Zeit., vol. XXIII, p. 284, 1862.

Liparis dispar, Prittw., Stett. Ent. Zeit., vol. XXIII, p. 382, 1862.

Liparis dispar, Newm., Proc. Ent. Soc. Lond., pp. 70, 77, 1862.

Ocneria dispar, Jaggi, Bull. Soc. Ent. Sulsse, vol. I, p. 313, 1862-65.

Liparis dispar, Bremer, Lepidopteren Ost-Siberlens, p. 41, 1864.

Liparis dispar, Bdv., Journ. Soc. Hort. France, p. 447, 1864.

Sericaria dispar, Mulder, Tijdschrift voor Ent., ser. I, vol. VII, p. 125, 1864.

Liparis dispar, Keppen, Horae Soc. Ent. Rossicae, pp. 81, 257, 287, 294, 1865.

Ocneria dispar, Tieffenbach, Berl. Ent. Zeit., vol. IX, p. 413, pl. 3, fig. 8, 1865.

Bombyx dispar, Samuels, Agriculture of Mass., p. 116, 1865-66.

Bombyx dispar, Ratz., Dię Waldverderbniss, vol. I, pp. 113, 226, 1866.

Ocnerla dispar, Maurissen, Tijdschrift voor Ent., ser. II, vol. IX, p. 176, 1866.

Liparis dispar, Brehm and Rossmassler, Die Thlere des Walden, vol. II, p. 107 , fig. 11 ; p. 108 , figs. $a-d, 1866-67$.

Ocnerla dispar, Pfutzner, Berl. Ent. Zeit., vol. XI, p. 199, 1867.

Liparis dispar, Westwood, Proc. Ent. Soc. Lond., pp. 44, 49, 1867.

Ocnerla dispar, de Gavere, Tijdschrift voor Ent., ser. II, vol. X, p. 200, 1867.

Bombyx dispar, Rudzky, Horae Soc. Ent. Rossicae, vol. V, p. 12, 1867.

*Ocneria Dispar, var. Disparina, Snell., Vlind. Nederl. Macro., p. 175, 1867. 
Liparis dispar, Bdv., Essai sur l'Entomologie Horticole, 1867.

Bombyx dispar, Ratz., Die Waldverderbniss, vol. II, pp. 12-151, etc., 1868.

Bombyx dispar, Berce, Bull. Ent. Soc. France, ser. III, vol. VIII, p. 61, 1868.

Liparis dispar, Dorfmelster, Stett. Ent. Zelt., vol. XXIX, p. 183, 1868.

Liparis dispar, Charault, Bull. Soc. Agr. Sci. Arts, vol. XI, pp. 688, 697, 1868.

Bombyx dispar, Senft, Systematische Bestimm. Deutsch., p. 77, pl. 1, 2, $3,5,1868$.

Llparis dispar, Girard, Bull. Soc. Ent. France, ser. III, vol. IX, p. 69, 1869.

Liparis dispar, Bull. della Soc. Ent. Italiana, vol. I, p. 69, 1869.

Bombyx dispar, Bull. della Soc. Ent. Italiana, vol. I, pp. 78-81, 1869.

Liparis dispar, Charault, Bull. Soc. Agr. Sci. Arts of Sarthe, vol. XII, p. 316, 1869.

Liparis Dispar, Kleferstein, Stett. Ent. Zeit., vol. XXX, p. 229, 1869.

Ocneria dispar, Speyer, Stett. Ent Zeit., vol. XXX, p. 246, 1869.

Phalaena Bombyx dispar, Ratz., Die Waldverderber, p. 184, pl. 5, flg. 1, 1869.

Liparis dispar, Newm., British Moths, p. 37, 1869.

Ocneria dispar, Jaggl, Bull. Soc. Ent. Suisse, vol. III, p. 100, 1869-70.

Hypogymna dispar, Riley, Annual Rep. Missouri, vol. II, p. 10, 1870.

Hypogymna dispar, Riley, Am. Ent., vol. II, p. 111, 1870.

Liparis dispar, Bargagli, Bull. della Soc. Ent. Italiana, vol. II, pp. 208, $262,279,1870$.

Bombyx dispar, Bazin, Bull. Soc. Hist. de l'Yonne, ser. I, vol. XXIV, pp. 11-20, 1870.

Ocneria dispar, Tratman, The Ent., vol. V, p. 172, 1870.

Ocneria dispar, Spiller, The Ent., vol. V, p. 183, 1870.

Ocneria dispar, Davidson, The Ent., vol. V, p. 213, 1870.

Ocneria dispar, Button, The Ent., vol. V, p. 393, 1870.

Ocneria dispar, Bowyer, The Ent., vol. V, p. 452, 1870.

Ocneria dispar, Hylaerts, Tljdschrift voor Ent., ser. II, vol. XIII, p. 148, 1870.

Ocneria Dispar, Kirby, Cassell's Eur. But. and Moths, p. 110, pl. 25, flgs. $a-c, 1870$ (?).

Liparis dispar, Briggs, Proc. Ent. Soc. Lond., p. 9, 1871.

Liparis dispar, Dohrn, Stett. Ent. Zeit., vol. XXXII, p. 29, 1871.

Liparis dispar, Dei, Bull. della Soc. Ent. Italiana, vol. III, pp. 75, 360, 1871.

Ocneria dispar, Hylaerts, Tijdschrift voor Ent., ser. II, vol. XIV, p. 38, 1871.

Bombyx dispar, Siebold, Bull. della Soc. Ent. Italiana, vol. IV, p. 121, 1872.

Liparis dispar, Plateau, Bull. della Soc. Ent. Italiana, vol. IV, p. 197, 1872.

Liparis dispar, Vinercati, Bull. della Soc. Ent. Italiana, vol. IV, p. 302, 1872.

Liparis dispar, Ghiliani, Bull. della Soc. Ent. Italiana, vol. IV, p. 365 , 1872.

Liparis dispar, Lelievre, Feuilles des Jeunes Naturalistes, vol. III, p. 77, 1872. 
Ocneria dispar, Hagen, Stett. Ent. Zeit., vol. XXXIII, p. 389, 1872.

Ocneria dispar, Nlckerl., Verh. z. B. Wlen., vol. XXII, p. 729, 1872.

Phalaena Bombyx dispar, Kauschinger, Die Lehre vom Walds., p. 65, fig. $13,1872$.

Liparis dispar, Greville, The Ent., vol. VI, p. 190, 1872.

Liparis dispar, Ciifford, The Ent., vol. VI, p. 289, 1872.

Liparis dispar, Standish, The Ent., vol. VI, p. 364, 1872.

Psilura dispar, Frey and Wullsch., Bull. Ent. Soc. Suisse, vol. IV, p. 258, 1873-76.

Ocneria dispar, Rigg.-Stehlin, Bull. Ent. Soc. Suisse, vol. IV, p. 597, 1873-76.

Liparis dispar, Rondani, Bull. della Soc. Ent. Italiana, vol. V, p. 164, 1873,

Ocneria dispar, Dihrik, Stett. Ent. Zeit., vol. XXXIV, p. 114, 1873.

Liparis dispar, Kaltenbach, Die Pflanzenfeinde, pp. 74, 158, 185, 205, 217, $429,1874$.

Ocneria dispar, Kaltenbach, Die Pflanzenfelnde, pp. 537, 548, 569, 594, $613,626,634,640,651,1874$.

*Liparis dispar, Barrett, Trans. Norwich Soc., suppl., p. 14, 1874.

Liparis dispar, Plateau, Recherches sur Digestion, etc., p. 84, 1874.

Bombyx (Liparis) dispar, Tasch., Ent. f. Gärt. und Garten, p. 219, figs. 58-61, 1874.

Liparis dispar, Targ. Tozz., Bull. della Soc. Ent. Itallana, vol. VI, p. 86, 1874.

Liparis dispar, Dubois, Lep. de Belgique, vol. II, p. 170, 1874.

Ocneria dispar, Lelievre, Feuilles des Jeunes Naturalistes, vol. V, pp. 97-100, 1874.

Liparis dispar, Girard, Bull. Soc. Ent. France, suppl., vol. IV, p. 129, 1874.

Liparis dispar, Girard, Bull. Soc. Ent. France, suppl., vol. V, p. 114, 1875.

Liparis dispar, Gaschet, Bull. Ent. Soc. France, ser. V, vol. V, p. ccxili, 1875.

Chenllles à oreilles, Ernst, Pap. de l'Europe, vol. IV, p. 106, pl. 138, 1875.

Liparis dispar, Villa, Lo. Studio Insetti in Lombardia, 1876.

Bombyx dispar, Blanchere, Rav. des For. et Arbres d'Align., pp. 178, 853, figs. 92, 93, 153, 154, 155, 156, 1876.

Ocneria dispar, Weithofer, Verh. ver Brünn., vol. XV, p. 39, 1876.

Liparis dispar, var. b, bordigalensis or disparoides, Mab. and Gasch., Bull. et Ann. Soc. Ent. France, ser. V, vol. VI, pp. 9, 521, 1876.

Liparis dispar, Mabille, Bull. Soc. Ent. France, suppl., vol.vI, p. 9, 1876.

Ocneria dispar, Bettonl, Considerazioni sopra casa, etc., p. 121, 1876.

Liparis dispar, Rondani, Bull. della Soc. Ent. Italiana, vol. VIII, p. 129, 1876.

Liparis dispar, Brehm, Thierleben, vol. IX, p. 15, 1877.

*Bombyx dispar, Bouché, Schwammraupe, Schwammspinner, vol. IV, p. 410, 1877.

Liparis dispar, Rondani, Bull. della Soc. Ent. Itallana, vol. IX, p. 55, 1877.

Liparis dispar, Depuisset, Les Paps., p. 248, pl. 24, fig. 2, $a-c, 1877$.

Ocneria dispar, Christoph., Stett. Ent. Zeit., vol. XXXIX, p. 408, 1878.

Ocneria Dispar, Cassel, Die Makrolep. der Amgegend Cassels, p. 113, 1878.

Ocneria dispar, Brants, Tijd. Ent., vol. V, p. 22, 1878.

Liparis dispar, Locard, Soc. Agr. Sci. and Arts of Lyons, 1878.

Ocneria dispar, Enock, The Ent., vol. XI, p. 170, 1878.

Ocneria dispar, Rondani, Bull. della Soc. Ent. Italiana, vol. X, p. 22, 1878. 
Ocneria dispar, Turati, Bull. della Soc. Ent. Italiana, vol. XI, p. 171, 1879.

*Dickkopfspinner, Hommerling, Isis, Russ., vol. IV, p. 86, 1879.

*Liparis dispar, Szalkay, Termeszet, Fuzetek, vol. IV, p. 105, 1879.

Liparis dispar, Pearce, The Ent., vol. XII, p. 229, 1879.

Bombyx dispar, Altum, Forstzoologie, vol. II, p. 324, 1880.

Psilura Dispar, Freyer, Lep. der Schweiz., p. 94, 1880.

*Liparis dispar, Slosarsk1, Der Polnische Gürtner, vol. II, pp. 69-92, 1880.

Liparis dispar, Wilson, Larvae of the Brit. Lep., p. 68, pl. 12, fig. 8, 1880 .

Ocneria dispar, Fiori, Bull. della Soc. Ent. Italiana, vol. XII, p. 214, 1880.

Ocneria dispar, Maassen, Stett. Ent. Zeit., vol. XLI, p. 168, 1880.

Ocneria dispar, Hering, Stett. Ent. Zeit., vol. XLII, p. 334, 1881.

Ocneria dispar, Standinger, Stett. Ent. Zeit., vol. XLII, p. 406, 1881.

Bombyx (Liparis) dispar, Schm-Gobel, Die Schädlichen Forstinseckten, part I, p. 99, fig. $95,1881$.

Bombyx (Llparis) dispar, Schm-Gobel, Die Schädlichen Forstlnseckten, part II, p. 96, 1881.

Bombyx dispar, Altum, Forstzoologie, vol. II, p. 324, 1881.

Liparis dispar, Goossens, Bull. Ent. Soc. France, vol. I, p. 232, 1881.

Liparis dispar, Lucas, Bull. Ent. Soc. France, vol. I, p. 148, 1881.

Liparis dispar, Girard, Bull. Ent. Soc. France, vol. II, 1882.

Ocnerla dispar, Gauckler, Katter's Ent. Nachtrichten, vol. VIII, p. 274, 1882.

Liparis dispar, Altum, Forstzoologie, vol. III, p. 94, 1882.

Ocneria dispar, Teich., Stett. Ent. Zeit., vol. XLIV, p. 171, 1883.

Ocneria dispar, Keppen, Injurious Insects, vol. III, p. 49, 1883.

Ocneria dispar, Mina, Naturalista Sicil. Giorna. Scl. Nat., vol. III, p. 54, 1883.

Ocneria dispar, Oudemans, Tijd. Ent., vol. XXVII, p. 16, 1884.

Ocneria Dispar, Homeyer, Stett. Ent. Zeit., vol. XLV, p. 424, 1884.

Ocneria dispar, Tasch., Brehm's Thierleben, Inseckten, p. 395, figs. 1-3, 1884.

*Ocneria dispar, Kalchberg, Naturalista Sicil. Giorna. Sci. Nat., vol. IV, p. 55, 1884-85.

Hypogymna dispar, Wood, Animated Creation, vol. III, p. 423, 1885.

Ocneria dispar, Bull. della Soc. Ent. Italiana, vol. XVII, p. 156, 1885.

Ocneria dlspar, Raynor, The Ent., vol. XVIII, p. 243, 1885.

Ocneria dispar, St. John, The Ent., vol. XIX, p. 250, 1886.

Ocneria dispar, Adkin, The Ent., vol. XIX, p. 281, 1886.

Ocneria dispar, Blaber, The Ent., vol. XIX, p. 281, 1886.

Ocneria dispar, Hall, The Ent., vol. XIX, p. 282, 1886.

Ocneria dispar, Buckler, Larvae of Brit. Butterflies, vol. III, p. 37, 1886.

Liparis dispar, Brocchi, Traitê de Zoologie Agricole, p. 451, 1886.

Ocneria dispar, ab. semlobscura, Thlerry, Le Naturalist, vol. VIII, p. 237, 1886.

Ocneria dispar, ab. erebus, Thlerry, Le Naturalist, vol. VIII, p. 237, 1886.

Ocneria dispar, ab. semiobscura, Meig., Le Naturalist, vol. VIII, p. 237, 1886.

Ocneria dispar, ab. erebus, Meig., Le Naturalist, vol. VIII, p. 237, 1886.

*The Gypsy Moth, Dictionary of Gardening (Insects), vol. II, p. 182, 1887.

Ocneria dispar, Edwards, The Eut., vol. XX, p. 275, 1887.

Liparis dispar, Goossens, Bull. Ent. Soc. France, ser. VI, vol. VII, p. 166, 1887. 
Liparis dispar, Bellier, Bull. Ent. Soc. France, ser. VI, vol. VII, p. 182, 1887.

Ocneria (Liparis) dispar, Hess, Der Forstschutz., ed. II, vol. II, pp. 70-75, fig. 53, $a-d, 1887$.

Ocneria dispar, Theile, Berl. Ent. Zelt., vol. XXXI, p. 23, 1887.

Ocneria dispar, Mina, Naturalista Sicil. Giorn. Sci. Nat., vol. VII, p. 225, 1887-88.

Ocneria Dispar, Graeser, Berl. Ent. Zeit., vol. XXXII, p. 125, 1888.

Ocneria Dispar, Ziegler, Berl. Ent. Zeit., vol. XXXII, p. 23, 1888.

*Liparis dispar, Oliv , Rev. Sci. Bourb., vol. I, p. 210, 1888.

Ocneria dispar, Bock, Ent. Nachr., vol. XIV, p. 56, 1888.

Ocneria dlspar, Jackson, The Ent., vol. XXI, pp. 235, 322, 1888.

Ocneria dispar, Waik., Ent. Mon. Mag., vol. XXV, p. 65, 1888.

Lymantria dispar, Leech, Proc. Zool. Soc. Lond., vol. LVI, pp. 30, 63, 1888.

Liparis dispar, Platner, Biol. Centralbl., vol. V, p. 521, 1888.

*Schwammspinner, Katzer, Zum Frasse des Schwammsp. in Kroatien, 1888-89.

Bombyx (Liparis) dispar, Fürst, Kauchinger's Lehre von Walds., ed. 4, pp. 140,141 , pl. $3,1889$.

Liparis (Ocneria) dispar, Targ. Tozz., Bull. della Soc. Ent. Ital., vol. XXI, pp. 113, 272, 1889.

Ocnerla dispar, Cuné, Act. Soc. Esp., vol. XVIII, p. 77, 1889.

Ocneria dispar, Berge, Schmett., p. 63, pl. 26, fig. 2, $a-c, 1889$.

Ocneria dispar, Porchinsky, Ins. Inj. to Fruit Gardens, Crimea, pp. 14-20, 1889.

Liparis dispar, Tunley, The Ent., vol. XXII, p. 259, 1889.

Ocneria dispar, Hall, The Ent., vol. XXII, p. 161, 1889.

Ocneria dlspar, St. John, The Ent., vol. XXII, p. 162, 1889.

Ocneria dispar, Arkle, The Ent., vol. XXII, p. 186, 1889.

Ocneria dispar, Fernald, Mass. Hatch Exp. Station, Special Bulletin, 1889. Hypogymna dispar, Buck, Larvae Brit. Moths, pl. 37, figs. 6, 6a, 1889.

Ocneria dispar, Howard, Proc. Ent. Soc. Wash., vol. I, p. 264, 1889.

Ocneria dlspar, Del, Bull. della Soc. Ent. Ital., vol. XXII, p. 276, 1890.

Ocneria dispar, Wingelmuller, Mem. Ill. Garten Zeltung, p. 269, 1890.

Liparis Dispar, Raspail, Bull. Soc. Zool. France, vol. XV, p. 94, 1890.

Liparis dispar, Montillot, Amateur d'Insectes, p. 252, 1890.

The Gypsy Moth, Rep. Mass. Bd. Agr., p. 58, 1890.

Ocneria dispar, Ent. Record, vol. I, p. 225, 1890.

Ocneria dispar, Ent. Record, vol. II, p. 24, 1890.

Ocneria dispar, Pack., Rep. U. S. Ent. Com., vol. V., p. 138, 1890.

The Gypsy Moth, Sargent, Garden and Forest, vol. III, p. 150, 1890.

Gypsy Moth, Jack, Garden and Forest, vol. III, pp. 273, 277, 1890.

Ocneria dispar, Riley and Howard, Ins. Life, vol. II, pp. 86, 208, 262, 1890.

Ocneria dispar, Rlley and Howard, Ins. Llfe, vol. III, pp. 41, 78, 126, 1890.

Ocneria dispar, Rlley and Howard, Ins. Life, vol. III, pp. 200, 297, 364, $368,381,472,474,491,1891$.

Ocneria dispar, Lintn., Rep. Ins. N. Y., vol. VII, pp. 302, 304, 335, 357, 1891.

Ocneria dispar, Forbush and Fernald, Rep. Mass. Bd. Agr., p. 289, 1891.

Ocnerla dispar, Butler, Ins. Life, vol. III, p. 277, 1891.

Ocnerla dispar, Weir, Ins. Llfe, vol. IV, p. 138, 1891. 
The Gypsy Moth, Jack, Garden and Forest, vol. IV, p. 111, 1891.

The Gypsy Moth, Fernow, Garden and Forest, vol. IV, p. 142, 1891.

The Gypsy Moth, Smith, Garden and Forest, vol. IV, p. 153, 1891.

Bombyx (Liparis) dispar, Demaison, Bull. Ent. Soc. France, vol. LX, p. $14,1891$.

Liparis dispar, Bezzl, Bull. della Soc. Ent. Ital., vol. XXXIII, p. 74, 1891.

Ocneria dispar, de Mnro, Bull. della Soc. Ent. Ital., vol. XXXIII, p. 328, 1891.

Ocneria dispar, Ent. Record, vol. III, pp. 53, 183, 1891.

Ocneria dispar, Fernald, Mass. Hatch Exp. Sta., Bull. 19, p. 109, 1892.

Ocneria dispar, Fernald, Can. Ent. vol. XXIV, p. 87, 1892.

Ocneria dispar, Forbush and Fernald, Rep. Mass. Bd. Agr., p. 259, 1892.

Ocneria dispar, Henshaw, U. S. Dept. Agr., Bull. 26, p. 75, 1892.

The Gypsy Moth, Jack, Garden and Forest, vol. V, p. 75, 1892.

The Gypsy Moth, S., Garden and Forest, vol. V, p. 81, 1892.

The Gypsy Moth, Nutter, Garden and Forest, vol. V, p. 119, 1892.

Ocnerla dispar, Riley and Howard, Ins. Life, vol. IV, pp. 227, 356, 1892.

Ocneria dispar, Riley and Howard, Ins. Life, vol. V, pp. 54, 194, 1892.

Ocneria dispar, Hertwig, Text Book of Embryology, translated by Mark, p. $34,1892$.

Ocneria dispar, Bethune, Rep. Ent. Soc. Ont., vol. XXIII, p. 86, 1892.

Gypsy Moth, Beddard, Animal Coloration, p. 272, fig. 36, 1892.

Ocneria dispar, Ent. Record, vol. III, pp. 699, 869, 1892.

Ocneria dispar, Ent. Record, vol. IV, p. 204, 1892.

Porthetria Dispar, Kirby, Cat. Lep. Het., vol. I, p. 475, 1892.

Ocneria dispar, de Carlini, Bull. della Soc. Ent. Ital., vol. XXIV, p. 86, 1892.

Ocneria dispar, South, The Ent., vol. XXV, p. 259, 1892.

Ocneria dispar, Hodkinson, The Ent., vol. XXVI, p. 20, 1893.

Ocneria Dispar, Hofman, Die Raupen der Gross-Schmett., p. 57, pl. 16, fig. 13, 1893.

Ocneria dispar, Ecksteln, Die Klefer, vol. I, p. 22, pl. 13, figs. 4-9, 1893.

Bombyx (Liparis) dispar, Fiurst and Nlsbet, Prot. of Woodlands, Eng. ed., pp. 126, 207, pl. 3, fig. 19, 1893.

Ocneria dispar, Forbush and Fernald, Rep. Mass. Bd. Agr., p. 263, 1893.

Ocnerla dispar, Lintn., Rep. Ins. N. Y., vol. IX, pp. 422, 433, 440, 1893.

Liparis dispar, Judeich and Nitsche, Lehrbuck der Mit.-Europ. Forstinseckt., vol. III, 1893.

Ocneria dispar, Seltz, Stett. Ent. Zeit., vol. LIV, p. 369, 1893.

Ocneria dispar, Rlley and Howard, Ins. Life, vol. VI, pp. 53, 235, 338, 1893.

Ocneria dispar, Skinner, Ent. News, vol. IV, p. 158, 1893.

Porthetria dispar, Dyar, Proc. Bos. Soc. Nat. Hist., vol. XXVI, p. 155, 1893.

Ocneria dispar, Weed, Am. Nat., vol. XXVII, p. 750, 1893.

Ocneria dispar, Kingsley, Am. Nat., vol. XXVII, p. 1070, 1893.

Ocneria dispar, Nicholson, Ent. Record, vol. V, pp. 236, 310, 1893.

Ocnerla dispar, Weed, N. H. Coll. Ag. Exp. Sta., Bull. 23, p. 30, 1894.

Hypogymna dispar, Barrett, Lep. Brit. Islands, part XX, p. 303, 1894.

Ocnerla dispar, Furneaux, Butterflies and Moths, p. 227, 1894.

Ocneria dispar, Kulagin, Ins. Inj. to Gard. and Orchards in Russia, 1894. 
Ocneria dispar, Rudzky, Ins. Useful and Inj. to Fruit Trees, pp. 9-13, 1894.

Ocneria dispar, Kane, The Ent., vol. XXVII, p. 15, 1894.

Ocneria dispar, South, The Ent., vol. XXVII, p. 25, 1894.

Ocneria dispar, Turner, The Ent., vol. XXVII, p. 153, 1894.

Ocneria dispar, Forbush and Fernald, Rep. Mass. Bd. Agr., 1894.

The Gypsy Moth, Ent. Record, vol. VI, p. 314, 1895.

The Gypsy Moth, Ent. Record, vol. VII, p. 146, 1895.

Ocneria dispar, Mocsary, Termeszet. Fuzetek, vol. XVIII, pp. 67, 72, 1895.

Porthetria dispar, Comstock, Manual for the Study of Insects, p. 312, fig. $378,1895$.

Ocneria dispar, Fletcher, Rep. Ent. Soc. Ont., vol. XXV, p. 67, 1895.

The Gypsy Moth, Fletcher, Trans. Royal Soc. Can., vol. I, p. 14, 1895.

Ocnerla dispar, Meyrick, Handbook of British Lepidoptera, p. 175, 1895.

\section{Distribution in Other Countries.}

The gypsy moth has a wide distribution in the old world. Speyer, in "Die Geographische Verbreitung der Schmetterlinge," published in 1858-62, Vol. I, page 401, and Vol. II, page 287 , informs us that it extends over the entire region, from the lowlands to the highlands, through middle and southern Europe, western Asia and northern Africa, reaching from Stockholm on the north to Algiers on the south, England on the west, the Altai Mountains and the Caspian Sea on the east. It extends also into eastern Asia, including Japan; and the tropics, Neitner having found it in Ceylon.

Bremer, in his "Lepidopteren Ost-Siberiens," published in 1864, reported it in south-eastern Siberia. Staudinger, in his "Catalog der Europæischen Faunengebiets," published in 1871, gives for the distribution of the gypsy moth the entire territory, except the northern countries, including southern Sweden and England. He also doubtfully includes Livonia. Græser states that the young caterpillars of this species were very common in the early part of June, 1881, near Vladivostock, Siberia. He further states that the caterpillars in Amoor have a very different appearance from those in Europe, the prevailing color being yellow; but all the moths bred from these caterpillars were entirely like those of Europe, "Berlin Ent. Zeits.," Vol. XXXII. In 1861, Homeyer reported the gypsy moth on the Island of Majorca in great abundance, destroying both deciduous and evergreen trees. In the "Entomologist's Monthly Magazine," Vol. 
XXV, page 65,1888 , Mr. J. J. Walker reported that he found this insect in great abundance in southern Spain, near the village of Los Barrios. In a work on "Injurious Insects," by Theodore Keppen, published in Russian and translated for me by Dr. F. B. Stephenson, U. S. N., it is stated that this insect occurs in the central and southern parts of Russia, in the Caucasus and all southern Siberia, but it does not occur in the vicinity of St. Petersburg. He further states that, according to Nolken, it does not appear in the Baltic Provinces, but has been found occasionally in Livonia, and, on the authority of Albrecht, it is very common in the vicinity of Moscow. Romanoff, in the sixth volume of his "Memoires sur les Lepidopteres," reports it in North China, and $I$ have in my collection three male gypsy moths fiom Pekin, China, received from Dr. O. Staudinger. In a letter from Dr. Ritzema-Boz of Holland, dated Sept. 3, 1895, he writes, "This insect is common in Holland and also in all western Europe."

\section{The Gypsy Moth in England.}

The earliest information that I have found of the presence of the gypsy moth in England, is given by Wilkes, in his work entitled "Twelve New Designs of English Butterflies," published in London in 1741-42, with twelve plates, but without text. Plate X, Fig. 2, represents the insect under the name "The Gipsey Moth."

Harris described it in his " Aurelian's Pocket Companion," published in 1775. Donovan, in his "Natural History of British Insects," Vol. V, published in 1796, figures this insect on Plate CLXIII, and describes it on pages 67-69, calling it the "Gipsey Moth." In his account he says: "That the Phalena Dispar was not uncommonly scarce about fifteen years ago, is evident from this circumstance, few collections of British insects that were in the hands of eminent collectors are without an English specimen, which was procured about that time." From his further account we infer that he considered it a rare insect in England. Haworth, in his "Lepidoptera Britannica," page 88, published in 1803, calls it Bombyx disparus, and for a common name "The Gipsy," and says it is very rare. Salisbury, in his "Hints to Pro- 
prietors of Orchards," published in London in 1816, gives the fullest and most complete account of the gypsy moth that I have seen in English up to that date. He states that this caterpillar is common in gardens and woods, where it does considerable damage.

Stephens, in Vol. II, page 56, "Illustrations of British Entomology," Haustellata, 1829, says it is not common near London, but appears to abound in the fens of Huntingdonshire. He also refers to the statement that it was introduced into Britain by eggs imported by Mr. Collinson, but says that the abundance with which it occurs near Whittlesea, and the dissimilarity of the indigenous specimens (which are invariably paler, with stronger markings) to the foreign, sufficiently refute the opinion.

Curtis, in his "British Entomology," Vol. XVI, 1839, alludes to the scarcity of this species in the time of Donovan, and speaks of finding them in considerable numbers, when a boy, in the marshes at Horning, in Norfolk. Mr. Stainton, in his " Manual of Butterflies and Moths," Vol. I, page 130, 1857 , says, "It is found plentifully in fenny districts, but is not generally common." George Kearley, in the "Entomologist's Weekly Intelligencer," Vol. IV, page 192, 1858, speaks of the gradual disappearance of the gypsy moth in England, and states that it was claimed by some to have actually become extinct in that country. Mr. Richard South, in the "Entomologist," Vol. XXV, page 259, 1892, states that entomologists in 1870 seem to have been a little troubled about the right of the gypsy moth to be considered a British insect, referring, of course, to those caterpillars or imagoes which were then found at large. He further says, after speaking of specimens having been found from time to time, that there is no reasonable doubt that this species is extinct in England; "that somewhere about the fourth decade of this century, the species began to decrease in numbers, and that toward the end of the fifties it had practically ceased to exist as a wildling in this country."

Numerous attempts have been made to introduce this insect into England again, but they do not appear to have been successful. Many entomologists have bred it in confinement, continuing until it can now be regarded only as a semi-do- 
mesticated species in England; and complete degeneration of the stock, by the process known as "in-and-in breeding," is possibly averted by the periodical introduction of eggs from the Continent.

The late Mr. J. Jenner Weir, in a letter to "Insect Life," Vol. IV, page 138, 1891, said that the gypsy moth had been unintentionally exterminated in England, and further writes, "I think the gypsy moth must have been destroyed simply by collectors." Mr. C. G. Barrett, in his "Lepidoptera of the British Islands," Vol. II, page 303, 1894, gives a very good history of the occurrence of this moth in England and of its probable disappearance, but without assigning any cause for such disappearance.

Mr. C. Nicholson read a paper on the life-history of the gypsy moth, before the City of London Entomological and Natural History Society, Sept. 18, 1894, in which he proposed for discussion, among others, the question why this insect had become extinct in England. Mr. J. W. Tutt gave it as his opinion that it was because the insect was not a native. " Its whole history proved it to be an imported species, even when it first became known. Thousands of specimens in all stages had been set loose in various parts of the country, but, with the exception of an odd specimen here and there, no specimens were taken wild. Its abundance in the fens for a year or two simply pointed to the care with which it was put out, and to the temporary existence of favorable conditions. There are thousands of acres of land, to all intents and purposes fitted for its establishment here, but it - possibly the agriculturists would say fortunately - will not establish itself."

The history of the gypsy moth in the United States does not seem to lend force to the view taken by Mr. Tutt, as much as we wish it might prove true, for it seems to thrive as well here as in any part of the old world. America is indebted to Europe for a long list of insect pests, many of which are far more injurious, because of their unrestricted increase, than in their native country; notable among these are the currant saw-fly (Nematus ribesii), the larch saw-fly (Nematus erichsonii), the cabbage butterfly (Pieris rapo), the Buffalo carpet-beetle (Anthrenus scrophularioe) and many 
others, none of which show any indications of a decline in a foreign country. The idea of Mr. Weir, that they were destroyed in England by collectors, hardly. seems worthy of consideration. I will not attempt to express an opinion as to the cause of their extinction in that country, but it seems to me that it must be due to causes not yet understood; and if the profound thinkers in entomological matters, of whom England has so many, have not satisfactorily settled this question, it would be folly for me to express any decided opinion on the subject. I wish, however, to call attention to one or two points. Great Britain, because of its insular position, the prevailing winds and the currents in the surrounding ocean, has a far different climate from that of Massachusetts or the interior of Europe and other parts of the old world, where this insect is usually most abundant. I noticed, when in England, that the foliage of all vegetation seemed darker than in this country, or, at least, than in the eastern part of it; and it occurred to me that this might be due, in part, to the larger amount of moisture in the atmosphere, especially as quite similar conditions of climate, with darker foliage occur in British Columbia, as I have been informed by my colleague, Mr. E. H. Forbush, who also states that the arboreal animals of that region are much darker than those in the eastern parts of the United States. Some years ago, while in England, my kind friend, Mr. C. G. Barrett, gave me a very complete series of British Tortricids, and I never look at my collection without noticing how much darker these insects are than the same species from Germany and other parts of Europe. It seems to me that this darkening may have resulted from natural causes, operating through a very long period of years. When these insects first made their way into the British forests and fens, with their darker surroundings, the lighter colored individuals, contrasting the most with the objects on which they rested, naturally fell a prey to their enemies more readily than the dark-colored individuals ; the darker ones were left to propagate the species, and, in time, a dark race was formed. I am well aware that I am now trespassing on ground which is far better understood by my English brethren, but I trust that I may be permitted to call attention to this matter for 
the purpose of considering the bearing of environment and climate on the gypsy moth.

If we suppose that the native home of this insect was in central Europe or south-western Asia, and that it was developed from some progenitor in which the sexes were of the same color, possibly not very unlike the males of the present time, we may well suppose that, as the females developed a larger number of eggs, rendering them so heavy that they flew but rarely, and, in time, not at all, their wings, not being used, would grow weaker and less useful as organs of flight, as we now find them. Under these circumstances, suppose them to be inhabiting trees and shrubs, the bark of which is of light color, as birch, their enemies, the birds, etc., could readily distinguish these strongly contrasting females on the trunks of the trees and destroy the darker forms, leaving the lighter examples to propagate the species; and, as this went on, in time permanently light-colored females would be produced.

The males fly actively during the day, and are captured, while on the wing, by insectivorous birds; but in this case slight variations in color would not be apparent to the birds, and no discrimination would be made in favor of such variations. For this reason the males have probably retained more of their primitive color and appearance, while the females have made a most remarkable change; and, as a result, this insect furnishes a most striking illustration of what is called sexual dimorphism.

Another reason for thinking that the males have changed far less than the females, and that the changes made were perhaps in a different direction, is the fact that they more nearly resemble the males of allied species than they do the females of their own. Compare Figs. 3 and 4, on Plate I., with Figs. 11, 14 and 17, on Plate 39, and also with Figs. 1 and 2, on Plate I. The three species of Orgyia just referred to have wingless females (one of which, O. leucostigma, is represented on Plate 39, Fig. 18), which are so heavy that it would be impossible for them to fly with wings of ordinary size. It is probahle, however, that the remote ancestors of these insects were winged in both sexes, and that, as the female developed a larger reproductive system and more eggs, she 
became too heavy for flight, and at last abandoned all attempts, just as the gypsy moth is now doing, and that by disuse these organs became atrophied, and nothing now remains but mere rudiments of the wings. A similar fate possibly awaits the gypsy moth. Two of the species of Orgyia, figured on Plate 39, Figs. 14 and 17, are so-called natives of this country; while the other, Fig. 11, is a native of Europe, and has been in this country probably a comparatively short time, not long enough, at any rate, for the new environment to produce any noticeable change. Since the introduction of $O$. definita (Fig. 14) and O. leucostigma into this country, whenever and in whatever way that may have happened, the three species have been in an environment which has produced marked changes in the males, while the wingless females have probably changed far less. The two American species have changed so little from each other that $O$. definita, for a long time, was not recognized as a distinct species. It may have branched off from the stem of leucostigma at a comparatively recent date.

If, in comparatively recent times, the gypsy moth made its way into England, by the help of man or otherwise, may not the darker color of the foliage and other surroundings have rendered the female moths more conspicuous objects to their enemies, so that, " in the struggle for existence," this species was exterminated before it had time to take on the darker colors, as may have been the case with the British Tortricids? It may be thought that the warm, damp climate of England would favor fungoid plants which are destructive to insect life ; but, if this caused the extermination of the gypsy moth in England, why has it not also caused the extermination of numerous other species with more or less similar larval habits? If any of the above conditions caused the extinction of this moth in England, we have little to hope for in America, since so very little of our territory has any such climatic conditions as England.

\section{INJURIES IN THE OLD WORLD.}

There are many accounts, in the older books, of extensive damage done by insects at different times in various parts of Europe, some of which was probably caused by the gypsy 
moth; but it is impossible to be quite sure what insects may have been referred to in these old accounts for the reason that only local common names were used before 1758 , when Linnæus introduced the custom of giving a scientific name to each insect, by which it should be known in all countries.

In a work entitled " Beschreibung von allerlei Insecten in Teutschland," by J. L. Frisch, published in Berlin, 1720, Vol. I, page 14 , is a brief notice of a garden and forest caterpillar which is evidently the gypsy moth. Plate III represents a male, a female laying her eggs, a caterpillar, the anterior and posterior ends of a caterpillar and a male antenna. He writes of this insect as follows: "This caterpillar, in the third part of the copper-plate, Fig. 1, is called Bunt-Knopffig, on account of the light violet-blue and purple-red tubercles on its back, and also Garten und Forstraupe (garden and forest caterpillar), because it not only destroys all the leaves of the fruit-bearing trees of the orchard, but also does not hesitate to attack forest trees, especially the oaks, on which it is found every year. In this year, 1720, this caterpillar entirely stripped every tree of the double row of lindens along the road from Neustadt to Berlin." In the appendix to this work, published later, is a statement that a certain injurious caterpillar (possibly the gypsy moth), in 1721 and 1722, ravaged not only the fruit trees, throughout Germany, but also oaks and other forest trees, and even killed many of them.

Thomas Brown, in the " Book of Butterflies," Vol. II, page 52 , published in London in 1832, states that in 1731 the caterpillars of the gypsy moth committed terrible havoc among the cork oaks of France.

In 1761, J. C. Schaeffer published a work on the gypsy moth, the first edition of which appeared in 1752. He states that in this last year the trees in the orchards and gardens, the bushes in the fields, and even whole forests, not only in many places in Saxony but also in Altenburg, Leitz, Naumburg, Sangerhausen and many other regions, were entirely stripped of their leaves. The branches and twigs were densely covered with caterpillars, instead of leaves, and they also crawled over the ground in great numbers. An examination proved that they all belonged to this one species, and 
that they had been more or less abundant for three years in succession. The first year there were not very many, the second they were comparatively numerous and the third year they were present in overwhelming numbers. Some of the common people thought that the caterpillars grew out of the ground, like the grass; others thought that they were created by the evil one; still others assured the author that they had seen with their own eyes thousands of the caterpillars brought by the wind; and, finally, there were many who thought these caterpillars were sent by God as a punishment for their sins. The author states that about eleven years before, he saw this same species in Saxony, after having stripped the leaves from every tree and shrub in the vicinity, feed on grass and grain.

In the " Naturforscher," Vol. XVI, page 130, 1781, Pastor C. J. Rimrod gave a long and very good account of the gypsy moth, and wrote of two invasions at his home in Quenstedt, one in 1760-61 and the other in 1781 .

Preyssler, as stated by Bechstein, in his " Vollstandige Naturgeschichte der schädlichen Forstinsekten," page 372, 1804 , says that the gypsy moth was once very common at Prague, and stripped the leaves from the fruit trees, so that they bore no fruit. Bechstein, in the same place, says that this is a formidable insect, against which very active measures must be taken, for, because of its large brood and great voracity, the damage done by the caterpillars may be easily understood. Linnæus and Fabricius call it the pest of the fruit garden.

Panzer, in his “ Faunæ Insectorum Germanicæ," Vol. II, page 22,1794, says the caterpillars of this insect appeared for many years in frightful numbers, and destroyed the fruit trees to the great injury of their owners. In 1818, the cork-oak forests extending from Barbaste to Podenas, in soutb-western France, were devastated by innumerable hosts of gypsy moth caterpillars. After having devoured both the leaves and the acorns, they attacked the maize, nillet, fodder and all the fruits. They even invaded the dwellings in the neighborhood of the trees, to the extreme annoyance of the occupants.

Godart says, in his "Iconographie des Chenilles, Les Bombycites," published in 1832 : “This caterpillar lives on nearly 
every species of tree, and, as it is as common as voracious, it often causes great damage to orchards of fruit trees as well as in the parks and forests, and, together with other caterpillars, often completely defoliates them." This same author, in his "Histoire Naturelle," Vol. IV, page 256, states that in 1823 the trees in the forest of Senart in Fontainebleau were entirely defoliated by the gypsy moth, so that the trees were as bare as in winter. Finding nothing further to devour, the caterpillars crawled over the ground in all directions, seeking food. M. Daudeville, writing in the "Annales de la Société d'Horticulture de Paris," Vol. III, page 98, 1828, after referring to this caterpillar and the descriptions that had been given of it, said that the pest extended from the west to the north-east of the city of Saint Quentin, for a distance of more than sixty miles, and had completely devastated the trees, so that they were entirely bare. These insatiable insects not only devoured the buds, leaves and flowers, but even the small twigs of fruit trees. For three years, in an orchard of three hundred apple trees, they had not left a leaf intact, and the gradual decay and death of several of the trees were attributed to these insects. In the same journal it was stated that Viscount Hericart of Thury, in a journey which he had just completed, observed that the apple trees in the departments of Calvados, the Eure, Eureet-Loir, the Seine-Inférieur, Seine-et-Oise, the Oise, the Somme and the Aisne were entirely ravaged by this insect.

Mons. N. Joly, in the " Revue Zoologique," Vol. V, page 115,1842 , says that during the years 1837,1838 and 1839 , there appeared in the forests around Toulouse in France an innumerable quantity of the gypsy moth. The caterpillars of this insect attacked the oaks with such avidity as to strip them completely of their foliage, so that after the first onslaught the trees appeared as they do in winter. The caterpillars were so numerous that persons passing through the woods could hear them eating, and might easily believe themselves in the midst of a menagerie. These devastating insects occupied an area of more than twenty-five square leagues.* On their approach to Toulouse they attacked

- An area nearly as large as the infested territory in Massachusetts. 
the willows, which they damaged much less, because of the ability this tree possesses of putting on new foliage. In the " Stettiner Entomologische Zeitung," Vol. IX, page 266, 1848 , it is stated that Riegel in 1838 saw about eight acres of oak woods entirely stripped of leaves by the gypsy moth. Ratzeburg, in "Die Waldverderbniss," published in 1868, Vol. II, page 154, says the gypsy moth, ten years before, had spread, in a space of three years, from Brandenburg to the zoölogical gardens. On page 189 he says that the size and voracity of this caterpillar (gypsy moth) and the vast numbers in which they sometimes appear make the results for the beech, as well as for the elm, frightful in the extreme. In the zoölogical gardens at Berlin the beeches are said to have been severely attacked. A very competent observer, Dr. Gerstäcker, as an eye-witness, stated that in 1852 many beeches became dry and dead. In that year all the caterpillars transformed, but in 1853, not having sufficient food, many died of starvation. On page 339, in speaking of the ravages of different species of caterpillars, he says that Bombyx dispar (the gypsy moth) may be mentioned first as being the largest and most ravenous, and further says that he knew of a devastation by which was caused the weakening and death of many trees. This author states (page 185) that in the great devastation which occurred in the zoölogical gardens at Berlin, in 1851-53, these caterpillars attacked not only the native but also the foreign trees and shrubs cultivated there, no species being entirely avoided by them.

Bazin, in an article on "The Ravages upon the Oaks by Bombyx dispar," published in "Bulletin de la Société des Sciences historiques et naturelles de l'Yonne," pages 11-20, 1870 , speaks of the abundance of this species everywhere. Before the middle of June, 1868, " there were spots in the woods that every day spread like spots of oil on the water, where not a leaf remained on the trees or shrubs." The oaks were attacked first, and after they had been stripped the birches, aspens, elms and even pines and larches were completely denuded. In the fields a large number of apple trees were defoliated by this caterpillar, and the apples themselves were sometimes eaten into to such an extent that they became malformed. In the same article M. Bazin states that it was 
reported that caterpillars of this species had occasioned the death of children who had eaten strawberries upon which these caterpillars had rested, and that, as a consequence, the sale of strawberries had been prohibited in certain regions. It did not seem possible that the story of the death of the children from this cause could be true, or even that any derangement of the digestive system could have occurred. To test the statement, M. Bazin put four gypsy moth caterpillars in a wide-mouthed bottle with twelve strawberries and a strawberry leaf. At the end of twenty-four hours they had eaten a very little of the leaf and also a little of the strawberries, but had not eaten them with the avidity that they do other kinds of food. They had been in contact with the strawberries more completely, however, than they would if they had been at liberty, for they had crawled over the berries again and again, and, if they had the power to impart to them any injurious properties by contact, they must have done so under these conditions. M. Bazin then ate four of these strawberries, and, a little later, feeling no inconvenience from these, ate the remaining eight, without the slightest disturbance in the stomach. As the opinion prevailed more or less widely that cows and other animals that had eaten these caterpillars had been made sick, he caused a dog to swallow some of them, but the animal gave no indication of inconvenience.

In reviewing Dr. E. L. Taschenberg's " Entomologie für Gärtner," etc., in the "Stettiner Entomologische Zeitung," Vol. XXXII, page 167, 1871, Dr. Dohrn, in speaking of the gypsy moth, says that from his experience the active caterpillars, after escaping from the eggs, can crawl about for eight or ten days without food. He states that on May 3,1854 , he was in Glogau, and noticed gypsy moth caterpillars crawling on his own clothing as well as on that of others. Under the roof of the shed, near which they sat, thousands of caterpillars which had hatched that day were crawling about. They had let themselves down by threads, and thus dropped upon the clothes of the people. Threads from many more caterpillars had become entangled into long chains, which waved in the almost imperceptible breeze, and from which hung, so far as he could judge, about a thousand 
caterpillars. In another village he saw, some time later on a fine day, caterpillars of this same species swaying on long threads from apple trees in an orchard, and which, although there was no wind, were directed towards a neighboring orchard which the owner had always kept carefully cleared of caterpillars and egg-clusters, and who had often complained of the laziness and ill-will of his neighbor. On the highway in Herms village, in Glogau, the same summer, a large apple tree was eaten almost bare of leaves, and the female moths were laying their eggs on the trunk. Later in the season Dohrn states that he saw the tenant carefully scraping off the egg-clusters, even from the highest branches, and he expected the tree would be quite free from these caterpillars the next year; but to his astonishment, in the following July, it was full of gypsy moth caterpillars, and eaten bare. The tenant said he would do nothing more in future, since all his work was of no avail; but, upon questioning him as to whether he had burned the eggs, he replied that such a thing had not occurred to him. He had simply trodden all the egg-clusters and scrapings into the ground, where they had been preserved, and the caterpillars, hatching out the following year, found their way up into the tree.

In an article in the "Bullettino della Societa Entomologica Italiana," Vol. III, page 360, 1871, published in Florence, Italy, Apelle Dei has an article on the "Ravages of Insects in the Senesian Country," in which he mentions the gypsy moth, stating that it had ravaged the oak forests of the high Chianti for many years, and during the year 1871 they had stripped the forests of Chianti to an extent and with a severity that was frightful, and that many of the oaks had been destroyed. Dubois, in his "Lepidopteres de Belgique," Vol. II, published in Brussels in 1874, states that in 1858, Brussels and its neighborhood suffered very much from the ravages of the gypsy moth, notably the boulevards and park.

Porchinsky, in his work on "Insects Injurious to Fruit Gardens in the Crimea, Russia," published in St. Petersburg in 1889 , states that the gypsy moth caterpillar appears in the Crimea not unfrequently in enormous quantities. This happened in 1842 , and also in the early sixties and seventies. Especially during 1871 were the gardens of the Crimea nearly 
destroyed. In 1884 these caterpillars were so numerous that they covered the railroad tracks so that trains were moved with difficulty. Again, in 1885, they occurred in great numbers along the southern shore. Observations in the Crimea show, however, that the gypsy moth rarely continues in the same locality in large quantities for more than three years. Thus in 1861, an unusually large number of caterpillars was noticed in the Crimea, and they continued to increase until 1863, when their highest number was reached. Although the greater part of the caterpillars succeeded in forming cocoons, yet very many of them were diseased, as was shown by their soft and withered condition, and, when broken open, there flowed out from some of them a dark-brown liquid mass. In 1864, there were decidedly less caterpillars than during the previous year, while only occasional individuals were met with in 1865 .

In a work on " Insects Injurious to Gardens and Orchards in Central and Northern Russia," by N. Kulagin of the University of Moscow, published in St. Petersburg in 1894, it is stated that the gypsy moth is very widely distributed. It is found in all the central provinces of Russia, in the Caucasus and in southern Siberia. Besides injuring fruit trees, the caterpillars destroyed the leaves of forest trees over an extent of territory comprising from one thousand to three thousand dessatines (2,860 to 8,580 acres).

In a work on " Injurious Insects," by Theodore Keppen, published in Russia in 1883, Vol. III, commencing on page 49 , it is stated, in speaking of the gypsy moth, that these caterpillars often appear in countless numbers. In 1852, in the vicinity of Kishenev, eighty-three miles north-west of Odessa, they occurred by millions in the gardens and forests. Having destroyed all the leaves, they attacked the bark of the young shoots and completely ruined a large number of different kinds of trees. In 1842, and also in the early sixties and seventies, Georg Seopru states that they were exceedingly injurious to the fruit trees in the Crimea. According to the statements of Professor Eversmann, the forests of oak and aspen, in the province of Orenboorg, were stripped of their leaves, presenting the same appearance as in winter. In 1852 , the caterpillars laid waste the forests 



\title{
Explanation of Plate 40.
}

\author{
Drawn in colors by Ella M. PAlmer.
}

I. Showing the feeding and spinning habits of gypsy moth caterpillars of different ages. The bark on the lower part of the apple twig has been eaten by the young caterpillars early in the season.

2. Showing the method of feeding upon a young growing shoot of white pine (Pinus strobus).

3. Red oak (Quercus rubra) leaf attacked by a nearly fullgrown gypsy moth caterpillar. 


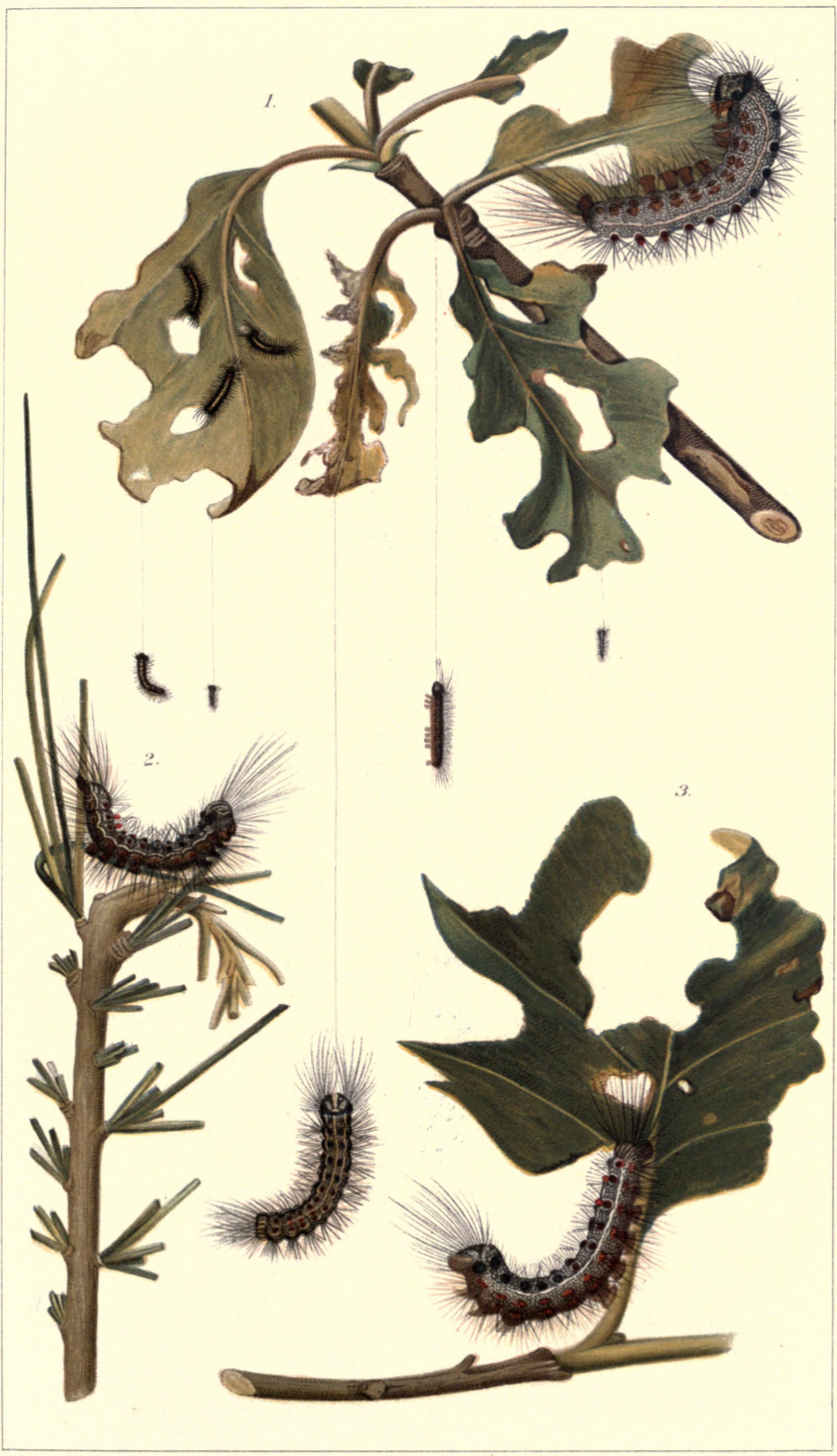

Ella M. Palmer de 

of oak, linden and beech in the province of Kazan, but subsequently these trees put out a new set of leaves.

The late V. E. Graff reported that the oak suffered greatly in the province of Yekaterin. In 1856, the gypsy moth was observed in great abundance in the province of Riazan. In 1857, the forests near the province of Tambov were visited by vast masses of these caterpillars. The trunks of the wild apple and cherry trees were wrapped about with a felt-like substance formed by the covering of the eggs. During 1863, these caterpillars were seen in vast numbers on the oak in various forests in the province of Kazan. Here, as stated by Tideman, the trees injured most were the oak, linden, maple, elm and birch, while the mountain-ash and hazel-nut did not suffer so much. In 1867 , the caterpillars were seen in other districts, and in 1868, their numbers became frightful to contemplate throughout the whole province of Kazan. In 1867 to 1869 , the gypsy moth caterpillars were very destructive in the province of Samara, and Rudzky states that they were very abundant at the same time in all parts of the province of Penza. During June, 1867, all the trees on many estates were entirely stripped of their leaves, and the forests in many cases to the extent of several hundred dessatines * appeared as they do in the winter. The caterpillars seemed to prefer the oak and linden, but after defoliating these they attacked other trees and shrubs, and finally destroyed the grass. In the forests near the city of Penza the dead caterpillars formed such putrid masses that the police were obliged to take measures to destroy the decaying heaps. An incalculable quantity of eggs were laid on the trunks of both deciduous and evergreen trees. In 1869 and 1871, the gypsy moth caterpillars appeared in great quantities in the Kupiansk district of the province of Kharkov.

In more recent times, 1879-80, these caterpillars multiplied in frightful numbers and spread over an immense territory, beginning in the province of Kiev and Poltava and extending through Kharkov, Voronezh, Tambov, Saratov, Simbeersk into Kazan. $\dagger$ Owing to defective reports concerning

- One dessatine is equal to 2.86 acres.

+ A territory about equal to all our Atlantic States, and in nearly the same latitude as Labrador. 
this unusual appearance of Porthetria dispar, it is hard to say where the calamity began. Considering the time of their appearance, it is supposed that they first appeared en masse in the province of Kharkov. According to Yaroschev, the caterpillars were seen in threatening numbers in the district of Zmiev during 1877-78. The insect may have spread westward in the province of Poltava and eastward in the province of Voronezh, and from these to more distant parts. The simultaneous appearance in different places so widely separated, led to the opinion that there were various places of origin from which the insect was distributed. Yaroschev states that the caterpillars were so abundant in the vicinity of $\mathrm{Zmiev}$, in 1878, that in going from one forest to another they literally covered the walls of the houses lying in the way. They fed on all sorts of plants, except ash (Fraxinus excelsior) and wild pear.

Anderson gives interesting details of the presence of the caterpillars in the forest of Shipov in the province of Voronezh. They first attacked the so-called winter oaks (Quercus pedunculata, var. tardiflora), and, after destroying the leaves as soon as they appeared, they devoured the leaves of the lime tree, aspen, hawthorn, spindle tree, hazel and others, and finally the numerous grasses were destroyed. Early in June they began to pupate, and by the middle of the month they were all in this stage. About 3,500 dessatines (10,010 acres) of the forest were laid bare, and detached trees in other parts of the woods were stripped of their leaves. By the middle of July the moths had emerged and laid an enormous number of eggs.

According to Gazen, vast quantities of these caterpillars were seen in the district of Kirsanov in the province of Tambov, in April, 1879. Having eaten all the leaves on the trees and shrubs, the caterpillars descended to the ground and literally covered it in all directions. In the district of Volsk, in the province of Saratov, the caterpillars of the gypsy moth appeared in vast numbers in April, 1879, eating the leaves of all sorts of trees, though preferring the birch and oak, and finally they attacked the pine. By the end of May, 10,000 dessatines $(28,600$ acres $)$ of forest were completely denuded of their leaves. After this they devoured the 
grass, and, coming to a field of grain in their march, they destroyed that also. In 1880 , they appeared in force in the forests of the provinces of Simbeersk and Kazan.

In a letter from Professor Henry of the School of Forestry, Nancy, France, dated July 27, 1895, he says: "Liparis dispar (the gypsy moth) is well known to French foresters. This caterpillar is a plague to fruit trees, oaks, chestnuts, lindens, elms, poplars and other trees, on all of which it thrives. In 1868, more than 60 hectares ( $148 \frac{1}{6}$ acres) of oak woods were entirely stripped by it. It was so common in 1880, on the sides of Mt. Ventoux near Avignon, that the legions of caterpillars covered the ground and entirely destroyed vegetation. In Savoy it made an invasion in 1887 upon the chestnuts and fruit trees. There is not a year passes, comparatively speaking, in which the caterpillars do not show themselves in our territory, if not in one place then in another." In a letter from Dr. J. Ritzema-Boz, from Amsterdam, Sept. 3, 1895, he writes that this insect is common in Holland and also in all western Europe, but the ravages of the caterpillar are very much more common in the eastern parts of Europe. In Holland the ravages of the gypsy moth are very rare indeed. In 1848, it stripped the leaves from the oak ( $Q$ uercus pedunculata) over 50 hectares (123 $\frac{7}{16}$ acres) near Lutphen in the Dutch province of Gelderland, and then attacked the other trees. In 1887 it was very abundant on oak near Wymegen in the province of Gelderland. In 1880 these caterpillars destroyed the leaves on a large number of hectares of oaks near Veenendeal in the province of Utrecht.

In a letter from N. Nasonov, of the University Museum of Zoölogy, in Warsaw, Poland, dated Aug. 7, 1895, he writes that he had the opportunity of knowing personally of an immense number of the caterpillars of the gypsy moth in the orchurds of the government of Warsaw during the years 1891 and 1892, and also on the deciduous trees in the government of Moscow in 1894. In 1892, the leaves of the fruit trees in Warsaw were eaten by these caterpillars to such an extent that they bore no fruit. According to the information received from the central Russian government, the caterpillars of the gypsy moth have this summer 
(1895) nearly defoliated the forests in the government of Kalonga.

Notwithstanding the general damage to all kinds of vegetation in Europe, the greatest complaint comes from the fruit-growing districts, where this insect shows a preference for the foliage of fruit trees.

Methods of Destroyiyg the Gypsy Moth in Europe.

The natural enemies of the gypsy moth, as the birds, parasites and predaceous insects, are relied upon to a great extent to keep it in check in European countries, except in localities where it is very abundant, and the outbreaks very frequent. It should be borne in mind that the European methods are not for the purpose of exterminating or even preventing the spread of this insect; for, as has already been stated, it is more or less common everywhere. The extermination of this pest in Europe by artificial means would probably be an absolute impossibility, and, therefore, all that is attempted is to destroy it wherever it appears in great abundance.

The usual methods are to scrape off the egg-clusters and burn them, or cover them over with raupenleim or other materials in the fall, winter or spring before they hatch, applying the substance by means of a brush on a long pole to those egg-clusters that are too far above the ground to be reached in any other way. Later in the season the trees are protected from those caterpillars that hatch from egg-clusters laid on the ground or elsewhere, by banding with raupenleim. The caterpillars are destroyed whenever found, generally by crushing them as soon as they hatch, and while they are still clustering on the egg-mass, forming the so-called "spiegel." The pupæ are destroyed by hand, and also the female moths before they have laid their eggs.

Dr. N. Nasonov, of the Warsaw University Museum of Zoölogy, in the letter previously cited, writes that, in Poland, the principal measures used in combating these insects are to destroy the eggs, band the trunk of the trees with raupenleim and gather the caterpillars and pupæ by 
hand. In a Russian work* by A. F. Rudzky, is given the following: "The eggs are laid on the trunks of the trees in large masses. These may be easily scraped off with a knife during ten entire months in southern Russia. If the eggclusters are not scraped off, it is necessary to destroy the caterpillars as soon as hatched, and while still clustering in groups. When the caterpillars have spread over the whole tree, it is as impossible to destroy them as the separate moths. When they have eaten the foliage from one tree, they go in a mass to another; but this may be, in a measure, prevented by putting the so-called ' catch bands' on the tree trunks. The cheapest of these bands are made of wadding, five or six inches in width, and bound on tightly, leaving an upper and lower edge, which is to be roughed up, so that the caterpillars may become entangled in the uneven surfaces. The wadding may be made fast to the trunks with strings, or glued together in bands. Where a large number of these bands are needed, it is advisable to paste the wadding (during the winter) on coarse paper, one side of which is smeared with tar. Bands of pitch or tar are frequently used, but these soon become dry. In the Crimea, a mixture of two parts of boiled tar and one part of rape oil, thoroughly heated together, is used; also a mixture of ten pounds of lard, twenty pounds of hemp-seed oil and eighty pounds of coal tar. This is applied directly to the tree and needs renewing twice a year. Labodsky recommends this same ointment, and says that, when well prepared, it will retain its sticky qualities an entire autumn."

Theodore Beling, inspector of forests at Seesen, wrote July 21, 1895, that the methods adopted there were to kill the caterpillars, pupæ and moths, but that the most important method was to destroy the egg-masses on the tree trunks by scraping them off and burning them, or by covering them with raupenleim, or with a mixture of four parts of wood tar and one part of petroleum. Dr. Richard Hess, in "Der Forstschutz," published in Leipzig, 1887 and 1890, gives the following concerning the gypsy moth: "Prevention: Protection of its enemies, bats, cuckoos, starlings, crows, 
titmice, tree-creepers, etc., ichneumons and tachinids are especially to be noted. Orchard trees should be smeared with a thin mixture of lime, black-soap, potash and cowdung. Killing: Destruction of the egg-masses, from August to April, by scraping them off and burning them, or by smearing them with wood-tar thinned with petroleum or raupenleim. Killing the 'spiegel' in May, and crushing the caterpillars when clustering on the trunks and branches of the trees, from the end of May through June; gathering the pupæ in July and August." In a letter from Dr. Ebermayer, professor in the University of Munich, dated July 22, 1895, substantially the same methods are recommended.

J. Porchinsky, in his work on "Insects Injurious to Fruit Gardens in the Crimea," says: "The eggs should be destroyed in the winter season, when time and circumstances permit. The egg-clusters should not be crushed, as this might allow some of them to escape; but they should be carefully scraped off and burned. The eggs having been destroyed, the tree should be protected from caterpillars that might come from neighboring trees by ' catch bands' (preventive bands). These preventive bands are almost the only means with which to combat insects of all classes most injurious to orchards; and, therefore, their consideration is of the first importance; but it is not so easy to find a paste that will, under all conditions of weather, retain the peculiar qualities desired. The most simple of these 'catch bands' is a belt of tar put around the trunk of the trees, on thick paper, smeared with tar and made fast to the trunks.

"In the Crimea, axle grease is placed about the tree trunks in belts from three and a half to seven inches in width, and about twenty-eight inches above the level of the ground. This ointment often retains its sticky qualities a long time, yet it is far from satisfactory.

"The experiments of Klausen, in which he used wadding as a catch band, are of importance in connection with the question of prevention. A large number of these bands of cotton were put around the trunks of trees, the upper and lower borders being well spread out, for, the more fluffy and open the cotton, the more easily the caterpillars become entangled. In the course of two hours a large number of 
caterpillars became entangled, and by evening were dead. After a rain these bands should be replaced."

By the advice of Prof. B. E. Fernow, of the Department of Agriculture, Washington, D. C., I wrote the following letter to Professor Altum :-

Prof. Dr. Bernard Altum.

Amhrest, Mass., U. S. A., Jan. 21, 1895.

Dear Sir:- I send you by post some papers which contain an account of the introduction and spread of the "Schwammspinner" (Ocneria dispar L.) in this country, and of the efforts that have been made to exterminate this insect. You will see by an examination of these papers that the insect has proved more destructive here than it usually does in Europe, while in England it has become extinct from unknown natural causes.

We have already found several parasitic and predaceous insects preying on $O$. dispar, as you will see mentioned in the reports which I send to you; but I very much wish to learn whether you think it would be wise for us to attempt to introduce the European parasites into this country; and, if so, what parasites would it be desirable for us to introduce, and where and how can they be best obtained? We have been advised to introduce some of the European predaceous beetles, as Calosoma sycophanta (L.), Calosoma inquisitor (L.) and Silpha quadripunctata L. Others have told us that Calosoma sycophanta is so large and conspicuous that insectivorous birds would destroy it to such an extent that it would prove of little assistance in destroying the "Schwammspinner." Will you be so kind as to give me your advice on this subject, and also any information you may hare of the methods used in Europe for the destruction of this insect? I have your valuable work on "Forstzoologie," but from all I can learn this insect is more troublesome and destructive in southern Europe than in Germany. I shall be very grateful for any information that you may be able to give me.

Very respectfully, your obedient servant,

C. H. Fernald.

In reply to the above letter Professor Altum wrote as follows : -

I have never known of a devastation in Germany equal in severity and extent to that in your country. So far as I know, all of the devastations of dispar in this region have occurred on limited areas, and have always quickly disappeared. 
An importation of predaceous insects to oppose this destructive dispar, e. g., Calosoma sycophanta, etc., cannot possibly be of any industrial importance. These work in no noteworthy degree even in our far smaller dispar calamities. There are small parasitic insects, especially the species of Microgaster, and even microbes (bacteria), which are valuable. But these can only be collected and sent away when they appear in multitudes, and I do not know at present of a single case in which there is such an appearance.

I can only recommend a single successful artificial remedy, namely, painting or moistening the egg-clusters with liquid fat (oil, petroleum, train oil) or with thin liquid wagon grease, raupenleim, etc. With brushes having long handles, and also by the use of ladders, most of the egg-clusters can be reached. As a rule, these egg-clusters stand out visibly from the darker green bark of the trunks and branches, the under side of which may be cleaned with a brush attached to a pole. This work can be done from September to April, and has always been a complete success here; but with such an enormous and extensive development as dispar presents with you, the successful execution of the above method of destruction does not seem possible ; moreover, no other artificial method is of value. You will, therefore, for the present, make use of this method where the insect appears in small numbers, or as single individuals beyond the area being destroyed, and also where the first colonies or gathering points appear, that is to say, where a great development of the insect is feared. Here the insects are in such numbers that it is possible to destroy them, and are, for the most part, to be found on the lower portion of the trunks of the trees, where they can be easily reached by the hand or with short-handled brushes. These later central points of the invasion usually have a small area and definite borders, and such a method of destruction must be adopted and carried on with all possible energy, for the protection of the surrounding territory. It is needless to say that the caterpillars, pupæ and female moths should be destroyed.

\section{The Eggs.}

The eggs (Plate I, Figs. 9 and 10) are nearly globular, slightly flattened on the lower side, and generally flattened or depressed on the upper side. They are about one-twentieth of an inch (1.5 mm.) in lateral diameter, and of a dark salmon color when first laid; but when fertile they change to a darker color, owing to the development of the embryo, which is quite fully formed in about three weeks. The egg 



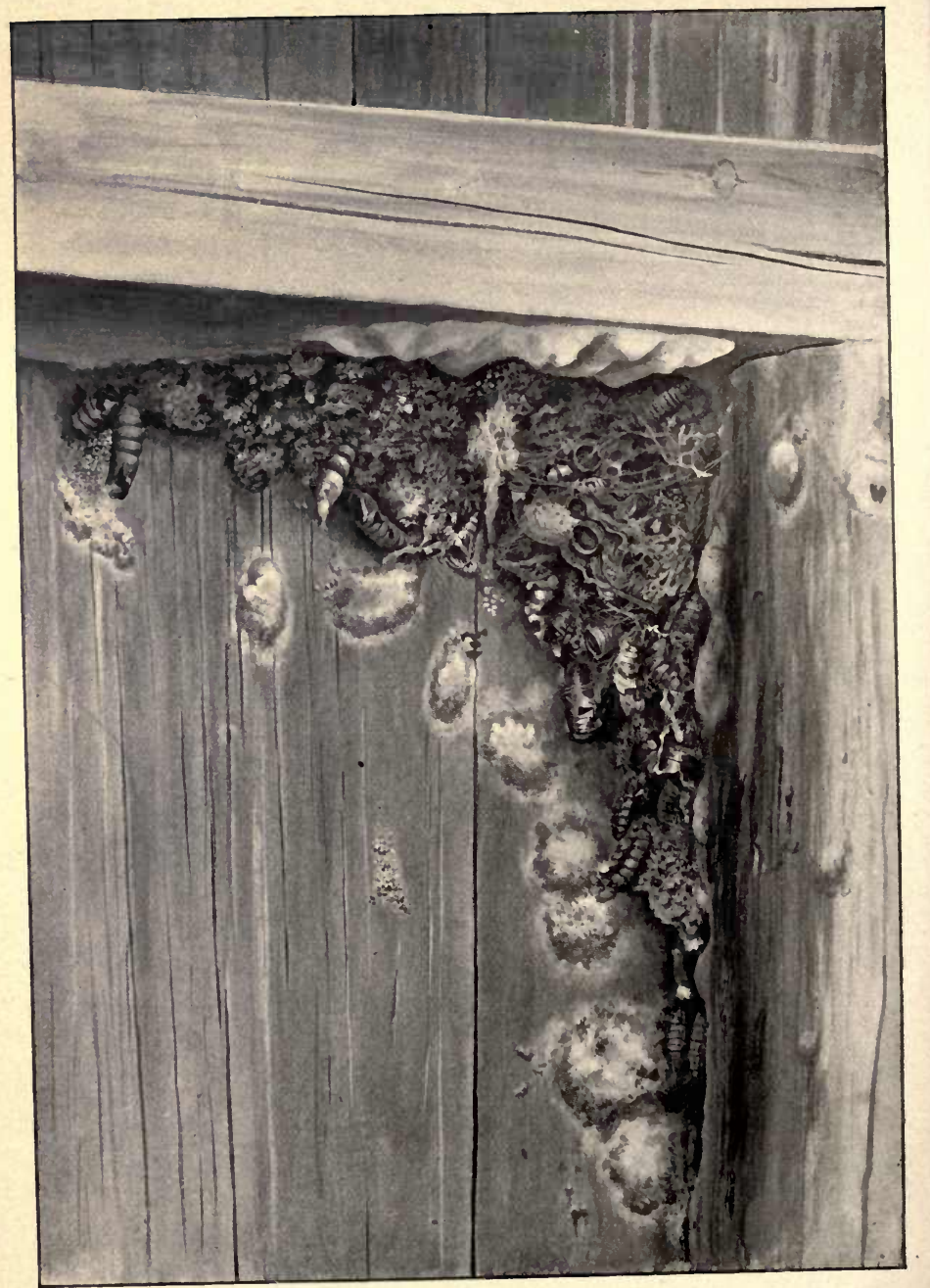

PLATE 41. Mass of pupa-cases and egg-clusters under a fence rail. 
appears to be smooth, when examined with a lens, but if the shell be very carefully removed and examined under a halfinch objective, or a higher power, it exhibits somewhat irregular hexagonal marks over the entire surface, except at the centre of the depression above, which is occupied by the micropyle with its surrounding rosette. This consists of three rows of somewhat pear-shaped cells, each row overlapping a part of the next outside of it (Plate 58, Figs. 11 and 12). The most successful method found for rendering the micropyle and surface markings visible was to remove the contents of the egg and mount the shell dry. When mounted in Canada balsam, glycerine or glycerine jelly, all the markings were obliterated. It was impossible to obtain any better, or even as good, results by first staining the shells in hæmatoxylin, eosin, aniline red, aniline blue, picro-carmine or methyl green. This last stain, however, gave better results than any of the others.

The eggs are laid in the summer, soon after the emergence of the moths, in oval or rounded clusters (Plate I, Fig. 8), usually containing from four hundred to five hundred eggs, but clusters have been found which contained one thousand eggs. These egg-clusters vary in size from one-half an inch to one and one-half inches in length, and from one-third of an inch to one inch in width. The average dimensions of fifteen clusters were found to be $21 \frac{1}{15} \mathrm{~mm}$. long, $11 \frac{4}{5} \mathrm{~mm}$. wide and $5 \frac{1}{2} \mathrm{~mm}$. deep. The female covers the eggs, as she deposits them, with the yellowish hairs from the under side and end of the abdomen, which cause the cluster to resemble a small piece of sponge in general appearance (Plate I, Fig. 8). In time, however, they fade, and more nearly resemble the eggs of the white marked tussock moth (Plate 39, Fig. 15). The female deposits her eggs in every conceivable place, as on the branches and trunks of trees (Plate 55 ), often below the surface of the ground when this has shrunken away from the tree; in cavities in trees or other concealed places; under bark which has separated from dead branches; under bands of tarred paper or cards tacked upon the trees; in stone walls; under stones and in cavities in the ground; in old tin cans, on dead leaves or other rubbish near the infested trees; under fence rails (Plate 41) or the 
loose boards or timbers of barns or out-buildings ; in birds' nests, and many other places, occasionally on leaves on the tree and sometimes on the fruit; but undoubtedly the trunks and branches of the trees (Plate 42) are the most natural places. As a rule, the eggs on the limbs are laid on the under side, although in a few instances they have been found on the upper side, but more or less concealed. In one case an egg-cluster was found on a piece of old rope hanging from a tree, and another on a thermometer hanging against the outside of a chimney. It is not an uncommon thing to find them in tent caterpillars' nests, and one was found deposited on a spider's web on a fence.

The typical form of an egg-cluster is elongated and slightly narrowed at the end last laid. This form is subject to all imaginable variations, according to the conditions under which the mass of eggs is laid. In one instance, six apparently complete egg-clusters were observed that had been laid nearly on top of each other; and in another, a female that appeared to have died on her egg-cluster was nearly half covered with eggs deposited by a second moth while laying close by. Eggs laid by unfertilized females are usually poorly covered with hair, and crippled females, as well as those which have trouble about emerging, often leave a large part of the hair of the abdomen in the pupal case. Eggs laid by such females are usually stuck together in a loose mass, poorly covered and easily separated. The adhesive substance by which the eggs are attached to each other and to the surface upon which they are deposited, as well as that which causes the hairs of the abdomen to adhere to them, is insoluble in dilute or absolute alcohol, chloroform or spirits of turpentine.

\section{Scattered Egas.}

In nearly every case where a fertilized female was confined in a box, she was found to scatter eggs while laying. The eggs were dropped accidentally, the moth being unable to attach them to the surface on which she rested. Frequently a considerable number were dropped before she succeeded in attaching a single egg; but after a small number had been securely deposited, fewer cggs were scattered, although occasionally they were dropped throughout the entire process of 


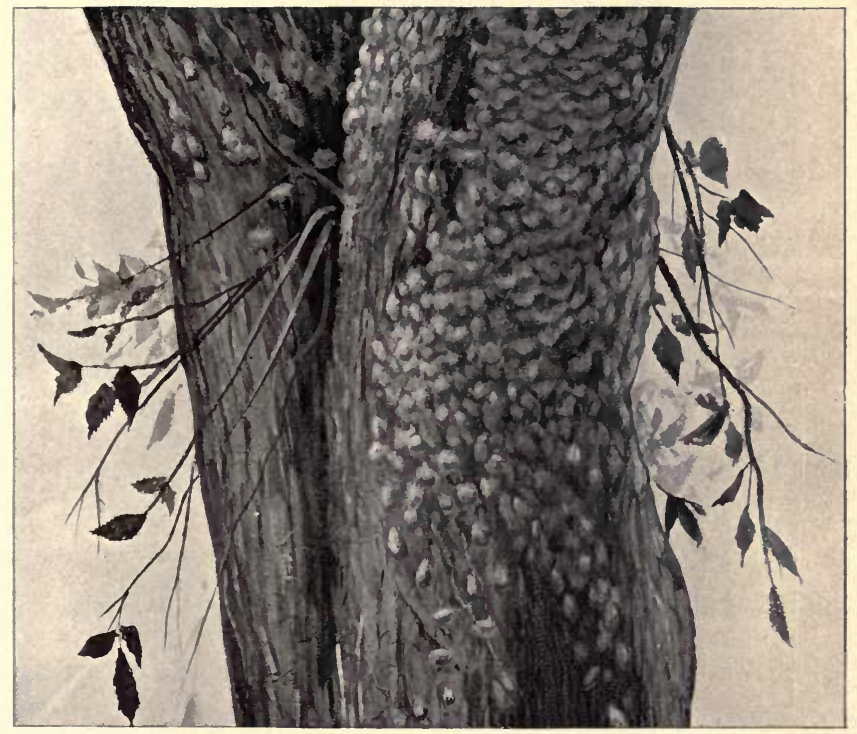

PLATE 42. Mass of egg-clusters on the trunk of a large elm. 
laying. The most marked cases of egg-scattering were those where the moth did not first form a hairy area on which to deposit eggs. Obserrations made on the egg-scattering of fifteen gypsy moths, ten in the insectary and five on trunks of trees in the field, showed that all of them scattered eggs, some of which were dropped before the moth mated and others afterwards. The number of eggs scattered by these insects ranged from one to thirty-four, the average being nine and three-fourths. Male moths, when numerous, in attempting to mate with females while they are laying, often disturb them to such an extent as to cause them to drop or scatter eggs. Eggs scattered by fertilized females have proved to be fertile. Observations made in the field show that many eggs are scattered by the moths when laying under the most natural conditions. In one colony in Saugus, in 1894, the greatest number of egg-clusters were on the rough bark of pine trees, and many scattered eggs were found at the base of these trees among the pine needles. Nearly all of these eggs were naked, and in many cases they were loose, though some were attached to pine needles or to fragments of bark at the base of the trees. Scattered eggs were also found in crevices of the rough bark below the clusters. Eighty-five per cent. of the scattered eggs taken at this place proved to be fertile. This scattering of eggs doubtless explains why caterpillars occur in places where the eggs on the trees have been destroyed the previous winter, and indicates the value of burlapping as a supplement to the work of egg destruction.

Resistance of Eggs of the Gypsy Moth to the Action of the Elements.

In January, 1895, a number of egg-clusters were thoroughly broken up, so that the eggs were entirely separated, and as much of the hair removed as possible. The eggs from each cluster were then placed in a small paper box which was covered with two thicknesses of thin, open cheesecloth. Six of the clusters were placed underneath the storehouse, where they were sheltered from storms, but otherwise wholly exposed to all climatic changes; and, to determine the effect of the actual out-door exposure, six more egg- 
clusters were taken from trees, and, after being prepared in the same manner, were placed in exposed positions on the ground, in the centre of a colony. The tops of the boxes were placed uppermost, so as to give free access to rains, and the localities marked, so that they might be readily found. The boxes were allowed to remain here through all the cold weather and storms of the season, sometimes being bare, and sometimes covered by the ice formed from the melting snow.

On the 4th of April, all of these egg-clusters, as well as those from underneath the storehouse, were collected and placed in the hatching-boxes. Those from the colony were more or less covered with débris which had been carried into the box by the action of rain or of thawing ice. All of the egg-clusters hatched from April 16 to April 20, and, judging from the small number of eggs remaining unhatched, produced as many caterpillars as similar clusters which had been kept intact, either in cold storage or out of doors, during the winter.

From this it is evident that, although the hairy covering of the egg-cluster may serve in a measure as a protection to the eggs, yet it is not essential to their successful hibernation. Certain European writers recommend scraping the eggs from the trees, and state that when this is done their vitality is destroyed by the severity of winter. This certainly is not true in Massachusetts, even if it be so in Europe.

Effect of Extremes of Temperature on the Eggs of THE GrPsy Moth.

During the spring of 1895 , considerable time was devoted to studying the effect of heat and cold, in extreme degrees, upon the eggs of the gypsy moth, with a view of obtaining a better knowledge of the capabilities of this insect to resist such extremes, which fact has a bearing in showing whether sudden climatic changes would aid in holding the insect in check.

The experiments with extremes of heat were conducted by use of a hot-water oven, the necessary degree of heat being obtained by means of a small oil stove, and the temperature of the interior being indicated by a small thermometer. 
To obtain extremes of cold, the eggs were placed in vials and enclosed in a small can, which was then placed in another can containing a freezing mixture (composed of equal parts of coarse granulated snow and salt, and in some cases one which was composed of four parts of snow and five parts of calcium chloride). The degree of cold was indicated by a thermometer placed in the freezing mixture, and so arranged as to be easily read through a glass window in the side of the can.

\section{Effect of Heat on Eggs.}

On April 3, ten egg-clusters of the gypsy moth were exposed for thirty minutes to a temperature of $80^{\circ} \mathrm{F}$. They were then placed in the hatching-boxes, where the temperature was normal, and daily observations made until April 16 , when all the egg-clusters were found to have hatched. April 3, ten egg-clusters were exposed for thirty minutes to a temperature of $90^{\circ}$, and were then placed in hatchingboxes; all of the clusters had hatched April 16. April 3 , ten egg-clusters were exposed for thirty minutes to a temperature of $100^{\circ}$, and then placed in hatching-boxes; by April 17, all had hatched. April 3, ten egg-clusters were exposed for thirty minutes to a temperature of $110^{\circ}$, and then placed in hatching-boxes; on the 17th of April all of these egg-clusters had hatched. March 26, three egg-clusters were exposed for thirty minutes to a temperature of $120^{\circ}$, and then placed in hatching-boxes; one of these hatched A pril 7 and the other two on April 9. On April 3, ten eggclusters were exposed for thirty minutes to a temperature of $130^{\circ}$, and then placed in hatching-boxes; on April 12, all of these egg-clusters commenced hatching. Having obtained this result, they were further experimented with by being placed in a cold box surrounded by ice and salt, and exposed for thirty minutes to a temperature ranging from zero to $8^{\circ}$ below; none of the egg-clusters hatched after this treatment. April 15, ten egg-clusters were exposed for a period of fifteen minutes to a temperature of $140^{\circ}$; none hatched. April 16, six egg-clusters were exposed to a temperature of $150^{\circ}$ for a period of fifteen minutes, and then placed in the hatching-boxes; none hatched. 
From the above experiments we conclude that a temperature of at least $140^{\circ}$ is necessary to destroy the vitality of the developed embryo in the egg. In March, 1895, the effect of the naphtha torch flame was tried upon egg-clusters, exposing them to the action of the flame for various short periods of time. This apparatus is sometimes used for destroying eggs laid in cavities in trees. Of thirty-one eggclusters treated in this manner none hatched.

\section{Effect of Cold on Eggs.}

Experiments in rapidly changing egg-clusters from a high to a low temperature were conducted with the following results: March 22, 1895, four egg-clusters were changed in twenty minutes from a temperature of $80^{\circ}$ above zero to $5^{\circ}$ above, and left over night in a freezing mixture of calcium chloride and snow. Two of the egg-clusters hatched April 9 and two April 11. Apparently these egg-clusters hatched as well as the average ones in the field, and the caterpillars from them fed and grew in as satisfactory a manner as normal caterpillars. March 26, two egg-clusters were exposed for some time to a temperature of $80^{\circ} \mathrm{F}$. They were then packed in a mixture of calcium chloride and snow, and in fifteen minutes reduced to a temperature of $20^{\circ}$ below zero, a fall of $100^{\circ}$. They were kept at this temperature for thirty minutes, and then taken out and placed in the hatching-box. By the 16th of April all had hatched.

\section{Date of Hatching.}

The eggs of the gypsy moth hatch in the spring, from the last of April to the middle of June, depending on the weather and the places in which they are deposited, those eggs which are laid in warm, sunny places hatching the earliest, while those that are laid in cold places, being protected from the heat of the sun, hatch much later. The earliest recorded date of hatching in the field was April 1, 1892, in Medford, and on May 14 of the same year a large part of the eggs in warm, sunny places had hatched. The latest date noted was June 17.

The embryo develops very rapidly, especially in a warm temperature. Eggs laid Aug. 10, 1894, showed well-de- 
veloped embryos August 26, and eggs were found in the field, Aug. 18, 1894, that contained mature embryos $1.4 \mathrm{~mm}$. long. Notwithstanding this early development of the embryo, up to this year no eggs were found to have hatched in the fall, though a careful watch was kept for them. In Europe fall hatching is reported in at least one instance. Ratzeburg, in "Die Forst-Insecten," Vol. II, page 112, says : "Here they remain [on the branches] much like a long mass of fungus until the next April or May, or by exception they hatch in the autumn, as I have seen them myself on the 5th of September, 1836."

\section{A Second Brood.}

In the early part of September, 1895, many of the gypsy moth egg-clusters were found to be hatching at the "Winning" colony, in Woburn, where the caterpillars had committed serious depredations during the summer months. The second brood, which appeared only in this particular colony, seemed to have hatched because of peculiar conditions of location and temperature. The colony is situated on the side of a hill, sloping towards the south, which is covered with a dense growth of medium-sized oak trees. When this colony was, discovered, in the early part of the summer, the caterpillars were much larger and more nearly ready to pupate than in any other colony, and this led to the opinion that the eggs must have hatched much earlier than in other localities. Many of the moths emerged and laid their eggs at this place before the caterpillars in other colonies, where the conditions for rapid development were not as favorable, had commenced to pupate.

While embryonic development in this insect appears to be more rapid in warm weather, a limited number of experiments performed in 1893 and 1894, seem to indicate that a certain degree of cold is probably necessary to mature the embryo. In the latter part of August on several nights the temperature fell quite low in the eastern part of the State, and on one night a frost occurred in some places. At this time a part of the eggs in the "Winning " colony had been deposited from four to six weeks, which was sufficient time for the development of the embryo. This cool weather was 
followed by a hot wave, during which a thermometer, exposed to the direct rays of the sun at Malden, reached a temperature of $112^{\circ} \mathrm{F}$. This extremely hot weather caused a part of the eggs in this colony to hatch, thus giving rise to a second brood, although in no case was the hatching complete, as only a few eggs (one to twenty-five) hatched from a cluster. Eggs brought to the insectary, and kept at an average temperature of $70^{\circ}$, gave rise to a few caterpillars, from time to time, for more than a month.

A number of the caterpillars from this second brood were collected and sacked in on a small red oak tree, and others were taken to the insectary and fed daily. At the time of this writing (Dec. 5, 1895) a part of the latter have pupated. Careful observations were made upon the caterpillars sacked in on the tree, and also upon those which were feeding under natural conditions in the colony. In neither case were they found to thrive in a normal manner, and with cooler weather and frosty nights they gradually died, until none were left. Those which survived longest had nearly all entered the second molt. The caterpillars reared at the insectary did not show as much strength and vigor as those which hatched normally in the spring, and over seventy-five per cent. of them died before reaching the fitth molt.

While this is the only positive record of a second brood of the gypsy moth in this country, it is presumably true that in some cases egg-cluster's may have partly hatched in the fall of previous years. Any egg-cluster taken in the field, which possesses marked peculiarities, is usually sent to the insectary for examination, and many of the clusters thus sent in during the winter and spring of 1894-95, were found to contain empty egg-shells. The size and appearance of the holes in the shells indicated that it was not the work of mites, since they eat out a ragged, irregular opening, while the hole left by the exit of the young caterpillar has a more regular outline, and varies from a small circular aperture to a narrow band eaten around the entire periphery of the shell. After studying a number of these egg-clusters during the spring of the present year, Mr. Kirkland suggested that fall hatching would best explain the occurrence of the empty egg-shells; but at that time there was no positive evidence 
that such hatching had actually taken place in the infested district. In the light of our present knowledge, however, it seems probable that fall hatching may have occurred occasionally during previous years, and also that, under the most favorable conditions, this insect shows a tendency to become double-brooded, like the related species of the genus Orgyia.

The death of the caterpillars of the second brood, feeding in the field, was to be expected, since the season was not long enough to permit them to reach maturity. Even if they had matured it is doubtful if the caterpillars would have seriously injured trees which had retained their foliage throughout the summer.

On the softer and more delicate foliage of those trees which had leaved out a second time, after being stripped early in the season, the caterpillars fed with great avidity, and, had the length of the season permitted, such trees night have been injured to a considerable degree.

\section{Hatching of the Eggs.}

The majority of the eggs hatch during the warm part of the day, from 10 A.M. to 2 P.M., and continue hatching for several days. It is apparent that, when hatching, the caterpillar first eats a hole through the side of the egg-shell, the flattened surfaces representing the top and bottom of the egg, and then eats more or less of a band around the shell on the side, often leaving only the upper and lower surfaces of the egg. Sometimes the caterpillar emerges from the egg by a single hole in the side, but usually it eats a band around the side of the egg, leaving only the upper and lower disks remaining.

\section{Number of Caterpillars from Sivgle EgG-clusters, and Trme required for Hatching.}

From one egg-cluster that had been kept in a warm room at the insectary during the winter of 1893-94, 1 egg had hatched Feb. 23, 1894, at 9 А.м. ; at 10 А.м., 49 more; at 11 А.м., 13 more; and at 5 P.M., 50 more, making 113 which hatched the first day. 
February 24, at noon, 80 more eggs had hatched; at 5 P.M., 43 more from the same cluster, or 123 on the second day.

February 25, at 10 A.M., 20 more eggs had hatched; at 1.15 P.M., 47 more; and at 6.15 P.M., 6 more, making 73 eggs which hatched on the third day.

February 26, at 7.30 A.M., 87 more had hatched; at 1.30 P.M., 172, and at 5 P.M., 16 more, or 275 on the fourth day.

February 27, at 7 A.M., 39 more had hatched; and at 5.40 P.M., 43 more, making 82 for the fifth day.

February 28, at 7 A.M., 2 ; at noon, 26 ; at 5 P.M., no more had hatched, making 28 eggs which hatched on the sixth day.

March 1, at 7 A.M., 2 more eggs had hatched; at noon, 5 ; and at 5 p.x., 2 more, making 9 for the seventh day.

March 2, at 7.20 A.M., 1 more egg had hatched; and at 5 P.M., 1 more, making 2 that hatched on the eighth day.

March 3, at 7.45 A.M., 1 more egg had hatched. No other eggs hatched from this cluster. The total number of eggs hatched from the cluster, in nine days, was 706. From another egg-cluster, kept under similar conditions, 997 hatched in eleven days.

To gain further information concerning the actual number of caterpillars which may hatch from one egg-cluster, and the time required for hatching, a number of egg-masses which had been taken from the field were brought into a warm room and placed in boxes, April 25, 1895. The caterpillars were counted and then removed as soon as hatched. From egg-cluster No. 1, 250 caterpillars were hatched in 2 days and 22 hours. From egg-cluster No. 2, 408 caterpillars were hatched in 3 days, 17 hours and 10 minutes. From eggcluster No. 3, 708 caterpillars were hatched in 3 days, 17 hours and 15 minutes. From egg-cluster No. 4, 679 caterpillars were hatched in 3 days and 1 hour. From eggcluster No. 5, 393 caterpillars were hatched in 3 days, 22 hours and 30 minutes. From egg-cluster No. 6, 438 eaterpillars were hatched in 4 days, 16 hours and 45 minutes. The whole number of caterpillars from the six egg-clusters was 2,876 , an average of 479 to each cluster. The average time in hatching was 3 days, 20 hours and $6 \frac{2}{3}$ minutes. 
From studies made on a large number of egg-clusters in the insectary, supplemented by observations in the field, it was discovered that in many cases some part of the eggs composing an egg-cluster did not hatch. Seven large eggclusters which had hatched were found to contain on an average 124 unhatched eggs, the smallest number being 43 , the largest 224. A small number of unhatched eggs is found in nearly all the old nests taken in the field.

\section{The Larva or Caterpintar.}

Relative Vitality of Caterpillars hatching at Different Times from the Same Egg-cluster.

The following observations were made under my directions by Messrs. Minott and Mosher, both careful and reliable observers : -

From a large cluster of eggs, laid by a single female gypsy moth, and kept in a warm room, 4 hatched late in the afternoon of March 11, 1894 ; at 10 A.M., March 13, 333 more eggs had hatched; at 5.20 P.M., 194 more had hatched; March 14, 233 had hatched; March 15, at 4.35 P.M., 48 more eggs had hatched; March 19, 10 more hatched; March 20,3 ; and on the 21st, 6 more eggs hatched, making 831 eggs hatched from this cluster. The caterpillars were removed as soon as hatched.

Fifty caterpillars were selected, as follows: 10 of those hatched on the second day, 10 of those hatched on the third day, 10 of those batched on the fourth, 10 of those hatched on the eighth and 5 of those hatched on the ninth and tenth days, making 6 sets of caterpillars taken from those which hatched at different times. Each caterpillar was fed on lettuce, in a box by itself, and under as nearly similar conditions as possible, careful records being made, for the purpose of learning whether there was any difference in the vitality of caterpillars hatched at different times, from the same egg-cluster; the period of rest before and after each molt, and the time between each molt. No perceptible difference was noticed in the vitality of those hatched at different times. It was observed that they all ate equally well and appeared equally healthy, and that all their transforma- 
tions agreed very closely, except that those which hatched latest did not require as many days in their molts, and therefore reached the adult stage as soon as the others, although marked variations occurred among the individuals of each hatch (Plate 43). Some grew faster than others, while some appeared to eat about the same amount as others and yet did not grow as rapidly.

\section{Description of the Larva or Caterpillar.}

The following descriptions were prepared from the study of from twenty-five to fifty caterpillars in each stage : -

First Larval Stage. - The larva, when first hatched, is $3.6 \mathrm{~mm}$. (about fourteen hundredths of an inch) in length, and the head is . $6 \mathrm{~mm}$. (about twenty-three thousandths of an inch) in width and somewhat thicker than the body, shining black, with a few (about forty) pale-yellow hairs scattered over the surface, the longest of which are not quite equal to the width of the head. There are a few additional hairs on the mouth parts. The body is more or less cylindrical, slightly tapering toward the posterior part which is blunt and rounded. When first hatched they are a pale brownish-yellow, with a brown spot on the forward side of segments four to twelve inclusive, on the subdorsal line of each side, but the ground color grows darker within a few hours. The subdorsal tubercles of the second segment (first after the head) are elongated laterally and joined at the dorsal line. These are of a dark-brown color. The lateral tubercles of this segment are fused, forming one very large lateral tubercle on each side, which extends obliquely out and forward. The third and fourth segments have three tubercles on each side, one subdorsal, one lateral and one stigmatal. The remaining segments, except the last, have large subdorsal and lateral tubercles, the latter being so large as to fuse more or less completely with those above them. There are three nearly equal-sized tubercles on each side of the last segment, so arranged as to form an arched row around the posterior end of the animal.

The insect at this stage has two kinds of hairs arising from the tubercles, the first of which (Plate 48, Fig. 8) is about as long as the thickness of the body, of a pale-brown 


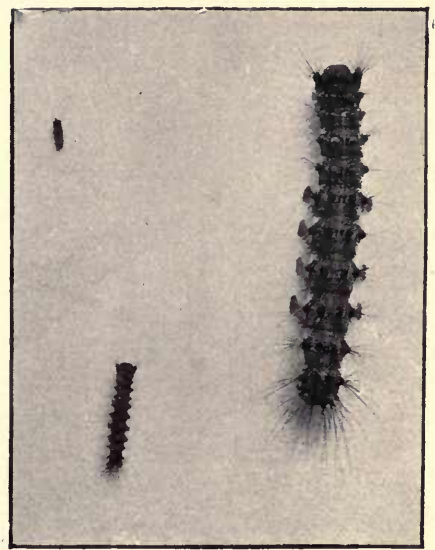

PLATE 43. Variation in size of caterplliars of the same age. Fifty caterpillars hatched from the same egg-cluster were reared separately on lettuce leaves, all recelving exactly the same treatment. When the caterpillars were five weeks old, the two extremes in size, together with a caterpillar of medium size, were photographed. The smallest caterpillar as here shown has not molted. The medium caterpillar has molted twice. The largest has molted four times and is approaching the flfth molt. 

color, smooth throughout, with a sharp point at the outer end; and at the basal third they have an inflated globule, the diameter of which is three times as great as that of the hair. The walls of this globule are delicate, and when the insect is alive they are fully distended, probably with air or gas; but when dead they collapse more or less completely, often causing the hair to be bent at this place. The first and second rows of tubercles on each side have only hairs of this kind on them. Similar hairs occur on the larva of the nun moth (Lymantria monacha) before the first molt, and have been called ærostatic hairs by Wachtl and Kornauth, and the globules ærophores. These authors believe that these inflated globules have the effect of small balloons, and aid in transporting the young caterpillars to a considerable distance when the wind blows. The other kind of hairs (filiform hairs) (Plate 48, Fig. 9) arise from the two lateral rows of protuberances, and are unusually long, some of them being longer than the body of the caterpillar; and they have several longitudinal rows of minute barbs extending the entire length.

Later the caterpillar changes color, the tubercles becoming black, the body reddish-brown with a row of dull reddish spots along the middle of the back, one each on the fifth to the eleventh segments inclusive. There are no retractile tubercles in this stage.

The time between hatching and the first molt, of twelve caterpillars bred in confinement, in an unheated room, was from eight to twelve days, the average being nine and onefourth days. The temperature very materially affects the time before molting, for, when caterpillars were kept in breeding cages near warm steam pipes, they molted in five days; while others, from the same egg-cluster, kept in a cool part of the room, molted in seven days.

Second Larval Stage. - Length, $7 \mathrm{~mm}$. (about twentyseven hundredths of an inch), and the head is $1 \mathrm{~mm}$. (about thirty-nine thousandths of an inch) in width, shining black, with numerous fine, pale-yellow hairs scattered over the surface. Body, dark brown, with the tubercles black, and a somewhat triangular yellowish spot on the top of segments nine, ten and eleven, in the middle of which, on segments ten 
and eleven, there is an orange-colored retractile tubercle, and also one on each side of the dorsal line, near the front edge of segments five, six, seven and eight, of the same color, but much smaller. There are four rows of tubercles on each side, which, named from above, may be called the subdorsal, the lateral, the stigmatal and the substigmatal row, each with one tubercle on each segment after the head. The tubercles of the subdorsal rows on the second segment (first after the head), on the front half of the segment, are subquadrate in form, and but slightly separated from each other by the dorsal line. The subdorsal tubercles of the third and fourth segments are smaller, and nearly elliptical in outline, while those on the remaining segments are larger and more nearly circular. The tubercles of the lateral row are smaller than those above, and on segments five to thirteen inclusive they are partially fused with those of the stigmatal row; but as they are a little further forward than those below, the fusion gives an obliquely elongated tubercle. To effect this fusion the tubercles of these two rows are brought towards each other. The tubercle of the stigmatal row, on the second segment, is large, somewhat produced, and directed obliquely forward. The substigmatal row consists of medium-sized tubercles, lying directly above the legs and prolegs, and about half-way between them and the stigmatal row. A little below, and behind these tubercles, on segments seven to eleven inclusive, is a very small tubercle, and on segments five, six, eleven and twelve there are two small tubercles on each side beneath, the inner ones being much the smaller. The tubercles of the subdorsal and lateral rows are armed with black, pointed spines and a few pale-yellow hairs, while the remaining tubercles are armed with longer pale-yellow hairs. On each side of the dorsal line, near the subdorsal tubercles, on segments three to twelve inclusive, is a very small tubercle, with one black spine and occasionally a few pale-yellow hairs.

Third Larval Stage. - Length, $10 \mathrm{~mm}$. (a little less than one-half of an inch), immediately after molting, and the head is $1.8 \mathrm{~mm}$. (about seven hundredths of an inch) in width, shining black, with numerous pale-yellow hairs scattered over the surface. The general color of the body is 
dark brown and very much broken, giving the appearance of a large spot on each segment. The lateral lines are dull yellowish-white. Arrangement of tubercles, bristles and hairs as in the last stage.

Fourth Larval Stage. - Length, $13 \mathrm{~mm}$. (about half an inch), immediately after molting, and the head is $2.8 \mathrm{~mm}$. (about eleven hundredths of an inch) in width, pale brownish-white, mottled on the sides and above with dark brown, and there is a dark-brown vertical stripe on each side of the clypeus and numerous pale-yellow hairs scattered over the surface. The body is dark brown, finely mottled with yellow; while the dorsal line is pale ochre-reddish, enlarged into small grayish spots on the middle of the sixth, seventh and eighth segments, and on the ninth, tenth and eleventh segments there are larger orange-colored spots. The lateral line is pale yellow, and below this the surface is ashy, mottled with dark brown. The tubercles, spines and hairs are as in the preceding stage.

Fifih Larval Stage. - Length, $23 \mathrm{~mm}$. (about nine-tenths of an inch), immediately after molting. The head is 3.6 to $4.4 \mathrm{~mm}$. (about fourteen to seventeen hundredths of an inch) in width, or about the same width as the following segments without the lateral tubercles. The ground color is cream-white, and there is a vertical, velvety-black stripe on each side of the clypeus, outside and above which, the surface is sprinkled more or less thickly with velvety-black dots, which are more or less confluent. The labrum and mandibles are of a watery, whitish color, and the mouth parts beneath are dull reddish. Scattered over the surface are numerous pale-yellow setaceous hairs, varying in length from the width of the head to half that length. The upper surface of the body is cream-white, marked with black in minute, irregularly formed spots, giving a general dark-gray color, but leaving the dorsal line of a lighter color. The subdorsal tubercles, on segments two to six inclusive, are blue, and those on segments seven to twelve inclusive, are red. All the tubercles and retractile tubercles are of the same form, and arranged the same as in the last two stages; the spines and hairs are also like those in the preceding stage. The fleshy, retractile tubercles on the dorsum of 
the tenth and eleventh segments usually have a convex cap of hardened reddish fluid, which may be removed with the point of a needle, and beneath which the tubercle is hollow to the depth of three or four mm., and filled with a reddish fluid, which has an agreeable odor, but I am not able to state what it is like.

Sixth Larval Slage. - Length, $30 \mathrm{~mm}$. (about one and eighteen hundredths inches), immediately after molting. The head is from 5.5 to $6 \mathrm{~mm}$. (about twenty-two hundredths of an inch) in width, dull or yellowish white, and more or less mottled with black or brown over the top and sides, with a vertical black or brown stripe on each side of the clypeus. There is a great variation in the ground color, and also in the amount of black or brown on the surface of the head. Fine yellow hairs are scattered over the surface, and the color and markings are as in the preceding stage.

Seventh Larval Stage. - Length, from 35 to $40 \mathrm{~mm}$. There is no marked difference in appearance, in this stage, from the preceding, except in size, and all caterpillars that we have bred to this stage have transformed into female moths. Only a comparatively small proportion of the caterpillars reach this stage before pupating.

\section{First and Last Appearance of Larva.}

The newly hatched caterpillars of the gypsy moth have been found in the field as early as April 20, and as late as June 17. In the summer of 1893, Mr. H. N. Reid found a caterpillar which did not begin to pupate until September 6 . The feeding period of the caterpillar generally extends from the first of May, to about the middle of July, but varies somewhat with the season, and, in a less degree, with the locality of the colony, those near the sea-shore being somewhat slower in development than those farther inland.

\section{Molts.}

In the latter part of the winter of 1893, Miss Carrie Gordon, one of the assistants at the Malden office, observed the molts of several caterpillars of the gypsy moth, taken from egg-clusters which had been kept in a warm room, and thus 
caused to hatch earlier than they otherwise would have done. The caterpillars were fed on the leaves of lettuce, and four of them completed their transformations, - two males and two females, - while three more died in pupating. The males molted five times and the females six times. Wishing to determine whether there would be any difference between these caterpillars, hatched out of season, and those reared under normal conditions, twelve newly hatched caterpillars of the gypsy moth, each in a separate box, were given to Miss Rose Davis, one of my assistants, early in May, 1893. These were fed on apple leaves, and each molt carefully noted. Of this lot, seven females molted five times, one female molted four times and four males molted four times. As these results differed so materially from those of Miss Gordon, I took fifty-five newly hatched caterpillars in May, 1894, fed each on apple leaves, in a separate box, and carefully observed the molts myself. Fifty-two of these caterpillars completed their transformations, with the following results: one female molted six times, twenty-nine females molted five times and nine females molted four times; seven males molted five times and six males molted four times. These results showed that in all probability no mistakes were made by the other observers, and also that the process of forcing the caterpillars makes no difference in the number of molts, though the small number carried through by Miss Gordon fails to make this point as conclusive as might be desired.

The time between the hatching of the eggs, which occurred Feb. 3, 1893, and the first molt, and also between the remaining molts, is as follows, according to Miss Gordon's observations : -

From the time of hatching till the first molt, 6 days.

From the time of the first till the second molt, 7,8 and 9 days. From the time of the second till the third molt, 6 and 7 days.

From the time of the third till the fourth molt, 5,6 and 7 days. From the time of the fourth till the fifth molt, 6,7 and 8 days. From the time of the fifth till the sixth molt, 8 days.

According to Miss Davis' observations, the time between the hatching of the eggs, which occurred May 7 and 8, 1893, 


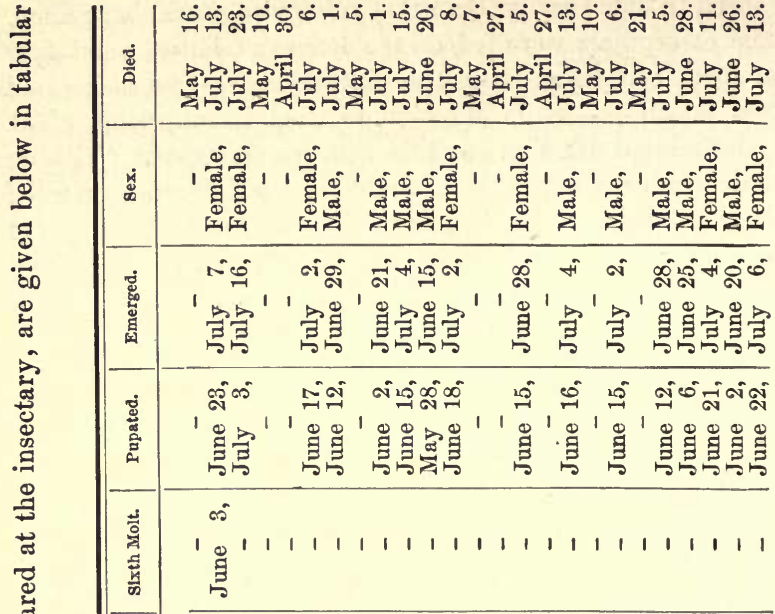

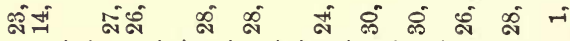

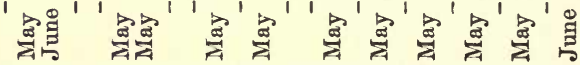

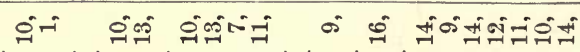

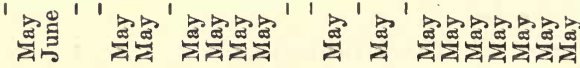

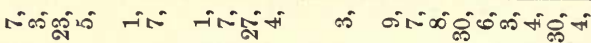

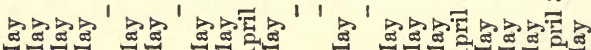

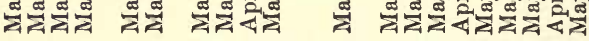

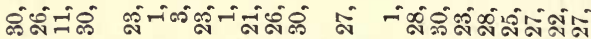

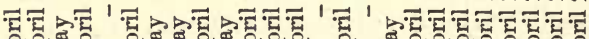

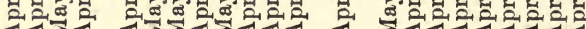

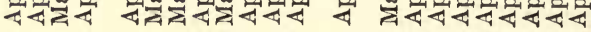

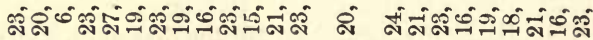

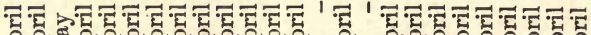

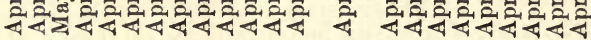

"




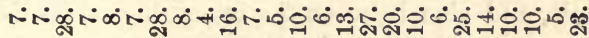

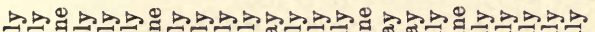

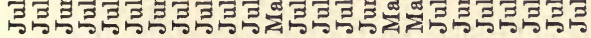

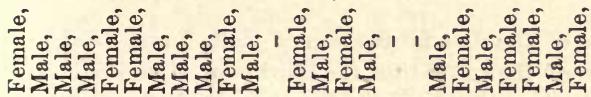

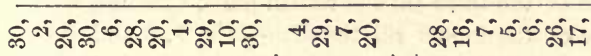

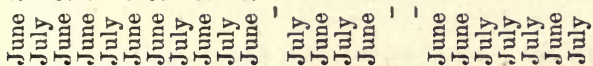

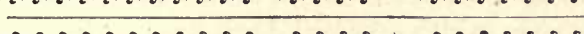

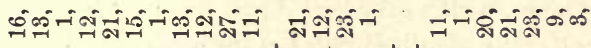

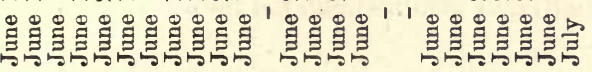

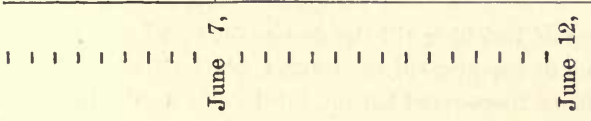

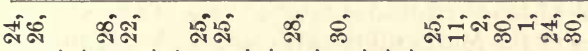

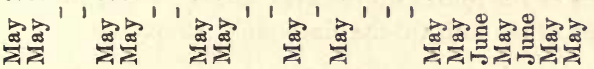

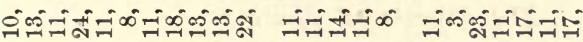

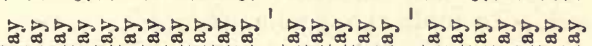

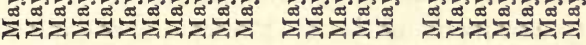

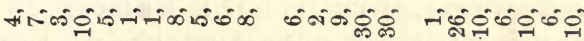

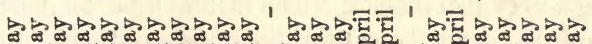

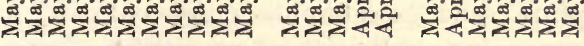

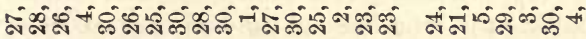

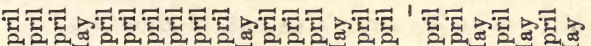

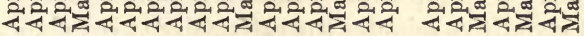

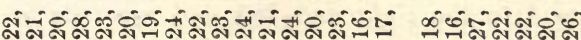

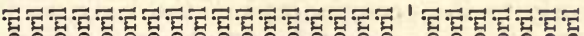

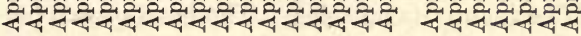

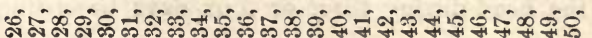


and the first molt, and also between the remaining molts, is as follows:-

From the time of hatching till the first molt, 8, 9, 10 and 11 days.

From the time of the first till the second molt, 7 and 8 days.

From the time of the second till the third molt, 7 and 8 days.

From the time of the third till the fourth molt, 6, 7 and 8 days.

From the time of the fourth till the fifth molt, 7, 8 and 9 days.

According to my own observations, the time between the hatching of the eggs, which occurred April 28 and 29, 1894, and the first molt, and also between the remaining molts, is as follows:-

From the time of hatching till the first molt, 9, 10 and 11 days. From the time of the first till the second molt, 11 days.

From the time of the second till the third molt, 5,6 and 7 days. From the time of the third till the fourth molt, 10 and 11 days. From the time of the fourth till the fifth molt, 8,9 and 10 days. From the time of the fifth till the sixth molt, 13 days.

\section{The Process of Molting.}

When preparing to molt the young caterpillars remain quiet for twenty-four hours or more. The head is withdrawn from the old head covering, giving the caterpillar the appearance of having a very small head. The skin behind the head covering is ruptured, and the caterpillar crawls out of it, the whole process occupying not more than two minutes. Immediately after molting the long hairs of the body are curled up considerably, but gradually straighten out in about an hour. At intervals of about five minutes the caterpillar twists about, bringing the head to the right and left and upwards and backwards, nearly to the posterior end of the body, as if stretching itself or trying its muscles. The head grows perceptibly darker, even within an hour from the time of molting, and in a few hours the head becomes black and shining and the caterpillar commences feeding.

The approach of the molting period, in the later molts, is indicated by the development of a light-colored area, which forms behind the bead during three or four days preceding 
molting. This area, which is but a narrow transverse line at first, gradually widens and extends down each side of the posterior margin of the head. It is widest on the dorsal line, and is formed by the separation and projection forward of the old chitinous covering of the head, while below and beneath, the new light-colored head covering becomes visible. The light-colored area is apparently the top of the head drawn back from the old covering, and protected by the tightly stretched integument of the annulation.

The caterpillar stops feeding usually from twenty-four to forty-eight hours before molting, and rests quietly except for occasional spasmodic twistings of the body. When the time for molting arrives, the integument splits on the ventral part of the annulation between the head and second segment and partly up the sides. The caterpillar clings by means of its prolegs to the surface on which it rests. It elevates the middle segments, depresses segments four and five and elevates the head and segments two and three. Its contortions, at this stage, somewhat resemble the travelling movements of a geometrid caterpillar, and, as the band over the lightcolored area behind the head is very tenacious, the caterpillar bends itself nearly double; the feet are then withdrawn by a series of successive movements; with a few more contortions of the body sufficient force is developed to burst the band in the rear of the head, and the dorsal surface of the thoracic segments is molted. This stage requires about five minutes from the first separation of the integument. The head covering generally remains attached.

By alternately contracting and expanding, the remaining segments are molted one after another. The last three segments are generally molted in rapid succession, and the molting, with the exception of the head, is completed in about fifteen minutes. After resting a few minutes the caterpillar begins to rid itself of the firm head covering. This is done by bending down the anterior segments, and then rubbing the top, front and sides of the head upon the surface to which the caterpillar clings. Finally, the top of the head covering is loosened and pushed off. This process of molting the head requires from fifteen minutes to half an hour, and the whole process is completed in less than an hour. After molting 
the caterpillar raises its head and swings it from side to side, resting at intervals, and begins feeding in about twenty-four hours. The increase in the size of the body over that of the preceding molt, is more plainly noticed after the caterpillar has taken its first meal, but the increased size of the head is apparent at once. When first emerged from the molted skin the head is nearly cream-white, with faint darker markings, and all the colors of the body are light, but after a few hours they darken to the normal shades. The dorsal retractile tubercles are very prominent immediately after molting, but regain their normal size in a short time.

\section{Caterpillars attracted to Light.}

When caterpillars hatch in hollow trees or other dark places, they invariably find their way out in a short time, being attracted, as it is supposed, towards the light. To determine how strongly the light influenced them in their movements, May 6, 1895, twenty-five newly hatched caterpillars were placed in small pasteboard boxes which had a small hole in each end. One end of each box was placed in the bright sunlight, while the other end was shaded. In an hour and a half all the caterpillars had emerged through the holes in the ends exposed to the sun.

\section{Distance Young Caterpillars are able to Travel.}

For the purpose of ascertaining how far from the eggcluster a newly hatched caterpillar can travel without feeding, seven were placed on a large sheet of white paper on a table. Their movements were traced by following them with the point of a pencil on the paper as they crawled, and these lines were carefully measured after the death of the caterpillars. In their movements it was observed that they showed a strong tendency to crawl towards the window during the day, and towards the light of the lamp during the night; but in no case were they observed to be attracted towards food, however near it was placed, provided it did not touch their hairs. The distance travelled by each caterpillar before it died was as follows: No. 1 travelled $90 \frac{1}{2}$ feet; No. 2, 93 feet; No. 3, 143 feet; No. 4, 85 feet; No. 5, 36 feet; No. 6, $46 \frac{5}{6}$ feet; and No. 7, 144 feet; aver- 
age, about 91 feet. These observations have a bearing on the question of how far the trees around a colony should be burlapped.

\section{Caterpillar Traps.}

In the summer of 1895 , at the suggestion of Mr. Forbush, several attempts were made to capture the caterpillars of the gypsy moth by means of traps, constructed with reference to their habit of seeking out cracks, crevices, etc., for shelter during the day. Different styles of traps were prepared, all made with small openings, closed by a fringe of hair-cloth or felt, through which the insect might enter but could not return. These traps were attached to the trunks of badly infested trees; and, while they caught and retained a small number of caterpillars, as a whole they were not a success.

When a number of old tin cans are placed along an infested hedge or wall, at the time the caterpillars are pupating, it has been found that they will enter them in large numbers and pupate. Females, emerging in these cans, deposit their eggs there; and by frequent examination of the cans a large number of pupæ and egg-clusters can be destroyed.

\section{Feeding Habits.}

In general, it may be said that the gypsy moth caterpillar is almost omnivorous so far as foliage is concerned, and its ability to adapt itself to nearly every food plant is one of the chief obstacles to its extermination. For this reason, also, it is capable of committing far greater depredations than any of our common native insects. A list of food plants attacked by the gypsy moth is given on succeeding pages, and, since the ravages of the insect on fruit and forest trees have been so fully described in Part I. of this report, we pass to a more detailed account of the feeding habits. The feeding habits of caterpillars of different ages are shown on Plate 40.

\section{Time and Manner of Feeding.}

To determine the time and manner of feeding of the caterpillars, a series of observations was made by $\mathrm{Mr}$. Minott in 
1893, and repeated by Mr. Kirkland in 1894. Many observations had been made by different members of the force, but none were so extensive or complete as those made by these gentlemen, yet all agreed more or less in regard to the habits. To enable one to make observations on caterpillars, on trees in the field or forest, it was necessary to have some system of marking; and for this purpose watercolors were found to be excellent, and in no way injured the insects; though, in the case of caterpillars which were to be continuously observed during the entire larval stage, it was, of course, necessary to reapply the color after each molt. Several different colors were used, especially those which contrasted strongly with the ground color of the caterpillars.

From these observations it appears that the caterpillars remain on the egg-cluster, after hatching, from one to five or more days, according to the weather, when they wander off to the leaves and commence feeding. The first food is the leaf hairs, and, unless one obscrves very carefully, he might suppose that they do not feed until they are four or five days old; from this time on, however, one can see where they have eaten the tissues, making small holes through the leaf, though occasionally they eat from the edge; but they are extremely irregular in their manner of feeding. Between the third and fourth molts their method of feeding is about equally divided between eating holes through the leaf and eating along the edge (Plates 40 and 44). From the fourth molt till they are ready to pupate, they eat almost entirely from the edge of the leaf, though there are occasional exceptions to this.

Mr. Kirkland's observations on full-grown caterpillars were made on the nights of July 7, 8 and 9, 1894. A medium-sized infested elm tree was selected, and all small twigs and branches that might interfere were removed. A band of burlap had been put around the trunk, about four feet from the ground. Twenty caterpillars, some partly and some fully grown, were under the burlap. Eight of these caterpillars were marked with water-colors, in such a manner that they could be distinguished from each other as well as from those not marked. The caterpillars were numbered, and 


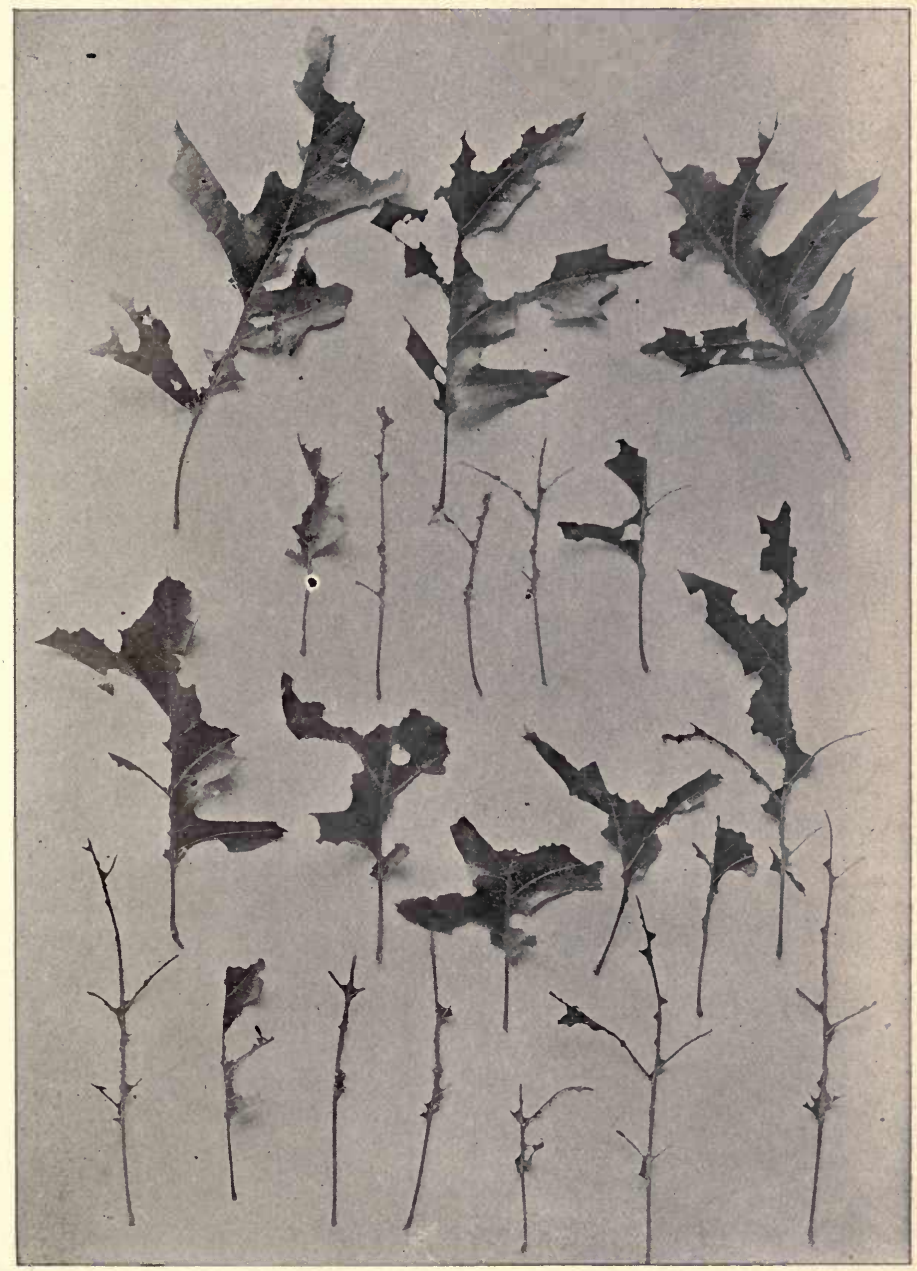

PLATE 44. Oak leaves eaten by the caterpillars of the gypsy moth. Taken from an infested tree, Saugus, July, 1894. 

observations made every ten minutes, from 6 o'clock in the afternoon till 5 the next morning. At 7.30 P.M., caterpillar No. 4 began to grow uneasy, and moved about under the burlap or on the trunk below it. At 8.20 the first one, No. 2, started up the tree from the burlap, and soon all the rest were on the move. Some of the caterpillars, after climbing up the trunk several feet, descended for a short distance and then ascended again; and they often stopped to rest on their way up or down the tree trunk. At 9.50 No. 3 had reached the leaves, sixteen feet from the burlap, and begun feeding. Others reached the leaves later, and fed during the night with intervals of rest. At about 3 A.M. they ceased feeding and descended the trunk, and at 4.25 all were at rest under the burlap or in crevices in the bark. One caterpillar about to molt and one about to pupate remained quietly under the burlap all night. It was further observed that the smaller caterpillars, as a rule, fed on the lower branches, while many of the larger ones went to the extreme tips of the upper limbs.

Mr. Minott's observations were made on the nights of July 26, 27, 28 and 29, 1893; and the results were substantially the same as in Mr. Kirkland's observations, except that the eaterpillars started from their places of concealment to ascend the trees a little earlier in the evening. The observations of Mr. Kirkland, on a single caterpillar, will illustrate fairly well the operations of the insect during the night, though others varied slightly in their work :-

P.M.

7.40. Caterpillar came out from under the burlap and began moving up the tree.

7.50. Ascended the trunk, twelve feet from the burlap.

8.00. Reached a leaf fifteen feet from burlap and commenced feeding.

8.10. Still feeding.

8.20. Had three feeding spells between 8 and 8.15 , with short rests between.

8.30. Feeding.

8.40. Moving.

8.50. Feeding.

9.00. Feeding. 
P.M.

9.10. Feeding. It began at the base of the leaf, clasping the petiole and twig with feet and prolegs, eating the base of the leaf close to the midrib, then, raising its head, worked out toward the margin of the leaf, making a crescent-shaped cut, then started from the midrib again.

9.20. Feeding.

9.30. Resting, after having eaten steadily twenty-five minutes.

9.40. Feeding (began at 9.31). The caterpillar then fed steadily until 11 P.M.

11.00. Resting a few seconds, after feeding one and one-half hours.

A.M.

12.10. Feeding. Has fed continuously since 11.10; has eaten the whole of one side of a leaf and is now working upon the tip.

12.20. Feeding upon the tip of the remaining half of the leaf. It begins at the midrib, actually 'eating it, then takes a strip square across the leaf to the margin, then begins eating again at the midrib. Sometimes it reverses this movement, and feeds from the margin to the midrib.

12.30. Feeding.

12.40. Feeding.

12.50. Left the remains of its leaf, having eaten nearly all through it, and started at once upon the second. The caterpillar then fed without interruption until 3.20 A.M.

3.20. Stopped feeding, crawled out to the end of the twig, turned back and crawled down the main branch.

3.30. Slowly descending (daylight approaching).

3.40. Descending.

3.50. Descending, about four feet above the burlap.

4.00. Descending.

4.10. Crossed the burlap, crawled under it, and at once became quiet.

Weather during the night, fair, cool and starlight.

Summary.

Detailed observations made on twenty-five caterpillars may be summarized as follows:- 

1. The large caterpillars leave the burlap or other places of concealment for their places of feeding between 7 and 8 o'clock in the evening, or sometimes a little later.

2. They proceed by easy stages, resting frequently, from their places of concealment to the places of feeding, though some of them wander up and down the trees more or less.

3. When the distance is short, they proceed directly to the leaves and begin feeding immediately.

4. They feed and rest alternately, at frequent intervals during the night.

5. As a rule, they go to the same feeding place each night and return to the same place of concealment, though they will accustom themselves to a new feeding place, especially in the younger stages.

6. They cease feeding at daylight (between 3 and 4 o'clock in the morning), but when it is cloudy they feed later. It would seem that the first indication of daylight is the signal for them to return to their places of concealment.

\section{Amount of Food consumed by Caterpillars.}

To learn the amount of food hungry caterpillars of different ages would consume in twenty-four hours, the following experiment was made during the summer of 1895: a known quantity of food was supplied to the caterpillars, and at the end of a specified time the remains of the leaves were carefully soaked in water and then measured. May 10 , at 4.30 P.M., three caterpillars, between the first and second molt, were placed in a breeding jar with 6 square inches of lettuce leaf. At 7.30 A.M., May 11, 4 square inches were added, making a total of 10 square inches. May 11, at 7.30 A.M., the refuse was removed, and equalled 2 square inches, thus giving 8 square inches as the amount consumed by the three caterpillars, or $2 \frac{2}{3}$ square inches per caterpillar for twenty-four hours. May 10, at 4.30 P.M., three caterpillars, between the second and third molt, were supplied with 9 square inches of lettuce leaf. The next morning 4 square inches were added, and at 1.30 P.M. 
2 square inches. The refuse, which was remored at 4.30 P.M., measured 3 square inches, making 12 square inches which had been eaten by the three caterpillars, or 4 square inches per caterpillar. May 10, at 4.30 P.M., three caterpillars, between the third and fourth molt, were supplied with lettuce as follows: May 10, at 4.30, 9 square inches; May 11, at 7.30, 4 square inches; and at 1.30 P.M. 4 square inches: total, 17 square inches. The refuse was removed May 11, and measured 3 square inches, leaving 14 square inches as the amount consumed, or $4 \frac{2}{3}$ square inches per caterpillar. Three caterpillars, between the fourth and fifth molt, were supplied with 18 square inches of lettuce at the same date and hour, and on May 11, at 7.30 A.M., 9 square inches were added; and at 1.30 P.M. 9 square inches more. The refuse, removed at 4.30 P.м., May 11, measured 5 square inches, leaving 31 square inches the amount consumed by all, or $10 \frac{1}{3}$ square inches per caterpillar. June 26, three caterpillars, between the last molt and pupation, were given 20 square inches of lettuce leaf at 7 A.M., and at 5 P.M., 20 square inches more were added. At 7 A.M., June 27 , the refuse was removed and soaked out. It then measured 5 square inches, making 35 square inches that had been eaten by the three caterpillars, or $11 \frac{2}{3}$ square inches per caterpillar.

These figures give evidence of the food capacity of the caterpillars, but it should be borne in mind that lettuce does not offer so much resistance to the jaws (mandibles) of the caterpillar as do the harder leaves of the apple, oak and others.

\section{Food Plants.}

A series of experiments was conducted during the part of the season of 1895 that the gypsy moth was in the caterpillar stage, for the purpose of determining so far as possible all the plants this insect will feed upon. For this purpose collectors brought in specimens of all the plants met with in the fields and forests of the infested territory. To Mr. H. L. Frost, a careful student of botany as well as entomology, was assigned the work of determining these plants and carrying out the details of the experiment. While the plants were 
still fresh they were placed in eight-ounce glass jars, and four caterpillars, in the fourth or fifth molt, were placed upon them. This number was about all that could feed without crowding, and at the same time give appreciable results before the plants wilted. The jars were covered at the top with thin cloth, to prevent the escape of the caterpillars and at the same time to allow ventilation. They were numbered, and the numbers, with the names of the plants, were booked at the time the caterpillars were placed on the food, the jars being kept in a place sufficiently cool to prevent undue evaporation, but at a temperature at which the caterpillars fed readily. Observations were made every twenty-four hours, and, if at the end of three days the caterpillars showed an unwillingness to feed on the plant, the experiment was repeated with a fresh stock of caterpillars on a fresh supply of the same food. If they did not attack it at the second trial, in view of their accustomed readiness to feed on nearly all plants, it was assumed that they would not feed on the plant in question. The flora of the region about Malden is maritime rather than inland, and some of the common plants of the central and western parts of the State do not occur there.

Attention is called to the fact that the caterpillars of the gypsy moth feed readily on common water plants, such as Nymphoea odorata, Pontederia cordata and Alisma plantago. Experiments performed this year proved that some of the caterpillars will live for several days floating on the water and without food. These two facts in connection may help to explain the distribution of this insect along streams.

In the following lists both the common and scientific names are given, as far as possible. The nomenclature is that of Gray's "Manual of Botany," 1889, for the wild plants, and Wood's "Botany" of 1889, for the cultivated plants. An asterisk before a name denotes that the caterpillars fed on the plant only when forced to do so by starvation. It will be noticed that about twenty-one per cent. of the plants in the following list are of economic value. 


\section{Plants upon which the Gypsy Moth Caterpillar has been known to feed in Massachusetts.}

Virgin's bower (Clematis Virginiana). *Wind flower (Anemone Virginiana).

White water crowfoot (Ranunculus aquatilis, var. trichophyllus).

Small-flowered crowfoot (Ranunculus abortivus).

Hooked crowfoot (Ranunculus recurvatus).

Bnlbous crowfoot (Ranunculus bulbosus).

Wild columbine (Aquilegia Canadensis).

Peony (Pronia officinalis).

Umbrella tree (Magnolia umbrella).

* Magnolia Soulangeana.

Tulip tree (Liriodendron Tulipifera).

Siberian pea tree (Caragana arborescens).

Barberry (Berberis vulgaris).

Holly barberry (Berberis Aquifolium).

White water lily (Nymphaa odorata).

Pitcher plant (Sarracenia purpurea).

Celandine (Chelidonium majus).

Poppy (Papaver orientalis).

*Pale corydalis (Corydalis glauca).

*Sweet alyssum (Alyssum maritimum).

Horseradish (Nasturtium Armoracia).

Hedge mnstard (Sisymbrium officinale).

Black mustard (Brassica nigra).

Turvip (Brassica rapa, var. depressa).

Savoy cabbage (Brassica oleracea, var. bullata).

Shepherd's purse (Capsella Bursa-pastoris).

Wild peppergrass (Lepidium Virginicum).

-Sea rocket (Cakile Americana).

Radish (Raphanus Raphanistrum).

Blue violet (Viola palmata, var. cucullata).

Primrose-leaved violet (Viola primulafolia).

Lance-leaved violet (Viola lanceolata). Dog violet (Viola canina, var. Muhlenbergii).

Pansy (Viola tricolor).

Carnation pink (Dianthus caryophyllus).

-Sweet, William (Dianthus barbatus).

Bouncing bet (Saponaria officinalis).

Corn cockle (Lychnis Githago).

Common chickweed (Stellaria media).

Mouse-ear chickweed (Cerastium vulgatum).
Sand spurrey (Buda rubra).

Purslane (Portulaca oleracea).

St. John's-wort (Hypericum perforatum).

Marsh St. John's-wort (Elodes campanulata).

Hollyhock (Althaa rosea).

Common mallow (Malva rotundifolia).

Indian mallow (Abutilon vexillarium).

-Chinese hibiscus (Hibiscus Rosa-Sinensis).

Cotton plant (Gossypium herbaceum).

Basswood (Tilia Americana).

European linden (Tilia Europaa).

Wild cranesbill (Geranium maculatum).

Geranium (Geranium sanguineum).

Yellow wood sorrel (Oxalis corniculata, var. stricta).

Nasturtium (Tropaolum majus).

Spotted touch-me-not (Impatiens fulva).

Fraxinella (Dictamnus albus).

*Shrubby trefoil (Ptelea trifoliata).

*Lemon (Citrus Limonum).

Tree of Heaven (Ailanthus glandulosus).

Black alder (Ilex verticillata).

Climbing bittersweet (Celastrus scandens).

European spindle-tree (Euonymus Europaus).

Grape (Vitis vinifera).

Northern fox grape (Vitis Labrusca).

Virginian creeper (Ampelopsis quinquefolia).

Ampelopsis veitchii.

Horse chestnut (Asculus Hippocastanum).

Red buckeye (Asculus Pavia).

Sugar maple (Acer saccharinum).

White maple (Acer dasycarpum).

Cut-leaved maple (Acer dasycarpum, var. Weirii).

Red maple (Acer rubrum).

Sycamore maple (Acer Pseudo-Platanus).

Box elder (Negundo aceroides).

Variegated box elder (Negundo aceroides, var. variegata).

Koeulreuteria paniculata.

Stag-horn sumach (Rhus typhina).

Smooth sumach (Rhus glabra).

Polson dogwood (Rhus venenata).

Polson Ivy (Rhus Toxicodendron).

Rhus vernex. 
Plants upon which the Gypsy Moth Caterpillar has been known to feed in Massachusetts - Continued.

Smoke tree (Rhus Cotinus).

Milkwort (Polygala polygama).

Wild indigo (Baptisia tinctoria).

Yellow wood (Cladrastis lutea).

Dyer's green weed (Genista tinctoria).

Rabbit-foot clover (Trifolium arvense).

White clover (Trifolium repens).

Red clover (Trifolium pratense).

Alsike clover (Trifolium hybridum).

Yellow clover (Trifolium agrarium).

Low hop clover(Trifolium procumbens).

False indigo (Amorpha fruticosa).

Locust (Robinia Pseudacacia).

Wistaria (Wistaria consequana).

Tick trefoil (Desmodium nudiflorum).

Common vetch (Vicia sativa).

Beach pea (Lathyrus maritimus).

Ground-nut (Apios tuberosa).

Scarlet pole bean (Phaseolus multiflorus).

Bush bean (Phaseolus nanus).

Red bud (Cercis Canadensis).

Kentucky coffee tree (Gymnocladus Canadensis).

Honey locust (Gleditschia triacanthos).

Chinese honey locust (Gleditschia Sinensis).

Coffee bean (Faba vulgaris).

Pea (Pisum sativum).

Cercidiphyllum Japonicum.

Beach plam (Prunus maritima).

Wild red cherry (Prunus Pennsylvanica).

Choke cherry (Prunus Virginiana).

Wild black cherry (Prunus serotina).

Damson plum (Prunus domestica).

English cherry (Prunus Avium).

Peach (Prunus vulgaris).

Purple-leaved plum (Prunus Pissardi).

Prunus Davidii.

Apricot (Prunus Armeniaca).

Japanese plum (Prunus Japonica).

Meadow sweet (Spircea salicifolia).

Hardhack (Spircea tomentosa).

Spircea Thunbergii.

Parple flowering raspberry (Rubus odoratus).

Dwarf raspberry (Rubus triflorus).

Wild red raspberry (Rubus strigosus).

Thimbleberry (Rubus occidentalis).

High blackberry (Rubus villosus).

Low blackberry (Rubus Canadensis).

*Avens (Geum macrophyllum).

Strawberry (Fragaria Virginiana).
*Cinquefoil (Potentilla Norvegica).

Silvery cinquefoil (Potentilla argentea).

Common cinquefoil (Potentilla Canadensis).

Shrubby cinquefoil (Potentilla fruticosa).

Agrimony (Agrimonia Eupatoria).

Prairie rose (Rosa setigera).

Dwarf wild rose (Rosa lucida).

Rose (Rosa nitida).

Crab apple (Pyrus coronaria).

Narrow-leaved crab apple (Pyrus angustifolia).

Choke berry (Pyrus arbutifolia).

American mountain ash (Pyrus Americana).

Pyrus sambucifolia.

Pyrus pinnatifida.

Pyrus decata.

Pear (Pyrus communis).

Apple (Pyrus Malus).

English hawthorn (Cratagus Oxyacantha).

Panl's thorn (Cratagus coccinea, var. Paulii).

Cockspur thorn (Cratagus Crus-galli).

Shad bush (Amelanchier Canadensis).

Amelanchier alnifolia.

Quince (Cydonia vulgaris).

Japan quince (Cydonia Japonica).

*Sweet-scented shrub (Calycanthus floridus).

Mock orange (Philadelphus coronarius).

* Deutzia gracilis.

Hydrangea paniculata.

Common red currant (Ribes rubrum).

Black currant (Ribes nigrum).

Gooseberry (Ribes grossularia).

English gooseberry (Ribes Uva-crispa).

Ditch stonecrop (Penthorum sedoides).

Garden orpine (Sedum Telephium).

Witch hazel (Hamamelis Virginiana).

Sweet gum tree (Liquidambar Styraceflua).

Swamp loosestrife (Decodon verticillatus).

Pomegranate (Punica granatum).

Great willow herb (Epilobium angustifolium).

Slender willow herb (Epilobium lineare).

Common evening primrose (Ginothera biennis). 
Plants upon which the Gypsy Moth Caterpillar has been known to feed in Massachusetts - Continued.

Evening primrose (Enothera pumila).

Ladies' eardrop (Fuchsia coccinea).

Squash (Cucurbita verrucosa).

Cucnmber (Cucumis sativus).

- Parsnip (Peucedanum sativum).

Zizia aurea.

Celery (Apium graveolens).

Spotted cowbane (Cicuta maculata).

Hercules' club (Aralia spinosa).

Wild sarsaparilla (Aralia nudicaulis).

Flowering dogwood (Cornus florida).

Cornus mas.

Common elder (Sambucus Cauradensis).

Cranberry tree (Viburnum Opulus).

Arrowwood (Viburnum acerifolium).

Downy arrowwood (Viburnum pubescens).

Arrowwood (Viburnum dentatum).

Viburnum tomentosum.

Sweet viburnum (Viburnum Lentago).

Black baw (Viburnum prunifolium).

Wayfaring tree (Viburnum Lantana).

Snowberry (Symphoricarpus racemosus).

Trumpet honeysuckle (Lonicera sempervirens).

Bush honeysuckle (Diervilla trifida).

Wiegelia rosea.

Button bush (Cephalanthus occidentalis).

Partridge berry (Mitchella repens).

Small bedstraw (Galium trifidum). Rough bedstraw (Galium asprellum).

Joe pye weed (Eupatorium purpureum).

Thoroughwort (Eupatorium perfoliatum).

Golden-rod (Solidago rugosa).

Golden-rod (Solidago arguta).

*Golden-rod (Solidago Canadensis).

Golden-rod (Solidago lanceolata).

Aster undulatus.

Aster cordifolius.

Aster levis.

Aster puniceus.

Aster miser.

Horse weed (Erigeron Canadensis).

Fleabane (Erigeron Philadelp ricus).

Elecampane (Inula Helenium).

Roman wormwood (Ambrosia artemisiafolia).

Cone flower (Rudbeckia hirta).

Sunflower (Helianthus annurs).

-Helianthus decapetalus.

Artichoke (Helianthus tukerosus).
Beggar ticks (Bidens frondosa).

Bur marigold (Bidens chrysanthemoides).

May weed (Anthemis Cotula).

Yarrow (Achillea Millefolium).

Ox-eye daisy (Chrysanthemum Leucanthemum).

Chrysanthemum (Chrysanthemum Sinense).

Tansy (Tanacetum vulgare).

Fireweed (Erechtites hieracifolia). .

Burdock (Arctium Lappa).

('ommon thistle (Cnicus lanceolatus).

Tall thistle (Cnicus altissimus).

Canada thistle (Cnicus arvensis).

Dwarf dandelion (Krigia Virginica).

Chicory (Cichorium Intybus).

Fall dandelion (Leontodon autumnale).

Rattlesnake root (Prenanthes altis$\operatorname{sim} a)$.

*White lettuce (Prenanthes alba).

Dandelion (Taraxacum officinale).

Lettuce (Lactuca sativa).

Common dahlia (Dahlia variabilis).

French marigold (Tagetes patula).

Indian tobacco (Lobelia inflata).

Lobelia spicata.

Venus' looking glass (Specularia perfoliata).

Dangleberry (Gaylussacia frondosa).

Black huckleberry (Gaylussacia resinosa).

Dwarf blueberry (Vaccinium Pennsylvanicum).

Low blueberry (Vaccinium vacillans).

Swamp blueberry (Vaccinium corymbosum).

Leather leaf (Cassandra calyculata).

Sheep laurel (Kalmia angustifolia).

Clummy azalea (Rhododendron viscosum).

Rhodora (Rhododendron Rhodora).

Great laurel (Rhododendron maximum).

Labrador tea (Ledum latifolium).

Sweet pepperbnsh (Clethra alnifolia).

Prince's pine (Chimaphila umbellata).

Shin leaf (Pyrola elliptica).

Pyrola rotundifolia.

Star flower (Trientalis Americana).

Steironema ciliatum.

Loosestrife (Lysimachia quadrifolia).

Sweet leaf (Symplocos cratagoides).

White ash (Fraxinus Americana).

Red ash (Fraxinus pubescens). 
Plants upon which the Gypsy Moth Caterpillar has been known to feed in Massachusetts - Continued.

Blne ash (Fraxinus quadrangulata). Black ash (Fraxinus sambucifolia). European ash (Fraxinus excelsior). Fraxinus Oregona.

Fraxinus rhycophylla.

Fraxinus Sag-Diana.

Fringe tree (Chionanthus Virginica).

Privet (Ligustrum vulgare).

Common lilac (Syringa vulgaris).

Japanese lilac (Syringa Japonica).

Forsythia viridissima.

Dogbane (Apocynum androsamifolium).

Swamp milkweed (Asclepias incarnata).

Common milkweed (Asclepias Cornuti).

Poke milkweed (Asclepias phytolaccoides).

Forget-me-not (Myosotis arvensis).

Heliotrope (Heliotropium Peruvianum).

Morning glory (Ipomcea purpurea).

Dodder (Cuscuta Gronovii).

Bittersweet (Solanum Dulcamara).

Potato (Solanum tuberosum).

Petunia nyctaginifolia.

Tomato (Lycopersicum esculentum).

Matrimony vine (Lycium vulgare).

*Virginia tobacco (Nicotiana Tabacum).

Nicotiana longiflora.

Mullein (Verbascum Thapsus).

Toad flax (Linaria Canadensis).

Butter and eggs (Linaria vulgaris).

* Monkey flower (Mimulus ringens).

Water speedwell (Veronica Anagallis).

*Purple gerardia (Gerardia purpurea).

Trumpet creeper (Tecoma radicans).

Catalpa (Catalpa bignonioides).

* White vervain (Verbena urticafolia).

* Blue vervain (Verbena hastata).

Spearmint (Mentha viridis).

Peppermint (Mentha piperita).

Bugle weed (Lycopus Virginicus).

Catnip (Nepeta Cataria).

Self heal (Brunella vulgaris).

Dead nettle (Lamium album).

Scarlet sage (Salvia splendens).

Common plantain (Plantago major).

Seaside plantain (Plantago maritima).

Green amaranth (Amarantus retroflexus).

Pigweed (Chenopodium album).

Coast blite (Chenopodium rubrum).

Spinach (Spinacia oleracea).

Beet (Beta vulgaris).

Garget (Phytolacca decandra).

Patience dock (Rumex Patientia).
Swamp dock (Rumex verticillatus).

Curled dock (Rumex crispus).

Sheep sorrel (Rumex Acetosella).

Rhubarb (Rheum Rhaponticum).

Coast knotgrass (Polygonum maritimum).

Door weed (Polygonum aviculare).

Polygonum Pennsylvanicum.

Water persicaria (Polygonum amphibium).

Polygonum Careyi.

Lady's thumb (Polygonum Persicaria). Water pepper (Polygonum hydropiperoides).

Smart weed (Polygonum Hydropiper).

Arrow-leaved tear thumb (Polygonum sagittatum).

Sassafras (Sassafras officinale).

Oleaster (Elcagnus hortensis).

Elaagnus Longipes.

Elcagnus umbellata.

Spurge (Euphorbia Cyparissias).

Slippery elm (Ulmus fulvus).

White elm (Ulmus Americana).

Cork elm (Ulmus racemosa).

English elm (Ulmus campestris).

Scotch elm (Ulmus montana).

Common hop (Humulus Lupulus).

Red mulberry (Morus rubra).

Tartarian mulberry (Morus Tartarica).

Nettle (Urtica gracilis).

Nettle (Urtica dioioa).

India rubber tree (Ficus elastica).

Sycamore (Platanus occidentalis).

Butternut (Juglans cinerea).

Shell-bark hickory (Carya alba).

White-heart hickory (Carya tomentosa).

Pig nut (Carya porcina).

Bayberry (Myrica cerifera).

Sweet fern (Myrica asplenifolia).

Black birch (Betula lenta).

Yellow birch (Betula lutea).

White birch (Betula populifolia).

Paper birch (Betula papyrifera).

River birch (Betula nigra).

Cut-leaved birch (Betula alba, var. laciniata).

Betula Danurica.

Speckled alder (Alnus incana).

Smooth alder (Alnus serrulata).

Wild hazelnut (Corylas Americana).

Hop hornbeam (Ostrya Virginica).

White oak (Quercus alba).

Swamp white oak (Quercus bicolor). 


\section{Plants upon which the Gypsy Moth Caterpillar has been known to feed} in Massachusetts - Concluded.

Red oak (Quercus rubra).

Scarlet oak (Quercus coccinea).

Black oak (Quercus coccinea, var. tinctoria).

Pin oak (Quercus palustris).

Scrub oak (Quercus ilicifolia).

Barren oak (Quercus nigra).

Chestnut (Castanea sativa, var. Americana).

Chinquapln (Castanea pumila).

Blue beech (Carpinus Caroliniana).

American beech (Fagus ferruginea).

Purple beech (Fagus sylvatica, var. purpurea).

Crack willow (Salix fragilis).

White willow (Salix alba).

Weeping willow (Salix Babylonica).

Heart-leaved willow (Salix cordata).

White poplar (Populus alba).

American aspen (Populus tremuloides).

Large-toothed aspen (Populus grandidentata).

Balm of Gilead (Populus balsamifera, var. candicans).

Black poplar (Populus nigra).

Lombardy poplar (Populus nigra, var. dilatata).

White pino (Pinus Strobus).

Pitch pine (Pinus rigida).

Scotch pine (Pinus sylvestris).

White spruce (Picea alba).

Norway spruce (Picea excelsa).

Fir (Abies balsamea).

Hemlock (Tsuga Canadensis).

Larch (Larix Americana).

European larch (Larix Europaa).

Arbor vitæ (Thuja occidentalis).

Common juniper (Juniperus communis).

Red cedar (Juniperus Virginiana).

*Ginkgo (Juniperus Salisburia adiantifolia).

Ladies' tresses (Spiranthes gracilis).

Yellow fringed orchis (Habenaria ciliaris).

Lady's slipper (Cypripedium acaule).

Banana (Musa sapientum).

Canna (Canna Indica).

Blue flag (lris versicolor).

Blue-eyed grass (Sisyrinchium angustifolium).

Snowdrop (Galanthus nivalis).

Carrlon flower (Smilax herbacea).

Common greenbrier (Smilax rotundifolia).
Day lily (Hemerocallis fulva). Adam's needle ( Yucca filamentosa). Lily of the valley (Convallaria majalis). Solomon's seal (Polygonatum biflorum). Asparagus (Asparagus officinalis).

False Solomon's seal (Smilacina racemosa).

* Maianthemum Canadense.

Bellwort (Oakesia sessilifolia).

Wood lily (Lilium Philadelphicum).

Wild yellow lily (Lilium Canadense).

Tiger lily (Lilium tigrinum).

Indian cucumber root (Medeola Virginica).

Pickerel weed (Pontederia cordata).

Yellow-eyed grass (Xyris flexuosa).

Common cat tail (Typha latifolia).

Bur reed (Sparganium simplex).

Indian turnip (Ariscma triphyllum).

Arrow arum (Peltandra undulata).

Skunk cabbage (Symplocarpus foetidus).

*Sweet flag (Acorus Calamus).

Phyllodendron Amurense.

*Water plantain (Alisma Plantago).

Arrow head (Sagittaria variabilis, var. gracilis).

Cotton grass (Eriophorum polystachyon).

Millet (Panicum miliaceum).

Finger grass (Panicum sanguinale).

*Barnyard grass (Panicum Crus-galli).

Herd's grass, Timothy (Phleum pratense).

* Meadow foxtail (Alopecurus pratensis).

Coinmon oat (Avena sativa).

Eragrostis pectinacea.

Low spear grass (Poa annua).

Kentucky blue grass (Poa pratensis).

Barley (Hordeum vulgare).

Orchard grass (Dactylis glomerata).

Quitch grass (Agropyrum repens).

Bamboo (Bambusa arundinacea).

Indlan corn (Zea Mays).

Common horsetail (Equisetum arvense).

Common brake (Pteris aquilina).

* Spleenwort (Asplenium ebeneum).

Shleld fern (Aspidium Noveboracense).

Sensitive fern (Onoclea sensibilis).

Flowering fern (Osmunda regalis).

Osmunda Claytoniana.

Cinnamon fern (Osmunda cinnamomea).

* Gronnd pine (Lycopodium obscurum).

Selaginella apus. 


\section{Plants upon which the Gypsy Moth Caterpillar has been found feeding in the Field.}

Tulip tree (Liriodendron Tulipifera). Barberry (Berberis vulgaris).

Bass wood (Tilia Americana).

European linden (Tilia Europaa).

Northern fox grape (Vitis Labrusca).

Horse chestnut (Esculus Hippocastanum).

Sugar maple (Acer saccharinum).

White maple (Acer dasycarpum).

Cut-leaved maple (Acer dasycarpum, var. Weirii).

Red maple (Acer rubrum).

Staghorn sumach (Rhus typhina).

Smooth sumach (Rhus glabra).

Poison ivy (Rhus toxicodendron).

Common locust (Robinia Pseudacacia).

Cercidiphyllum Japonicum.

Wild red cherry (Prunus Pennsylvanica).

Choke cherry (Prunus Virginiana).

Wild black cherry (Prunus serotina).

Damson plum (Prunus domestica).

Purple-leaved plum (Prunus Pissardi).

Wild red raspberry (Rubus strigosus).

Thimbleberry (Rubus occidentalis).

High blackberry (Rubus villosus).

Low blackberry (Rubus Canadensis).

Strawberry (Fragaria Virginiana).

Rose (Rosa nitida).

Dwarf wild rose (Rosa lucida).

Choke berry (Pyrus arbutifolia).

American monntain ash (Pyrus Americana).

Pear (Pyrus communis).

Apple (Pyrus Malus).

Paul's thorn (Cratagus coccinea, var. Paulii).

Shad bush (Amelanchier Canadensis).

Quince (Cydonia vulgaris).

Arrow wood (Viburnum acerifolium).

Ox-eye daisy (Chrysanthemum Leucanthemum).

Burdock (Arctium Lappa).

Dangleberry (Gaylussacia frondosa).

Low blueberry (Vaccinium vaciblans).

Swamp blueberry (Vaccinium corymbosum).
Clammy azalea (Rhododendron visco sum).

White ash (Fraxinus Americana).

Common lilac (Syringa vulgaris).

Bittersweet (Solanum Dulcamara).

Mullein (Verbascum Thapsus).

Slippery elm (Ulmus fulva).

White elm (Ulmus Americana).

English elm (Ulmus campestris).

Sycamoro (Platanus occidentalis).

Bntternut (Juglans cinerea).

Shell-back hickory (Carya alba).

White-heart hickory (Carya tomentosa).

Pig nut (Carya porcina).

Bayberry-(Myrica cerifera).

American whito birch (Betula populifolia).

Paper birch (Betula papyrifera).

Rlver birch (Betula nigra).

Cut-leaved birch (Betula alba, var. laciniata).

Smooth alder (Alnus serrulata).

Wild bazel nut (Corylus Americana).

White oak (Quercus alba).

Swamp whlte oak (Quercus bicolor).

Red oak (Quercus rubra).

Scrub oak (Quercus ilicifolia).

Chestnut (Castanea sativa, var. Americana).

Blne beech (Carpinus Caroliniana).

American beech ( $F$ agus ferruginea).

Purple beech (Fagus sylvatica, var. purpurea).

White willow (Salix alba).

Weeping willow (Salix Babylonica).

American aspen (Populus tremuloides).

Balm of Gilead (Populus balsamifera, var. candicans).

White pine (Pinus Strobus).

Pitch pine (Pinus rigida).

Common greenbrier (Smilax rotundi folia).

False Solomon's seal (Smilacina racemosa).

Kentncky blue grass (Poa pratensis). Common brake (Pteris aquilina).

\section{Plants upon which the Gypsy Moth Caterpillar did not feed.}

Red baneberry (Actaa spicata, var. rubra).

Rocket larkspur (Delphinium Ajacis).
Bee larkspur (Delphinium elatum). Great-flowered larkspur (Delphimium grandiflorum). 
Plants upon which the Gypsy Moth Caterpillar did not feed-Concluded.

Winter cress (Barbarea vulgaris).

Balsamine (Impatiens balsamina).

Myrtle (Myrtus communis).

Bur cucumber (Sicyos angulatus).

Everlasting (Antennaria plantaginifolia).

Commoneverlasting (Gnaphalium polycephalum).

Common mugwort (Artemisia vulgaris).
Blue bottle (Centaurea Cyanus).

Rattlesnake weed (Hieracium venosum). Indian pipe (Monotropa uniflora).

Red pepper (Capsicum annuum).

Ground hemlock (Taxus Canadensis).

Pogonia ophioglossoides.

Ground pine (Lycopodium complanatum).

Marsilia quadrifolia.

\section{Cotton as a Food Plant.}

The question was raised whether the gypsy moth would prove destructive to the cotton plant in the South, should it by any means escape from its present locality and become distributed in the cotton States. To decide this question, cotton seeds were planted and two small plants were raised. When one of these was about two inches high, gypsy caterpillars were placed on it, and they devoured not only the leaves but nearly all the stem, during a single night. The second plant died before reaching the size desired for the experiment.

By correspondence with Mr. F. B. Carpenter of the agricultural experiment station at Raleigh, N. C., a dozen small cotton plants were obtained, which were from two to two and a half feet high. Although the plants were well packed, they were badly wilted when they arrived. All but two were set out in the ground in different places, in the hope that some of the varied soils would prove congenial, but unfortunately none of them lived. The leaves of one remaining plant were taken off and put into a jar with ten caterpillars. Notwithstanding the fact that the leaves were badly wilted, the caterpillars on the second day had eaten about one-fourth of them, but at the end of this day the leaves had become so dry that this experiment was discontinued. The remaining plant, having been kept in water, had revived somewhat, and on July 22 twenty caterpillars, of the fifth molt, were placed upon it, the base of the plant being kept in water. The caterpillars at once began feeding heartily on the plant, appearing to prefer the fresh leaves at the top to the lower wilted ones. They continued to feed till July 25, at which time they had devoured the greater part of the plant, having eaten leaves, tender petioles and half-developed boll. From this 


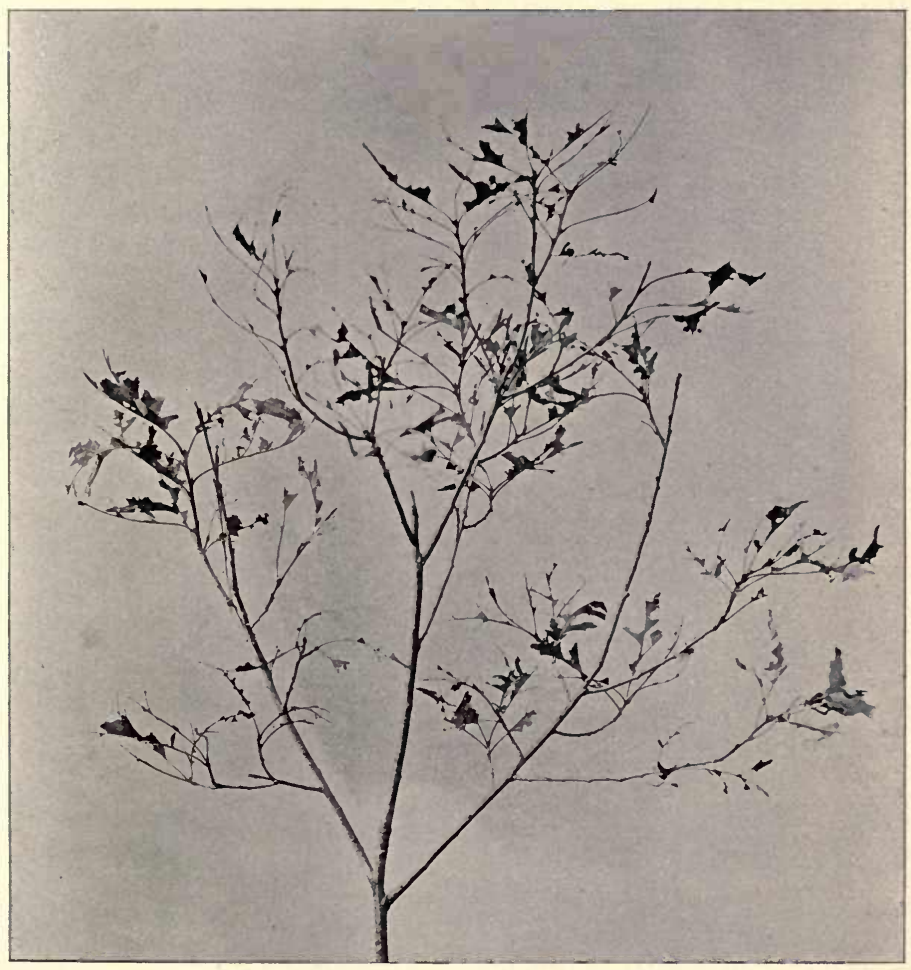

PLATE 46. Oak branch attacked by gypsy moth caterpillars, Saugus, July, 1894. 

experiment it seems evident that, if they were numerous in a Southern cotton field, they might prove quite as destructive as the cotton worm (Aletia argillacea).

Plants upon which the Gypsy Moth Caterpillar has been known to feed in Europe.

Cabbage (Brassica oleracea).

Rock rose (Cistus Laurifolius).

Linden (Tilia Europaa).

Spindle tree (Euonymus verrucosus).

Sycamore (Acer Pseudo-Plantanus).

Tartar maple (Acer Tartaricum).

White Inpine (Lupinus albus).

Maple (Acer platanus) and other species.

Sainfoin (Onobrychis sativa).

Chinese wistaria (Wistaria Sinensis).

Pea vines (Pisum sativum).

Honey locust (Gleditschia triacanthos).

Plum (Prunus domestica).

Prune (Prunus occidentalis ?).

Peach (Prunus Persica).

Apricot (Prunus Armeniaca).

Sloe (Prunus spinosa).

English cherry (Prunus Avium).

Laurel cherry (Prunus Laurocerasus).

Black service berry (Prunus padus).

White thorn (Cratagus Pyracantha).

Hawthorn (Cratagus Oxyacantha).

Quince (Cydonia vulgaris).

Mountain ash (Pyrus aucuparia).

Apple (Pyrus malus).

Pear (Pyrus communis).

European medlar (Mespilus Germanica).

Chinese medlar (Photinia serrulata).

Loquat tree (Eriobotrya Japonica).

Strawberry (Fragaria vesca).

Rose (Rosa canina).

Rose (Rosa centifolia).

Pomegranate (Punica granatum).

Currant (Ribes alpinum).

Gooseberry (Ribes Uva-crispa).

Cucumber (Cucumis sativus).

Spotted hemlock (Conium maculatum).

Water hemlock (Cicuta virosa).

Lettuce (Lactuca sativa).

Heath (Erica Melaleuca).

Heather (Calluna vulgaris).

Azalea, various species.

Pimpernel (Anagallis arvensis ?).
Olive (Olea Europaa).

Ash (Fraxinus excelsior).

Rhubarb (Rheum Rhaponticum).

Elm (Ulmus campestris).

Elm (Ulmus effusa).

Elm (Ulmus pedunculata).

Elm (Ulmus subrosa).

Fig (Ficus Carica).

Plane tree (Platanus orientalis).

Walnut (Juglans nigra).

Cork oak (Quercus suber).

Holm oak (Quercus Ilex).

Winter oak (Quercus pedunculata, var. tardiflora).

Oak (Quercus pubescens) and other species.

Chestnut (Castanea vesca).

Beech (Fagus sylvaticus).

Hazel-nut (Corylus Avellana).

Hornbeam (Carpinus betulus).

Hornbeam (Carpinus orientalis).

Sweet gale (Myrica gale).

Birch (Betula alba) and other species.

Alder (Alnus glutinosa).

Speckled alder (Alnus incana).

Osier willow (Salix viminalis).

White willow (Salix alba).

Brittle willow (Salix fragilis).

Poplar willow (Populus nigra).

Aspen (Populus tremula).

Willow (Populus alba) and other spocies.

Fir (Pinus Abies).

Scotch fir (Pinus sylvestris).

Pine (Pinus Picea).

Larch (Larix Europaa).

Sprnce (Abies excelsa).

Arbor vitæ (Thuja occidentalis).

Savin (Juniperus Sabina).

Cypress (Cupressus sempervirens).

Lime tree (Cupressus Limetta).

Yew (Taxus baccata).

Grass, various species.

Grain.

\section{An Experiment in Starving Caterpillars.}

March 20, 1895, twenty-five newly hatched caterpillars, and also the same number from each of the first, second and 
third molts, were placed in corked vials without food, and kept in a normal temperature, in order to see how long they would live under such conditions. Observations were made on them at intervals of twenty-four hours. The following table gives the number of caterpillars dying on the specified dates:-

\begin{tabular}{|c|c|c|c|c|c|c|c|c|c|c|c|c|}
\hline & & हूँ & 혈 & 它 & 总 & 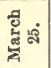 & 它 & 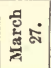 & 总 å & 究 & 淽。 & 苂 \\
\hline Just hatched, . & - & - & - & 5 & 8 & 12 & - & - & - & - & - & 25 \\
\hline First molt, . & . & - & - & 1 & 11 & 13 & - & - & - & - & - & 25 \\
\hline Second molt, . & . & - & - & - & 7 & 9 & 9 & - & - & - & - & 25 \\
\hline Third molt, . & . & - & - & - & 9 & 7 & 3 & 1 & 3 & - & 2 & 25 \\
\hline
\end{tabular}

This shows that caterpillars in the earlier stages will readily live four days without food; that an appreciable number of second-molt caterpillars will live under the same conditions for five days, while the third-molt caterpillars may exist on starvation diet for nine days.

To gain further knowledge of the period of time it is possible for gypsy moth caterpillars to live without food, a number of them were placed in cold storage, and a few removed from time to time and supplied with food. For this work, which was carried on during the month of April, 1895, use was made of a double box packed with sawdust and stored in a refrigerator, the temperature of which averaged about $40^{\circ} \mathrm{F}$. The caterpillars were kept in corked vials and removed as needed. At the ordinary temperature of the refrigerator the caterpillars became rigid and inactive, and remained so throughout the time involved in the experiment. April 3, 1895, a number of caterpillars in each of the different molts, from those just hatched to those between the fourth and fifth molt inclusive, were placed, without food, in corked vials in the refrigerator box. All of those between the fourth and fifth molt died within a day or two, possibly due to contact with the large quantity of saliva which they ejected soon after being placed in the box. 
At intervals of a few days several of the caterpillars of the different ages were removed from the refrigerator and placed on suitable food in a warm room; and in this way the length of time the caterpillars could exist without food, was determined. None of the caterpillars between the third and fourth molt were alive when removed from the box April 6 . Of those between the second and third molt, a single caterpillar remained alive April 24, and this one, when supplied with lettuce leaves, revived, fed and molted at the end of nine days. April 12, a number of caterpillars between the first and second molt were removed, and when supplied with food revived and began feeding. Several of the newly hatched caterpillars were found to be alive April 24, and when supplied with food a number of them were able to feed, and so reached maturity, after having been deprived of food for a period of three weeks.

A nearly full-grown caterpillar, confined in a box July 30, 1894, without food, lived until August 9, but died the night of that day. Lodi states that a caterpillar of this moth in Europe went without food for twenty-seven days without injury (“Opuscol. scelt.," vol. XII, page 183, 1789).

\section{Effect of Extremes of Temperature on Caterpillars of the Gypsy Moth.}

Effect of Heat. - Fifty caterpillars, in lots of ten, taken from the different molts, from those just hatched up to and including the fourth molt, were exposed for fifteen minutes to a temperature of $110^{\circ} \mathrm{F}$., and were then placed in jars and supplied with food. Of those just hatched, only one died; of those of the first molt, three; of the second molt, three; of the third molt, three; and of the fourth molt, three. The rest of the caterpillars survived and molted. Fifty caterpillars, selected in the same manner as those of the preceding experiment, were exposed to a temperature of $120^{\circ}$ for a period of fifteen minutes. Of those just hatched, ten died; of the first molt, ten; of the second molt, ten; of the third molt, nine; and of the fourth molt, only one. April 4, fifty caterpillars were exposed to a temperature of $130^{\circ}$ for a period of fifteen minutes. The caterpillars used in this experiment comprised those just hatched 
and the various molts up to and including the fourth. When taken from the oven, all but one were dead.

Effect of Cold. - Ten caterpillars just hatched, also ten from each molt up to the fourth, were selected and placed in vials, after which they were subjected to a temperature of $85^{\circ}$ for a period of five minutes. They were then placed in a cold box, where they were exposed to a temperature of $2^{\circ}$ above zero for a period of thirty minutes, at the end of which time they were removed to a room where the temperature was $70^{\circ}$, and examined. Only one caterpillar survived the above treatment, but this one, after a few days, fed and grew in a normal manner. Fifty caterpillars, in lots of ten, from the different molts, were transferred from a normal temperature of $70^{\circ}$ and exposed to a temperature of zero for a period of half an hour, when they were returned to the temperature from which they were first taken. When removed, all were dead. Fifty caterpillars in the various molts, up to and including the fourth, were placed in vials (the mouths of which were stopped with cloth instead of cork), and then removed from a temperature of $82^{\circ}$ to a cold box, where they remained fourteen hours, exposed to an approximate temperature of zero. All were dead when taken out.

A study of these experiments shows that, as a rule, the small caterpillars possess the ability to resist a considerable degree of cold but not of heat; while the larger caterpillars possess the ability to resist the heat better than the cold. This is as one would naturally expect to find it, since at the time of hatching the weather is usually cool, while the increase in size of the caterpillars keeps pace with the ordinary increase of temperature, so that by the time the caterpillars are full grown we often have a considerable degree of heat.

\section{Experiment in drowning Caterpillars.}

In many places the gypsy moth infests the trees along the course of streams, under such circumstances as to lead to the impression that they were distributed by falling into the water while in the caterpillar stage, and, drifting down stream with the current, reached the shore, and, making 
their way to suitable food plants, passed their transformations and thus established new colonies down stream.

To determine the actual resistance of these caterpillars to water, the following experiments were made in July, 1895. July 12, four jars were filled with water, and at 9 A.M. five gypsy moth caterpillars of the fifth molt were placed in each. In jar No. 1, half of the caterpillars were alive the third day; the remainder died July 17. In jar No. 2, one caterpillar died the first and two the second day; the other two lived until the morning of the fifth day. In jar No. 3, one died the first and the rest the fifth day. In jar No. 4 , one died the first and one the second day, the rest living until the morning of the fourth day. These results show that the gypsy moth caterpillars are able to live in water for two or three days, during which time, if they should fall into swiftly moving streams, they would be carried a considerable distance, and in this manner some of the colonies found along the shores of streams may have been established.

\section{Position of Caterpillars on Trees.}

To ascertain the normal position of the caterpillars of the gypsy moth on trees, a tight board fence was built around a medium-sized apple tree upon which a number of caterpillars were feeding. The fence was five feet in height, and enclosed an area of eighteen by eighteen feet. At a height of three feet from the ground a wide band of raupenleim was placed around the fence on the inside, and at the base the earth was banked up to the height of one foot, in order to prevent the escape of the caterpillars. Careful observations were made every morning by Mr. W. L. Tower, on the location of the caterpillars and the places where they had gone to rest after they stopped feeding. As the number of caterpillars on the tree was not always the same, no tabulated list of their positions could be made; yet the relative number found each day, in the same place and position, was more constant than could be expected. By adding the number found in each location and the number found on the tree every day, the percentage in each place was found to be fairly constant. 


\begin{tabular}{|c|c|c|c|c|c|}
\hline 1894. & $\begin{array}{c}\text { Number } \\
\text { under Burlap. }\end{array}$ & $\begin{array}{c}\text { Number } \\
\text { on Trunk. }\end{array}$ & $\begin{array}{c}\text { Number } \\
\text { on Branches. }\end{array}$ & $\begin{array}{l}\text { Number } \\
\text { on Leaves. }\end{array}$ & $\begin{array}{l}\text { Number } \\
\text { on Tree. }\end{array}$ \\
\hline $\begin{array}{l}\text { July } 16, . \\
\text { July } 17, . \\
\text { July } 18, . \\
\text { July } 19, . \\
\text { July } 21, \cdot \\
\text { July } 23, . \\
\text { July } 25, .\end{array}$ & $\begin{array}{r}14 \\
30 \\
31 \\
80 \\
75 \\
100 \\
74\end{array}$ & $\begin{array}{c}1 \\
3 \\
2 \\
-* \\
\overline{11 \dagger} \\
7 \dagger\end{array}$ & $\begin{array}{l}12 \\
16 \\
12 \\
47 \\
38 \\
28 \\
25\end{array}$ & $\begin{array}{l}\overline{3} \\
\overline{7} \\
- \\
- \\
-\end{array}$ & $\begin{array}{r}27 \\
52 \\
45 \\
134 \\
113 \\
139 \\
106\end{array}$ \\
\hline $\begin{array}{l}\text { Total, } \\
\text { Per c ent. } \\
\quad \text { (about), }\end{array}$ & $\begin{array}{r}404 \\
66\end{array}$ & $\begin{array}{l}6 \\
1\end{array}$ & $\begin{array}{r}178 \\
29\end{array}$ & 10 & $\begin{array}{l}616 \\
-\end{array}$ \\
\hline
\end{tabular}

The average per cent. of the number under the burlap did not vary much from sixty-six. The number found elsewhere on the trunk and on the leaves of the tree together did not constitute three per cent. of the whole.

In the early morning, before the rays of the sun struck the burlap, the caterpillars were found under it on all sides of the tree, but as the sun rose higher, the greater part of them were on the west and northern sides, away from the heat and light. As the sun went from east to west they moved around the tree, keeping on the shady side. This was true of the larger portion of the caterpillars, but in some instances they have been found at mid-day resting under the direct rays of the sun, with no covering whatever. The caterpillars that were on the larger branches of the tree, where the sun did not strike them, remained in the same position all day unless disturbed, while those on the smaller branches moved around, keeping on the shady side nearly all the time.

\section{Spinning Habits of Caterpillars.}

The amount of silk a gypsy moth caterpillar is capable of spinning has an important bearing on the distribution of these insects, since it is known that by spinning down upon passing teams, etc., the caterpillars are carried from place to place. The more silk a caterpillar is capable of spinning, 
the greater are its chances of being carried into new localities. To learn the quantity of silk that one of these caterpillars can spin, a reel was made and mounted in a frame. Caterpillars were taken on a soft brush and then jarred off into space. This caused them to spin, when, by attaching the end of the thread to the wheel and manipulating the caterpillars carefully, the silk was reeled off and a record kept of the number of revolutions of the wheel, until the caterpillars could not or would not spin. It was found that they spun best when a slight current of air was blown upon them. In this manner caterpillars of known ages were experimented with. Many of these experiments gave only negative results, for the manipulation necessary in getting the thread started often disturbed them so that they would spin only a few feet. The following results were obtained from a number of the experiments :-

March 22 : Four caterpillars, just hatched, were taken before any of their store of silk had been drawn upon. The first spun 4 feet and 6 inches, the second spun 9 feet and 1 inch, the third spun 38 feet and 2 inches, and the fourth spun 69 feet and 4 inches, - a distance greater than the height of an average shade tree. March 14: Of five first-molt caterpillars, the first spun 53 feet and 2 inches, the second 24 feet and 2 inches, the third 3 feet and 2 inches, the fourth 6 feet and 4 inches and the fifth 7 feet.

April 23: Three more caterpillars, of the first molt, were experimented with, and the following results obtained: the first spun 25 feet and 3 inches, the second 22 feet and 6 inches and the third 47 feet and 9 inches. March 22: Of two second-molt caterpillars, the first spun 8 feet and the second 2 feet. Other caterpillars, in the later molts, were tried, but they could not be induced to spin. There seems to be a decrease in spinning power as the caterpillar grows older. Caterpillars of the second, third and fourth molt have been seen spinning down to a considerable distance from trees on which they were feeding, and in this manner they were able to make the wind and passing teams aid them in finding their way to suitable food plants.

The last thing before entering upon the rest previous to molting is the spinning of a number of threads, forming a 
small silk mat, a little longer in diameter than the length of the body of the caterpillar. When rocks have been burned over, caterpillars have been seen spinning down to escape the smoke and heat. They frequently spin threads from fences to the neighboring trees. The insect also spins a scanty cocoon for a shelter and support during the pupal stage.

\section{The Process of Pupation.}

Cocoon. - When the caterpillar is fully grown, it seeks some sheltered spot (Plates 47,49), and rests quietly for about twenty-four hours. It then empties its alimentary canal, the discharge being of a semi-fluid nature, and containing an abundance of chlorophyl, showing it to be, in part at least, the remains of food. In about one hour after this discharge, the caterpillar begins to spin a frail cocoon, which is composed of a few coarse brown silken threads, occasionally enclosing a leaf or other material. In spinning, it first places its spinneret close to the surface on which the cocoon is to be formed, and presses out a drop of the silkforming fluid, which serves as an anchor for the silk thread which is then spun out. It first spins a few long threads, which usually exceed the length of the cocoon when finished. After a number of these long threads, which connect various points and serve as a sort of frame, have been formed, the caterpillar begins to spin more rapidly, and to place short threads between the long ones, working always from the inside, and changing at intervals from one side of the cocoon to the other. Where the threads cross each other they are fastened together by a drop of the fluid in much the same manner as at the starting of the cocoon. In spinning, the labial palpi and the feet are used to grasp the threads. As a rule, the spinning is not completed at a single operation, since the caterpillar rests several times, the rests ranging from a few minutes to five or six hours. The actual time spent in spinning is about six hours. After completing its network of silk the caterpillar rests quietly, except for occasional spasmodic twitchings of the body, hanging head downward, and pupates at the end of about three hours.

Pupation. - When the process of pupation begins, the skin commences to contract and wrinkle on the posterior 


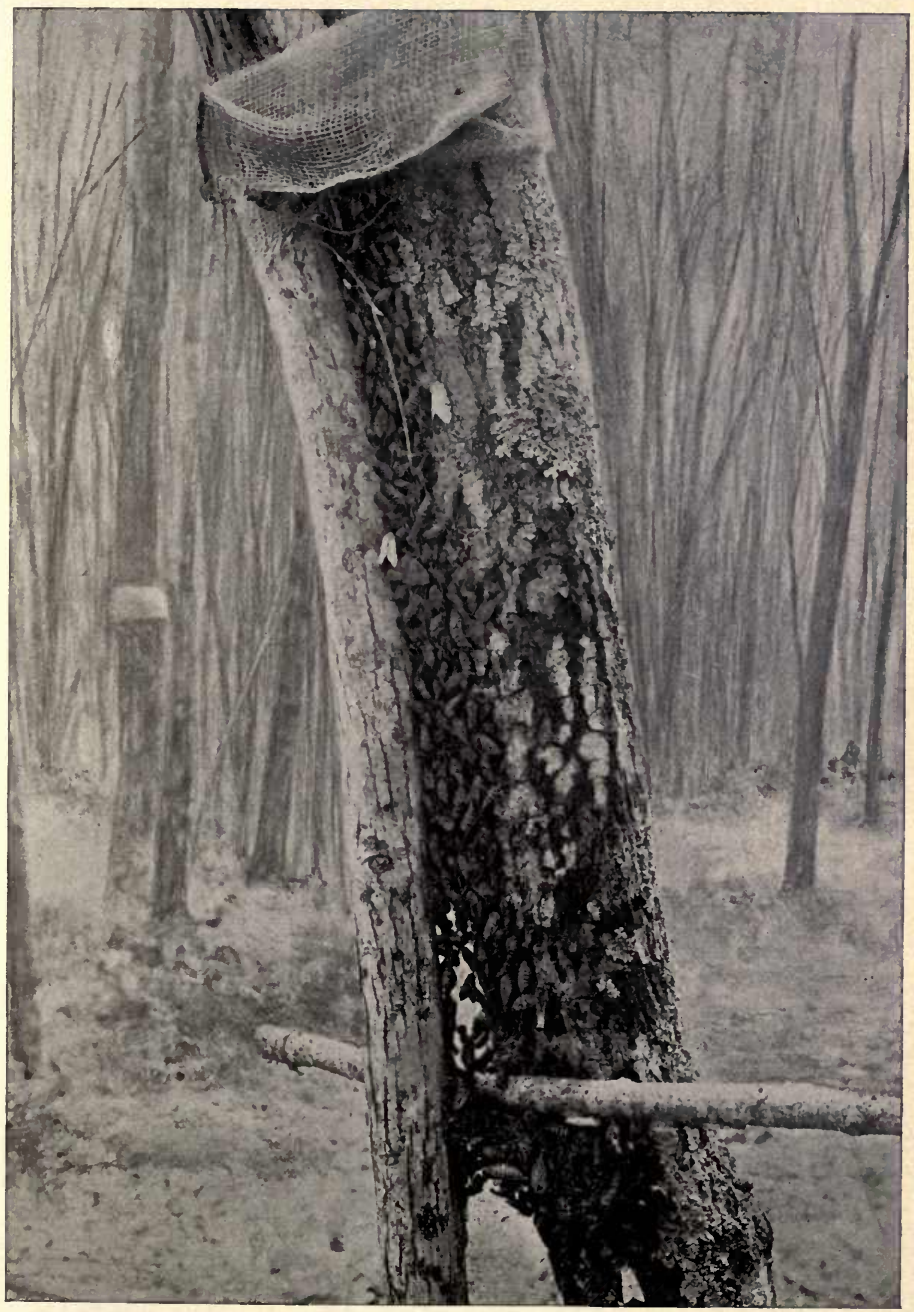

PLATE 47. Mass of pupw between the trunks of two trees. From a photograph taken at the Winning colony, Woburn, July, 1895. 


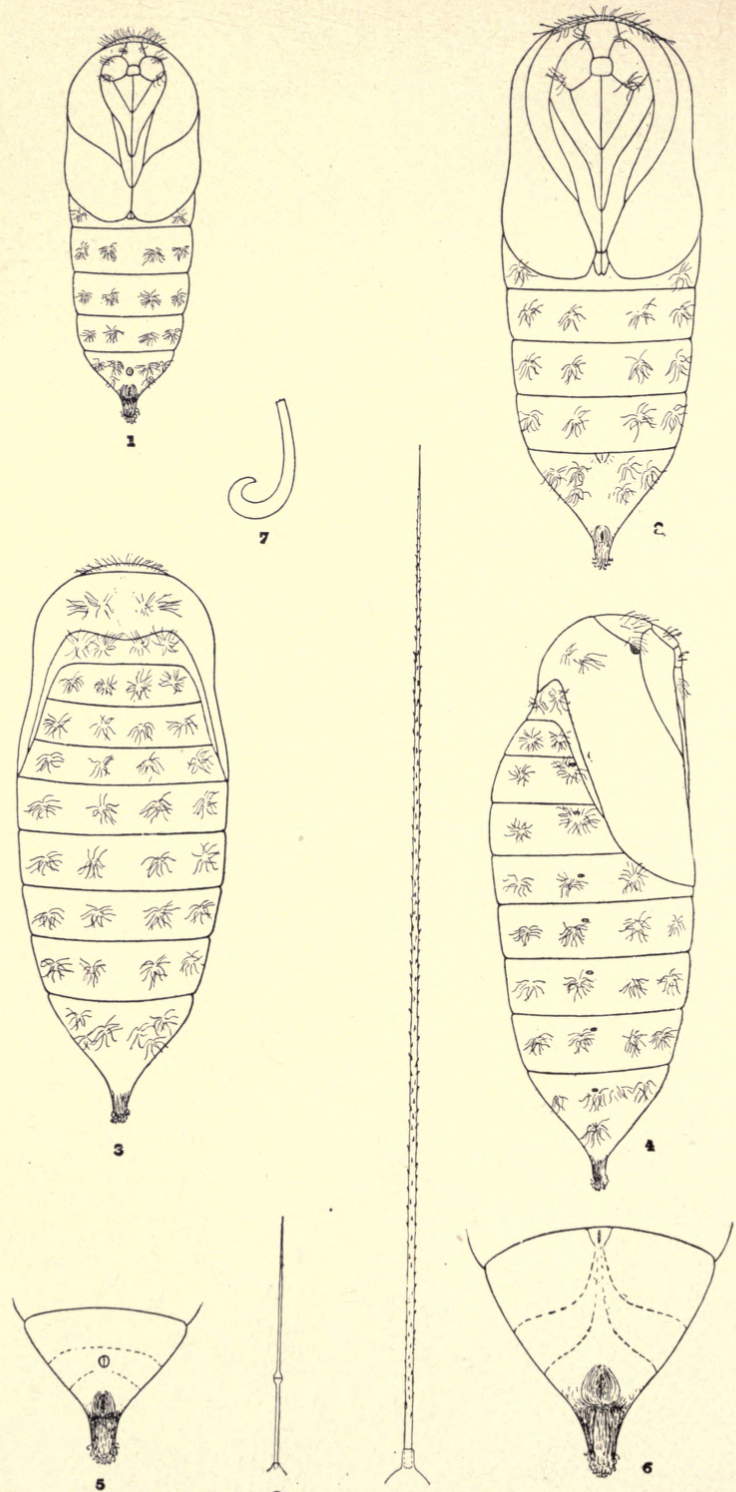


\section{EXPLANATION OF PLATE 48.}

\section{[AII figures enlarged.]}

Drawn by R. A. Cooley.

I. Ventral view of male pupa.

2. Ventral view of female pupa.

3. Dorsal view of female pupa.

4. Lateral view of female pupa.

5. Genital markings of male pupa.

6. Genital markings of female pupa.

7. Chitinized hook from cremaster of pupa, greatly enlarged.

8. Aerostatic hair from newly hatched caterpillar, greatly enlarged.

9. Normal hair from caterpillar, greatly enlarged. 

segments of the caterpillar, showing that the pupa is being withdrawn from that part. The pupa is pushed forward by a vigorous use of the cremaster. In this manner the skin on the posterior segments is pushed back, and the pressure on the anterior segments becomes so great as to nearly bend under that part of the body. The insect takes short rests at intervals during this process. Next, the skin on the fourth segment splits along the dorsal line, the split continuing forward and backward, and in a few seconds extends from the base of the head to the annulation between the fourth and fifth segments, the pupa, in the mean time, forcing itself outward against the opening thus made. In a few seconds more the movements of the pupa, aided by the pressure from behind, which it is able to exert by means of its cremaster, splits the head down on each side of the clypeus to the mouth parts, and the pupa emerges by passing outward through the opening, the whole process taking about fifteen minutes.

The newly formed pupa is very soft and of a light color, with the remains of the larval tubercles and markings plainly visible, but these disappear and the pupa grows harder and darker when exposed to the air. Caterpillars, in their attempts to pupate, sometimes burst the thin pupal skin and die from the escape of the fluids from the body. In changing from the larval to the pupal stage, the insect loses about thirty-five per cent. in size and nearly forty-five per cent. in weight. A small part of the weight is left in the larval skin and silk. How the insect, as a rule, fastens itself to the silk in which it is enclosed, is not fully known. In one case, however, a pupa was seen to emerge and fall into the network of silk, when, by a wriggling motion, it picked up the silk threads on its cremaster and then hung, from gravity, head downward.

The maximum time spent in the pupal stage by one hundred females was found to be 14 days, the minimum 7 and the average 10.65. The maximum time spent in the pupal stage by eighty-eight males was found to be 17 days, the minimum 9 and the average 13.41 days.

Pupa (Plate I, Fig. 5, and Plate 48). - The pupæ of the males vary in length from three-fifths to four-fifths of an inch, 
including the cremaster, or blunt spine at the end of the abdomen, while thge of the females vary from three-fifths to one and two-fifths inches. Fig. 5, Plate I, was taken from one of extraordinary size. The following description was made from the study of thirty-nine males and one hundred and twenty-one females:

They vary in color from chocolate to dark reddish-brown, and are cylindrical or fusiform, rounded anteriorly and tapering posteriorly to the cremaster, which is armed at the tip with a cluster of minute hooks, one of which is shown at Fig. 7, greatly enlarged. The covers to the various parts of the body, as the wings, legs, antennæ, etc., are plainly marked; those of the wings are quite broad, and reach to the posterior third of the fifth segment, while those of the antennæe are strongly curved, being much wider in the males than in the females. At the front edge of the mesothorax, on each side, is an oval, dark reddish-brown velvety spot, very distinct in some examples but nearly invisible in others. Ochre-yellow hairs, arranged in groups, occur on the eye, head and palpi covers, across the collar and thorax, and in eight equidistant rows along the abdominal segments. Some of the hairs in the groups across the collar and thorax are dark brown. The abdominal segments are more or less punctured, and the hairs arise in small circles. At the base of the cremaster, on the ventral side, is an elliptical depression, with curved ridges on each side. In the males, on the middle of this segment, in front of the depression, is a small raised tubercle, with a longitudinal slit on the top of it (Fig. 5), while in the females this tubercle is wanting; on the extreme front edge of this same segment, however, there is a fine longitudinal slit, but the surface at this place is not raised (Fig. 6).

Attached Pupa. - In order to determine the best plan for raising the finest specimens of gypsy moths, a number of experiments were made in the laboratory. In six of the experiments the pupæ were fastened to the bottom of a small pasteboard box, in which they were confined by means of a pin put through the little bunch of silk at the end of the cremaster, and then into the bottom of the box. The moths all emerged from these pupæ, and were in good condition. In 



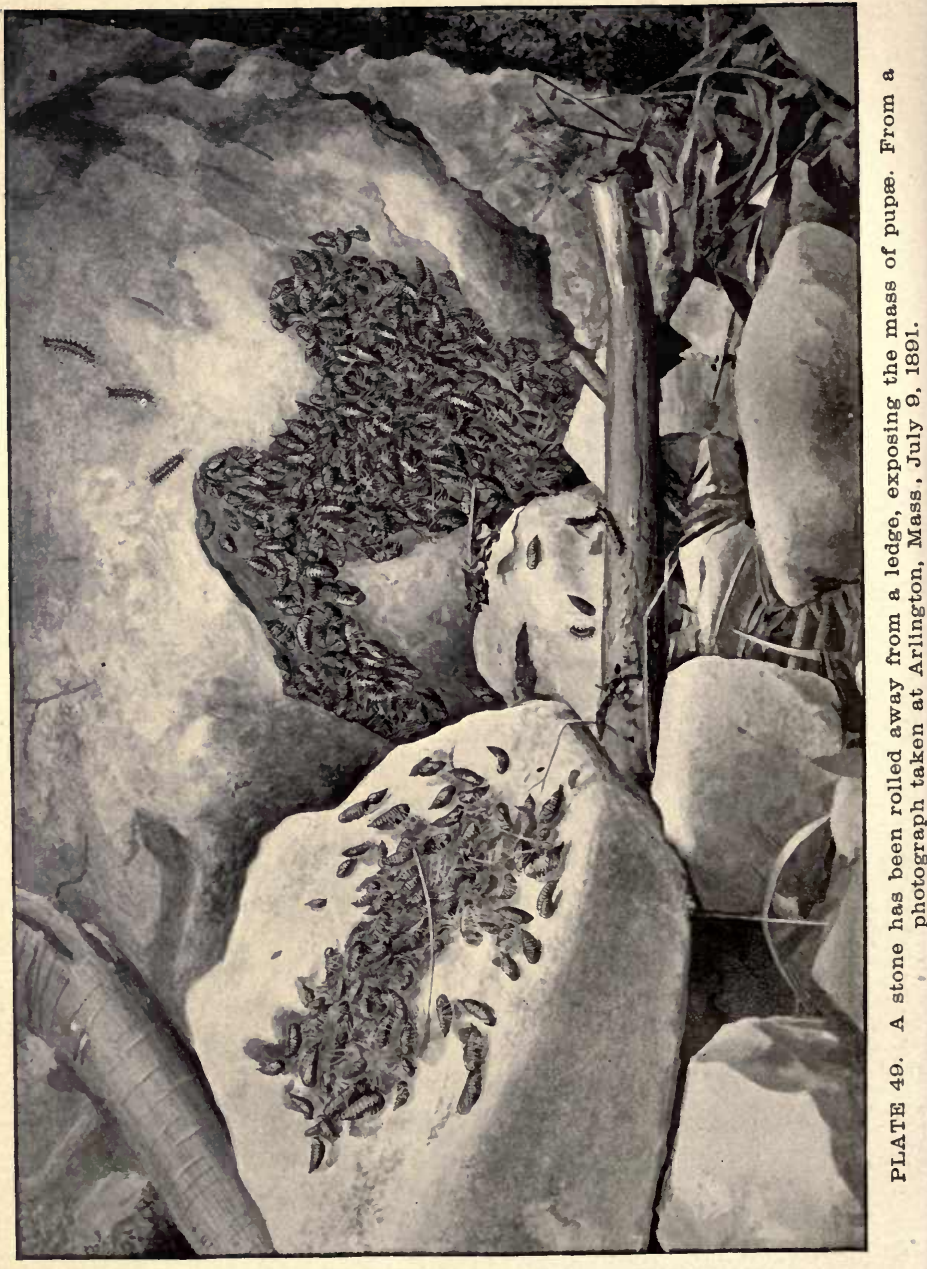


two experiments a very fine pin was run through the cremaster, as near to the end as possible; but it was found that the pin injured the pupæ, and consequently they died without emerging. A very fine pin was run through the last segment of a pupa, which began to emerge, but died, being unable to complete the process. In several other cases pupæ were stuck to the bottom of the box by means of a drop of mucilage or a drop of sticky fly-paper gum. This was unsatisfactory, however, for the pupæ, in wriggling about, got themselves covered with the gum, and the few which did emerge were in very poor condition.

Mass of Pupo. - When about to pupate, the caterpillars, when numerous, collect in masses to spin their cocoons. On the flat side of a rock one of these masses (Plate 49) was found which measured eighteen inches in length and eight inches in width, the whole being covered by one large network of silk. Beneath two partly eaten leaves of oak fortynine caterpillars had pupated, and another mass was found in a groove between the trunks of two small trees (Plate 47), containing at least three hundred pupæ and pupa-cases.

\section{Pupation in the Field.}

To learn the proportion of caterpillars which pupate on trees and on the ground, as well as the per cent. of those parasitized, a study was made of the "Winning" colony at Woburn, in the latter part of July, 1895, the results of which show that the larger part of the caterpillars pupated in the trees. On the border of the colony, about forty per cent. pupated above the burlap; while in the centre, about sixty per cent. were found to have pupated above it. These facts confirm the generally accepted opinion that, when very abundant, the per cent. of caterpillars pupating upon the trees is somewhat increased.

Of the caterpillars which pupated elsewhere in the colony, the proportion was equally divided between those that pupated on the ground and those which passed the pupal stage on the trunks and under the burlaps on the trees. All pupæ which gave evidence of parasites, as well as the empty pupa-cases from which parasites had apparently emerged, were counted as parasitized. The per cent. of the 
sexes found to be parasitized was 9.7 per cent. of the males and 7.5 per cent. of the females. This does not agree with observations previously made, where the larger per cent. parasitized were found to be females. The greater part of the parasitized pupæ were brought in, and many were found to contain Dipterous larvæ. In most cases no parasite imagoes were obtained from these pupæ, although some of the Dipterous maggots have not yet transformed.

\section{The Imago.}

\section{The Process of Emerging.}

The emerging of the imago from the pupa is accomplished as follows: when the insect is fully developed and ready to come forth, it forces off the cap on the anterior ventral part of the pupa, comprising the antennæ, head and leg shields, and through the opening thus formed the antennæ appear, and then the first two pairs of legs are drawn out. The cap is attached to the rest of the pupa at its apex, and its larger anterior end is pushed away from the body by means of the feet. The legs at first are stiff at the joints between the tibiæ and tarsi. Next, the juncture of the wing covers on the top of the back splits, then the posterior margin of the wing covers comes off, and the insect crawls up and out of the pupa-case, the hind legs coming out at the same time as the wings. This process requires from five minutes to five hours, according to the resistance of the pupacase and the vigor of the enclosed imago. When the moth first emerges it is quite moist, but soon dries off. From twenty minutes to two hours are required for the development of the wings.

\section{Description of the Imago.}

The following description was made from thirty males and thirty-seven females. The males (Plate I, Fig. 3) measure from 37 to $50 \mathrm{~mm}$. (one and one-half to two inches) between the tips of the expanded wings. The ground color of all the wings is brownish yellow, varying in intensity in different examples, but somewhat lighter beneath. The head, thorax, antennæ and upper side of the palpi are 
grayish brown, inclining to mouse color in some specimens. The under side of the entire body, legs and palpi is somewhat lighter than the under side of the wings.

The markings on the fore wings are dark brown, and are as follows: the half line starts from the costa, near the base of the wing, and extends half way across the wing. The transverse anterior line arises from the basal fourth of the costa and crosses the wing as a scalloped line. Just outside of this line, on the cell, is the small orbicular spot. The reniform spot is crescent shaped, and, resting on the outer end of the cell, extends across its entire width. The median shade is quite obscure, but is bent out around the end of the cell, and toothed along the outside. The transverse posterior line arises from the outer fourth of the costa, is somewhat curved and toothed on the veins, and terminates just within the anal angle. The subterminal line, a little outside, is similar to the transverse posterior line and parallel with it. The terminal space is usually somewhat darker than the rest of the wing, and all the cross lines are heavier on the costa than elsewhere. The fringe is cut with dark brown between the veins.

The hind wings have a faint discal lunule at the end of the cell, and the terminal shade is darker brown than the rest of the wing. The upper side of the abdomen is of the same color as the upper side of the hind wings, and has a row of brownish spots along the middle.

The outside of the third and fourth joints of the tarsi and the ends of the femora on the upper side are brown; the fore and middle tibix are pale mouse colored on the outside.

The females (Plate I, Fig. 1) measure from 37 to $62 \mathrm{~mm}$. (one and one-half to two and one-half inches) between the tips of the expanded wings. The entire body and wings above and beneath are yellowish white, except the abdomen beneath and towards the end above, which is pale yellow. The markings of the fore wings are dark brown or nearly black, but vary much in intensity in different specimens, being almost entirely obliterated in some examples. The half line at the base of the wing, the orbicular and reniform spots, the costal end of the transverse lines and the black spots in the cilia are quite pronounced. The form and 
position of the lines and spots are the same as in the males. The fore wings are longer, narrower and more pointed than in the males. The hind wings have a faint discal spot and a subterminal line which is toothed along the outside on the veins, and the cilia have black basal spots between the veins. The antennæ and legs are dark brown, but the hair on the femora and tibiæ is yellowish white.

The imago is subject to considerable variation in size. The following table gives the dimensions of the largest and the smallest imagoes of each sex, taken in the field :-

\begin{tabular}{lcc|c|c|c|c|c}
\hline \hline & & $\begin{array}{c}\text { Expanse } \\
\text { of Fore } \\
\text { Wings. }\end{array}$ & $\begin{array}{c}\text { Expanse } \\
\text { of Hind } \\
\text { Wings. }\end{array}$ & $\begin{array}{c}\text { Length } \\
\text { of } \\
\text { Body. }\end{array}$ & $\begin{array}{c}\text { Diameter } \\
\text { of } \\
\text { Thorax. }\end{array}$ & $\begin{array}{c}\text { Diameter } \\
\text { of } \\
\text { Abdomen. }\end{array}$ \\
\hline Largest male, &. &. & 46 & 37 & 18 & 5 & 3 \\
Smallest male, &. & - & 33 & 25 & 12 & 4 & 2 \\
Largest female, &. & 71 & 53 & 31 & 8 & 12 \\
Smallest female, . &. & 44 & 34 & 16 & 5 & 6 \\
\hline \hline
\end{tabular}

Mr. J. H. Leech, in the "Proceedings of the Zoölogical Society of London," Vol. LVI, page 630, expresses the opinion that the Japanese gypsy moths, which have been described as distinct species, do not differ from those of Europe, except in size, and he regards them only as forms, and not distinct species. He gives the extremes of size of males and females in Japan and Corea as follows: "Expanse of wings of largest male, $71 \mathrm{~mm}$.; smallest male, $37 \mathrm{~mm}$.; largest female, $114 \mathrm{~mm}$.; smallest female, 48 mm." Mr. Leech also gives the size of European examples of the gypsy moth as follows: "Largest male, $54 \mathrm{~nm}$.; smallest male, $32 \mathrm{~mm}$.; largest female, $93 \mathrm{~mm}$.; smallest female, $42 \mathrm{~mm}$." I have in my collection three males from Pekin, China, which measure 46,50 and $54 \mathrm{~mm}$., respectively, in expanse of wings; and several male examples from Europe, the largest of which measures $43 \mathrm{~mm}$. and the smallest $37 \mathrm{~mm}$. I can see no difference between the examples from China and those from Europe, except in size. 

PLATE 50.

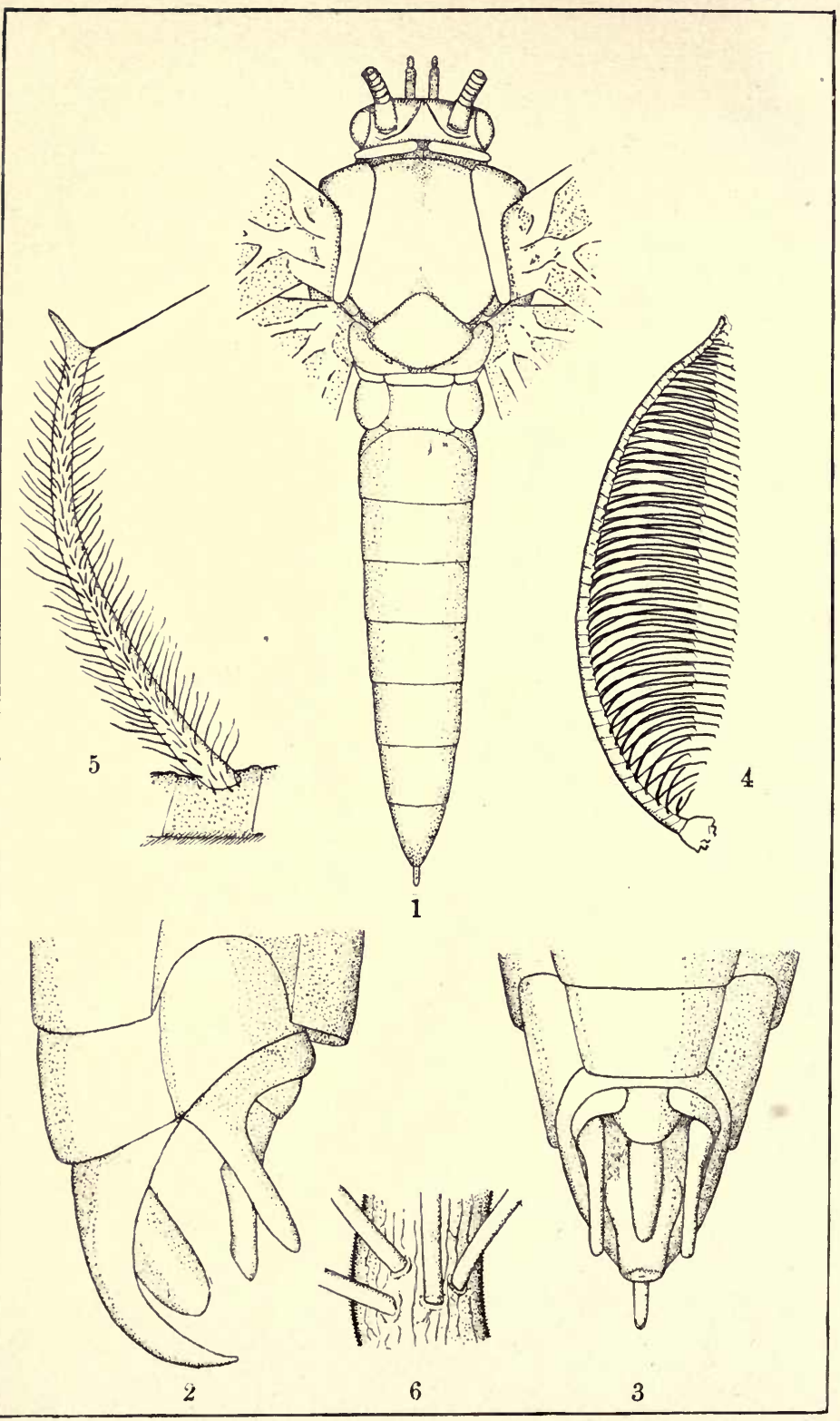




\section{EXPLANATION OF PLATE 50.}

\section{[A11 figures greatly enlarged.]}

Drawn by C. P. LounsBury.

I. Dorsal view of male moth.

2. Lateral view of genitalia.

3. Ventral view of genitalia.

4. Antenna of the male.

5. Single filament from antenna.

6. Section of antennal filament, showing insertion of the finer lateral filaments. 



\section{Hermaphrodites.}

Three specimens of the gypsy moth were taken in Medford, Mass., which are what Ochsenheimer would eall perfect hermaphrodites. One has the right half of the body, with the wings and antenna of that side, of the form, color and markings of the female; while the left side of the body, with its wings and antenna, is male. The second specimen is male on the right side, and female on the left. In both of these examples the frenulum is single on the male side, but divided on the female. In the third specimen, the antenna and both wings, on the left side, are female, while on the right side, the antenna and both wings are male. The abdomen is female in size and form, but the right side is darker than the left, looking more like the male in color.

As the sexes of this moth differ so much in the form and color of the wings and in the pectinations of the antennæ, an hermaphrodite is a remarkable insect in appearance, and seems almost to suggest that it is a work of art. Hermaphroditism in this species is occasionally met with in Europe, several cases being on record in the European journals.

\section{External Anatomy of the Moth.}

The head is rather small, and joined by a very short neck to the comparatively large thorax. This is followed by the abdomen, which, in the male (Plate 50, Fig. 1), is medium in size, gradually tapering to the last two segments. These taper more rapidly to the genitalia or external genital organs, which consist of a genital hook and pair of clasps (Plate 50, Figs. 2 and 3). The abdomen of the female is enormously distended. The front is smooth and very slightly rounded; the maxillæ or sucking tube is rudimentary; the palpi small, extended forward horizontally (Plate 51, Fig. $1 \mathrm{a})$, the basal and terminal joints being about equal in length, while the middle joint is about three times as long as either of the others, and covered with fine hairs loosely arranged over the surface, similar to those that cover the surface of the head. There are no ocelli present. The antennæ are bipectinated very strongly in the male (Plate 50, Fig. 4), while in the female the pectinations are very 
much shorter and stouter (Plate 51, Fig. 3). The pectinations of the male antennæ (Plate 50, Fig. 5) are somewhat curved, and taper slightly toward the outer end, where they terminate in a tooth on one side and a much longer spine on the other; there are numerous hairs, about twice as long as the diameter of the pectinations, scattered over the surface. Plate 50, Fig. 6 , shows a portion of a pectination, with the bases of four of these hairs, and still finer hairs, scattered over the surface, which is thrown into very minute, irregular longitudinal ridges, visible only under a high power of the microscope. The female antennæ (Plate 51, Fig. 3) have minute, elongated, tooth-like scales and bristle-like hairs over the surface (Plate 51, Fig. 4), and the pectinations are cylindrical, stout and terminate obliquely in a point at the outer end, near which, on the lower side, is a short bristle. There are minute hairs sparsely scattered over the surface, as shown in Plate 51, Fig. $4 b$, and scattered between these are minute pits, around the edge of which is a row of minute hairs (Plate 51, Fig. $4 a$ ).

The legs (Plate 51, Figs. 5, 6 and 7) are moderately long and of medium size, with the first or coxal segment somewhat conical in form; the second segment (trochanter) much smaller, its length being about equal to the thickness; the third and fourth segments (femur and tibia) are of nearly equal length. The outer part of the leg (tarsus) consists of five segments, the first of which is about the length of the three following, and the last has a pair of diverging claws at the end, with a fleshy organ (pulvillus) between them (Plate 51, Figs. 9 and 10). The claws have a somewhat flattened under surface, with a row of small blunt teeth along each side. The fore legs (Plate 51, Fig. 5) have a long sinuous spur (tibial epiphysis) attached to the tibia near the base and extending a little beyond the end. The whole side of this epiphysis next to the tibia is covered with fine bristles, forming a brush-like organ. The tibiæ of the middle legs have a pair of unequal spurs at the end, and the hind tibiæ have a similar pair at the end and a pair about onefourth of the length of the tibia above. All these spurs have the outer part obliquely flattened, with a row of short, blunt 


\title{
EXPLANATION OF Plate 51. [A11 figures greatly enlarged.]
}

\author{
Drawn by C. P. Lounsbury.
}

I. Lateral view of the anterior part of body of female.

2. Ventral view of female genitalia.

3. Antenna of the female.

4. Section of antenna, showing sensory pits.

5. Fore leg.

6. Middle leg.

7. Hind leg.

8. Part of hind leg, with abnormal appendage.

9. Foot, seen from below.

ı. Foot, seen from the side. 
PLATE 51.

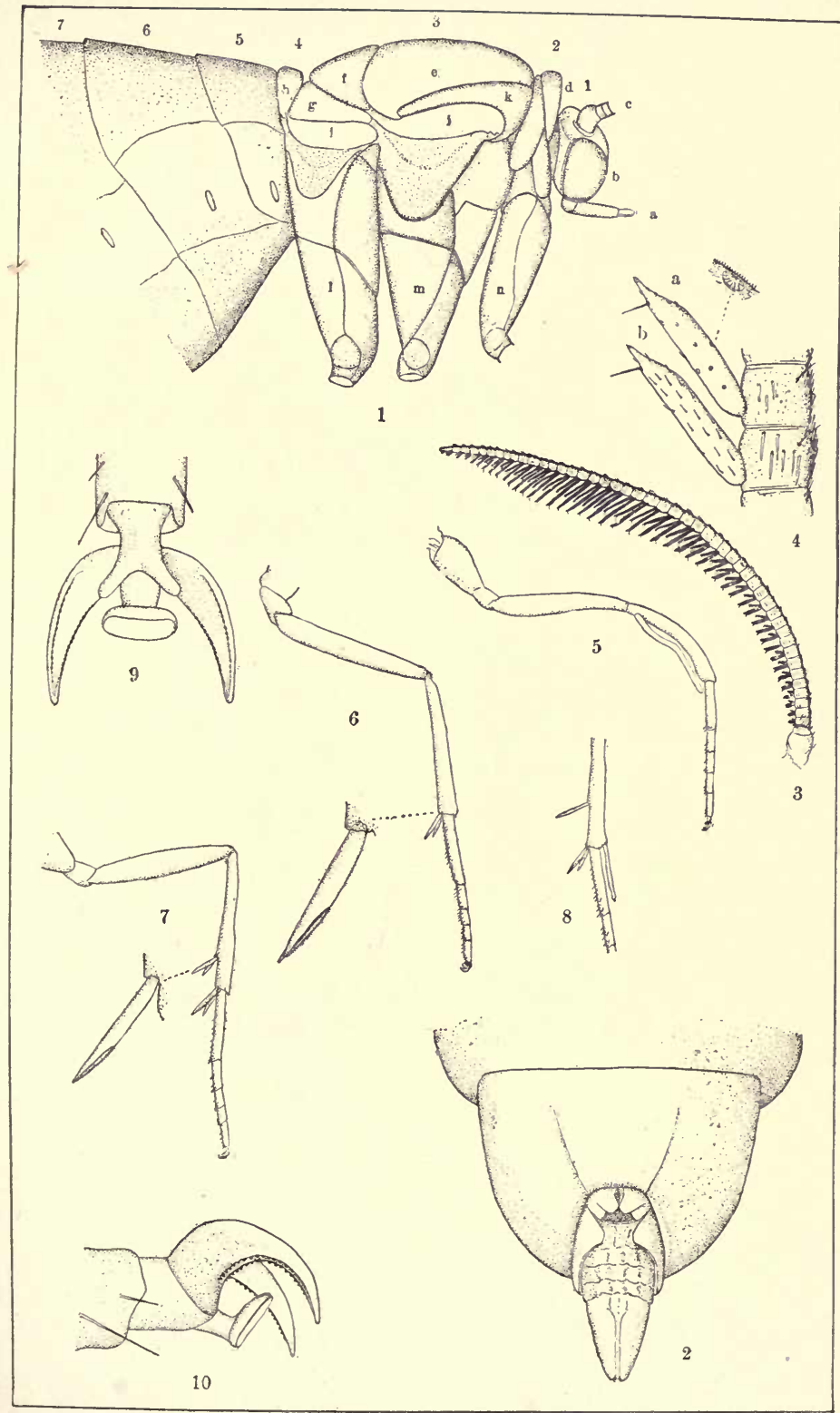


teeth around the edge of the flattened surface (Plate 51, Figs. 6 and 7). On one of the hind legs of the male, at the end of the tibia, was found an additional appendage on the side opposite to the spurs (Plate 51, Fig. 8). This is the only monstrosity we have thus far seen in the gypsy moth.

The wings differ somewhat in form in the two sexes, the fore wings of the female being longer and more pointed than those of the male. The venation is shown in Plate 52, Figs. 1 and 2 (male), 3 and 4 (female). The frenulum at the base of the hind wing of the male consists of a single pointed bristle, while in the female it is composed of a cluster of much finer pointed bristles (Fig. 4). The surface of the wings is sparsely covered with scales and hairs (Fig. 7), and around the outer border of both the fore and hind wings, at quite equal distances apart, is a row of blunt spines, two of which are shown in Fig. 8, and one still more enlarged is represented in Fig. 9. These spines appear to be hollow, with a fine aperture at the outer end. Near the hinder margin, towards the base of the fore wing, is an oval area (Plate 52, Fig. 5), the surface of which is covered with minute stout spines (Fig. 6). The lateral surface of the metascutum (Plate 51, Fig. $1 \mathrm{~g}$ ) is covered with a similar series of spines.

In the "Berliner Entomologische Zeitschrift," Vol. XXXI, 1887, Dr. W. Donitz describes a singing Lepidopteron. After referring to the list of Lepidoptera which produce sounds, given by Swinton in his work on "Insect Variety," be describes an apparatus which he discovered in Dionychopus niveus Men., a Bombycid moth found in Japan, and also in Siberia. He states that when a fresh male is held in such a manner that the wings can be moved back and forth on each other, one can hear a slight chirping sound, which continues as long as the wings are moved. He figured and described an apparatus, on the basal part of the fore wings, similar to that described above; and a corresponding area on the hind wings, where that of the fore wings overlies this organ on the hind wings. In the gypsy moth no such organ exists on the hind wing, but its counterpart is found on the side of the metathorax, as stated above, where the organ in 
the fore wings, when closed, rests on the side of the thorax. A similar organ occurs in Ocneria rubea of Europe, of the same structure and in the same place as in the gypsy moth.

The scales on the wings vary in form, as shown in Plate 52, Figs. 10-20. The striations are not shown in all these figures. Fig. 15 represents one of the short and broad scales with the longitudinal striæ. Figs. 21 and 22 represent cross-sections of a scale, the first from near the base, the second from the broader part of the scale. After suitable preparation and embedding in paraffine, a portion of the wing was sectioned and these figures drawn from the mounted sections. The surface of the scale next the membrane of the wing is smooth, while the outer surface is covered with longitudinal ridges.

The abdomen of the female (Plate 51, Fig. 1) is very large, and densely clothed with yellowish hairs, especially on the under side towards the posterior part. One of these hairs is represented in Plate 52, Fig. 19, and a section of it, near the basal fourth of the hair, greatly enlarged at Fig. 10. The surface is covered with minute spines, which incline towards the apex, and it also appears to be marked with irregular cross-wrinkles. The ovipositor of the female is shown in Plate 51, Fig. 2.

\section{Mating.}

After emerging the female crawls a short distance from the pupa-case, and, by the time the wings have expanded, and sometimes before, she begins to attract or " assemble" the imagoes of the opposite sex. In colonies where the males are abundant, they often attempt to mate with females almost as soon as the latter emerge. Seeking the female, the male flies in a zigzag course until she is found, when he hovers around her for a few minutes, rapidly vibrating his wings.

The time spent in mating has been found to vary from twenty-five minutes to three hours and eighteen minutes; the average time of twenty-four pairs being one hour and nine minutes. Arter mating, the male is quite stupid, but in about half an hour regains his normal activity. 


\section{EXPLANATION OF PLATE 52.}

[A1I figures endarged.]

Drawn by R. A. CoOLEy.

I. Venation of fore wing of male.

2. " " hind " " "

3. " " fore wing of female.

4. " " " hind " " "

5. Base of fore wing, showing outline of the spiny area.

6. Portion of the spiny area, showing the spines, greatly enlarged.

7. Area from near the middle of the upper side of the fore wing of female, showing scales and hairs.

8. External outer border of wing, showing spines and a fringe scale.

9. Single blunt spine from outer border.

10. Section of figure 19 greatly enlarged, showing spiny surface.

I1, I2, I3, I4, I6. Various types of scales from the wings.

15. Scale from the upper side of the fore wing of the female, showing the striæ.

I 7 18. Scales from the fringe of the fore wing.

19. Hair from the end of the abdomen of the female.

20. 66 6 66 6 66 6 6 male.

21. Section of a scale near the base.

22. 6 "6 6 "6 middle. 
PLATE 52.

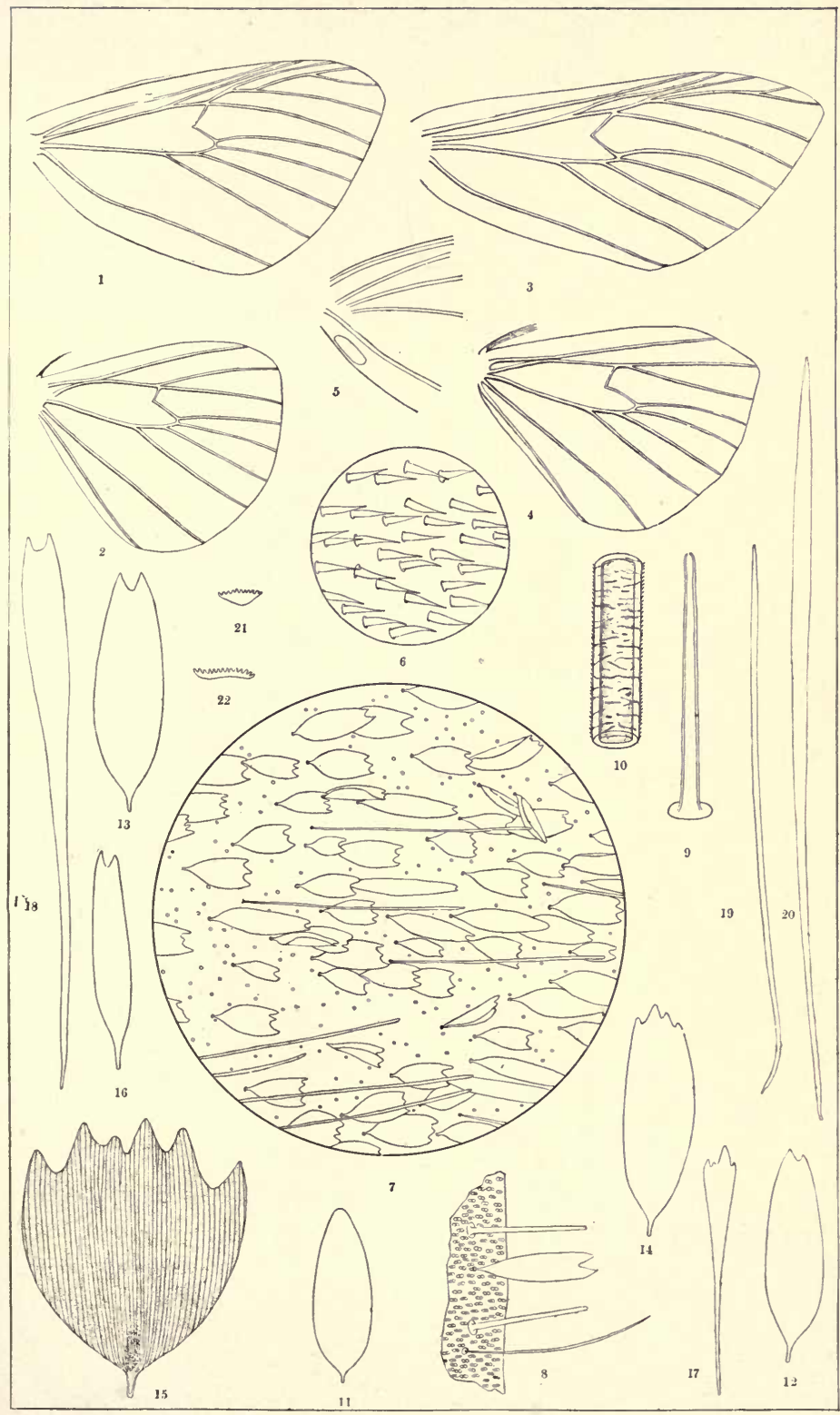




\section{Fertilization Experiment.}

To determine the length of time necessary for fertilization, twenty-five virgin females were exposed in infested localities. After mating had commenced, the males were removed at the end of given periods of time, varying from one minute to one hour; the females were placed in boxes, and allowed to deposit their eggs.

In all cases where the male was removed before six minutes, the eggs proved infertile; but where they were allowed to remain beyond that time, the eggs were fertile.

\section{Polygamy.}

As a rule, the males of this species mate with but one female, or with two at the most, but instances have been recorded where single males mated with six females, and five other males mated with three females each. Polygamy is exceptional among the females. In August, 1894, a female moth, at the insectary, mated with three males; but nearly all females reared in confinement, as well as those whose mating has been observed in the field, paired with but a single male.

The fact that a male imago may fertilize several females has a practical bearing on the work of destroying the gypsy moth. It would seem to indicate that the destruction of the males, either through natural or artificial agencies, is of but little importance.

\section{Lexgth of Life of Inago.}

The maximum number of days of the life of thirty-four females which had not mated was found to be 10 , the minimum 1 , and the average 6.15 days. The maximum number of days of the life of forty-two females which mated was found to be 12 , the minimum 1 , and the average 7.69 days. The actual length of life of the male moth is hard to determine, as they probably live much longer when free than when kept in confinement. Five males which had not mated lived respectively $6,7,8,11$ and 8 days. 


\section{Habits of Flight.}

The gypsy moth is not nocturnal, and, unless disturbed, but few of the males fly before 9 А.м. The time of greatest activity is between 10 A.M. and 3 or 4 P.M., after which time they seldom fly voluntarily. As already stated, they fly most vigorously on warm days, and in a zigzag course.

The female moth has never been seen to fly in this country, except on one occasion, and that was after the laying of the eggs. Mr. F. H. Mosher, one of our most reliable observers, while making observations in a colony of the gypsy moth in the forest at Woburn, Mass., July 18, 1895, saw a female gypsy moth that had finished or nearly finished laying her eggs, upon being disturbed by males, drop to the ground and fly about twenty feet, striking the ground and rising again at distances of about two feet. In Europe, C. Wingelmuller, in the "Wiener Illustrirte Garten-Zeitung," Jan. 15, 1890, page 269, says that " the female gypsy moth does not shake off her sluggishness even during the night, the especial time of her activity; and a short, lazy flight from one tree to another close by is the most that she accomplishes." This helplessness is only on account of her body being stored with eggs, which prevents her from taking a longer flight. I have tried, again and again, at various times during the day, to oblige the females to fly, by throwing them into the air and also by knocking them off from the trees; and in every case they only fluttered to the ground without any attempt to move forward by using their wings. On July 14, 1889, I was in the zoölogical gardens in Berlin, and saw the gypsy moths in great abundance. They were then in the imago stage, and occasionally females fluttered down from the trees in precisely the same manner that they do in this country when disturbed by the males. As our employees have observed the habits of this insect at all hours of the day and night, and have seen no real flight except in the case above mentioned, and as the statement of Wingelmuller seems a little indefinite, I am inclined to think that the female gypsy moth never voluntarily flies, nor indeed can she do so before laying her eggs, because of the enormous weight she would have to sustain. It may further be 
said that, although the wings of the female are of fair size, they are not nearly as firm as those of the male, and it would seem that by disuse they have become weakened; and, if the present conditions are continued sufficiently long, the wings of the female gypsy moth may suffer the same fate as those of the female of the white-marked Tussock moth (Plate 39, Fig. 18).

The peculiar zigzag flight of the male may be the result of natural selection. As the female does not fly, the male is guided to her by the odor which she gives off, and which is disseminated by currents of air; and it is evident that males flying in a straight line would not meet with the scent-laden currents in as many cases as those which fly in a zigzag course. It is therefore probable that more of those having a tendency to an irregular course in flight would find and mate with the females, and thus transmit to their male offspring a like tendency to this particular flight, which, in the course of generations, has become a fixed characteristic of this species.

\section{The Assembling of the Gypsy Moth.}

It is a well-known fact that unfertilized females of the gypsy moth are able to attract the males to them from a greater or less distance. This is called assembling, and this power to assemble is possessed by quite a large number of moths more or less nearly related to the gypsy moth.

As has been previously stated, the caterpillars of this insect have the habit of spinning down, or suspending themselves from the trees on which they feed, especially when disturbed; and they frequently fall upon passing teams or animals, and are carried by them to places more or less remote. If, in any such case, caterpillars should be carried into an uninfested region, and, making their way to suitable food plants, should, in transforming, give rise to female moths, there would be little or no danger of their establishing a new colony, unless they should attract male moths from the infested region, and, having mated with them, should therefore lay fertile eggs.

The following experiments were made by Mr. A. H. Kirkland, assisted by Mr. J. P. Hylan, for the purpose of deter- 
mining, as fully as possible, how far the males might be assembled by the females. The question to be solved was, from how great a distance can a male moth recognize and follow up the scent of the female? There are many conditions affecting the distance over which assembling may be possible. The following are a few of the more important :-

1. The place in which the female emerges. If this occurs in a stone wall or rubbish heap, or in a hollow tree, the odor could not possibly escape and be diffused as fully as if the moth were exposed to the air on the outside of the tree, and at some height from the ground.

2. The condition of either the male or female after emerging. If the female is strong and in perfect condition, she will assemble more males than a female partly denuded. If the male is strong and active, he will, of course, be superior in flight and action to one partially crippled or enfeebled.

3. The direction and velocity of the wind. The wind must blow from the place where the female emerges toward some place where male moths occur. A wind of high velocity will carry the odors farther than a light breeze, but, at the same time, offer greater resistance to the flight of the male while following up the scent.

4. Weather and temperature. The flight of the males is more vigorous on bright, warm days than when the air is cold and damp.

5. The contour of the land and whether it is wooded or not, thus forming wind-breaks. If there are forests or hills between the female in question and the males to be attracted, they will interfere with the direct passage of currents of air carrying the odor, so that males may fail to be attracted from much shorter distances than if in a region without these obstructions.

\section{Details of the Experiments.}

A level area on the salt marsh between Edgeworth and Somerville, entirely free from obstructions, was selected for the scene of operations, and stations were established from day to day, according to the direction of the wind.

Stations. - The first station chosen in each experiment was the one where one or more females were to be located, 
and this was always on the windward side of the marsh. The females were enclosed in a moth trap (Plate 54), which was painted on the outside with a mixture of castor oil and resin, and placed a few feet above the ground. The second station was established directly to leeward of the first, and at a measured distance from it. In many cases a third and even a fourth station was established at a known distance from the first and other intervening stations. It was often found necessary to establish three or even more stations, a short distance apart, on the arc of a circle, the radius of which was a known distance from the trap, to compensate for the veering of the wind, which sometimes carried the scent of the female out of a direct line to the stations first established.

Marking the Males. - In order to carry on this work and obtain results at all satisfactory, it was necessary to adopt some system of marking the males which were to be liberated, in such a way as to enable one not only to recognize them afterwards, but also to determine from what station they came. At first they were marked by cutting a small notch in a certain part of the margin of the wing, with fine scissors. This method, while not apparently injuring them in any way, was objectionable, because of its being a mutilation which might affect the results more or less, and therefore it was abandoned in the later experiments, and water-colors were used. It was found impossible to make the colors adhere to the wings, when mixed in water; but fifty per cent. alcohol was found to mix well with dry carmine colors, and, when applied to the wing, made a tolerably permanent mark. There was no difference in the results obtained from moths marked in the two ways. In marking, the color was applied, by means of a soft brush, to a particular spot on the wings, a different mark being used for each station, and a different set of marks each day. The male moths were marked and boxed each morning, the marks recorded, and the moths taken into the field. The females were enclosed in the eage of the trap at station No. 1 , and the males were liberated at the other stations according to their marks. In this way it was possible, when a male was taken at station No. 1 , to determine from which 
of the other stations it came, and the direct distance from that station. The negative results in so many of the experiments were not due to lack of care or attention to details, but in some cases to a change of wind immediately after the liberation of the males, and in others to a dying out of the wind before the males had reached the females. Many of the male moths, as is common with them when handled, would drop to the ground and remain in the grass for a long time; and it was found necessary to liberate a number of them at each station, in order to increase the chance of meeting with the scent from the female. The following experiments were made in July, 1895 :-

\section{Experiment No. 1.}

Weather, fair and clear. Wind, north-west; average movement, 12 miles. Two traps, containing seven female moths each, were set up at 9.15 A.M., at station No. 1. At station 2, one-fourth of a mile to leeward of the first station, eight marked male moths were liberated at 9.25 A.M. At station 3, one-half a mile to leeward of No. 1, seven marked male moths were liberated at 9.35 A.M. Nothing resulted from this experiment.

\section{Experiment No. 2.}

Weather, fair. Wind, at 6.10 A.M., west; from 10 А.м. to 3 P.M., east; average movement, 10 miles. Two traps, containing six female moths each, were set up at 10 A.M., ten feet from the ground. At station 2, one hundred and fifty yards to leeward, nine marked male moths were liberated at 10.15 A.M. At station 3, half a mile to the leeward of station 1, nine marked male moths were liberated. Four males were seen flying about station 1 , but only one was captured, and this one was from station No. 3, half a mile distant.

Experiment No. 3.

Cloudy. Wind, south-west to west; average movement, 10 miles. Two traps, containing six female moths each, were set up at station 1 . Seven marked male moths were let loose at 8.10 A.M. from station 2 , two hundred yards to leeward of the first station, and at 8.20 A.M. seven marked 
males were liberated from station 3 , half a mile to leeward from station 1. No males reached the first station, but the rain which fell from 11 A.M. till night may have prevented the males from flying.

Experiment No. 4.

Weather, fair. Wind, north to east ; average movement, 10 miles. Two traps, containing six females each, were set up at 10.30 A.M. Forty marked males were liberated at 10.45 A.M. from station 2, one-fourth of a mile from the first station, and thirty-eight marked males were liberated at 10.55 A.M. from station 3, one-half a mile from the first station. At 3.30 P.M. one male moth appeared in the vicinity of the first station. An attempt to capture it was unsuccessful. In all probability it eame from either station 2 or 3, since there were no infested areas in the direction toward which the wind was blowing.

\section{Experiment No. 5.}

Cloudy. Wind, east; average movement, 9 miles. Two traps, containing six female moths each, were set up at 8 A.M. Nine marked males were liberated at 8.30 A.M., onefourth of a mile to leeward of the first station, and nine marked males were liberated at 9 A.M., half a mile to leeward of station 1 . None of these males reached station 1.

\section{Experiment No. 6.}

Damp and cloudy, with light rains at intervals until 2 P.M. Wind, north-east; average movement, 6 miles. One trap, containing a single female moth, was set up at 1.45 P.M. Six marked males were liberated at 2.10 P.M., 427 yards to leeward of the first station, and fifty marked males were liberated at 2.30 P.M., at station 3. This station was located 713 yards to leeward of the first station. At 3.30 P.M. one male from station 2 reached the trap, and at 4.15 P.M. one from station 3 .

\section{Experiment No. 7.}

Fair. Wind, north-west; average movement, 12 miles. Two traps, containing twelve female moths each, were set up 
at 8 A.M. At station 2, one-fourth of a mile to leeward of station 1, six marked males were liberated at 8.30 A.M., and at 2 P.M. seven more males were liberated at this station. At station 3, one-half mile to leeward of station 1, six marked males were liberated at 8.45 А.м., and at 2.15 Р.м. eight others similarly marked were also allowed to escape at this station. There were no results from this experiment.

\section{Experiment No. 8.}

Fair. Wind, from nearly all directions; average movement, 5 miles. Two traps, containing six female moths each, were set up at 8.30 A.M. At station No. 2, one-fourth of a mile to leeward of station 1, eight marked males were liberated at 9.50 A.M. At station 3 , one-half mile to leeward of station 1 , six marked males were liberated at 9.08 A.M., and six other males similarly marked were liberated at a distance of sixteen yards to the right of station 1 . One male moth from station 2 returned at 10.30 A.M. The wind shifted to east and south-west, and at 1.30 a heavy rain prevented all further work.

The data concerning the direction and wind movement, given in these experiments, were kindly furnished by Mr. J. W. Smith, the Boston local forecast official, and, as the place where the experiments were performed was within four miles of the Boston observatory, the figures in all probability are approximately accurate for the locality.

\section{Remarks on the Above Experiments.}

These experiments show that, under favorable conditions, female gypsy moths will assemble males from various distances up to half a mile, and it is possible that they might have been attracted from somewhat greater distances had males been liberated in larger numbers from stations more remote from the female. It must be borne in mind that these experiments were conducted under what would seem to be the most favorable conditions, namely, upon a level area, where a sweep of the wind could be obtained; yet it may be possible that what was gained by the favorable conditions was in a measure offset by a slight weakening of the males caused by the handling necessary while marking them. 
As shown by these records, males were assembled 427 yards (see experiment No. 6), 440 yards (see experiment No. 8), 713 yards (see experiment No. 6) and 880 yards (see experiment No. 2).

A series of experiments, to determine the manner in which the male gypsy moth recognizes the presence of the female, was made at the insectary and in the field, with the following results :-

\section{Experiment No. 9.}

July 25. To determine the effect of alcohol upon the antennæ, as the shellac to be used later was dissolved in alcohol, the antennæ of a male moth were thoroughly bathed in ninety-three per cent. alcohol at 10.50 A.M. The first effect of this application might well be called a complete intoxication. The moth lay for two or three minutes flat on the table without stirring. At 10.53 he began to move, but had only partial control of his limbs, and travelled with unsteady gait a short distance on the bench. By degrees he completely recovered his normal condition, and at 1.15 P.M. he mated with a female in a normal manner.

Experiment No. 10.

July 30 . At 9.30 A.м., the wings of four unfertilized females were completely covered with shellac, after which the moths were placed in the experimental room, and two males in normal condition were liberated. At 10 A.M., a female attracted and mated with one of the males. At 10.50 A.м., the other male was attracted to a second female, but did not mate. At 11.30 A.M., the same male was attracted to a third female, with the same results as in the preceding case. At 3 P.M., one of these females attracted a male, which mated with her at once.

\section{Experiment No. 11.}

July 30 . At 9.30 A м., the dorsal surface of four females (with the exception of the wings) was coated with shellac varnish, the moths then being introduced into the experimental room with a number of normal males. At 10.30 A.M., one female mated with a male. At 11.40 a female 
attracted a male, but did not succeed in mating. At 12 м., a female attracted a male, with the same result as in the preceding case.

Experiment No. 12.

July 30. At 9.30 A.M., the head and thorax of four females were completely coated with shellac varnish, after which operation the moths became quite stupid and one of them seemed apparently dead. At 4.30 P.M., one of the females mated with a male, but none of the others mated.

\section{Experiment No. 13.}

July 30. At 10.15 A.M., four unfertilized females were coated with varnish along the sides of the thorax and abdomen. They were then placed in a wire-gauze can, which was attached to a tree, in the Woburn colony, at a height of about six feet from the ground. This trap was visited by thirty-eight males from 10.15 A.M. to 3 P.M.

\section{Experiment No. 14.}

July 30 . Another can, containing four unfertilized females in normal condition, and used as a check, was visited by thirty-eight males from 10.15 A.M. to 3 P.M.

\section{Experiment No. 15.}

July 30. Another can, containing four unfertilized females, whose wings were covered on both surfaces with shellac, was exposed under similar conditions. This trap was visited by seventy-six males from 10.15 A.M. to 3 P.M.

\section{Experiment No. 16.}

July 30. A can containing four unfertilized females, with the whole of the body, except the wings, covered with shellac, was exposed under the same conditions. This trap was visited by only one male. A check can containing four unfertilized females, in normal condition, exposed in the same manner and at the same place as those in the preceding experiments, to determine what would be the normal rate of assembling, was visited by seventy-seven males from 10.15 A.M. to 4 P.M. 
Experiment No. 17.

August 1. A can containing four unfertilized females, with the last three segments of the abdomen coated entirely with shellac, was exposed as in the previous experiments, and was visited by twelve males from 10.15 A.M. to 4 P.M.

\section{Experiment No. 18.}

August 1. Another can, containing four unfertilized females, which were coated with shellac over the whole body, with the exception of the three posterior segments, was exposed under the same conditions as in the preceding experiments, and was visited by twenty-six males from 10.15 A.M. to 4 P.M.

\section{Experiment No. 19.}

August 1. A can containing four unfertilized females, with the tips of their abdomens covered with shellac, so as to close the external openings of the body, was exposed under the same conditions as in the preceding experiments, and was visited by eleven males from 10.15 A.M. to 4 P.M.

\section{Experiment No. 20.}

August 2. A single unfertilized female, in normal condition, was placed in a small cardboard box, having a cheesecloth top, and exposed on the branch of a tree, at a distance of five feet from the ground. This box was visited by twenty-eight males from 10.30 A.M. to 3 P.M.

\section{Experiment No. 21.}

August 2. A wire-gauze can, containing an unfertilized female that had been denuded of hair, but whose wings were in a normal condition, was exposed under the same conditions as in the preceding experiments, and was visited by thirteen males from 10.30 A.M. to 1 P.M.

\section{Experiment No. 22.}

August 2. This experiment was conducted under the same conditions and at the same time as preceding experiments, 
except that the can contained a female whose wings were removed close to the body. This trap was visited by fourteen males from 10.30 A.M. to 3 P.M.

\section{Experiment No. 23.}

August 6. A female, with all appendages and down removed, was suspended in a mosquito-net bag in the centre of a colony in Hawke's woods, Saugus. She received no visits from males up to 5 P.M.

\section{Experiment No. 24.}

August 6. Same place as above. At 10.45 A.M., a denuded female was suspended in a mosquito-bar box from a tree, at a height of five feet from the ground. At 5 P.M. she had received no visits from males.

\section{Experiment No. 25.}

July 25. At 1.45 P.M., the antennæ of two male moths were covered with shellac varnish. This produced no apparent effect upon the moths. The males were kept in close proximity to females during the remainder of the afternoon, but none of them attempted to mate. July 25. At 1.45 P.M., the antennæ of two males were covered with a coating of shellac, and the moths were then placed in a small cardboard box with four unfertilized females. July 26 , at 7 A.M., the moths had not mated.

Experiment No. 26.

July 25. At 1.45 P.M., the antennæ of a male moth, which had just begun to mate with a female, were covered with shellac varnish. This apparently produced no effect, as the male did not leave the female until 2.20 P.M.

\section{Experiment No. 27.}

July 25. At 3.48 P.M., a fresh, vigorous male was deprived of both fore legs and then placed on the experimental bench near a female. The odor of the female was driven towards him by the use of a fan, and he at once recognized her presence, and at 3.51 P.M. the moths mated. 


\section{Experiment No. 28.}

July 26. At 8.50 A.M., one male moth, with three legs removed, was placed on the experimental bench three feet from four unfertilized females. At 9 A.M., he flew to the partially drawn curtain and remained there until 10.45, when he flew down from the window and mated with a female. At 11 A.M. his antennæ were cut off, but this did not produce any appreciable effect. They remained together until 11.30. After leaving the female, he remained inactive during the rest of the day.

Experiment No. 29.

July 26 . At 8.50 A.M., a male moth, with its wings removed, was placed on the experimental bench at a distance of three feet from four unfertilized females. At 10.20 A.M., he approached rapidly within two inches of the females, but eventually crawled away to a distance of three feet from them. At 1.40 P.M., he was placed near a female on the bench, but after a few minutes went away from her. At 2.05 , he was placed within one foot of a female, and after crawling slowly toward her, mated with her.

\section{Experiment No. 30.}

July 26 . At 8.50 A.M., a male moth with both antennæ removed was placed three feet from four unfertilized females. At 9, he had crawled a distance of one foot toward the females. He remained quiet until 11 A.M., when he was placed close to a female moth. He, however, paid no attention to her, and, up to 5 P.M., made no attempt to mate.

\section{Experiment No. 31.}

July 26 . At 9.28 A.м., the antennæ of a small male were coated with shellac and he was placed on the experimental bench, at a distance of two feet from a number of females. At 11.30, he had made no effort to mate with any of them. He was then placed on a box containing a large number of unfertilized females, but showed no animation. Other males, with their antennæ not coated, were continually hov- 
ering about the box. The male in question remained quiet until 5 P.M.

Experiment No. 32.

July 26. At 3 P.M., the eyes of three male moths were covered with shellac, and they were then placed within two feet of two mature, unfertilized females. At 3.05, one male flew to the females and attempted to mate, but was unsuccessful. At 3.25 , another male approached the females, in the same manner, but with no better success, but at 3.35 two of the males were successful in mating with two females.

\section{Experiment No. 33.}

July 27. At 9.30 A.M., two males with eyes and a part of the head covered entirely with shellac were placed on the experimental bench, three feet from four unfertilized females. At $12 \mathrm{M}$., one of these males began to fly about, and at 1 P.M. he was found mating with a female five feet from the place where he was at noon. At 1.45 he left the female, and at this same time the other male, whose eyes had been covered with shellac, mated with a female and remained with her up to the time the experiment elosed, at 5 P.M.

From the preceding experiments the following conclusions may be drawn:-

1. Coating the abdomen of the female with varnish or denuding it of hair deprives her, in a great measure, of the power to assemble males. The amount of assembling which takes place under these conditions varies inversely with the amount of body surface coated or denuded.

2. The presence or absence of wings in either sex does not greatly influence the assembling process.

3. The sense of sight is not necessary to the operations of assembling.

4. The antennæe are absolutely necessary to the male in locating the female, and without them assembling is impossible. It is a well-known fact that the males of this species coming from any distance always approach from the leeward side of the female, thus apparently indicating that the assembling is the result of an odor given off by the female, and carricd by the wind. 


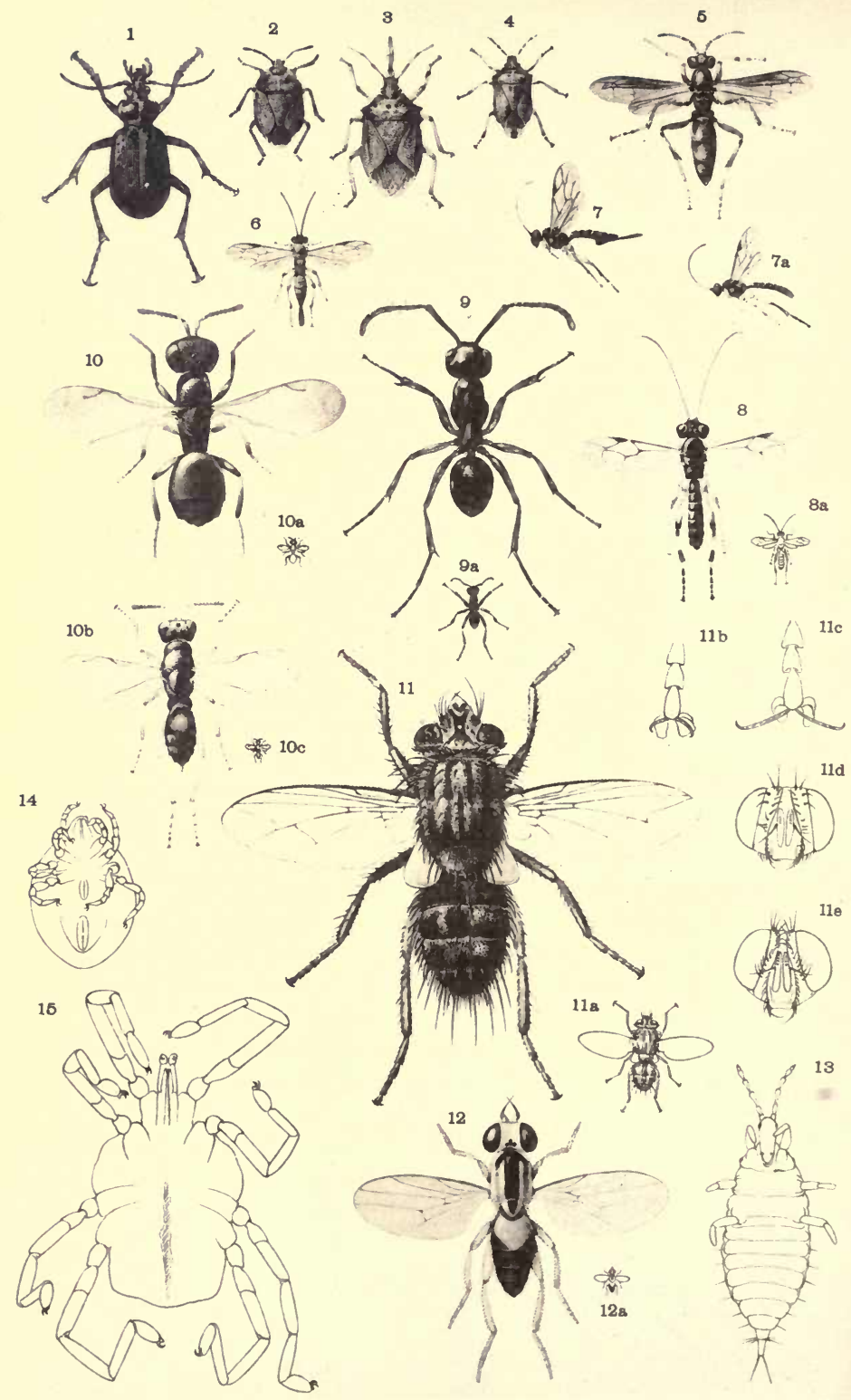


\section{EXPLANATION OF PLATE 53.}

Drawn by J. H. EMERTON.

I. Calosoma frigidum Kirby, natural size.

2. Menecles insertus (Say), "6 66

3. Podisus cynicus (Say), "6 66

4. Podisus serieventris Uhl., 66 66

5. Polistes pallipes St. Farg., "6 6

6. Theronia melanocephala (Brullé), "6 "6

7. Pimpla pedalis Cress., female, "6 "6

7 a. 66 6 66 male, 66 66

8. Pimpla tenuicornis Cress. $\mathrm{X}_{4}$.

8 a. "6 6 "6 natural size.

9. Formica subsericea Say, worker X 4 .

9 a. " 6 6 6 6 " 6 natural size.

10. Diglochis omnivorus (Walk.), female X 8 .

$\begin{array}{llllll}\text { ro a. } & 6 & 6 & 6 & \text { " natural size. } \\ \text { ro b. } & 6 & 6 & 6 & \text { male } \mathrm{X} 8 \text {. } \\ \text { ro c. } & \text { 6 } & 6 & \text { 6 } & \text { 6 } & \text { natural size. }\end{array}$

I I. Achatoneura fernaldi Williston, female X 4 .

\begin{tabular}{|c|c|c|c|c|c|}
\hline I I a. & 66 & 66 & 66 & 66 & natural \\
\hline I I b. & 66 & 66 & 66 & foot of & female. \\
\hline I I c. & 66 & 66 & 66 & 66 & male. \\
\hline I I d. & 66 & 16 & 6 & face of & female. \\
\hline I I e. & 66 & 66 & 66 & 66 & maie. \\
\hline
\end{tabular}

12. Elachiptera dispar Williston X 8 .

I2 a. 66 6 6 natural size.

13. Phlaothrips sp.? $\mathrm{X} 32$.

14. Nothrus sp.? $\mathrm{X} 32$.

15. Trombidium bulbipes Pack. X 32. 
Concerning the assembling process in the Bombycidæ, the late Prof. C. V. Riley wrote as follows: "The power of assembling among certain moths, for instance, especially those of the family Bombycidæ, is well known to entomologists, and many remarkable instances are recorded. ... Now, in the moths of this family the male antennæ are elaborately pectinate, the pectinations broad and each branch minutely hairy. These feelers vibrate incessantly, while in the female, in which the feelers are less complex, there is a similar movement connected with an intense vibration of the whole body and of the wings. There is, therefore, every reason to believe that the sense is in some way a vibratory sense, as, indeed, at base is true of all senses; and no one can study the wonderfully diversified structure of the antennæ in insects, especially in males, as very well exemplified in some of the commoner gnats, without feeling that they have been developed in obedience to, and as a result of, some such subtle and intuitive power, as this of telepathy. Every minute ramification of the wonderfully delicate feelers of the male mosquito, in all probability, pulsates in response to the piping sounds which the female is known to produce, and doubtless through considerable distance" ("Insect Life," Vol. VII, page 39).

In view of the fact that the males of the gypsy moth will assemble nearly as readily to empty boxes, bags, etc., in which females of the species have been previously confined, as to the females themselves, we are led to believe that with this insect, at least, the process is one depending upon the sense of smell alone.*

\section{On Trapping Males.}

The following experiments were made under my direction by Mr. H. N. Reid in 1893, for the purpose of determining whether it is possible to trap the males of the gypsy moth, in any infested region, to such an extent that there would not be enough left to mate with any considerable number of females, so that a large proportion of the females would be compelled to lay infertile eggs, and therefore greatly reduce

* In one case males were found to visit an empty pasteboard box which had contained female moths three days before. 
the number of gypsy moths in that locality the following season.

For this purpose wooden boxes, 12 by 8 by 3 inches, were made, without top or bottom, these being covered with brass wire gauze. A hole was bored in one end for the introduction of the female moths, and this was closed by a cork. Several different substances were used on these traps, to capture the males when they flew against them, as molasses, raupenleim, sticky fly-paper, etc. Molasses proved of no value, as it ran too easily, and was not sticky enough. The raupenleim was not sticky enough, and soon dried on the outside, so that it would not hold the males when they flew against it. Sheets of sticky fly-paper, with holes 9 by 4 inches cut from the centre, were tacked over the gauze; these proved very efficient in securing and holding the males, but it was necessary to replace them with fresh ones frequently, and, to avoid this, they were painted over with a preparation of castor oil and resin, which proved to be better for the purpose required than the original fly-paper. When a trap was first put up a sheet of fly-paper was tacked on it, and each time the trap was visited the captured males were removed and the paper recoated so far as necessary. This gum was found to keep in good condition for several days, unless a large number of males were caught in it, or the trap was in a very dusty place. Even when the males were not caught the first time they touched the paper, they were so persistent that they would immediately fly against it again, and be caught in a few minutes.

The fly-paper was removed from one trap (No.14) after a few days, and a pan of water with a little kerosene on the top of it was suspended directly beneath the trap. On account of the rapidity with which the males fly, and the lightness with which they struck the trap, it was not expected that they would be caught in the kerosene; but, being very persistent, in trying to go under the trap from one side to the other they came in contact with the kerosene and were destroyed. This plan was not very satisfactory, not only on account of the expense, but also because the kerosene and water were so frequently spilled by the wind.

To obtain "bait" for these traps, it was found better to 
collect the female pupæ and allow them to emerge in confinement, because in this way the matter could be controlled more successfully than in any other. It was also found that the traps attracted best when placed but a few feet above the ground.

Fifteen traps were used during these experiments. No. 7 was removed after six days, to be placed elsewhere, as nothing was captured on it up to that time. No. 14 had sticky fly-paper on it the first five days, during which time it caught two hundred males. The fly-paper was then removed, and a pan containing the water and kerosene was suspended an inch or two below the trap. During the next twelve days sixty-five males were captured in the pan. The traps were put out from July 31 to August 10, and were taken in from August 19 to August 30. The records of the traps are given below :-

No. 1 was put out July 31, and taken in August 19, having captured 82 males.

No. 2 was put out July 31, and taken in August 19, having captured 34 males.

No. 3 was put out August 1, and taken in August 28, having captured 175 males.

No. 4 was put out August 1, and taken in August 28, having captured 87 males.

No. 5 was put out August 2, and taken in August 30, having captured 36 males.

No. 6 was put out Augnst 2, and taken in August 25, having captured 88 males.

No. 7 was put out August 2, and taken in August 8, having captured nothing.

No. 8 was put out August 8, and taken in August 30, having captured 167 males.

No. 9 was put out August 8, and taken in August 26, having captured 37 males.

No. 10 was put out August 8, and taken in August 30, having captured 85 males.

No. 11 was put out August 8, and taken in August 26, having captured 213 males.

No. 12 was put out August 8, and taken in August 28, having captured 131 males. 
No. 13 was put out August 9, and taken in August 30, having captured 163 males.

No. 14 was put out August 10, and taken in Angust 30, having captured 265 males.

No. 15 was put out August 10, and taken in August 28, having captured 208 males.

\section{Summary.}

Omitting No. 7, which remained out but a few days, the whole number of males taken by all the traps was 1,771 . The smallest number taken by any one of them was 34, the largest number was 265 and the average 126.5.

During the months of July and August, 1894, these experiments were repeated by Mr. F. C. Schrader and four other assistants. One hundred and ninety-one traps were put up in the worst infested districts of Malden, Medford and Everett, and kept in working order during the time that the males were flying. The traps were visited every day, fresh gum applied when necessary, new females put into the traps as often as needed, and careful records were kept of the results. The trapping season began July 19, and closed August 13. Two different styles of traps were used. The first kind was made of two-quart tin varnish cans, from each of which was suspended, about two inches below it, a tin base 9 by 12 inches, dished, so as to slope from the edges toward the centre, and attached by two strips of tin to a loop on each of the narrow sides of the can. A strip of tin was removed from each side of the can, and this was replaced by brass wire gauze. The unfertilized females were placed in the can, through the hole at the top, which was kept closed by a cork stopper. The traps were suspended from branches of trees by hooks eight inches long, attached to the handle of the cans.

The other kind was a four-leaved wooden trap, commonly called the "Shaw" trap (Plate 54), devised by Mr. H. J. Shaw. It consisted of a horizontal base board of half-inch lumber, one foot square, with narrow grooves at right angles across the middle of the upper side. Two thin boards, twelve inches wide and seven inches high, notched together in the middle at right angles, were secured in the grooves in the base board, thus forming four vertical wings. An opening 


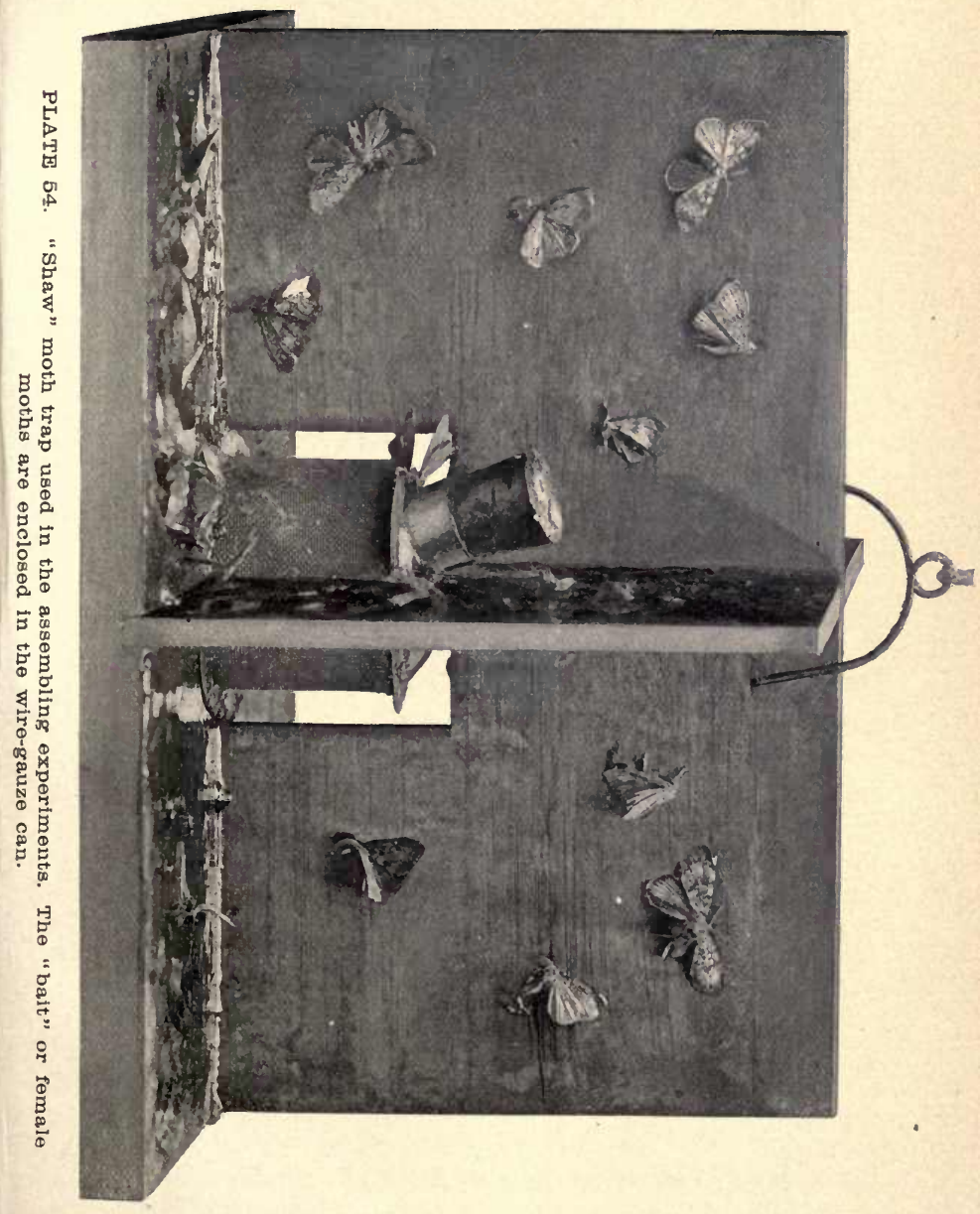



was cut in the lower edge of the vertical boards at the centre, and in this opening was secured a cylindrical wiregauze cage, three inches in diameter and height, and with a convex tin top and bottom. The unfertilized females were placed in this cage through a round hole in the top, which was kept closed by a cork. The trap was suspended by means of a hook fitting into a wire loop at the centre of the top of the vertical wings. Several other kinds of traps of various patterns were tried, but none proved so satisfactory as the two described above; and of these the four-leaved wooden trap proved to be the best, as it allowed the females to be exposed to the air on all sides, and also because it presented a greater area of the sticky surface. The majority of the males were caught on the base boards of the traps, the greater number invariably being taken on the leeward side. The "bait" used in all of these traps was unfertilized female moths bred from pupæ in confinement, though the pupæ themselves, and dead and fertilized females, were also tried for the purpose of ascertaining whether they would attract the males. It was found advantageous, when keeping pupæ in confinement, to moisten them with a fine spray of water from time to time, to keep them from drying up so much as to prevent them from emerging. The "bait" in the traps was renewed as often as necessary. The best means of carrying the newly emerged females was found to be a cloth-lined box, as they would cling to the lining, and could be transported in this way with little or no injury. The traps were painted over with a sticky gum composed of sixty per cent. of crude resin and forty per cent. of crude castor oil. The resin and oil were melted together, and applied, while warm, to the traps by means of a flat varnish brush, care being taken not to put the gum on the gauze. Most of the traps required repainting about every second day, though some required it oftener. A small pointed trowel was used in removing the captured males from the glue, and a pole with a small hook at the end was used in removing and replacing the traps in the trees. The trapping operations were closed August 13, for lack of "bait," and also because so few males were then captured that it did not seem wise to continue the work. 
It was repeatedly demonstrated, in different towns and with different traps, that they can be handled much more easily and will capture more males when hung low, or placed near the ground, than when they are placed high in the trees. The gum, when made in the proportion given above, runs and drips in hot weather and in the warm sunshine, more on the tin than on the wooden traps, so that great care was required in placing them in certain localities near residences, lest the dropping gum should do harm. The adhesive power of this gum is remarkable. Two young birds were caught on the foot board of the tin traps in Malden. They were both dead when found, and showed evidence of desperate efforts to extricate themselves. In the struggle they had pulled out a large quantity of feathers, and, in the case of a half-grown English sparrow, which lay upon its side with the head directed from the trap, the feathers adhered so firmly that the bird could not be pulled off without tearing the body apart. Careful observations showed that at least ninety per cent. of the male moths were captured on the foot board. It was also found that where the moths are abundant the traps can be used advantageously within ten rods of each other, or in adjacent lots.

The essential point for the successful working of a moth trap is to have the female well exposed on all sides, so that the wind may pass freely over her body, and carry the odors away without obstruction in any direction that the air may be moving; and, at the same time, she should be sufficiently protected to insure her existence as long as possible. The average length of life of unfertilized female moths, in the wooden, four-leaved traps, was seven days. One female moth, put into the trap July 31, was alive August 9, but was dead at the time of the next visit, August 11. Another female was put into a trap August 1, and died August 11. In some cases the moths put into the traps were caught in the gum, which worked in at the bottom of the cans, and died in a day or two. In the tin traps the female moths did not live more than two or three days, and those in the old wooden box traps used the year previous did not live any longer, seldom exceeding two days.

In some instances, when there were no unfertilized females 



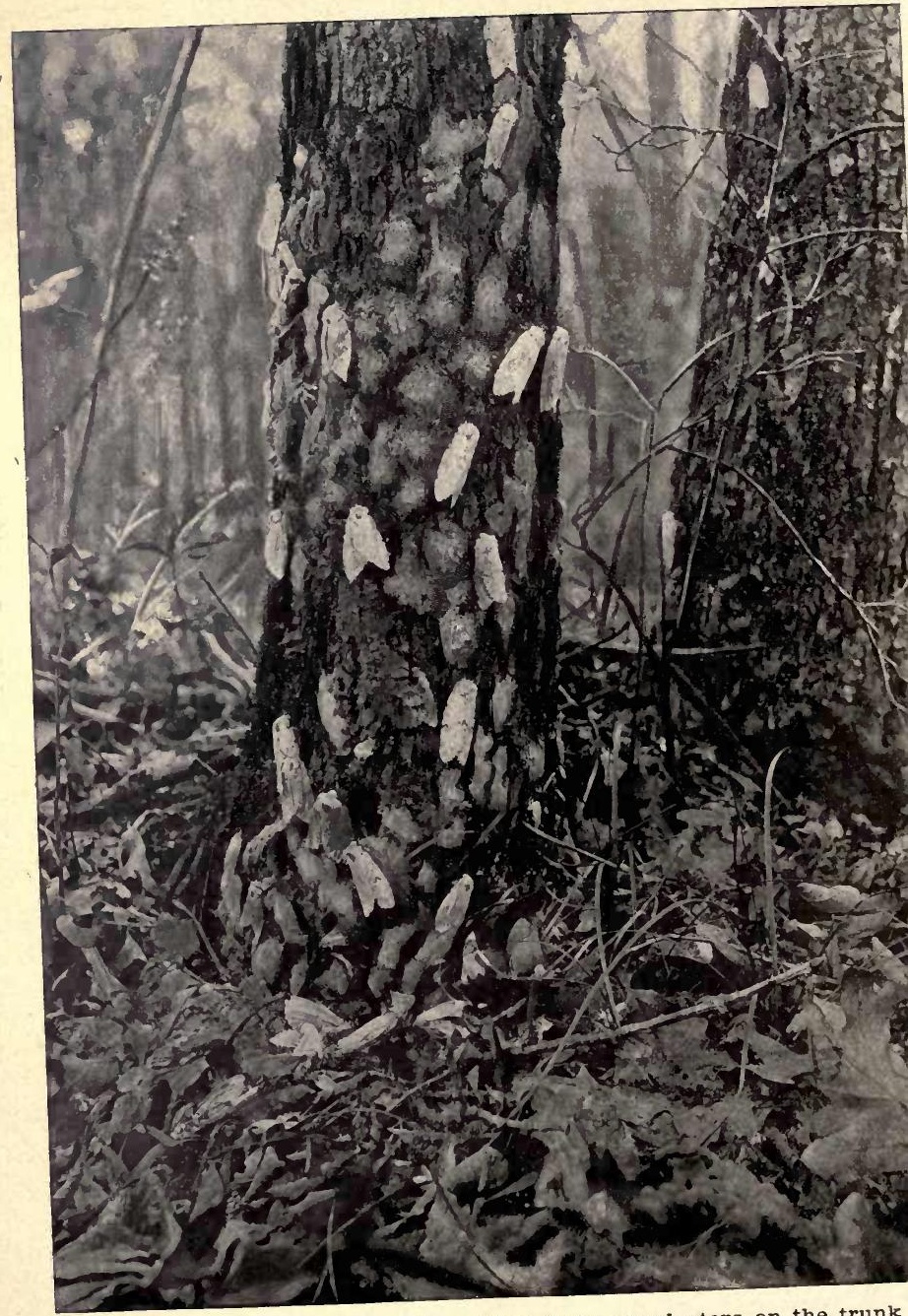

PLATE 55. Female moths depositing their egg-cl
of an oak tree, Saugus, 1895. 
for " bait," fertilized moths, dead moths or female pupæ were used. The fertilized females attracted the males in about half the cases where they were used. Of eight traps "baited" with fertilized females, three caught nothing, two caught one each, two caught two each and one caught fourteen, being an average of two and one-half each. The average catch of the same traps, "baited" with unfertilized females, was twenty and eight-tenths each. In nineteen of the traps dead females were used at times, but they proved to be of little value, for only five out of the nineteen attracted any males. The total number of females used was twentythree, and only twenty-four males were captured by such " bait." In some cases, female pupæ were used in the traps, and gave rather surprising results, which seem to indicate that the pupæ possess in some degree the power to assemble male moths, as twenty-one female pupæ attracted seventytwo males.

The following is a summary of the results obtained: 191 traps; total eatch, 9,767 males; average, 51.2 each; maximum catch, 431 males; minimum catch, 0 ; maximum eatch by a single female, 420 ; minimum catch by a single female, 0 .

After the trapping season was over, the localities in Medford, where the greatest number of males was captured, were carefully explored and the egg-clusters collected. In the latter part of December these eggs were carefully examined and their fertility determined, with the following results : of 659 egg-clusters examined, 16, or 2.4 per cent., proved to be infertile. As a check on the work, an equal number of egg-clusters taken from places not trapped for males were collected and examined, and all proved fertile.

\section{Oviposition.}

The abdomen of the female is so heavy before depositing her eggs that she simply clings head upward to the trunk of a tree or other object on which she happens to be resting (Plate 55); and when preparing to lay, and even during the process of depositing the egg-cluster, she drops or scatters more or less eggs accidentally. A small hairy area is first formed by rubbing the abdomen over the surface, thus 
depositing a small quantity of hair, which is caused to adhere, probably by a slight discharge of fluids. One egg is fastened to the surface, another is placed beside it and others on each side of these. As soon as the foundation is started, other eggs are laid upon it and the mass is built along; that part of the cluster next to the surface on which the moth rests is always kept a little in advance of the eggs laid on top of it, and is the widest part of the structure. The eggs when laid are covered with an adhesive fluid, which not only causes them to adhere where they have been placed by the ovipositor, but also causes the abdominal hair of the female, which she rubs off by the continual movement of the abdominal segments, to adhere to them. As laying progresses, the abdomen shortens, and the hair from the under side of the anterior segments furnishes the covering for the last-laid eggs.

The term layer may properly be applied to the eggs that are deposited on the surface upon which the moth is resting, for they conform to that surface, however smooth or uneven it may be, but those outside of this layer are packed in very irregularly. In nearly every case where the eggs are laid upon a vertical or nearly vertical surface, the laying is done from below upwards, the lower eggs being the first deposited, while the upper ones are the last. In general, from two to three days are required for oviposition, but the time is subject to considerable variation. The greater part of the egg-cluster is usually deposited during the first twenty-four hours. In one case a large female moth which began laying at 6 P.M., Aug. 6, 1895, did not complete her egg-cluster until 11.30 A.M., August 16. The female does not usually deposit all the eggs contained in the body. In the case of the female mentioned above, there were 201 eggs remaining in the abdomen of the moth, while the egg-mass which she had deposited contained 794 eggs.

\section{Eggs removed by Dissection of Female Moths.}

The female moths are often attacked while laying, and mutilated or entirely consumed by a few insectivorous birds and predaceous insects. Of the latter, the large wood ants, Camponotus pennsylvanicus (De G.), sometimes kill the fe- 


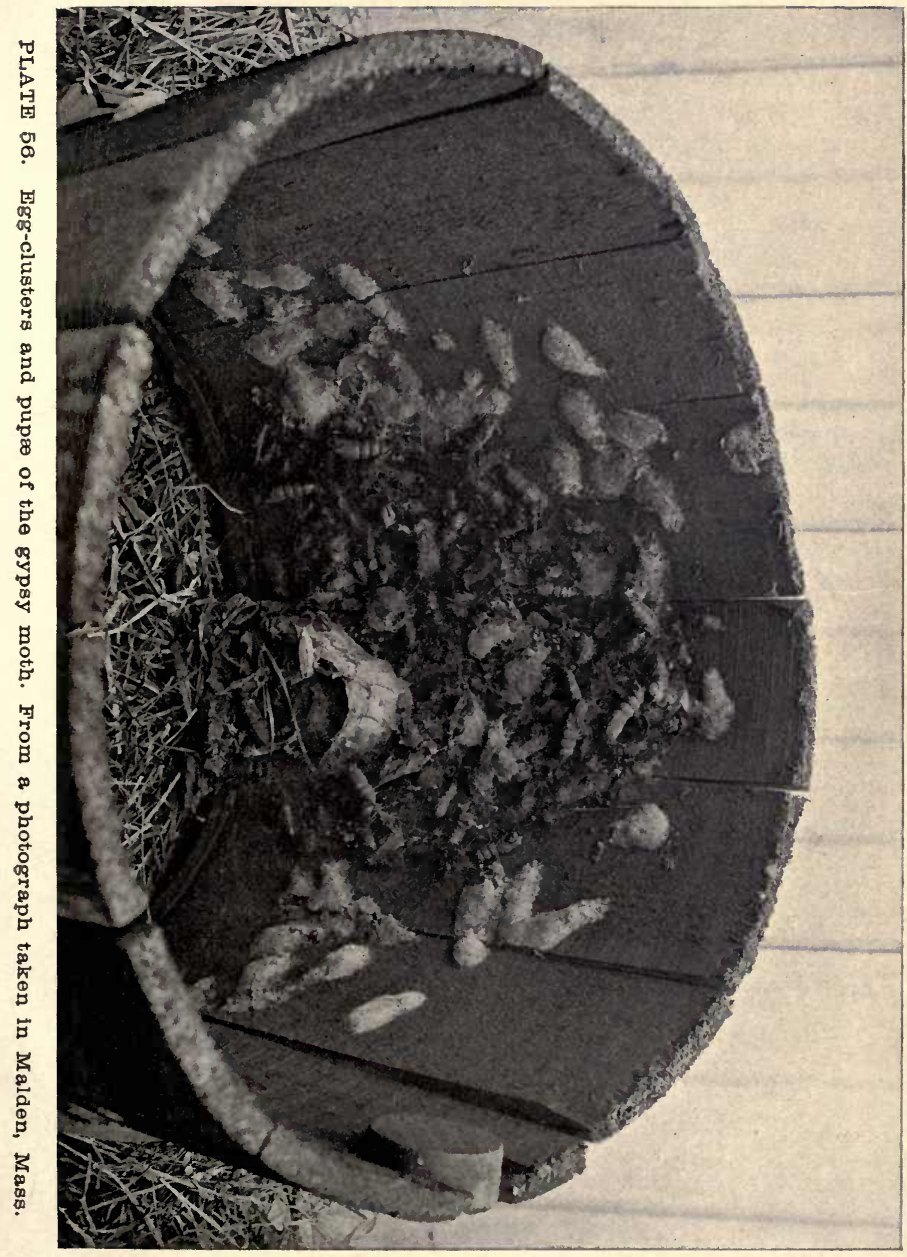




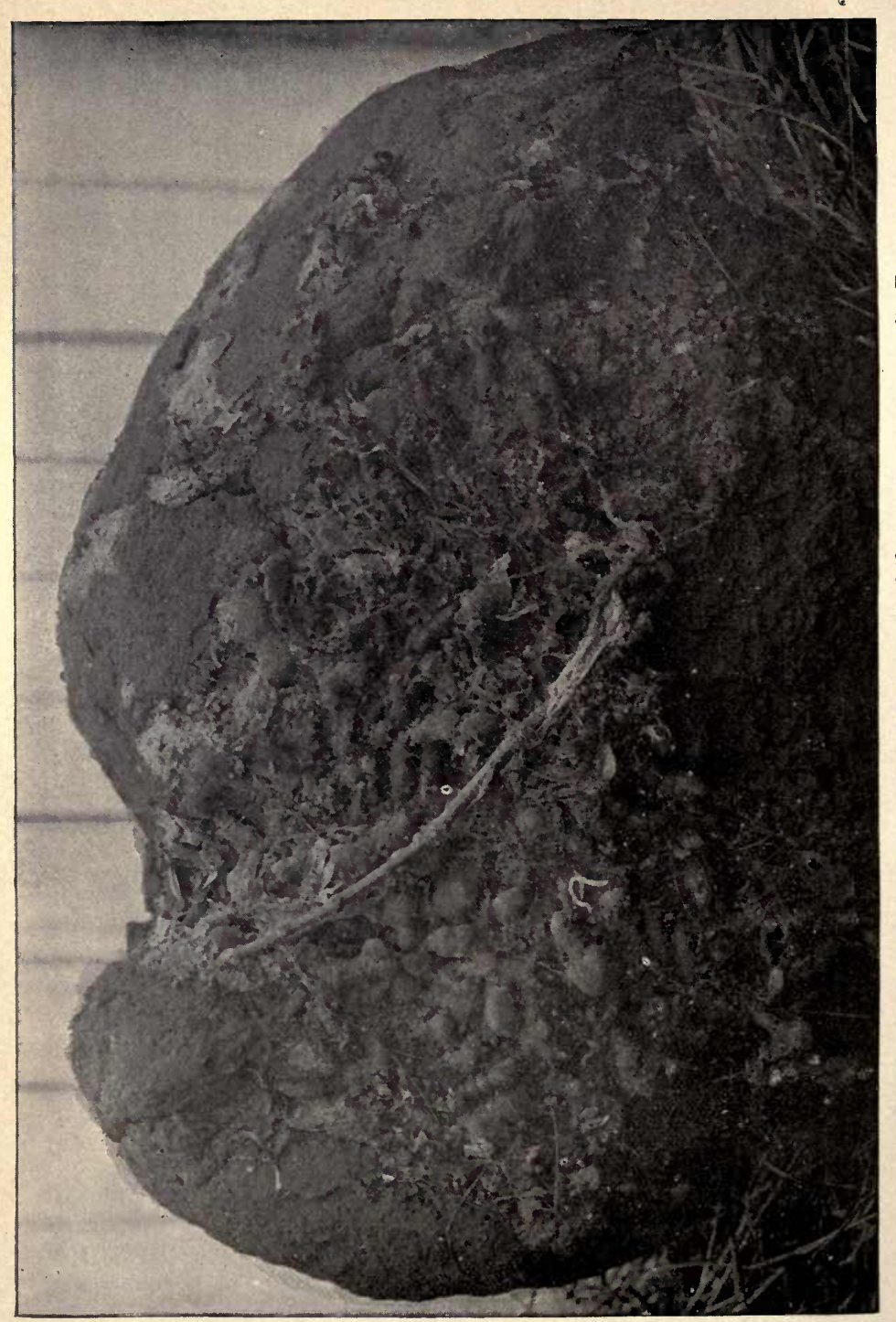


male moths, gnaw open the abdomen, and, after removing the egg-mass, drag it to their nests. With the discovery of these facts the question naturally arose, whether the eggs thus removed from fertilized females would hatch and thus start new colonies in the places to which they had been carried. To settle this point, during the summer of $\mathbf{1 8 9 5}$, studies were made on fifty female moths. Some of these moths were taken when the egg-cluster was about one-third completed, some when the egg-cluster was one-half completed, some when two-thirds, and others which had very nearly completed laying. These moths were dissected, and all of the eggs still remaining in the abdomen removed and preserved in boxes. Examinations of these eggs, made subsequently, showed that none of them were fertile.

A part of the egg-cluster deposited by twenty-five of these moths was preserved, all of which proved more or less fertile. This seems to demonstrate that, notwithstanding the mating of the moth, the eggs are not fertilized till during the process of laying.

\section{Parthenogenesis.}

Parthenogenesis, or reproduction by means of the eggs of unfertilized females, was thought to offer an explanation for the existence of certain peculiarly situated colonies in the infested territory. As has been previously stated, caterpillars are sometimes dropped uninjured by the birds when they are carrying them away to feed their young; or they may spin down from the trees upon passing teams or animals, and be carried to greater or less distances and then escape to suitable food plants, where they can feed and pass their transformations. If a single caterpillar should be carried, in any such way, to a distance from any colony greater than males could be attracted, and from it should emerge a female moth, she would doubtless lay her eggs, and, if parthenogenesis occurs in this moth, these eggs might hatch, even though no male had been present to mate with her.

To ascertain whether eggs laid by unfertilized females will hatch, in July and August, 1893, 990 female pupæ were put in small pasteboard boxes and kept under a variety of 
circumstances, but all at the normal out-door temperature. Some were kept covered with cheese cloth, others with the regular box covers, and still others were kept covered a part of the time with the covers and the rest of the time with cheese cloth. One hundred and sixty of these pupre were from larvæ raised in confinement, while the rest were collected in the field. Two hundred and thirty-three moths emerged and laid their eggs, but without that regularity that characterizes the egg-clusters of fertilized females. Most of the females laid a considerable number of eggs, though four laid no eggs but deposited some of their hair; one laid only a single egg, while two other females laid four and five eggs respectively. The boxes containing these eggs were kept under the same conditions as other boxes which contained fertile eggs, which hatched at the usual time in the spring; but no trace of embryonic development could be discovered within them during the fall, and they were again critically examined the last of January, 1894, when they were found to be more or less shrunken, and showed no sign of an embryo within, as is the case with fertile eggs. Early in the spring a piece of glass was glued over the top of each box, so that the young caterpillars could not escape, should any of the eggs hatch. They were daily inspected till after the time when they should have hatched, and then once a week till July, and less frequently till October, 1894, but not an egg hatched. While this experiment does not prove that parthenogenesis does not sometimes occur in the gypsy moth, it would seem to indicate that it is probably of rare occurrence. A few cases have been reported in Europe. Carlier states that he has seen three generations without mating having taken place, but the last generation gave only males. Siebold, who refers to this case in "Entomologische Zeitung, Stettin," Vol. XXII, page 443 , expresses some doubt, since no exact account of events was given. Weijnbergh, however, has given a very complete account of breeding this species from unfertilized eggs for three generations, until, at last, the eggs dried and brought his observations to a close. Dohrn, who reports this case in "Entomologische Zeitung, Stettin," Vol. XXXII, page 30, expresses the opinion that the dry- 
ing up of the eggs of the last brood was not due to their parthenogenetic characteristics, but to outside influences, and further states that it would be premature to limit the vitality of the products of parthenogenesis to two generations. It is a matter of regret that Weijnbergh did not examine the eggs each fall, and see whether the embryo had formed; for, had this been found, there would have been greater reason to have supposed that the eggs had dried up because of outside influences, as Dohrn conjectured. Mr. W. J. Pearce of Bath, England, reports in "The Entomologist," Vol. XII, page 229, that he had a female of this moth, which had not mated, lay eggs which hatched the following year.

\section{EgG-Clusters of Unfertilized Females.}

The egg-clusters deposited by unfertilized females, in the experiments on parthenogenesis, in 1893, were, as a rule, irregular, scattering and poorly covered with hair. As these were all laid in boxes, it was thought that it might be due, in part at least, to the smoothness of the box, which did not allow the moth as good a foothold for oviposition as is afforded by the surfaces usually selected for the purpose, such as the rough bark of trees, etc. The observations of the field inspectors led them to various conclusions, some contending that unfertilized females never lay the regular egg-clusters characteristic of the fertilized female, while others were of the opposite opinion. Investigations were made during the summer of 1895 , to learn whether it is possible to determine, from the form and completeness of an egg-cluster, whether the eggs contained in it are fertile. August 2, twenty-five recently emerged, unfertilized female moths were placed in a cage, made by tacking cheese cloth over a hoop, which projected from the trunk of a white oak (Quercus alba). This species of tree was selected because the bark is of such a nature as to give the moths the most favorable opportunity for egg-laying. At the end of two weeks, all the moths being dead, the cage was opened and six very imperfectly formed egg-clusters were found. They were, in fact, simply small patches of eggs, with but little of the usual covering of hair. October 10, the eggs were 
shrivelled, and the clusters partly washed away by the rains. From these as well as other observations made this season it seems more than probable that a female gypsy moth that has not mated does not make a perfect egg-mass, and that an experienced observer may distinguish in most cases an egg-cluster that is infertile from one that is fertile.

\section{IN-AND-IN BREEDING.}

A cluster of eggs laid by one female gypsy moth was placed in a breeding cage in the spring of 1893 , to determine whether the two sexes would emerge at the same time, mate and lay fertile eggs. This was for the purpose of ascertaining whether it would be possible for a fertile female, if transported to a new region, to lay eggs capable of establishing a new colony ; or, if a single cluster of eggs should be carried outside of the infested region, whether a new colony would result. The eggs used in this experiment commenced hatching May 5, 1893, and the caterpillars were fed on apple leaves till they reached maturity, when they pupated. The moths emerged as indicated in the following table :-

\begin{tabular}{c|r|r|r|r|r|r|r|r|r|r|r|r|r|r|r|r|}
\hline Dats. & $\begin{array}{c}\text { June } \\
\text { 20. }\end{array}$ & $\begin{array}{c}\text { July } \\
\text { 1. }\end{array}$ & $\begin{array}{c}\text { July } \\
\text { 2. }\end{array}$ & $\begin{array}{c}\text { July } \\
\text { 8. }\end{array}$ & $\begin{array}{c}\text { July } \\
\text { 4. }\end{array}$ & $\begin{array}{c}\text { July } \\
\text { 5. }\end{array}$ & $\begin{array}{c}\text { July } \\
6 .\end{array}$ & $\begin{array}{c}\text { July } \\
\text { 7. }\end{array}$ & $\begin{array}{c}\text { July } \\
8 .\end{array}$ & $\begin{array}{c}\text { July } \\
\text { 9. }\end{array}$ & $\begin{array}{c}\text { July } \\
\text { 10. }\end{array}$ & $\begin{array}{c}\text { July } \\
\text { 12. }\end{array}$ & Total. \\
\hline Male, & 3 & 5 & 8 & 32 & 13 & 60 & 76 & 26 & 2 & 20 & 19 & 3 & 267 \\
Female, & - & - & 2 & 16 & 15 & 62 & 69 & 20 & 4 & 16 & - & 7 & 211 \\
\hline
\end{tabular}

In all there were 478 moths, 267 males and 211 females, which mated as readily as those from different egg-clusters; and, as their eggs proved fertile, there is every reason to believe that, under favorable circumstances, this cluster of eggs could have established a colony of moths. See "The Entomologist," Vol. XIX, page 281 (1886).

\section{Intiernal Anatomy.}

The following description of the internal anatomy of the different stages of the gypsy moth was prepared by Mr. A. H. Kirkland. 

PLATE 58.

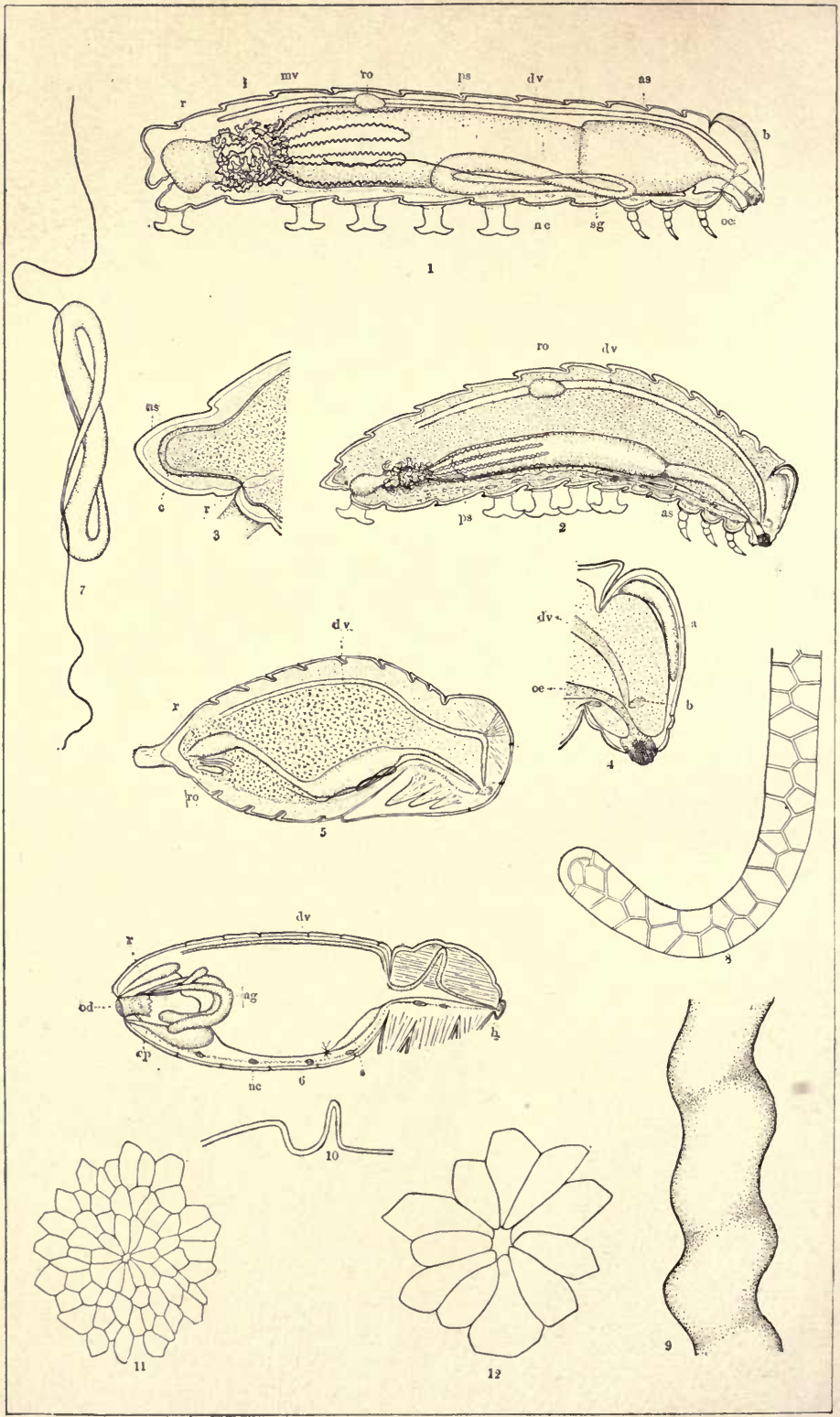




\section{EXPLANATION OF PLATE 58.}

Drawn by A. H. Kirkland.

I. Internal anatomy of larva of gypsy moth $\mathrm{X} 2$ : nc., nerve cord; sg., silk gland; œ., œsophagus; b., brain; as., anterior stomach; dv., dorsal vessel; ps., posterior stomach; ro., reproductive organ; mv., malpighian vessels; i., intestine; r., rectum.

2. Internal anatomy of larva about to pupate $\mathrm{X}_{2}$ : as., anterior stomach; ps., posterior stomach; dv., dorsal vessel; ro., reproductive organ.

3. Section through anal segment of larva about to pupate, showing development of cremaster in anal shield $\mathrm{X}_{4}$ : as., anal shield; c., cremaster; r., rectum.

4. Section through head of larva about to pupate, showing the development of the antenna cases beneath the larval head covering $\mathrm{X}_{4}$ : dv., dorsal vessel; œ., œsophagus ; b., brain; a., antenna case.

5. Internal anatomy of female pupa $X_{2}$ : dv., dorsal vessel; ro., rudimentary accessory organs of reproductive system; r., rectum.

6. Internal anatomy of female moth $\mathrm{X}_{2}$ : od., oviduct; cp., copulatory pouch; nc., nerve cord and ganglia; s., atrophied stomach; b., brain; dv., dorsal vessel; r., rectum; ag., accessory glands of reproductive system.

7. Right silk gland of full-grown larva, enlarged.

8. Posterior tip of silk gland, greatly enlarged.

9. Part of malpighian vessel, greatly enlarged.

Io. Part of dorsal vessel of imago, showing aortic arch.

Drawn by R. A. COOLEY.

I I. Micropyle of egg with surrounding rosette, greatly enlarged.

I 2. A part of the same, still more enlarged 

The figures of the internal anatomy were made from dissections of alcoholic specimens of the different stages, the work being performed at the entomological laboratory of the Massachusetts Agricultural College. In preparing the material for dissection the insects were first placed for twenty-four hours in fifty per cent. alcohol, then, for the same period of time, in seventy-five per cent. alcohol, and then kept in commercial alcohol until needed for use. The dissections were made under water, by using a small waxbottomed dissecting pan. The dissections of the pupæ were not wholly satisfactory, since the rapid breaking down of the larval organs and the correspondingly rapid development of the organs of the imago obscured the relations of the different parts, and made the correct interpretation of them a difficult task. The longitudinal section of the pupa, as shown in Plate 58, Fig. 5, is a composite figure, made up from the dissections of several pupæ from five to seven days old.

\section{The Alimentary Canal and its Appendages.}

From the medium large mouth cavity the esophagus (Plate 58, Fig. 1, oe) leads back through the œsophageal collar formed by a division of the double commissure which connects the brain (b) with the sub-asophageal ganglion in the first thoracie segment. Here it expands into a peculiar thin-walled organ, which, from its position and size, may be called the anterior stomach (as). This anterior stomach, which is practically an enlarged continuation of the œsophagus, is distinctly separated from the posterior stomach, stomach proper, by a well-defined constriction formed by a strong sphincter muscle, possibly valvular in function. The anterior stomach fills the thoracic and a part of the first abdominal segments. A marked distinction from the posterior stomach is the fact that it is not supplied with the prominent annular muscle bands which are characteristic of the latter organ, although it possesses both annular and longitudinal muscle fibres. In the larger caterpillars it is usually distended by a dark, viscid, semi-fluid mass, containing the recently devoured food, and, as shown by microscopic examination, numberless bacteria. The posterior 
stomach (ps) extends backward from the anterior stomach to the eleventh segment and nearly fills the body cavity. The contents of this organ are of a more solid nature than those of the anterior stomach. In the eleventh segment this organ tapers abruptly to form the short intestine (i), which has two enlargements, separated from each other by a sharp constriction. Between the stomach and the intestine, and also where the intestine enters the rectum, there is a well-marked constriction. In the last body segment the intestine expands into the large distended rectum (r), which completely fills the cavity and discharges at the anus beneath the anal shield. Six narrow longitudinal muscles extend the entire length of the alimentary canal. These muscles form six definite depressions on the intestine and rectum, and give to the excrement of the larva its peculiar incised appearance.

The malpighian vessels (Fig. 1, mv) consist of six double convoluted tubes which are attached to the walls of the posterior stomach and discharge into the intestine. These vessels are simply convoluted tubes (Fig. 9), and do not possess the bulbose lateral enlargements found in many other Lepidoptera. They are composed of a thin outer membrane and an inner layer of thick-walled nucleated cells, arranged around a central lumen, some parts of which, in the alcoholic specimens, are often filled with a yellow-brown crystalline mass (urates). Fresh malpighian vessels macerated in water give quantities of minute crystals. I have been able to demonstrate the presence of uric acid in these vessels by the use of the "murexid" test.

Small white granules are occasionally found deposited throughout all the different tissues of the larva, but, owing to their extremely small size, I have been unable to collect a sufficient quantity for analysis. In similar granules removed from the tobacco worm (Protoparce celeus) I have found uric acid, as shown by the "murexid" test, and phosphoric acid, as demonstrated by the reaction with ammonium molybdate.

The silk glands, two in number, lie along the lateral walls of the body cavity of the larva. Each gland consists of a small thread-like tube, which leads forward from the poste- 
rior part of the body, gradually enlarging in the seventh segment, thence extending forward to the fourth segment, where it bends on itself and leads backward and upward to near the middle of the eighth segment. Here it reaches its maximum diameter. It bends downward and gradually tapers again to a thread-like duct, which extends forward, and, after a more or less irregular course, discharges at the spinneret on the under side of the labium.

In the full-grown larva (Fig. 1, sg) these glands are distended with the silk-forming fluid; in those which have spun their cocoon (Fig. 2) they have contracted to less than one-half of their original size. One of these glands is shown in Fig. 7, and its extreme posterior tip in Fig. 8.

When the caterpillar is ready to pupate (Fig. 2), the alimentary canal is emptied of its contents, the anterior stomach (as) shrinks to less than one-half of the diameter of the posterior stomach (ps), the latter having also shrunken to about one-half of its original diameter. The intestine and rectum undergo a corresponding diminution. In the pupal stage (Fig. 5) the anterior stomach grows still narrower, the posterior stomach and rectum shorten, while the intestine, although less than one-fourth of the diameter of the larva, elongates to nearly twice its original length. In the imago (Fig. 6) the digestive system is atrophied, the anterior part being represented by a slender thread-like remnant of the œsophagus and anterior stomach, while the posterior stomach has been transformed into the small shrunken stomach (Fig. 6), at the hinder end of which may be found the remains of the malpighian vessels. A slender intestinal tube connects the stomach with the rectum (r), which lies in the upper posterior part of the abdominal cavity, and is usually filled with a thick cream or salmon colored fluid.

It is interesting to note that the digestive system of the male imago does not appear to have undergone so marked a degeneration as that of the female. The stomach is much better developed, and the relation of the different parts can be more clearly demonstrated. 


\section{Dorsal Vessel or Heart.}

This organ, in a caterpillar, is a simple longitudinal tube (Fig. 1, dv), lying immediately beneath the dorsal line and extending the whole length of the body. It is closed at the posterior end, while the anterior end opens at the base of the brain. Bands of muscle fibres, placed more or less obliquely, appear in the walls of the organ, while it is supported at the sides by fan-shaped mnscles (alæ) which are attached to the upper body walls.

In the pupal stage (Fig. 5, dv) a marked bend is found near the anterior end of the dorsal vessel, while faint muscle fibres can be traced, extending from the bend to the dorsal wall of the thorax.

In the imago (Fig. 6) the dorsal vessel (dv) follows the contour of the upper surface of the abdomen, bends abruptly downward at the junction of the abdomen and thorax, enters the thoracic cavity, bends obliquely upward to the dorsal wall, where it is firmly attached by muscle fibres, then extends downward and slightly backward, thence forward to the head, where it terminates at the base of the brain. I have been unable to discover any aortal chamber, such as was found by Burgess in Anosia plexippus, although the aortal arch (Fig. 10) is well defined.

\section{Respiratory System.}

This system is not figured in the plates, but possesses the general features common to Lepidoptera. The spiracles open internally by short tubes which communicate with two long lateral tracheæ. These extend the whole length of the body, and give off ramifications to all the organs. Opposite the spiracles are clusters of tracheæ of medium size, which are distributed over the surface of the alimentary canal. The tracheæ are composed of an outer semi-transparent sheath, made up of large, thin cells, the nuclei of which are readily revealed by staining with hæmatoxylin. Within this sheath is a chitinous tube, bearing on its inner surface a fine spiral ridge, which gives the tracheæ their distinguishing characteristic. 


\section{Nervous System.}

This consists of a double supra-nsophageal ganglion or brain (Fig. 1, b) in the head, an œsophageal collar, a subœsophageal ganglion and a row of ganglia extending along the median ventral part of the body cavity. The ventral ganglia are connected by a double commissure (nc). The brain gives off nerves to the ocelli, the sub-œsophageal ganglion supplies the mouth parts, while from the ventral ganglia nerves are distributed to the feet, prolegs and internal organs.

In the caterpillar there are eleven ventral ganglia, including the sub-œsophageal. The posterior one is by far the largest, being formed by a fusion of two ganglia. During the pupal stage (Fig. 5) the number of ganglia is reduced by fusion. In the imago we find two thoracic and four abdominal ganglia, which are connected with the brain by a double commissure.

\section{The Fat Body.}

In its fullest development this body forms an internal cylinder of fat, which surrounds the alimentary canal and lines the body cavity of the caterpillar. It is represented by the dark dotted area in Plate 58, Fig. 2. It is liberally supplied with tracheæ and is most prominent in wellfed, full-grown caterpillars. In the pupal stage (Fig. 5) the fat body diminishes as the reproductive system develops, the development of the latter taking place at the expense of the former. One fact, which seems worthy of record in this connection, is that almost no fat can be found in the female imago, while there is an appreciable quantity present in the male. Since the male is the sex that flies, this fat may be necessary to furnish the energy expended in flight.

\section{Reproductive System.}

This system is represented in the caterpillar by a pair of small reddish-brown organs (Fig. 1, ro), which lie one on each side of the dorsal vessel in the ninth segment. From these organs a pair of thread-like appendages (ducts?) lead 
backward for a short distance. A careful sectioning of a single reproductive body shows it to be composed of fila- ments, which are coiled upon each other, forming a compact mass, which is enclosed in the external envelope. In the mature caterpillar, and even in those of the fourth molt, there is a marked difference in the structure of the reproductive organs, seemingly indicative of sexual differentiation. One form, apparently that of the female, is made up of medium long, thick tubes, composed of an outer wall, a thicker inner layer and a central lumen, which is enlarged at intervals, and contains in these enlargements large celllike bodies surrounded by many smaller cells (nutritive cells?).

That which is apparently the male form is made up of much smaller and somewhat longer tubes of a more nearly even diameter. These tubes are closely coiled on each other within the sac formed by the outer envelope. These organs increase in size as the insect approaches the pupal stage. Although our studies on the reproductive system in the pupa are not yet completed, one point is well established: the development of the reproductive system of the future imago is accompanied by a corresponding diminution of the fat body with which the newly formed pupæ are filled. In this stage the accessory organs and glands of the reproductive system are first recognizable (Fig. 5, ro). The reproductive organs of the male imago (Plate 59, Fig. 1) consist of a single button-shaped testis (t), formed by the fusion of the two reproductive bodies of the caterpillar; the paired seminal vessels (vs) and duct with the accessory glands. Four enlargements occur on each of the seminal vessels, two near the testis and two near the junction of the two vessels. The last enlargement has a blunt, lateral projection, which receives the duct from the accessory gland. The common duct formed by the union of the two seminal vessels tapers for a considerable part of its course, then enlarges to form the seminal reservoir proper (sr) at the base of the penis (p), into which it discharges. Around the base of the penis, and attached to the lateral body walls, are bands of muscle fibre (m), which evidently serve to exsert the organ. The whole system is so compli- 


\section{EXPLANATION OF PLATE 59.}

Drawn by A. H. KirKLAND.

I. Reproductive system of male imago, greatly enlarged: t., testis; ag., accessory gland; vs., vesicula seminalis; sr., seminal reservoir; m., muscle at base of penis; p., penis; co., clasping organs.

2. Reproductive system of female imago, enlarged: rs., receptacle of semen or copulatory pouch; od., oviduct; ag., accessory glands; oo., ovaries. 

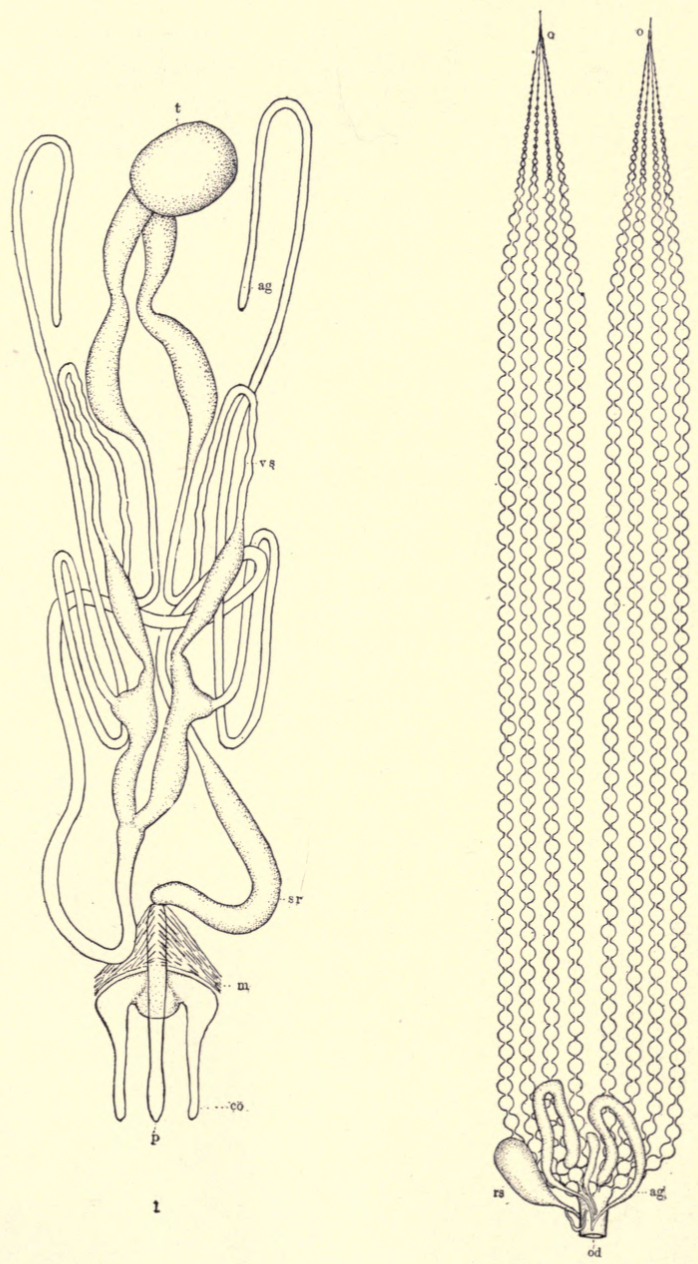
cated that no attempt has been made in the plate to represent the various windings of the vessels and glands as they occur in the insect.

The female reproductive system (Fig. 2, also Plate 58, Fig. 6) consists of the two ovaries (oo), each composed of four egg-bearing tubes, the oviduct (od) formed by the union of the ovarian tubes, the accessory glands (ag), and the copulatory pouch or receptacle of semen (rs). The ovarian tubes are closely coiled upon each other, and form an egg-mass which completely fills the body cavity. On the dorsal surface of the oviduct is the point of union with the large paired and small single accessory glands. These glands probably secrete the viscid coating of the eggs, which enables the latter to adhere in masses to the surface on which they may be deposited. Beneath the oviduct, and connected with a separate external opening, is the copulatory pouch (Plate 58, Fig. 6, ep). This is a mediumsized pear-shaped organ, and connects with the oviduct by means of a slender tube.

\section{Natural Enemies of the Grpsy Moth.}

The birds which play so very important a part in destroying the gypsy moth have been fully treated of in Part I of this work by my colleague, Mr. Forbush, and we pass to the consideration of the other natural enemies of the insect. Under these we will consider the animal and vegetable parasites, the predaceous insects and other insectivorous animals, except the birds.

\section{Hymenoptera.}

In all our field operations we have endeavored, from the first, to learn as much as possible about our native parasites, and particularly to what extent they attack the gypsy moth. For this purpose we have paid especial attention to collecting the different species found to be parasitic upon this insect, and to studying their habits. The Hymenopterous parasites of the gypsy moth thus far found are as follows: Theronia melanocephala (Br.), Pimpla pedalis Cress., Pimpla tenuicornis Cress. (Plate 53, Figs. 8, 8a), Anisocyrta sp., Diglochis omnivorus (Walk.) (Plate 53, Figs. 10, 10a). 
The first two and perhaps the last are the most useful in destroying the gypsy moth, and probably are far more successful than the Dipterous parasites, since the latter lay their eggs on the outside of the caterpillars, and many of them are thrown off on the molted skin before they hatch; while the eggs of the Hymenopterous parasites are deposited in the tissues beneath the skin.

During the summer of 1895 , Theronia melanocephala (Plate 53, Fig. 6) was the most abundant of the Hymenopterous parasites, and in the larger colonies could be seen on warm days flying about from tree to tree, almost invariably alighting on the burlap bands, and even crawling under them in its search for pupæ. In Lexington, on one occasion, one of these insects was seen to go from tree to tree until it had examined seven burlaps. After searching the burlaps, the trunk of the tree above and below was inspected, the antennæ all the time being kept in constant motion. It has been reported that this parasite attacks the caterpillar when about to pupate; but in nearly all the cases where its oviposition was observed this year, some eight or ten, the insects attacked were in the pupal stage. The point of attack was on the ventral surface, at the lower margin of the wing-cases, next the abdominal segments. Here the chitinous integument is very thin, and offers the least resistance to the insertion of the ovipositor. When a suitable pupa is found, the parasite, after selecting the point for attack, curves the end of the abdomen beneath the body between the legs, and inserts the ovipositor into the pupa by $a^{\circ}$ succession of movements, the whole operation requiring about a minute and a half. When disturbed by the writhing of the pupa or otherwise, the parasite withdraws her ovipositor and later stings again. Only one parasite has been reared from each parasitized gypsy moth, and therefore we may infer that but a single egg is deposited in a pupa. Mr. C. E. Bailey captured a specimen of Theronia melanocephala in the act of stinging a gypsy moth pupa which already contained a Dipterous maggot. Unfortunately, the pupa was so crushed that it was impossible to ascertain what the result would have been.

On one occasion a wood pewee was seen to snap up one 
of these parasites, while apparently in search of pupæ. There is no doubt that our birds which take small insects on the wing also destroy many Hymenopterous and Dipterous parasites.

Pimpla pedalis (Plate 53, Figs. 7, 7a) was obtained from the pupæ of the gypsy moth the past season, as well as in previous seasons, and was also bred in great numbers from the cocoons of the tent eaterpillar (Clisiocampa americana). From about two quarts of the cocoons of the latter insect only twenty-five moths were obtained, the rest producing parasites, most of which were Pimpla pedalis, though a few specimens of Theronia melanocephala were also obtained. Pimpla pedalis was seen ovipositing in the cocoons of the tent caterpillar; but as I have bred this parasite from larvæ of Tortrix fumiferana received by mail, and reared under such conditions that it was impossible for parasites to approach them, I am led to believe that Pimpla pedalis, as well as Theronia melanocephala, oviposits not only in pupæ but also in caterpillars. The fact that these parasites breed in the tent caterpillar and other insects, as well as in the gypsy moth, is of special interest; for the tent caterpillars pupate about four weeks earlier than the gypsy moth, and the parasites emerge from them just in time to attack that insect, so that this succession of hosts favors the multiplication of the parasites. How these parasites pass the winter I do not know, but think it very probable that they hibernate as imagoes. Ichneumon grandis was taken in January, 1895, hibernating in the imago stage, in a stone wall at Swampscott, along with pupa shells of the gypsy moth and cocoons of Pyrrharctia isabella.

The following is a list of the European Hymenopterous parasites of the gypsy moth, some of which, however, are known to be hyperparasites :-

Pteromalus halidayanus Rtz. (hyper).

Pteromalus pini Hartig. (hyper).

Pteromalus boucheanus Rtz. (hyper).

Eupelmus bifasciatus Giraud.

Eurytoma abrotani Panz.
Microgaster calceatus Hal.

Microgaster (?) tenebrosus Wesm.

Microgaster tibialis Nees.

Microgaster (?) liparidis Rtz.

Microgaster pubescens Rtz. = calceatus Hal.

Microgaster fulvipes. 
Apanteles glomeratus L.

Apanteles fulvipes Hal.

Apanteles melanoscelus Rtz.

Apanteles solitarius Rtz.

Pimpla flavicans Rtz.

Pinupla instigator Gr.

Mesochorus pectoralis Rtz.

Mesochorus gracilis Brischke.
Mesochorus splendidulus $\mathbf{G r}$.

Mesochorus confusus.

Campoplex conicus Rtz.

Campoplex difformis Gr. = Limneria.

Pesomachus hortensis Gr. (hyper).

Hemiteles fulvipes $\mathbf{G r}$.

Trogus flavatorius Pnz.

Ichneumon disparis Poda.

It is interesting to note that all the genera included in the above list are represented by species in this country; yet, aside from the genus Pimpla, no members of the different genera have been found to attack the gypsy moth.

\section{Predaceous Wasps and Hornets.}

The following species of wasps and hornets have been observed feeding upon the different stages of the gypsy moth: Vespa maculata Linn., Vespa consobrina Sauss., Vespa germanica Fab., Polistes pallipes St. Farg.

At a new colony of gypsy moths, in North Saugus, in the early part of August, a large number of Vespa maculata were observed flying close to the ground, around the base of the trees or carefully searching the trunks up and down, sometimes even going up into the tops of the trees. They were closely watched, and a maculata was seen to fly after a male moth, follow its zigzag flight as it attempted to escape, and finally capture and carry it to a small branch. The hornet soon dismembered the moth and began feeding upon the abdomen.

Two other hornets of the same species were seen flying after male moths. The first one chased a moth up above the tree tops and then off to one side and out of sight. The other followed a moth for about eight rods through the woods, and then caught him, but flew off before it could be taken with a net.

At another time a number of large brown wasps (Polistes pallipes) (Plate 53, Fig. 5) were noticed flying about the trees. When they discovered a branch on which caterpillars had clustered they alighted, and, running along the under side of the branch and leaves, each wasp located its prey, left the branch, and, flying about the caterpillar, finally 
alighted upon its back, at the same time stinging it upon or near the head, usually from behind. The result of this was to completely paralyze the caterpillar, for a time at least, when the wasp sucked the fluids from the body by cutting holes through the body wall, beginning near the head and working toward the posterior end. In some cases the wasp nearly cut the head and first or second segment from the body, and not unfrequently they were seen to cut off a part of the caterpillar and fly away with it.

The work of the wasps was not confined to a few isolated cases, but they were busy every day between the hours of 9 A.M. and 3 P.M., killing and carrying away the caterpillars.

One of the most remarkable observations of the season of 1895 was made by Mr. C. E. Bailey, a most careful and reliable field observer. While watching the birds at Wayte's Mount, Malden, for the purpose of discovering to what extent the different species of birds destroy the gypsy moth, he saw a large insect seizing gypsy moth caterpillars and flying away with them. Being provided with a net, he succeeded in capturing this insect while it was flying away with a third-molt gypsy moth caterpillar. The insect proved to be the American saw-fly (Cimbex americana). I am not aware that this species has ever before been discovered to be predaceous in its habits, but its mandibles and other mouth parts are so developed that one can well believe it capable of predaceous propensities.

Mr. W. L. Tower reported that on July 17, 1894, he saw a specimen of Tremex, or of a closely allied genus, take a full-grown gypsy moth caterpillar and fly away with it. As the insect was not captured, and under the circumstances could not be closely identified, we should not have considered it worth while to mention it here but for the reason that it may also have been the American saw-fly, and, if so, a verification of the predaceous habits of that insect. An examination of the mouth parts of Tremex columba will convince one that this insect is not predaceous, and therefore the probabilities are increased that the insect seen by Mr. Tower was the American saw-fly. 


\section{Ants attacking Female Imagoes.}

The following field observations show that the female imagoes, while laying, are often attacked and killed by black ants.

Aug. 11, 1894, a female, trying to deposit an egg-cluster on the trunk of an oak tree, was attacked at 10.20 A.M. by a large black ant, which seized her antennæ with its mandibles. The ant was captured, and the moth resumed laying; but at 1.40 P.M. was found in a hole in the ground, with a number of ants working upon her. One leg was gone and two more nearly severed from the body. At 2.40 all of the legs and both antennæe were missing, and the wings nearly destroyed. At 4.40 , the thorax having been severed from the body and the abdomen opened from the anterior end, the ants commenced to earry off the eggmasses.

Another female moth, while crawling in the grass, was attacked by the ants at 11.40 A.M., which seized her by the ovipositor and dragged her some distance. At 2.40 P.M. the ants, still at work, had torn the head from the body and carried it up into the tree, and soon after they opened the abdomen and greedily devoured the ovarian tubes. A third female, just beginning to lay, was seized by a large black ant, which dragged her to the ground, where nine more ants began to dissect her. The antennæ and legs were removed, the abdomen opened, and the ants soon began feeding upon the egg-masses.

To determine whether the ants will eat the eggs, the following investigations were made: Four female moths were divested of their heads and wings, the abdomens opened so as to expose the egg-masses, and then placed at the base of four trees. In about half an hour two of the moths were visited by several black ants, and a short time later nine ants were working upon one moth. These ants feasted for an hour or more upon the egg-masses, with their mandibles closed and their heads thrust down among the eggs, as if sucking up the body fluids. Then they began to sever the thorax from the abdomen and to tear off small clusters of eggs, from three to seven each, and carry them with the 
other parts of the body into their nests, in an oak tree, two and a half feet from the ground. When the last piece had been removed, the large ants left the field and were succeeded by a smaller species, that gathered up the scattered eggs and minute pieces of tissue and carried them off. Soon the large black ants returned to another moth, and began carrying away masses of eggs. The smaller species worked upon the same insect, but were not able to make so much progress. In no case were the ants seen to eat a single egg; they only devoured the body tissues and fluids, particularly the ovarian tubes enclosing the eggs. Two harvest spiders also appeared and fed upon the egg-masses.

Specimens of these ants were sent to Mr. Theo. Pergande, who identified them as Camponotus pennsylvanicus De G. (Plate 53, Fig. 9, 9a), and the large and small workers of Formica subsericea Say.

In connection with the attack of ants upon the gypsy moth, the following note is of interest: In the early part of the work of trapping the male moths, in 1894, attention was called to the fact that in the midst of the most densely infested part of a grove there was a single hickory tree on which no egg-clusters, caterpillars or any trace of the gypsy moth had been found, in spite of the fact that the trees and shrubs almost touching it on every side were all found to be badly infested. The tree in question was inhabited by small black ants, in fact, was full of them, and to these probably owed its escape from the ravages of the gypsy moth, while other trees of the same species, not inhabited by ants, were infested. The larger species of black ants have also been seen feeding on dead caterpillars and pupæ of the gypsy moth.

\section{Predaceous Coleoptera.}

Several species of beetles have for some time been known to destroy the gypsy moth. On the 20th of May, 1892, Mr. C. H. Rowe found the fiery hunter (Calosoma calidum) devouring the young gypsy moth caterpillars at the base of an oak tree in Malden. The beetle was captured, and subsequently liberated in a breeding cage containing thirty-six full-grown caterpillars, and others were added as they were 
needed. In five days ninety-three caterpillars were destroyed, only portions of the larval skins remaining. The beetle was fed for two weeks with various species of caterpillars and the larvæ of leaf-eating beetles. There seemed to be no choice made of the different species of caterpillars supplied, but all were in due time attacked and more or less eaten. From the number of caterpillars eaten in the five days, Mr. Rowe estimates that the average daily consumption of this beetle is about equal to six full-grown gypsy moth caterpillars. Mr. Rowe also reports the larvæ of two species of Harpalus feeding on young gypsy moth caterpillars.

For the purpose of ascertaining more fully the habits of the predaceous beetles, the following species were observed in confinement, in the insectary at Malden, during the summer of 1895, and later they were confined and fed in cages out of doors. One specimen of Calosoma scrutator was brought in June 28, and put into a cage with ten gypsy moth caterpillars, which were at once attacked by the beetle. The favorite place of attack seemed to be the middle of the body. As the viscera of the caterpillar came out the beetle chewed away steadily, apparently seeking the fatty parts. In two days fourteen caterpillars were eaten. At the end of this time the beetle was placed in a cage with another individual of the same species. July 1, the two beetles killed seven gypsy moth caterpillars, and eleven more were put in the cage. The next day ten were dead, and ten more of the fourth and fifth molt were put in. One caterpillar pupated, and the pupa was destroyed by the beetles. July 3 , six caterpillars were killed, and eight more of the fourth and fifth molt were put in. July 4, one of the beetles died. The remaining beetle killed four caterpillars July 5, but died on the next day, after killing two more caterpillars. These two beetles killed, in all, thirty-six gypsy moth caterpillars.

Another individual of this species was placed in a cage July 2, and kept supplied with gypsy moth caterpillars. July 18, another beetle of the same species was placed in the cage and supplied with food. The first beetle, during the 
fifteen days before the second was put in, destroyed thirtyone caterpillars and three pupæ; and, after the other beetle was put in with it, the two destroyed fifty gypsy moth caterpillars and one Sphinx drupiferarum caterpillar before July 24, when the first beetle died. The remaining beetle destroyed four gypsy moth caterpillars, one sphinx caterpillar and one male gypsy moth between July 24 and July 30. Another Calosoma scrutator was then put into the cage, and August 5, when they were placed out of doors, they had killed eight caterpillars, three pupæ and two female moths.

Two specimens of Calosoma frigidum (Plate 53, Fig. 1), male and female, were put into a cage together at the insectary, June 28, and supplied with gypsy moth caterpillars. This species is much smaller and more active than $C$. scrutator. They are not so clumsy, but are able to seize the caterpillars and destroy them while on a vertical surface, as on the trunk of a tree. July 27 , one of these beetles died, and the other was removed to be used by the artist. During this time they killed ninety-two gypsy moth caterpillars, three pupæ and one female moth.

Three other individuals of this species were put into a cage in the insectary, July 21, and supplied with gypsy moth caterpillars. One of the beetles died the second day, and on August 5 the other two were placed in an outside cage. During the fifteen days that these beetles were fed in the insectary they killed thirty-nine gypsy moth caterpillars, two pupæ, two sphinx caterpillars and one cutworm.

Calosoma calidum. - Three specimens of this beetle were placed in a cage July 12, and supplied with gypsy moth caterpillars. July 19, twenty-three caterpillars had been killed, and another beetle was put into the cage. July 27, one of the beetles died, the four having killed thirty-four caterpillars and one pupa since July 19. Fifteen gypsy moth caterpillars, four pupæ, eight cut-worms and two Sphinx drupiferarum caterpillars were killed between July 27 and August 5.

One specimen of Carabus serratus was supplied with gypsy moth caterpillars, and killed five before it died. 
Platynus limbatus was also found feeding on pupæ in the field, but it would not feed upon them in confinement.

For the purpose of keeping and feeding some of our predaceous beetles, under as natural conditions as possible, $\mathrm{Mr}$. Kirkland very ingeniously arranged a number of cages (Plate 60), and attached them to the trunks of trees in the woodland near the insectary. These cages were of wire netting, bent into a nearly cylindrical form. The edges were fastened to the two sides of the tree trunk, the lower end extending down into the ground and the upper end covered by a piece of cloth, one side of which was secured to the tree, the other covering the top of the wire screen cage, and held in place by a rubber strap, the ends of which were fastened to the trunk of the tree. This rubber band could easily be removed from the top of the cage and the cloth lifted sufficiently to give free access to the interior. A few small stones and some moss were so arranged on the ground, at the bottom of the cage, as to furnish hidingplaces for the beetles. Each cage had a tag attached to it, on which was the number and other necessary data.

Two specimens of Calosoma scrutator were placed in cage No. 1, August 9, and supplied with gypsy moth caterpillars. August 20, fourteen caterpillars had been killed.

Five specimens of Calosoma frigidum and one of Calosoma calidum were put into cage No. 2, August 9, and supplied with caterpillars. One specimen of $C$. frigidum died August 13, and August 20, twenty-five eaterpillars had been killed by these beetles.

Ten specimens of Harpalus caliginosus were put into cage No. 3, August 9, and supplied with eaterpillars, and August 20 , twenty-two of these caterpillars had been destroyed by the beetles.

Ten specimens of Harpalus pennsylvanicus were placed in cage No. 4, August 9, and furnished with caterpillars; August 20, twenty-three caterpillars had been killed by the beetles.

During the summer of 1891, Mr. E. P. Felt obtained a specimen of Dermestes lardarius from a mass of gypsy moth pupæ. 


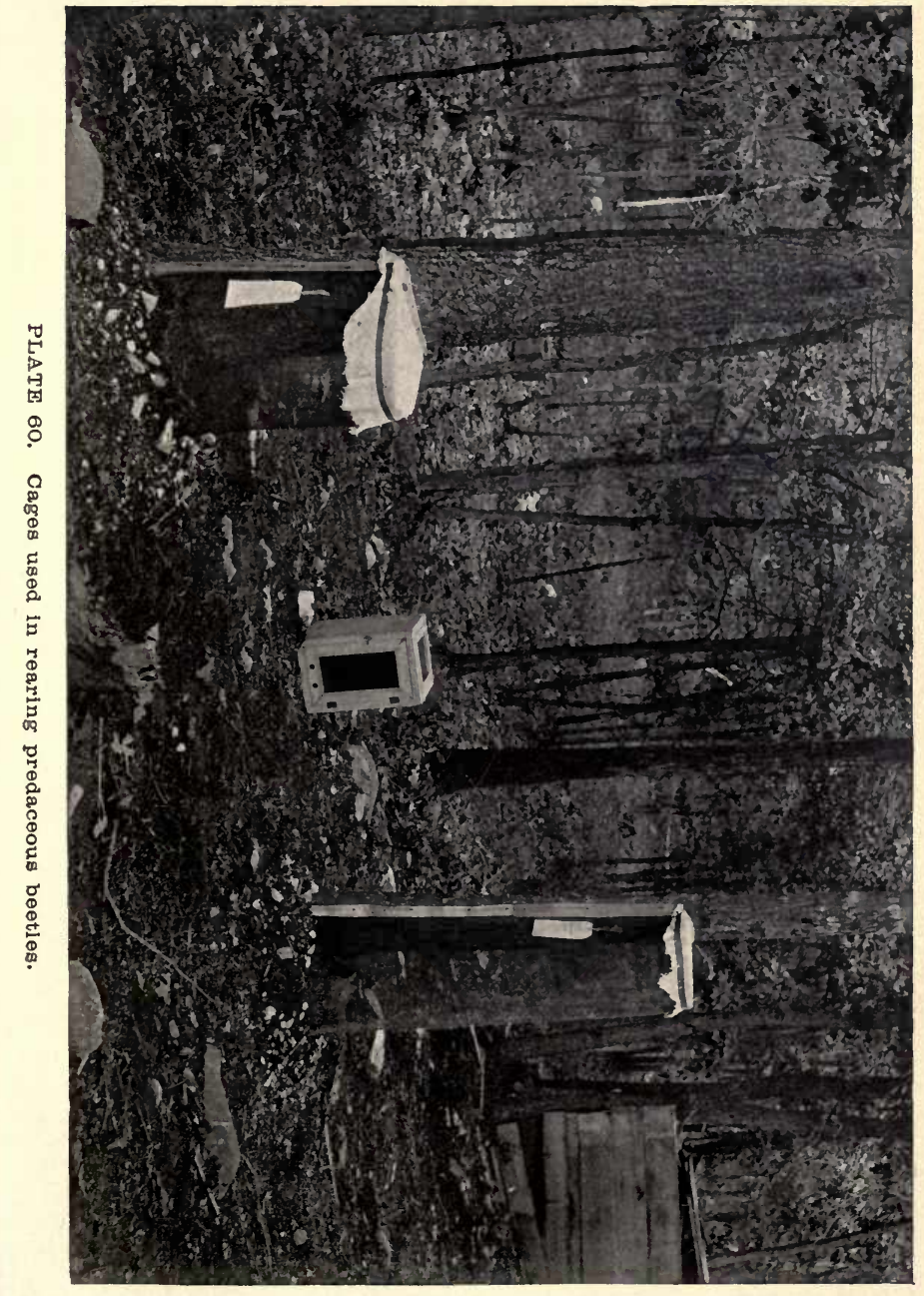


the $x^{5} y^{2}$

$3 \frac{3 x}{2}$

4

$x$

4

$+x$

2. 
Several Coleopterous larvæ have been found feeding upon the egg-clusters of the gypsy moth, but we have been unable to obtain the imagoes from them. During the past year Mr. C. H. Rowe succeeded in rearing a specimen of Ptinus brunneus from a gypsy moth egg-cluster.

The following species of predaceous beetles are said to attack the gypsy moth in Europe :--

Calosoma sycophanta (L.) (larva).

Tiresias serra (Fab.) (eggs).

Dermestes ater (Panz.) (eggs and pupæ).

Dermestes lardarius (L.) (eggs and pupæ).

\section{Diptera.}

In June, 1891, while on a visit to the territory infested by the gypsy moth, my attention was first called to the fact that flies were depositing their eggs on the caterpillars; and since that time the field workers have reported these parasitic flies in no less than ten towns, showing that they probably occur throughout the entire infested region. The number of these eggs on a single caterpillar was reported by twelve different inspectors who observed them, as varying from one to twenty, though some state that they have seen the caterpillars " nearly covered," and others " eggs in great numbers on them." Directions were then given to collect and rear the parasitized caterpillars till these parasites should emerge. It was found that many of the caterpillars molted their skins before the eggs of the parasites hatched, and therefore comparatively few of them were able to make their way into their insect hosts and destroy them. If the caterpillars had not molted before the eggs of the parasites hatched, their destruction would have been vastly greater. During the summer of 1893, Mr. Reid collected a number of caterpillars on which the eggs of the parasites had been laid. Two hundred and thirty-five of these caterpillars, having from one to thirty-three eggs on them, were fed in cages until they changed to pupæ; and from these two hundred and twenty-six moths emerged, but only four Dipterous parasites were secured from this entire number. The caterpillar which had thirty-three parasite eggs on it 
when brought in molted before these eggs hatched, passed all its transformations, and the moth emerged from it in good condition.

In July, 1895, a careful examination was made to determine the proportion of caterpillars in the field that had the eggs of the Dipterous parasites attached to them. July 3, five trees were examined in Dorchester, and 2,200 caterpillars were found, 500 of which had the eggs of parasites on them. July 8, six trees were examined in Medford, and 1,847 caterpillars found, 397 of which bore parasite eggs. The total number of caterpillars examined was 5,547, of which 1,597 , or nearly 29 per cent., had the eggs of Dipterous parasites attached to some part of the body.

Several Dipterous parasites were bred, during the summer of 1895 , from infested pupæ, the majority of which produced only one parasitic fly, while a few produced two. Many parasitized pupæ contain maggots which have not yet pupated. The vitality of these Dipterous parasitic larvæ is very remarkable. One of them was placed in a twenty per cent. solution of formol at night, August 15, and twentyfour hours later it was found swimming around, apparently uninjured. The larva was at once removed from its formol "bath," and was still living October 1, but had not pupated. In several cases where two larvæ were found in a small pupa of the gypsy moth, and there seemed an insufficient amount of food for them, a large female pupa was cut open and a parasite larva placed on the eut end of each half. They at once burrowed into the tissues and fed there several days. One larva ate the substance of six female pupæ in this way before reaching its full growth.

Fifty gypsy moth caterpillars, having eggs of a Dipterous parasite on them, were collected in Dorchester, June 21, 1895, and carefully bred in separate boxes. The eggs were deposited without regularity on nearly every part of the body. Forty-three of these caterpillars passed their transformations, producing perfect moths, six males and thirtyseven females; while seven died, but not because of the parasites, for the caterpillars had all molted before the eggs of the parasite had hatched. Two hundred and fifty-two 
other caterpillars taken in the field, and bearing Dipterous eggs, were fed and earried through their transformations with the same result as in the case cited above.

All the Dipterous parasites bred from the gypsy moth, and also those collected in 1891 , were sent to Dr. S. W. Williston for determination. They were determined by him as follows :-

Exorista, two species; Phorocera, four species. These are true parasites.

Gaurax anchora Loew, whose larvæ had been observed by Osten Sacken in multitudes upon the pupæ enclosed in the cocoons of the Cecropia moth; Phora scalaris Loew; Phora incisuralis Loew, var. The last three species are regarded by Dr. Williston as accidental parasites entering the pupæ of the gypsy moths while the flies are in the larval state, and then feeding in and destroying the moths.

Sarcophaga, two species. Schiner expresses very grave doubts whether the species of Sarcophaga ever feed on anything but dead animal matter, while Brauer states that their larvæ are sometimes parasitic.

Cyrtoneura stabulans Fall. Aceording to Hartig and Bremi, the larva of this species is sometimes found in the eaterpillars of certain Bombycid moths.

In 1894, I sent another lot of Diptera bred from the gypsy moth to Dr. Williston for determination, and in reply he wrote as follows: "I send you herewith the manuscript on the Diptera sent me, except a portion of that formerly sent to you, the specimens of which have got mislaid or rather lost in the general collections, and have not yet been found. There were several specimens, how many I do not know, but not including the Tachinids which I had separated out." Should the above-mentioned species be found, there may prove to be something of interest to add to our list. Dr. Williston kindly sent the following descriptions for publication in this report:-

Achotoneura fernaldi n. sp. (Plate 53, Fig. 11, a-e.) Male. - Frontal stripe deep brown, a little narrower than the sides of the front; sides light golden yellow, reaching a little way on the sides of the face. At each angle of the 
eye there is a stout bristle curved backward; on either side of the frontal stripe a single row of bristles, of which the two uppermost are stronger than those before them, and are curved backward. The frontal row extends down on the sides of the face for a short distance beyond the base of the antennæ and to nearly opposite the uppermost bristle of the facial row ; the proclinate ocellar bristles moderately strong. Antennæ wholly black, the third joint but little more than three times the length of the second joint. Face satiny white; vibrissal bristles situated a little distance above the oral margin; above them is a row of not very strong bristles extending about midway to the root of the antennæ. Sides of the face wholly bare, except for the previously mentioned bristles. Cheeks covered with short, black, bristly hairs, their length equal to about half that of the eyes. Eyes wholly bare. Palpi yellowish. Mesonotum shining blue black, with inconspicuous stripes. Scutellum broadly reddish on the apex, the apical pair of bristles small and decussate. Abdomen shining blue black, with a broad, variable, white pollinose, basal band on the segments; first and second segments each with a pair of marginal bristles; third segment with a posterior row; the general covering of the abdomen is composed of rather stout bristly hairs, which are more abundant, longer and intermixed with finer hairs distally. Legs wholly black, the front femora whitish pollinose behind; pulvilli much elongated; the claws elongate and slender. Wings grayish hyaline; third vein with a few short bristles at the very beginning; angle of the fourth vein without a stump, though with a fold appearing somewhat like one.

Female. - Differs from the male in the front being wider, in the presence of two proclinate orbital bristles on each side, in the abdomen being less hirsute and in the short claws and pulvilli. Length of male, $10 \mathrm{~mm}$.; of female, $12 \mathrm{~mm}$.

Twenty-five specimens from Professor Fernald, labelled as follows: "From larvæ which died in parasitic cage Aug. 27 (male), 28 (male and female), 29 (male), 1893, laboratory Gypsy Moth Department, Malden." “Emerged 
from pupa of $P$. dispar Aug. 22, 1893 " (female); and " Emerged from gypsy moth pupæ Aug. 24 (male), 27 (female), 29 (female), 1891; Sept. 2 (female), 1891."

I have compared these specimens with a female type of $A$. (Masicera) frenchi Williston, with which the species is closely allied, and find the following differences: The facial bristles ascend higher in $A$. frenchi, reaching two-thirds or more of the distance to the root of the antennæ, while in A. fernaldi they do not go more than half way, and sometimes even less than that. The bristles of the front do not descend so far as in $A$. frenchi. But the chief difference, and one by which the species will be readily recognized, is the relatively much shorter third joint of the antennæ in the present species. In $A$. fienchi it is fully five times the length of the second. The marginal bristles of the abdomen seem to be stronger in $A$. frenchi. In the type female compared there are none on the first segment, but I suspect that the species has them normally.

From Achotoneura (Masicera) sphingivora Towns., Trans. Am. Ent. Soc., Vol. XIX, page 286, the length of the antennæe and the red sides of the abdomen are sufficient to distinguish. From A. (Masicera) eufitchice Towns. the differences are also evident.

Sarcophaga, sp. Female. - Sides of the front and face wholly silvery white; median frontal stripe black. Antennæ black, third joint between three and four times the length of the second joint. Abdomen black, silvery white, marmorate; fourth segment wholly black. Legs black, the hind tibiæ not ciliate. Palpi black. Length, $12 \mathrm{~mm}$.

One specimen, labelled “From parasitic material, Aug. 1, 1893, Gypsy Moth Department, Malden.” The single specimen is not in the best state of preservation, and it is difficult, if not impossible, to either identify it with any previously described species or to give a description which will enable the species to be again determined with certainty. The diagnosis given above wil serve to exclude all but nearly related species.

Cyrtoneura stabulans. - Musca stabulans Fallen. Meigen, Schiner (Cyrtoneura), etc. Europe, New Zealand, North America. 
Female. - Front a little less than one-third of the width of the head, gray pollinose on the sides, the median stripe deep reddish brown or black, broader than the sides, narrowed below; a pair of proclinate ocellar bristles present; the lateral row of bristles has an outward curvature. Second joint of the antennæ reddish; in front somewhat blackish, and with erect bristles; third joint black, about three times the length of the second; arista thickened at the base, plumose. Sides of the face narrow, bare. Cheeks in width about equal to the length of the third joint of the antennæ, with a row of bristles on the inferior margin reaching to the moderately stout vibrissæ a little above the oral margin; bare on the upper part, and with short bristly hairs below. Sides of the face and the upper part of the cheeks reddish in ground color, covered with silvery pubescence. Mesonotum gray pollinose, variable, with four narrow, shining black stripes, the lateral ones interrupted. Scutellum broadly reddish at the apex; apical bristles long, decussate. Abdomen uniformly covered with gray pollen, moderately variable in different reflections, the ground color everywhere shining black. Legs yellow; the front femora in large part and the base of the middle femora black; all the tarsi blackish. Wings grayish hyaline; first posterior cell only a little narrowed at the tip; penultimate section of the fourth vein shorter than the antepenultimate section. Length, 6-7 mm.

Three specimens, labelled “ Emerged from gypsy moth pupæ, Aug. 20-21 and 25, 1891." This species is the one which I have commonly identified as $C$. stabulans Fall., but I have never compared it directly with European specimens. According to Schiner, it has been bred from Bombyx pyri and Lophyrus, and also from various species of Boletus.

Elachiptera dispar n. sp. (Plate 53, Figs. 12 and 12a.) Female. - Head yellow, a minute spot at the ocelli and the arista black. Thorax light yellow; a narrow median stripe extending from the front margin of the mesonotum to the tip of the scutellum; a small oblique spot on each side, contiguous with the front end of the stripe, and the disk of the mesonotum, black. Abdomen yellow; second segment, 
except a broad triangle whose apex reaches the hind margin, and all of the following segments, black. Legs light yellow; the front tibiæ and tarsi brown, the other tarsi brownish. Wings cinereous hyaline. Length, $2 \mathrm{~mm}$.

Two specimens, labelled “ Emerged from gypsy moth pupæ, Aug. 21, 1891." The arista has been broken away in both specimens, save the basal part; this part, however, is so thickened and pubescent that I believe that I am not in error in referring the species to Elachiptera (Crassiseta), where it finds its nearest ally in $E$. eunota Loew.

Phora setacea Aldrich, Can. Ent., Vol. 24, page 144, Brookings, South Dakota (reared from Cimbex americana).

Notwithstanding the difference of locality and habits, I believe that the specimens bred from the gypsy moth parasitic material and sent to me by Professor Fernald are of the same species as those described by Professor Aldrich. I have only males, and it is possible that the females may show some discrepancies. The specimens differ from the description only in the male genitalia, which do not have the projecting abdominal segment as described, and in the first weak vein of the wings, which is distinctly curved and not " almost straight." The species will be best recognized by the arrangement of the lowermost frontal bristles, for the position of which the reader is referred to the figure and description given by Aldrich. Otherwise the species may be briefly described as follows : -

Male. - Head black, antennæ fuscous; palpi yellow, with black bristles; proboscis yellow. Thorax black. Abdomen black; halteres light yellow. Front and middle legs yellow, the hind ones more brownish. One spur at the tip of the tibire, save of the front pair, where there are none. Wings hyaline; second heavy vein (third longitudinal) furcate; bristles on costal border long. Length, $1.5 \mathrm{~mm}$.

It is probably true that the species of Phora are not truly parasitic, but live in any dead or decayed material that comes in their way; still, it is not certain but that they may attack the living insect.

The following list of the European Dipterous parasites of the gypsy moth has been compiled from various sources. 
Many of the names are taken from a list furnished me by Dr. S. W. Williston:-

Exorista lucorum Meig.

Exorista (Myxexorista) libatrix Panz.

Exorista erythrostoma Hrtg. Parexorista sussurans Rond.

Meigenia bisignata Schin.

Tachina bella Meig.

Tachina pinivora Ratz.

Tachina larvincols Ratz.

Tachina monacha Ratz.

Tachina noctuarum $R$. D.

Tachina quinqueritala Hrtg.

Tachina rustica Fall.

Tachins larvicols Hrtg. (?)
Tachina moreti R. D.

Tachina (Echinomyia) conjugata Rond.

Tachina (Echinomyia) fera $\mathrm{L}$.

Tachina bimaculata Hrtg.

Eutachins larvarum L.

Phorocera concinnata Meig. = M.

serrieventris Rond. (?)

Sarcophaga affinis $\mathbf{F a l l}$.

Thelymorpha vertiginosa $\mathrm{Fall}$.

Argyrophylax gilva Hrtg.

Parasitigena segregats Rond.

Macharæa serriventris Rond.

Chrtomyia crassiseta Rond.

It will he observed that the single species of Tachinidoe thus far known to infest Porthetria dispar, in North America, belongs to a different genus, or sub-genus, from any in the above list, all of which are Tachinids except one. It will be of interest to determine the earlier or normal host of Achotoneura fernaldi.

\section{Predaceous Diptera.}

Of the predaceous Diptera the following species have been taken feeding upon the imagoes of the gypsy moth: Dasyllis sacrator Walk., attacking the females while laying; Asilus sericeus Say, capturing the male imagoes on the wing.

\section{Predaceous Hemiptera Heteroptera.}

The following account of the predaceous Hemiptera Heteroptera, known to feed on the gypsy moth, has been prepared for this report by A. H. Kirkland, B.Sc., assistant entomologist.

An important factor in the destruction of the gypsy moth caterpillars is the aid rendered by several species of predaceous bugs, which, in badly ínfested localities, attack the caterpillars in considerable numbers, and in some places apparently feed upon them in preference to any other kinds of Lepidopterous larvæ. The predaceous bugs thus far found feeding upon the gypsy moth are Podisus cynicus (Say), 
P. serieventris Uhl. and Menecles insertus (Say). Perillus circumcinctus Stal. has also, this year, been doubtfully recorded, in a single instance, as attacking gypsy moth caterpillars. The following pages present the facts we have ascertained concerning the habits of each species, together with the life history of $P$. serieventris.

General Habits. - All these species appear to be arboreal in habits, although they are occasionally taken on the ground. Their chosen food in this region seems to be the caterpillars of the different Lepidoptera, and in the search for them the bugs often climb trees to a great height. The bugs seek out caterpillars in their hiding-places in the rough bark, or even follow them to their feeding-places on the foliage, and attack them both during the day and at night. These predaceous insects possess a considerable degree of activity, most noticeable on warm days, and have also the ability to exist for some time without food, especially in the earlier stages. During the present summer, at the insectary, specimens of $P$. serieventris were found to be alive and fairly active at the end of five days from hatching, without once having taken food. This marked degree of vitality of the young bugs is perhaps not surprising, since from the time of hatching to the time of first feeding, the element of chance enters most strongly into their career, for they may often, of necessity, travel over a large part of a tree before finding food for the first time. These species are found on all parts of the trees, and, while they are more or less gregarious in the first and second stages, in the later stages they usually feed independently of each other. I have repeatedly seen the imagoes of $P$. serieventris fly short distances, which would indicate that this is its ordinary mode of transit from one tree to another. This latter species shows a considerable attraction to light.

Of the three species mentioned, $\boldsymbol{M}$. insertus seems to be the most local in its distribution in the infested district. In the restricted areas in which it occurs it is fairly abundant, but its limited distribution in the territory infested by the gypsy moth renders it of less importance than $P$. cynicus or $P$. serieventris. The two latter species are very gener- 
ally distributed throughout the infested region, and the good they do in destroying the caterpillars of this insect is of no little importance. The larger of the two species, $P$. cynicus, occurs in smaller numbers than $P$. seripventris, and, although it will destroy more caterpillars during its feeding season, yet from the moderate numbers in which it occurs it is not so valuable an ally as $P$. serieventris. Whether these insects are devoured by birds to any great extent I am unable to state. The odoriferous glands with which they are provided would seem to be a means of protection against their natural enemies. A pair of crows, confined at the insectary, devoured all specimens offered them of the three species of these bugs, and Mr. Forbush informs me that in nature these insects may possibly be destroyed to some extent by crows, since these birds are known to include the Heteroptera in their bill of fare.

Method of rearing Predaceous Bugs. - The problem of breeding any Heteropterous insect presents at the outset many difficulties, and but little assistance is given by the literature on this sub-order of insects. Concerning this subject, Douglas and Scott, in their work on "British Hemiptera," Vol. I, page 5, 1865, wrote: “It is probable, in consequence of the fact that the Hemiptera-Heteroptera are in all stages of their existence active and suctorial, and the consequent difficulty of supplying them, in confinement, with fresh, appropriate food, that but few observations upon their natural history have been recorded. . . But, whether each species casts its skin the same number of times; how long the individuals of each species remain as larva, pupa or imago; what species have more than one brood in a year, and what constitutes the food of each species, - are matters that, in the great majority of instances, remain to be determined. There is, therefore, a wide field for research in the natural history of this sub-order of insects."

While considerable has been done toward gaining a knowledge of the life histories of many of our plant-feeding Heteroptera, in the thirty years which have elapsed since the above was written, as yet we know but little of the life history of those members of the family which are predaceous 

PLATE 61.

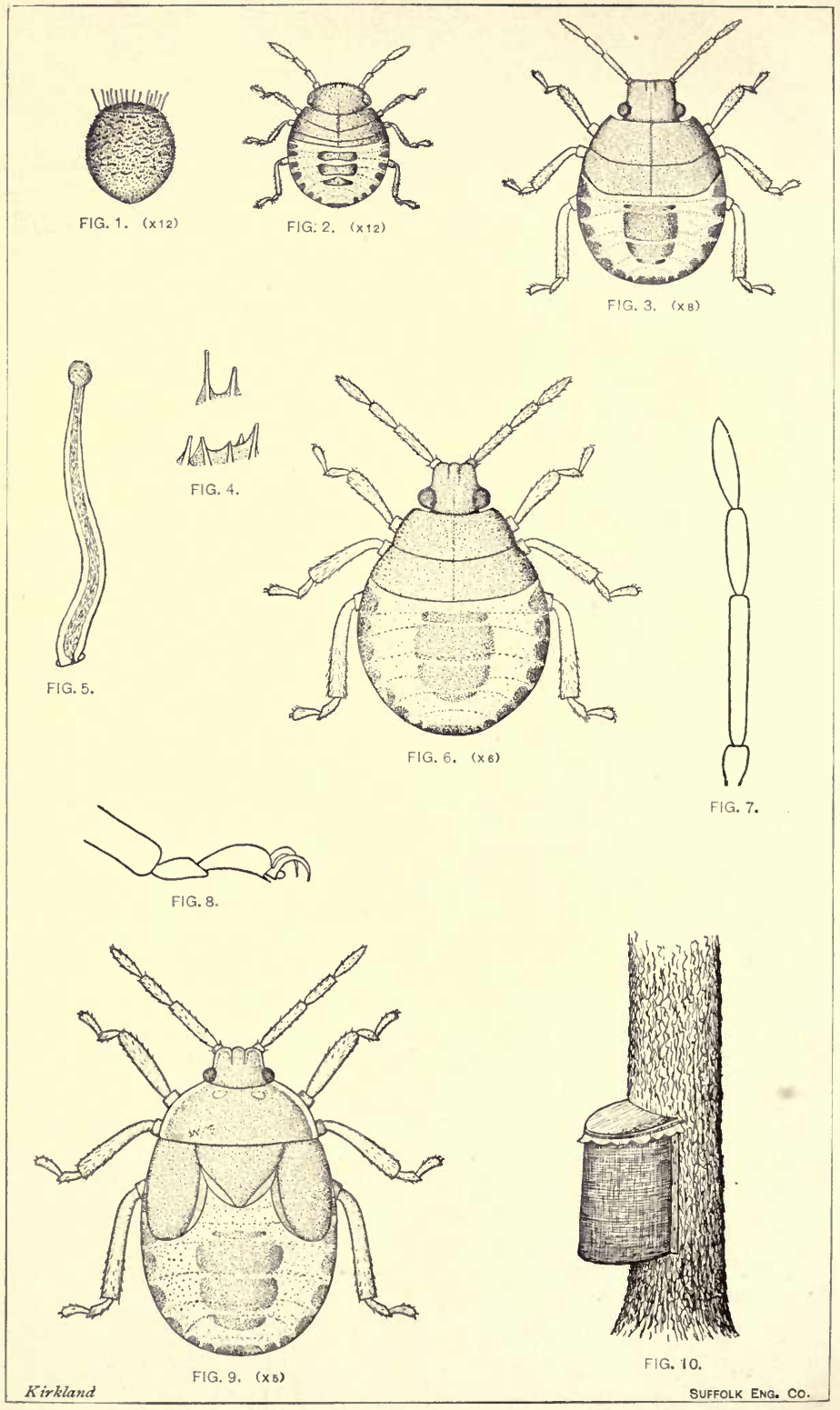




\title{
EXPLANATION OF Plate 61.
}

\author{
Drawn by A. H. KIRKLAND.
}

Podisus serieventris Uhl.

I. Egg.

2. Newly hatched nymph.

3. Nymph after first molt.

4. Spiny armor on surface of egg, greatly enlarged.

5. Curved spine from upper part of egg, greatly enlarged.

6. Nymph after second molt.

7. Antenna of nymph.

8. Tarsus of nymph.

9. Nymph after third molt.

ro. Out-door cage used in rearing this species. 
upon other insects. The first stumbling block met with, in attempting to raise these insects, was the provision of a suitable breeding-cage, and many attempts made, both during 1894 and 1895 , to breed them in confinement in boxes, jars, etc., gave only negative results. With the establishment of an insectary at Malden and increased facilities for out-door experimentation, in June, 1895, other attempts were made to construct a cage in which one might rear these insects under the nearest possible approach to natural conditions. After several experiments a breeding-cage was devised which gave the desired result (Plate 61, Fig. 10). This consists of a fine wire gauze, semi-ellipse, fastened tightly at the sides to a small tree trunk, and closed at the bottom by a tight-fitting wooden base, the cage, on the whole, being quite similar to those used in rearing the predaceous beetles. The top is covered by a piece of cloth, held firmly in place by a rubber band, while a small wooden hoop is placed around the inside of the top of the cage, in order to prevent the band from pulling the cage out of shape. The cages used are twelve inches in height by four inches in width, the maximum distance of the outer part from the tree being five inches. In cages like the one described the bugs were fed on Lepidopterous larvæ and reared through their different stages. For many careful notes on the feeding habits of these insects I am indebted to Mr. H. L. Frost, who assisted me in the work. In these cages we were able to successfully carry specimens of $P$. serieventris through all their transformations.

\section{Life History of $P$. serieventris $U h l$.}

The Egg. - The eggs have been found deposited in small clusters on the bark of trees, on leaves and on the burlap bands. When first laid they are of a glistening, whitishgray color, but this soon changes to a bronze, which grows darker as the embryo develops, up to within about a day previous to hatching. At that time the eggs grow lighter in color, possibly due to the entrance of air into the shell. Each egg-cluster contains from ten to thirty eggs, two or three clusters being laid by each female. The eggs (Plate 
61, Fig. 1) are ovoid, .9 mm. in length and .8 mm. in width. The smaller end of the egg is attached to the surface on which the cluster is deposited. At the top of the egg is a well-defined circular cap. The greater part of the surface of the egg is covered by irregular rows of minute short spines (Plate 61, Fig. 4), nearly absent at the base of the egg, while around the circumference of the cap is a row of long, slightly curved capitate spines (Plate 61, Fig. 5 ), arranged in a circle. The eggs hatch in about eight days. Four lots of eggs kept at the insectary hatched in seven, eight, eight and nine days respectively. In hatching, the circular disk at the top of the egg is pushed back, but usually remains attached at one point.

First Stage. - The newly hatched bug (Plate 61, Fig. 2) is $1.5 \mathrm{~mm}$. in length. Form, ovate, head, thorax and abdomen distinctly separated. Head smooth, broadly elliptical, wider than long, of a deep copper color, and sparsely clothed with short, pale-brown hairs; eyes large, projecting laterally. Antennæ $1 \mathrm{~mm}$. long, four-jointed, of the same color as the head, but lighter at the joints, and clothed with a few hairs. The basal joint is stout, slightly curved outward; the second and third joints are of the same length as the basal, and each is enlarged at its outer end, which is quite sharply truncate. The fourth joint is from one-fourth to one-third longer and wider than the other joints, being quite broadly dilated. The thorax is of the same color as the head, and widened posteriorly. A faint sulcus, indicated. by a narrow line, extends from the centre of the head down the dorsal line of the thorax to the abdominal segments. Abdomen yellowish red, varying to vermilion. On the dorsum of the abdomen are three large, dark, bronze-colored spots, exteriding transversely, and separated by a narrow line of the body color. A short, narrow line of the same color as the spots sometimes occurs in front of the anterior $\mathrm{s}_{1}^{n}$ ot, and also immediately behind the posterior one. Around the lateral margin of the abdomen on each side is a row of semi-elliptical bronze-colored spots. Just anterior to the first of these spots is a narrow, wedge-shaped marking of the same color, while at the extreme posterior 
end of the abdomen is a larger horizontal spot, which covers the anal segments and often connects the two posterior lateral spots. The under surface of the body is yellowish red, darkest on the abdominal segments. The lateral row of semi-elliptical spots, similar to those upon the upper surface, extends around the entire margin of the abdomen. Beak stout, four-jointed. Both beak and legs are of a dark copper color. Tarsi two-jointed; claws simple, two in number, light brown, each with a darker pulvillus; legs sparsely clothed with pale-brown hairs.

The first molt takes place in about four days from the time of hatching, and is accompanied by a marked increase in size.

Second Stage. - The second stage of this insect is represented on Plate 61, Fig. 3. Length, $3.5 \mathrm{~mm}$.; body a little longer in proportion to the width than in the first stage; head quadrangular, with two faint sulci, extending backward from the anterior margin for about one-third of the length of the head. Eyes prominent. Basal joint of antennæe short and stout; second joint cylindrical, truncate at the end, twice as long as the basal joint; third joint slightly longer than basal joint, and somewhat rounded at the outer end; fourth joint appressed at each end, and of nearly the same length as the second joint. The thorax is slightly serrate around the outer margin, and its outer angles project by the base of the head for a short distance. The color of the head and thorax is dark seal brown, varying to a pitchy black. Abdomen of the same color as in the preceding stage, but with four horizontal spots instead of three, the second and third spots being much larger than the first and fourth. Lateral spots as in the first stage. The under surface of the head and thorax is marked with dark brown, that of the abdomen being the same color as in the preceding stage. Beak and legs dark brown, lighter on the tarsi.

The second molt, with an accompanying increase in size, takes place from eight to ten days after the first molt.

Third Stage. - The third stage is represented by Plate 61, Fig. 6. Length of body, $6 \mathrm{~mm}$.; form somewhat ovate, narrowest in front. The head is narrowed from that of the 
preceding stage, and the eyes are very prominent. Antennæ as in the second stage. The outer anterior angles of the head are rounded, as well as that part of the anterior margin included between the two sulci; the latter extend backward about one-third the length of the head. The outer margin of the thorax is serrated, as in the preceding stage. The color of the body in this stage is subject to great variation, but brown or black predominates upon the head and thorax and some shade of red upon the abdomen. Usually the head and thorax are margined with a narrow, pale-yellowish-white line, while four small spots of pale-yellowish brown occur on opposite sides of the dorsal line of the pro-thorax, and two spots of the same color on each side of the dorsal line of the meso-thorax. The abdomen bears the same markings as in the preceding stages, but the ground color varies to a considerable degree. From each side of each dark marginal spot a creamy-white line extends in towards the large dorsal spots. In some cases these lines are very wide, and give to the abdomen a very light and somewhat striped appearance ; in other cases they are nearly obscured by the red ground color. The beak, legs and under surface of the body are marked the same as in the second stage. As the nymph of the third stage approaches the molting period, the outlines of the scutellum and wing pads become somewhat apparent.

The third molt occurs from five to six days after the preceding one.

Fourth Stage. - This stage is shown on Plate 61, Fig. 9. Length of body, $8.5 \mathrm{~mm}$. General form of body, aside from head, nearly elliptical, slightly widened posteriorly. Head with two deep sulci, and closely appressed to the anterior margin of the thorax. Antennæ as in the preceding stage, the second joint much the longest. The yellow marginal band of the head and thorax is wider than in the third stage, otherwise the colors of the upper surface of the body are the same as those of the third stage. The under surface of the body sometimes varies to a brownish tint, but in general it is like that of the preceding stage. The color of the legs and beak is not changed from that of the third stage. The wing pads and scutellum appear in this stage. Nymphs in 
the fourth stage show great rapacity, and a corresponding growth is made.

The fourth and last molt takes place in from twelve to seventeen days from the third molt, and the insect attains the imago form.

Fifth Stage, or Imago. - The following is Professor Uhler's original description of this species, taken from "Proceedings of the Boston Society of Natural History," page 94, Vol. XIV., 1870 :-

“P. serieventris, n. sp. Similiar to $P$. modestus Dallas, but of a more blackish-gray color. Pronotum, sides less deeply sinuated, the humeral angles not so prominent, obtusely triangular, blackish; the surface less regularly punctured, those each side anteriorly and in the corners finer, confluent, presenting the appearance of four blackish spots, the middle surface somewhat bald, yellow. Seapus and basal joint of the antennæ blackish outwardly. Scutellum punctured with black, the punctures at the base aggregated in a large patch, the basal angles with a large, smooth, whitish spot, the tip smooth, white. Pectus remotely punctured with fuscous, the impressed portion of the propleura, the middle of the mesopleura and exterior part of the metapleura with a large patch of black, confluent punctures, the exterior margin smooth; exterior end of the osteolar duct black, the sulcus broad, not reaching to the tip. Legs pale orange yellow, the femora pointed with black, the dots more or less aggregated beyond the middle. Corium less coarsely punctured, the punctures fuscous or rufous; those of the costal area coarser, the finer ones aggregated in small patches; the surface adjoining the inner surface and tip of the medium suture smooth, with a more or less embrowned spot before the tip; embolium yellow, with a fuscous spot at base; the membrane tinged with brown; the basal margin, nervures basally, and a broad, longitudinal streak running to the tip, blackish. Tergum with large clouded spots each side and behind; connexivum bright yellow above, with a quadrangular black spot at the base and apex of each segment, on the under side having a corresponding series of spots which are sometimes reduced to mere dots. Venter punctured 
with rufous and black, the latter arranged each side in a longitudinal series of patches; interior to these is a row of blackspots, and upon the middle line four round spots, with the largest one at the posterior end.

" Length to tip of abdomen, 9 millims. Humeral width, 5 millims.

“ No. 40, Harris Collection § · ' Cambridge, Mass., April 20, 1827.'

"The specimens vary very much in depth of cclor and in the size and distinetness of the markings.

"In my own collection are specimens from Maine and Minnesota. A female from Massachusetts is twelve millims. in length."

In the imago state the antennæ and tarsi (Plate 62, Figs. 4 and 5) are increased by an additional joint, and become respectively five and three jointed. The imago varies in color from a blackish gray to a light brownish gray, though none of the specimens so far taken or reared are of as light color as P. modestus Dall. The males (Plate 62, Fig. 1), as a rule, are slightly smaller than the females (Plate 62, Fig. 2), and their humeral angles are somewhat sharper, more nearly approaching those of $P$. spinosus Dall.

For the identification of the specinens reared at the insectary I am indebted to the courtesy of Prof. P. R. Uhler.

The following extract from notes upon an individual of the third brood, reared from eggs laid Aug. 14, 1895, will serve to illustrate the life history of a single generation: Predaceous bug, No. 142, Podisus serieventris Uhl.

Hatched August 22; the first molt occurred August 26. Up to this date the bug had been fed upon the remains of four climbing cut-worms (Noctua c-nigrum). The second molt took place September 3. Between the first and second molt it killed four larvæ of Noctua c-nigrum and two larvæ of Rhynchagrotis alternata. The bug molted for the third time September 8, having killed in the mean time two fullgrown caterpillars of Vanessa antiopa and two of Anisota senatoria. The fourth molt occurred September 21. Between the third and fourth molt it had killed eight fullgrown caterpillars of Vanessa antiopa, two larvæ of Ani- 



\section{EXPLANATION OF PLATE 62.}

Drawn by A. H. Kirkland.

Podisus serieventris Uhl.

I. Male imago.

2. Female imago.

3. Rostrum of imago.
4. Antenna of imago.

5. Tarsus of imago.

6. Wings of imago. 


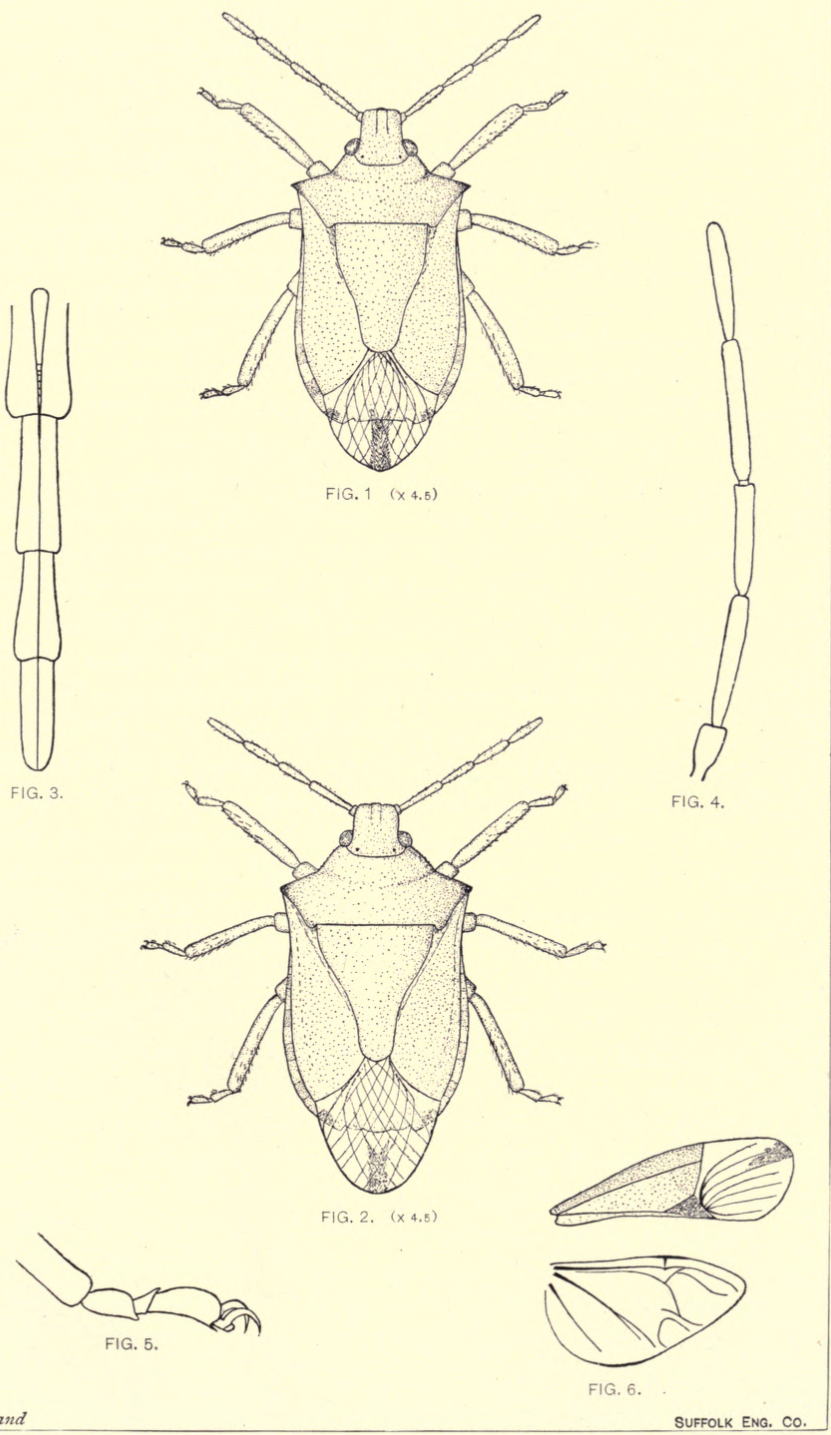



sota senatoria and one partly grown larva of Telea polyphemus. In the imago stage the insect (female) killed five larvæ of Anisota senatoria. It was placed with a male September 25, and mated September 30. On October 12, it was found partly hidden under some loose bark and leaves which had been placed in the bottom of the breeding-cage, and at the present writing (Jan. 1, 1896) it is still alive, and hibernating without having deposited its eggs.

Feeding Habits. - In attacking a full-grown larva the bug apparently first makes a preliminary investigation, and, with antennæe elevated, carefully inspects the caterpillar on all sides. After sidling around for some time, the point of attack is selected, usually the softer integument at the annulations of the body, the beak (Plate 62, Fig. 3) is swung down and out, projected horizontally forward and inserted in the side of the larva. Its entrance is at first unnoticed by the caterpillar, but after a few minutes a vigorous struggle ensues, which sometimes, but rarely, results in the bug being obliged to release its hold. In a short time the caterpillar grows weaker, apparently becomes stupefied, and the bug, after inserting its beak in new places, till the greater part of the body fluids have been extracted, finally leaves the dead, empty and flaccid larva hanging to the tree. The time consumed in feeding on a full-grown gypsy moth caterpillar varies from ten minutes to two or three hours, the bug as a rule feeding longest upon the thoracic segments.

The newly hatched bug seems to be unable to cope with large caterpillars, and I am led to believe that under natural conditions their early food is small larvæ. On June 10, 1895, at Winthrop, Mass., I found twelve nymphs of $P$. serieventris, of the first and second stage, feeding upon small, dark beetle larvæ, which were abundant upon leaves of Plantago major. In the breeding cage the young nymphs were first fed upon the remains of soft-skinned larvæ, such as Rhynchagrotis alternata and Noctua c-nigrum, the caterpillars being cut up into small bits before feeding them to the bugs. It was necessary to place the young bugs in close proximity to the food thus provided, and for this purpose a 
small camel's-hair brush was found to be of great assistance. After passing the first molt the nymphs were able to care for themselves, and would boldly attack full-grown cutworms, of the species mentioned, when the latter were placed in the cages. With increasing age and size they fed readily upon hairy larvæ ( $P$. dispar, Tolype velleda, et al.). The period of greatest rapacity and of greatest growth is between the third and fourth molt, during which time the nymph feeds almost continuously.

This insect has been taken in the field attacking all stages of the gypsy moth. Individuals in the first stage were this year found feeding upon the eggs of the gypsy moth, but when confined to this food died at the end of a few days. It is not an uncommon thing for them to attack a pupa, and on one occasion I found four nymphs in the second and third stages feeding upon a single female pupa. Female gypsy moths while depositing their egg-clusters, and males while mating, are also occasionally attacked by this insect.

This species has been found feeding upon the larvæ of Vanessa antiopa, Hyphantria cunea, Orgyia leucostigma, Attacus promethea, Clisiocampa americana and disstria and Paleacrita vernata. It has also been known to devour the dead imagoes of Limenitis ursula and Pyrophila pyramidoides. In confinement it readily attacks the larvæ of Datana ministra, Attacus cecropia, Telea polyphemus, Anisota senatoria, Dryocampa rubicunda, Tolype velleda, Rhynchagrotis alternata, Noctua c-nigrum and Cimbex americana.

When pressed by hunger these insects develop cannibal tendencies and feed upon other individuals of the same species, and also occasionally attack Podisus cynicus and Menecles insertus, while the two latter species have in turn been found feeding upon $P$. serieventris. I have seen $P$. serieventris feeding in confinement upon leaves of Quercus mubra, but I think it very doubtful if it is phyllophagous to any marked degree.

Mating - Polygamy - Oviposition. - Mating takes place in from three to six days from the time the insect reaches 
the imago state. The time required for the process' of mating varies from twelve to forty-eight hours.

That the males of this species are polygamous is evident from the fact that one male confined in a breeding cage at the insectary successfully fertilized three females. With the exception of the females of the last brood, oviposition takes place in from eight hours to two or three days from the time of mating. The female deposits a cluster of from ten to thirty eggs, then rests and feeds for a few hours, but later resumes the work of egg-laying. In this way some three or four clusters of eggs are deposited, the whole process of egg-laying usually taking from one to four days.

Hibernation. - That the insect hibernates in the imago state seems to be an assured fact, since specimens of the last brood reared at the insectary, and left in the breeding eages out of doors, are alive at the time of this writing (Jan. 1, 1896). The imagoes of the last brood mate soon after reaching the mature form, and the fertilized females feed at intervals for a week or two ; but with the advent of cooler weather seek hibernating quarters, such as the crevices in the rough bark of trees, under burlap bands, etc., or even under the dead leaves upon the ground, sometimes burying themselves one or two inches beneath the surface. All of the males reared during the past year died without attempting to hibernate.

Number of Annual Broods. During the summer of 1895, imagoes of this species were more or less abundant about the last of June and the middle of August, and in fewer numbers from the middle to the last of September, although individuals were taken throughout the summer. Nymphs were found in considerable numbers at such intervals, subsequent to the appearance of the imagoes, as would lead one to believe that they were distinct broods. I have reared two broods of this species between the last of June and the latter part of September; and this, in connection with the facts that young nymphs have been found in early June, and that the fertilized female imagoes of the last brood hibernate, would seem to be nearly conclusive evidence that the species is three-brooded in this region. 


\section{Spiders.}

At occasional intervals during the past four years, spiders have been seen to attack and destroy the eggs, and also the eaterpillars and imagoes, of $P$. dispar. In the summer of 1895, a predaceous spider, found in Chelsea, was brought into the insectary and supplied with gypsy moth caterpillars, which it readily destroyed. This spider was kindly determined by Mr. J. H. Emerton as Phidippus tripunctatus.

Our common harvest spider (Phalangium dorsatum) was found by Mr. Mosher feeding on a male gypsy moth.

Mites have been found so frequently destroying the eggs that we must acknowledge that in some localities they are very important factors in reducing the numbers of the gypsy moth. Mr. E. P. Felt observed the work of these mites on the gypsy moth eggs in confinement, and found that they destroyed the eggs very rapidly. They are most abundant in the fall, but do not feed to any marked degree during the winter. These mites were referred to Prof. Herbert Osborn, who determined them as two different species. The first was Nothrus, near ovivorus Pack. (Plate 53, Fig. 14), and the other was Trombidium bulbipes Pack. (Plate 53, Fig. 15). A species of Phloothrips (Plate 63, Fig. 13) was also found destroying the eggs.

\section{Insectivorous Vertebrates.}

Of the vertebrate enemies of the gypsy moth, the common skunk, Mephitis mephitica (Shaw), has been found feeding upon the female moths which were laying their eggs at the base of trees, or upon rocks, rubbish, etc. It is probable that these animals also feed upon the pupæ to some extent in badly infested regions.

The wood frog (Rana sitvatica LeC.) has been reported in one instance as attacking the female moths. In August, 1895, Mr. F. H. Mosher took a specimen of the tree frog (Hyla pickeringii Holbr.), feeding upon the caterpillars of the second brood of the gypsy moth, at Woburn.

The common garden toad (Bufo lentiginosus americanus LeC.) was this year found by Mr. Kirkland to be devouring 
great numbers of the caterpillars in infested brushlands. Stomach examinations of three toads, taken in such a place, June 6, 1895, showed them to contain respectively seven, fifteen and sixty-five gypsy moth caterpillars, or remains of the same.

Mr. Samuel Henshaw published a report upon the gypsy moth in Massachusetts, in Bulletin No. 26, United States Department of Agriculture, Division of Entomology, page 75 , in which he gives the following list of invertebrates that destroy the larvæ of the gypsy moth: Cicindela 6-guttata, Camponotus herculaneus, Sinea diadema, and undetermined Syrphus, and Chrysopa, Lithobius forficatus; also the following spiders : Epeira strix, Steatoda borealis, Lycosa sp., Drassus sp., Agalena novia, Phidippus galathea (mystaceus), Epiblemum scenicum, Marptusa familiaris and Thomixus sp.

Mr. Henshaw's letter of submittal is dated "Cambridge, Mass., Dec. 7, 1891," and therefore his observations were probably made during the summer of 1891 .

\section{Vegetable Parasites.}

A very careful watch has been kept for any indication of vegetable parasites, either fungi or microbes, and nothing has thus far been discovered. We consulted with Drs. Farlow and Thaxter of Harvard University, both eminent authorities on the subject, and, after describing to them the habits of the insect, neither of these gentlemen gave us encouragement that vegetable parasites would prove to be a very important factor in the destruction of the gypsy moth; yet, in wet seasons, where the caterpillars were very abundant, the parasitic fungi, if any could be found to attack this species, might prove more or less serviceable.

The caterpillars of the nun moth (Lymantria monacha), in Europe, when very abundant, are often attacked by an epidemic or contagious disease known as the top or head sickness (Wipfelkrankheit), a very good account of which has been given. by Wachtl and Kornauth in their " Beitrage zur Kenntniss der Morphologie, etc., der Nonne,” page 17. Drs. Tangl, Scheuerlen, Hofmann, Tubeuf and Jäger have 
made careful investigations of this disease, but have had very little success in inoculating healthy caterpillars with cultures made from those which were diseased.

\section{Importing Parasites.}

No attempt has been made to import parasites thus far, for the reason that the law requires the work to be conducted with direct reference to the extermination of the gypsy moth, and, therefore, the general destruction of the insect would also destroy the parasites. There is no reason why our native Hymenopterous parasites may not prove quite as effective as those of any other country, since there is no parasite known which confines itself exclusively to the gypsy moth, and, as has been shown, we have several species which attack it as readily as any in its native country.

\section{INSECTARY.}

In the early part of the work on the gypsy moth, the more difficult and important experiments and observations were conducted in the insectary at Amherst; but it seemed desirable, and even necessary, to repeat many of the experiments on a far more extensive scale than was possible at that place, and it was therefore decided to fit up and equip a room for this purpose, in the store-house on Commercial Street, Malden. This building stands on piles, about six feet from the ground, which is swampy and wet. The front of the building is on a level with the street, which is built up to the grade indicated.

In the room thus fitted up many experiments were conducted, a large number of which gave very satisfactory results. But in the experiments on insecticides, where a check series was conducted, with no poisons used on the food, the mortality was often so great that we felt very uncertain about the results in the cages where the caterpillars were fed on leaves sprayed with insecticides, whether they died from the effects of the poison, or because of the unhealthful surroundings.

In the early part of the summer of 1895, a small lot of land, in the edge of the woodland in the suburbs of Malden, 


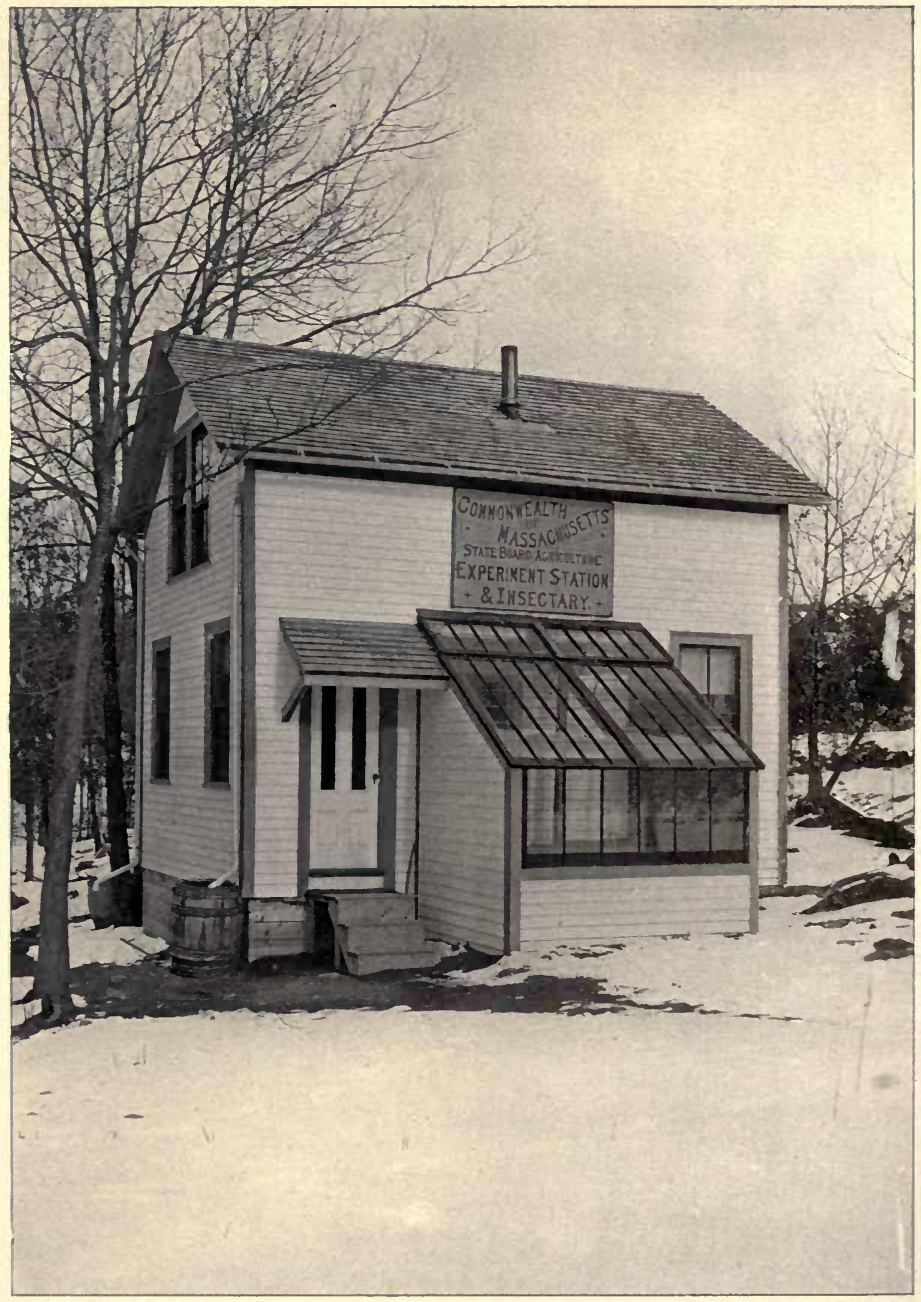

PLATE 63. Experiment station and insectary, Malden, Mass. 
was leased, and an insectary was erected for experimental purposes. This building (Plate 63) is sixteen by twenty feet on the ground, with a greenhouse on the south side, six by eight feet, and a covered shed on the north side, seven by eight feet. It contains, on the first floor, besides the main laboratory with tables, closets, etc., a private laboratory and a chemical room. The second floor contains a lodging-room for the employees.

The experimental work carried on in this building, during the summer of 1895 , has proved far more satisfactory than that in the building on Commercial Street, because of the greater conveniences and more healthful conditions.

\section{INSECTICIDES.}

Experiments with Substances for destroying Eggs.

The value of egg-destruction, as an exterminative measure, was recognized at an early stage in the work of combating the gypsy moth, and led to an extensive study of substances which might be advantageously used for this purpose. The requisites necessary in such a substance are : that it shall be effective wherever applied; that it shall leave a permanent stain or color, enabling one to distinguish treated from untreated egg-masses; and that its price shall be within practical limits. The substances found to be of the greatest value, together with an explanation of the method of applying them, have already been described in Part I.

During the year 1892, Mr. F. C. Moulton experimented with the following substances on the eggs of the gypsy moths, to discover something that could be readily applied to the egg-clusters and effectually destroy them. To some of the preparations were added substances which contain no destructive power, but were used simply to change the color of the egg-clusters on trees, so that those which had been treated might be readily distinguished from the others.

Ammonia. - January 21. Five egg-clusters were treated for five minutes with ammonia gas, made by heating strong aqua-ammonia. Apparently the eggs were not affected, for, by March 24, nearly all had hatched. 
Benzine. - January 22. A small amount of benzine was poured upon an egg-cluster and then allowed to evaporate. Apparently the eggs were not affected, for by March 24, about three-tenths of them had hatched. Nearly five-tenths of the caterpillars died while hatching.

Bromine. - January 19. Five egg-clusters were placed in a box and a small amount of liquid bromine turned on them. At the end of fifteen minutes they were entirely destroyed.

Bromine Vapor. - January 19. Five egg-clusters were submitted to the action of bromine vapor in a closed box for ten minutes. At the end of this time the eggs were destroyed. Another experiment on the same date, in which the eggs were exposed for fifteen minutes, gave similar results. From egg-clusters treated, on the same date, with bromine vapors for a period of ten minutes, the vapor not being closely confined, a few caterpillars hatched. Four caterpillars hatched from other egg-masses treated in the same manner.

Chlorine. - January 15. One egg-cluster was submitted for five minutes to the action of chlorine gas, made by adding ten parts (by weight) of hydrochloric acid to eight parts of black oxide of manganese, and then applying a strong heat to the mixture. The egg-cluster was bleached and the eggs destroyed. Four other experiments, in which egg-clusters were exposed to the action of chlorine for seven, ten, fifteen and thirty minutes respectively, gave similar results. March 12. Some chloride of lime was put into a flask and sulphuric acid added to it. The chlorine was then conducted into a bottle containing gypsy moth egg-clusters. It entirely destroyed the eggs, with but one exception. January 19. Five egg-clusters were treated with chlorine under a hood made of oil-cloth stretched over a frame, but, as the oil-cloth was not large enough to entirely cover it, a part of the gas escaped. One egg-cluster was bleached, while the others were apparently not affected; about one-third of the eggs hatched the following spring.

Carbon Bi-sulphide. - January 19. Five egg-clusters were submitted to the action of hot vapors of carbon bi-sul- 
phide for five minutes. The carbon bi-sulphide was put into a flask and slightly heated, the vapors passing over a bottle containing the egg-clusters, condensing and wetting them, which caused the eggs to become white and soft, after which they all dried up. Two lots of eggs exposed to the vapors of carbon bi-sulphide, in a similar manner, for ten and fifteen minutes respectively, were completely destroyed. January 19. Fire egg-clusters, placed in a tin box covered with paper, were treated for fifteen minutes with carbon bisulphide, which caused them to grow white and soft, thus destroying them. January 21. Five egg-clusters were treated with cold vapors of carbon bi-sulphide for fifteen minutes, eare being taken that the vapors should not wet the egg-clusters. The eggs apparently were not affected, and, by the 24th of March, about one-half of them had hatched. January 25. Five egg-clusters were treated for fifteen minutes to the action of cold vapors of carbon bi-sulphide. The eggs were placed in a glass, which was put in a large tin box containing carbon bi-sulphide. The eggs were not affected by this treatment, and, by the 24th of March, all had hatched. February 9. A number of eggclusters were treated in the same manner as in the preceding experiment, and, although the eggs did not appear to be affected, none hatched.

Calcic Chloride. - January 21. One egg-cluster was soaked for half a day in a solution of calcic chloride, made by dissolving one-eighth ounce of calcic chloride in two cubic centimeters of water. The solution did not penetrate the egg-cluster, and nearly all the eggs hatched.

Corrosive Sublimate. - February 1. A few crystals of corrosive sublimate were dissolved in alcohol, and the solution poured over five egg-clusters. March 22, some of the eggs had partly hatched, but the caterpillars soon died. February 1. Five egg-clusters were treated in the same manner as in the preceding experiment. Two or three caterpillars hatched and others came partly out of the shell, but, March 22, all were dead. Three other lots of eggs were treated in the same manner, March 3. None of these eggs hatched. 
Creosote Oil. - March 14. A small amount of creosote oil was dropped upon five egg-clusters, and, although it did not appear to injure the eggs, none of them hatched. March 31. A nixture of creosote oil and pine tar, fifty per cent. of each, was dropped upon some egg-clusters. It penetrated them at once, and, later, shrivelled the eggs so that none hatched. March 31. Another lot of egg-clusters was treated in the same manner, and the eggs destroyed. Two experiments with a mixture of creosote oil, fifty per cent., and turpentine, fifty per cent., gave results like those of the preceding experiments. April 7. About eight thousand eggs were saturated with a solution of pine creosote oil, forty-five per cent., turpentine, forty-five per cent., and coal tar, ten per cent. It penetrated the egg-clusters readily, and attacked the eggs so that none hatched.

Coal Tar.-March 5. A mixture of coal tar, thirty per cent., phenol, forty per cent., and turpentine, thirty per cent., was dropped upon ten egg-clusters. It quickly penetrated the eggs, turning them black and softening the shell so that none hatched. Several other experiments with similar tar mixtures gave equally as satisfactory results.

Eagle Mills Powder. - March 11. A mixture of Eagle Mills Powder, fifty per cent., and turpentine, fifty per cent., was dropped upon ten egg-clusters, but the mixture was too thick to penetrate. March 11. A solution of Eagle Mills Powder, ten per cent., water, sixty per cent., and alcohol, thirty per cent., was dropped on some egg-clusters, and quickly penetrated to the bottom. This did not injure the eggs, for, by April 12, nearly all had hatched.

Hydrocyanic Acid Gas. - January 11. One egg-cluster was submitted to the action of pure concentrated hydrocyanic gas, in the following apparatus: A Florence flask, containing one-half an ounce of potassium cyanide and about twenty cubic centimeters of water, was connected with a wide-mouthed bottle by a tube bent twice at right angles. The bottle also contained an escape tube. An unbroken egg-cluster was placed in the bottle, then sulphuric acid was added to the potassium cyanide in the flask. The hydrocyanic acid gas passed over into the bottle, driving the air 
out through the delivery tube. After the air was all out, the delivery tube was stopped by a cork; and, as the action was still going on, the gas in the apparatus was under pressure and remained so for thirty minutes, when the eggcluster was removed. No change could be detected, either with the naked eye or by use of the microscope, and, by March 24, about one-half of the eggs had hatched. On the same date, nine other egg-clusters were treated in the same manner, using the same apparatus under the same conditions. An examination of the eggs failed to show any change. These eggs hatched February 6. January 12. Five egg-clusters were treated with hydrocyanic acid gas, for thirty minutes, under a hood made by spreading oilcloth over three bottles. The edge of the cloth came down to the table, but not close enough to exclude the air, as there were numerous crevices under the cloth. The density of hydrocyanic acid gas, being .706 , causes it to rise. The egg-clusters were placed on a small card-boárd stand which reached nearly to the top of the hood, which was punctured several times, so that the gas might readily pass through. Forty cubic centimeters of sulphuric acid were then added to one-half ounce of potassic cyanide, the gas being passed under the hood. No change was visible in the eggs after this treatment, and nearly all of them hatched. January 12. Five egg-clusters were treated with hydrocyanic acid gas, under a hood made of wet unbleached cotton, the cloth being drawn closely to the table and weighted down, so that no air could pass under the hood; with this exception, the process and conditions were the same as in the preceding experiment. Nearly all of the eggs hatched after being subjected to this treatment. January 12. Ten egg-clusters were treated with pure, concentrated hydrocyanic acid gas for one hour. The apparatus consisted of three four-ounce Florence flasks, marked A, B and C. Flask A contained about one-half an ounce of potassic cyanide, B contained concentrated sulphuric acid, and $\mathrm{C}$ the ten egg-clusters. A was connected with $\mathrm{B}$ by means of a tube which dipped below the surface of the sulphuric acid in $\mathrm{B}$. The escape tube from $\mathrm{B}$ passed through the stopper of C. There was 
also a small escape tube for the air to pass out. Sulphuric acid was added to the potassic cyanide in flask $A$, and the hydrocyanic acid gas passed through the sulphuric acid in $\mathrm{B}$, which thoroughly dried it; it then passed out into $\mathrm{C}$. After the air had all passed out of $\mathrm{C}$, the escape tube was stopped. The gas was generated for an hour, after which time an examination of the eggs showed no change, and nearly all of them subsequently hatched. A duplicate experiment gave similar results. January 13. Five eggclusters were treated with pure, concentrated hydrocyanic acid gas for one hour and a half. None of the eggs hatched. January 13. Five egg-clusters were treated for two hours with hydrocyanic acid gas under a hood. An examination of the eggs, made January 14, showed them to be slightly dried, but, by March 24, about eight-tenths of the eggs had hatched. January 15. Five egg-clusters were treated with hydrocyanic acid gas for fifteen minutes. The eggs did not appear to be affected, although none of them hatched.

Hydrogen Arsenide. - April 7. Five egg-clusters were treated for fifteen minutes with hydrogen arsenide, made by pouring a solution of arsenic into a mixture of granulated zinc and hydrochloric acid. None of these eggs hatched. November 5. A number of egg-clusters were treated for one hour with hydrogen arsenide. None of the eggs hatched. February 6. About twenty-five broken egg-clusters were treated with hydrogen arsenide for forty-five minutes. The gas was made as follows: A solution of arsenic was poured into a mixture of hydrochloric acid and zinc. The gas which was given off was dried by passing through a $U$ tube containing calcium ehloride, then into the bottle containing the eggs. None hatched. Several other experiments with this gas gave similar results.

Hydrogen Sulphide. - April 7. Some egg-clusters were submitted to the action of hydrogen sulphide for ten minutes. At the end of this time the eggs were shrivelled and none hatched. January 30. Several egg-clusters were treated for one hour with hydrogen sulphide gas, which was made by adding dilute sulphuric acid to iron sulphide. It was passed through a $\mathbf{U}$ tube and then into a bottle con- 


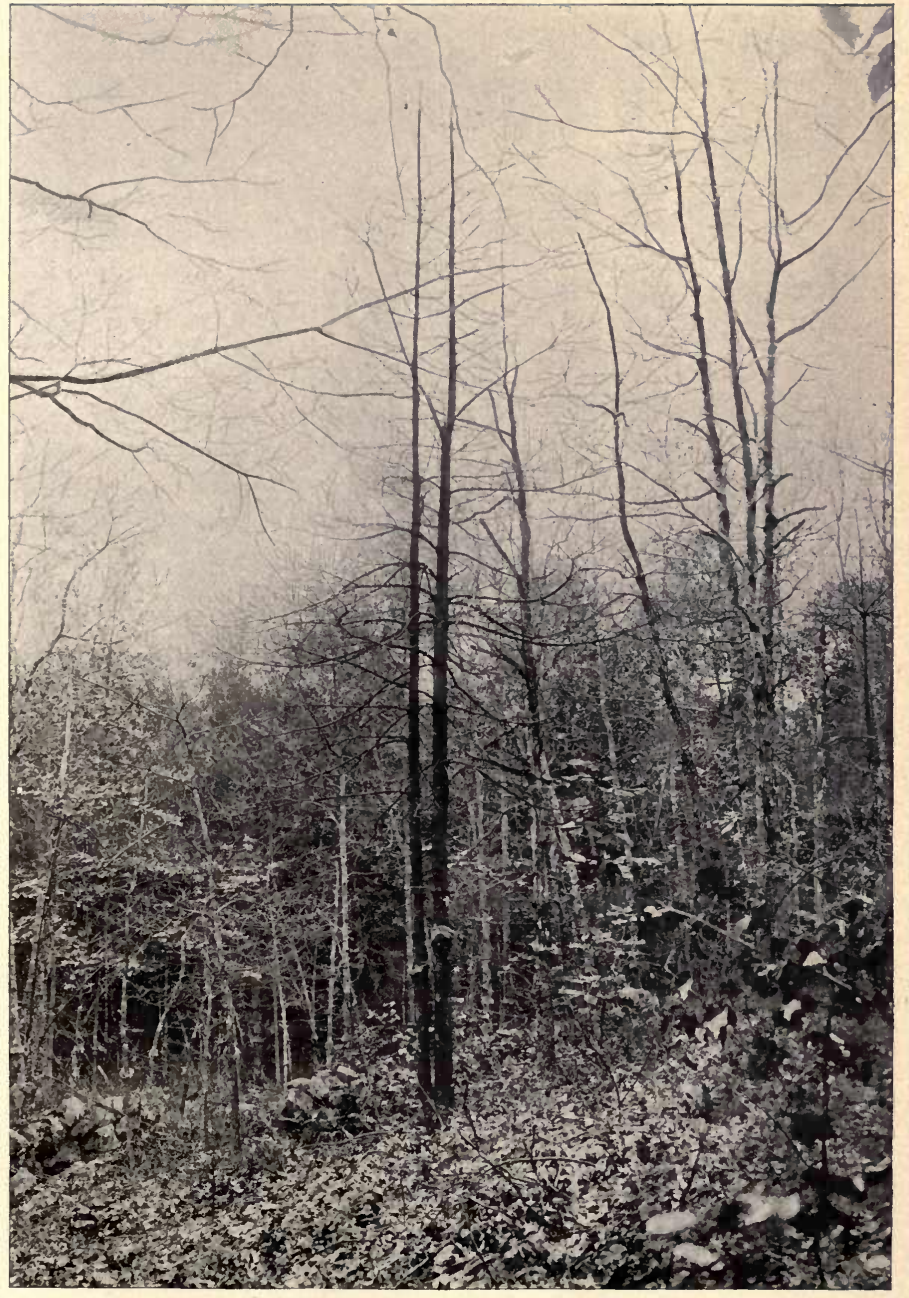

PLATE 64. Pine and other trees attacked by the gypsy moth caterpillars at Lexington. 
taining the egg-clusters. None hatched. February 3. Ten egg-clusters were treated with hydrogen sulphide for one hour. None hatched. April 12. Some broken egg-clusters were treated, in an open bottle, for two hours, with hydrogen sulphide. None of them hatched.

Hydrochloric Acid Gas._- March 31. Some egg-clusters were submitted for fifteen minutes to the action of hydrochloric acid gas, formed by adding sulphuric acid to salt. This destroyed the eggs by drying them up. Several eggclusters were submitted to the action of hydrochloric acid gas for thirty minutes. None hatched.

"Infernal" Mixture. - February 17. A number of new egg-clusters were treated with a gas made by adding fifty per cent. of sulphuric acid to fifty per cent of turpentine. They were left exposed to the action of the gas over night, which destroyed them so that none hatched. February 19. Five egg-clusters were treated for two hours with this gas. The eggs were bleached a little, and none hatched. February 22. Five egg-clusters were subjected for five hours to the action of the above-mentioned gas. The eggs were stained red, and shrivelled so that none hatched. February 22. Five egg-clusters were submitted for ten hours to the action of this gas, which entirely destroyed the eggs. Eggs exposed to the action of this gas on February 19, for a period of thirty minutes, were uninjured, and hatched on March 24.

Nitrogen Dioxide. - March 31. Several egg-clusters were submitted to nitrogen dioxide for fifteen minutes. The gas was formed by adding sulphuric acid to salt and nitre. The eggs were entirely destroyed. April 1. A number of egg-clusters were submitted for five minutes to the action of nitrogen dioxide. The eggs were entirely destroyed. August 24. Eggs were treated with nitrous dioxide in a hollow tree. The gas was generated as in the preceding experiments. After this treatment the eggs were taken into a warm room, where they began to hatch on February 31.

Potassic Cyanide.-March 15. A solution of potassic cyanide in water, fifty per cent., and of alcohol, fifty per cent., was dropped upon five egg-clusters, which it pene- 
trated readily, but did not affect the vitality of the eggs. March 15. Several egg-clusters were treated in the same manner as in the preceding experiment, and about one-tenth of the eggs hatched.

Pine Tar Mixtures. - February 1. A mixture, composed of fifty per cent. of pine tar and fifty per cent. of phenol, was poured upon five egg-clusters. It soaked into the clusters readily, and blackened them, apparently destroying the eggs. February 3. A mixture of pine tar, fifty per cent., and turpentine, fifty per cent., was dropped upon five egg-clusters. It penetrated readily, turning the eggs black and apparently destroying them. February 3. A mixture containing equal parts of pine tar, phenol and turpentine was dropped upon five egg-clusters, completely destroying the eggs. A mixture composed of forty per cent. of pine tar, forty per cent. of phenol, twenty per cent. of alcohol, with corrosive sublimate, was dropped upon ten egg-clusters, and, although the eggs did not appear to be destroyed, none hatched. March 6. A mixture of pine tar, fifty per cent., alcohol, forty-five per cent., tannic acid, two and one-half per cent., and ferrous sulphate, two and one-half per cent., was dropped upon a number of eggclusters, which it readily penetrated, rendering the eggs soft. The object of the last two substances was to give the solution a black color. March 6. A mixture of pine tar, fifty per cent., alcohol, forty-five per cent., and Stafford's ink, five per cent., was dropped upon some egg-clusters. It readily penetrated to the bottom layer, destroying the eggs.

Phenol. - January 21. A small amount of liquid phenol was poured upon an egg-cluster. This burned the eggs to a crisp. January 21. Five egg-clusters were treated for ten minutes with vapors of phenol, one hundred per cent., care being taken that the egg-clusters should be dampened by the vapors. The eggs were badly burned. January 21. Five egg-clusters were treated for fifteen minutes in the same manner as in the preceding experiment, except that the vapors were not allowed to wet the egg-clusters. Apparently the eggs were not injured, for, by March 24, nearly 
all had hatched. January 25. A mixture of phenol, ten per cent., and alcohol, ninety per cent., was poured upon five egg-clusters, which were blackened and burned. January 25. Five egg-clusters were treated with a mixture of phenol, twenty per cent., and water, eighty per cent. This mixture was stirred until it became milky white, then a little was poured upon the egg-clusters, and seriously burned them. January 30. A mixture of phenol, four per cent., and water, ninety-six per cent., was poured upon five eggclusters. The mixture penetrated only a part of the eggcluster, and nearly one-half of the eggs hatched. January 30. A mixture of phenol, three per cent., and water, ninety-seven per cent., was poured upon five egg-clusters. About nine-tenths of the eggs hatched. February 1. A mixture composed of phenol, fifty per cent., and sulphuric acid, fifty per cent., was dropped upon five egg-clusters. This mixture slowly penetrated the egg-clusters and destroyed the eggs. February 2. A mixture containing fifty per cent. alcohol, twenty-five per cent. phenol and twentyfive per cent. of sulphuric acid, was dropped upon five eggclusters, destroying the eggs. February 26. A mixture of fifty per cent. alcohol, twenty-five per cent. phenol, twenty-five per cent. sulphuric acid, with a little potassic ferricyanide and ferrous chloride, was dropped upon some egg-clusters. The mixture readily penetrated the clusters, turning them dark blue and completely destroying the eggs. February 2. A mixture of alcohol, fifty per cent., phenol, twenty-five per cent., and sulphuric acid, twenty-five per cent., was dropped upon five egg-clusters. It readily penetrated the clusters, turning them black and completely destroying the eggs. February 25. A mixture of alcohol, sixty per cent., phenol, twenty per cent., and sulphuric acid, twenty per cent., was dropped upon some egg-clusters, turning them black and completely destroying the eggs. March 1. A mixture of phenol, fifty per cent., turpentine and nitric acid, fifty per cent., was dropped upon some egg-clusters, entirely destroying the eggs. March 14. A mixture composed of phenol, fifty per cent., turpentine with a small amount of concentrated nitric acid, fifty per cent., 
was dropped upon some egg-clusters, entirely destroying the eggs.

Pyroligenous Acid. - February 10. Eight egg-elusters were moistened with pyroligenous acid, but it would not penetrate the clusters.

Spruce Gum. - Twenty per cent. of spruce gum, thirtyfive per cent. of rosin, thirty-five per cent. of eotton-seed oil, five per cent. of turpentine and five per cent. of pine tar were melted and mixed together, and some egg-clusters saturated with the solution. None of the eggs hatched.

Sulphur Di-oxide.-January 25. Five egg-clusters were placed in a tight box and submitted for ten minutes to the fumes of burning sulphur. Mareh 24, about three-fifths of the eggs had hatched. January 25. Five egg-elusters, plaeed in a tight wooden box, were submitted for twenty minutes to the fumes of burning sulphur. March 24, nearly all of the eggs had hatched.

Turpentine. - A quantity of turpentine was poured on five egg-clusters. It readily penetrated, but apparently did not affect the eggs, as nearly all of them hatched.

During the month of October, 1893, Mr. C. W. Minott experimented in the field with a number of mixtures having creosote oil as a basis. All of these mixtures were effective in destroying the eggs of the gypsy moth. The lowest per cent. of creosote oil used was in a mixture composed of eighty per cent. of turpentine and twenty per cent. of creosote oil. Even when diluted to this degree, it was found to be effective.

The following experiments on the eggs of the gypsy moth were conducted by Mr. Kirkland, in 1895 : -

Kerosene. - January 5. Twelve egg-clusters were treated with kerosene oil ; these hatched April 20. April 25. Five egg-clusters treated with kerosene oil; hatched May 1.

Turpentine. - January 5. Ten egg-clusters treated with turpentine; hatched April 18.

Kerosene and Turpentine. - May 2. Egg-clusters which had commenced hatching were soaked in a mixture eomposed of equal parts of kerosene and turpentine. May 6 . 
Six eggs-clusters re-commenced hatching, and a few caterpillars emerged.

Crude Castor Oil and Turpentine.-January 5. Five egg-clusters, treated with the above mixture, hatched April 30 .

Paraffine Gas or Residuum Oil. - Thinking this oil might be of some value for treating egg-clusters, a number of experiments were made which gave very satisfactory results. January 5. Twelve egg-clusters were treated with paraffine gas oil, none of which hatched. During the winter and spring of 1895 , from one hundred to two hundred eggclusters were treated with paraffine gas oil, with the result that none of them hatched.

Raupenleim.-April 27. Five egg-clusters were carefully covered with Raupenleim, the layer being about oneeighth of an inch thick. None of the eggs hatched.

The experiments in treating egg-clusters with various gases were made with a view to finding some practical way of dealing with stone walls, hollow trees and other more or less inaccessible places, in which eggs had been laid in large quantities. The substances which were found to give the most satisfactory results, $i$. e., chlorine and bromine vapors, were tested on a large scale in the field, but here their use was found to be, at best, only partially effective.

\section{Insecticides for Destroying the Caterpillars.}

Spraying with the common arsenical poisons, such as Paris green, London purple, etc., was one of the first methods employed for the destruction of the caterpillars of the gypsy moth, and the failure of these poisons to do effective work in the field has already been stated. When it became evident that the caterpillars were not being destroyed in any great numbers by these poisons, an effort was made to discover a more effective poison, and much time and labor were spent in this undertaking. The most careful attention was given to this problem; for, with modern spraying machinery, the thorough application of a poison to trees is easily accomplished, and thus a cheap, 
practical and effective method of destroying the caterpillars of the gypsy moth would be provided if a poison could be found which would meet the exigencies of the case. It will be seen by the records which follow that we have experimented with insecticides in general use, which are adapted to our work, and also with many new insecticides which were prepared for this purpose by our former chemist, Mr. F. C. Moulton.

All of the insecticide experiments here recorded were performed under my immediate supervision, by Messrs. Reid and Schrader in 1893, Messrs. Minott, Mosher and Kirkland in 1894, and by Mr. Kirkland and his assistants in 1895 .

\section{Details of the Experiments.}

The caterpillars used in the field or out-door experiments were taken from infested trees near the place of experimentation. Those used in the in-door experiments were, as a rule, from eggs hatched early in the season by means of artificial heat.

In the in-door experiments on young caterpillars lettuce was the food plant generally used, leaves of elm, apple or willow being substituted as soon as such foliage could be obtained. In the field experiments the caterpillars were confined upon branches of trees on which they were known to feed readily.

All poisons used in the experiments of 1893 , and the greater part of those used in 1894, were carefully weighed out in the insectary at Amherst. During the latter part of 1894 , and throughout the season of 1895 , they were weighed on a very accurate set of balances at the Malden office.

The poison was applied to the foliage used in the in-door experiments both by dipping the leaves in the poison mixtures and by spraying with small hand bellows. In the field experiments the poison was always applied by use of the spraying bellows. After heavy rains the branches on which the caterpillars were confined were resprayed in the same manner as would be adopted in spraying operations in the field. In nearly all cases a small amount of glucose 
was added to the poison mixtures, in order to increase the adhesive qualities. In the experiments conducted at the insectary the caterpillars were confined in glass jars or in lantern globes. In the ficld experiments the caterpillars were sacked in (enclosed by means of a thin cloth bag of proper dimensions) upon the branches of trees. In the case of the in-door experiments the poisoned food was renewed and the jars cleaned daily. For the field experiments branches of sufficient size to allow the caterpillars to feed till reaching maturity were chosen, and thus, as a rule, no change was necessary.

Each jar or sack used in the experiments was given a number, which was recorded in a book, in which the records of the ten caterpillars used in each experiment were carefully noted. In many of the experiments a "check" was employed, to determine the normal death rate of caterpillars feeding on unpoisoned food. This check consisted of the same number of caterpillars confined in a jar or bag in the same manner as those in the experiment, with the exception that they were kept supplied with fresh, unpoisoned food.

Daily observations were made both upon caterpillars feeding on the poisoned and unpoisoned food, and the results recorded. Many of the experiments on young caterpillars were discontinued at the end of about a fortnight, or after they had entered the succeeding molt.

The following pages contain the records of the experiments which have been conducted with the different insecticides : -

\section{Experiments with Paris Green. \\ $\frac{1}{2} l b$. Paris Green to $150 \mathrm{gal}$. Water.}

No. 1.- March 7, 1894. Ten eaterpillars, three days old, were placed on lettuce leaves which had been treated with Paris green, in the proportion of $\frac{1}{2} \mathrm{lb}$. to $150 \mathrm{gal}$. of water. Two died on the third, three the fourth, one the fifth, three the sixth and one the seventh day.

Check experiment: none dead.

No. 2. - April 26, 1894. Ten caterpillars, six days old, were placed on lettuce leaves which had been treated with Paris green, in the proportion of $\frac{1}{2} \mathrm{lb}$. to $150 \mathrm{gal}$. of water. 
Three died the second, three the third, one the fourth and one the fifth day, and two escaped.

Check experiment: none dead.

No. 3. - May 28, 1894. Ten caterpillars, of the first molt, were placed on lettuce leaves which had been treated with Paris green, in the proportion of $\frac{1}{2} \mathrm{lb}$. to $150 \mathrm{gal}$. of water. Two died the third, one the fourth, three the sixth, two the seventh and two the eighth day.

Check experiment: one died the third day.

No. 4. - June 10, 1894. Ten caterpillars of the second molt were placed on elm leaves which had been sprayed with Paris green, in the proportion of $\frac{1}{2} \mathrm{lb}$. to $150 \mathrm{gal}$. of water. One died on the seventh, two the eighth, five the ninth and two the tenth day.

Check experiment: none dead.

No. 5. - June 21, 1894. Ten caterpillars, of the third molt, were placed on elm leaves which had been sprayed with Paris green, in the proportion of $\frac{1}{2} \mathrm{lb}$. to 150 gal. of water. One died the fourth, two the fifth, two the sixth, two the seventh, one the eighth, one the ninth and one the eleventh day.

Check experiment: none dead.

No. 6. - June 29, 1894. Ten caterpillars, of the fourth molt, were placed on elm leaves which had been sprayed with Paris green, in the proportion of $\frac{1}{2} \mathrm{lb}$. to $150 \mathrm{gal}$. of water. Three died the third, two the fourth, one the fifth, one the sixth and three the seventh day.

Check experiment: one died the fifth and one the sixth day.

No. 7 (field experiment).-June 28, 1893. A branch of hop-hornbeam was sprayed with Paris green, in the proportion of $\frac{1}{2} \mathrm{lb}$. to 150 gal. of water, and ten fourth-molt caterpillars placed upon it. July 5, the foliage was so badly burned that the caterpillars were removed to an unsprayed branch. July 30 , the food supply having given out, they were again removed to another unsprayed branch. Five of these caterpillars died before pupating, and, of the five that began to pupate, three emerged. Foliage very badly burned. 
No. 8 (field experiment). - June 28, 1893. A branch of hop-hornbeam was sprayed with Paris green, in the proportion of $\frac{1}{2} \mathrm{lb}$. to $150 \mathrm{gal}$. of water, and six fourth-molt caterpillars placed upon it. July 5 , the foliage was so badly burned that the caterpillars were transferred to a freshly sprayed oak branch. July 19, the branch was resprayed on account of heavy rains. Of the six caterpillars, only two, and possibly one of these was injured, died before pupating. Of the four that pupated, two emerged. The foliage of the hop-hornbeam was very badly burned, while that of the oak was in good condition.

No. 9. - July 10, 1894. Ten caterpillars, of the fifth molt, were placed on elm leaves which had been sprayed with Paris green, in the proportion of $\frac{1}{2} \mathrm{lb}$. to $150 \mathrm{gal}$. of water. One died the third day; one pupated the fourth, three the seventh and three the eighth day; two died the eleventh day.

Check experiment: three pupated the fourth day; one died the seventh and one the eighth day.

No. 10 (field experiment). - July 7, 1894. Ten caterpillars, of the fifth molt, were placed on willow branches which had been sprayed with Paris green, in the proportion of $\frac{1}{2} \mathrm{lb}$. to $150 \mathrm{gal}$. of water. One died the eighth and one the eleventh day; one pupated the thirteenth day; one died and two pupated the fourteenth day; one pupated the twentieth, one the twenty-third, one the twenty-eighth and one the twenty-ninth day.

No. 11 (field experiment). - June 28, 1893. A branch of hop-hornbeam was sprayed with Paris green, in the proportion of $\frac{1}{2} \mathrm{lb}$. to $150 \mathrm{gal}$. of water, and ten caterpillars, of the fifth molt, placed upon it. July 5 , the foliage was so badly burned that the caterpillars were transferred to a freshly sprayed branch of oak. On the 15th of July, for lack of food, they were again removed to another branch of oak which had also been sprayed. Only one caterpillar died before pupating, and that one lived twenty-four days after the first spraying. Of the nine that pupated, five emerged. The foliage of the hop-hornbeam was very badly burned, while that of the oak was only slightly so, if at all. 
No. 12. (field experiment). - June 28, 1893. A branch of hop-hornbeam was sprayed with Paris green, in the proportion of $\frac{1}{2} \mathrm{lb}$. to $150 \mathrm{gal}$. of water, and ten fifth-molt caterpillars placed upon it. July 5, the foliage was so badly burned that the caterpillars were removed to another branch of hop-hornbeam which was not sprayed. July 11, the foliage having been entirely stripped from the branch, they were again removed to another unsprayed branch. Of these caterpillars, none died before pupating, and four of them completed the process of pupation and emerged. Foliage very badly burned.

\section{26 . Paris Green to 150 gal. Water.}

No. 13. - April 26, 1894. Ten caterpillars, three days old, were placed on lettuce leaves which had been treated with Paris green, in the proportion of $\frac{3}{4} \mathrm{lb}$. to $150 \mathrm{gal}$. of water. Four died the second, five the third and one the fourth day.

Check experiment: none dead.

No. 14. - May 9, 1894. Ten caterpillars, six days old, were placed on lettuce leaves which had been treated with Paris green, in the proportion of $\frac{3}{4} \mathrm{lb}$. to $150 \mathrm{gal}$. of water. Three died the second, four the third, two the fifth and one the sixth day.

Check experiment: none dead.

No. 15. - May 28, 1894. Ten caterpillars, of the first molt, were placed on lettuce leaves which had been treated with Paris green, in the proportion of $\frac{3}{4} \mathrm{lb}$. to $150 \mathrm{gal}$. of water. One died the fourth, one the fifth, one the sixth, one the seventh, three the eighth and three the ninth day.

Check experiment: none dead.

No. 16. - June 10, 1894. Ten caterpillars, of the second molt, were placed on elm leaves which had been sprayed with Paris green, in the proportion of $\frac{3}{4} \mathrm{lb}$. to $150 \mathrm{gal}$. of water. One died the fifth, one the seventh, three the eighth, two the ninth and three the eleventh day.

Cheek experiment : none dead.

No. 17. - June 21, 1894. Ten caterpillars, of the third molt, were placed on elm leaves which had been sprayed 
with Paris green, in the proportion of $\frac{3}{4} \mathrm{lb}$. to 150 gal. of water. One died the second, three the third, three the fifth, three the sixth and one the seventh day.

Check experiment: one accidentally killed the seventh day.

No. 18. - June 29, 1894. Ten caterpillars, of the fourth molt, were placed on elm leares which had been sprayed with Paris green, in the proportion of $\frac{3}{4} \mathrm{lb}$. to $150 \mathrm{gal}$. of water. Two died the second, three the third, three the fifth and two the sixth day.

Check experiment: one pupated the third and one died the fourth day.

No. 19 (field experiment). - June 27, 1893. A branch of hop-hornbeam was sprayed with Paris green, in the proportion of $\frac{3}{4} \mathrm{lb}$. to $150 \mathrm{gal}$. of water, and six fourth-molt caterpillars placed upon it. July 8 , the foliage was so badly burned that the leaves fell off, and the caterpillars were removed to another branch which had not been sprayed. By August 12, all of the eaterpillars were dead, with the exception of one which pupated and emerged.

No. 20 (field experiment). - June 27, 1893. A branch of hop-hornbeam was sprayed with Paris green, in the proportion of $\frac{3}{4} \mathrm{lb}$. to $150 \mathrm{gal}$. of water, and ten fourth-molt caterpillars were placed upon it. July 8 , one caterpillar had died and the foliage had become badly burned. The remaining eaterpillars were transferred to a freshly sprayed oak branch. July 19, all the caterpillars were dead. Foliage slightly burned.

No. 21. - July 10, 1894. Ten caterpillars, of the fifth molt, were placed on elm leaves which had been sprayed with Paris green, in the proportion of $\frac{8}{4} \mathrm{lb}$. to $150 \mathrm{gal}$. of water. One died the second and one the third day; two died and one pupated the fourth day; two died and one pupated the sixth day; one died the eleventh and one the twelfth day.

Check experiment: one pupated the third day; one died the fourth day; one pupated the sixth, two the eighth, one the ninth and one the eleventh day.

No. 22 (field experiment). - July 7, 1894. Ten cater- 
pillars, of the fifth molt, were placed on willow branches which had been sprayed with Paris green, in the proportion of $\frac{8}{4} \mathrm{lb}$. to $150 \mathrm{gal}$. of water. Two died and one pupated the seventh day; two pupated the fourteenth, two the sixteenth, one the nineteenth, one the twenty-first and one the twenty-third day.

No. 23 (field experiment). - June 27, 1893. A branch of hop-hornbeam was sprayed with Paris green, in the proportion of $\frac{3}{4} \mathrm{lb}$. to $150 \mathrm{gal}$. of water, and ten fifth-molt caterpillars placed upon it. July 8, one died, and the food having given out, those remaining were transferred to another branch. Of these, six pupated and emerged, while the other three pupated, but died without emerging. The foliage which was sprayed was so badly burned that the leaves curled and fell off.

No. 24 (field experiment). - June 27, 189.4. A branch of hop-hornbeam was sprayed with Paris green, in the proportion of $\frac{3}{4} \mathrm{lb}$. to 150 gal. of water, and nine fifth-molt caterpillar's placed upon it. July 8 , two having died, the remaining caterpillars were transferred to a freshly sprayed oak branch, as the foliage of the hop-hornbeam was burned to a crisp. By the 4th of August all the caterpillars were dead. While the foliage of the hop-hornbeam was badly burned, that of the oak remained in good condition.

\section{$1 \mathrm{lb}$. Paris Green to 150 gal. Water.}

No. 26.-April 26, 1894. Ten caterpillars, three days old, were placed on lettuce leaves which had been treated with Paris green, in the proportion of $1 \mathrm{lb}$. to $150 \mathrm{gal}$. of water. Two died the first, five the third and one the fourth day; two escaped.

Check experiment: none dead.

No. 27. - May 9, 1894. Ten caterpillars, six days old, were placed on lettuce leaves which had been treated with Paris green, in the proportion of $1 \mathrm{lb}$. to $150 \mathrm{gal}$. of water. One died the first, two the second, five the third, one the fourth and one the fifth day.

Check experiment: none dead.

No. 28. - May 28, 1894. Ten caterpillars, of the first 
molt, were placed on lettuce leaves which had been treated with Paris green, in the proportion of $1 \mathrm{lb}$. to 150 gal. of water. Three died the third, one the fourth, one the fifth, four the sixth and one the seventh day.

Check experiment: one dead.

No. 29. - June 10, 1894. Ten caterpillars, of the second molt, were placed on elm leaves which had been sprayed with Paris green, in the proportion of $1 \mathrm{lb}$. to 150 gal. of water. One died the second, one the third, two the fourth, one the fifth, four the seventh and one the eighth day.

Check experiment: none dead.

No. 30.-June 21, 1894. Ten caterpillars, of the third molt, were placed on elm leaves which had been sprayed with Paris green, in the proportion of $1 \mathrm{lb}$. to $150 \mathrm{gal}$. of water. Two died the second, three the third, two the fourth, one the sixth and two the seventh day.

Check experiment : none dead.

No. 31.-June 29, 1894. Ten eaterpillars, of the fourth molt, were placed on elm leaves which had been sprayed with Paris green, in the proportion of $1 \mathrm{lb}$. to $150 \mathrm{gal}$. of water. Four died the third, one the fourth, one the fifth, two the sixth, one the seventh and one the eighth day.

Check experiment: one died the fifth day; one pupated and one died the sixth day.

No. 32 (field experiment). - June 26, 1893. A branch of apple tree was sprayed with Paris green, in the proportion of $1 \mathrm{lb}$. to $150 \mathrm{gal}$. of water, and ten fourth-molt caterpillars placed upon it. Of these, four died without pupating, and, of the six which began to pupate, none emerged. Foliage slightly burned.

No. 33 (field experiment). — June 26, 1893. An appletree branch was sprayed with Paris green, in the proportion of $1 \mathrm{lb}$. to $150 \mathrm{gal}$. of water, and nine fourth-molt caterpillars placed upon it. July 16, the branch having been broken off by the wind, the caterpillars were transferred to another tree, and the branch sprayed. Five died before pupating, and, of the four which pupated, two emerged. Foliage badly burned.

No. 34.-July 10, 1894. Ten caterpillars, of the fifth 
molt, were placed on elm leaves which had been sprayed with Paris green, in the proportion of $1 \mathrm{lb}$. to $150 \mathrm{gal}$. of water. One died the fourth day; three died and one pupated the sixth day; two died the ninth, one the tenth, one the eleventh and one the twelfth day.

Check experiment : one died the second day; two pupated the sixth, one the seventh, one the ninth and one the tenth day.

No. 35 (field experiment). - July 7, 1894. Ten caterpillars, of the fifth molt, were placed on willow branches which had been sprayed with Paris green, in the proportion of $1 \mathrm{lb}$. to $150 \mathrm{gal}$. of water. Two pupated the fourteenth, two the sixteenth and three the eighteenth day; one died the nineteenth and two pupated the twentieth day.

No. 36 (field experiment). - June 26, 1893. A branch of apple tree was sprayed with Paris green, in the proportion of $1 \mathrm{lb}$. to $150 \mathrm{gal}$. of water, and ten fifth-molt caterpillars were placed upon it. Of these, six died before pupating; four pupated, three of which emerged. For some reason the foliage appeared to be quite badly burned, although the Paris green was in the proportion commonly used for spraying.

No. 37 (field experiment). - June 26, 1893. A branch of apple tree was sprayed with Paris green, in the proportion of $1 \mathrm{lb}$. to $150 \mathrm{gal}$. of water, and ten fifth-molt caterpillars placed upon it. In this experiment the poison took effect more quickly than in the corresponding experiments, all of the caterpillars having died within three weeks:

No. 38 (field experiment). - July 12, 1893. A branch of hop-hornbeam was sprayed with Paris green, in the proportion of $1 \mathrm{lb}$. to $150 \mathrm{gal}$. of water, and ten caterpillars of the fifth molt placed upon the branch. July 21, the foliage was so badly burned that the caterpillars were transferred to a freshly sprayed branch of oak, which was resprayed July 27, on account of the rain. Four caterpillars pupated, two of which emerged. Foliage of the hop-hornbeam very badly burned; that of the oak burned somewhat less.

No. 39 (field experiment). - July 12, 1893. Paris green, in the proportion of $1 \mathrm{lb}$. to $150 \mathrm{gal}$. of water, was allowed 
to stand for nearly three hours, to determine the difference in action between this and the experiments where the poison had not been allowed to stand. An oak branch was sprayed with this mixture, and ten large fifth-molt caterpillars placed upon it. July 21, the branch was resprayed on account of heavy rain, and on July 25 the foliage became so badly burned that the caterpillars were transferred to a freshly sprayed oak branch. Seven of the ten began to pupate, but of these only two emerged, and one of those was imperfect. Foliage of the first branch was very badly burned, while that of the second was in good condition.

\section{$1 \frac{1}{2}$ lbs. Paris Green to 150 gal. Water.}

No. 40.-April 26, 1894. Ten caterpillars, three days old, were placed on lettuce leaves which had been treated with Paris green, in the proportion of $1 \frac{1}{2} \mathrm{lbs}$. to $150 \mathrm{gal}$. of water. One died on the first, one the second and six the third day; two escaped.

Check experiment: none dead.

No. 41. - May 9, 1894. Ten caterpillars, six days old, were placed on lettuce leaves which had been treated with Paris green, in the proportion of $1 \frac{1}{2} \mathrm{lbs}$. to $150 \mathrm{gal}$. of water. Five died the second, three the third and two the fourth day.

Check experiment: none dead.

No. 42. - May 28, 1895. Ten caterpillars, of the first molt, were placed on lettuce leaves which had been treated with Paris green, in the proportion of $1 \frac{1}{2} \mathrm{lbs}$. to $150 \mathrm{gal}$. of water. Four died the third, three the fourth and three the fifth day.

Check experiment: one died the fourth day.

No. 43. - June 10, 1894. Ten caterpillars, of the second molt, were placed on lettuce leaves which had been treated with Paris green, in the proportion of $1 \frac{1}{2} \mathrm{lbs}$. to $150 \mathrm{gal}$. of water. Two died the second, one the third, one the fourth, one the fifth, two the sixth, two the seventh and one the eighth day.

Check experiment: none dead.

No. 44. - June 21, 1894. Ten caterpillars, of the third 
molt, were placed on elm leaves which had been sprayed with Paris green, in the proportion of $1 \frac{1}{2} \mathrm{lbs}$. to $150 \mathrm{gal}$. of water. Two died the third, two the fourth, three the fifth, one the sixth and two the seventh day.

Check experiment: none dead.

No. 45. - June 29, 1895. Ten eaterpillars. of the fourth molt, were placed on elm leaves which had been sprayed with Paris green, in the proportion of $1 \frac{1}{2}$ lbs. to 150 gal. of water. Two died the second, four the third, three the fourth and one the fifth day.

Check experiment: one died the fourth day.

No. 46 (field experiment).-June 26, 1893. An appletree branch was sprayed with Paris green, in the proportion of $1 \frac{1}{2} \mathrm{lbs}$. to $150 \mathrm{gal}$. of water, and eight fourth-molt caterpillars placed upon it. Six caterpillars in this experiment died gradually, one lived over ten weeks on the foliage and pupated. Another lived on the foliage a month, then pupated and finally emerged. Foliage somewhat burned.

No. 47 (field experiment). - June 26, 1893. An appletree branch was sprayed with Paris green, in the proportion of $1 \frac{1}{2} \mathrm{lbs}$. to $150 \mathrm{gal}$. of water, and ten fourth-molt eaterpillars placed upon it. Of these, all but one died before beginning to pupate, and that one was not able to complete the process. It took more than a week for the poison to begin to act, and the last caterpillar lived over six weeks. The foliage was badly burned.

No. 48. - July 10, 1894. Ten caterpillars, of the fifth molt, were placed on elm leaves which had been sprayed with Paris green, in the proportion of $1 \frac{1}{2} \mathrm{lbs}$. to $150 \mathrm{gal}$. of water. Two died and one pupated the third day; one died the fourth, two the sixth, three the eighth and one the twelfth day.

Check experiment: one died the second day; one pupated the fourth, one the fifth, one the sixth and one the seventh day.

No. 49 (field experiment). - July 7, 1894. Ten caterpillars, of the fifth molt, were placed on a willow branch which had been sprayed with Paris green, in the proportion of $1 \frac{1}{2} \mathrm{lbs}$. to $150 \mathrm{gal}$. of water. One died and one pupated 


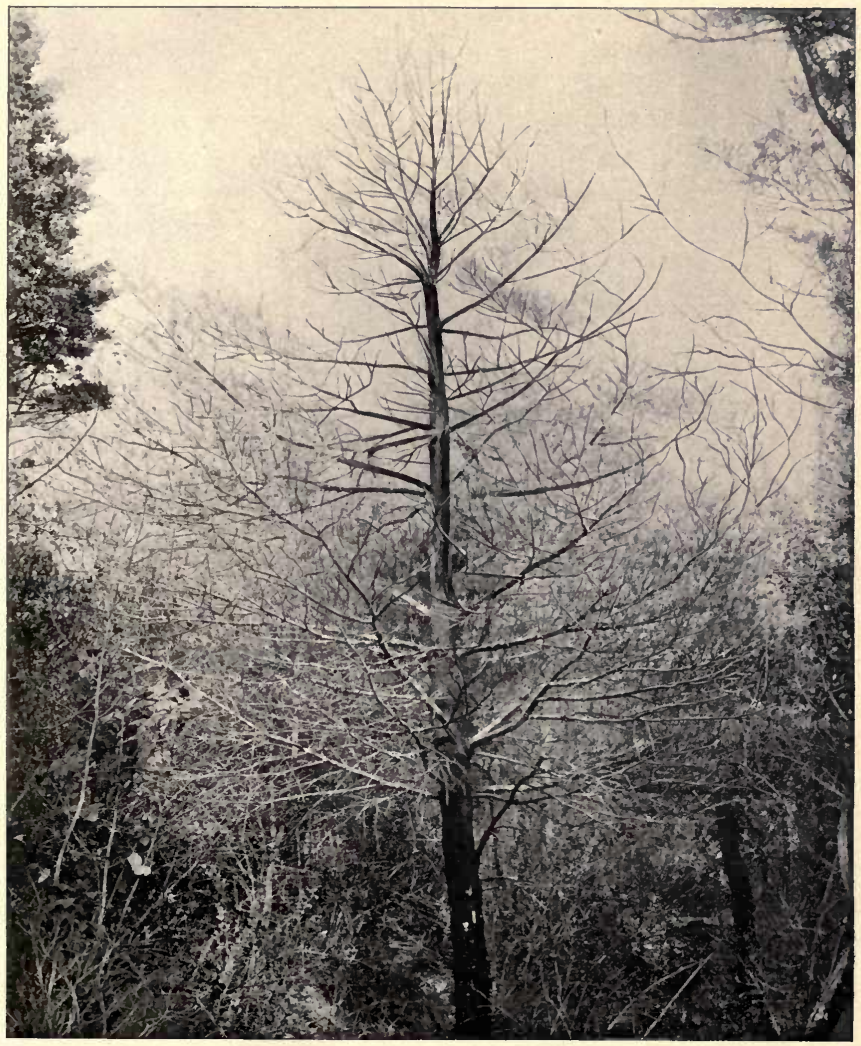

PLATE 65. White pine and other trees stripped by the caterpillars of the gypsy moth. 
the seventh day; one died the thirteenth day; one died and two pupated the fourteenth day; two pupated the eighteenth, one the twenty-seventh and one the thirty-first day.

No. 50 (field experiment). - June 26, 1893. An appletree branch was sprayed with Paris green, in the proportion of $1 \frac{1}{2} \mathrm{lbs}$. to $150 \mathrm{gal}$. of water, and ten fifth-molt caterpillars placed upon it. By the 5th of August all had died, none having completed the process of pupation, although two or three had begun. The foliage was badly burned.

No. 51 (field experiment). - June 26, 1893. An appletree branch was sprayed with Paris green, in the proportion of $1 \frac{1}{2} \mathrm{lbs}$. to $150 \mathrm{gal}$. of water, and ten fifth-molt caterpillars placed upon it. Of these caterpillars, six died without pupating; three began to pupate, but died later; and ore pupated and emerged. The foliage was badly burned.

No. 52 (field experiment).- July 14, 1893. An oak branch was sprayed with Paris green, in the proportion of $1 \frac{1}{2} \mathrm{lbs}$. to 150 gal. of water, and ten fifth-molt caterpillars placed upon it. On July 20, the branch was resprayed on account of rain. Seven of the caterpillars pupated, four of which emerged. Three of these seven began pupating before they had time to eat any of the poisoned food. Foliage badly burned.

2 lbs. Paris Green to $150 \mathrm{gal}$. Water.

No. 53.-April 26, 1894. Ten caterpillars, three days old, were placed on lettuce leaves which had been treated with Paris green, in the proportion of $2 \mathrm{lbs}$. to $150 \mathrm{gal}$. of water. Two died the first, one the second, six the third and one the fourth day.

Check experiment: none dead.

No. 54. - May 9, 1894. Ten caterpillars, six days old, were placed on lettuce leaves which had been treated with Paris green, in the proportion of 2 lbs. to 150 gal. of water. One died the second, four the third, one the fifth and four the sixth day.

Check experiment: none dead.

No. 55.-May 28, 1894. Ten caterpillars, of the first molt, were placed on lettuce leaves which had been treated 
with Paris green, in the proportion of $2 \mathrm{lbs}$. to $150 \mathrm{gal}$. of water. Five died the third, two the fourth, one the sixth, one the seventh and one the ninth day.

Cheek experiment: one died the fourth day.

No. 56. - June 10, 1894. Ten eaterpillars, of the second molt, were placed on elm leaves which had been sprayed with Paris green, in the proportion of $2 \mathrm{lbs}$. to $150 \mathrm{gal}$. of water. One died the second, two the third, one the fourth, four the seventh and two the eighth day.

Check experiment : none dead.

No. 57. - June 21, 1894. Ten caterpillars, of the third molt, were placed on elm leaves which had been sprayed with Paris green, in the proportion of 2 lbs. to $150 \mathrm{gal}$. of water. One died the second, one the third, four the fifth, two the sixth and two the seventh day.

Check experiment: one died the seventh day.

No. 58. - June 29, 1894. Ten caterpillars, of the fourth molt, were placed on elm leaves which had been sprayed with Paris green, in the proportion of $2 \mathrm{lbs}$. to $150 \mathrm{gal}$. of water. Two died the second, five the third, one the fourth, fifth and sixth days.

Cheek experiment: one died the fourth and one the sixth day.

No. 59. - July 10, 1894. Ten caterpillars, of the fifth molt, were placed on elm leaves which had been sprayed with Paris green, in the proportion of $2 \mathrm{lbs}$. to 150 gal. of water. One pupated the fifth day; two died and four pupated the sixth day; one pupated the seventh day; one died the tenth and one the fourteenth day.

Check experiment: four pupated and one died the fourth day; one pupated the fifth day, one the sixth, one the ninth and one the eleventh day.

No. 60 (field experiment). - July 7, 1894. Ten eaterpillars, of the fifth molt, were placed on willow branches which had been sprayed with Paris green, in the proportion of $2 \mathrm{lbs}$. to $150 \mathrm{gal}$. of water. One pupated the fourth and one died the thirteenth day; three pupated the fourteenth and one died the seventeenth day; two pupated the nineteenth and two the twenty-sixth day. Foliage badly burned. 


\section{3 lbs. Paris Green to 150 gal. Water.}

No. 61. - April 26, 1894. Ten caterpillars, three days old, were placed on lettuce leaves which had been treated with Paris green, in the proportion of $3 \mathrm{lbs}$. to $150 \mathrm{gal}$. of water. Five died the second, four the third and one the fifth day.

Check experiment: none dead.

No. 62. - May 9, 1894. Ten caterpillars, six days old, were placed on lettuce leaves which had been treated with Paris green, in the proportion of 3 lbs. to 150 gal. of water. Two died the second, one the third, three the fourth, one the fifth and three the sixth day.

Check experiment: none dead.

No. 63. - May 28, 1894. Ten caterpillars, of the first molt, were placed on lettuce leaves which had been treated with Paris green, in the proportion of $3 \mathrm{lbs}$. to 150 gal. of water. Eight died the third day, one the seventh and one the eighth day.

Check experiment: none dead.

No. 64. - June 10, 1894. Ten caterpillars, of the second molt, were placed on elm leaves which had been sprayed with Paris green, in the proportion of $3 \mathrm{lbs}$. to 150 gal. of water. One died the second day, one the third, four the fifth, three the seventh and one the ninth day.

Check experiment: none dead.

No. 65. - June 21, 1894. Ten caterpillars, of the third molt, were placed on elm leaves which had been sprayed with Paris green, in the proportion of $3 \mathrm{lbs}$. to $150 \mathrm{gal}$. of water. One died the second, two the third, two the fourth, four the fifth and one the sixth day.

Check experiment : none dead.

No. 66. - June 29, 1894. Ten caterpillars, of the fourth molt, were placed on .elm leaves which had been sprayed with Paris green, in the proportion of $3 \mathrm{lbs}$. to $150 \mathrm{gal}$. of water. Two died the first, one the second, three the third, two the fourth and two the sixth day.

Check experiment: none dead.

No. 67. - July 10, 1894. Ten caterpillars, of the fifth 
molt, were placed on elm leaves which had been sprayed with Paris green in the proportion of $3 \mathrm{lbs}$. to $150 \mathrm{gal}$. of water. One died and one pupated the third day; one pupated the fourth and one the fifth day; one pupated and one died the sixth day; one died the seventh, two the ninth and one the fourteenth day.

Check experiment: three pupated the fourth day, one pupated and one died the sixth day; one pupated and one died the ninth day; three died the fourteenth day.

No. 68 (field experiment). - July 7, 1894. Ten caterpillars, of the fifth molt, were placed on willow branches which had been sprayed with Paris green, in the proportion of $3 \mathrm{lbs}$. to $150 \mathrm{gal}$. of water. One died the third, one the fourth and one the firth day; one pupated the sixth, one the fifteenth, one the eighteenth, one the twenty-first, one the twenty-fourth, one the twenty-eighth and one the thirtyfirst day. Foliage badly burned.

\section{$4 \mathrm{lbs}$. Paris Green to 150 gal. Water.}

No. 69. - April 26, 1894. Ten caterpillars, three days old, were placed on lettuce leaves which had been treated with Paris green, in the proportion of $4 \mathrm{lbs}$. to $150 \mathrm{gal}$. of water. Five died the second and four the third day; and one escaped.

Check experiment: none dead.

No. 70. - May 9, 1894. Ten caterpillars, six days old, were placed on lettuce leaves which had been treated with Paris green, in the proportion of $4 \mathrm{lbs}$. to 150 gal. of water. Two died the second, five the third, one the fourth and one the fifth day; and one escaped.

Check experiment: two died the fourth day.

No. 71. - May 28, 1895. Ten caterpillars, of the first molt, were placed on lettuce leaves which had been treated with Paris green, in the proportion of $4 \mathrm{lbs}$. to $150 \mathrm{gal}$. of water. One died the fourth, two the fifth and seven the sixth day.

Check experiment : one died the fifth day.

No. 72. - June 10, 1894. Ten caterpillars, of the second molt, were placed on elm leaves which had been 
sprayed with Paris green, in the proportion of $4 \mathrm{lbs}$. to 150 gal. of water. Two died the second, three the fourth, two the fifth, two the sixth and one the eighth day.

Check experiment: none dead.

No. 73. - June 21, 1894. Ten caterpillars, of the third molt, were placed on elm leaves which had been sprayed with Paris green, in the proportion of $4 \mathrm{lbs}$. to $150 \mathrm{gal}$. of water. Four died the second, four the third, one the fifth and one the sixth day.

Check experiment: none dead.

No. 74. - June 29, 1894. Ten caterpillars, of the fourth molt, were placed on elm leaves which had been sprayed with Paris green, in the proportion of $4 \mathrm{lbs}$. to $150 \mathrm{gal}$. of water. Four died the third day; two pupated the fourth day; three died the fifth and one the sixth day.

Check experiment: one died the third day.

No. 75. - July 10, 1894. Ten caterpillars, of the fifth molt, were placed on elm leaves which had been sprayed with Paris green, in the proportion of $4 \mathrm{lbs}$. to $150 \mathrm{gal}$. of water. One died the second day, two pupated and two died the third day; two pupated and one died the sixth day; one died the seventh and one the eighth day.

Check experiment: one pupated the fourth day; one died the sixth day.

No. 76 (field experiment). - July 7, 1894. Ten caterpillars, of the fifth molt, were placed on willow branches which had been sprayed with Paris green, in the proportion of $4 \mathrm{lbs}$. to $150 \mathrm{gal}$. of water. One died and two pupated the fifth day; one died the sixth and two the seventh day; one pupated the fourteenth, one the fifteenth, one the nineteenth and one the twenty-second day. Foliage badly burned.

\section{5 lbs. Paris Green to 150 gal. Water.}

No. 77. - April 26, 1894. Ten caterpillars, three days old, were placed on lettuce leaves which had been treated with Paris green, in the proportion of $5 \mathrm{lbs}$. to $150 \mathrm{gal}$. of water. Two died the first and seven the third day; and one escaped.

Check experiment: none dead; one escaped. 
No. 78. - May 9, 1894. Ten caterpillars, six days old, were placed on lettuce leaves which had been treated with Paris green, in the proportion of $5 \mathrm{lbs}$. to 150 gal. of water. One died the first, three the second, two the third, three the fourth and one the fifth day.

Check experiment: one died the second day.

No. 79. - May 28, 1894. Ten caterpillars, of the first molt, were placed on lettuce leaves which had been treated with Paris green, in the proportion of $5 \mathrm{lbs}$. to $150 \mathrm{gal}$. of water. Five died the third, three the fourth and two the sixth day.

Check experiment: one died the third day.

No. 80. - June 10, 1894. Ten caterpillars, of the second molt, were placed on elm leaves which had been sprayed with Paris green, in the proportion of $5 \mathrm{lbs}$. to $150 \mathrm{gal}$. of water. Two died the second, three the third, one the fourth, one the fifth, one the sixth, one the seventh and one the eighth day.

Check experiment: none dead.

No. 81. - June 21, 1894. Ten caterpillars, of the third molt, were placed on elm leaves which had been sprayed with Paris green, in the proportion of $5 \mathrm{lbs}$. to $150 \mathrm{gal}$. of water. Six died the second and four the third day.

Check experiment: none dead.

No. 82. - June 29, 1894. Ten eaterpillars, of the fourth molt, were placed on elm leaves which had been sprayed with Paris green, in the proportion of 5 lbs. to $150 \mathrm{gal}$. of water. Two died the second, two the third and two the fourth day; one died and one pupated the fifth day; two died the eighth day.

Check experiment: one died the third day; one pupated the fourth day; two died the fifth day.

No. 83. - July 10, 1894. Ten caterpillars, of the fifth molt, were placed on elm leaves which had been sprayed with Paris green, in the proportion of $5 \mathrm{lbs}$. to $150 \mathrm{gal}$. of water. Two died the third day; two pupated the sixth and one the seventh day; one pupated and one died the eighth day; two died the ninth day; one pupated the eleventh day. 
Check experiment: five pupated the fourth and one the fifth day; one died the eleventh day.

No. 84 (field experiment).- July 7, 1894. Ten caterpillars, of the fifth molt, were placed on willow branches which had been sprayed with Paris green, in the proportion of 5 lbs. to $150 \mathrm{gal}$. of water. One pupated the fourth, three the seventh, one the thirteenth, three the fourteenth, one the seventeenth and one the twenty-first day. Foliage badly burned.

\section{6 lbs. Paris Green to 150 yal. Water.}

No. 85. - April 26, 1894. Ten caterpillars, three days old, were placed on lettuce leaves which had been treated with Paris green, in the proportion of $6 \mathrm{lbs}$. to 150 gal. of water. One died the first, six the second and three the third day.

Check experiment: none dead; one escaped.

No. 86. - May 9, 1894. Ten caterpillars, six days old, were placed on lettuce leaves which had been treated with Paris green, in the proportion of $6 \mathrm{lbs}$. to $150 \mathrm{gal}$. of water. Five died the second, one the third and four the fourth day.

Check experiment: none dead.

No. 87. - May 28, 1894. Ten caterpillars, of the first molt, were placed on lettuce leaves which had been treated with Paris green, in the proportion of $6 \mathrm{lbs}$. to $150 \mathrm{gal}$. of water. Four died the third, three the fourth, one the fifth, one the seventh and one the eighth day.

Check experiment: one died the fourth day.

No. 88. - June 10, 1894. Ten caterpillars, of the second molt, were placed on elm leaves which had been sprayed with Paris green, in the proportion of $6 \mathrm{lbs}$. to $150 \mathrm{gal}$. of water. Four died the first, one the second, two the fourth, one the fifth and one the sixth day; one was lost.

Check experiment: none dead.

No. 89. - June 21, 1894. Ten caterpillars, of the third molt, were placed on elm leaves which had been sprayed with Paris green, in the proportion of $6 \mathrm{lbs}$. to $150 \mathrm{gal}$. of water. Five died the second, two the third, two the fifth and one the sixth day.

Check experiment : none dead. 
No. 90. - June 29, 1894. Ten caterpillars, of the fourth molt, were placed on elm leaves which had been sprayed with Paris green, in the proportion of $6 \mathrm{lbs}$. to 150 gal. of water. Four died the first, two the second, one the third, fourth, fifth and sixth days.

Check experiment : one died the third day.

No. 91. - July 10, 1894. Ten caterpillars, of the fifth molt, were placed on elm leaves which had been sprayed with Paris green, in the proportion of $6 \mathrm{lbs}$. to $150 \mathrm{gal}$. of water. Two died the third day; one died and one pupated the fourth day; two died and one pupated the sixth day; two died the eighth and one the twelfth day.

Check experiment: one pupated the fifth day; one died the seventh day; two died and two pupated the eighth day; one pupated the ninth and one the tenth day.

No. 92 (field experiment). - July 7, 1894. Ten caterpillars, of the fifth molt, were placed on willow branches which had been sprayed with Paris green, in the proportion of $6 \mathrm{lbs}$. to $150 \mathrm{gal}$. of water. Two died the fourth, one the sixth and one the seventh day; one pupated the eighth and one the thirteenth day; one died the fourteenth day; one pupated the fifteenth, one the nineteenth and one the twentieth day. Foliage badly burned.

\section{Experiments with Paris Green and Lime.}

$\frac{1}{2} l b$. Each of Paris Green and Lime to 150 gal. Water.

No. 1.-April 26, 1894. Ten caterpillars, three days old, were placed on lettuce leaves which had been treated with Paris green and lime, in the proportion of $\frac{1}{2} \mathrm{lb}$. each to $150 \mathrm{gal}$. of water. One died the second and nine the third day.

Check experiment: none dead.

No. 2. - May 9, 1894. Ten caterpillars, six days old, were placed on lettuce leaves which had been treated with Paris green and lime, in the proportion of $\frac{1}{2} \mathrm{lb}$. each to 150 gal. of water. One died the second, one the third, seven the fifth and one the sixth day.

Check experiment: none dead.

No. 3. - May 28, 1894. Ten caterpillars, of the first 
molt, were placed on lettuce leaves which had been treated with Paris green and lime, in the proportion of $\frac{1}{2} \mathrm{lb}$. each to $150 \mathrm{gal}$. of water. Three died the third, two the fourth, two the sixth, one the seventh and two the eighth day.

Check experiment: none dead.

No. 4. - June 10, 1894. Ten caterpillars, of the second molt, were placed on elm leaves which had been treated with Paris green and lime, in the proportion of $\frac{1}{2} \mathrm{lb}$. each to 150 gal. of water. One died the fourth, one the sixth, four the ninth, two the tenth and two the eleventh day.

Check experiment: none dead.

No. 5. - June 21, 1894. Ten caterpillars, of the third molt, were placed on elm leaves which had been sprayed with Paris green and lime, in the proportion of $\frac{1}{2} \mathrm{lb}$. each to $150 \mathrm{gal}$. of water. One died the fourth, four the sixth and five the seventh day.

Check experiment: none dead.

No. 6. - June 29, 1894. Ten caterpillars, of the fourth molt, were placed on elm leaves which had been sprayed with Paris green and lime, in the proportion of $\frac{1}{2} \mathrm{lb}$. each to $150 \mathrm{gal}$. of water. Two died the first, one the second, fourth, fifth, sixth and seventh and three the eighth day.

Check experiment: one pupated the sixth day.

No. 7. - July 11, 1894. Ten caterpillars, of the fifth molt, were placed on elm leaves which had been sprayed with Paris green and lime, in the proportion of $\frac{1}{2} \mathrm{lb}$. each to $150 \mathrm{gal}$. of water. One died the first day; one died and one pupated the second day; two pupated the third day; one died the fifth, one the eighth, one the ninth and two the tenth day.

Check experiment: two pupated the fifth day; one died and one pupated the eighth day; one pupated the ninth day.

No. 8 (field experiment). - July 7, 1894. Ten caterpillars, of the fifth molt, were placed on willow branches which had been sprayed with Paris green and lime, in the proportion of $\frac{1}{2} \mathrm{lb}$. each to $150 \mathrm{gal}$. of water. One died the fourth, one the fifth and one the seventh day; one pupated the tenth, one the fourteenth, one the sixteenth and four the eighteenth day. 


\section{lb. Each Paris Green and Lime to 150 gal. Water.}

No. 9.-April 26, 1894. Ten caterpillars, three days old, were placed on lettuce leaves which had been treated with Paris green and lime, in the proportion of $\frac{3}{4} \mathrm{lb}$. each to $150 \mathrm{gal}$. of water. Two died the second, six the third and two the fourth day.

Check experiment: none dead.

No. 10. - May 9, 1894. Ten caterpillars, six days old, were placed on lettuce leaves which had been treated with Paris green and lime, in the proportion of $\frac{3}{4} \mathrm{lb}$. each to 150 gal. of water. Two died the second, five the third and three the fourth day.

Check experiment: none dead.

No. 11. - May 2, 1894. Ten caterpillars, of the first molt, were placed on lettuce leaves which had been treated with Paris green and lime, in the proportion of $\frac{3}{4} \mathrm{lb}$. each to $150 \mathrm{gal}$. of water. One died the third, one the fifth, four the seventh, two the eighth and two the ninth day.

Check experiment: none dead.

No. 12. - June 10, 1895. Ten caterpillars, of the second molt, were placed on elm leaves which had been sprayed with Paris green and lime, in the proportion of $\frac{3}{4} \mathrm{lb}$. each to $150 \mathrm{gal}$. of water. Two died the sixth, six the seventh and two the eighth day.

Check experiment: none dead.

No. 13. - June 21, 1894. Ten caterpillars, of the third molt, were placed on elm leaves which had been sprayed with Paris green and lime, in the proportion of $\frac{3}{4} \mathrm{lb}$. each to 150 gal. of water. Four died the fifth, one the sixth, four the seventh and one the eighth day.

Check experiment: none dead.

No. 14. - June 29, 1894. Ten eaterpillars, of the fourth molt, were placed on elm leaves which had been sprayed with Paris green and lime, in the proportion of $\frac{3}{4} \mathrm{lb}$. each to 150 gal. of water. One died the third, five the fourth, one the fifth, two the sixth and one the seventh day.

Check experiment: one died the fourth day.

No. 15. - July 11, 1894. Ten caterpillars, of the fifth 
molt, were placed on elm leaves which had been sprayed with Paris green and lime, in the proportion of $\frac{8}{4} \mathrm{lb}$. each to 150 gal. of water. Two died the first day; two pupated the fifth day; three died the ninth, two the tenth and one the fourteenth day.

Check experiment: one lost and one pupated the third day; one pupated the fourth, one the fifth and one the sixth day; one died the eighth, three the twelfth and one the thirteenth day.

No. 16 (field experiment). - July 7, 1894. Ten caterpillars, of the fifth molt, were placed on willow branches which had been sprayed with Paris green and lime, in the proportion of $\frac{3}{4} \mathrm{lb}$. each to $150 \mathrm{gal}$. of water. Two died the third day; two pupated the sixth and one the thirteenth day; one died and one pupated the fourteenth day; one died and two pupated the eighteenth day.

1 lb. Each Paris Green and Lime to 150 gal. Water.

No. 17. - April 26, 1894. Ten caterpillars, three days old, were placed on lettuce leaves which had been treated with Paris green and lime, in the proportion of $1 \mathrm{lb}$. each to 150 gal. of water. Eight died the second, one the fourth and one the fifth day.

Check experiment: none dead; five escaped.

No. 18. - May 9, 1894. Ten caterpillars, six days old, were placed on lettuce leaves which had been treated with Paris green and lime, in the proportion of $1 \mathrm{lb}$. each to 150 gal. of water. One died the second, six the third, one the fourth, one the fifth and one the sixth day.

Check experiment: one died the second day.

No. 19.-May 28, 1894. Ten caterpillars, of the first molt, were placed on lettuce leaves which had been treated with Paris green and lime, in the proportion of $1 \mathrm{lb}$. each to 150 gal. of water. One died the fourth, two the fifth, three the sixth, two the eighth, one the ninth and one the tenth day.

Check experiment: one died the sixth day.

No. 20. - June 10, 1894. Ten caterpillars, of the second molt, were placed on elm leaves which had been sprayed with Paris green and lime, in the proportion of $1 \mathrm{lb}$. each 
to 150 gal. water. One died the second, four the sixth, four the seventh and one the tenth day.

Check experiment: none dead.

No. 21. - June 21, 1894. Ten caterpillars, of the third molt, were placed on elm leaves which had been sprayed with Paris green and lime, in the proportion of $1 \mathrm{lb}$. each to $150 \mathrm{gal}$. of water. One died the third, two the fifth, two the sixth and five the seventh day.

Check experiment : one died and one lost the seventh day. No. 22. - June 29, 1894. Ten caterpillars, of the fourth molt, were placed on elm leaves which had been sprayed with Paris green and lime, in the proportion of $1 \mathrm{lb}$. each to 150 gal. of water. Three died the second, two the third and one the fourth, fifth, sixth, seventh and eighth days.

Check experiment: one died the third day.

No. 23. - July 11, 1894. Ten caterpillars, of the fifth molt, were placed on elm leaves which had been sprayed with Paris green and lime, in the proportion of $1 \mathrm{lb}$. each to 150 gal. of water. One died and one pupated the second day; two pupated the fourth, two the fifth and one the eighth day; two died the tenth and one the fourteenth day.

Check experiment: one died and one pupated the third day; one died the seventh, one the eighth and one the tenth day.

No. 24 (field experiment). - Ten caterpillars, of the fifth molt, were placed on willow branches which had been sprayed with Paris green and lime, in the proportion of $1 \mathrm{lb}$ : each to 150 gal. of water. One died the sixth and three the seventh day ; one pupated the eleventh, one the twelfth, two the thirteenth, one the fifteenth and one the seventeenth day.

11 lbs. Each Paris Green and Lime to 150 gal. Water.

No. 25. - April 26, 1894. Ten caterpillars, three days old, were placed on lettuce leaves which had been treated with Paris green and lime, in the proportion of $1 \frac{1}{2}$ lbs. each to 150 gal. of water. Five died the second, two the third and one the fourth day, and two escaped.

Check experiment: one died the fifth day, and five escaped. 
No. 26. - May 9, 1894. Ten caterpillars, six days old, were placed on lettuce leaves which had been treated with Paris green and lime, in the proportion of $1 \frac{1}{2} \mathrm{lbs}$. each to 150 gal. of water. Four died the second, five the third and one the fourth day.

Check experiment : one died the second day.

No. 27. - May 28, 1894. Ten caterpillars, of the first molt, were placed on lettuce leaves which had been treated with Paris green and lime, in the proportion of $1 \frac{1}{2} \mathrm{lbs}$. each to $150 \mathrm{gal}$. of water. Four died the third, one the fourth, two the fifth and three the sixth day.

Check experiment: one died the fifth day.

No. 28.-June 10, 1894. Ten caterpillars, of the second molt, were placed on elm leaves which had been sprayed with Paris green and lime, in the proportion of $1 \frac{1}{2} \mathrm{lbs}$. each to $150 \mathrm{gal}$. of water. One died the second, one the fourth, four the sixth, three the seventh and one the eighth day.

Check experiment: none dead.

No. 29. - June 21, 1894. Ten caterpillars, of the third molt, were placed on elm leaves which had been sprayed with Paris green and lime, in the proportion of $1 \frac{1}{2} \mathrm{lbs}$. each to 150 gal. of water. Three died the third, one the fourth, four the fifth and two the sixth day.

Check experiment: none dead.

No. 30. - June 29, 1894. Ten caterpillars, of the fourth molt, were placed on elm leaves which had been sprayed with Paris green and lime, in the proportion of $1 \frac{1}{2} \mathrm{lbs}$. each to 150 gal. of water. Four died the third, two the fourth, two the fifth and two the sixth day.

Check experiment: one pupated the fourth day.

No. 31. - July 11, 1894. Ten caterpillars, of the fifth molt, were placed on elm leaves which had been sprayed with Paris green and lime, in the proportion of $1 \frac{1}{2} \mathrm{lbs}$. each to 150 gal. of water. Two pupated the third and one the fifth day; two died and one pupated the seventh day; one died the eighth, two the ninth and one the eleventh day.

Check experiment: one died the third day; one pupated the fourth, two the fifth, one the eighth and one the tenth day. 
No. 32 (field experiment). - July 7, 1894. Ten caterpillars, of the fifth molt, were placed on willow branches which had been sprayed with Paris green and lime, in the proportion of $1 \frac{1}{2} \mathrm{lbs}$. each to 150 gal. of water. One died the fourth day; one died and one pupated the seventh day; one pupated the ninth, one the thirteenth, one the sixteenth, two the eighteenth, one the twenty-sixth and one the twentyeighth day.

2 lbs. Each Paris Green and Lime to 150 gal. Water.

No. 33.-April 26, 1894. Ten caterpillars, three days old, were placed on lettuce leaves which had been treated with Paris green and lime, in the proportion of $2 \mathrm{lbs}$. each to $150 \mathrm{gal}$. of water. Three died the second, four the third and three the fourth day.

Check experiment: none dead.

No. 34. - May 9, 1894. Ten caterpillars, six days old, were placed on lettuce leaves which had been treated with Paris green and lime, in the proportion of $2 \mathrm{lbs}$. each to 150 gal. of water. One died the second, five the third, two the fourth and two the fifth day.

Check experiment: none dead.

No. 35. - May 28, 1894. Ten caterpillars, of the first molt, were placed on lettuce leaves which had been treated with Paris green and lime, in the proportion of $2 \mathrm{lbs}$. each to 150 gal. of water. One died the third, one the fourth, one the fifth, two the sixth, four the seventh and one the eighth day.

Check experiment: none dead.

No. 36. - June 10, 1894. Ten caterpillars, of the second molt, were placed on elm leaves which had been sprayed with Paris green and lime, in the proportion of $2 \mathrm{lbs}$. each to $150 \mathrm{gal}$. of water. One died the second, one the fourth, two the fifth, three the sixth and three the seventh day.

Check experiment: none dead.

No. 37.-June 21, 1894. Ten caterpillars, of the third molt, were placed on elm leaves which had been sprayed with Paris green and lime, in the proportion of 2 lbs. each to $150 \mathrm{gal}$. of water. Two died the second, two the third, one the fifth, three the sixth and two the seventh day. 
Check experiment : two lost the seventh day.

No. 38. - June 29, 1894. Ten caterpillars, of the fourth molt, were placed on elm leaves which had been sprayed with Paris green and lime, in the proportion of $2 \mathrm{lbs}$. each to $150 \mathrm{gal}$. of water. Two died the second, two the third, two the fourth, two the fifth, one the sixth and one the eighth day.

Check experiment : one died the fourth, one the fifth and one the sixth day.

No. 39.-July 11, 1894. Ten caterpillars, of the fifth molt, were placed on elm leaves which had been sprayed with Paris green and lime, in the proportion of $2 \mathrm{lbs}$. each to 150 gal. of water. Two pupated the second day; one died the third day; one died and one pupated the fifth day; one pupated the sixth day; one died the seventh, one the ninth and two the tenth day.

Check experiment: one died the third day; two died and two pupated the ninth day.

No. 40 (field experiment).-July 7, 1894. Ten caterpillars, of the fifth molt, were placed on willow branches which had been sprayed with Paris green and lime, in the proportion of $2 \mathrm{lbs}$. each to $150 \mathrm{gal}$. of water. One pupated the sixth day; two died the seventh day; one pupated the eighth day; one died and one pupated the thirteenth day; one pupated the fourteenth, one the sixteenth, one the twentieth and one the twenty-second day.

3 lbs. Each Paris Green and Lime to 150 gal. Water.

No. 41. - April 26, 1894. Ten caterpillars, three days old, were placed on lettuce leaves which had been treated with Paris green and lime, in the proportion of $3 \mathrm{lbs}$. each to $150 \mathrm{gal}$. of water. Four died the second, two the third, one the fourth and three the fifth day.

Check experiment: none dead.

No. 42. - May 9, 1894. Ten caterpillars, six days old, were placed on lettuce leaves which had been treated with Paris green and lime, in the proportion of $3 \mathrm{lbs}$. each to 150 gal. of water. Two died the second, three the third, one the fourth and four the fifth day. 
Check experiment: none dead.

No. 43. - May 28, 1894. Ten caterpillars, of the first molt, were placed on lettuce leaves which had been treated with Paris green and lime, in the proportion of 3 lbs. each to $150 \mathrm{gal}$. of water. One died the third, three the fifth, four the sixth and two the seventh day.

Check experiment: none dead.

No. 44. - June 10, 1894. Ten caterpillars, of the second molt, were placed on elm leaves which had been sprayed with Paris green and lime, in the proportion of $3 \mathrm{lbs}$. each to $150 \mathrm{gal}$. of water. One died the second, two the third, one the fourth, two the fifth, three the sixth and one the seventh day.

Check experiment: none dead.

No. 45. - June 21, 1894. Ten caterpillars, of the third molt, were placed on elm leaves which had been sprayed with Paris green and lime, in the proportion of 3 lbs. each to 150 gal. of water. Five died the third, two the sixth and three the seventh day.

Check experiment: two died the seventh day.

No. 46. - June 29, 1894. Ten caterpillars, of the fourth molt, were placed on eim leaves which had been sprayed with Paris green and lime, in the proportion of $3 \mathrm{lbs}$. each to $150 \mathrm{gal}$. of water. Two died the first, one the second, two the third, one the fourth, one the fifth, two the sixth and one the seventh day.

Check experiment: none dead.

No. 47. - July 11, 1894. Ten caterpillars, of the fifth molt, were placed on elm leaves which had been sprayed with Paris green and lime, in the proportion of 3 lbs. each to 150 gal. of water. Two pupated the second and one the third day; two died the seventh and four the ninth day; one pupated the eleventh day.

Check experiment: one died the third day; two pupated the fifth day; one died the eighth and one the tenth day.

No. 48 (field experiment).- July 7, 1894. Ten caterpillars, of the fifth molt, were placed on willow brauches which had been sprayed with Paris green and lime, in the proportion of $3 \mathrm{lbs}$. each to $150 \mathrm{gal}$. of water. One died the fourth and two the fifth day; two died and one pupated 
the seventh day; one pupated the tenth, one the fourteenth, one the fifteenth and one the twenty-first day.

4 lbs. Each Paris Green and Lime to 150 gal. Water.

No. 49. - April 26, 1894. Ten caterpillars, three days old, were placed on lettuce leaves which had been treated with Paris green and lime, in the proportion of $4 \mathrm{lbs}$. each to 150 gal. of water. Six died the second and four the third day.

Check experiment: none dead.

No. 50. - May 9, 1894. Ten caterpillars, six days old, were placed on lettuce leaves which had been treated with Paris green and lime, in the proportion of $4 \mathrm{lbs}$. each to 150 gal. of water. Five died the second, four the third and one the fifth day.

Check experiment: none dead.

No. 51. - May 28, 1894. Ten caterpillars, of the fifth molt, were placed on lettuce leaves which had been treated with Paris green and lime, in the proportion of $4 \mathrm{lbs}$. each to $150^{\prime}$ gal. of water. Three died the fourth, three the fifth, three the sixth and one the serenth day.

Check experiment: none dead.

No. 52. - June 10, 1894. Ten caterpillars, of the second molt, were placed on elm leaves which had been sprayed with Paris green and lime, in the proportion of $4 \mathrm{lbs}$. each to $150 \mathrm{gal}$. of water. One died the third, two the fourth, three the fifth and four the seventh day.

Check experiment : none dead.

No. 53. - June 21, 1894. Ten caterpillars, of the third molt, were placed on elm leaves which had been sprayed with Paris green and lime, in the proportion of $4 \mathrm{lbs}$. each to 150 gal. of water. Three died the second, four the third, one the fifth and two the sixth day.

Check experiment: none dead.

No. 54. - June 29, 1894. Ten caterpillars, of the fourth molt, were placed on elm leaves which were sprayed with Paris green and lime, in the proportion of $4 \mathrm{lbs}$. each to 150 gal. of water. One died the first, one the second, two the third, four the fourth and two the fifth day.

Check experiment: none dead. 
No. 55. - July 11, 1894. Ten caterpillars, of the fifth molt, were placed on elm leaves which had been sprayed with Paris green and lime, in the proportion of $4 \mathrm{lbs}$. each to 150 gal. of water. Three pupated the second day; one died the third, one the fourth, one the fifth, two the sixth, one the seventh and one the eighth day.

Check experiment: two pupated the third, one the fourth and one the sixth day.

No. 56 (field experiment). - July 7, 1894. Ten caterpillars, of the fifth molt, were placed on willow branches which had been sprayed with Paris green and lime, in the proportion of $4 \mathrm{lbs}$. each to 150 gal. of water. One died the fourth, one the fifth, one the sixth and one the seventh day; one pupated the ninth day; one died and one pupated the tenth day; one pupated the thirteenth, one the seventeenth and one the eighteenth day.

\section{5 lbs. Each Paris Green and Lime to 150 gal. Water.}

No. 57.-April 26, 1894. Ten caterpillars, three days old, were placed on lettuce leaves which had been treated with Paris green and lime, in the proportion of $5 \mathrm{lbs}$. each to 150 gal. of water. One died the first, two the second and five the third day; and two escaped.

Check experiment: none dead.

No. 58. - May 9, 1895. Ten caterpillars, six days old, were placed on lettuce leaves which had been treated with Paris green and lime, in the proportion of $5 \mathrm{lbs}$. each to 150 gal. of water. One died the second, one the third, five the fourth and three the fifth day.

Check experiment: none dead.

No. 59. - May 28, 1894. Ten caterpillars, of the first molt, were placed on lettuce leaves which had been treated with Paris green and lime, in the proportion of $5 \mathrm{lbs}$. each to 150 gal. of water. Two died the third, one the fourth, two the fifth, three the sixth and two the eighth day.

Check experiment: none dead.

No. 60. - June 10, 1894. Ten caterpillars, of the second molt, were placed on elm leaves which had been sprayed with Paris green and lime, in the proportion of 5 lbs. each 
to 150 gal. of water. Four died the second, one the third, two the fourth, two the fifth and one the sixth day.

Check experiment: none dead.

No. 61. - June 21, 1894. Ten caterpillars, of the third molt, were placed on elm leaves which had been sprayed with Paris green and lime, in the proportion of 5 lbs. each to $150 \mathrm{gal}$. of water. Two died the second, one the third, two the fourth, two the sixth, two the seventh and one the eighth day.

Check experiment: one died the seventh day.

No. 62. - June 29, 1894. Ten caterpillars, of the fourth molt, were placed on elm leaves which had been sprayed with Paris green and lime, in the proportion of $5 \mathrm{lbs}$. each to 150 gal. of water. Two died the second, four the third, three the fourth and one the sixth day.

Check experiment: none dead.

No. 63. - July 11, 1894. Ten caterpillars, of the fifth molt, were placed on elm leaves which had been sprayed with Paris green and lime, in the proportion of $5 \mathrm{lbs}$. each to $150 \mathrm{gal}$. of water. Two pupated and two died the second day; one died and one pupated the third day; one died the seventh and three the eighth day.

Check experiment: two pupated the third day; one died and three pupated the fifth day; one pupated the eighth day.

No. 64 (field experiment). - July 7, 1894. Ten caterpillars, of the fifth molt, were placed on willow branches which had been sprayed with Paris green and lime, in the proportion of $5 \mathrm{lbs}$. each to $150 \mathrm{gal}$. of water. One died the fourth, one the fifth, one the sixth and one the seventh day; two died and one pupated the eighth day; one pupated and one was lost the fourteenth day; one pupated the thirtythird day.

6 lbs. Each Paris Green and Lime to 150 gal. Water.

No. 65. - April 26, 1894. Ten caterpillars, three days old, were placed on lettuce leaves which had been treated with Paris green and lime, in the proportion of $6 \mathrm{lbs}$. each to 150 gal. of water. Six died the second, three the third and one the fourth day. 
Check experiment: none dead.

No. 66. - May 9, 1894. Ten caterpillars, six days old, were placed on lettuce leaves which had been treated with Paris green and lime, in the proportion of $6 \mathrm{lbs}$. each to 150 gal. of water. One died the second, three the third, three the fourth and three the fifth day.

Check experiment: one died the third day.

No. 67. - May 28, 1894. Ten caterpillars, of the first molt, were placed on lettuce leaves which had been treated with Paris green and lime, in the proportion of $6 \mathrm{lbs}$. each to $150 \mathrm{gal}$. of water. Six died the third, two the fourth, one the fifth and one the sixth day.

Check experiment: none dead.

No. 68. - June 10, 1894. Ten caterpillars, of the second molt, were placed on elm leaves which had been treated with Paris green and lime, in the proportion of $6 \mathrm{lbs}$. each to 150 gal. of water. Three died the second, three the third, two the fifth, one the sixth and one the seventb day.

Check experiment : none dead.

No. 69. - June 21, 1894. Ten caterpillars, of the third molt, were placed on elm leaves which had been sprayed with Paris green and lime, in the proportion of $6 \mathrm{lbs}$. each to 150 gal. of water. Two died the second, one the third, two the fourth, one the sixth and four the seventh day.

Check experiment : one accidentally killed the seventh day. No. 70. - June 29, 1894. Ten caterpillars, of the fourth molt, were placed on elm leaves which had been sprayed with Paris green and lime, in the proportion of $6 \mathrm{lbs}$. each to 150 gal. of water. Six died the second, two the third and two the fourth day.

Check experiment: one died the third day.

No. 71. - July 11, 1894. Ten caterpillars, of the fifth molt, were placed on elm leaves which had been sprayed with Paris green and lime, in the proportion of $6 \mathrm{lbs}$. each to 150 gal. of water. One died the first day; one died and two pupated the second day; one died the third day; one pupated the firth day; three died the seventh and one the eleventh day.

Check experiment: one pupated the third day; one died and four pupated the fifth day; one died the tenth day. 
No. 72 (field experiment).- July 7, 1894. Ten caterpillars, of the fifth molt, were placed on willow branches which had been sprayed with Paris green and lime, in the proportion of $6 \mathrm{lbs}$. each to $150 \mathrm{gal}$. of water. One died the fourth, one the sixth, two the seventh and one the eighth day; one pupated the fourteenth, one the fifteenth, one the sixteenth and two the eighteenth day.

\section{Experiments with Arsenate of Lead.}

$\frac{1}{8}$ lb. Arsenate of Lead to 150 gal. Water.

No. 1.-March 7, 1894. Ten caterpillars, three days old, were placed on lettuce leaves which had been treated with arsenate of lead, in the proportion of $\frac{1}{8} \mathrm{lb}$. to $150 \mathrm{gal}$. of water. One died the fifth, one the sixth and one the seventh day; those remaining lived and molted.

No. 2.-May 9, 1894. Ten caterpillars, six days old, were placed on lettuce leaves, which had been treated with arsenate of lead, in the proportion of $\frac{1}{8} \mathrm{lb}$. to $150 \mathrm{gal}$. of water. One died the fifth day; those remaining lived and molted.

Check experiment: none dead.

No. 3. - May 28, 1894. Ten caterpillars, of the first molt, were placed on lettuce leaves which had been treated with arsenate of lead, in the proportion of $\frac{1}{8} \mathrm{lb}$. to $150 \mathrm{gal}$. of water. All lived through the experiment.

Check experiment : none dead.

No. 4. - June 10, 1894. Tẹn caterpillars, of the second molt, were placed on elm leaves which had been sprayed with arsenate of lead, in the proportion of $\frac{1}{8} \mathrm{lb}$. to $150 \mathrm{gal}$. of water. All lived through the experiment.

Check experiment: none dead.

No. 5. - June 21, 1894. Ten caterpillars, of the third molt, were placed on elm leaves which had been sprayed with arsenate of lead, in the proportion of $\frac{1}{8} \mathrm{lb}$. to $150 \mathrm{gal}$. of water. One died the seventh, three the eighth and one the ninth day; one pupated the tenth day; one died the eleventh day. The remainder lived through the experiment.

Check experiment: one was lost the seventh day; one pupated the eighth day; two died the tenth day. 


\section{1 lb. Arsenate of Lead to 150 gal. Water.}

No. 6.-March 7, 1894. Ten caterpillars, three days old, were placed upon lettuce leaves which had been treated with arsenate of lead, in the proportion of $\frac{1}{4} \mathrm{lb}$ to $150 \mathrm{gal}$. of water. On the ninth day six were dead and four lost.

No. 7. - May 9, 1894. Ten caterpillars, six days old, were placed on lettuce leaves which had been treated with arsenate of lead, in the proportion of $\frac{1}{4} \mathrm{lb}$. to $150 \mathrm{gal}$. of water. All lived through the experiment (seventeen days).

Check experiment: none dead.

No. 8. - May 28, 1894. Ten caterpillars, of the first molt, were placed on lettuce leaves which had been treated with arsenate of lead, in the proportion of $\frac{1}{4} \mathrm{lb}$. to $150 \mathrm{gal}$. of water. One died the third, one the fourth, one the seventh and one the ninth day; the remainder lived through the experiment.

Check experiment: none dead.

No. 9.-June 10, 1894. Ten caterpillars, of the second molt, were placed on elm leaves which had been sprayed with arsenate of lead, in the proportion of $\frac{1}{4} \mathrm{lb}$. to $150 \mathrm{gal}$. of water. One died the fifth and two the eleventh day; the remainder lived through the experiment.

Check experiment: none dead.

No. 10. - June 21, 1894. Ten caterpillars, of the third molt, were placed on elm leaves which had been sprayed with arsenate of lead, in the proportion of $\frac{1}{4} \mathrm{lb}$. to $150 \mathrm{gal}$. of water. One died the fourth, one the fifth and one the sixth, two died and one pupated the seventh, two died the eighth, one the tenth and one the eleventh day.

Check experiment: one died the seventh and one the ninth day; one was lost the tenth day.

No. 11 (field experiment). - June 29, 1893. A branch of oak was sprayed with arsenate of lead, in the proportion of $\frac{1}{4} \mathrm{lb}$. to $150 \mathrm{gal}$. of water, and nine fourth-molt caterpillars placed upon it. July 31, for lack of food, they were transferred to a fresh branch, which was left unsprayed. All these caterpillars pupated and six emerged. Foliage uninjured.

No. 12 (field experiment). - June 29, 1893. A branch 
of oak was sprayed with arsenate of lead, in the proportion of $\frac{1}{4} \mathrm{lb}$. to $150 \mathrm{gal}$. of water, and ten caterpillars, of the fourth molt, were placed upon it. Three of these died before pupating, the last one dying thirty-seven days after the first spraying. Of the seven that pupated, all emerged. Foliage uninjured.

No. 13 (field experiment). - June 29, 1893. A branch of a small oak was sprayed with arsenate of lead, in the proportion of $\frac{1}{4} \mathrm{lb}$. to $150 \mathrm{gal}$. of water, and ten fifth-molt caterpillars placed upon it. July 20, the branch was resprayed on account of the rain on the 18th. Only one caterpillar died before pupating, and seven were able to complete the process of pupation and emerge. Another one fed on the leaves for nine days after the spraying and pupated, but was injured in removing, and therefore not counted in the above summary. Foliage uninjured.

No. 14 (field experiment). - June 29, 1893. A branch of a small oak tree was sprayed with arsenate of lead, in the proportion of $\frac{1}{4} \mathrm{lb}$. to $150 \mathrm{gal}$. of water, and nine fifth-molt caterpillars were placed upon it. July 20, the branch was resprayed on account of rain. Only one caterpillar died before pupating, and that on the forty-first day after the first spraying. Of the eight that pupated, two died without emerging. Foliage uninjured.

\section{$\frac{1}{2} l b$. Arsenate of Lead to 150 gal. Water.}

No. 15. - March 7, 1894. Ten caterpillars, three days old, were placed on lettuce leaves which had been treated with arsenate of lead, in the proportion of $\frac{1}{2} \mathrm{lb}$. to $150 \mathrm{gal}$. of water. On the eighth day all were dead.

No. 16. - May 9, 1894. Ten caterpillars, six days old, were placed on lettuce leaves which had been treated with arsenate of lead, in the proportion of $\frac{1}{2} \mathrm{lb}$. to $150 \mathrm{gal}$. of water. One died the fifth day ; the remainder lived through the experiment and molted.

Check experiment: none dead.

No. 17. - May 28, 1894. Ten caterpillars, of the first molt, were placed on lettuce leaves which had been treated with arsenate of lead, in the proportion of $\frac{1}{2} \mathrm{lb}$. to $150 \mathrm{gal}$. of water. One died the third, one the fourth, two the fifth, 
one the tenth and one the eleventh day; the remainder lived through the experiment.

Check experiment: none dead.

No. 18. - June 10, 1894. Ten caterpillars, of the second molt, were placed on elm leaves which had been sprayed with arsenate of lead, in the proportion of $\frac{1}{2} \mathrm{lb}$. to $150 \mathrm{gal}$. of water. Two died the fifth, one the seventh, three the eighth, two the ninth, one the tenth and one the twelfth day.

Check experiment: none dead.

No. 19. - June 21, 1894. Ten caterpillars, of the third molt, were placed on elm leaves which had been sprayed with arsenate of lead, in the proportion of $\frac{1}{2} \mathrm{lb}$. to 150 gal. of water. Two died the third, three the seventh, two the eighth, one the tenth and two the twelfth day.

Check experiment: two died the seventh and one the eighth day; two were lost.

No. 20 (field experiment). - June 28, 1893. A branch of hop-hornbeam was sprayed with arsenate of lead, in the proportion of $\frac{1}{2} \mathrm{lb}$. to $150 \mathrm{gal}$. of water, and ten fourth-molt caterpillars placed upon it. On the 19th of July, the food having given out and two of the caterpillars having died, those remaining were transferred to a freshly sprayed branch. Of the ten, two died before pupating, and of the eight that pupated, five emerged. Foliage uninjured.

No. 21 (field experiment). - June 28, 1893. A branch of hop-hornbeam was sprayed with arsenate of lead, in the proportion of $\frac{1}{2} \mathrm{lb}$. to $150 \mathrm{gal}$. of water, and nine fourthmolt caterpillars placed upon it. July 19, as the food supply was nearly gone, the caterpillars were removed to a freshly sprayed branch. One died before beginning to pupate, and of the eight which pupated, six emerged. Foliage uninjured.

No. 22 (field experiment).- - June 29, 1893. A branch of a small oak tree was sprayed with arsenate of lead, in the proportion of $\frac{1}{2} \mathrm{lb}$. to 150 gal. of water, and nine fourthmolt caterpillars were placed upon it. July 20, they were transferred to a freshly sprayed branch, both on account of the food supply and rain. It was noticeable that on the old branch the caterpillars had eaten all of the old, tough leaves, and left the young and fresh ones. Two died before pupat- 
ing, and, of the seven that pupated, four emerged. Foliage uninjured.

No. 23 (field experiment).- June 29, 1893. An oak hranch was sprayed with arsenate of lead, in the proportion of $\frac{1}{2} \mathrm{lb}$. to 150 gal. of water, and ten fourth-molt caterpillars were placed upon it. July 20, the branch was resprayed on account of rain. One died before pupating, and eight of the nine that pupated emerged. Foliage uninjured.

No. 24 (field experiment). - June 28, 1893. A branch of hop-hornbeam was sprayed with arsenate of lead, in the proportion of $\frac{1}{2} \mathrm{lb}$. to $150 \mathrm{gal}$. of water, and nine fifth-molt caterpillars placed upon it. On the 19th of July, they were removed to a freshly sprayed branch. Of the eight that pupated, six emerged. Foliage uninjured.

No. 25 (field experiment). - June 28, 1893. A branch of hop-hornbeam was sprayed with arsenate of lead, in the proportion of $\frac{1}{2} \mathrm{lb}$. to 150 gal. of water, and ten fifth-molt caterpillars placed upon it. July 15, as the food supply was getting low, the caterpillars were removed to another branch which was not sprayed. Three died before pupating, and, of the seven which pupated, six emerged. Foliage uninjured.

No. 26. - June 29, 1893. An oak branch was sprayed with arsenate of lead, in the proportion of $\frac{1}{2} \mathrm{lb}$. to $150 \mathrm{gal}$. of water, and nine fifth-molt caterpillars placed upon it. July 5, they were transferred to a freshly sprayed branch. Only one of these caterpillars died before beginning to pupace, and, of those that pupated, seven emerged. Foliage uninjured.

No. 27 (field experiment). - June 29, 1893. A branch of oak was sprayed with arsenate of lead, in the proportion of $\frac{1}{2} \mathrm{lb}$. to $150 \mathrm{gal}$. of water, and ten fifth-molt caterpillars placed upon it. July 15, for lack of food, they were trans. ferred to a freshly sprayed branch. None of these cater. pillars died before pupating, and five emerged. Foliage uninjured.

8. $7 b$. Arsenate of Lead to 150 gal. Water.

No. 28. - March 7, 1894. Ten eaterpillars, three days old, were placed on lettuce leaves which had been treated with arsenate of lead, in the proportion of $\frac{8}{4} \mathrm{lb}$. to $150 \mathrm{gal}$. of water. On the fourth day one died, on the fifth three, on 
the sixth two and on the seventh three; the remaining one was lost.

No. 29. - May 9, 1894. Ten caterpillars, six days old, were placed on lettuce leaves which had been treated with arsenate of lead, in the proportion of $\frac{3}{4} \mathrm{lb}$. to $150 \mathrm{gal}$. of water. All lived through the experiment.

Check experiment: none dead.

No. 30. - May 28, 1894. Ten caterpillars, of the first molt, were placed on lettuce leaves which had been treated with arsenate of lead, in the proportion of $\frac{3}{4} \mathrm{lb}$. to $150 \mathrm{gal}$. of water. One died the eighth and three the tenth day; those remaining lived through the experiment.

Check experiment: none dead.

No. 31. - June 10, 1894. 'Ten caterpillars, of the second molt, were placed on elm leaves which had been sprayed with arsenate of lead, in the proportion of $\frac{3}{4} \mathrm{lb}$. to $150 \mathrm{gal}$. of water. Two died the fifth, one the ninth, one the eleventh, two the thirteenth and four the eighteenth day.

Check experiment : none dead.

No. 32. - June 21, 1894. Ten caterpillars, of the third molt, were placed on elm leaves which had been sprayed with arsenate of lead, in the proportion of $\frac{3}{4} \mathrm{lb}$. to $150 \mathrm{gal}$. of water. One died the third, one the seventh and one the ninth day; one pupated the tenth day; one died and one pupated the eleventh day; and four died the twelfth day.

Check experiment: one pupated the tenth day and two died the eleventh day.

No. 33 (field experiment). - June 27, 1893. A branch of hop-hornbeam was sprayed with arsenate of lead, in the proportion of $\frac{3}{4} \mathrm{lb}$. to $150 \mathrm{gal}$. of water, and nine fourthmolt caterpillars placed upon it. Of these, three died before pupating, and, of the six which pupated, three emerged. Foliage uninjured.

No. 34 (field experiment).- June 27, 1893. A branch of hop-hornbeam was sprayed with arsenate of lead, in the proportion of $\frac{3}{4} \mathrm{lb}$. to $150 \mathrm{gal}$. of water, and nine fourthmolt caterpillars placed upon it. Of these, seven pupated and emerged, one began pupating but died later, and one died in the larval stage. Foliage uninjured.

No. 35 (field experiment). - June 27, 1893. A branch 
of hop-hornbeam was sprayed with arsenate of lead, in the proportion of $\frac{3}{4} \mathrm{lb}$. to 150 gal. of water, and ten caterpillars, of the fourth molt, placed upon it. July 8, the foliage was so badly burned that the nine remaining caterpillars were transferred to a freshly sprayed branch of oak. By the 19th of July all were dead. The foliage of the oak was slightly burned.

No. 36 (field experiment). - June 27, 1893. A branch of hop-hornbeam was sprayed with arsenate of lead, in the proportion of $\frac{3}{4} \mathrm{lb}$. to $150 \mathrm{gal}$. of water, and ten fifth-molt caterpillars placed upon it. All died without pupating.

No. 37 (field experiment). - June 27, 1893. A branch of hop-hornbeam was sprayed with arsenate of lead, in the proportion of $\frac{3}{4} \mathrm{lb}$. to $150 \mathrm{gal}$. of water, and nine fifth-molt caterpillars placed upon it. Of these, only one completed the process of pupation and emerged, three having died before beginning to pupate. Foliage uninjured.

\section{$1 \mathrm{lb}$. Arsenate of Lead to $150 \mathrm{gal}$. Water.}

No. 38. - March 7, 1894. Ten caterpillars, three days old, were placed on lettuce leaves which had been treated with arsenate of lead, in the proportion of $1 \mathrm{lb}$. to $150 \mathrm{gal}$. of water. One died the fifth, three the sixth and one the seventh day; and five were lost.

No. 39. - May 9, 1894. Ten caterpillars, six days old, were placed on lettuce leaves which had been treated with arsenate of lead, in the proportion of $1 \mathrm{lb}$. to $150 \mathrm{gal}$. of water. All lived through the experiment and molted.

Check experiment : none dead.

No. 40. - May 28, 1894. Ten caterpillars, of the first molt, were placed on lettuce leaves which had been treated with arsenate of lead, in the proportion of $1 \mathrm{lb}$. to $150 \mathrm{gal}$. of water. Four died the fourth, one the seventh, one the eighth and one the ninth day; the remainder lived through the experiment.

Check experiment : one died the third and one the seventh day.

No. 41. - June 10, 1894. Ten caterpillars, of the second molt, were placed on elm leaves which had been sprayed with arsenate of lead, in the proportion of $1 \mathrm{lb}$. to $150 \mathrm{gal}$. 
of water. One died the second, one the seventh, three the ninth, four the tenth and one the eleventh day.

Check experiment: none dead.

No. 42. - June 21, 1894. Ten caterpillars, of the third molt, were placed on elm leaves which had been sprayed with arsenate of lead, in the proportion of $1 \mathrm{lb}$. to $150 \mathrm{gal}$. of water. One died the fifth, two the sixth, three the seventh and four the eighth day.

Check experiment: one died the seventh and one the eighth day.

No. 43. - June 29, 1894. Ten caterpillars, of the fourth molt, were placed on elm leaves which had been sprayed with arsenate of lead, in the proportion of $1 \mathrm{lb}$. to $150 \mathrm{gal}$. of water. One died the second, one the third, two the fourth and one the fifth, sixth, seventh, eighth, ninth and tenth days.

Check experiment : one lost and one dead the seventh day. No. 44 (field experiment). - June 26, 1893. An appletree branch was sprayed with arsenate of lead, in the proportion of $1 \mathrm{lb}$. to $150 \mathrm{gal}$. of water, and eight fourth-molt caterpillars placed upon it. Of these, only one died before pupating, and, of the seven which pupated, three emerged. Foliage uninjured.

No. 45 (field experiment)._-June 26, 1893. A branch of an apple tree was sprayed with arsenate of lead, in the proportion of $1 \mathrm{lb}$. to $150 \mathrm{gal}$. of water, and eight fourthmolt caterpillars placed upon it. Of these, six died before pupating, and, of the two which pupated, one emerged. Foliage uninjured.

No. 46. - July 9, 1894. Ten caterpillars, of the fifth molt, were placed on elm leaves which had been sprayed with arsenate of lead, in the proportion of $1 \mathrm{lb}$. to $150 \mathrm{gal}$. of water. One died and one pupated the second day; one died the third, one the fourth, two the fifth, one the seventh, tenth, eleventh and sixteenth days.

Check experiment: one pupated the third day; one died the seventh, eighth, ninth and eleventh days; two pupated the twelfth day; one died the thirteenth and one the fourteenth day; and one was living at the close of the experiment. 
No. 47 (field experiment). - July 9, 1894. Ten caterpillars, of the fith molt, were placed on willow branches which had been sprayed with arsenate of lead, in the proportion of $1 \mathrm{lb}$. to $150 \mathrm{gal}$. of water. One pupated the fifth and one the sixth day; one died and one pupated the seventh day; one pupated the twelfth day; one died the thirteenth, one the fifteenth and one the sixteenth day; one pupated the twenty-fourth and one the twenty-eighth day.

No. 48 (field experiment). - June 26, 1893. An appletree branch was sprayed with arsenate of lead, in the proportion of $1 \mathrm{lb}$. to $150 \mathrm{gal}$. of water, and eight fifth-molt caterpillars placed upon it. Of these, only one died before pupating, and, of those that pupated, one died without emerging. Foliage uninjured.

No. 49 (field experiment). - June 26, 1893. An appletree branch was sprayed with arsenate of lead, in the proportion of $1 \mathrm{lb}$. to $150 \mathrm{gal}$. of water, and ten fifth-molt caterpillars placed upon it. One of these died before pupating, and, of the remaining nine, eight completed the process of pupation and emerged. The foliage was uninjured.

No. 50 (field experiment). - July 1, 1893. A small oak branch was sprayed with arsenate of lead, in the proportion of $1 \mathrm{lb}$. to $150 \mathrm{gal}$. of water, and ten large fifth-molt caterpillars placed upon it. All died within twelve days after spraying. Foliage uninjured.

\section{$1 \frac{1}{2} \mathrm{lb}$. Arsenate of Lead to $150 \mathrm{gal}$. Water.}

No. 51. - March 7, 1894. Ten caterpillars, three days old, were placed on lettuce leaves which had been treated with arsenate of lead, in the proportion of $1 \frac{1}{2} \mathrm{lbs}$. to 150 gal. of water. One died the fourth, three the fifth, one the sixth and one the twelfth day; those remaining lived through the experiment.

No. 52. - May 9, 1894. Ten caterpillars, six days old, were placed on lettuce leaves which had been treated with arsenate of lead, in the proportion of $1 \frac{1}{2}$ lbs. to $150 \mathrm{gal}$. of water. Three died the fifth day ; the remainder lived through the experiment and molted.

Check experiment: none dead.

No. 53. - May 28, 1894. Ten caterpillars, of the first 
molt, were placed on lettuce leaves which had been treated with arsenate of lead, in the proportion of $1 \frac{1}{2}$ lbs. to 150 gal. of water. One died the third, one the fourth, two the fifth, three the sixth and two the ninth day; the remainder lived through the experiment.

Check experiment: none dead.

No. 54. - June 10, 1894. Ten caterpillars, of the second molt, were placed on lettuce leaves which had been treated with arsenate of lead, in the proportion of $1 \frac{1}{2}$ lbs. to 150 gal. of water. One died the fifth, two the sixth, one the seventh, two the eighth, three the ninth and one the eleventh day.

Check experiment: none dead.

No. 55. - June 21, 1894. Ten caterpillars, of the third molt, were placed on elm leaves which had been sprayed with arsenate of lead, in the proportion of $1 \frac{1}{2} \mathrm{lbs}$. to 150 gal. of water. Two died the third, two the fifth and one the sixth day; one died and one pupated the seventh day; two died the eighth and one the ninth day.

Check experiment : one died the ninth day.

No. 56. - June 29, 1894. Ten caterpillars, of the fourth molt, were placed on elm leaves which had been sprayed with arsenate of lead, in the proportion of $1 \frac{1}{2} \mathrm{lbs}$. to $150 \mathrm{gal}$. of water. One died the first, one the second, two the third, two the fourth, two the fifth and two the seventh day.

Check experiment: one pupated the second day; one died the fourth and one the sixth day.

No. 57 (field experiment). - June 24, 1893. An appletree branch was sprayed with arsenate of lead, in the proportion of $1 \frac{1}{2} \mathrm{lbs}$. to $150 \mathrm{gal}$. of water, and nine fourth-molt caterpillars placed upon it. Two died before pupating, and, of the seven that pupated, one died without emerging. Foliage uninjured.

No. 58. - July 9, 1894. Ten caterpillars, of the fifth molt, were placed on elm leaves which had been sprayed with arsenate of lead, in the proportion of $1 \frac{1}{2} \mathrm{lbs}$. to $150 \mathrm{gal}$. of water. One died and one pupated the fourth day; one died and one pupated the fifth day; two died the sixth and one the seventh day; one pupated the ninth day; two died the eleventh day. 
Check experiment: three pupated the fourth and two the fifth day; one died and one pupated the seventh day; one died the eighth day; and two were living at the close of the experiment.

No. 59 (field experiment). - July 9, 1894. Ten caterpillars, of the fifth molt, were placed on willow branches which had been sprayed with arsenate of lead, in the proportion of $1 \frac{1}{2}$ lbs. to 150 gal. of water. One died the fifth day; one pupated the eleventh and one the twelfth day, one died the fourteenth day; one pupated the fifteenth day, one died the sixteenth day; one pupated the eighteenth, one the twentieth, one the twenty-first and one the twenty-fourth day.

No. 60 (field experiment). - June 24, 1893. A branch of apple tree was sprayed with arsenate of lead, in the proportion of $1 \frac{1}{2}$ lbs. to $150 \mathrm{gal}$. of water, and ten fifth-molt caterpillars placed upon it. July 10, one caterpillar having pupated and been removed, those remaining were transferred to a freshly sprayed apple branch. Only four of the ten which pupated emerged. Foliage uninjured.

2 lbs. Arsenate of Lead to 150 gal. Water.

No. 61. - March 7, 1894. Ten caterpillars, three days old, were placed on lettuce leaves which had been treated with arsenate of lead, in the proportion of $2 \mathrm{lbs}$. to $150 \mathrm{gal}$. of water. One died the first, four the fourth, two the fifth and two the sixth day; and one was lost.

No. 62. - May 9, 1894. Ten eaterpillars, six days old, were placed on lettuce leaves which had been treated with arsenate of lead, in the proportion of $2 \mathrm{lbs}$. to $150 \mathrm{gal}$. of water. On the fifth day five were dead; two died the sixth and three the seventh day.

Check experiment : none dead.

No. 63. - May 28, 1894. Ten caterpillars, of the first molt, were placed on lettuce leaves which had been treated with arsenate of lead, in the proportion of $2 \mathrm{lbs}$. to $150 \mathrm{gal}$. of water. On the fourth day two died; on the fifth, three; on the sixth, two; on the seventh, one; on the eighth, one; and on the eleventh, one.

Cheek experiment: one died the sixth day.

No. 64. - June 10, 1894. Ten caterpillars, of the second 
molt, were placed on elm leaves which had been sprayed with arsenate of lead, in the proportion of $2 \mathrm{lbs}$. to 150 gal. of water. One died the second, three the fourth, three the fifth, one the sixth, one the serenth and one the tenth day.

Check experiment: none dead.

No. 65. - June 21, 1894. Ten caterpillars, of the third molt, were placed on elm leaves which had been sprayed with arsenate of lead, in the proportion of $2 \mathrm{lbs}$. to $150 \mathrm{gal}$. of water. Four died the third, three the fourth, two the sixth and one the seventh day.

Check experiment: one lost the seventh and one the eighth day.

No. 66. - June 29, 1894. Ten caterpillars, of the fourth molt, were placed on elm leaves which had been sprayed with arsenate of lead, in the proportion of $2 \mathrm{lbs}$. to $150 \mathrm{gal}$. of water. Two died the fourth, four the fifth, two the sixth and two the seventh day.

Check experiment: one died and two pupated the second day; two died the third day, two the fourth and three the fifth day.

No. 67 (field experiment). - June 21, 1893. A branch of hop-hornbeam was sprayed with arsenate of lead, in the proportion of $2 \mathrm{lbs}$. to $150 \mathrm{gal}$. of water, and ten fourthmolt caterpillars placed upon it. Four of these caterpillars began to pupate, and, as the food gave out, those remaining were transferred to a branch which had not been sprayed, two more pupating after their removal. The other four caterpillars died from the effects of the poison. Foliage uninjured.

No. 68 (field experiment). - June 24, 1893. A branch of apple tree was sprayed with arsenate of lead, in the proportion of $2 \mathrm{lbs}$. to $150 \mathrm{gal}$. of water, and eight fourth-molt caterpillars placed upon it. On account of the rain, the branch was resprayed twice. One caterpillar pupated, and from the pupa a male moth emerged. The rest were all dead by the 9th of August. Foliage uninjured.

No. 69 (field experiment).- - June 24, 1893. A branch of apple tree was sprayed with arsenate of lead, in the proportion of $2 \mathrm{lbs}$. to 150 gal. of water, and nine fourth-molt caterpillars placed upon it. Five of the caterpillars died before pupating, and, of the four that pupated, three emerged. 
The poison acted very slowly, as none of the caterpillars died for nearly three weeks, and one lived eight weeks.

No. 70.-July 9, 1894. Ten caterpillars, of the fifth molt, were placed on elm leaves which had been sprayed with arsenate of lead, in the proportion of 2 lbs. to 150 gal. of water. One died the second day; three died and one pupated the fifth day; one died and one pupated the sixth and seventh days; and one pupated the tenth day.

Check experiment: two pupated the fourth, three the fifth, one the sixth, seventh and eighth days; and two were living at the close of the experiment.

No. 71 (field experiment). - July 9, 1894. Ten caterpillars, of the fifth molt, were placed on willow branches which had been sprayed with arsenate of lead, in the proportion of $2 \mathrm{lbs}$. to $150 \mathrm{gal}$. of water. One died the first day ; one pupated the third day; one died the fourth and one the fifth day; one pupated the eighth and one the twelfth day; one died and one pupated the thirteenth day; one pupated the fifteenth and one the eighteenth day.

No. 72 (field experiment). - June 21, 1893. A branch of a small hop-hornbeam was sprayed with arsenate of lead, in the proportion of $2 \mathrm{lbs}$. to $150 \mathrm{gal}$. of water, and ten fifthmolt caterpillars were placed upon it. July 14, all were dead. In this experiment the caterpillars died gradually, the first one dying two days after the poison had been applied, the last one living twenty-two days. The foliage of the tree was uninjured.

No. 73 (field experiment). - June 24, 1893. A branch of apple tree was sprayed with arsenate of lead, in the proportion of $2 \mathrm{lbs}$. to $150 \mathrm{gal}$. of water, and nine fifth-molt caterpillars placed upon it. In this experiment the poison was nearly all washed off by heavy rains soon after it was applied. Four of the caterpillars molted and two pupated, but all were dead August 2. Foliage uninjured.

No. 74 (field experiment).- June 24, 1893. A branch of apple tree was sprayed with arsenate of lead, in the proportion of $2 \mathrm{lbs}$. to $150 \mathrm{gal}$. of water, and nine fifth-molt caterpillars placed upon it. Six of the nine caterpillars died before pupating, and, of the three which pupated, only one emerged. Foliage uninjured. 
No. 75 (field experiment)._-July 7, 1893. A branch of oak was sprayed with arsenate of lead, in the proportion of $2 \mathrm{lbs}$. to $150 \mathrm{gal}$. of water, and ten caterpillars, of the fifth molt, placed upon it. On July 22, and also on the $27 \mathrm{th}$, the branch was resprayed on account of rain. In this experiment only one caterpillar began pupating, and that one was not able to complete the process.

No. 76 (field experiment).-July 7, 1893. A branch of oak was sprayed with arsenate of lead, in the proportion of 2 lbs. to $150 \mathrm{gal}$. of water, and ten fifth-molt caterpillars placed upon it. Three of these began pupating, and one emerged; but, as this one began to pupate very soon after the poison was applied, it probably did not get any ill effect from it. Foliage uninjured.

\section{3 lbs. Arsenate of Lead to 150 gal. Water.}

No. 77. - March 7, 1894. Ten caterpillars, three days old, were placed on lettuce leaves which had been treated with arsenate of lead, in the proportion of $3 \mathrm{lbs}$. to $150 \mathrm{gal}$. of water. Six died the third, one the fourth and three the sixth day.

No. 78. - May 9, 1894. Ten caterpillars, six days old, were placed on lettuce leaves which had been treated with arsenate of lead, in the proportion of $3 \mathrm{lbs}$. to $150 \mathrm{gal}$. of water. One died the third, three the fourth, two the fifth, one the sixth and one the seventh day; the remainder survived.

Check experiment: none dead.

No. 79. - May 28, 1894. Ten caterpillars, of the first molt, were placed on lettuce leaves which had been treated with arsenate of lead, in the proportion of $3 \mathrm{lbs}$. to $150 \mathrm{gal}$. of water. Two died the fourth, one the fifth, two the sixth, one the seventh, three the eighth and one the ninth day.

Check experiment: one died the sixth day.

No. 80. - June 10, 1894. Ten caterpillars, of the second molt, were placed on elm leaves which had been sprayed with arsenate of lead, in the proportion of $3 \mathrm{lbs}$. to $150 \mathrm{gal}$. of water. One died the fourth, eight the fifth and one the sixth day.

Check experiment: none dead. 
No. 81. - June 21, 1894. Ten caterpillars, of the third molt, were placed on elm leaves which had been sprayed with arsenate of lead, in the proportion of $3 \mathrm{lbs}$. to $150 \mathrm{gal}$. of water. Three died the fourth, fire the sixth and two the seventh day.

Check experiment: one died the seventh day.

No. 82. - June 29, 1894. Ten caterpillars, of the fourth molt, were placed on elm leares which had been sprayed with arsenate of lead, in the proportion of $3 \mathrm{lbs}$. to $150 \mathrm{gal}$. of water. Two died and one pupated the second day; two died the third, two the fourth and three the fifth day.

Check experiment: two pupated the second and one the fifth day.

No. 83 (field experiment). - June 30, 1893. A branch of a small oak tree was sprayed with arsenate of lead, in the proportion of $3 \mathrm{lbs}$. to $150 \mathrm{gal}$. of water, and seven fourthmolt caterpillars placed upon it. The branch was resprayed July 20, on account of rain. All of these caterpillars died within twenty-five days after the first spraying, and five days after the second. Foliage uninjured.

No. 84 (field experiment). - June 30, 1893. A branch of oak was sprayed with arsenate of lead, in the proportion of $3 \mathrm{lbs}$. to $150 \mathrm{gsl}$. of water, and eight fourth-molt caterpillars placed upon it. August 27, all were dead. Foliage uninjured.

No. 85. - July 9, 1894. Ten caterpillars, of the fifth molt, were placed on leaves which had been sprayed with arsenate of lead, in the proportion of $3 \mathrm{lbs}$. to $150 \mathrm{gal}$. of water. One died and one pupated the third day; one pupated the sixth day; three died the serenth day; one died and two pupated the ninth day; and one pupated the thirteenth day.

Check experiment: one pupated the fourth, fifth and sixth days; one died the serenth day; one pupated the eighth and two the ninth day ; and one died the eleventh day.

No. 86 (field experiment). - July 9, 1894. Ten caterpillars, of the fifth molt, were placed on willow branches which had been sprayed with arsenate of lead, in the proportion of $3 \mathrm{lbs}$. to $150 \mathrm{gal}$. of water. One died the first and one the second day; one pupated the fifth, two the sixth and 
two the eighth day; one died the fourteenth day; one pupated the twenty-fifth and one the twenty-eighth day.

No. 87 (field experiment). - June 30, 1893. A branch of oak was sprayed with arsenate of lead, in the proportion of $3 \mathrm{lbs}$. to $150 \mathrm{gal}$. of water, and ten caterpillars of the fifth molt placed upon it. All died within three weeks, and six of the ten in less than one week after the branch was sprayed. Foliage uninjured.

No. 88 (field experiment). - June 30, 1893. A branch of oak was sprayed with arsenate of lead, in the proportion of $3 \mathrm{lbs}$. to $150 \mathrm{gal}$. of water, and ten caterpillars of the fitth molt placed upon it. July 20, the branch was resprayed on account of rain. Only two of these caterpillars pupated and but one emerged. Foliage uninjured.

4 lbs. Arsenate of Lead to 150 gal. Water.

No. 89.-March 7, 1894. Ten caterpillars, three days old, were placed on lettuce leaves which had been treated with arsenate of lead, in the proportion of $4 \mathrm{lbs}$. to $150 \mathrm{gal}$. of water. Three died the third, two the fourth and five the fifth day.

No. 90. - May 9, 1895. Ten caterpillars, six days old, were placed on lettuce leaves which had been treated with arsenate of lead, in the proportion of $4 \mathrm{lbs}$. to $150 \mathrm{gal}$. of water. One died the third, two the fourth, five the fifth and two the sixth day.

Check experiment: none dead.

No. 91. - May 28, 1894. Ten caterpillars, of the first molt, were placed on lettuce leaves which had been treated with arsenate of lead, in the proportion of $4 \mathrm{lbs}$. to $150 \mathrm{gal}$. of water. Two died the third, three the fourth, two the fifth and three the seventh day.

Check experiment : none dead.

No. 92. - June 10, 1894. Ten caterpillars, of the second molt, were placed on elm leaves which had been sprayed with arsenate of lead, in the proportion of $4 \mathrm{lbs}$. to $150 \mathrm{gal}$. of water. One died the second, one the third, one the fourth, two the fifth, one the sixth, two the seventh and two the eighth day.

Check experiment: none dead. 
No. 93. - June 21, 1894. Ten caterpillars, of the third molt, were placed on elm leaves which had been sprayed with arsenate of lead, in the proportion of $4 \mathrm{lbs}$. to $150 \mathrm{gal}$. of water. One died the third, one the fourth, two the fifth, three the sixth and three the seventh day.

Check experiment: one died the seventh day.

No. 94. - June 29, 1894. Ten caterpillars, of the fourth molt, were placed on elm leaves which had been sprayed with arsenate of lead, in the proportion of 4 lbs. to $150 \mathrm{gal}$. of water. One died the second, five the third, two the fourth, one the fifth and one the sixth day.

Check experiment: one pupated and one died the second day; one pupated the third day; and one died the fifth day.

No. 95 (field experiment). - June 21, 1893. A branch of hop-hornbeam was sprayed with arsenate of lead, in the proportion of 4 lbs. to 150 gal. of water, and ten fourth-molt caterpillars placed upon it. In this experiment eight of the ten eaterpillars died within nine days; the other two lived twelve and thirteen days longer. Foliage uninjured.

No. 96. - July 9, 1894. Ten caterpillars, of the fifth molt, were placed on elm leaves which had been sprayed with arsenate of lead, in the proportion of 4 lbs. to 150 gal. of water. One pupated and two died the fourth day, two pupated and three died the fifth day; one died the sixth and one the seventh day.

Check experiment: one died the fourth day.

No. 97 (field experiment). - July 9, 1894. Ten caterpillars, of the fifth molt, were placed on willow branches which had been sprayed with arsenate of lead, in the proportion of 4 lbs. to $150 \mathrm{gal}$. of water. One died and one pupated the third day; one died the fifth and one the sixth day; one pupated the seventh and one the ninth day; one died the eleventh day; one pupated the twelfth day; one died the fifteenth day; one pupated the twenty-ninth day.

No. 98 (field experiment). - June 21, 1893. A branch of hop-hornbeam was sprayed with arsenate of lead, in the proportion of $4 \mathrm{lbs}$. to 150 gal. of water, and ten fifth-molt caterpillars placed upon it. July 12, all were dead. Although these were fifth-molt caterpillars, they succumbed to the poison much quicker than those of the fourth molt, six 
dying within a week, and the last one dying in a little over two weeks. Foliage uninjured.

\section{5 lbs. Arsenate of Lead to 150 gal. Water.}

No. 99. - March 7, 1894. Ten caterpillars, three days old, were placed on lettuce leaves which had been treated with arsenate of lead, in the proportion of 5 lbs. to 150 gal. of water. One died the first, two the third, one the fourth, four the fifth, and one died and one was lost the sixth day.

No. 100. - May 9, 1894. Ten caterpillars, six days old, were placed on lettuce leaves which had been treated with arsenate of lead, in the proportion of $5 \mathrm{lbs}$. to $150 \mathrm{gal}$. of water. Four died the third, three the fourth and three the fifth day.

Check experiment: none dead.

No. 101. - May 28, 1894. Ten caterpillars, of the first molt, were placed on lettuce leaves which had been treated with arsenate of lead, in the proportion of $5 \mathrm{lbs}$. to $150 \mathrm{gal}$. of water. Three died the fourth, one the fifth, four the sixth and two the seventh day.

Check experiment : none dead.

No. 102.-June 10, 1894. Ten caterpillars, of the second molt, were placed on lettuce leaves which had been treated with arsenate of lead, in the proportion of $5 \mathrm{lbs}$. to 150 gal. of water. Two died the second, three the fifth, one the sixth, three the seventh and one the ninth day.

Check experiment: none dead.

No. 103. - June 21, 1894. Ten caterpillars, of the third molt, were placed on elm leaves which had been treated with arsenate of lead, in the proportion of $5 \mathrm{lbs}$. to $150 \mathrm{gal}$. of water. Two died the third, two the fourth, one the fifth and five the sixth day.

Check experiment: none dead.

No. 104. - June 29, 1894. Ten caterpillars, of the fourth molt, were placed on elm leaves which had been treated with arsenate of lead, in the proportion of $5 \mathrm{lbs}$. to $150 \mathrm{gal}$. of water. Three died the second, two the third, two the fourth, one the fifth and two the sixth day.

Check experiment: one died and two pupated the second 
day; one pupated the third day; two died the fourth and one the fifth day.

No. 105 (field experiment). - June 21, 1893. A branch of oak was sprayed with arsenate of lead, in the proportion of $5 \mathrm{lbs}$. to $150 \mathrm{gal}$. of water, and ten fourth-molt caterpillars placed upon it. July 5, the last one was dead. In this experiment five or six days were required for the poison to take effect; after that time, however, the caterpillars died rapidly.

No. 106. - July 9, 1894. Ten caterpillars, of the fifth molt, were placed on elm leaves which had been sprayed with arsenate of lead, in the proportion of $5 \mathrm{lbs}$. to $150 \mathrm{gal}$. of water. One pupated the third day; one died the fourth and one the fifth day; one pupated and one died the sixth day; two died the seventh and one the eighth, twelfth and thirteenth days.

Check experiment: one died the third day; one pupated the fifth day; two died the sixth and one the seventh day; one died and one pupated the eleventh day; one pupated the twelfth day.

No. 107 (field experiment). - July 9, 1894. Ten caterpillars, of the fifth molt, were placed on willow branches which had been treated with arsenate of lead, in the proportion of $5 \mathrm{lbs}$. to $150 \mathrm{gal}$. of water. One died and one pupated the fourth day; two died the eleventh and two the twelfth day; one pupated the seventeenth, one the nineteenth and two the twentieth day.

6 lbs. Arsenate of Lead to $150 \mathrm{gal}$. Water.

No. 108. - March 7, 1894. Ten caterpillars, three days old, were placed on lettuce leaves which had been treated with arsenate of lead, in the proportion of $6 \mathrm{lbs}$. to $150 \mathrm{gal}$. of water. One died the first, one the second, three the third, four the fourth and one the fifth day.

No. 109. - May 9, 1894. Ten caterpillars, six days old, were placed on lettuce leaves which had been treated with arsenate of lead, in the proportion of $6 \mathrm{lbs}$. to $150 \mathrm{gal}$. of water. Two died the first, five the third and three the fifth day.

Check experiment: none dead. 
No. 110. - May 28, 1894. Ten caterpillars, of the first molt, were placed on lettuce leaves which had been treated with arsenate of lead, in the proportion of $6 \mathrm{lbs}$. to $150 \mathrm{gal}$. of water. Two died the third, one the fourth, two the fifth, two the sixth and three the eighth day.

Check experiment: one died the sixth day.

No. 111. - June 10, 1894. Ten caterpillars, of the second molt, were placed on elm leaves which had been sprayed with arsenate of lead, in the proportion of $6 \mathrm{lbs}$. to $150 \mathrm{gal}$. of water. One died the third, two the fourth, three the fifth, three the sixth and one the eighth day.

Check experiment : none dead.

No. 112. - June 21, 1894. Ten caterpillars, of the third molt, were placed on elm leaves which had been sprayed with arsenate of lead, in the proportion of $6 \mathrm{lbs}$. to $150 \mathrm{gal}$. of water. One died the second, three the third, two the fourth, one the fifth, two the sixth and one the seventh day.

Check experiment: none dead.

No. 113. - June 29, 1894. Ten caterpillars, of the fourth molt, were placed on elm leaves which had been sprayed with arsenate of lead, in the proportion of $6 \mathrm{lbs}$. to $150 \mathrm{gal}$. of water. Three died the second, two the third, three the fourth and two the sixth day.

Check experiment: one died and one pupated the second day; one died the third and one the fifth day.

No. 114 (field experiment). - July 1, 1893. A branch of a small oak tree was sprayed with arsenate of lead, in the proportion of $6 \mathrm{lbs}$. to $150 \mathrm{gal}$. of water, and ten large fifthmolt caterpillars placed upon it. All died within three weeks from the time of spraying. Foliage uninjured.

No. 115. - July 9, 1894. Ten caterpillars, of the fifth molt, were placed on elm leaves which had been sprayed with arsenate of lead, in the proportion of $6 \mathrm{lbs}$. to $150 \mathrm{gal}$. of water. Two died and three pupated the fourth day; three died the seventh, one the ninth and one the tenth day.

Check experiment: one died and two pupated the fourth day; one died the fifth day; two pupated the sixth and one the seventh and eighth days.

No. 116 (field experiment). - July 9, 1894. Ten cater- 
pillars, of the fifth molt, were placed on willow branches which had been treated with arsenate of lead, in the proportion of $6 \mathrm{lbs}$. to $150 \mathrm{gal}$. of water. One died the second day; one pupated the third day; two died the fifth, two the sixth and one the eleventh day; one pupated the thirteenth, one the sixteenth and one the nineteenth day.

\section{7 lbs. Arsenate of Lead to 150 gal. Water.}

No. 117. - March 7, 1894. Ten caterpillars, three days old, were placed on lettuce leaves which had been treated with arsenate of lead, in the proportion of $7 \mathrm{lbs}$. to $150 \mathrm{gal}$. of water. Three died the first, three the second and four the fifth day.

No. 118. - May 9, 1894. Ten caterpillars, six days old, were placed on lettuce leaves which had been treated with arsenate of lead, in the proportion of $7 \mathrm{lbs}$. to 150 gal. of water. One died the second, five the third, two the fourth, one the fifth and one the seventh day.

Check experiment: none dead.

No. 119. - May 28, 1894. Ten caterpillars, of the first molt, were placed on lettuce leaves which had been treated with arsenate of lead, in the proportion of $7 \mathrm{lbs}$. to 150 gal. of water. Five died the third, one the fourth, two the sixth and two the seventh day.

Check experiment : one died the fourth day.

No. 120.-June 10, 1894. Ten caterpillars, of the second molt, were placed on elm leaves which had been sprayed with arsenate of lead, in the proportion of $7 \mathrm{lbs}$. to 150 gal. of water. One died the fourth, one the fifth, seven the sixth and one the ninth day.

Check experiment: none dead.

No. 121. - June 21, 1894. Ten caterpillars, of the third molt, were placed on elm leaves which had been sprayed with arsenate of lead, in the proportion of $7 \mathrm{lbs}$. to $150 \mathrm{gal}$. of water. One died the second, four the third, four the sixth and one the seventh day.

Check experiment: none dead.

No. 122. - June 28, 1894. Ten caterpillars, of the fourth molt, were placed on elm leaves which had been sprayed 
with arsenate of lead, in the proportion of $7 \mathrm{lbs}$. to $150 \mathrm{gal}$. of water. One died the first, one the second, five the fourth and three the fifth day.

Check experiment: two pupated the second and three the third day; two died the fifth day.

No. 123. - July 9, 1894. Ten caterpillars, of the fifth molt, were placed on elm leaves which had been sprayed with arsenate of lead, in the proportion of $7 \mathrm{lbs}$. to $150 \mathrm{gal}$. of water. One pupated the third day; three died and one pupated the fifth day; one died the seventh, one the eighth, two the ninth and one the twelfth day.

Check experiment: two pupated the fifth day; one died the seventh, ninth and tenth days.

No. 124. - July 9, 1894. Ten caterpillars, of the fifth molt, were placed on willow branches which had been sprayed with arsenate of lead, in the proportion of $7 \mathrm{lbs}$. to 150 gal. of water. One pupated the second day; one died the third, one the fifth, one the sixth, one the eighth and one the tenth day; one died and one pupated the eleventh day; one pupated the sixteenth and one the thirty-first day.

8 lbs. Arsenate of Lead to 150 gal. Water.

No. 125. - March 7, 1894. Ten caterpillars, three days old, were placed on lettuce leaves which had been treated with arsenate of lead, in the proportion of $8 \mathrm{lbs}$. to $150 \mathrm{gal}$. of water. Three died the second, four the third and three the fifth day.

No. 126. - May 9, 1894. Ten caterpillars, six days old, were placed on lettuce leaves which had been treated with arsenate of lead, in the proportion of $8 \mathrm{lbs}$. to $150 \mathrm{gal}$. of water. Two died the third, three the fourth, four the fifth and one the sixth day.

Check experiment: none dead.

No. 127. - May 28, 1894. Ten caterpillars, of the first molt, were placed on lettuce leaves which had been treated with arsenate of lead, in the proportion of $8 \mathrm{lbs}$. to $150 \mathrm{gal}$. of water. Two died the third, two the fourth, two the fifth, three the sixth and one the seventh day.

Check experiment : none dead.

No. 128. - June 10, 1894. Ten caterpillars, of the 
second molt, were placed on lettuce leaves which had been sprayed with arsenate of lead, in the proportion of $8 \mathrm{lbs}$. to 150 gal. of water. Four died the second, two the fourth, one the fifth, one the sixth and two the seventh day.

Check experiment: none dead.

No. 129. - June 21, 1894. Ten caterpillars, of the third molt, were placed on elm leaves which had been sprayed with arsenate of lead, in the proportion of $8 \mathrm{lbs}$. to $150 \mathrm{gal}$. of water. One died the second, three the third, one the fourth, three the fifth and two the sixth day.

Check experiment: none dead.

No. 130. - June 29, 1894. Ten caterpillars, of the third molt, were placed on elm leaves, which had been sprayed with arsenate of lead, in the proportion of $8 \mathrm{lbs}$. to $150 \mathrm{gal}$. of water. One died the second, three the third, four the fourth and two the fifth day.

Check experiment : four pupated the second, one the third and one the fifth day.

No. 131. - July 9, 1894. Ten caterpillars, of the fifth molt, were placed on elm leaves which had been sprayed with arsenate of lead, in the proportion of $8 \mathrm{lbs}$. to $150 \mathrm{gal}$. of water. One pupated the fourth day; three pupated and two died the fifth day; two pupated the seventh day; one died the ninth and one the twelfth day.

Check experiment: one pupated the fourth, fifth, seventh and ninth days.

No. 132 (field experiment). - July 9, 1894. Ten caterpillars, of the fifth molt, were placed on willow branches which had been sprayed with arsenate of lead, in the proportion of 8 lbs. to 150 gal. of water. One died the third and one the fourth day; one pupated the eighth day; one died the thirteenth day; three pupated the sixteenth, two the twentieth and one the twenty-second day.

\section{$10 \mathrm{lbs}$. Arsenate of Lead to 150 gal. Water.}

No. 133. - March 7, 1894. Ten caterpillars, three days old, were placed on lettuce leaves which had been treated with arsenate of lead, in the proportion of $10 \mathrm{lbs}$. to $150 \mathrm{gal}$. of water. Five died the second, four the third and one the fourth day. 
No. 134. - May 9, 1894. Ten caterpillars, six days old, were placed on lettuce leaves which had been treated with arsenate of lead, in the proportion of $10 \mathrm{lbs}$. to $150 \mathrm{gal}$. of water. Three died the second, two the third, two the fourth and three the fifth day.

Check experiment: none dead.

No. 135. - May 28, 1894. Ten caterpillars, of the first molt, were placed on lettuce leaves which had been treated with arsenate of lead, in the proportion of $10 \mathrm{lbs}$. to $150 \mathrm{gal}$. of water. One died the third, three the fourth, three the fifth, one the sixth and two the seventh day.

Check experiment : none dead.

No. 136. - June 10, 1894. Ten caterpillars, of the second molt, were placed on lettuce leaves which had been sprayed with arsenate of lead, in the proportion of $10 \mathrm{lbs}$. to 150 gal. of water. Three died the second, one the third, one the fourth, two the fifth, two the sixth and one the seventh day.

Check experiment: none dead.

No. 137. - June 21, 1894. Ten caterpillars, of the third molt, were placed on elm leaves which had been sprayed with arsenate of lead, in the proportion of $10 \mathrm{lbs}$. to $150 \mathrm{gal}$. of water. Three died the fourth, four the sixth and three the seventh day.

Check experiment : none dead.

No. 138. - June 29, 1894. Ten caterpillars, of the fourth molt, were placed on elm leaves which had been sprayed with arsenate of lead, in the proportion of $10 \mathrm{lbs}$. to $150 \mathrm{gal}$. of water. One died the second, three the third, five the fourth and one the fifth day.

Check experiment: one pupated the second and one the third day; one pupated and one died the fifth day.

No. 139. - July 9, 1894. Ten caterpillars, of the fifth molt, were placed on elm leaves which had been sprayed with arsenate of lead, in the proportion of $10 \mathrm{lbs}$. to $150 \mathrm{gal}$. of water. Two died and one was lost the fifth day; four died the sixth and three the seventh day.

Check experiment: one pupated the fourth, two the fifth, one the sixth and one the seventh day.

No. 140 (field experiment). - July 9, 1894. Ten cater- 
pillars, of the fifth molt, were placed on willow branches which had been sprayed with arsenate of lead, in the proportion of $10 \mathrm{lbs}$. to $150 \mathrm{gal}$. of water. Two died the second day; three pupated the fourth day; two died the fifth and one the sixth day; one pupated the thirteenth and one the fifteenth day.

No. 141 (field experiment). - June 21, 1893. A branch of a small oak tree was sprayed with arsenate of lead, in the proportion of $10 \mathrm{lbs}$. to $150 \mathrm{gal}$. of water, and eight fifthmolt caterpillars placed upon it. August 19, all were dead.

\section{5 lbs. Arsenate of Lead to 150 gal. Water.}

No. 142. - July 1, 1893. A small branch of oak was sprayed with arsenate of lead, in the proportion of $25 \mathrm{lbs}$. to 150 gal. of water, and ten large fifth-molt caterpillars placed upon it. All died within one week. Foliage uninjured.

Even larger proportions of this poison than the above were occasionally used in spraying operations in the field, with fairly satisfactory results.

Comparative Effects of Paris Green, Paris Green and Lime and Arsenate of Lead.

A careful study of the comparative effect of equal weights of the three substances used in the preceding experiments shows that there is practically no choice between Paris green and Paris green and lime, so far as the destruction of the caterpillars is concerned. The largest amount of these poisons which can be used without injuring the foliage is about $1 \mathrm{lb}$. to $150 \mathrm{gal}$. of water, and at this, or even a much larger rate, the percentage of caterpillars destroyed is not satisfactory. Since arsenate of lead in almost any strength is not injurious to foliage, a much larger amount can be used than of any of the more soluble arsenical compounds; thus the superiority of this poison as an insecticide is at once evident. While arsenate of lead may be considered the best insecticide for destroying the gypsy moth in the caterpillar stage, even this poison is of small value in exterminating this insect, since many of the caterpillars survive after feeding upon leaves sprayed with large proportions of this poison. 
The experiments previously recorded show that a considerable amount of time is required for the poison used to affect the caterpillars. Those in the earlier molts were killed in a short time, but in the later molts a much smaller per cent. was destroyed, many of the caterpillars transforming and producing imagoes.

In considering these experiments, it should be remembered that the insects were in confinement, and obliged to eat the poisoned leaves, while in field work they may sometimes find leaves that have not been sprayed, or that have received but little of the poison, and, therefore, the results in some cases might be somewhat different from those obtained in these experiments.

The remarkable ability of the gypsy moth to resist the action of arsenical poisons is shown in the case of other poisons. Mr. Moulton covered a piece of lettuce leaf with strychnine, and fed it to a caterpillar. In about an hour the caterpillar appeared to be dead, but soon revived and fed again for a short time upon the poisoned leaf, when it rolled over on its back and for several hours remained apparently dead, but afterwards revived again and appeared as well as ever.

\section{Analyses of Poisoned Larve.}

The remarkable resistance to the action of arsenical poisons shown by the gypsy moth led us, in the summer of 1894 , to institute a series of investigations on the disposition of arsenic by caterpillars when feeding on poisoned food. For this purpose, gypsy moth eaterpillars which had fed for some time upon poisoned leaves without apparent injury, and also those which had died as a result of arsenical poisoning, were carefully dissected, the different organs and tissues being subsequently analyzed at the chemical laboratory of Harvard University. The work was performed, under my direction, by Messrs. Kirkland and Moulton, the former preparing the material and making the dissections, the latter conducting the analyses. All the operations involved were carried on with extreme care, in order to prevent the accidental introduction of any arsenical substance. After each dissection the instruments used were 


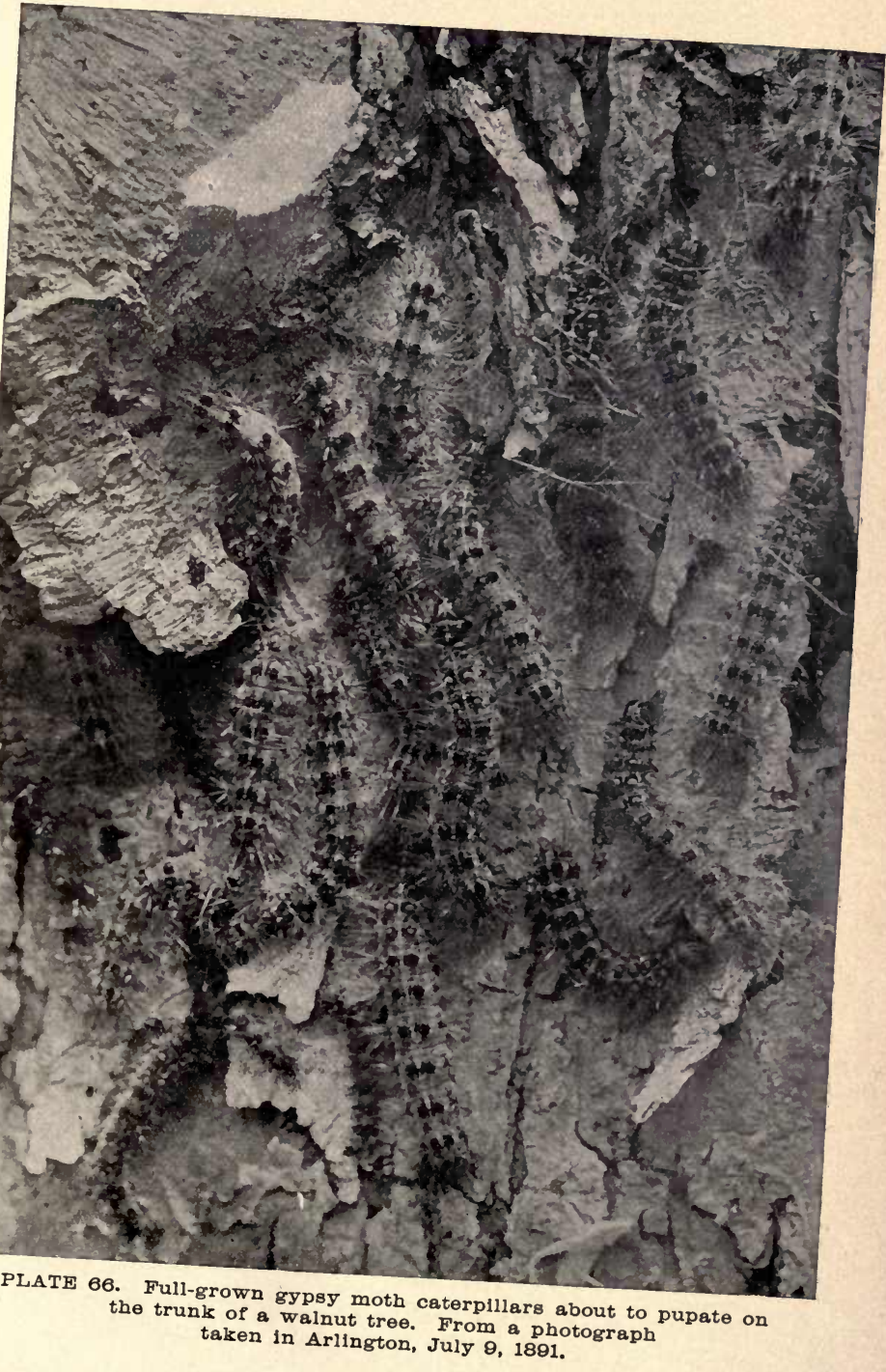


carefully washed in dilute acid and in distilled water, while the purity of all chemical reagents employed in the analytical work was demonstrated by a number of preliminary tests. The method used in testing for the presence of arsenic was the so-called Berzelius-Marsh process (American Chemical Journal, October, 1891), by means of which a minute quantity of this poison can be readily recognized. The results obtained from analyses of the organs and tissues of a large number of eaterpillars, which were feeding unharmed on food treated with a liberal amount of Paris green or arsenate of lead (the only poisons used), did not differ materially from those of analyses of the same parts of caterpillars which had died from arsenical poisoning, while in many caterpillars no arsenic was found.

In both cases arsenic was found chiefly in the stomach, intestinal and rectal contents, and throughout the walls of the alimentary canal. It was also found in the excrements, in the malpighian vessels, the dorsal vessel and blood and in the muscular tissue, thus showing that the arsenic probably passes from the alimentary caral, where it is quite equally distributed, into the blood, and is carried by the circulation throughout the body, and thus eventually permeates all organs and tissues. Owing to the small size of the parts subjected to analysis, some of them being of almost microscopic dimensions, it was an extremely difficult process to determine quantitatively the amount of arsenic present; yet this was accomplished by a comparison of the results of the analyses with a series of finely graduated arsenic "mirrors," for the use of which we are indebted to the courtesy of Professor Hill of Harvard University.

In some caterpillars, which had fed for a long time upon food treated with the arsenical compounds previously mentioned, a considerable amount of arsenic was found; while those which had fed for a shorter time, as a rule, contained smaller quantities of the poison. Many of those which had thus fed for two or three weeks, when killed, were found to contain more arsenic than caterpillars which had succumbed to arsenical poisoning. One caterpillar, which had fed in an out-door cage, upon willow leaves sprayed with arsenate 
of lead in the proportion of 2 lbs. to 150 gal. of water, from July 9 to July 28, 1894, and which at the time of dissection was full grown, normally active and healthy, yielded .025 milligrams of arsenic. If, for the purpose of illustration, the weight of arsenic thus found be compared with the weight of this caterpillar, and this ratio applied to the average weight of the adult human being, we obtain the rather surprising result that such a caterpillar would withstand uninjured an amount of arsenic, in proportion to its weight, equivalent to twelve and one-half times the fatal dose for an adult human being, in proportion to the weight of the latter. This illustrates the ability of this insect to resist arsenical poisoning.

Since the quantities of arsenic found were small in comparison with the amount the insect consumed, it is evident that a considerable part of the poison must have been eliminated from the body. The presence of arsenic in the excrements of poisoned caterpillars indicates one source of elimination. These investigations upon poisoned caterpillars show that an apparently large quantity of arsenic may enter and even permeate all parts of the body of the caterpillar without interfering with the vital processes, and that a considerable part of the poison consumed with the food is eliminated, chiefly in the excreta.

One interesting result obtained from the analyses of the different stages of the gypsy moth, made in 1893 and 1894 , is that pupæ and imagoes from caterpillars which have been reared on leaves sprayed with Paris green or arsenate of lead may contain arsenic in recognizable quantities. Several pupæ and a few female imagoes, obtained under these conditions, when subjected to chemical analysis gave ample evidence of the presence of arsenic in their bodies. This shows that the presence of arsenic in the pupa may not materially interfere with the processes involved in the development of the imago.

Since, as has been repeatedly demonstrated, moths reared from poisoned larvæ are capable of reproduction, it is also evident that the arsenic contained in their systems does not injure the reproductive function. 
Experiments with London Purple and Acetate of LEAD.

No. 1. - July 7, 1893. London purple and acetate of lead, in the proportion of $\frac{3}{4} \mathrm{lb}$. each to $150 \mathrm{gal}$. of water, were thoroughly mixed and allowed to stand and settle for one hour and a half. It was then stirred and allowed to stand one-half hour longer, at the end of which time it was strained through two thicknesses of chcese cloth, a small amount of glucose added, and an oak branch sprayed with the mixture. Ten caterpillars, of the fifth molt, were then placed upon the branch. July 22, for lack of food, they were transferred to a freshly sprayed branch. None of these caterpillars died for nearly two weeks after the branch was first sprayed, but after they were transferred to the second sprayed branch they died more rapidly. Three began pupating, but none emerged. The foliage of the first branch was slightly burned, while that of the second was in good condition.

No. 2. - July 6, 1893. A branch of a small oak tree was sprayed with London purple and acetate of lead, in the proportion of $\frac{3}{4} \mathrm{lb}$. each to $150 \mathrm{gal}$. of water. The London purple and acetate of lead were mixed in a little water, glucose added and thoroughly stirred; the rest of the water was then added and the mixture thoroughly stirred again. Ten fifth-molt caterpillars, five very large and five small, were then placed on the branch. July 25, the branch was resprayed, on account of rain. Two of these caterpillars began to pupate, but none emerged. They died gradually, the last one living nearly a month. Foliage considerably burned.

No. 3. - July 6, 1893. A branch of oak was sprayed with London purple and acetate of lead, in the proportion of $1 \mathrm{lb}$. each to $150 \mathrm{gal}$. of water. The London purple and acetate of lead were thoroughly mixed with water in a beaker, a teaspoonful of glucose was added and the mixture thoroughly stirred. Eleven fifth-molt caterpillars were placed on the branch. July 20, the branch was resprayed, on account of rain. Of the eleven caterpillars, only two 
were able to complete the process of pupation and emerge. Foliage in good condition.

No. 4. - July 6, 1893. A branch was sprayed with the same mixture and at the same time as in the preceding experiment, and ten fourth-molt caterpillars placed upon it. Only two of these began to pupate, and both died without emerging. Foliage but slightly, if at all, burned.

No. 5. - July 6, 1893. A branch of a small oak tree was sprayed with the same mixture as in the preceding experiment, and at about the same time. Ten fifth-molt caterpillars, some of which were very large, were placed on the branch. July 20, the branch was resprayed, on account of rain. Only two of the caterpillars began to pupate, one of which emerged. The remainder died on the twentyfourth day after the first spraying. The foliage was slightly burned.

No. 6. - July 7, 1893. A branch of oak was sprayed with $1 \mathrm{lb}$. of London purple and $2 \mathrm{lbs}$. acetate of lead to 150 gal. of water, and ten fifth-molt caterpillars placed upon it. Of these ten, only one began to pupate, and this one died before completing the process. Foliage only slightly burned.

No. 7. - July 7, 1893. A branch of oak was sprayed with London purple and acetate of lead, in the proportion of $2 \mathrm{lbs}$. each to $150 \mathrm{gal}$. of water. The London purple and acetate of lead were thoroughly mixed in a beaker, the proper amount of glucose added, and, after being stirred, the mixture was poured into the sprayer, the rest of the water added and the whole mixed together. Ten fifth-molt caterpillars, five large and five small, were then placed on the branch. July 20, the branch was resprayed, on account of rain. All of the caterpillars except one died before beginning to pupate, and this one was not able to complete the process. Foliage in good condition.

No. 8.-July 8, 1893. An oak branch was sprayed with London purple and acetate of lead, in the proportion of $3 \mathrm{lbs}$. each to $150 \mathrm{gal}$. of water. A teaspoonful of glucose was added, and the mixture thoroughly stirred. Ten large fifth-molt caterpillars were placed on the branch. All 
but one of these died before pupating, and this one did not emerge. Foliage slightly burned.

No. 9. - July 8, 1893. A branch of oak was sprayed with the same mixture and at the same time as in the preceding experiment, and ten fifth-molt caterpillars placed upon it. Only one of these pupated, and that one did not emerge. Foliage slightly burned.

No. 10. - July 8, 1893. A branch was sprayed at the same time and in the same manner as in the preceding experiment, and ten fifth-molt caterpillars placed upon it. July 22, and again on the 25th, the branch was resprayed, on account of rain. Six of the ten caterpillars pupated, three of which emerged. The foliage was somewhat burned.

\section{"Antinonnin."}

No. 1.-July 22, 1893. A branch of oak was sprayed with antinonnin, in the proportion of $3 \mathrm{lbs}$. to $150 \mathrm{gal}$. of water, and fifteen caterpillars of the fifth molt placed upon it. July 24, the branch was resprayed, on account of rain. Six of the caterpillars pupated, four of which emerged. Foliage in good condition. The antinonnin, when sprayed on the leaves, presents a bright yellow, glistening appearance, and badly stains everything with which it comes in contact. It is also easily washed off by rain.

No. 2.-July 24, 1893. A branch of oak was sprayed with antinonnin, in the proportion of $3 \mathrm{lbs}$. to $150 \mathrm{gal}$. of water, and ten caterpillars of the fifth molt placed upon it. Five of these pupated, three of which finally emerged. Foliage slightly burned.

No. 3. - July 27, 1893. A branch of oak was sprayed with antinonnin, in the proportion of $3 \mathrm{lbs}$. to $150 \mathrm{gal}$. of water, and fifteen caterpillars of the fifth molt placed upon it. Two of these died before beginning to pupate, and ten pupated and emerged. Foliage in good condition.

No. 4. - July 24, 1893. A branch of hop-hornbeam was sprayed with antinonnin, in the proportion of $3 \mathrm{lbs}$. to 150 gal. of water, and ten fifth-molt caterpillars placed upon it. Six of these pupated and finally emerged. Foliage quite badly burned. 
No. 5.-July 27, 1893. A branch of oak was sprayed with antinonnin, in the proportion of $3 \mathrm{lbs}$. to $150 \mathrm{gal}$. of water, and ten fifth-molt caterpillars placed upon it. This experiment was started too late to be of any great value as a test for the insecticide, as all the caterpillars pupated very soon after the branch was sprayed, so that probably few if any of them ate enough of the poisoned food to affect them.

\section{Arsenate of Znnc.}

Prepared in the same manner as arsenate of lead, by substituting a soluble zinc salt for the acetate of lead.

No. 1. - July 11, 1893. A branch of oak was sprayed with arsenate of zinc, in the proportion of $1 \frac{1}{2} \mathrm{lbs}$. to $150 \mathrm{gal}$. of water, and ten fifth-molt caterpillars placed upon it. July 22, and again on the 25th, the branch was resprayed, on account of heavy rains. Three of the caterpillars began pupating, but none emerged. Foliage badly burned.

No. 2. - July 11, 1893. A branch of oak was sprayed with arsenate of zinc, in the proportion of $1 \frac{1}{2} \mathrm{lbs}$. to $150 \mathrm{gal}$. of water, and five large and five small caterpillars placed upon it. July 22, the branch was resprayed, on account of rain. Six of the caterpillars pupated, four of which emerged; two of these, however, began to pupate before they had time to eat much of the poisoned food. Foliage slightly burned.

No. 3. - July 10, 1893. A branch of oak was sprayed with arsenate of zinc, in the proportion of 2 lbs. to $150 \mathrm{gal}$. of water, and ten large fifth-molt caterpillars placed upon it. Six of these began pupating, but none emerged. Foliage badly burned.

No. 4.-July 10, 1893. A branch of oak was sprayed with arsenate of zinc, in the proportion of $3 \mathrm{lbs}$. to $150 \mathrm{gal}$. of water, and five large and five small caterpillars of the fifth molt placed upon it. July 22, the branch was resprayed, on account of rain. Five of the ten caterpillars began pupating, but none emerged. Foliage badly burned.

No. 5.- July 10, 1893. A branch of oak was sprayed with arsenate of zinc, in the proportion of $3 \mathrm{lbs}$. to $150 \mathrm{gal}$. of water, and ten very large fifth-molt caterpillars placed upon it. July 20, they were transferred to a freshly sprayed 
branch, which, July 25, was resprayed on account of rain. Five of the ten pupated, one of which emerged. Foliage badly burned.

No. 6. - July 10, 1893. A branch of oak was sprayed with arsenate of zinc, in the proportion of $3 \mathrm{lbs}$. to 150 gal. of water, and ten fifth-molt caterpillars placed upon it. Five of these began pupating, but none emerged. Foliage badly burned.

No. 7.- July 6, 1893. A branch of oak was sprayed with arsenate of zinc, in the proportion of $6 \mathrm{lbs}$. to $150 \mathrm{gal}$. of water, and ten fifth-molt caterpillars placed upon it. At the end of two weeks all were dead. Foliage burned.

No. 8.- July 6, 1893. A branch of oak was sprayed with arsenate of zino, in the proportion of $6 \mathrm{lbs}$. to $150 \mathrm{gal}$. of water, and ten fifth-molt caterpillars placed upon it. All but one died within a week, and this one died eleven days after the branch was sprayed. Foliage burned.

\section{Arsenic.}

No. 1. - July 12, 1893. A branch of oak was sprayed with arsenic, in the proportion of 6 lbs. to $150 \mathrm{gal}$. of water, and ten caterpillars of the fifth molt placed upon it. July 19 , the branch was resprayed, on account of rain, and again on the 25th. Of the ten caterpillars, six began pupating, one of which pupated and emerged. Foliage badly burned.

No. 2. - July 12, 1893. A branch of hop-hornbeam was sprayed with arsenic, in the proportion of $6 \mathrm{lbs}$. to $150 \mathrm{gal}$. of water, and ten caterpillars of the fifth molt placed upon it. July 19, the foliage was so badly burned that the caterpillars were transferred to a freshly sprayed branch of oak. Only one began pupating, and this one did not emerge. Foliage of hop-hornbeam very badly burned, while that of the oak was in good condition.

\section{" Cinloro-Naptholeum."}

No. 1.-May 15, 1894. Ten caterpillars, before the first molt, were placed on a leaf which had been sprayed with chloro-naptholeum. At the end of seven days, all the caterpillars but one were alive and in good condition. 
No. 2. - May 15, 1894. Ten caterpillars, before the first molt, were placed on a leaf and sprayed with chloro-naptholeum. One died on the fifth and one on the eighth day; those remaining seemed in good condition.

No. 3.- May 15, 1894. Ten caterpillars were placed in a dish and sprayed with chloro-naptholeum, and then placed on a fresh leaf. Fresh leaves for food were given them at four different times. One died on the fourth day and one on the sixth day; those remaining were in good condition. The strength of the chloro-naptholeum used in this trial was in the proportion of $1 \mathrm{lb}$. to 100 gal. of water. As this neither killed the caterpillars nor burned the leaves, it was repeated with a stronger solution.

No. 4. - May 22, 1894. Ten caterpillars, before the first molt, were placed on a leaf which had been sprayed with chloro-naptholeum. One died on the fifth, two on the sixth, two on the seventh, two on the eighth and one on the ninth day; the remaining two were alive and in good condition at the end of thirteen days.

No. 5. - May 22, 1894. Ten caterpillars, before the first molt, were placed on a leaf and both sprayed with chloronaptholeum. One died on the fourth, three on the sixth and six on the eighth day.

No. 6. - May 22, 1894. Ten caterpillars, before the first molt, were placed in a dish and sprayed with chloro-naptholeum, and then placed on a fresh leaf. Three died on the third, one on the fourth, three on the fifth and three on the sixth day. The strength of the chloro-naptholeum used in this trial was in the proportion of $1 \mathrm{lb}$. to $50 \mathrm{gal}$. of water.

\section{“ Electric" Insecticide.}

No. 1. - June 22, 1894. A leaf was sprayed with electric insecticide, and ten caterpillars, of the second molt, placed upon it. Six died on the second and four on the third day. The leaf was badly burned.

No. 2. - July 22, 1894. Ten second-molt caterpillars were placed on a leaf and sprayed with electric insecticide. All died on the second day. Leaf badly burned.

No. 3. - June 2, 1894. Ten caterpillars, of the second 
molt, were dipped in electric insecticide and then placed on a fresh leaf. Nine died on the second and one on the third day. The leaf was burned by contact with the caterpillars.

\section{“ Elphona."}

No. 1. - May 15, 1894. Ten caterpillars, before the first molt, were placed upon a leaf which had been sprayed with Elphona. On the third day all were dead.

No. 2.-May 15, 1894. Ten caterpillars, before the first molt, were placed on a leaf and sprayed with Elphona. Four died on the third, three on the fourth and three on the fifth day.

No. 3. - May 15, 1894. Ten caterpillars, before the first molt, were placed in a dish and sprayed with Elphona. Nine died on the first and one on the second day. Foliage badly burned.

These three insecticides, "Chloro-naptholeum," “Electric" and "Elphona," were sent to the department by their manufacturers with the claim that they would kill the gypsy moth, but experiments with them proved that when used in proportion sufficiently large to destroy the caterpillars they burned the foliage very seriously.

\section{"Hyannis Tobacco Mixture" (a Contact Insecticide with Tobacco as a Basis).}

No. 1.-May 15, 1894. Ten caterpillars, before the first molt, were placed on a leaf which had been sprayed with Hyannis tobacco mixture. One died on the fourth and one on the sixth day.

No. 2.-May 15, 1894. Ten caterpillars, before the first molt, were placed on a leaf and both sprayed with Hyannis tobacco mixture. One died on the third, three on the fifth, one on the sixth and two on the seventh day.

No. 3.-May 15, 1894. Ten caterpillars, before the first molt, were placed in a dish and sprayed with Hyannis tobacco mixture. One died on the third, three on the fourth and two on the sixth day. The strength of the Hyannis tobacco mixture used in this trial was in the proportion of 1 part to 100 parts of water. 
No. 4.-May 22, 1894. Ten caterpillars, before the first molt, were placed on a leaf which had been sprayed with Hyannis tobacco mixture. Three died on the fourth, five on the fifth and two on the sixth day.

No. 5.-May 22, 1894. Ten caterpillars, before the first molt, were placed on a leaf and both sprayed with Hyannis tobacco mixture. Seven died on the third, two on the fourth and one on the sixth day.

No. 6. - May 22, 1894. Ten caterpillars, before the first molt, were placed in a dish and sprayed with Hyannis tobacco mixture, and then put on a fresh leaf. Six died on the fourth, two on the fifth and two on the seventh day. The strength of the mixture used in this trial was in the proportion of 1 part to 50 parts of water.

\section{"SUlPho-Naphthol."}

No. 1. - May 15, 1894. Ten caterpillars, before the first molt, were placed on a leaf which had been sprayed with sulpho-naphthol. Two died on the fourth, one on the sixth and one on the seventh day.

No. 2. - May 15, 1894. Ten caterpillars, before the first molt, were placed on a leaf and both sprayed with sulpho-naphthol. Two died on the second, one on the third, one on the fifth, one on the sixth and one on the seventh day.

No. 3.-May 15, 1894. Ten caterpillars, before the first molt, were placed in a dish and sprayed with sulphonaphthol, then placed on a fresh leaf. Three died on the second and one on the fourth day. The strength of the sulpho-naphthol used in this trial was in the proportion of 1 part to 100 parts of water.

No. 4. - May 22, 1894. Ten caterpillars, before the first molt, were placed on a leaf which had been sprayed with sulpho-naphthol. Three died on the fourth, two on the fifth, one on the sixth, three on the seventh and one on the ninth day.

No. 5. - May 22, 1894. Ten caterpillars, before the first molt, were placed on a leaf and sprayed with sulphonaphthol. Eight died on the fourth, one on the fifth and one on the sixth day. 
No. 6. - May 22, 1894. Ten caterpillars, before the first molt, were placed in a dish and sprayed with sulphonaphthol, and then put on a fresh leaf. Six died on the fourth, one on the fifth, one on the sixth and two on the seventh day. The strength of the sulpho-naphthol used in this trial was in the proportion of 1 part to 50 parts of water.

\section{Cranides.}

Studies on the anatomy of the caterpillars, made in 1894, by Mr. Kirkland, showed that the contents of the alimentary canal were strongly alkaline. This suggested the idea that some compound might be prepared which would be inert under ordinary circumstances, but when taken into the digestive system of the insect would decompose in the alkaline medium and form a deadly poison. Following out this idea, Mr. Moulton prepared a number of the compounds of cyanic acid, which were experimented with during the summer of 1895. The substances tried were the cyanides of lead, copper, antimony, zinc and mercury. The last-mentioned compound burned the foliage badly, hence but few experiments were made with it. Of the other compounds, cyanide of copper was the only one which gave effective results, and these were not as satisfactory as can be obtained from the use of the same weight of Paris green. The other cyanides are practically valueless, since caterpillars were fed throughout their entire life on foliage treated with large proportions of these three compounds, without suffering injurious effects.

\section{Contact Insecticides.}

Whale-oil soap, several proprietary soap powders, soft soap and kerosene emulsion were experimented with during the summer of 1891 , for the purpose of finding a cheap contact insecticide, for use where the caterpillars cluster in masses on trees, fences, etc. All of these insecticides were found to be fairly effective.

\section{Food Selection.}

The following experiments were conducted, both at the storehouse and in the field, by Mr. Kirkland, during 
the summer of 1894 , to determine, if possible, whether the gypsy moth caterpillars are able in any way to select their food, and thus choose the non-poisoned leaves in preference to leaves treated with arsenical poisons. For this purpose, a definite number of caterpillars were confined upon leaves treated with poisons applied in various ways, and the results carefully noted for several days, or as long as there was a sufficient amount of food for them to eat without being forced to partake of either the poisoned or non-poisoned leaves.

Experiment No. 1. - Six elm leaves were selected, and a series of bands and dots painted upon each, with Paris green, in the proportion of $3 \mathrm{lbs}$. to $150 \mathrm{gal}$. of water. When the poison was sufficiently dry, so that it did not run upon the surface of the leaves, each one was placed in a box with three fourth-molt caterpillars. Sixty-five per cent. of the feeding was upon the unpainted parts of the leaves and thirty-five per cent. upon the painted parts.

Experiment No. 2.-A series of bands and dots was painted upon six willow leaves, with Paris green, in the proportion of $3 \mathrm{lbs}$. to $150 \mathrm{gal}$. of water. After the poison had been applied, each leaf was placed in a box with three caterpillars of the fourth molt. These fed about equally upon the painted and unpainted parts.

Experiment No. 3.-Six willow leaves were selected, and a number of transverse bands painted upon each with Paris green, in the proportion of $3 \mathrm{lbs}$. to $150 \mathrm{gal}$. of water. The bands were one-fourth of an inch wide, and the unpainted space between them one-half of an inch in width. Each leaf was then placed in a box with three fourth-molt caterpillars. Sixty per cent. of the feeding was upon the non-poisoned part of the leaves and forty per cent. upon the poisoned parts.

Experiment No. 4. - A medium-sized twig on an apple tree was selected, and from it were removed all the damaged and a part of the perfect leaves, so that there were only twenty-five leaves left upon the twig. On each of these were painted three broad, transverse bands, with Paris green and lime in water, in the proportion of $3 \mathrm{lbs}$. of Paris green and $5 \mathrm{lbs}$. of lime to 150 gal. of water. Ten 
caterpillars of all sizes below the third molt were then placed upon the twig, and sacked in by drawing a bag, made of cheese cloth, over it, and tying the open part closely around the base of the twig, to prevent the escape of the caterpillars. Sixty per cent. of the feeding was upon the unpoisoned and forty per cent. upon the poisoned portion of the leaves.

Experiment No. 5. - Three large willow leaves were painted with Paris green, in the proportion of 3 lbs. to 150 gal. of water, as follows: on leaf No. 1, three transverse bands; on leaf No. 2, three oblique bands; on leaf No. 3, a band one-fourth of an inch in width around the entire margin of the leaf. Each leaf was then placed in a box with a full-grown caterpillar. Leaf No. 1 was eaten equally on the poisoned and unpoisoned areas; leaf No. 2 was eaten wholly upon the unpoisoned parts ; leaf No. 3 had the margin eaten in two places.

Experiment No. 6. - Three willow leaves were prepared in the same manner as in the preceding experiment, except that, besides the Paris green, $5 \mathrm{lbs}$. of lime were added to the water. Leaf No. 1 had a long, narrow strip eaten from the margin, passing through the ends of the three transverse bands of poison; leaf No. 2 was eaten equally on the poisoned and unpoisoned parts; leaf No. 3 was eaten deeply on the margin.

Experiment No. 7. - Three willow leaves were prepared as before, using arsenate of lead, in the proportion of $6 \mathrm{lbs}$. to 150 gal. of water, instead of Paris green and lime. Leaf No. 1 was eaten equally from the painted and unpainted portions; No. 2 was eaten in the same manner; and No. 3 had the margin eaten in two places.

Experiment No. 8.-A small twig of oak, bearing six leaves, was sprayed with Paris green, in the proportion of $10 \mathrm{lbs}$. to $150 \mathrm{gal}$. of water, and another twig, bearing the same number of leaves, was left unsprayed. Both were enclosed in a sack with ten full-grown caterpillars. July 15. The greater part of the feeding was upon the unsprayed leaves. July 16. More was eaten from the unpoisoned than the poisoned leaves, yet six of the caterpillars had died. 
Experiment No. 9. - Two twigs of wild cherry were trimmed so that only six leaves remained on each. One of these twigs was sprayed with Paris green, in the proportion of $3 \mathrm{lbs}$. to $150 \mathrm{gal}$. of water, and the other was left unsprayed. Ten full-grown caterpillars were placed upon the twigs, which were then enclosed in a sack. July 15. None of the leaves were eaten. July 16. Very little was eaten from the unpoisoned leaves and a larger amount from the poisoned leaves. July 17 . The result was the same. July 18. Ten times as much had been eaten from the poisoned as from the unpoisoned leaves. July 19. Nearly all of the leaves upon the poisoned twig had been eaten, and but a small portion on the unpoisoned. Three of the caterpillars died.

Experiment No. 10. - A twig of apple, bearing five leaves, was thoroughly sprayed with Paris green and lime in water, in the proportion of $3 \mathrm{lbs}$. of Paris green and 5 lbs. of lime to $150 \mathrm{gal}$. of water, and a similar twig was left unsprayed. Ten full-grown caterpillars were sacked in upon the two twigs. The first day the larger part of the feeding was upon the poisoned leaves; on the succeeding day nearly all of the poisoned and about half of the unpoisoned leaves were eaten.

Experiment No. 11. - Alternate leaves of a twig of wild cherry were painted with Paris green and lime, in the proportion of $3 \mathrm{lbs}$. of Paris green and $5 \mathrm{lbs}$. of lime to $150 \mathrm{gal}$. of water, in such a manner as to cover the entire surface of the leaves. Ten fourth-molt caterpillars were then sacked in upon the twig. The feeding was nearly equal upon the poisoned and unpoisoned leaves.

Experiment No. 12. - A twig of apple was prepared in the same way, using arsenate of lead, in the proportion of 3 lbs. to $150 \mathrm{gal}$. of water, and ten fifth-molt caterpillars were sacked in upon it. Nearly all of the feeding was upon the poisoned leaves.

Experiment No. 13. - A twig of wild cherry was sprayed with arsenate of lead, in the proportion of $6 \mathrm{lbs}$. to $150 \mathrm{gal}$. of water, and a similar twig on the same branch left unsprayed. Ten caterpillars of the fifth molt were sacked 
iu upon the twigs. The amount eaten upon each twig was about equal, possibly a little more from the unpoisoned than from the poisoned twig.

Experiment No. 14. - A twig of apple was sprayed with arsenate of lead, in the proportion of 2 lbs. to 150 gal. of water, and a similar twig left unsprayed. These twigs were enclosed in a sack containing ten caterpillars of the fifth molt. The feeding was about equal upon the poisoned and unpoisoned leaves.

Experiment No. 15. - Alternate leaves on a small twig of apple were painted with arsenate of lead, in the proportion of $6 \mathrm{lbs}$. to $150 \mathrm{gal}$. of water, and ten caterpillars of the fifth molt were sacked in upon it. The poisoned and unpoisoned leaves were eaten equally.

\section{Summary.}

Of the four experiments where the caterpillars ate more of the poisoned than of the unpoisoned leaves, Nos. 9 and 10 give most decided results against the choice of unpoisoned food. Of the four cases where the caterpillars ate more from the unpoisoned than from the poisoned food, Nos. 1, 3 and 4 give but a small margin upon which to base a conclusion. The fourth, No. 8 , is of somewhat doubtful value, because six of the caterpillars died upon the second day of the experiment. Balancing experiments Nos. 1, 3, 4 and 8 against Nos. $6,9,10$ and 12, there remain seven experiments where there was no apparent choice of food.

A fair conclusion from these results is that there was no discrimination against foliage treated with the poisons employed.

Effect of Insecticides on Foliage.

No. 1. - June 26, 1893. A mixture of $\frac{3}{4} \mathrm{lb}$. of Paris green, $\frac{1}{2} \mathrm{lb}$. of lime and 2 quarts of glucose to 150 gal. of water was applied to some quince bushes. About onefourth of the leaf surface was destroyed by burning.

No. 2. - July 12, 1893. A branch of apple tree was sprayed with Paris green and lime, in the proportion of 1 
lb. of each to $150 \mathrm{gal}$. of water. The branch was sprayed twice, on account of rain. The foliage was very badly burned.

No. 3. - July 12, 1893. A branch of apple tree was sprayed with the same mixture, and by July 30 the foliage was very badly burned.

No. 4. - July 12, 1893. In order to get as near as possible the exact effects of lime on the foliage, the two following experiments were used as checks on those preceding. They were sprayed within an hour of each other, and all conditions were as nearly the same as it was possible to have them. In this experiment a branch of hop-hornbeam was used as a check to No. 1. The branch was resprayed, on account of rain. July 30, the foliage was burned worse than that of experiment No. 1 , even though the branch in the latter had been sprayed three times.

No. 5. - July 12, 1893. An apple-tree branch was used as a check to experiment No. 2. The branch was resprayed, on account of rain, and August 6 the foliage, though somewhat burned, was not as much so as in experiment No. 2 .

No. 6. - July 12, 1893. An apple-tree branch was sprayed with Paris green, in the proportion of $1 \mathrm{lb}$. to 150 gal. of water, the mixture having been allowed to stand for nearly three hours. August 6 the foliage was very badly burned.

No. 7. - July 13, 1893. A branch of hop-hornbeam was sprayed with Paris green and lime, in the proportion of 1 lb. each to 100 gal. of water. The branch was resprayed twice, on account of rain. July 27 , the foliage was very badly burned.

No. 8. - July 12, 1893. A branch of apple tree was sprayed with arsenic, in the proportion of $1 \mathrm{lb}$. to $25 \mathrm{gal}$. of water. July 19, the branch was resprayed, on account of rain, and again on the 25th. August 6, the foliage was badly burned.

No. 9. - July 20, 1893. A branch of apple tree was sprayed with arsenate of zinc, in the proportion of $1 \mathrm{lb}$. to 50 gal. of water. August 6, the foliage was badly burned. No. 10. - July 1, 1893. A small hop-hornbeam branch 
was immersed in a solution of 2 lbs. of arsenate of lead mixture, making $1 \mathrm{lb}$. of precipitate to $150 \mathrm{gal}$. of water. Foliage uninjured.

No. 11. - July 1, 1893. This experiment was similar to the one preceding, except that the branch was sprayed, instead of being immersed. A branch of a small oak tree was sprayed with arsenate of lead mixture, in the proportion of $2 \mathrm{lbs}$. to $150 \mathrm{gal}$. of water. Foliage uninjured.

The " burning" effect of Paris green, when used in any proportion greater than $1 \mathrm{lb}$. to 150 gal. of water, has been ascribed to the presence of a small quantity of soluble arsenic contained in the poison. Many chemists and entomologists have recommended the addition of lime to the mixture of Paris green and water used in spraying, in order to neutralize this soluble arsenic. Our experiments, however, have tended to prove that the addition of lime is of questionable value.

In some cases we have used a considerable strength of Paris green and lime without burning the foliage, while in other cases a marked burning has resulted. The same variation in burning effects is often noticed where Paris green is used alone. We are led to believe that the burning caused by the use of Paris green and lime is dependent in a great measure upon the amount of lime added, and also upon the length of time the mixture is allowed to stand, as our experiments have shown that, where a considerable quantity of lime is added to the Paris green mixture and allowed to stand for some time, there is far greater danger of burning the foliage than there would be from the use of Paris green alone, thus apparently indicating that the lime decomposes the Paris green in part, and forms a more soluble compound of arsenic.

At my request, Dr. Charles Wellington, professor of chemistry at the Massachusetts Agricultural College, has made a series of analyses of Paris green mixed with water and of Paris green and lime mixed with water, with a view of determining whether the lime would decompose the arsenite of copper contained in the Paris green, and increase the per cent. of soluble arsenic in the mixture. An 
extract from his report on the result of these investigations is given below :-

Paris green, a preparation of arsenite of copper, is insoluble in water, but yields to it a small amount of arsenious oxide, with a mere trace of copper.

The Paris green employed in these examinations was a mixture of several samples, all obtained from the Hampden Paint and Chemical Company of Springfield, Mass.

Its composition was as follows : -

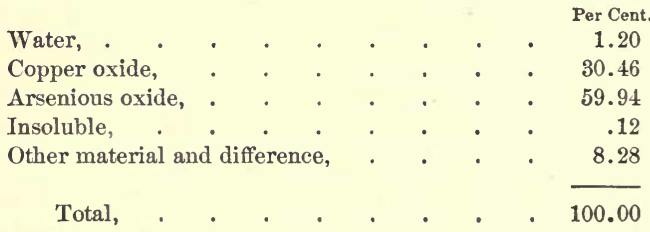

After allowing mixtures of Paris green and water to stand with occasional agitation, $I$ have found the following amounts of arsenious oxide in solution:-

\begin{tabular}{|c|c|c|c|c|c|c|}
\hline \multicolumn{5}{|c|}{ TAKEN. } & \multirow{2}{*}{$\begin{array}{l}\text { Time } \\
\text { of Standing } \\
\text { (Hours). }\end{array}$} & \multirow{2}{*}{$\begin{array}{l}\text { Found Arsenions } \\
\text { Oxide (Grains } \\
\text { per Gallon). }\end{array}$} \\
\hline & $\begin{array}{l}\text { Paris Green } \\
\text { (Pounds). }\end{array}$ & & Lime (Pounds). & $\begin{array}{c}\text { Water } \\
\text { (Gallons). }\end{array}$ & & \\
\hline$a$, & . & 1 & None. & 150 & 3 & 0.33 \\
\hline$b$, & . & 1 & None. & 100 & 3 & 0.46 \\
\hline$c$ & - & 1 & None. & 125 & $\frac{1}{4}$ & 0.11 \\
\hline
\end{tabular}

The free arsenious acid would appear to be the cause of the damage to the foliage.

Alkaline substances generally neutralize arsenious acid, forming with it salts known as arsenites. Lime, soda and potash are materials which thus act. Any one of these could be added to the mixture in such proportion as to exactly neutralize all free acid.

These substances, however, are sufficiently powerful as bases to withdraw the arsenious acid from the copper. This is accomplished either partially or wholly, according to the favoring cir- 
cumstances of concentration and heat. In moderately concentrated solutions of soda or potash (i.e., sodium hydrate or potassium hydrate) all the copper is removed from Paris green as insoluble cuprous oxide. Soluble soda or potassa arsenite is then formed.

In such dilute solutions as are here considered, this could not occur, and yet considerable portions of the arsenious acid may be removed from the copper compound. To show this, I have made the following determinations with the use of lime. In each case the Paris green and lime were mixed, placed in the water, the mixture agitated occasionally and at the end of the designated time filtered : -

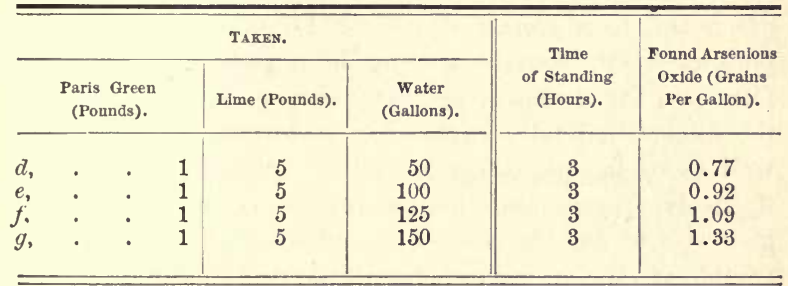

By substituting for this very large amount of lime smaller quantities, proportionally smaller quantities of arsenious oxide were dissolved.

To illustrate the relative solvent effect in different periods of time, the following determinations serve :-

\begin{tabular}{|c|c|c|c|c|c|c|}
\hline \multicolumn{5}{|c|}{ TAKEN. } & \multirow{2}{*}{$\begin{array}{c}\text { Time } \\
\text { of Standing } \\
\text { (Hours). }\end{array}$} & \multirow{2}{*}{$\begin{array}{l}\text { Found Arsenlons } \\
\text { Oxide (Gralns } \\
\text { Per Gallon). }\end{array}$} \\
\hline & $\begin{array}{l}\text { Paris Green } \\
\text { (Pounds). }\end{array}$ & & Lime (Pounds). & $\begin{array}{c}\text { Water } \\
\text { (Gallons). }\end{array}$ & & \\
\hline $\begin{array}{l}h, \\
i, \\
j, \\
k,\end{array}$ & $\begin{array}{l}\dot{0} \\
\dot{0} \\
\dot{0}\end{array}$ & $\begin{array}{l}1 \\
1 \\
1 \\
1\end{array}$ & $\begin{array}{l}5 \\
5 \\
5 \\
5\end{array}$ & $\begin{array}{l}125 \\
150 \\
1 \div 5 \\
125\end{array}$ & $\begin{array}{r}\frac{1}{4} \\
\frac{1}{4} \\
3 \\
10\end{array}$ & $\begin{array}{l}0.69 \\
0.74 \\
1.09 \\
1.23\end{array}$ \\
\hline
\end{tabular}

Trials with the use of soda gave the following results:-

\begin{tabular}{|c|c|c|c|c|c|c|}
\hline \multicolumn{5}{|c|}{ TAKEN. } & \multirow{2}{*}{$\begin{array}{c}\text { Time } \\
\text { of Standing } \\
\text { (Hours). }\end{array}$} & \multirow{2}{*}{$\begin{array}{l}\text { Fonnd Arsenious } \\
\text { Oxdde (Grains } \\
\text { Per Gallon). }\end{array}$} \\
\hline & $\begin{array}{l}\text { Paris Green } \\
\text { (Pounds). }\end{array}$ & & Soda (Pounds). & $\begin{array}{c}\text { Water } \\
\text { (Gallons). }\end{array}$ & & \\
\hline$l$, & . $\quad$. & $\begin{array}{l}1 \\
1\end{array}$ & $\frac{1}{\frac{1}{2}}$ & $\begin{array}{l}125 \\
125\end{array}$ & $\frac{1}{\frac{1}{4}}$ & $\begin{array}{l}0.17 \\
0.31\end{array}$ \\
\hline
\end{tabular}


The lime is understood to be quicklime, the soda to be crystallized neutral soda carbonate.

It is thus seen that either with the use of lime or of soda a certain quantity of arsenions oxide is removed from Paris green beyond that which water alone would remove. The actual amount removed depends upon the proportions of the substances mixed, as well as the time allowed for solution. In every case this amount is in the form either of lime or soda arsenite, and is in solution.

The "burning" of foliage which occurs as the result of spraying with arsenical poisons is due to the presence of soluble arsenic, which is found to some extent in Paris green and to a greater degree in London purple. Other poisons which contain arsenic in a practically insoluble form, as, for instance, arsenate of zinc, when sprayed on the foliage and fully exposed to atmospheric influences as well as to the physiological action exerted by the leaves themselves, sometimes decompose to a certain extent, and give ríse to soluble compounds of arsenic. The effect of soluble arsenic on leaves is to kill the protoplasmic contents of the cells which compose the living or assimilative part of the leaf, as is shown by the illustrations given below :-

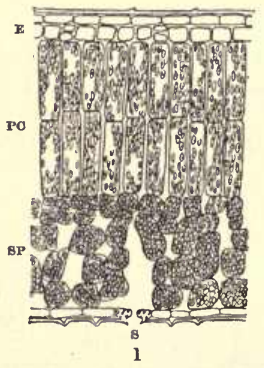

Fig. 1. Section through normal leaf of plg-nut hickory (Carya porcina), showing structural elements. $E$, epldermis; $P C$, palisade cells; $S P$, spongy parenchyma; $S$, stoma or breathing pore. (After Kirkland.)

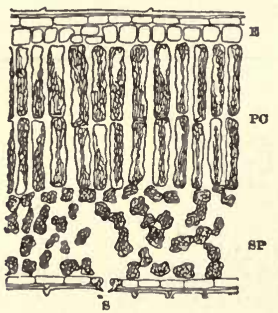

2

Fic. 2. Section through leaf of same tree, "burned" by excess of Parls green. Cell contents ( protoplasm) of palisade cells and spongy parenchyma dead and dried up; cell walls shrivelled. (After Kirkland.)

\section{Leaf Area of Trees.}

To gain a better knowledge of the surface which needs to be covered in spraying operations, during the summer of 
1895 studies were made, under my direction, by Messrs. Kirkland and Hylan, upon the leaf area of three averagesized trees, as follows :-

The dimensions of a medium-sized Baldwin apple tree were carefully measured and the leaves upon one-fourth of the tree counted. The average area of a single leaf was computed by careful measurement of ten average leaves, and the total leaf area ascertained by multiplying the whole number of leaves by this last factor. The data concerning the tree are given below:-

Height of tree, 23 feet.

Diameter of top, 23 feet, 9 inches.

Diameter of trunk, 1 foot, $5 \frac{1}{2}$ inches.

Number of leaves, 99,040.

Average area of single leaf, 30.188 square centimeters.

Leaf area of tree, 298.981952 square meters or $3,218.25$ square feet.

A second Baldwin apple tree afforded data as follows :-

Height, 18 feet, 5 inches.

Diameter of top, 26 feet, 7 inches.

Diameter of trunk, 1 foot, $5 \frac{1}{2}$ inches.

Number of leaves, 108,540.

Arerage area of single leaf, 29.294 square centimeters.

Leaf area of tree, 317.957076 square meters or $3,422.49$ square feet.

The leaf area of a red oak (Quercus rubra) was computed with the following result:-

Height of tree, 41 feet, 6 inches.

Diameter of top, 37 feet.

Diameter of trunk, 1 foot, 3 inches.

Number of leaves, 35,764 .

Average area of single leaf, 83.5705 square centimeters.

Leaf area of tree, 298.88 square meters or $3,217.16$ square feet.

In the actual spraying of trees the poison mixture should be thoroughly applied to both surfaces of the leaf; so that, to find the amount of surface necessary to be covered in spraying these trees, the area should be doubled. 
APPENDICES. 


\section{APPENDix A.}

\section{REPORT OF A CONFERENCE HELD AT THE ROOMS OF THE STATE BOARD OF AGRICULTURE, BOSTON, MASS.}

MARCH 4, 1891.

Present: Profs. C. V. Riley and C. H. Fernald, Mr. Samuel Scudder of Cambridge, Mayor WigGris of Malden, Selectmen L. S. Gould of Melrose, W. C. Craig of Medford, and W. A. Pierce of Arlington, Messrs. Shaler, Appleton and Sessions of the Gypsy Moth Commission, and others.

Professor Shaler. You know that about twenty years ago an interesting Frenchman brought an interesting bug to this country. His name was Trouvelot, and he brought the creature thinking to introduce it as a valuable silk-worm. I begged him to destroy his specimens, and at one time he said he had. It appears, however, that they got away from him. Last year I went before the Legislature and begged for some money, advising them to put a hundred thousand dollars at the disposition of a trustworthy commission. They appropriated fifty thousand dollars and appointed a commission which did a good deal of work and expended a good deal of money and energy. I begged them to bend their energies to bringing in the boundaries as far as possible, to pay the market price for eggs and grubs, and to put their inspection work in progress; but they went into a miscellaneous sprinkling and burning over the whole territory. The result now is that, as nearly as I can ascertain, it would take a line thirty miles long to enclose the area these insects occupy. They are found in a territory of not far from fifty square miles, though not all over it. I should think that not more than ten square miles were solidly occupied. On the rest of it there are colonies here and there. The situation seems to me discouraging in a certain way, but it is an encouraging fact that in about twenty years they have not occupied more than about fifty square miles, and it shows that they are not to be readily transported to a great distance. Another encouraging fact is that, as far as I can learn, save at two or three very limited points south of the Charles River, the creature may be enclosed in this line on this side the 
river [a map was shown], which it does not seem to have passed easily. It passed these few points probably in hauling manure.

Professor Fernald. Are you quite sure of the boundaries? They are reported in Maine and Western Massachusetts.

Professor Shaler. I know they are, but putting the worst face upon it, as I am at present doing, I think an area of something like five by ten miles is the region that has got to be closely studied. There is a reasonable suspicion of it over an area of say fifty square miles, and the work has got to be done over that area. One of the discouraging features is that there is a great traffic through this territory. Railroads and wagon roads go through it, and there is a large traffic in manure out of the district. We have twenty-four thousand dollars to spend for certain, and I am sure the Legislature will give us anything in reason we ask for.

Mr. Appleton. It seems to me the situation is this: Can we eradicate this thing, and, if so, how? If we cannot eradicate it entirely, what is the best we can do? Now, the first question to consider, it seems to me, is, Can we eradicate it, or not?

Professor Shaler. We should like to have the opinion of experts on that point. Professor Riley, will you give us your word?

Professor Riley. I will be very glad to give you whatever suggestions I can on the subject. I have taken the same interest in this matter since it was so prominently announced that $\mathrm{I}$ do in all matters of applied entomology, and $\mathrm{I}$ have felt that in the main Professor Fernald's original suggestions were very wise. The insect, as Professor Shaler has well said, has but limited powers of spreading. While the female has wings, it is heavy bodied and flies but little, and the history of the past twenty years shows that its spread has been very gradual. Therefore we have a condition of affairs totally different from that prevailing in the insect's native home, Europe, and we are justified in making a strong effort to undo the harm that has been done. That brings up, first of all, the question: Is it practicable to exterminate it, or not? In view of Professor Shaler's statement, I have serious doubts, because, if it may be said to occur in an area of say fifty square miles, if it is found even in a number of central points of distribution in that area, there is great danger, in my judgment. My own fears would be that it has got into the woods and on to trees that are not so easily treated. So long as it was confined to cultivated trees and plants under cultivation I think there would have been no difficulty at all, and the authorities would have been blameworthy in allowing it to go out from Massachusetts over the rest of the country.

Professor Shaler. I don't think it has gotten into the woods. I think it is still confined to the artificial grounds, as yet. 
Mr. Appleton. Don't you think it would be a good plan to ask these gentlemen representing the different towns what their experience is in that direction?

Mr. Craig thought, in a general way, that they did not attack forest trees; were confined, as a rule, to orchard trees and trees surrounding houses. Thought the reason the spread was not greater the last twenty years was because the people took the insect for some kind of canker-worm, and took pains to burn them off the trees, which they did until they became too numerous to control. He recommended the use of tarred paper tied round the trees with a string. Undoubtedly the commissioners had destroyed a great many of the insects.

Professor Riley. It is well known to feed upon a number of different forest trees that grow with us, and in the event of its getting beyond cultivated plants I should, as I said, have very little hope of its ultimate extermination. I am not an alarmist, and I do not believe that our people need be so very seriously affected if it is not exterminated; but, aside from that, the loss would go on increasing annually, and it would become a very grievous additional pest to those the farmer and fruit grower already have to contend with. The thing you have to consider is this : from what I could gather from the accounts in the newspapers, three measures were adopted: first, by attempting to destroy the eggs; secondly, by attempting to destroy the caterpillars after they had hatched by means of arsenical spraying; thirdly, by endeavoring to stop the artificial spread of the pest on vehicles, manure wagons, etc.

Individually I have always felt, and so expressed myself, and still feel, that the proper way would be to use whatever funds the State will give you during a limited time, and concentrate all effort and all expenditure in the month of June on the destruction of caterpillars, and not to bother about the destruction of the eggs or the prevention of the spread of the insect. These latter methods, necessarily intrusted to persons who may be efficient or who may not, are apt to bring the whole subject into popular disrepute and disfavor. You may reduce the numbers, but you will never exterminate it by destroying the eggs. Therefore, as a single spraying of a tree will kill five thousand caterpillars just as well as one, there is nothing to be gained by the work of destroying the eggs. Moreover, I do not believe there is much to be gained in the work of preventing its spread by the examination of vehicles on the main thoroughfares and on the railroads. On the contrary, I believe that the only way to accomplish that end is by a very strict law which the Legislature should pass, giving the power to some 
committee to absolutely prohibit the sending of nursery stock or any plant growth or material, probably including manure, out of an infected district without inspection. My belief is that a rigid quarantine law, making it a penal offence for a nurseryman to send cuttings or trees from any given infected area, without first having the sanction of this commission, would be effective in preventing the spread. That is to say, there should be a competent person or persons appointed, to whom all such shipments should be submitted, and only upon their approval should such shipments be allowed to pass out from that area. That would be the only simple and efficient way of preventing its spread. My impression is that the danger is far greater from overlooking a batch of eggs during the months of the year when such a thing is possible, and of the insects being transmitted in that way, than there would be in the mere carrying of the caterpillars. I would therefore concentrate all effort on the destruction of the caterpillars.

I believe that even in an area as extended as Professor Shaler indicates, if the Legislature would appropriate a hundred thousand dollars the thing could be done. Let it be used under the intelligent guidance of some one who has had experience, who knows practically how to spray, who can go to work intelligently and instruct his men, and have a sufficient force to examine every tree and cultivated plant upon which this insect is known to feed, and make sure that wherever it is it will be destroyed before the change into the chrysalis state takes place. In other words, I do not see why, with one hundred thousand dollars, a single year ought not to suffice to stamp it out from the area in which you know it to be found. I believe it can be done, and that the State of Massachusetts would be justified in making the attempt.

In Europe this injury is at times not great, at other times it is quite extensive; but it is chiefly notable in those places where there are very large areas of cultivated forests. Bavaria, for instance, has lately suffered greatly from it. Experience there has shown that it is easily checked by the use of sticky bands, very much the same methods as you have employed here for the canker-worm. They use several kinds of glue (manufactured and some of them patented by different firms), which is procured in large quantities and smeared on the trees, being made in such a way that it does not dry. I presume it comes nearest to our printers' roller glue. The caterpillars never pass above it from below. Coming down the tree they jump over it. The devices for putting it on are very simple. That is the method which experience has shown to be the most satisfactory there, but it is a preventive method, and chiefly to be considered when you have 
given up the fight for extermination. The main thing for you to do is to try to stamp it out during the active season and use all your energies to that end. The arsenicals are not expensive, and if an analysis is made of the Paris green, or whatever form of arsenic is used, to insure its purity, I can see no reason why the whole area should not be practically cleared off during a single season. That should be carefully followed up by close observation, with a view of repeating it in the case of some omitted centre or point where they may be found in a subsequent year. In case they have not gone into the woods, it seems to me feasible to exterminate them.

I would make one other suggestion, and that is, that as an auxiliary method it would be well to spend five hundred or six hundred dollars in sending one or two persons abroad next summer with no other object than to go to some section of northern Europe to collect and transmit to authorized persons here a certain number of the primary parasites of this species, which are known to check its ravages over there. The insect was nndoubtedly brought over by Trouvelot without any of its natural checks. In my judgment it would be well worth trying to import its parasites from abroad. The advantage would be this: if you failed to exterminate it by spraying, its parasites, seeking for this particular host, would be more apt to find the orerlooked or escaped specimens than man would.

Professor Fernald. Do you think that any of our native parasites will be liable to attack this insect?

Professor RiLEY. Experience justifies the belief that some of them may, in time.

Professor Fernald. Have we a case on record?

Professor Riley. Yes, though they are not numerous. Pieris rapoe, or the imported cabbage-worm, has some native parasites. There are other eases, but I should have to consult my notes.

[Note by Professor Riler. Several native species attack Scolytus rugulosus: the same is true of the hop aphid, Phorodon humuli, and of several important species of bark lice.]

Professor Fernald. In reply to the question which was first asked, as to whether it is possible to eradicate the insect at all, let me suppose a case. Suppose we have a tree like the elm I see yonder, and suppose we know it to be the only tree in America that is infested. I think you will all agree with me that for a small sum of money all moths on it could be destroyed. Suppose there were two, - suppose all the trees on the Common were infested. If they could be destroyed on all those trees, it is only a question of time and money to eradicate them from a much larger 
territory. It is a question of time and intelligent labor. I say intelligent advisedly. Right here I would suggest very earnestly that the committee or commission employ a scientific man upon it. This is the advice I gave, with all the force I could, to the former commission, for there are a thousand and one things constantly coming up in work of this kind, and it is necessary to have some one who knows and is able to answer questions. As to the question of territory, I only raised that to know how it had been determined. It is possible it is not so extensive as indicated, but it may be.

Professor Shaler. I thought it best to put it at the highest figure. My own opinion is that we shall not have to deal with an actual area of more than nine or ten square miles.

Professor Riley. Is it not true that so far you have found this pest chiefly on orchard trees?

Professor Shaler. On orchard trees and elms.

Professor RiLex. That is unfortunate, because it increases the difficulty of treatment.

Mr. Craig. They are more numerous on and generally select orchard trees, but even pine trees have been attacked by them and in some cases the branches stripped. Maple trees are also attacked.

Professor Shaler. I have seen them on some maple trees and heard of others, but it seems to be a case of starvation when they come to that.

Mr. Craig. My observation is that the older the tree the more they will attack it.

Professor Fernald. With regard to a scientific man on the commission, if you can get an entomologist who is also a business man you will be fortunate, but in my judgment it is important to have a business man too.

To go back to the question of territory, I agree with Professor Riley that it is rather stupendous; but if you can destroy the insects over a small area, why cannot you over a large one? The whole thing is experimental; it is unprecedented to destroy so many insects scattered over so large a territory, but my impression is that they can be destroyed. The question is, how to do it. I was informed last summer that Paris green destroyed the larvæ of this insect up to a certain size; beyond that size they were able to eat it and grow fat. I urged the commission to try a branch with caterpillars that had not eaten any Paris green, but I cannot learn that they did it. If their statements are correct, I must lose the little faith I had in regard to the efficacy of Paris green. My experiments at Amberst on the use of Paris green do not seem to 
tally with the results they obtained. They used one pound of Paris green to one hundred and fifty gallons of water, and when Mr. Sessions and I went over there in the summer we saw that the trees were burned very little. The same proportions used at Amherst burned the trees very badly. Yet Professor Cook and others have reported that a much larger proportion of Paris green could be used. The Paris green I used I had analyzed and know just what it was. I expect there is either some great difference between the climate of Amherst and this region - or something else.

Mr. Craig. So far as my own orchard is concerned, where the Paris green was used a streak was burned here and there, in other places not. I think it was not kept stirred up.

Professor Fernald. Suppose it is not possible to destroy these insects: even then I believe it would pay to make annual appropriations to hold them in check. We know what the farmers are paying annually to destroy the potato beetle, and if this insect spreads over the Commonwealth of Massachusetts I should suppose it was capable of doing more damage than the potato beetle. It seems to me, if it is not possible to stamp it ont, it is wise to hold it in check where it is.

Mr. Sessions. I have heard the idea advanced by somebody from Medford that possibly the reason the caterpillars apparently eat Paris green and live is that after a certain stage of their existence they stop eating altogether.

Professor Fervald. They do not stop eating long before they spin their cocoons. The time is not more than twenty-four hours.

Professor Shaler. I should like to ask about the chances for more satisfactory insecticides. I should like to ask if we may reckon among the insecticides certain compound salts of calcium which are very acrid, and whether a solution of them would be efficacious?

Professor Fernald. I have had no experience with them.

Professor Shaler. The question is, whether it would serve in this case. Do you know, Professor Riley?

Professor Rilex. I should have most faith in the arsenicals. The relative value of the different forms of arsenic spraying depends partly upon the kind of tree treated, partly upon the condition of the atmosphere, and very materially upon the purity of the material. Paris green has this advantage, that it may be used much more strongly with less injury to the trees; and it has this disadvantage, as compared with London purple or pure arsenic, that it is not soluble in water, and you have to keep stirring it. I have no doubt that the experience Professor Fernald referred to was 
due to the inferior character of the Paris green in the one case and its purity in the other. It should be applied with a spraying nozzle that would simply touch it to the leaves, and it should be mixed with a substance to make it adhere. In other words, all this work should be superintended by a careful, practical man, who knows what to do. A part of the advantage of using the arsenicals in this part of the country would be that, aside from the destruction of Ocneria, it would pay to use it as against the tent caterpillar, the codling moth and various other insects that are so prevalent in your orchards. It is one of the curious things which strike a man travelling through Massachusetts that in a State where applied entomology has had its origin in America, an insect as common as the tent caterpillar, and which may be so easily mistaken for this very Ocneria, should be so abundant, and that so little should be done to control it. You will have the same trouble with the Ocneria. You can't get the average Massachusetts farmer to bestir himself about it.

Professor Shaler. Am I not right in supposing that our first care should be to drive this pest in on the periphery at all costs, but to make surest of its destruction on the periphery? The number of inspectors we could have would be limited, therefore we should take the extremest care with the periphery. With that in view, how would it do, from now until the time the eggs hatch (they are conspicuous things, - you can see them a great distance, and boys could gather them in quantities), to pay the school-boys what would be a tempting price per ounce for the eggs? We would secure a very large destruction on that basis, I think, between now and the time the eggs hatch. We could put a person in each town who should gather the eggs once a day, pay for and destroy them, - that is, in the regions that are thoroughly infected. In that way $I$ think we should diminish the number that are to be killed in the spring, and that at small cost.

Professor Fernald. In reply to that, Professor Riley has already expressed his opinion. A year ago I had just the same opinion that Professor Riley has, and expressed it to the commissioners, but they had already gone to work. I talked with some entomologists about it, and they differed from me; they thought it was beneficial to use other means than Paris green. Theoretically it seems to me that any other means would be a needless expenditure of money, and Professor Riley's suggestion to exterminate them in one year would be a good one if it could be accomplished; but I question whether it would be wise for us to go from this meeting to the Legislature with that proposition. If you failed to do it in one year and came back for a second appro- 
priation, you might find it difficult to get it. This is merely a policy suggestion. I can conceive that, even with the most thorough work that can be done with Paris green in spraying trees, a few might escape and start a new colony. Then in another twenty years this thing would come up again.

Professor Shaler. Do you gentlemen agree that we must look forward to a careful and continuous work against this moth?

Professor Riley. As I said before, we have nothing to do with the experience or methods of Europe, where the insect prevails over vast areas, and where nobody expects to exterminate it. Yet there have been instances of similar extermination, as, for instance, what the Prussian government did with the potato beetle; and here you have an opportunity to show that you can stamp this thing out. I expect a few will escape. That is why I made the suggestion that it would be wise to introduce such parasites as can be used against it, with a view of permitting them to search out those which may have escaped. The matter, as I said, may not be possible; but, if it is, it is only possible in that way, and all other efforts would, I think, be rather puerile, and serve to bring the whole thing into popular disfavor. Set the school-boys to work on the eggs; that is good as a prophylactic measure, and would do a certain amount of good, but the good would be very slight as compared with the effective work you ought to do in the actual destruction of the caterpillars. As I said before, the fact that the insect has been diminished in numbers would be rather against the efficient extermination of the larvæ in summer, for the reason that it is harder to find an isolated bunch of caterpillars in a county than when they are numerous. I still hold to the belief that whatever funds the Legislature can give you should be devoted to a prompt and effective attempt at stamping out.

Professor Shaler. Suppose every tree sprayed, what reason have we to believe that we should have disposed of the pest?

Professor Rilex. There would be need for some years afterward of the greatest care. I would not attempt to kill the young caterpillars; wait until they are somewhat advanced, so that the work could be concentrated within a narrow limit of time.

[At this point Mr. Scudder came in.]

Professor Shaler. The discussion has been, Mr. Scudder, on the question as to whether it would be well to proceed at once to the destruction of the eggs. There are places where the eggs are abundant, and, as we know, they are conspicuous, and it seems that between now and hatching time we might collect a considerable per cent. of them, paying for them by weight or measure, 
and at once destroying them. Professor Riley thinks that would diminish the conspicuousness of the colonies, so to speak, and make it harder to find them, and thinks that an equal amount of money would go further in poisoning with spray than it would in collecting the eggs. I should like to hear from Mr. Scudder what he thinks about the desirableness of doing anything with the eggs.

Mr. Scodder. I feel that I have no right to speak in the presence of others here who have given special study to economic entomology, while I have not. All I can speak upon is the natural history of the moth, and on that side of the question it might be well to ask whether it is behaving the same in this country as in the old country. There are a number of moths single-brooded in the old country which are double-brooded here.

Professor Rilex. I have assumed that it was single-brooded.

Professor Fernald. I have bred it twice, two years in succession.

Mr. Scudder. If it is single-brooded, there is this point to be brought out, that, as the caterpillar is a very liberal feeder, so, of course, it is very much more difficult to reach by spraying, because the spraying is not to be confined to a few kinds of trees, but to a very large number, so that one would say you would have to spray almost everything you came across. So with the eggs, which are laid not always on trees, but on almost anything else. It therefore becomes the most dangerous insect enemy we have had for a long time, I think. If it is single-brooded, it seems to me that nature has indicated the easiest means of attack. The eggs are laid in batches, and are exposed for eight months of the year. Therefore it seems to me that the egg is the place to attack. I should suppose that the same amount of money expended in the destruction of the eggs would effect a very much larger end than the same amount of money spent in spraying.

Professor Riley. I have been trying to bring out what knowledge there is as to the actual range of the insect, and my remarks on the possibility of stamping it out have all been based on that. I want to say that if the insect has spread beyond the limits indicated by Professor Shaler, and got into the larger trees, I think the question of stamping it out a very doubtful one. At the same time there is an opportunity here for the State of Massachusetts to make the experiment, and show what can be done by efficient means and intelligence. I would rather offer a higher bounty to every school-boy for pointing out where the caterpillars are to be found during two weeks in June, than for gathering the eggs. I believe that there is a chance of stamping it out, if it is not 
beyond the region where the trees are comparatively few in number and not very large.

Professor Shaler. How would it do, as one of the early steps in this work, to get all the information we can as to the periphery, and publish maps showing it? Let us ask for information as to the spread of the pest beyond those limits. I should hesitate about offering a reward for the location of the caterpillars, because there is the possibility of the school-boys planting them. A reward for the eggs is much more easy, and we could probably interest the school-boys in searching for them; but it would hardly do to offer a reward which might serve to spread the plague. All these rewards for animals are very dangerous.

Professor Riley. On general principles it is bad policy, but the same objection would apply to a reward for the eggs. If the boys once learned that they could get a certain amount of money for the eggs, they would not be so interested in exterminating them, and thus cutting off future revenue.

Professor Shaler. I should state a definite reward, and not go beyond a certain time.

Mr. CraIg. We have two or three village-improvement associations especially to take care of the trees. We extended an invitation to the citizens to take part in the work, and they were to notify certain committees wherever they found any eggs. This was done to a large extent, and I think it aided the commissioners very largely in finding out where the moths were.

Professor Shaler. You can tell us about the extent of the pest in Medford. Over about how large a territory did it extend?

Mr. Craig. More or less from the Malden line over to Arlington.

Professor Shaler. About a mile and a half in the worstinfested district.

Professor RILEy. What was the result of the commission's work? Are the eggs found abundantly in that neighborhood?

Mr. Craig. I don't believe there are one-tenth the eggs there were when the commission commenced.

Professor Rilex. What was the result of the commission's work last year? Was it appreciable on the number of eggs known to have been there?

Mr. Crarg. Yes, certainly. I differ from you two gentlemen about destroying the eggs. I think it was the means of destroying a great many of the pests. On many trees they were controlled by gathering the eggs.

Mr. Sessions. I have no scientific knowledge on the subject, but it seems to me the first and most important thing we have to 
do is to find the outside line, even if we don't do any more than that in one season. The old commissioners claim that they have found it; our first business should be to verify that.

Professor Shaler. Did they make a map?

Mr. Sessions. I think not.

Mr. Scudder. How do they know the moth wasn't blown fifty miles away by a storm?

Professor Shaler. It may have been; but it is a strong point in our favor that after the creature has been twenty years on the scene it still has a tolerably distinct periphery.

Professor Riley. That is what $I$ have based my recommendation to exterminate it on. I should not like to see the attempt abandoned, but my remarks have all been made with a view of economizing means and time in one effective effort to exterminate it. All these other measures will come in if we have to deal with the pest as a permanent thing among us. As a mere State measure, with a view to not having the unenviable reputation of having given a pest to the rest of the country or done nothing to prevent its spread, Massachusetts has an excellent opportunity of showing what may be done by intelligent, concentrated effort. All other means are puerile as compared with destruction by the arsenicals. All other means are now abandoned in fighting the canker-worm, the codling moth and some other insects, and intelligent spraying at the proper time has come to be looked upon as the most efficient means of protection against these insects. My idea is that what you ought to do is to employ a sufficient force of intelligent persons to scour that whole region in the month of June, and indicate every plant that has a brood upon it.

Professor Shaler. Suppose you had a hundred persons searching at the same time, what general instructions could you give them in determining what trees were infested?

Professor Riley. The insect is gregarious, and therefore conspicuous. There is no reason why intelligent search should not detect it, even on the highest trees.

Professor Shaler. How much time could you reckon on having for your search after the creature came out?

Professor Rilex. I should say you could count on ten days after it was hatched. Its gregarious nature makes that feasible.

Professor Shaler. How much time is there before it begins to spin?

Professor RILEy. I believe it takes three or four weeks.

Professor Fernald. I think it highly desirable to make the attempt to stamp it out. I don't know that it can be done, but it 
is worth trying. If we cannot exterminate it, the other excellent remedies can be used for holding it in check.

Professor Shaler. Had we not better wait until we can strike a hard blow, and do the best we can this year with prevention?

Professor RILEY. I am strongly of opinion that you had better not wait. Some contingencies may arise to give it a sudden impetus. I would adopt the auxiliary methods of introducing parasites, etc., and I would also have a special committee authorized to inspect all nursery stock that goes out from the infested region, and not allow it to go until passed upon by competent men.

Professor Fernald thought the Federal government might take charge of the work. Professor Riley stated that he would be glad to assist in any way possible, but that since the establishment of State experiment stations the Federal government felt it had no further function in the States, so far as local insects are concerned. Professor Shaler thought the State of Massachusetts should make the fight itself, and only ask for Federal aid in case it could not exterminate the pest. Twenty-four thousand dollars were on hand, and he thought that twenty-five thousand dollars or fifty thousand dollars more could be counted on from the Legislature.

Mr. Scudder. I don't understand the force of the arguments used by my neighbors on either side [Professors Riley and Fernald] of delaying the work by not taking the eggs at present. Why do they want all the caterpillars out that they can get, in order to exterminate them?

Professor Shaler. It is a question of seeing them, I believe.

Mr. Scudder. I understand. But, if you destroy so many eggs that say only one tree out of five is attacked, you have to deal with only one-fifth as many trees in spraying.

Prof essor Riley. I want to tell Mr. Scudder just why I rather urge the policy I have advised. First of all, it is from the political side. If you ask for an appropriation to stamp it out, you must do your best to stamp it out. As Professor Fernald has suggested, it is simply a question of means, and I would not think of asking for less than one hundred thousand dollars, and I would concentrate that where it would do the most good. Killing the eggs is frittering the money away at a time when it is not of so much value as if concentrated. Secondly, I hare little faith in the destruction of eggs in this case, where they are laid on so many different objects. I remember distinctly a little cedar tree not more than six feet high in my own grounds that was attacked by the bagworm. I thought I would see whether I could not clear them off. I worked for two consecutive months picking off from 
the tree the issue of not more than two females. Almost daily I went to that tree, and found fresh specimens that I had overlooked the day before. Yet in the Smithsonian grounds I have absolutely stopped similar injury on larger trees in a few minutes by spraying. It would have been no use, in my judgment, to have attempted to eradicate them by hand picking. Suppose you have somebody climb a tree and gather twelve batches of eggs, but he fails to get the thirteenth. It will cost no more to spray a tree for the thirteen batches than it will for the one.

Professor Shaler. When I came here I was strongly in favor of offering a reward for the eggs, but I admit I am shaken now.

Mr. ScudDer. I don't think you can get sufficient force to spray the trees thoroughly in the time allowed.

Professor Shaler. I think we shall have to ask the Agricultural College to lend us say eighty or a hundred of their young men for this work.

Mr. Sessions. There are many people living in the neighborhood of this spraying who claim that it was of no sort of value. Do any of these gentlemen believe that?

Professor Riley. I think the reasons that have been given explain why they had that experience. It was simply due to the impurity of the Paris green and the imperfect manner of applying it. You will always have more or less of failure until you put this matter into the hands of men who can give their whole time to it during that period. Only those men should be employed who have ability and experience; and one man, particularly, should be engaged to superintend the whole work, and as many other competent persons as possible.

A tree fifty feet high is very easily sprayed. If the caterpillars could not be killed by spraying, it would be better to cut the trees down over the whole of the Middlesex Fells. It pays better to make one grand effort than to fritter your energies away over a number of years, and then fail. The Board in control of the work should control ererything. If Paris green is used, it should all be issued by the Board, after being tested.

Professor Shaler. I should like to ask your opinion, gentlemen, whether any considerable risk to health is to be apprehended from this large use of arsenic in the country. Is there any risk of poisoning the water or of poisoning animals or men?

Mr. Appleton. The committee on public health is having an extended hearing on the use of arsenicals.

Professor Riler. If the spraying is copious and careless, which is unnecessary, there is danger of stock feeding upon grass which has been so impregnated, but there is no necessity for that. 
The spraying should be of such a character that there would be comparatively little falling from the tree or shrub sprayed.

Professor Shaler. Have you known of any cases of poisoning in persons employed in spraying?

Professor Riley. No; I have seen none, but I have known of cases where negroes would sit on the back of a mule with spraying pumps, going through cotton fields, and carelessly allow the water to fall on them. I have known them to become sore in the groin, but never knew of a fatal case.

Mr. Appleton. The spraying is washed off by the first rain, of course?

Professor Riley. It should not be. The whole tree is enshrouded in a vapor which is all-sufficient, and which is more effective than a more copious spraying.

Professor Shaler. Is there any particular form of engine which will give that form of spraying?

Professor RiLey. There are various spraying devices in use, depending largely on the height of the vegetation. If you want to throw to any great height without the use of ladders, you need a spraying device that will throw a strong jet. In almost all cases you can use the cyclone nozzle in its Vermorel modification.

Mr. Sccdder. I should like to say before going that it does not seem to me likely that the thing will be exterminated, but that it can be held in check for many years. The reason why I don't think it can be exterminated is because we have not enough persons used to looking for the caterpillars to examine the trees and say for certain that there are none there. I do think, however, that it can be held in check.

Selectman W. A. Perrce of Arlington said they had very little trouble with it in his neighborhood. The sentiment of the people there was in favor of the continuation of the work.

Mayor Wiggis of Malden. We went through and marked every tree that was infested, and then went through again and sprayed them. The trees were not so infested as to be particularly noticeable.

Mr. Gould of Melrose. The selectmen did not believe there were any gypsy moths in their town. As far as he knew, the people were not disturbed by their presence. They would be glad, however, to have the inspectors go through the town and look for it, and would gladly second their efforts.

Professor Shaler. I think it would be a tax of probably more than one hundred thousand dollars annually if not checked.

Professor Rilex. There is no question of that, if it is allowed to take its course. That is what makes it so vitally interesting to 
me, and why I am so impatient of any efforts to simply check it. I have nothing to say about checking it; I speak for stamping it out. Mr. Scudder simply says he doesn't think it will be exterminated. As to how much of any given territory one individual is capable of critically examining, a man who is capable of distinguishing between this caterpillar and others, doing nothing else, would, in my judgment, be able easily to go over a square mile of ground a day, except in dense forest.

Professor Shaler. I don't think so; nothing like it. If the work was done closely (and two together would do better work than one), my impression is they would be doing good work to get over a hundred acres a day.

Professor RiLEY. Well, say a hundred acres -

Professor Shaler. If we could get from the college say forty young men as inspectors, we would have four thousand acres a day inspected, and my impression is that the region covers about ten thousand acres. That area can be thoroughly inspected by twenty parties of selected men doing nothing else. They should mark the infested trees and plat them on a map. As we are no longer a paid commission, I would devote that money to experts. We want the best expert we can select to superintend the actual application of the remedies. When a tree is marked as infested, let it be numbered so and so; and when it is sprayed, let an account be taken of that tree, so that by some system of checking we can find whether every tree has been disposed of or not.

Professor Riley. The suggestion seems to me eminently wise. But I suppose you could get the leading citizens in a community interested also?

Mr. Sessions. I don't believe you can get the college boys to come.

Professor Riley. Not if you paid them? It would be an excellent education for agricultural students; and if you offered them a hundred dollars each, you would have no difficulty in getting them, I think.

Professor Shaler. What month should the work be done in?

Professor Riley. As far as I can learn, the month of June. I believe that about the second week in June will be the time to strike, after having made all your plans, got your forces ready and trained your men. It may be that the thing is not practicable, but I can see nothing impracticable. It is simply a question of money and men. After this one thorough effort you need not ask for another appropriation; everybody will be interested, and then you could afford to offer a big reward for any eggs that might escape. The attempt is well worth making. 
Mr. Sessions. A great obstacle is in procuring help you can depend on.

Professor RiLey. Let me make one other suggestion. While the infested area is stated in the rough at fifty square miles, from what Professor Shaler said there would probably be large portions of it that would require nothing but inspection. Now, wherever there are large trees difficult to climb, I would certainly take the precaution to ring or band them, because that will prevent any stray caterpillars from climbing up those trees. No caterpillars will ascend such trees; and if any escape, you will find them at the foot of the trees. European experience shows this.

Professor Shaler. Where can we get on the track of the mixture they use in Europe for that purpose?

Professor Rilex. You can use printers' ink for that purpose. In Newark I recommended the use of the fire department for spraying certain very tall $\mathrm{elm}$ trees.

Professor Shaler. I presume we could make such an arrangement with the fire departments.

Mr. Craig. We have an engine that could be so used.

Professor Rilex. I would modify my objection to egg collecting just so far that in the case of large trees it would be advisable to do the work prior to æstivation. I think boys could go over them, and in this direction winter work would be adrisable. It would also be advisable to have these large trees very carefully inspected for the eggs; but I do not believe you would be justified in attempting to destroy the eggs over the whole area.

Professor Shaler. Is the energy of diffusion and the tendency of the females to travel at all proportioned to their numerousness?

Professor Rilex. Yes; it is a general principle with insects that, in proportion as they become unduly multiplied, the migratory instinct is developed.

Professor Shaler. So that, in so far as we reduce the number in a given field, we tend to reduce the expansive energy?

Professor Riley. Without doubt.

Professor Shaler. And, therefore, if we fail to exterminate it this year, we shall at least diminish its expansire energy. 
APPENDIX B.

\section{REVISED RULES AND REGULATIONS ADOPTED BY THE STATE BOARD OF AGRICULTURE,}

Under Chapter 210, ACts of 1891.

Reles and Regulations for the Public.

1. All persons are forbidden by law to remove the eggs or any other form of the gypsy moth from one city or town to another, and are requested to exercise care against so transporting the gypsy moth on teams and carriages.

2. All persons are forbidden to remove from any locality in the towns of Medford, Everett, Chelsea, Malden, Melrose, Cambridge, Winchester, Somerville and Arlington any hay, manure, wood, bark, trees, rags, lumber or shrubbery of any kind, without a written permit from the Board of Agriculture. Persons desiring to remove such materials will notify the field director, 13 Stanwood Hall, Malden.

3. All persons are forbidden to in any way imitate or erase the marks employed by this Board to designate trees, fences or buildings which are infested or have been cleaned.

4. All vehicles leaving the above-named district may be stopped by the officers of the Board and delayed until their contents have been sufficiently inspected to determine the fact that they are not liable to transport the eggs or any other form of the insect.

5. No person shall trim, scrape or cut down trees within the district known to be infested by the gypsy moth, or remore them without first notifying this Board, and having said trees thoroughly inspected, and, if found infested, cleaned under its direction.

The eggs of the gypsy moth are frequently scattered abroad by scraping the trees and by careless gathering; therefore, all persons except the authorized agents of this Board are forbidden to remove the eggs of the gypsy moth from the trees or other objects upon which they may have been deposited, or to remove such infested trees or objects from one place to another.

Land owners and tenants are requested to destroy all other forms of the moth which they may find upon their premises. 
6. All persons, upon notice, are required to confine their dogs while the agents of this Board are at work upon their premises.

7. Owners or tenants are requested to gather and burn all rubbish and useless material upon their premises that may provide nesting-places for the gypsy moth, and to fill with cement or other solid material all holes in trees upon their premises.

8. All persons are requested to keep the windows of their houses protected by screens during the summer months, as the moth often lays its eggs in houses, wherever it can gain admittance.

9. All persons having reasonable cause to believe that the eggs, caterpillars or other forms of the gypsy moth exist on or about their premises are earnestly requested to forthwith notify E. H. Forbush, director, by letter addressed to his office in Malden, Mass. Information of the moth's existence in isolated or nnsuspected localities will be gratefully received, and all persons furnishing such information will receive the thanks of the Board.

10. Notice is hereby given that it will, in some cases, be necessary to remove boards from fences or buildings. In all cases such boards will be eventually replaced, if possible, without damage to the structure. Attention is called to the fact that any damage done by the agents or servants of this Board, in the work of exterminating the moth, may be recovered under provisions of section 2 , as above printed.*

Attention is also called to section 6, as above printed,* which sets forth the penalties for obstructing any servant or agent of the State Board of Agriculture under this act.

11. Courteous and considerate conduct is expected of all agents and employees of the Board. Complaints in writing concerning any infraction of this rule should be sent to the director, and will be heard by him or the committee.

\author{
E. W. WooD, \\ Augustus Pratt, \\ F. W. SARGENT, \\ J. G. AVERT, \\ S. S. Stetson, \\ WM. R. Sessions, \\ Committee of the State Board of Agriculture.
}

Rules and Regulations for Agents and Employees.

It shall be the duty of employees to familiarize themselves with the rules governing the gypsy-moth work. The violation of any of the rules will be sufficient cause for discharge at any time without notice. 


\section{General Rules.}

1. No person will be employed or retained who is known to use intoxicating liquors as a beverage.

2. Smoking is strictly prohibited during hours of labor.

3. Courteous and considerate conduct is required of all agents and employees of this Board.

4. All agents and employees (unless otherwise ordered by the director) must wear at all times during working hours the uniform caps and badges issued by the quartermaster.

5. Employees must provide themselves with the uniform prescribed by the State Board of Agriculture and said uniform mast be worn during working hours.

6. No employee shall sign the pay-roll for another unless he has a written order from the person for whom he signs. Said order must be made out on one of the blanks furnished by the Board and must be sent with the pay-roll to the director's office.

7. Superintendents and inspectors are empowered to recommend men for employment, promotion or discharge. Delinquents should be sent with a sealed note of explanation to the office.

8. If an employee is unsatisfactory in any way, the inspector or other officer immediately in authority over him should inform him at once of the fact and note it on the report of that day.

9 . If men are delayed in getting to work by the lateness or negligence of an inspector or a teamster, or if any inspector shall order or allow his men to cease work before the regular hour, said inspector or teamster will have the hours lost by himself and the men deducted from his time, and superintendents shall report the facts of the case.

10. Employees before signing receipts for tools should assure themselves that the numbers on the tools and receipts agree.

11. If a transfer of tools from one employee to another is made in the field, the tools will remain charged to the man who took them from the storehouse, unless a record of such transfer is taken in or mailed to the office within twenty-four hours of the time of such transfer. Unless such notice is received, the employee to whom the tools were originally charged will be held responsible for them.

12. Inspectors may use time cards, when necessary, as a medium for ordering tools.

13. Drivers and owners of wagons are responsible fol tools committed to their charge.

14. An employee leaving the service of this Board must at once return to the quartermaster all property of the Commonwealth 
which has been in his charge. Otherwise, the full value of the same will be deducted from his wages then due.

\section{Rules for Inspecting Sections, Marking Trees and Destroying Eggs.}

15. Each inspector must keep in his note-book a complete record of all work done in his section. This book is to be returned to the director's office when called for, and to be left there when the inspector's term of office expires.

16. Each inspector must carry his section map with him in the field and locate upon the map (by means of such marks as may be ordered by the director) each tree or locality that he finds infested.

17. Each tree found infested must be at once marked with such characters as may be designated by the director, the mark to be on the trunk at three points equidistant from each other and five feet from the ground.

18. When a tree is found infested which has been marked in a previous season, the new mark is to be placed two inches above each of the latest marks.

19. Each object on which egg-clusters of the gypsy moth are found in "outside towns" must be marked with a spot of white paint the size of a ten-cent piece, this spot to be within an inch of each egg-cluster. Egg-clusters found in woodland must be surrounded with a ring of white paint.

20. No trees on highways, in orchards or upon grounds about residences are to be cut, burned or trimmed unless it is found to be actually necessary. In every case where a large branch is cut off the stump must be covered with coal-tar. Trees must not be cut down unless written permission is obtained of the owner, or unless it is so ordered by the director.

21. Each inspector will pay special attention to the trees and shrubbery along the lines of railroad in his territory. The grounds around railroad stations must be carefully inspected.

22. Inspectors are not to call at the office except to leave reports, or unless by special order of the director.

23. Each inspector or acting inspector having charge of two or more men will form his men in line and call the roll at seven A.M. at the place where he begins work. He will again form them in line and call the roll at the close of the day's work.

24 . When the roll is called at night inspectors must state distinctly to their men the point at which they will call the roll on the following morning, and any employee who fails to answer this roll-call will not be allowed full time. 
25. Employees will exercise great care that they do not carry living larvæ from place to place either on their vehicles and clothing or in any receptacle.

26. When employees under the direction of an inspector are obliged to injure or destroy any property, or when property is accidentally destroyed, or accidents of any kind occur, the facts must be reported at once to the inspector, and he must make a note of the same in his report, giving an estimate of the amount of damage done and names of all witnesses.

27. Inspectors must note (and ask their men to note) and state in their reports the language and means used by persons obstructing their work.

28. When troublesome dogs are encountered inspectors may require the owners to confine them, under penalty of the law.

29. Employees must not leave ladder's standing or lying by the curbstone in the street. They must be taken down when not in use and removed to some safe place. Care must be used in handling ladders and also in climbing trees, not to break or otherwise injure the branches.

30. Employees must exercise great care in blazing trees. The inner bark should never be cut.

\section{Fires.}

31. No fires shall be kindled except by order of the division superintendent.

32. Superintendents will demand that due caution is observed in the kindling and management of fires. They will see that the necessary appliances are at hand for the management and extinguishing of all fires ordered kindled. Inspectors in charge will be held responsible for the proper management of fires, or if fires are left at the close of the day's work without being extinguished.

33. No fires are to be built upon sidewalks, or near the curbstones in the streets.

\section{Spraying.}

34. Inspectors must notify pedestrians not to walk under trees which are being sprayed, and must avoid spraying on vehicles.

35. In spraying always station the tank to windward of the sprayers, so that the spray may not blow over it.

36. Before beginning work on an estate inspectors must request occupants to take clothing from lines, close windows and remove anything that may by any possibility be injured by spraying.

37. Employees must use great care not to injure lawns, flowerbeds, vegetable gardens or other property. 
38. Inspectors are to handle and mix poisons.

39. The solution in the tank must be constantly stirred from the time it is first mixed until the tank is empty.

40. Tanks must be fastened on the wagons in such a way that they cannot be overturned.

41. If, during the spraying, a tree is found infested and unmarked, it must be marked. Each time a tree is sprayed it must be marked with three round dots, the size of a ten-cent piece, the first set being placed five feet from the ground, and each succeeding set an inch above.

42. Inspectors will carefully notice the effect of the spraying and record the same in their daily reports.

43. The spray thrown on the trees must be as fine as possible.

44. Drivers of spraying wagons, when at work, will be under the direction of the inspector in whose section they are employed. Each inspector will keep the time of his driver and report the same.

45. Inspectors must, when possible, draw water from the standpipes. When hydrants are used the inspector only shall open and close them, exercising great caution to open and close them slowly, but not closing them so tightly as to prevent opening.

46. At morning and at noon, before beginning spraying, each nozzle must be turned into the bottom of the tank and a full stream pumped for five minutes.

\section{Reports.}

47. The rating of superintendents and inspectors will be based, not only on the quality of the work done by their men, but on the fulness and excellence of their own reports. All reports must be sent to the director's office and are subject to his approval. Each inspector must make out his report daily and give it to his superintendent, or send it to the office (by mail or otherwise) on the following day. Observations on the habits of the insect and other items of interest, and any statements or complaints by citizens, should be embodied in the reports.

48. Superintendents must notice whether the streets are reported in their proper sections.

49. Inspectors must give time of employees on each day's report.

50. In case of the absence of an employee the inspector must give the reason (when known to him) for such absence on the report of the day when such absence occurs.

51. Inspectors must observe the printed headings on reports and fill spaces reserved under the same. 
52. Inspectors must give the correct street and number of each building and estate inspected and the full name of the property owner or tenant.

53. If at work in two or more sections in a day, inspectors must make a separate report for each section.

54. The name of the inspector, if at work, must appear in the employees' column.

55. When a man enters the employ of this Board the inspector with whom he first serves shall make note of it at the time on his daily report.

56. Each inspector will designate on each day's report and time card the exact point at which he will begin work on the next working day and on what street and in what direction be will more; also the exact hour and place of roll-call and the place designated for roll-call the following morning.

57. Whenever a marked tree is cut the inspector in charge shall incorporate the fact (giving marks) in his daily report.

58. Inspectors will report as trees all young growth abore three inches in diameter.

59. When brush is cut and ground burned orer inspectors will report in square yards the area cleared daily.

60. If men are sent away on special duty by an inspector he must state the reason on his report and mark time card "see report" opposite such names.

61. Superintendents, special inspectors and all other assistants in the field must state on their daily reports when and where they meet their men; and inspectors must also note on their reports the time of such visits.

Per order of the committee,

E. H. Forbush, Director. 



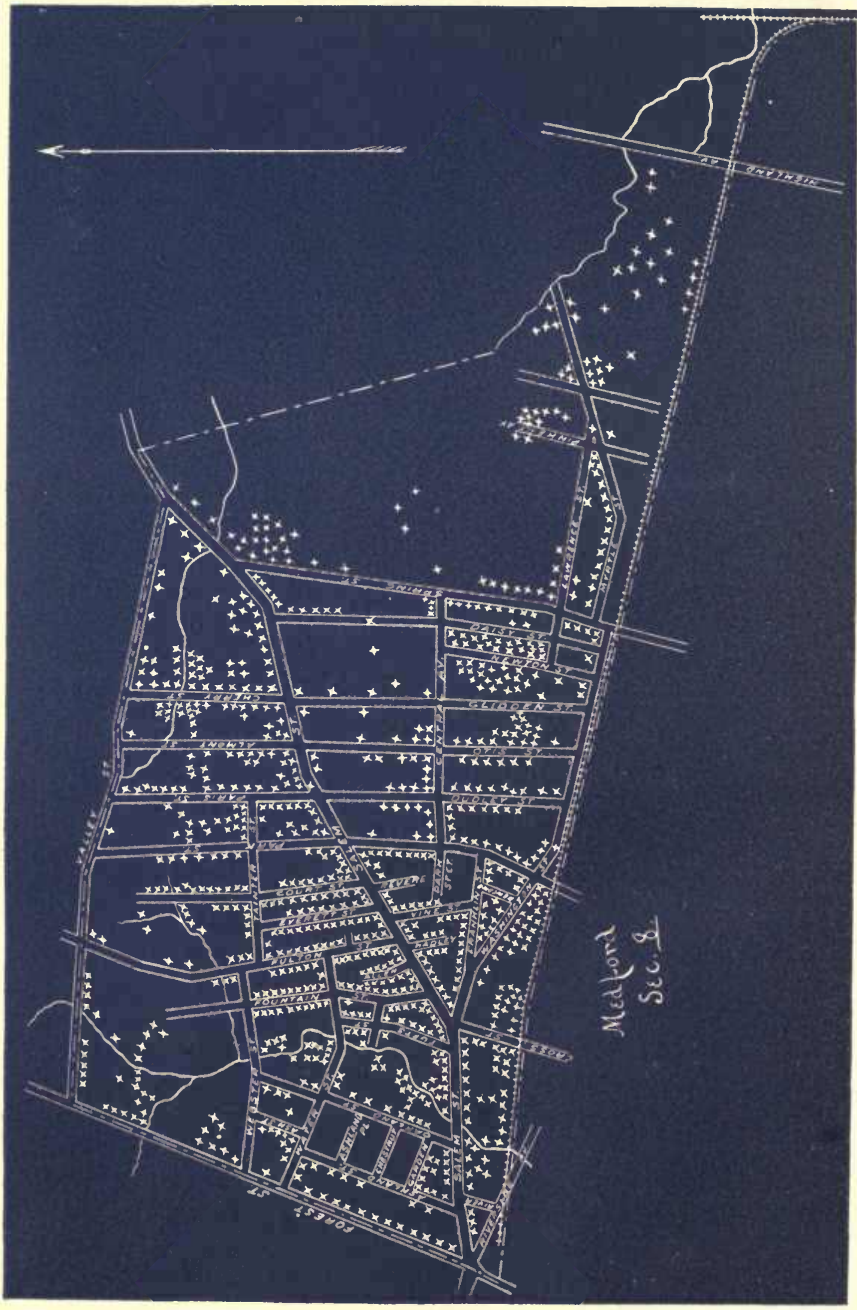




\title{
Appendix C.
}

AN EXTRACT FROM A DESCRIPTION OF SECTION 8, MEDFORD, AS IT APPEARS IN THE SECTION BOOK, SHOWING THE CONDITION OF THAT SECTION AND THE WORK DONE IN IT IN 1891. [THIS SECTION INCLUDES THE GLENWOOD DISTRICT.]

\author{
Medford, Section 8.
}

Boundaries.

Commencing at a point on the centre line of Main Street, in front of the Boston \& Maine station of the Medford branch railroad; thence easterly by the centre line of said railroad to the centre line of the main line of the Boston \& Maine Railroad; thence northerly on said main line of railroad to a creek flowing nnder said railroad (the centre line of said creek being the boundary line between Medford and Everett); thence northwesterly and northerly by said boundary line to the centre line of Salem Street to Valley Street; thence westerly by said Valley Street to Forest Street; thence southerly by the centre line of said Forest Street and Main Street to the point in front of the railroad station, the point of beginning.

\section{Description.}

Section 8, Medford, contains the cottage formerly occupied by Mr. L. Trouvelot, the gentleman who imported the gypsy moth and accidentally liberated it here. The southwestern angle of the section near the Medfora branch railroad station constitutes a large part of the business portion of the town. It is quite compactly built up with dwelling-houses, shops, stores, etc. The traffic with outside towns is considerable. The principal thoroughfare, Salen Street, is the high-road to Malden and the towns to the east. Forest Street, which forms the western boundary, is much used for carriage driving. On the Medford branch railroad and within this section are the Park Street and Glenwood stations. Near these stations and on the intervening land along the line are the homes of small householders and people whose business is in Boston. Here, as elsewhere through much of this section, each house has its lot of land and generally a small garden or orchard. 
The streets are usually well provided with shade and ornamental trees, many of which are large and stately elms. In the spring of 1891, when work was first begun by the commission, the greater portion of this plain, including the swamp, was corered with a young coppice intermingled with bushes and undergrowth. Near the southern border of this tract the Anderson Pressed Brick Company erected extensive works in 1886 on the ground used more than twenty years ago by Trouvelot for his silk-worm pasture.

Gravelly creek runs through the western part of the section near the Forest Street boundary. The northern boundary of the section lies close to the rocky ledge which marks the beginning of the Middlesex Fells. Near the centre where the insect was first colonized there is a large tract of woodland suitable for the shelter and propagation of an insect pest. Upon the west several streets much travelled, and with gardens and orchards on either hand, lead toward the centre of the town. On the south is a railroad which terminates at the heart of the infested district and is supported by a traffic with Boston. The principal thoroughfare connecting Medford with eastern towns runs through the heart of the section. Another large thoroughfare marks its eastern border, and a stream which flows north or south as the tides rise and fall rises in the section and flows to the Mystic River. Here we have all the requisites for the sustenance of the insect and all facilities for its transportation in all directions.

The commission appointed by Governor Brackett to " check the spreading and secure the extermination" of the gypsy moth undoubtedly destroyed large numbers of moths in this section by burning, by scraping off the eggs and by spraying; yet when the agents of the Board of Agriculture first entered the section, in March, 1891, its condition was, to say the least, alarming. Some parts of the brush and woodland were so infested with the eggs of the species that it was utterly impossible with the men and means at our command to destroy them by hand. There were acres of ground where egg-clusters were numerous. Many eggs were laid on the ground and were found in great numbers in excavations where people had dug out clay or sand. A stone wall which was torn down (the lower surfaces of the rocks being thereby exposed) presented a remarkable spectacle. There being no large trees near the wall, it formed a refuge and concealment for the moths that fed on the neighboring bushes and saplings. On one rock over one hundred large egg-clusters were counted. When the number of eggs contained in a single egg-cluster is considered, it is apparent that millions of caterpillars would have hatched in 
this wall had the eggs not been destroyed. The trunks of some of the trees were actually yellow with egg-clusters. Though the insects were not distributed equally over the entire section, there were many places where eggs were found in sufficient numbers to have let loose a destroying host upon the entire neighborhood. A large per cent. of the yards within one-half mile of the Trouvelot house were thus infested.

The yard of the Anderson Pressed Brick Company includes a part of the wooded section hereinbefore described. At the present time the eastern portion of the yard is covered with a scattered growth of young oaks and bushes. Near the buildings and attached to them on the east are several sheds in which are piled many thousands of the finest quality of pressed brick. East of these are several detached sheds also filled with brick. Near them is a pile of broken bricks about thirty yards in length, fifteen feet in width and ten feet in height. These sheds and the brick-bat pile are among the oaks, the pile being heaped against some of the trees. When the work in the brick yards was begun by the commission on March 21, 1891, the entire premises were infested by the gypsy moth. About three hundred thousand bricks were stacked in the sheds and two hundred thousand outdoors under the trees. The crevices between these bricks gave opportunity for the moths to deposit their eggs. The bricks under the sheds near the buildings had not been much frequented by the moth, but three-fifths of those under the trees were more or less covered with eggs. The egg-clusters were found on the ground and under the floors, on the sides and under the roofs of the sheds, under the stumps and about the roots of trees, on their trunks and limbs and in almost every conceivable sheltered place. As the infested bricks were likely to be transported in all directions, the danger of the distribution of the moth by this means appeared great. A capable man was at once stationed in the yard to examine all bricks sent out. The finest quality of bricks sent out previous to this time had been shipped to a distance. Most of them were used for fireplaces and were cleaned by the brick company before shipment, and in this way all eggs were probably taken off. Many localities to which bricks had been shipped were afterwards examined. The work in this yard was pushed with the greatest energy. Two hundred and thirty-two thousand one hundred and ninety-five bricks were examined, and all those infested were cleaned and the eggs burned. The shed most badly infested was burned. The floors, roofs, etc., of the others were torn up wherever necessary, and the eggs taken from them. Some of the trees near the shed were cut down and burned. The 
brick-bat pile was surrounded by a board fence eighteen inches high. This was covered with tarred paper, and before the caterpillars began to hatch in the pile the paper was covered with a mixture of pine tar, printers' ink and crude petroleum. This fence the young caterpillars were unable to scale. The trees in the brick yard were inspected and the eggs on them destroyed. Fire was run through the underbrush, but this did not kill all the eggs. One section of the yard was burned experimentally by spraying the ground with crude petroleum after the brush had been set on fire. On this section no signs of the caterpillars were seen during the year. In other sections, where some eggs survived the burning and hatched, all vegetation was sprayed with Paris green several times during the season. At the end of the season it was difficult to find any sign of the moth in the yard. Trees and bushes were cut down over a tract of one hundred acres, and fire was run over it. Any spot that escaped the fire was thoroughly burned by the use of crude petroleum.

The inspection of the towns on the border line of the infested district occupied so much time in the spring of 1891 that it was found necessary to neglect until egg-hatching time a large tract near the centre of the district in Malden and Medford. Time was found, however, to inspect the large trees along the highways and railroads. The eggs found on them were destroyed and the trees were banded with tarred paper, which was kept covered with the mixture used in the brick yard. This prevented the larvæ from ascending these trees, and reduced the danger of their being carried out of the district. Most of the trees in the section were sprayed two or three times during the season with a mixture containing Paris green, in some places where badly infested they were sprayed four times; nearly all vegetation, in fact, was sprayed. Holes in the tree trunks which offered hiding-places for the larvæ were filled with cement. Burlap bands were put about the trees after the caterpillars began to cluster, and by these means the vast increase was kept down.

As soon as the female moths had laid their eggs and died, a small force of men began destroying the eggs. It was soon noticeable that, while vast numbers of last season's egg-clusters which had hatched were found, very few newly laid clusters appeared. Every nook and crevice was searched with the greatest care to discover and destroy all traces of, the moth. While the leaves remained on the trees, buildings, fences, woodpiles and all hiding-places near the ground were searched. As the leaves fell the trees were examined and cleaned of eggs. Where the trees were thickly infested the leaves were raked up and burned; thus 
every possible effort was made to exterminate the moth by gathering the eggs.

After going over the entire section carefully, an estimate of the number of eggs found was made. Comparing this with the estimated number found in the spring, it was seen that the number found in the fall was about twenty per cent. of the number found in the spring. The data for this estimate were very complete, and were taken from the daily reports of the inspectors. 


\section{A P PENDIX D.}

\section{REPORTS OF ENTOMOLOGISTS WHO VISITED THE INFESTED REGION IN 1893.}

Report of Dr. A. S. Packard of Brown University, late of the United States Entomological Commission.

Prof. C. H. Fernald.

Providence, R. I., June 19, 1893.

Mr Dear Sir:- Having been asked to give my impressions of the work now being done at Malden and vicinity in exterminating the gypsy moth, I will say that it made a good impression on me, and I have no adverse criticisms to make. Mr. Forbush seems exactly adapted for the work intrusted to him. I was struck with the ability shown in organizing and systematizing the whole work, and the readiness and interest shown by the men under $\mathbf{M r}$. Forbush. The office and its system, the storehouse and its apparatus, interested me very much, and the new and ingenious devices for spraying and in other ways destroying the eggs and worms. It seems to me the work is practical and thorough throughout, and must bear good fruit this season.

In the short time I spent I saw nothing to find fault with, but much to commend. I say this without wishing to merely say something pleasant, but because I mean it.

Yours very truly,

A. S. PACKard.

Report of Dr. J. A. Lintner, State Entomologist of New YORK.

Ortici of State Entomoloeist, Room 27, Capitel, Prof. C. H. Fernald.

ALBANY, Jane 22, 1893.

Mr Dear Sir:- The two days that I passed last week, in compliance with the request of the gypsy moth committee of the State Board of Agriculture and of yourself, in inspecting the operations of the committee through its director, Mr. E. H. Forbush, were highly gratifying and satisfactory to me. I was not pre- 
pared to see that such progress had been made toward the extermination of the notorious gypsy moth. It was a surprise to me that in the brief space of three years the fearful ravages of the insect as described to me and as pictured in photographs could have been reduced to such a comparative harmlessness that to the ordinary observer no indication of its presence was visible, and that in a ride of an entire day through several of the "infested towns," including a visit to localities which had been frightfully scourged, not a single example of the caterpillar was found by $\mathrm{me}$, although diligent search for it was made.

How a work of such magnitude, extending over so large a territory, could have been accomplished, was a wonder and an enigma to me, until I became acquainted with the means by which it had been brought about. These are, in part:-

First. Your work at the insectary is largely supplementing that being conducted at the Malden headquarters. I regard it so exceedingly valuable and so absolutely essential to the best results in field work, the one to check and therefore to aid the other.

Second. The committee, I am confident, have been both wise and fortunate in their selection of Mr. Forbush as director of field work. I think that I estimate correctly when I say that he is eminently fitted for the important and responsible position. A high degree of judgment and discretion has evidently been exercised in the selection of those employed by him and the retention of those best qualified for the duties assigned them. The executive ability displayed by him in the organization of his force, its direction, guidance, supervision, equipment, accountability, etc., seems to me remarkable, and to go far toward the accounting for the singular success that has attended his administration.

Third. The "storehouse" greatly interested me. It may properly be called an "arsenal," for it is furnished with all the appliances needed for conducting in the most effective manner the warfare in which you are engaged. In it are found not only all of the more important instruments and materials that economic entomology had tested in former years but many new ones, called into use for the first time, as the need had become apparent and the ability for their conception and production was at command.

With such means, as above indicated, your State, which has been liberal in its appropriations, has a right to expect ample returns. It will not be disappointed, for you have already accomplished more than could have been reasonably expected.

I trust that your Legislature will see the wisdom of continning the work under suitable appropriations, until the extermination of the insect has been attained, or at least until it shall have been 
reduced to entire harmlessness, and in position never again to develop in injurious numbers or to invade other States.

I have been asked to offer such criticisms or suggestions as I might deem it proper to make. I have found nothing to criticise, but, on the contrary, have received instruction from what I saw.

Under the permission given, I will offer two suggestions :-

1. As what may be called the mechanical details of field work, as burlapping, liming, spraying, egg collecting, etc., are steadily diminishing, there will be the greater need (as well as the opportunity) of scientific work, to round up, as it were, the labors of the committee, to aid in its completion, to render it available for future use wherever the necessity may arise in this or similar insect invasions, and to make such a contribution to science as Massachusetts has ever been ready to do when the occasion has offered.

I would, therefore, suggest (and recommend, if I dare venture to do so) that the committee, if possible, avail themselves of more of your time and service. Your habits of thought, observation and study seem specially fitted to the work that you are now conducting for the committee. Further, the experience that you have gained is of so great value that it should not be lost to them. I do not, however, see how this could be brought about under your existing relations with the college and agricultural station. I am sure that there is an ample field for your entire service. If the committee could offer you a sufficient inducement, is it not possible that, while retaining your connection with the college and station, you could be released from the discharge of the duties, say for two or three years, and devote yourself wholly to the gypsy moth ? So positive am I of the utility of such an arrangement, that I sincerely hope that it may be accomplished.

2. Just at this stage of the committee's work I would suggest that the cultivation of the parasites of the gypsy moth be entered upon and conducted with all the knowledge and skill that can be brought to bear upon it. Far more is to be hoped from this than from the costly and problematical search for and importation of its European insect enemies. Nearly a score of native parasites are already known to prey upon it, and we may expect this number to be materially increased. Something like the following method of cultivation might be pursued :-

Collect the pupæ as soon as they are to be found, so as not to give opportunity for the escape of the earlier maturing parasites. None should be destroyed, but carry all carefully to headquarters at Malden, suitable provisions having been previously made for their reception and care. 
If 80,000 , as reported, were collected last year, perhaps from 15,000 to 20,000 might be secured this year. Arranged in a single layer, a case not exceeding twenty-five square feet of area would be ample for them, and leave space at one end for feeding larvæ.

By means of cold storage, delay the development and emergence of the parasites until larvæ are in readiness in which they may oviposit.

Egg-clusters collected this season shall be so regulated by temperature that they will give out their larvæ as soon as food is obtainable for them.

With the feeding larvæ in one part of the case with the pupæ, they will at once be found by the parasites and all of their eggs deposited in them if the larval supply is proportioned to their need.

When the parasitism is finished, the larvæ may be fed in confinement to maturity, if practicable, provided that conditions favorable to the prevention of disease or other fatality can be given them; or they may be transferred to isolated trees selected for the purpose, where they may complete their growth and be protected from destruction by birds by inclosing the trees in netting. The following season the parasites, unless desired to extend their multiplication by again rearing them in confinement, may be permitted to escape and seek their prey abroad.

The parasitized caterpillars might be conveyed to the localities where the parasites are the most needed.

Gathering the parasites from the case after their death would give every species which was parasitic on the larvæ and pupæ (except such as may have emerged from the larvæ), and their proportionate number, from which the most efficient could be ascertained. Examination would also show the proportionate number of pupæ that had been destroyed by parasites.

The above plan may not have been properly digested by me, and there are no experiments of the kind to serve as a guide. So far as I know it has not been attempted on a large scale (the multiplication of icerya parasites in California was somewhat similar), but if done with the knowledge that you could bring to bear upon it, I am sanguine of its success. Possibly by this means only can the desired extermination of the gypsy moth be attained.

If, under the existing law, the carrying of the living insect from one town to another is prohibited, amendment for the abovenamed purpose could no donbt be secured.

Very truly yours,

J. A. Lintner. 


\section{Report of Prof. John B. Smith, D.Sc., of Rutgers College, State Entomologist of New Jersey.}

New Brunswick, N. J., June 20, 1893.

Dear Dr. Fernald : - Since my return to New Brunswick I have been thinking over what I saw of the work of the gypsy moth committee near Malden, Lynn and Swampscott, and with the lapse of time my admiration for the work accomplished has increased rather than dimiuished. When I received your invitation I was, I think I can truly say, free from actual prejudice, yet with a disposition to believe that the work of the committee was palliative merely, and that actual extermination was impossible, an impression to which I had given public expression. I am pleased to say that $I$ have seen ample evidence to induce a change of opinion, and my belief is now that if the committee is as well supported as it deserves to be it will accomplish the end for which it was created. With this expression of my present belief, you will understand that my suggestions are not in the nature of adverse criticism.

First, concerning the experiments in progress at Amherst, at the present time. These consist of a test of the action of certain insecticides on larvæ of all ages, and in contemplation are experiments concerning possible parthenogenesis, fixing the relative time of issuing of the sexes from one batch of eggs and the effect upon the fertility of the eggs of close breeding, - that is, between males and females bred from the same egg-mass.

All these experiments are not only of the highest scientific interest, but also of the utmost practical importance.

If parthenogenesis is possible, the danger of spreading the insects by carrying off single specimens is vastly increased, and the most stringent measures to prevent such distribution are justified. While parthenogenesis in the Lepidoptera is extremely rare, yet cases have been recorded in the same natural group to which this insect belongs, and the inquiry is therefore by no means a merely curious one.

Fixing the relative time of the emergence of the sexes of the same brood is of very great importance, for, if males and females issue at such intervals as to make it unlikely that they can pair, the danger from the distribution of even several larvæ from the same batch of eggs is materially lessened.

The determination of the effect of in-breeding is equally important, for much the same reason.

Finally, the experiments with insecticides are of peculiar interest, 
from the fact that the caterpillars seem unusually resistant to the action of arsenic in doses fatal to most of the insects known to us.

There is one criticism to be made on all the above experiments : they are on too small a scale to render the results altogether convincing and they are made in the wrong place at Amherst rather than at Malden, Lynn or elsewhere in the infested region. The extreme caution necessary to prevent the escape of specimens of the larvæ prevents the practice of certain lines of out-door work, the results of which would supplement the in-door or laboratory experiments.

I would therefore suggest that the experiments now carried on at Amberst be duplicated or transferred to some point within the infested district where material is more abundant, and where there is no danger of introducing the insect into new localities.

These experiments must of course be made by a trained entomologist, or by a competent man under detailed instructions. By all odds the most satisfactory plan would be to have you carry on the experiments yourself, for they would then command unirersal acceptance and would be generally regarded as conclusive.

The result of the insecticide experiments thus far is so unusual that I would recommend a further series of experiments to determine exactly what becomes of the arsenic eaten by the insects; whether it is absorbed or whether it is excreted, and how much arsenic an insect will contain when its intestinal canal is filled with poisoned food and excreta therefrom. This could be done by feeding larræ on leaves sprayed with a maximum amount borne by the foliage for say three or four days, and then substituting fresh food free from poison. A chemical test should be made thereafter every day or every day or two, to ascertain the presence or absence of arsenic in the larvæ. Microscopic examinations of the digestive tract of poisoned larvæ should also be made, and should be compared with that of healthy larvæ, to ascertain whether any lesion were cansed that might result in a degenerated adult. The excreta of larvæ fed upon poisoned food should also be analyzed to determine the amount disposed of in this way.

This is of course suggestive merely; but in my opinion the present occasion is an unusually good one to gather a mass of facts whose importance to economic entomology it would be difficult to estimate.

If I had reason to speak in approbation of the line of experiments laid out by yourself at Amberst, I found very much more to admire in the infested district, in the actual field work under the direction of Mr. Forbush. The mere organization of the force and the plan of the work is excellent; as to the results of the metbods adopted, the fact that in the entire infested district 
visited by me - Malden, Lynn and Swampscott - only a single half-grown larva was discovered speaks loudest.

I was extremely interested in the office organization, in which the system of entering and classifying reports enables the director and the members of the committee to determine at once the exact condition of affairs in any district. The notes of observations made by inspectors are many of them of the greatest interest, and merit editing by an entomologist capable of recognizing facts and separating them from inferences made by the observer.

The inspection of the tool-house was a revelation in the variety of apparatus it afforded, all of it adapted to the special end in view. The practical value of all the apparatus is obvious, and while for an orchard the spraying outfits might be considered clumsy and somewhat wasteful, yet when the character of the work is considered the apparatus designed for the fruit grower is manifestly insufficient. A most commendable feature in the work has been seeking out means of taking advantage of the peculiarities of the insect's habits, which is, after all, the most philosophical way of accomplishing the work in hand.

It would be altogether too long a task to go into details concerning the outfit of insecticide machinery, and I need only say that I can find absolutely nothing to suggest in the way of improving the methods of work.

The force under the direction of Mr. Forbush has accomplished wonders, and I feel now that there is very good reason for the belief that the gypsy moth can be exterminated, provided the means are furnished by the Legislature of Massachusetts in as liberal a spirit at least as past appropriations have been made.

I have been asked to give an opinion on the feasibility of introducing European parasites of this insect, to keep it in check. I feel very decidedly that this would be money wasted. This and its ally, the Nonne, are frequently destructive in Europe, and if its parasites do not succeed in mastering it there, there is no reason for believing that they can do better here.

Nature never works for the extermination of any of its creatures, and if parasites ever exterminated their hosts the parasites themselves would be exterminated for the want of food. A balance is all that nature aims for. A parasite which would be able to exterminate the grpsy moth in this country must be one that would prey on this one insect only; and even then it is very problematical whether the result would be very satisfactory, for to enable the parasites to do their work, artificial means of destroying the larvæ would have to be abandoned for fear of killing the parasites as well.

I am very strongly of the opinion, therefore, that nothing can be'gained by an attempted introduction of parasites. 
The oft-cited case of Vedalia destroying the cottony cushion scale in California can have no application to this case, for the circumstances there were so peculiar that they can rarely be duplicated, and are not similar here.

I am asked to express an opinion as to the work done and to be done by the committee. I can only repeat what I have already said, - the work done by the committee as at present organized is admirable, and I am unable to point out a method in which it could be improved.

Both the entomologist and the director thoroughly understand the problem, and are working for success, - a success that $I$ now think they will attain.

As to the work yet to be done, I am not in a position to give an opinion, because I had no time to cover the entire ground. From what I could see at Malden, Lynn and Swampscott, I believe that for at least two years more a full force of men should be employed, using the methods that have proved so successful and working from the outer limits toward the central district.

The most useful men should in all cases be retained from year to year, for they will be worth at least double the sum any new man could be valued at, and will know just exactly what is to be done in all cases and just what to look for. After a few years the force of men could be safely reduced to the inspectors and a few ordinary workmen, whose principal business would be a continuous examination of the once-infested district, prepared to destroy any isolated brood that may have escaped; and finally this force could be reduced to the director and a very few inspectors, who, with the experience gained, could easily command the entire region until lapse of time proved the insects exterminated.

Very truly yours,

ЈонN B. Sмгтн.

Dr. C. H. Fernald, Entomologist, Gypsy Moth Commission, Amherst, Mass.

Report of Prof. Clarence M. Weed, D.Sc., of the New Hampshire College of Agriculture and the Mechanic Arts, Entomologist of the Agricultural Experiment Station.

To the Gypsy Moth Committee.

Havover, N. H., June 16, 1893.

Gentlemen:- In response to the invitation extended by you through Professor Fernald, I recently visited the various departments of gypsy-moth work, and beg leave to inform you of the impressions thus received. 
I first inspected the work in progress at the insectary at Amherst, and found that a series of experiments with remedies was being conducted under the most careful conditions; in fact, I have never seen a series of similar experiments carried on in so large a scale in so thoroughly scientific a manner. They ought certainly to furnish reliable results, which will be of great value outside of the gypsy-moth work.

I next went to Malden, and in company with the other visitors, Professor Fernald, Mr. Forbush and Mr. Reid, looked over the ground carefully. The general impression received was very favorable as to the amount and methods of work. The results already reached seem to be remarkable, and I was greatly surprised at the scarcity of gypsy caterpillars. The methods of fighting the pest have evidently been developed along with the knowledge concerning it, and are well adapted to the end in view.

The only suggestion $I$ have to make concerns the lack of adequate facilities for studying the life history of the pest at headquarters. It seems to me that if a room adapted to the purpose could be set apart, and a man of entomological training be detailed to make out the biological points yet in doubt, valuable results might be reached. I should suppose that it would hardly be necessary to call in an entomologist of note if Professor Fernald is willing to supervise the work of the one detailed to carry on such observations and experiments. In fact, the results would have an added value if carried on both at Malden and Amherst under one direction.

I was especially interested to learn of the results that have been reached with the arsenate of lead. Even if it does not kill gypsy caterpillars as quickly as does Paris green, it seems probable that it will make a valuable insecticide for many other purposes.

Thanking you for the opportunity you afforded, and assuring you of whatever support I may be able to render, I am,

Yours respectfully,

Clarence M. Weed.

Report of Dr. H. T. Fernald, of the Penngylunata State College.

Statr College, Centre County, Pa., June 19, 1893.

To the Gypsy Moth Commission.

Gentlemen:- In accordance with your request, extended to me by Prof. C. H. Fernald, I have examined the work in progress at Malden and Amberst, and $2 \mathrm{~m}$ both interested and pleased with what I have seen. 
Previous to my visit to Malden I felt some doubt as to whether it was possible to exterminate the gypsy moth, as I had had some previous knowledge of it and of its ravages in Massachusetts, being at Amherst when it was first reported to the experiment station there in 1889 , and having carefully looked over the matter at that time. Since my visit a careful consideration of the methods used and of the results already obtained has convinced me that extermination is not only probable, but certain, if the work be prosecuted for a sufficient length of time.

On one or two points I have gathered impressions which may perhaps be worthy of mention here :-

1. I think that the position so far held by the committee with reference to the effect of parasites is a wise one. I have never heard of a case where an insect was exterminated by its parasites, the relation of the two forms at any one time being, in numbers, very close. A reduction in the numbers of the host is always followed by a similar reduction in the numbers of the parasites, leaving to those individuals of the host which have escaped an opportunity for rapid and unchecked increase until overtaken by a corresponding but later increase in numbers of the parasites. For this reason parasites cannot be relied upon to do the work needed in the case of the gypsy moth.

2. The method of burning over infested areas in connection with burlapping the trees seems to me to be a most effective method of procedure if the precaution of burning for a sufficiently great distance beyond the limits of the infested area be carefully observed. My impression is that the edge of the burned area should always be at least two hundred feet outside these limits, as far as these can be ascertained.

The work so far accomplished shows on its face that the methods in use are the result of experience, and that they are most efficacious.

It seems to me that two things are greatly to be feared:-

1. That the time is near when searches with negative results may tend to produce carelessness on the part of the searchers.

2. That the apparent disappearance of the moths may lead the Legislature into the error of abolishing the committee at the time when its work will show the fewest results, but will in reality be the most valuable, - in fact, would be absolutely necessary to insure the prevention of some future invasion.

The work done by the committee in the way of testing insecticides in the field at Malden and in the laboratory at Amberst is of great value, and the importance of learning with the greatest 
accuracy just how successful each method is, cannot be overestimated. The care with which the experiments at Amherst are conducted guarantees the accomplishment of this most important task, while the discovery of a new insecticide with the properties which the arsenate of lead apparently possesses must certainly be worth more to the State than all the money it has spent for the extermination of the gypsy moth.

Yours respectfully,

H. T. Fernald. 


\section{APPENDIX E.}

REPORTS OF ENTOMOLOGISTS WHO VISITED THE INFESTED REGION IN 1894.-OPINION OF THE UNITED STATES ENTOMOLOGIST.

\section{Report of Dr. George H. Perkins of the University of Ver- mont, Entomologist of the Vermont State Agricultural Experiment Station.}

Prof. C. H. Fernald.

Burlington, Vt., July 10, 1894.

DeAR SIR:- In accordance with your invitation to visit the region infested by the gypsy moth, I went to Malden, as you are aware, and through the very cordial assistance of both yourself and $\mathrm{Mr}$. Ware, assistant director, was enabled to see in a most complete and satisfactory manner the appliances used and the various methods of using them.

I wish to express my appreciation of the thorough and careful manner in which the work was being done, and the evident desire of those engaged in it to execute the trust committed to them as faithfully and economically as possible. No work of the sort which I have ever seen or heard of has impressed me as favorably as did that of the officials engaged in the work of exterminating the gypsy moth.

The whole nation should be grateful to the committee for what it has already accomplished; for it is my belief that, had not the work been so well done in Massachusetts, the insect would ere this have spread beyond the borders of that State and now threaten the whole land. It is most gratifying to find, instead of this, that the ravages of the moth have been very much reduced by the efforts of the committee.

No one interested in economic entomology can investigate the work in office and field without at once discovering that a vast amount of very useful information has been gathered which should not on any account be lost to science. On this account it is very greatly to be desired that as full and complete a report as possible 
of the work of the committee be published, for much that such a report would contain would necessarily be of general and permanent value.

The question has been asked, Is it possible to exterminate an insect which has become so abundant as the gypsy moth? Before I visited the infested region, and saw what had already been done, I was quite doubtful as to the expediency or the possibility of extermination; but after investigation I thought differently. It seems to me very clearly the wisest and most economical course, for the present at any rate, to continue the work as it is now going forward, and aim at extermination. The men and the methods now employed are so successful that it would be unwise to discontinue them for several seasons to come.

It also seems to me that the functions of the committee might be very advantageously extended, so that in their discretion they conld direct their destructive agencies against such other insects as might be easily taken in hand.

When passing through some of the towns infested by the gypsy moth we noticed many trees the foliage of which had been wholly destroyed by the canker-worm; and many of these trees could have been sprayed by those engaged in spraying neighboring trees for the moth at small cost of time or money.

It was very evident that private enterprise could not be depended upon to deal with these pests. It is my own conviction that the most efficient and the cheapest method of dealing with any insect which has become numerous and destructive is that adopted in the case of the gypsy moth, not leaving to private citizens the too great task, and thus ensuring failure, but bringing the authority and the resources of the State to the work, and carrying it forward to success.

Is it not probable that, had the gypsy moth not been stayed in its destruction, the loss to property through the destruction of shade and fruit trees would have been more than the cost of extermination has thus far been?

It is to be hoped that the work so well done thus far will not now be suffered to lag through lack of either funds or popular support. There is every reason for continuing it, while to stop or reduce it would be a great calamity.

I have not been asked to praise the work of the committee, but rather to suggest improvements in their methods, and to criticise whatever I might find deserving it. I have no criticism to offer, nor am $I$ able to make suggestions other than those given above.

I am, sir, very truly yours,

Geo. H. Perkins. 
Refort of Prof. F. L. Hartet of the Maine State College, Botanist and Entomologist of the Manne Experiment Station, Orono, Me.

\section{To the Members of the Gypsy Moth Committee of the State Board of Agriculture of Massachusetts.}

Gentremen:- In compliance with your courteous invitation (extended to me through Prof. C. H. Fernald) "to inspect the work of the gypsy moth committee and give my impressions and advice," I visited Malden the latter part of July, and spent two days examining the work of the committee in the office, laboratories and field. Through the courtesies of Director E. H. Forbush and others of the department every opportunity was afforded me to gain a thorough knowledge of the scope and character of the work of the committee.

I went to Malden with an entirely inadequate conception of the territory affected, and the stupendous undertaking of the committee to reduce or exterminate the gypsy moth. I first visited the office, and was surprised by the ingenuity and thoroughness displayed in keeping the field notes and indexing them for ready reference. A mass of information regarding the habits, natural history and anatomy of this insect has been accumulated by Professor Fernald, Director Forbush and their assistants. This seems so important that for the good of entomological science it is hoped it may be sifted by a competent entomologist and published as a monograph by the committee. The pains taken in examining the men for field work and the almost military exactness required of them in their labor and reports reflect great credit upon the organizing ability of the director, and speak much for the efficiency of the service.

The work being done in the laboratory and insectary upon the life-history of the moth, its parasites and histology, and upon remedies, was timely and thorough. I was especially interested in the histological work, conducted by Mr. A. H. Kirkland, to determine if possible what becomes of the arsenical poison the full-grown larvæ are known to eat with impunity, and also the trap experiments under the direction of Mr. Kirkland.

The storehouse for apparatus and supplies impresses one with the magnitude of the work, and is instructive in the novel apparatus invented to fight this pest.

The results obtained in the experiments on insecticides, by $\mathrm{Mr}$. F. C. Moulton, are most important, and bid fair to be of great usefulness to economic entomology. 
The field methods of searching for the eggs, larvæ and pupæ, the burlapping of the trees and the careful burning of infested areas was thorough and practical.

Upon the whole, the methods which have been born of experience and adopted by the committee for coping with the pest impressed me as ingenious and effective. I have no critieisms to offer upon the work of the committee, and regard the results obtained as marvellous.

Entomologists are generally agreed that it is impossible to exterminate an insect by means of its parasites, so all that can be hoped for in this direction is uncertain aid in holding it in check. Whether it is possible to exterminate an insect by persistent and thorough hand-picking, use of insecticides and fire is problematical, because it has never been tried. It is a plausible problem, which we hope, for the good of economic entomology, the gypsy moth committee may have the opportunity to settle. By the efficient work of the committee, in three years' time, this insect, which was legion and doing great damage over a wide area, has been reduced beyond detection by common observation. We spent a whole day in the field, and, though constantly on the alert for specimens, saw only four male moths and no larvæ, pupæ or eggs. So thoroughly has the work been done that intelligent people in the district wrongly regard the work of the committee aceomplished. It is the scattering colonies, the last one per cent., that will demand more thorough work than the other ninety-nine per cent., and your Legislature and citizens will need to be thoroughly impressed with this fact.

Two policies present themselves : first, whether an attempt be made to fight the moth to the finish; second, whether an attempt be made to merely keep it in check, and prevent an increase to harmful numbers.

The gratifying work of the committee so far would suggest continuance in the good work, with the idea of extermination. This would absolutely require the employment of a force of men large enough to keep the whole infested area under constant surveillance for some time. The present number of men employed seems to me to be inadequate, as large areas in the infested distriet have to be neglected while inspection is going on in others. Unless a large force can be kept constantly employed for some years, the idea of extermination will have to be abandoned by the committee.

If the second policy be adopted, then the work of the committee for the present is practically done. Yet a permanent force would be needed to keep the area under occasional surveillance, 
and its energies directed to checking local ontbreaks. This would be an interminable job, constantly menaced with the danger of the pest spreading over large areas to adjoining States, until so widely disseminated as to be beyond human power to control. It would seem to me to be wiser to attempt the extermination of the pest while in its greatly reduced numbers by the adoption of a liberal financial policy, than to drop the work and in a decade or sooner have it to do all over again.

We regret to learn (unofficially) that naturalists are breeding this pest for purposes of study outside of the Commonwealth of Massachusetts, in defiance of the strict laws regarding its dissemination.

I heard the committee criticised by citizens and others because they would not destroy other injurious insects besides the gypsy moth in the infested district. We understand this criticism to be unjust, as the Legislature confined the duties of the committee strictly to the suppression of this one insect, and to use the money to destroy the others would be a perversion of funds.

That it would be a wise policy for every State to have an entomological commission, with duties as broad as the requirements of economic entomology, we have no doubt. The fact that the gypsy moth committee has paid strict attention to business is the reason why they have in such a short time accomplished so much.

In closing, I desire to thank the committee for the opportunity offered me to study the life-history of this insect, and to become familiar with the ingenious and effective methods used in coping with it. I hope the committee will receive the financial support from the Legislature that will enable it to succeed in this stupendous undertaking, which does not alone interest Massachusetts but also the adjoining States and the whole country.

Respectfully submitted,

F. L. HaRvey.

Report of Prof. John H. Comstock of Cornell University, late United States Entomologist.

IтHACA, N. Y., July 17, 1894.

Mr. Writiam R. Sessions, Secretary of the Committee on the Extermination of the Gypsy Moth of the State Board of Agriculture.

SrR :- In compliance with the request of your committee, transmitted to me through Professor Fernald, I visited the region infested by the gypsy moth, and spent several days studying, what is being done towards the extermination of this species. During 
the greater part of this time $I$ was accompanied by Professor Fernald and Mr. E. H. Forbush, who explained to me very fully the details of the work.

I was filled with admiration of the work that is being done by these gentlemen, and, although $I$ have given the matter very careful thought, I am unable to suggest any changes in their methods. It seems to me that the methods they are following are the best possible, so long as the object of the work is the extermination of this insect.

But, after going over the infested region, I have come to have grave doubts as to the advisability of attempting to exterminate this pest. I am not prepared to say that I consider extermination impossible, but it seems to me that the attainment of this desired end is highly improbable. It is true there are certain peculiarities in the habits of this insect that give hopes of the possibility of extermination. Thus the slowness with which the species spreads naturally, owing to the fact that the female does not fly, and the fact that the larva in its later stages descends from the trees and hides during the day-time, rendering it possible to trap it, greatly facilitate the work of destruction. On the other hand, the wide range of food plants, the extent of the area infested, including as it does large forests, and the ease with which the species may be artificially spread by means of vehicles, all combine to make the task a very great one. Still, if you could be provided with sufficient funds extending over a sufficiently long period, I believe these difficulties could be overcome.

But I feel that this is too much to hope. If at this time, so soon after the terrible rarages of the pest, the Legislature appropriates less than two-thirds of the sum which your committee, after careful investigation, deems necessary to carry on the work, it is hardly probable that succeeding Legislatures would furnish the means necessary to carry this work to a conclusion, involving as it would a large outlay for many years after the insect had ceased to be a pest. As I do not believe that the financial support would be furnished you, I respectfully suggest that you consider the advisability of adopting a different method of combating the pest. Much of the work that is being done now would be unnecessary if the object was merely to keep the insect from being unduly destructive ; and, if there is no hope of your receiving the support necessary to exterminate the insect, the continuance of the present methods would certainly involve a large unnecessary expenditure.

It is probable that if your warfare against this insect was restricted to those localities in which its injuries are of a serious nature, its natural enemies would greatly increase and tend to 
keep it in check. Already a considerable number of parasites is known to infest it. There will be a tendency for them to increase, so that in time serious outbreaks of this pest will probably be only occasional and in limited areas. Such outbreaks could be easily subdued.

While I believe that a change in the object of the work of your committee seems imperative, I would not consider for a moment the giving up of your warfare against the pest, but would advise its continuance in the following manner: I would suggest no change in the organization for carrying on the entomological work of the State. A committee of the State Board of Agriculture, constituted as is your committee, seems to me to be the most appropriate organization for this purpose. I would, however, recommend the broadening of the scope of the work of this committee, so that it should have authority to deal with any serious outbreak of insect pests. I will not presume to indicate in detail the method of conducting this work, beyond suggesting that in their more general features the horticultural laws of the State of California might serve as a model.

Very respectfully, your obedient servant,

J. H. Coмstock.

Extract from the President's Address by L. O. Howard, Entomologist of the United States Department of Agriculture, delivered before the Sixth Anndal Meeting of the Association of Economic Entomologists, Brooklyn, AשG. 14, 1894.*

The work upon the gypsy moth, by the way, which has been done by the State of Massachusetts since 1889, is one of the most remarkable pieces of work, judging by results, which has yet been done in economic entomology. The operations have been carried on by a committee of the State Board of Agriculture, and the means have been furnished by large annual appropriations by the State Legislature. Three hundred and twenty-five thousand dollars have already been appropriated.

A territory comprising something over one hundred square miles was infested by the insect, which occurred in such extraordinary numbers as to destroy many trees and almost to threaten the ultimate extinction of living vegetation, not only within the infested 
territory, but in all localities to which it might spread. It is unnecessary to detail the steps by which relief was brought about. Mistakes were undoubtedly made at first, and it is to the work of the present committee that the main credit is due. The infested territory has been reduced by one-half, and within the districts in which the gypsy moth at present exists it is, practically speaking, a comparatively rare species.

The future of the insect is, however, problematical. The continuance of sufficiently large appropriations from the State Legislature to enable the work to be carried on on its present scale is doubtful, and yet those in charge believe that still larger appropriations are necessary to bring about extermination. They are confident, however, that with sufficient means, the insect can be absolutely exterminated from the State of Massachusetts. With the Legislature disinclined to continue the large appropriations, the methods of the committee at present pursued will have to be seriously altered. Given a small appropriation of say $\$ 25,000$ annually, it will become necessary to adopt some law, like that enforeed in California, whereby much less frequent inspection may be made, and the committee will have to rely in part upon voluntary observers for information. Moreover, they will be unable to conduct spraying operations upon a large scale, and the expense of the destruction of insects will have to be assessed upon the owners of the property upon which the insects are found, provided such owners will not themselves undertake the destruction of the insects. There will be many disadvantages from such a course, and in the case of unproductive lands the expense will be so great that the owner will prefer confiscation. Between some such course as this and the continuance of the present methods, however, there seems to be little choice, since if the appropriation were taken away the insect will not only speedily reach its former destructive height, but will spread far and wide over the country.

It may be urged that it will be only a few years before the insect will take its place as a naturalized member of our fauna, and will become subject to the same variations of increase and decrease as our native species, and that it will, in fact, become little more to be feared than species already existing with us, particularly if its European natural enemies are introduced. Against this view, however, it must be urged that the gypsy moth seems an exceptionally hardy species, and that even in Europe it is a prime pest. The caterpillar is tough and rugged, and seems little subject to disease and to climatic drawbacks, and is wonderfully resistant to the action of ordinary insecticides. The gypsy-moth larva will feed for days without apparent injury upon trees which have 
been sprayed with Paris green or London purple in a solution so strong as to somewhat burn the leares. In fact, the committee, in the spraying which they are carrying on at present, have found it necessary to use arsenate of lead in as strong proportion as ten pounds to one hundred and fifty gallons of water. The wellknown vitality of previously introduced European injurious insects is apparently increased to a striking degree by this species, while the fact that it feeds on nearly all plants renders it a much more serious pest than any of its forerunners. Under these circumstances, therefore, any course other than energetic and welldirected effort to keep the insect within its present boundaries will be short-sighted in the extreme, although it is very doubtful to my mind whether absolute extermination will or can ever be brought about. 


\section{APPENDIX F.}

\section{THE DANGERS OF ARSENICAL POISONING RESULTING FROM SPRAYING WITH INSECTICIDES.}

Much has been written in regard to the supposed danger of fatal poisoning to the consumers of fruit which has been gathered from vines or trees which have been sprayed with arsenical mixtures. The fallacy of these ideas has been repeatedly shown, and it is now well understood that there is practically no danger of fatal poisoning from eating sprayed fruit. There are, however, other dangers, arising from the widespread and careless use of arsenical insecticides, which have been almost entirely ignored. Entomologists and pomologists officially connected with the experiment stations of the country, the agricultural press and writers of works on pomology and horticulture all join in recommending some of the most deadly poisons as insecticides; but they add scarcely a word of caution in regard to their use. While the danger of acute or fatal poisoning, which may arise from eating or drinking food or liquids in which Paris green or some other form of the arsenites has been accidentally mixed, is occasionally pointed out, the evils arising from contact with the poison are seldom even noticed. Arsenical preparations are applied broadcast to many cultivated crops, and few if any precautions are taken against their effects on the human system. Paris green is commonly sold without any restrictions whatever, though fatal eases of accidental poisoning from its use have been frequently chronicled.*

* "Next to arsenious oxide, arsenite of copper gives rise to the largest nnmber of cases of acute arsenical poisoning. This compound forms the whole or a part of the pigments known as Scheele's green or Paris green, Schweinfurt or emerald green (aceto-arsenite of copper). When pure, these pigments contain from fifty-five to sixty per cent. of arsenious acid, to which their poisonous properties are mainiy due. During the past few years arsenite of copper has been sold extensively, under the name of Paris green, for the purpose of killing potato bugs. Owing probabiy to the ease with which It can be obtained, it has given rise to a considerable number of cases of suicidal poisoning. Many cases of accidental poisoning have resulted from the nse of these compounds as pigments." (Buck's " Reference Handbook of Medical Science," Vol. I, page 344.) 
The action of arsenic upon the human system is poisonous, no matter how it may find entrance, whether through the skin, wounds, the respiratory organs or the alimentary tract. Nor are the symptoms essentially different, whatever its manner of entrance. Thus, when applied outwardly to an abraded surface, it exerts a specific action upon the mucous membrane of the stomach. Hunter found that the stomach of a dog was considerably inflamed in an experiment in which he applied arsenic to a wound, the animal dying within twenty-four hours. In other cases, upon applying a bandage to prevent the dog licking the arsenic from the wound, Brodie found that the inflammation in the stomach was more acute and more immediate than when the poison was taken internally.

The curious fact that the mucous membrane of the stomach inflames when arsenic is absorbed from a cutaneous surface or from a wound is explained by the absorption of the arsenic into the blood and its separation from the blood by the mucous membrane of the stomach, the arsenic in its passage exerting an irritant action.

According to Blyth, a quack applied an arsenical caustic to a chronic ulcer, with the result that the patient was seized with symptoms of violent poisoning, and died six days after the application. Blyth says such fatalities are frequent.

The injurious effects produced by the absorption of poisons through the pores of the skin are well known to toxicologists and to the medical fraternity. Cases where sudden death has been caused by the cutaneous absorption of deadly mineral or vegetable poisons are on record. A case is mentioned by Blyth of a woman aged fifty-one years, who died after a protracted illness, the result of using a solution of arsenious acid to cure the itch.* Less serious attacks of poisoning are not very uncommon among those who use arsenic, while continued exposure to the influences of mineral poisons often produces symptoms of chronic poisoning.

"The arsenical pigments more frequently give rise to external local eruptions and chronic poisoning than to acute poisoning." $\dagger$

The first symptoms of chronic arsenical poisoning result from the local action of the arsenic. Externally they consist of cutaneous irritations, eruptions and even ulcers on the various exposed portions of the body. The eruption of the face is sometimes so serious as to render the victim unrecognizable. Inflammation

" "Poisons, their Effect and Detection," A. W. Blyth.

t "Reference Handbook of Medical Science," Vol. I, page 344. 
of the scrotum, sometimes resembling hydrocele, is a frequent symptom, and this inflammation extends to the adjacent parts. There is frequently an irritation of the mucous membrane of the eye, also œdema of the eyelids. This conjunctival inflammation is manifested by redness and an intolerance of light. Other inflammations of the mucous membrane, resulting in irritation of the nasal passages and throat, dry cough, loss of appetite, thirst, nausea, a feeling of uneasiness or pain in the stomach and intestines, and sometimes romiting and diarrhœa ensue. Often these symptoms are not very severe, but they are sometimes continued for a long period, and in a few cases they have resulted fatally. Other symptoms sometimes produced by the constitutional action of the poison are headaches, sleeplessness, muscular debility, emaciation, depression of spirits, neuralgic pains in various parts of the body, muscular trembling, occasional convulsions and paralysis of the extremities. It is said that fatty degeneration of the liver, kidneys and other organs sometimes takes place by a process analogous to that caused by the action of phosphorus.*

The effects of the arsenical preparations when taken internally are well known, but the dangers arising from their absorption and inhalation are not generally understood. Many people who have been accustomed to using arsenic in some process of manufacture or trade have occasionally suffered from acute attacks of arsenical poisoning without being aware of the real cause of their sufferings. Others, who have suffered for years from chronic arsenical poisoning, being ignorant of the cause of their symptoms, have neglected to remove it, and have attributed their condition to other agencies or to disease. The inflammation of the mucous membrane of the nasal passages and throat is often attributed to catarrh, while the trouble with the stomach and intestines is usually attributed to dyspepsia. Amateur and professional taxidermists, especially those who use white arsenic in its dry form, sometimes suffer from all the symptoms of both acute and chronic poisoning. Not infrequently the death of taxidermists is caused or hastened by the use of arsenic. In one case a taxidermist was rendered almost totally blind for a considerable period by the use of arsenic.

Browne mentions a case of a man who formerly used dry arsenic in preserving natural history specimens, and whose constitution was, he says, thoroughly broken up by it. An amateur of long standing became paralyzed in one hand. This man was

- "Poisons, their Effect and Detection," Vol. II, page 495. 
not aware of the source of his trouble, and had never mentioned the fact of his using arsenic to his numerous physicians, who had therefore worked in the dark as to the real cause of his condition.*

Mr. C. J. Maynard, author of the " Naturalists' Guide," "Birds of Eastern North America" and other works, was at one time so seriously affected by the arsenic used in the preparation of skins of birds and mammals that he was obliged to discard the preservative, suffering for several years from the symptoms of chronic arsenical poisoning. Workmen in factories where arsenical preparations are made frequently suffer from arsenical poisoning, either acute or chronic, and fatal cases are on record. Some of the men employed in handling arsenate of soda, Paris green and other insecticides in the storehouse connected with the gypsy moth work have been somewhat affected by arsenical poisoning. The effect of poisoning from arsenical wall paper is well known.

The cases of poisoning so far given are those of people who have been exposed to the dust or fumes of arsenic in-doors. It might be thought that persons working out of doors would not be similarly affected. Out-door conditions, such as atmospheric currents and sunlight, may lessen the danger of poison by inhalation. Yet arsenic, being chemically unchangeable and its poisonous properties not being affected by light, air or water, has practically the same effect when brought in contact with the skin or mucous membranes, whether the person using it is out-doors or in-doors. Among the workmen employed in the manufacture of an arsenical green which is obtained from arsenite of soda by treating it with sulphate of copper and then with pyroligneous acid, the symptoms of arsenical poisoning are very marked. The process of manufacture usually takes place in the open air. The evil consequences of working over the mixture appear in boils, pimples and an itching rash about the nostrils and in the flexures of the arms. In severe cases headache, thirst and nausea occur. Eruptions on the hands, face and other exposed parts, ulcers in the groin and other symptoms of arsenical poisoning by absorption are not uncommon among those who use Paris green in the field, either in spraying trees or in dusting the poison over potatoes or other field crops.

In these cases poisoning is probably caused by the absorption through the pores of fine arsenical dust or spray, floating in the atmosphere, or by the absorption of particles of arsenic which reach the hands, face and other portions of the body in various

" Montague Browne, “Practical Taxidermy,” pages 66, 67. 
ways. The absorption of the poison is likely to be greater when the subject is perspiring freely, and the danger is greatest when one is handling a form of arsenic which is more or less readily soluble. Therefore the danger in handling arsenate of soda, London purple or white arsenic is probably greater than that in handling Paris green or arsenate of lead; yet serious effects may in time be produced by either of these latter poisons, and they should be always used with the greatest care. The danger of poisoning by respiration is probably greatest when the insecticide is used in the form of a powder and thrown broadcast in air, although, if the poison is mixed in water and a fine spray is allowed to drift over the person, a small amount may be inhaled. In either case the effects of the poison inhaled will be felt first in the mouth, nasal passages and throat.

The danger of poisoning by spraying is increased in the case of some individuals by their peculiar susceptibility to the effects of the poison. The difference in susceptibility to these poisons shown by different individuals under the same conditions is remarkable. It is possible that some persons may gradually become accustomed to the use of arsenic, and eliminate from the system, without experiencing ill effects, an amount of poison which would prove very injurious to others more susceptible to its influence. Some people who have once suffered from the symptoms of chronic arsenical poisoning exhibit a marked susceptibility to the effects of arsenic for years afterward.

During the spraying in 1891 two cases were known where women, in whose faces a spray of Paris green was accidentally blown by the wind, were immediately affected with a burning sensation of the skin, followed soon after by eruptions. An elderly woman-who was also exposed to the spray suffered from arsenical poisoning to such an extent that she required the services of a physician for a considerable period. Her symptoms appeared to arise from this exposure.

It is not generally known that serious effects sometimes follow poisoning from arsenical spraying. Though there is ordinarily little danger from the spraying of a few trees, even this may be dangerous to one peculiarly susceptible to the action of the poison. In such a case complete prostration, inflammation, serious ulceration of the face and mouth and other parts of the body, suppuration, copious salivation and delirium have followed within a few days. A case of arsenical poisoning resulting fatally to an elderly farmer has recently been reported. In this case death is said to 
have been caused or hastened by his spraying orchard trees for several years in succession with Paris green. If the poison comes in contact with wounds or abrasions of the skin, ulcers are sometimes formed which will not heal until spraying is given up. Symptoms of a mild form of this poisoning resemble those produced by the poison ivy (Rhus toxicodendron), and sprayers who are poisoned usually attribute their symptoms to that cause. While serious poisoning from spraying is rare, the mild symptoms are quite frequently shown; and in some cases, if spraying is done continuously for a considerable period of time, chronic poisoning will result. There is probably little danger of fatal poisoning except in cases of invalids or elderly people.

In spraying with arsenites, serious effects may usually be avoided by using the following precautions : cover any wound or abrasion of the skin, so that the insecticide cannot come in contact with it; when spraying with an extension nozzle or pole, use an elongated leather washer below the nozzle, so as to carry off the drip; wear rubber clothing and a rubber or oil hat of the shape of a "souwester" or tarpaulin, and take care to stand as far as possible to windward of the spray. The face and hands should be thoroughly washed immediately after spraying, and the entire body should be bathed daily.

The usual treatment for arsenical poisoning is well known to medical men. An antidote for local exterual poisoning not generally known is acetate of lead, commonly called sugar of lead. A strong solution of this in water will allay serious inflammations of the skin, caused by arsenical poisoning, but it should only be applied externally, and even then with care, as it possesses poisonous properties. 
A Prenix G.

A LIST OF RESIDENTS OF THE INFESTED DISTRICT WHO HAVE FURNISHED INFORMATION IN REGARD TO THE GYPSY MOTH IN MASSACHUSETTS.

Statements in regard to the ravages, habits and spread of the gypsy moth or the work of destroying it in Massachusetts have been received from eitizens whose names appear below. Lack of space has made it impossible to print these statements, but extracts from some of them will be found in Part I.

\section{Arlington :-}

Benjamin Campbell.

H. A. Fernald.

Chas. A. Greene, M.D.

Belmont :-

Mrs. Edwin F. Atkins.

Edward W. Brown.

W. L. Chenery.

Thomas L. Creeley.

Irving B. Frost.

C. F. and R. Hittinger.

Daniel F. Learned.

Gilman Osgood.

James K. P. Sargent.

Edward Skahan.

John W. Skahan.

Merton Simonds.

J. o. Wellington.

Chas. W. Winn.

Boston:-

J. B. Alden.

John A. Bruen.

Mrs. T. J. Lane.

A. I. McCormack.

Wm. Tyner.

Cambridge :-

Wm. H. Eveleth.
Chelsea :-

J. T. Bond.

Martin Curley.

J. Waldo Denny.

L. E. H. Jones.

Wm. Jones.

S. Kimball.

Everett :-

Timothy Murphy.

Lynn:-

J. G. Olin.

Malden :-

Mrs. Peter Campbell.

Michael Cleary.

Mrs. Margaret Connell.

Mrs. M. Cronin.

Richard Dexter.

Mrs. John Dowd.

James F. Eaton.

Mrs. J. W. Flinn.

Mrs. Daniel Kelly.

Wm. McLaughlin.

T. J. Neville.

Miss Abbie Snllivan.

Mrs. B. Wallace.

Medford :-

Miss R. M. Angelbeek.
Medford - Con.

Mrs. J. H. Archibald.

Geo. H. Bean.

James Bean.

Mrs. Wm. Belcher.

Mrs. John Benson.

Almon Black.

Miss A. B. Bockman.

Mrs. John Brown.

Oran Brown.

Miss Charlotte E. Camp.

E. Clark.

J. C. Clark.

L. M. Clifford.

J. S. Cotton.

W. C. Craig.

John Crowley.

A. W. Crockford.

D. W. Daly.

J. P. Dill.

C. R. Drew.

Mrs. G. H. Dudley.

Mrs. J. E. Fairbanks.

Mrs. M. F. Fenton.

Mrs. S. J. Follansbee.

F. E. Foster.

J. T. Foster. 


\section{APPENDIX.}

Medford - Con.

J. N. French.

R. Gibson.

F. M. Goodwin.

J. O. Goodwin.

N. P. Hallowell.

Mrs. I. W. Hamlin.

J. W. Harlow.

Wm. B. Harmon.

Fred H. Hanshalter.

E. G. Holmes.

John Hutchins.

A. R. Kervin.

Sylvester Lacy.

Mrs. Chas. A. Lawrence. Edward Loeffler.

Mrs. Thomas F. Mayo.

Miss R. A. McCarty.

Mrs. E. E. Merrill.

J. C. Miller, Jr.

A. P. Perry.

Mrs. F. P. Peirce.

Richard Pierce.

Mrs A. H. Plnmmer.

Mrs. M. M. Ransom.

Wm. S. Richards.

D. M. Richardson.

Jotham H. Rogers.

Mrs. E. M. Rnssell.
Medford-Con.

G. C. Rnssell.

Mrs. P. N. Ryder.

Miss Z. Sawyer.

Japhet Sherman.

Walter Sherman.

Mrs. W. H. Snowdon.

Mrs. F. T. Spinney.

Wm. R. Taylor.

Mrs. R. Tuttle.

Geo. H. Webster.

J E. Wellington.

S. F. Weston.

John G. Wheeler.

Miss H. T. Wild.

Melrose :-

Henry Lynde.

Mrs. E. A. Mansfield.

Mrs. A. C. Peyser.

Revere:-

J. W. Copeland.

S. S. Pratt.

Benj. Shurtleff.

Josiah B. Shurtleff.

Salem :-

Geo. W. Creesy.

Sangus :-

L. Mansfield.

W. H. Penny.
Somerville :-

J. H. Cahalan.

Asa Durgin.

Thos. H. Eames.

Sarah E. Fisk.

Albert Kenneson.

F. L. Newton, M.D.

I. L. Russell.

Swampscott:-

A. R. Bunting.

Jas. Pitman.

Wakefield :-

J. H. Carter.

Rufus Kendrick.

Watertown :-

M. W. Chadbourne.

Nathan Drake.

J. W. Lovering.

J. E. Skinner.

Samnel Walker.

Solon F. Whitney.

Winchester :-

Lonis Godda.

H. W. Hight.

Chas. R. Mason.

W. D. Sanborn.

Winthrop:-

F. W. Belcher.

Chas. Burrill. 



\section{INDEX.}

\section{A.}

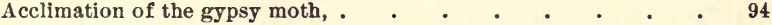

Achatoneura fernaldi, . • . . . . . . . 387,392

Acids used for destroying eggs, . . . . . $\quad 63,123,413,416$

Act to provide against depredations by the gypsy moth, . . . . 36, 47

Adviser, entomological, Prof. C. H. Fernald appointed, . $\quad$ - 57

Erostatic hairs, . . . . . . . . . . . 301

Africa, occurrence of gypsy moth in, . . . . . . . $\quad$. 267

Agalena navia, . . . . . . . . . . . 405

Age of egg-clusters, how determined, . $\quad$. $\quad$ • $\quad . \quad$. 95

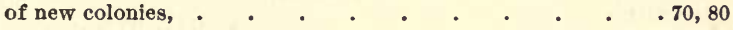

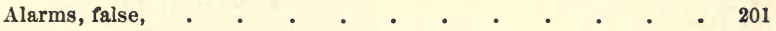

Albrecht on distribution of gypsy moth, . . . . . 268

Aletia argillacea, . • • • • • • • • • . 325

Alglers, occurrence of gypsy moth in, . . . . . . $\quad$ - 267

Alisma plantago as a food plant, . . . . . . $\quad .317$

Altum, Dr. Bernard, advice concerning importation of parasites, . 288

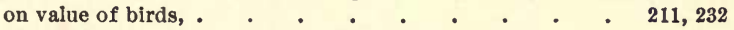

America, importation of gypsy moth into, . . . . . . . 33

importation of English sparrow into, . . . . . . . 233

occurrence of gypsy moth in, recorded by Professor Riley, . 3

American redstart attacking the gypsy moth, . . . . 208

robin attacking the gypsy moth, . . . . . . 208

Ammonia, eggs treated with, . . . . . . . 407

Amount of food consumed by caterpillars, . . . . . . 315

Anabrus simplex, destruction of crops by, . . . . . 206

Analyses of Paris green, • • • • • • • . 492

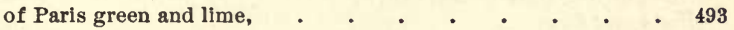

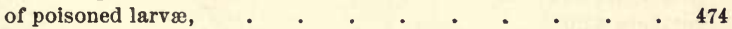

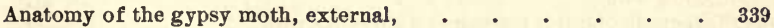

of the gypsy moth, internal, . . . . . . . . . 368

Anderson Brick Company, shipments from, . . . . 110

Anderson on ravages of gypsy moth in Shipov, . $\quad$. $\quad .282$

Angelbeek, Miss R. M., statement of, . . . . . 20, 27, 29

Animals, distribution of the gypsy moth by, . . . . 103

injured by spraying, . . . . . . . . . 161

Anisocyrta sp., . . . . . . . . . . . . 375 
Anisota senatoria,

400,402

Anisopteryx pometaria destroyed by chickadee, . . . . . 204

food plants of,

Annual inspection, the,

Antennæ of gypsy moth,

function of,

Anthrenus scrophularia, damage from,

Antinonnin, .

Ants attacking female moths, . . . . . . . $\quad$. 364,380

Apanteles, species parasitic on gypsy moth in Europe, . . $\quad$. 378

Apple trees attacked by gypsy moth in Europe,. . . . . . $\quad$. 277

trees injured by bad pruning, . . . . . . . . 174

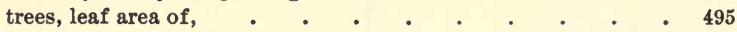

Appleton, F. H., at conference on gypsy moth (Appendix A).

member of committee, . . . . . . . . . . 49,76

resignation from committee, . . . . . . . 77

visit to Washington, . $\quad . \quad$. $\quad . \quad$. $\quad . \quad$. 83

Appropriation, balance of, on hand Jan. 1, 1894, . . . . $\quad 72$

efforts to secure an, from Congress, . $\quad$. $\quad$. $\quad$. $\quad$. $\quad$. 83

expended by first commission, . . . . . . . 73

expended by second commission, . $\quad$. $\quad$. $\quad$. $\quad . \quad$. $\quad$. 73

insufflcient, . $\quad . \quad . \quad . \quad$. $\quad . \quad .39,61,64,69,87,88$

loss by delay of, . $\quad$. $\quad . \quad$. $\quad . \quad 63,68,78,79,84,85$

necessity of, in order to inspect woodland, . $\quad$ - . $\quad$. 80

Appropriations, yearly, $\quad$. $\quad$. $\quad ~ \quad 36,39,49,63,68,77,84$

Area, infested. See Infested region.

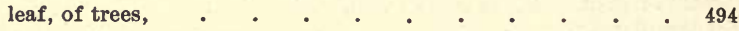

spiny, of wings of gypsy moth, . . . . . . . . 341

Argyrophylax gilva, . . . . . . . . . . 392

Arlington, area of woodland infested in, . . . . . $\quad . \quad 87$

gypsy moths found in, . $\quad . \quad$. . . . . . 58

petition presented by selectmen of, . . . . . . 36

Army worm, cyclone burner recommended against, . . . . 121

gypsy moth mistaken for, - . . . . . . . 33

Arsenate of lead, . $\quad$. $\quad$. $69,80,87,142,143,145,449,473,449$

of soda, experiments with, . . . . . . . . 143

of zinc, experiments with, .. . . . . . . . 480

Arsenic as an insecticide, . . . . . . . . . 481

effects of, . . . . . . . . . . . . 162

Arsenical poisoning (Appendix F).

poisons, comparative effects of, . . . . . . . 473

effects on follage, . $\quad . \quad$. $\quad . \quad$. $\quad . \quad$. 489

spraying with, . $\quad . \quad$. $\quad . \quad$. $\quad . \quad . \quad 55,417$

Arsenites, entomologists recommend spraying with, . . . . 45

Ash, exempt from ravages of gypsy moth in Russia, . . 282

Asia, distribution of gypsy moth in, . . . . . . 267

Asilus sericeus, . . . . . . . . . . . 392

Aspens attacked by gypsy moth, . . . . . . . 277

Assembling of the gypsy moth, . . . . . . . 342,345

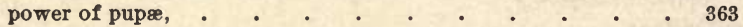

Atlanta Exposition, exhibit at, . . . . . $\therefore . .201$ 
Attacus cecropia,

promethea,

Aughey, Prof. Samuel, experiments on plover, .

402

on birds $v$. locusts,

204

205

Australia, importation of rabbits into, . . . . . . 233

importation of sparrow into, . . . . . . . 233

Avery, John G., elected member of gypsy moth committee, . $\quad$ - 84

\section{B.}

Bacteria, aid rendered by, . . . . . . . . . 288

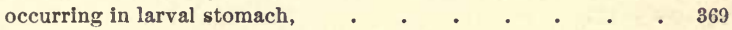

Bailey, C. E., observation on blrds distributing the gypsy moth, $\quad 236$

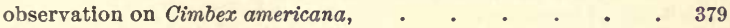

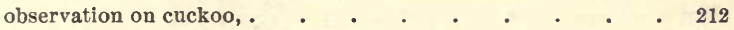

observation on downy woodpecker, . . . . . . 221

observation on egg-feeding birds, $\quad . \quad$ • $\quad . \quad$. $\quad . \quad 229$

observation on Theronia melanocephala, . $\quad$ - $\quad$. $\quad . \quad 376$

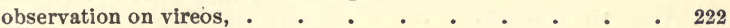

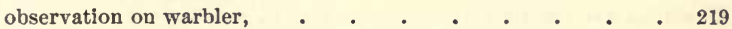

Baltimore oriole attacking the gypsy moth, . . . . 213,225

Bands, burlap, . . . . . . . . . . . 167

pitch, . $\quad . \quad$. $\quad . \quad$. . . . . . 285

raupenleim, . $\quad . \quad+\quad . \quad \cdot \quad \cdot \quad \cdot \quad \cdot 64,129,195$

tar, $\quad \cdot \quad \cdot \quad \cdot \quad \cdot \quad \cdot \quad \cdot \quad \cdot \quad \cdot \quad \cdot 285,286$

tree ink,. $\quad . \quad . \quad . \quad . \quad . \quad . \quad . \quad .64,128$

wadding, $. \quad \cdot \quad \cdot \quad \cdot \quad \cdot \quad \cdot \quad \cdot \quad \cdot \quad \cdot 127,285$

Barrett, C. G., on disappearance of gypsy moth in England, . $\quad$. 270

Bavaria invaded by nun moth, . . . . . . . 208

Bay State Brick Company, shipments of wood to, . . . - 111

Bazin on ravages of gypsy moth in France, . . . . $\quad$ - 277

Bean, James, statement of, . . . . . . . . . . $\quad .20,29$

Bechstein on egg killing, . . . . . . . . . 117

on ravages of gypsy moth, . . . . . . . . 275

Bees, danger to, from spraying, . $\quad$ • $\quad . \quad . \quad . \quad 157$

Beetles, cages for breeding, . . . . . . . 384

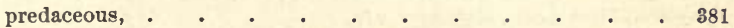

Belcher, Mrs. William, statement of, . $\quad$ • $\quad$ - . $8,11,17,26$

Beling, Theodore, on methods of destroying the gypsy moth, . $\quad 285$

Belmont, colonies found in, . . . . . . . . 47

Benson, Mrs. John, statement of, . . . . . . 19,27

Benzine, eggs treated with, . . . . . . . . 408

Berlin, occurrence of gypsy moth at, . . . . . . 274,277

Bibliography of gypsy moth, . . . . . • . 257-267

Birch attacked by gypsy moth in Europe, • • . . . 277,282

Birds as destroyers of locusts, . . . . . . . 205

attacking the gypsy moth, . . . . . . . 207

attracted to infested localitles, . . . . . . . 223

destroyed for miliiners, . . . . . . . . . 243

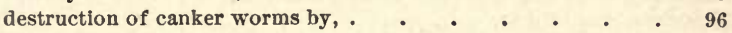

destruction of parasites by, . . . . . . . 240,376 
Birds, distribution of gypsy moth by,

European, introduction of,

feeding on the caterpillars,

feeding on female gypsy moth,

feeding on male gypsy moth,

feeding on the pupæ of the gypsy moth,

folly of destroying,

most nseful as moth destroyers,

native, driven away by English sparrows,

protection of,

that may devour gypsy moth eggs,

value of,

value of, in Europe,

v. useful insects,

Black, Almon, statement of, . $\quad$. $\quad$. $\quad$. $\quad 20,24,28$

Black-and-white warbler attacking the gypsy moth, . . . 208, 225

Black-billed cuckoo attacklng the gypsy moth, . . . . 207, 212

Blackbird attacking the gypsy moth, . . . . . . . 207

value of, . . . . . . . . . . . . 204

Black-throated green warbler attacking the gypsy moth, . . . 208

Bluebird attacking the gypsy moth, . . . . . 208, 218, 227 driven away by sparrows, . . . . . . . . 234

Blue-jay attacking the gypsy moth, . . . . . . . 6, 207,225

distributing the gypsy moth, . . . . . . . 236

Board of Agriculture, State, advice of, concerning extermination, . 70

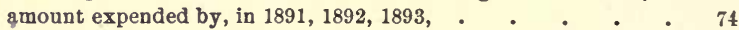

appropriations recommended by, . . . . . $62,68,77,84$

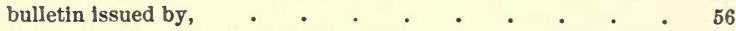

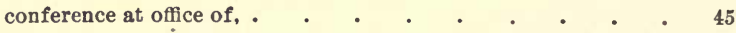

extracts from reports of the, . . . . $65-67,78,81,82$

petition for an additional appropriation by the executive com-

mittee of,

reorganization of, suggested by Wm. H. Bowker, . . . 83

special meeting of, . . . . . . . . . . 49

supersedes commission of $1891, \quad$. $\quad . \quad . \quad . \quad . \quad . \quad .47$

Boards of health, information furnished by, . . . . 107

Bockman, Miss A. B., statement of, . . . . . . . 20

Bombycidæ, assembling in the, . . . . . . . . 357

Books, section, record of infested estates kept in, . . . $\quad 52$

Boston \& Maine Railroad, inspection of, . . . . . 111

Boston, danger from traffic to, . . . . . . . 107

gypsy moth found in, . . . . . . . . 70,80

result of Inspection of, in 1894, . . . . . . . 80

Bowker, Wm. H., elected a member of the committee, . . $\quad$ - 76

reorganization of State Board of Agriculture suggested by, $\quad$. 83

retirement of, from State Board of Agriculture,. $\quad$. . $\quad$. 83

Brackett, Gov. J. Q. A., commission appointed by, . . . . 38

extract from message, • • . • • • . • . 35

Bradley, J. Howard, appointed commissioner, . . . . . 38

Branches, how broken, . . . . . . . . 174 removal of, . . . . . . . . . . 182, 184 
Breeding cage for predaceous insects,

Bremer on distribution of gypsy moth,

Brown, Thomas, on ravages of gypsy moth in France, . . $\quad 274$

Brown thrush attacking the gypsy moth, . . . . . 208, 225

Brush,'cutting and burning, . . . . . . 85, 167, 193

Brussels, ravages of gypsy moth in, . . . . . . 279

Buffalo carpet beetle, damage from, . . . . . . 270

Bufo.lentiginosus, . ‘ . . . . . . . 404

Bugs, predaceous, • • • • • • • • • 241, 392

Buildings, comparison of yearly work on, . $\quad$ - . . $\quad$. 93

Bulletin of information, publication of, - . . . 34, 56, 199, 200

Bullock, Representative W. J. D., order presented by, . . $\quad 72$

Bunting, towhee, attacking the gypsy moth, . . . . 225

Burlap, . . . 57, 64, 69, 79, 114, 167, 168, 169, 170, 188, 213, 291, 335

Burner, cyclone, . . . . . . . . . . . 121

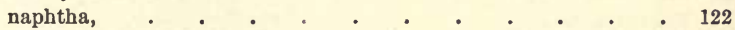

Burning, caterpillars killed by, . . . . $\quad 57,58,59,87,126,165$

hollow trees,. . . . . . . . . . . 121

machines, . . . . . . . . . . 119-121

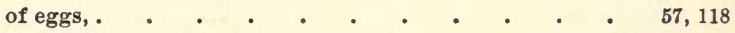

of foliage by arsenites, $\quad . \quad . \quad . \quad . \quad . \quad . \quad .159,491$

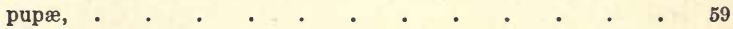

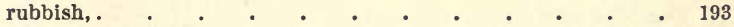

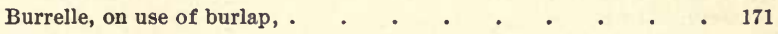

\section{C.}

Cabbage butterfly, damage from, . . . . . . 270

Cadey, E. J., statement of, . . . . . . . . . 40

Cages for breeding predaceous insects, . . . . . $\quad$ - 384,395

Calcic chloride, eggs treated with, . . . . . . 409

Calosoma calidum, . . . . . . . . . . 381,383

frigidum, . . . . . . . . . . 383

inquisitor, . . . . . . . . . . 287

scrutator, - • • • • • • • • 382

sycophanta, . . . . . . . . . 287,385

Camp, Miss C. E., statement of, . . . . . . . . 26

Camponotus pennsylvanicus, . . . . . . . . 364,381

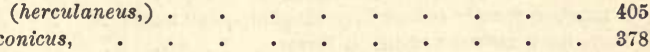

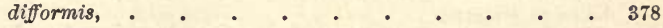

Canker worms destroyed by birds, . . . . $\quad$. 96, 204, 219

destroyed by spraying, . . . . . . : . . 140

importation of sparrows, against, . . . . . . 233

influence on destruction of gypsy moth caterpillars, . $\quad$ - 222

Cannon, Hon. George Q., on cricket ravages, • • • • 206

Carabus serratus, . . . . . . . . . . 383

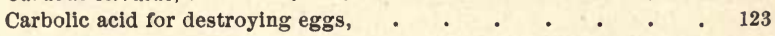


Carbon bt-sulphide, eggs treated with,

Carller on parthenogenesis, . . . . . . . . . . 366

Carpenter, F. B., cotton plants received from, . . . . . 324

Carpocapsa pomonella taken nnder burlaps, . . . . . 171

Castor oil on eggs, . $\quad$ • . . . . . . 417

Catbird attacking the gypsy moth, . . . . . . 6, 208, 213 destruction of silkworms by, . . . . . . . . 6

feeding habits, . . . . . . . . . . 237

Caterpillars of the gypsy moth attacked by Polistes pallipes, . $\quad$ - 378

attacked by predaceous bugs, . . . . . . . 392

attracted to light, . $\quad . \quad$. $\quad . \quad$. $\quad . \quad$. 310

become a serious nuisance, . . . . . . . . 14

comparison of numbers of, destroyed annually, . $\quad$. $\quad$. 93

description of, . . . . . . . . . . 300

destroyed by birds, . . . . . . . . $7,96,209,228$

destruction of, by burning, . . . . $\quad 57,58,59,87,126,165$

destruction of, by spraying, . $\quad . \quad$. $\quad . \quad$. $\quad . \quad$. 58

detrimental to real estate, . $\quad . \quad$. $\quad . \quad . \quad . \quad .21$

disease among, . . . . . . . . . . 280

distance travelled by, . $\quad . \quad$. $\quad$. $\quad$. 58,310

distributed by birds, . $\quad . \quad$. $\quad . \quad$. $\quad$. $\quad$ • 214, 236

distributed by spraying, . . . . . . . . . 113

distribution of, . $\quad . \quad$. $\quad . \quad$. $\quad .54,58,97,112$

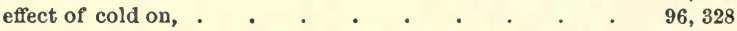

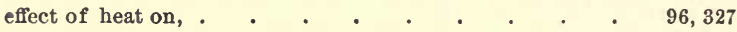

European methods for destroying, . . . . . 117, 284

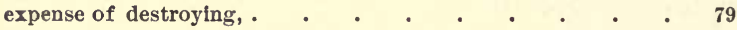

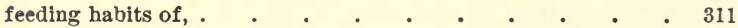

feeding on cotton plant, $\quad . \quad$. $\quad . \quad$. $\quad . \quad$. $\quad . \quad$. 324

irst and last appearance of, . . . . . . . . . 304

food selection by, . . . . . . . . . . . 485

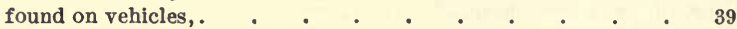

indications of presence of, . . . . . . . . . 86

insecticides for destroying, . . . . . . 137, 417, 477

killed by spraying, . . . . . . . . $.57,64$

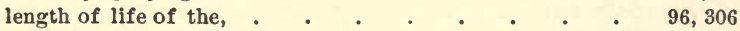

loss of weight in pupating, . . . . . . . . . . 333

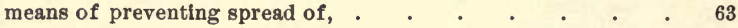

molting of, . . . . . . . . . . 304,308

not affected by insecticides, . . . . . . . 157,474

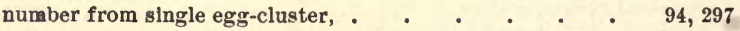

number greatly reduced by exterminative methods, . . . 60

obstruct rallroad trains in Europe, . . . . . $\quad 280$

places of pupation, . . . . . . . . . . 335

poisoned, analyses of, . . . . . . . . . 474

prevented from ascending trees, . . . . . . . . 64

scattering of. See Distribution.

spinnirg habits of, . . . . . . . . 102,330

sprayed with contact insecticides, . . . . $57,163,485$

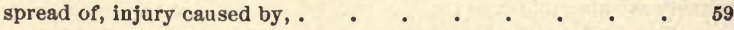


Caterpillars of the gypsy moth taken under burlaps, . . . . 114 traps for, . . . . . . . . . 170,311 value of burlap against, $\quad . \quad \ldots \quad . \quad . \quad . \quad . \quad . \quad 169$

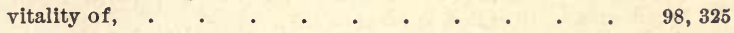
Caucasus, The, occurrence of the gypsy moth in, . . . 268 Cement, use of, on trees, . $\quad$. $\quad$. $\quad$. $\quad$. $40,172,187,188$ Ceylon, occurrence of gypsy moth in, . . . . . . 267

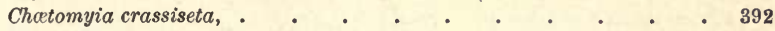

Chelsea, outbreak of the gypsy moth $\mathrm{in}$, . . . . . . $\quad$. 58

Chemicals for killing eggs, . . . . . . . . . 122,407

Chestnut-sided warbler attacking the gypsy moth, . . . . 208

Chewink attacking the gypsy moth, . . . . . . 207,219

Chianti, ravages of the gypsy moth in, . . . . . 279

Chickadee, destruction of gypsy moth by, . 208, 210, 214, 224, 227, 231, 236 feeding habits of, . . . . . . . . . 230,237

China, North, occurrence of the gypsy moth in, . . . 268

Chipping sparrow attacking the gypsy moth, . . $\quad 207,215,226,227$

Chlorine used on eggs, . . . . . . . . $\quad$. $63,125,408$

Chloro naptholeum, experiments with, . . . . . 481

Chrysomela scalaris attacking elm trees, . . . . . . 235

Chrysopa sp., . . . . . . . . . . . 405

Cicindela 6-guttata, - . $. \quad . \quad . \quad . \cdot \quad . \quad . \quad . \quad . \quad .405$

Cimbex americana, . . . . . . . . . . 379,402

Circumstances favoring extermination, . . . . . 244

Cities and towns from which false alarms have been received, . . 201 beyond Infested area, inspected, . . . . . . . . 198

Citizens, assistance of, in destroying the gypsy moth, $\quad$. $\quad 34,68,77,84$ of Medford on escape of the gypsy moth, . . . . . 4

Clark, J. C., statement of, . • . . . . . . 19, 24, 31

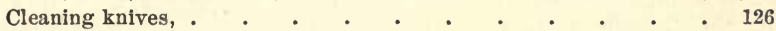

Clercy, J. O., on birds $v$. insects, . . . . . . $\quad$. 205

Clifford, L. M., statement of, . . . . . . . $\quad$. 24

Climate, increase of the gypsy moth retarded by, . $\quad$. $\quad$. 5 of England, influence on foliage, . . . . . . . . . 271

Clisiocampa americana, . . . . . . . . . . 402 destroyed by Baltimore oriole, . . . . . . . 213 parasites of, . . . . . . . . . . . 377

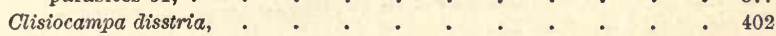

Coal tar, eggs treated with, . . . . . . . . 410

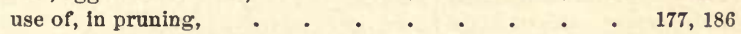

$\left.\begin{array}{c}\text { Coccyzus americanus. } \\ \text { erythrophthalmus. }\end{array}\right\}$ See Cuckoo.

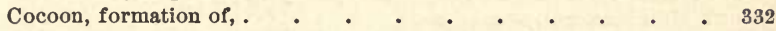

Codling moth taken under burlaps, . . . . . . $\quad$. 171

Cogswell, Hon. Wm., resolution introduced into Congress by, . . 83

Colaptes auratus. See Flicker.

Cold, effect of, on caterpillars, . . . . . . . . . 96,328 effect of, on eggs, . . . . . . . . . 294, 295

Coleoptera, predaceous, . . . . . . . . . 381

Collinson, Mr., importation of the gypsy moth Into England by, 269 
Colonies of the gypsy moth, age of new, exterminated, . . . . . . . . . $65,70,248$ found in woodland, . . . . . . $70,85,86,107$ found outside of region infested in 1891, . $\quad . \quad$. $\quad . \quad 70$ Isolated, . $\quad . \quad \cdot \quad \cdot \quad \cdot \quad \cdot \quad \cdot \quad \cdot \quad \cdot 54$ Isolated, normal rate of increase in, . . . . . . . 95

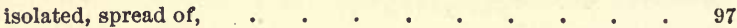
means taken to find new, . . . . . . . . 105 resulting from traffic, . $. \quad . \quad . \quad . \quad . \quad . \quad .109$

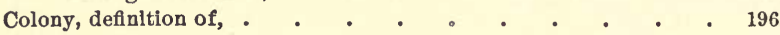

Colors of gypsy moth, explanation of, . . . . . . 272

Colt, W. C., observations on the flicker, . . . . . 221

Commission appointed by Governor Brackett, . . . . $\quad$ - 38 appointment of second, . . . . . . . . 45 flrst, amount expended by, . . . . . . . . 73 Metropolitan Park, hold meeting with the gypsy moth commlssion, removal of first, . $\quad . \quad$. $\quad . \quad . \quad . \quad . \quad 45$ report area of infested territory, . $\quad$. $\quad . \quad$. $\quad . \quad$. $\quad . \quad 39$ second, amount expended by the, . . . . . . . 73

Commissions, consultation of first and second, . $\quad$. . . 45 Commissioners, second, receive no remuneration, . . . $\quad 45$ Committee, agricultural, hearing held by, • • • • . 84 agricultural, Medford visited by, . . . . . . . 36

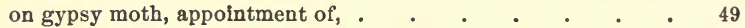
entomological adviser appointed to, . . . . . $\quad .57$ information concerning the gypsy moth in Europe obtained by, 67

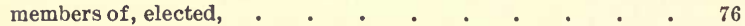

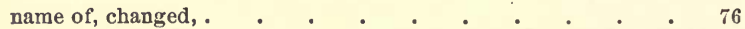

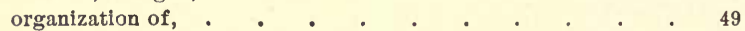
plans of, presented to legislature, . . . . . . $\quad$. 66 report of, on the inspection of towns bordering infested region, $\quad 65$ report of Professor Fernald and the director to, $\quad$ - $\quad . \quad$. 69 work of, . . . . . . . . . . . . 49 Common names of the gypsy moth, . . . . . . . $\quad$. 256 Comparative effects of different arsenical poisons, . . . . 473 Comstock, Prof. J. H., infested region visited by, . $\quad$. $\quad$ - 79 report of (Appendix E).

Condition of infested region in 1891, . . . . . . . 53

Conference at office of State Board of Agriculture (Appendix A), . 45

Congress, efforts to secure an appropriation from, . . . $\quad 83$

resolve asking for aid sent to, . . . . . . . 68

Connell, Mrs. Margaret, statement of, . . . . . $\quad$ - 23

Consumption of food by gypsy moth caterpillars, - . . 315

Contact insecticides, . $\quad$. $\quad$. $\quad$. $\quad .57,58,163,485$

Contopus virens. See Wood pewee.

Cook, Prof. A. J., experiments with Paris green, . . . 162 Corea, gypsy moth from, . . . . . . . . 338

Cork oaks attacked by the gypsy moth, . . . . . . 274 Corrosive sublimate, eggs treated with, . . . . . . 409 Corvus americanus. See Crow. 
Cotton as a food plant,

Cotton, John, statement of, . . . . . . . . 27,44

Coxe, Wm., on tree pruning, . . . . . . . 178

Craig, W. C., at conference on gypsy moth (Appendix A), • $\quad 45$ statement of, . . . . . . . . . . 19,27

Creepers attacking the gypsy moth in Europe, . . . . 209 attracted by meat, . . . . . . . . . 229

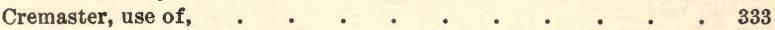

Creosote and paint tube, . . . . . . . . . 124 eggs treated with,. $\quad . \quad$. . . . . $63,123,410$ for destroying caterpillars, . $\quad$ • $\quad$ • . . . 126

Cricket, destruction of crops by, . . . . . . 206

Crimea, The, ravages of the gypsy moth in, . . . . 279

Crockford, A. W., statement of, . . . . . . . . 27, 30,42

Cronin, Mrs. Margaret, statement of, . . . . . 23

Crow blackbird attacking the gypsy moth, . . . . 207

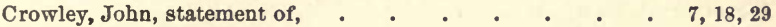

Crows attacking the gypsy moth, . . . . . 207, 217, 224

attacking the gypsy moth in Europe, . . . . . 209

attracted by meat, . . . . . . . . . 229

destroying predaceous insects, . . . . . . 241, 394

distributing the gypsy moth, . . . . . . . 237

experiments on gypsy moth eggs with, . . . . 239

time required in digestion by, . $\quad . \quad$. $\quad . \quad$. 204

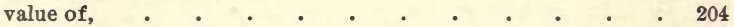

Cuckoo as an insect destroyer, . . . . . . . 205

attacking the gypsy moth, $\cdot \quad$. $\quad$. 6, 207, 211, 212, 225, 227

attacking the gypsy moth in Europe, . . . . . 208, 211

Currant sawfly, damage from, . . . . . . . 270

Curtis on occurrence of the gypsy moth in England, . . $\quad 269$

Cutting and burning infested growth, . . . . 39, 85, 164, 193

Cyanide of potash on eggs, . . . . . . . . . . 413

Cyanides as insecticides, . . . . . . . . . 485

Cyanocitta cristata. See Biue jay.

Cyclone burner for destroying the gypsy moth, . . . . 121,127

nozzle, . . . . . . . . . . . . 150

nozzle nsed for burning, $\quad$. $\quad$. $\quad$. $\quad$. $\quad . \quad 120$

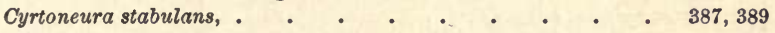

\section{D.}

Daly, D. W., statement of, . • • • • • • • • 9

Damage by gypsy moth in Oid Worid, . . . . . 273

Danger from bad pruning, • • • • • • • . . 173

from freight shipments, .. . . . . . . . 110

from steady traffic, $\quad . \quad+\quad . \quad . \quad . \quad . \quad . \quad .109$

Dasyllis sacrator, . . . • • . . . . . 392

Datana ministra, . . . . . . . . . . . 402

Date of hatching of the gypsy moth, . . . . . . 294

Daudeville on ravages of gypsy moth in France, . . . . 276 
Davis, Miss R. L., observations on

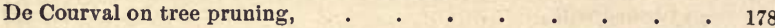

Defoliation of trees, . . . . . . . 8-28, 85, 86, 273-284

Dendrolene, description of, . . . . . . . . 135

Dermestes ater,

lardarius,

- 385

384,385

Des Cars on tree pruning,
Destruction of birds, folly of,

of caterpillars,

of egg-clusters. See Egg ciuster.

of gypsy moth, methods for,

of pupæ and moths,

Destructiveness of the gypsy moth,

of introduced insects,

$58,59,87,126,165$

Dexter elm, the,

Digestion of birds,

of eggs of the gypsy moth by birds,

117

194

$23,40,57,273-284$

250

247

204

239

369

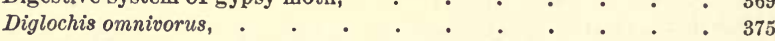

Dimorphlsm, sexual, of gypsy moth, . . . . . . $\quad 272$

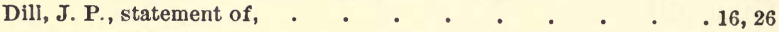

Dionychopus niveus, . . . . . . . . . . 341

Diptera, predaceous, . $\quad . \quad$ • $\quad$ • . . . . 392

Dipterous parasites, . . . . . . . . $336,376,385$

how reared, . . . . . . . . . . . 386

Dei, Apelle, on ravages of gypsy moth in Europe, . $\quad$. $\quad$. 279

Director of fleld work, inspection of infested region by, . . . 46

visit to Washington by, . . $\quad$ . . . . . 83

recommendations of entomologists considered by, $\quad . \quad$. $\quad . \quad 69$

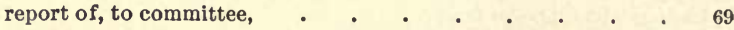

visit to Amherst by, - . . . . . . . . 46

Description of different stages of the gypsy moth, $\quad$. $\quad 288,300,333,336$

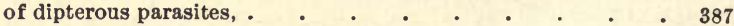

Disease among caterpillars, . $\quad$. $\quad . \quad$. $\quad . \quad 280,405$

Distance females can assemble males, . . . . . 240,351

travelled by caterpillars, . . . . . . . . 310

Distribution of the gypsy moth, . . . . . . . . 94

affected by extermination, . . . . . . . . 113

affected by food supply, . . . . . . . . . 95,97

affected by natural causes, . . . . . . . . 97

a study of methods and routes, . . . . . . . 106

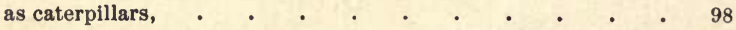

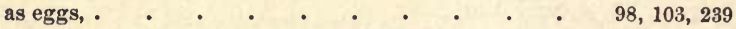

by animals, . . . . . . . . . . . 103

by birds, $\quad . \quad . \quad . \quad . \quad . \quad . \quad .98,215,231,235,239$

by man, . . . . . . . . . . . . .

by traffic, . . . . . . . . 102-105, 109, 345

by travelling of caterpillars, . . . . . . . . 310

by wind, . $\quad . \quad+\quad . \quad$. . . $98,278,301$

compared with that of other insects, - . . . . . 97

in other countries,. $\quad$. . . . . . . . . 267 
PAGE

Distribution of the gypsy moth, peculiarities of, $\quad$. $\quad . \quad .98,99$ period of greatest,. . . . . . . . . . . 104 primary, . . . . . . . . . . . 104

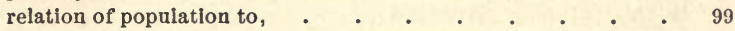
results of study of methods, . . . . . . . . 107 secondary, . . . . . . . . . . . . . . 104

District infested by gypsy moth. See Infested region.

Dohrn, Dr., on parthenogenesis,. . . . . . . . 366

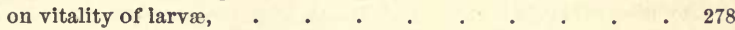

Donitz on singing Lepidopteron, . . . . . . 341

Donovan on occurrence of gypsy moth in England, ? . . . $\quad$ - 268

Douglass and Scott on breeding Heteroptera, . . . . . 394

Dowd, Mrs. John, statement of, . $\quad$. $\quad$. . . . . 22

Downy woodpecker attacking the gypsy moth, . . . . 207, 221

Drassus sp. attacking the gypsy moth, . . . . . . 405

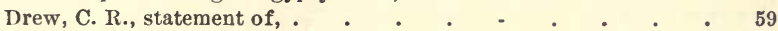

Dryobates pubescens. See Downy woodpecker.

villosus. See Hairy woodpecker.

Dryocampa rubicunda, . . . . . . . . . . 402

Dubois on ravages of the gypsy moth in Belglum, . $\quad . \quad$. 279

\section{E.}

Ebermayer, Dr., on birds $v$. the gypsy moth, . . . . . 209

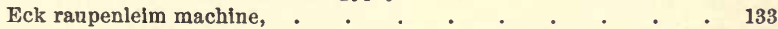

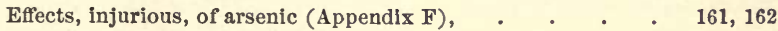
of extermination on distribution, . . . . . . 113

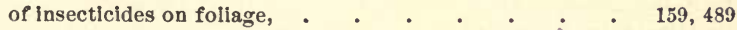

Egg-clusters of the gypsy moth, advantage of destruction of, 84, 117, 284 age of, how determined, . . . . . . . . . . 95 comparison of number destroyed annually, . $\quad$. $\quad . \quad$. 93

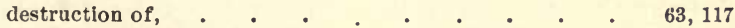
destruction of, in Europe, . $\quad$. $\quad$. $\quad$. $\quad$. . $\quad 284$

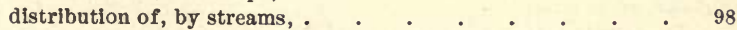
how laid, . $\quad . \quad . \quad . \quad . \quad . \quad . \quad . \quad . \quad .363$ number of caterplliars from, $\quad . \quad$. $\quad . \quad . \quad . \quad 94,297$ number destroyed in 1891, . $\quad . \quad . \quad . \quad . \quad . \quad . \quad .54$ of unfertilized females, . . . . . . . . $\quad$. 290,367 old distinguished from new,. $\quad$. $\quad . \quad . \quad . \quad . \quad . \quad . \quad .95$

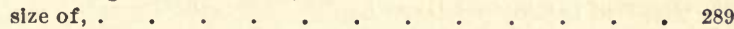
treated with acids, . . . . . . . $63,123,413,415$ treated with creosote, . . . . . . . $63,123,410$

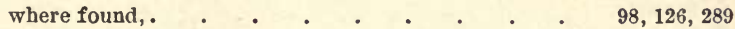

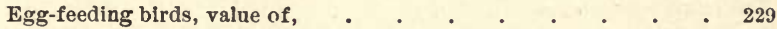

Egg-gathering and fall inspection, . . . . . . . 60

Eggs of the gypsy moth, birds which may eat, . . . . $\quad 228,229$ burning of, . . . . . . . . . 57, 519,284 danger from transportation of, . . . . . . . 111 description of, . . . . . . . . . . . 288 destruction of, . . . . $35,39,53,63,69,78,84,125,195$ distributed by birds, . . . . . . . . 230,239 
Fogs of the grpsy moth, effects of digestive processes of birds npon, effects of extremes of temperature on, . . . . . . 292 experiments with insecticides on, . . . . . . 407 hatching of, how accomplished, . . . . . . 297 how covered, implements used in search for, . . . . . . . 125

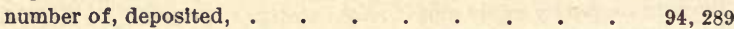
number of, in female, . . . . . . . . . 364 number of, laid by poorly fed females, . $\quad$. $\quad$. $\quad .95$ of dipterous parasites, . $\quad . \quad$ • $\quad . \quad . \quad . \quad . \quad .385$ removed by dissection, . . . . . . . . . . 364 scattering of, . . . . . . . 117, 239, 290, 363 time required for fertilization, . . . . . . . 343 vitality of, . . . . . . . . . . 279,291

Eichorn raupenleim machine, . $\quad . \quad$. . . . 131 Elachiptera dispar, • • • • • • • . . . 390 Electric insecticide, . $\quad . \quad$. $\quad . \quad$. . . . 482

Elm, the Dexter, . . . . . . . . . . . . 247

trees attacked by Chrysomela scalaris, . . . . . . 235

Elms attacked by gypsy moth, . . . . . . . . 277

“Elphona,". . . . . . . . . . . . . 483

Embryo, development of, . . . . . . . . 288, 294, 295

Emerging, process of,. . . . . . . . . . . 336

Emerton, J. H., spiders identified by, . . . . . . . 404

Empidonax minimus, • • • • . • . • . 207

Employees, number of, yearly, . $\quad . \quad$. $\quad . \quad$. . . 89-91

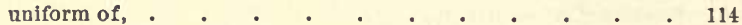

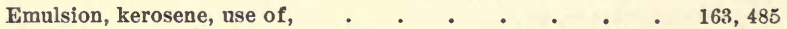

Enemies, natural. See Natural enemies.

England, extermination of gypsy moth in, . . . . . 269 occurrence of gypsy moth in, . . . . . . 267, 268

English sparrow attacking the gypsy moth, - . . 208, 231, 234 importation of, into America, . . . . . . 233, 234

Eutachina larvarum, . . . . . • • . . 392

Entomological adviser, Prof. C. H. Fernald appointed, . . $\quad .57$ opinion of, in regard to extermination, . . . . . $\quad$. 67

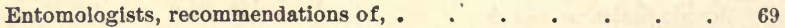

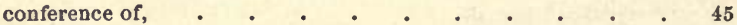
infested region inspected by, $\quad . \quad . \quad . \quad . \quad . \quad .69,79$ reports of (Appendices D and E). spraying recommended by, . . . . . . . . 45

Enwright, Wm. J., statement of, . . . . . . 40

Epeira strix, . • . . . . . . . . . . 405

Epiblemum scenicum, . . . . . . . . . . 405

Escape of the gypsy moth, statements in regard to, . . . . 4

Essex County Agricultural Society, petition presented by, . $\quad 36$

Eupelmus bifasciatus, . . . . . . . . . . 377

Europe, distribution of gypsy moth in, . . . . . 267 methods of destroying the gypsy moth in, . . . . 117, 284

European birds attacking gypsy moth eggs, . . . . . 231 birds, introduction of, . • . . . . . . . 232 


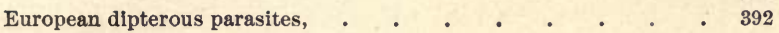

food plants, . . . . . . . . 325

hymenopterous parasites, . . . . . . . 377

methods for destroying the gypsy moth, . . . . . 284

predaceous beetles, $. \quad . \quad . \quad . \quad . \quad . \quad . \quad 385$

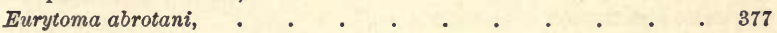

Everett, petition presented by selectmen of, . $\quad$ - $\quad$ • . $\quad 36$

Eversman, Professor, on ravages of gypsy moth in Orenboorg, 280

Examination of stomachs of various birds, . . . $\quad 212,215,231$ of stomach of toad, . $\quad . \quad . \quad . \quad . \quad . \quad 405$

Excresences from bad pruning, . . . . . . . . $\quad$. 177

Exhibit at Atlanta Exposition, . . . . . . . 201

at Mechanics Fair, . . . . . . . . . 201

at World's Columbian Exposition, . . . . . 200

Exorista sp., parasitic, on gypsy moth in America and Europe,. $\quad 387,392$

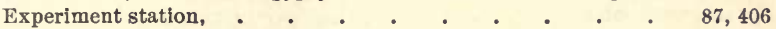

Experiments, amount of food consumed, . . . . . . 315

assembling, . . . . . . . . . . 345

birds $v$. gypsy moth eggs, . . . . . . . . . 229

cotton as a food plant,. $\quad$. $\quad . \quad$. $\quad . \quad . \quad$. 324

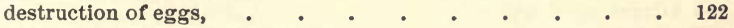

distance travelled by caterpillars, . . . . . 310

effects of light on caterpillars, . $\quad$ - . $\quad$ • $\quad$. 310

extremes of heat and cold on caterpillars, . $\quad . \quad$ - 327

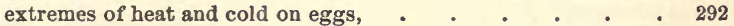

fertilization of female moths, . . . . . . . 343

food plants, . . . . . . . . . . . 316

food selection, . $\quad$. $\quad$. . . . . . 485

insecticide, . $\quad$. $\quad$. $\quad$. $\quad . \quad 55,69,87,407,417,477$

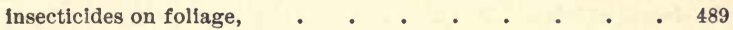

parthenogenesis, . . . . . . . . . . 365

trapping caterpillars, . . . . . . . . . 311

trapping male moths, . . . . . . . . . 357

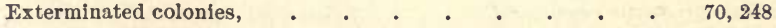

Extermination, advice of State Board of Agriculture concerning, 70

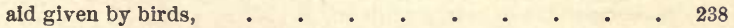

by burlapping and hand killing, . . . . . . . 64

circumstances favoring, . . . . . . . . 244

effect on distribution, . . . . . . . . . 113

how accomplished, . $\quad . \quad . \quad . \quad . \quad$. 127

in orchards, . $\quad . \quad$. $\quad . \quad . \quad . \quad . \quad . \quad 248$

in outer towns, . . . . . . . . . . 115

in woodland, . $\quad . \quad . \quad . \quad . \quad . \quad . \quad$. 88,248

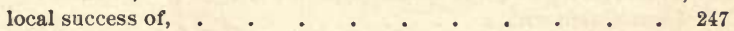

measures urged to provide for, . . . . . . . 35

obstacles to,. . . . . . . . . . . 245

opinions of entomologist in regard to, . $\quad . \quad$. $\quad . \quad 67$

progress of, . $\quad . \quad$. . . . . . . 244

results of efforts toward, . . . . . . . . 70

spraying not successful as a means of, $\quad$ - . . . 56, 62, 138

Exterminative measures, numbers of caterpillars reduced by, . . 60

External anatomy of moth, . $\quad$ - . . . . . . 339 
F.

Fall hatching,

False alarms, places from which recelved,. . . . . . 201

Farlow, Dr., on vęgetable parasites, . . . . . . . 405

Farmers, distribution of moth by, . . . . . . 109

methods most usefui for, . . . . . . . . 194

Feeding habits of gypsy moth, . . . . . . . . 311

time of, . . . . . . . . . . . . 311

Fells, Middlesex, colonies of the gypsy moth found in, . $\quad$. 86

condition of, . $\quad . \quad+\quad . \quad . \quad . \quad . \quad . \quad . \quad . \quad . \quad 87$

control of by Metropolitan Park Commission, . . . . 78

Felt, E. P., experimental work by, - . . . . . $\quad$. 57

observations on chipping sparrow, . . . . . . 215

observations on Dermestes lardarius, . . . . . . $\quad$ • 384

on whale-oil soap, . $\quad . \quad$. . . . . . . 163

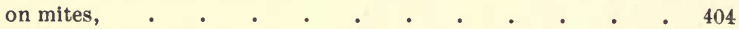

Female gypsy moth, abdomen, hair of, . . . . . . 342

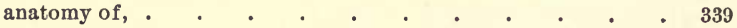

attacked by ants, . . . . . . . . . . 380

attraction of males by, . . . . . . . . . . 240

birds feeding on, . . . . . . . . . 217,228

description of, . $. \quad . \quad . \quad . \quad . \quad . \quad . \quad .337$

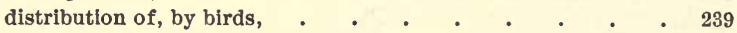

does not fly, . . . . . . . . . $97,112,344$

eggs laid by infertile, . . . . . . . . . 365

eggs removed by dissection of, . . . . . . . . 364

eggs scattered by, . . . . . . . . . 290

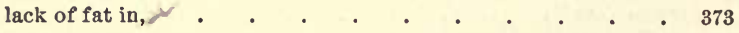

length of life, . $\quad$ • . . . . . . . 343,362

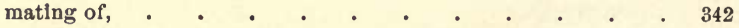

number of eggs deposited by, . . . . . . . . 94,95

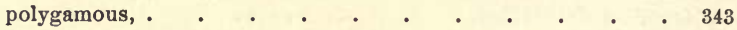

reproductive system of, . . . . . . . . 375

unfertilized, eggs laid by, . $\quad . \quad$. $\quad . \quad$. $\quad . \quad 290$

Fences, comparison of yearly work on, . $\quad$. $\quad . \quad$. $\quad . \quad 93$

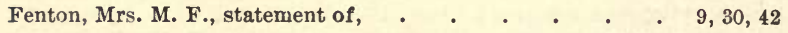

Fernald, Dr. H. T., report of (Appendix D).

Fernald, Mrs. C. H., identiflcation of gýpsy moth by, . . . 32

Fernald, Prof. C. H., advice concerning egg killing, . . . 119

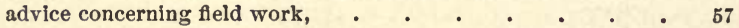

appointed entomological adviser,. $\quad$. $\quad . \quad . \quad . \quad . \quad 57$

at conference on gypsy moth (Appendix A).

consultation with,..$\quad$ • . . . . . . . 46

experiments by, . . . . . . . . . . 142

fleld work examined by, . . . . . . . . $\quad .34,57$

invitation to entomologists to visit infested region, . . $\quad 69$

recommendations of entomologists considered by, . . . 69

recommendation of policy of State work, . . . . . 251

record of introduction of gypsy moth,. . . . . . 3

report of, to committee, . . . . . . . 69 
Fertllity of scattered eggs, .

Fertilization, time required,

Fertilized females, assembling by, . . . . . . . 363

Field force discharged,

organization of,

. 63,84

reductions of,

operations criticised by Professor Riley,

$60,64,79$

pupation of the gypsy moth in the,

work begun, .

335

Fifleld, Mrs. George, on migration of caterpillars, . . . . 13

Fifleld, W. W., statement of,

Fingerling, Prof. Max on egg killing,

Fire, ald furnished by,

caterpillars destroyed by,

eggs destroyed by,

numbers of moths destroyed by, .

. 21,44

- 118

7,166

$58,59,87,126$

$57,118,119$

Fires, rules concerning (Appendix B).

First destructive appearance of the gypsy moth,

Fish-oil soap, use of,

Fitchburg Railroad, Inspection of,

Flicker attacking the gypsy moth,

Flight habits of gypsy moth,

Flinn, Mrs. J. W., statement of,

Flood, M. J., observations on blue-jay,

Fly-catchers attacking the gypsy moth,

Foliage, area of, on trees,

destruction of, by caterpillars,

effect of Insectlcides on,

Follansbee, Mrs. S. J., statement of, .

Food, amount consumed by caterplliars,

amount necessary for birds, .

distribution of the gypsy moth from lack of, existence of caterpillars without, . plants of the canker worm,

$97,112,342,344$

$8,22,25,27$

$7,207,219,226,227$,

214
7,236

$8-28,59,85,96,273-284$

$159,489,494$

$\cdot 17,27$

315

204

Forests attacked by gypsy moth, . . . . . . 97, 274

possible danger to, from gypsy moth, . . . . . . 70,87

Formica subsericea, . . . . . . . . . . 381

Foster, F. E., statement of, $\quad$. $\quad$. $\quad . \quad . \quad . \quad . \quad .18,29$

Fowls affected by arsenlc, . . . . . . . . 162 
Fowls feeding on gypsy moth caterpillars, .

France, ravages of the gypsy moth in,

Fraxinus excelsior, exempt from ravages of gypsy moth, .

Freezing mixtures,

French, J. N., statement of,

Frisch, J. L, on injuries by gypsy moth, ${ }^{\circ} 27,30,3$

Frost, $H$. $I$, on food plants of the gypsy moth, on predaceous bugs,

Fruit crop increased by spraying, loss of, . poisoned by spraying, . trees in Europe attacked by gypsy moth, .

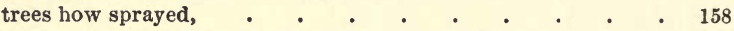

Fürst, Hermann, quoted on birds attacking caterpillars, . . $\quad 208$

\section{G.}

Galeruca xanthomelona, increase of, due to sparrows, . . $\quad$. 235

Garden crops destroyed, . . . . . . . . . 26

Gases for destroying eggs, . $\quad$. $\quad . \quad$. $\quad . \quad$. $\quad . \quad 125$

Gaurax anchora, . . . . . . . . . . 387

Gazen on ravages of gypsy moth in Kirsanov, . $\quad$. . . $\quad$ - 282

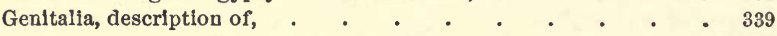

Germany, ravages of the gypsy moth in, . . . . . 274

Gerstäcker, Dr., on the killing of trees by gypsy moth, . . $\quad$ - 277

Gibson, R., statement of, . . . . . . . . . 20

Glands, accessory, of gypsy moth, . . . . . . $\quad 375$

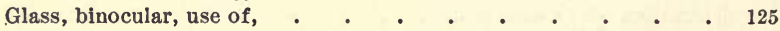

Glover, Townend, on insectivorous birds, . . . . . 207

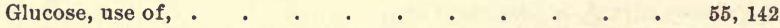

Godart, on injuries by gypsy moth, . . . . . . 275

Goodell, Pres. H. H., aid of, In securing assistants, . . . . 46

letter to Governor-elect Brackett by, . . . . . . 35

Goodwin, F. M., statement of, . . . . . . . . 12,19

Goodwin, J. O., description of movements of gypsy moth caterpil-

lars, . . . . . . . . . . . 13

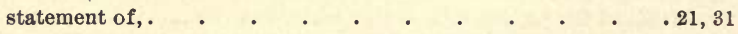

Gordon, Miss Carrle, observations on molting, . • . . $\quad 304$

Gould, L. S., at conference on gypsy moth (Appendix A), . $\quad 45$

Gould pumps, . . . . . . . . . . . 150

Grackle, purple, attacking the gypsy moth, . . . . 207

Græser on distribution of gypsy moth, . . . . . 267

Graff, V. E., on ravages of gypsy moth in Riazan, . . . . 281

Grafting wax, use of, in pruning trees, . . . . . $\quad .177$

Grain attacked by gypsy moth in Europe, . . . . . 283

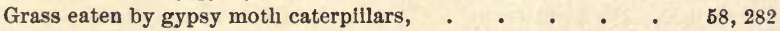

Great-crested flycatcher attacking gypsy moth caterplllars, . $\quad 207$

Great titmouse attacking other birds, . . . . . . . 233

Green, I. C., observations on the redstart, . $\quad$. $\quad$. $\quad . \quad$. 219

Green, Paris. See Paris green.

Grimm on feeding babits of blrds, . . . . . . 208,222 
Grosbeak, rose-breasted, attacking gypsy moth,

caterpillars. See Caterpillars of the gypsy moth. colonies of, exterminated, . . . . . . . . . 65

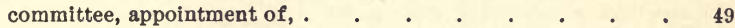

committee, meeting of, with Metropolitan Park Commlssion, . 78

committee, name of, changed, . . . . . . . . 76

comparison of numbers destroyed yearly, . . . . . . 93

common names of, $\quad . \quad$. $\quad . \quad$. $\quad . \quad . \quad 256$

conditions favoring rapid increase of, . . . . . . . 95

description of caterpillar, . $\quad . \quad$. $\quad . \quad$. . 300

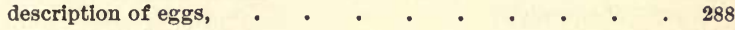

description of imago, . $\quad . \quad$. $\quad . \quad$. . . 336

description of pupa, . $\quad . \quad$. $\quad . \quad$. . 333

destruction of, by birds, . . . . . . $7,96,209,272$

destruction of, by burlapplng, . . . . . . . 167

destruction of, by burning, . . . . . . . 119,127

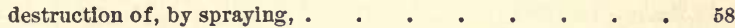

destructiveness of, . . . . . . . $23,40,57,70$

distribution of. See Distribution.

efforts of citizens to destroy,

$34,68,77,84$

egg-clusters. See Egg-clusters.

exterminative methods to reduce number of, . . . 60

female. See Female.

flrst destructive appearance of, - . . . . . 7

food plants of,

form in which imported, . . . . . . . . 4

hermaphrodites, • • • • • • • • • 339

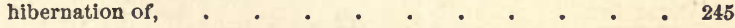

history in America, . . . . . . . . . 3

history in the Old World, . . . . . . . . 273

identification of, . $\quad . \quad$. $\quad . \quad$. $\quad . \quad$. 32

in America, occurrence of, recorded by Professor Rlley, . . 3

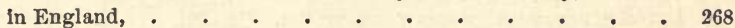

in England, how exterminated, . . . . . . $\quad$. 272

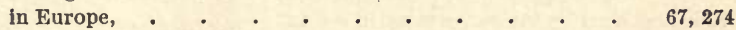

in Europe, methods for destroying, . . . . . . 284

Increase of, checked, . . . . . . . . . . 94

increase of, due to English sparrow, . . . . . . 235

increase of, retarded by fires, . . . . . . . 7

increase of, retarded by Isolation, . . . . . . 6

injuries of, in Old World, • . • • • • • • 273

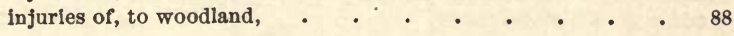


Gypsy moth, introduction of into America by Leopold Trouvelot,

introduction of, recorded by Professor Fernald, . . . . 3

Japanese, size of, . $\quad . \quad$. . . . . . . . 338

males. See Male moth.

means of preventing spread of, caterpillars, $\quad$ - $\quad$. $\quad .63$

means taken to find new coloules, . . . . . . 105

migration of, in search of food, - . . . . . . 13,97

natural enemies of, $\quad$. $\quad$ - . . . $\quad$. $6,95,203,375$

number of, colonies exterminated, . . . . . . 70

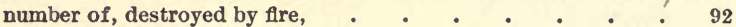

number of, destroyed by spraying, • • • . . . . 92

number of eggs deposited by, . $\quad$. $\quad$ • . . . . 94

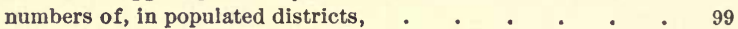

origin of isolated colonies, . . . . . . . . . . 103

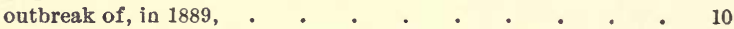

parasites of, . $\quad . \quad$. $\quad$ • . $\quad . \quad 57,96,375,385$

peculiarities of the distribution of, $\quad$. $\quad . \quad$. $\quad . \quad 98,99$

period of greatest distribution, . . . . . . . 104

plants destroyed by the, . . . . . . . 70,318

possible spread of, . $\quad . \quad+\quad . \quad$. $\quad$ • 250

pupæ. See Pupæ.

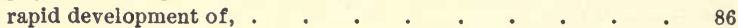

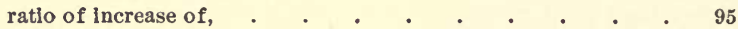

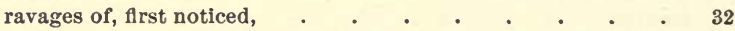

result of the transportation of, . . . . . . . . 102

seasons favorable for the increase of, . . . . . . . . . 95,96

second brood of, . $\quad . \quad$. . . . . . 86,295

secondary distribution of, . $\quad . \quad . \quad . \quad . \quad . \quad . \quad . \quad 104$

spread of, compared with that of canker worm, . $\quad$ - $\quad . \quad 97$

statements from citizens concerning escape of, . . . . 4

study of the distribution of, . . . . . . . 94

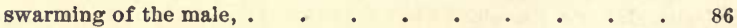

systematic position of, . $\quad . \quad$. $\quad . \quad . \quad . \quad . \quad .256$

v. English sparrow, . . . . . . . . . 234

weather favorable for the increase of, . . . . . 84

H.

Habia ludoviciana, . . . . . . . . . 207

Habits, feeding, of gypsy moth caterpillars, . . . . . 311

of flight of gypsy moth, . . . . . . . . 344

of the gypsy moth, observations on the, . . . . . 87

spinning, of gypsy moth caterpillars, . . . . $279,330,332$

Hair deposited by the gypsy moth in laying, . . . . 342, 364

Hairs, ærostatic, of caterpillars, . . . . . . . . 301

Hairy caterpillars, immunity of, from birds, . . . . 208, 210

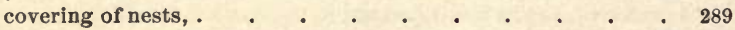

woodpecker attacking the gypsy moth, . . . . 207,221

Hamlin, Mrs. I. W., statement of, . . . . . . 11, 20,30

Hand-killing of caterpillars, efficiency of, . . . . . . 64

Harlow, J. W., statement of, . . . . . • . . 25, 28 
Harmon, Wm. B., statement of, .

Harpalus caliginosus, .

Harris, Dr. T. W., on occurrence of gypsy moth in England, . $\quad 268$

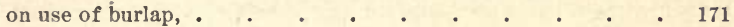

Hartig, Dr. R., on raupenleim, . . . . . . . 130 on tree pruning, . $\quad . \quad$. $\quad . \quad$. . . . 180

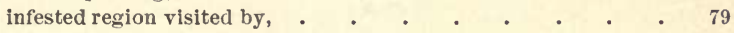

Harvey, Prof. F. L., report of (Appendix E).

Hatch Experiment Station Bulletin, introduction of gypsy moth recorded in,

Hatching of gypsy moth caterpillars, date of, . fall,

Hauenstein raupenleim machine,

Haushalter, F. H., statement of,

Haworth on occurrence of gypsy moth in England, . . . $\quad 268$

Heat, effect of, on gypsy moth caterpillars, . . . . $\quad$ • 327 effect of, on gypsy moth eggs, . . . . . . 119, 293

fall hatching produced by, . . . . . . . . . 296

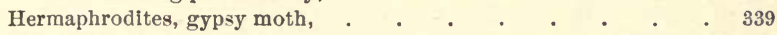

Hemiptera, predaceous, . . . . . . . . . 392

Hemiteles fulvipes, . . . . . . • . • 378

Henry, Professor, on egg-killing, . . . . . . . 118

on ravages of the gypsy moth in France, . $\quad$. $\quad$. $\quad .283$

Henshaw, Samuel, appointed entomologist to first commission, $\quad 38$

on enemies of gypsy moth, . . . . . . . . . 405

Hericart, F., Viscount, on ravages of gypsy moth, . . . . 276

Hess, Dr. Richard, on means of destroying the gypsy moth, . $\quad 285$

Hibernation of the gypsy moth, . . . . . . . 245

of parasites, . $\quad . \quad . \quad . \quad . \quad . \quad . \quad . \quad . \quad . \quad . \quad 377$

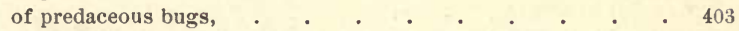

Highways, caterpillars of gypsy moth found along, . $\quad$. $\quad$ - 99 inspection of, $\quad . \quad+\quad . \quad . \quad . \quad . \quad . \quad . \quad . \quad . \quad 197$

History of gypsy moth in America, . . . . . . . 3

of gypsy moth in the Old World, . . . . . . $\quad$. 273

Hochleim raupenleim machine, . . . . . • . 132

Hofmann, Dr., on disease of nun moth, . . . . . . 405

Holland, occurrence of gypsy moth In, . . . . . 268,283

Homeyer on distribution of gypsy moth, . . . . . 267

Hornets, predaceous, . $\quad$ • . . . . . . . 378

Hose, Eck raupenleim, . $\quad$. $\quad$. . . . . . . . 133

for spraying, . $\quad . \quad$. $\quad . \quad$. $\quad . \quad . \quad . \quad . \quad .147$

House swallows driven away by sparrows, . . . . . 234

House wren attacklng the gypsy moth, . $\quad . \quad$. $\quad 208,227$

Howard, L. O., opinions of, on gypsy moth work (Appendix E).

Hutchins, John, statement of, . . . . . . . 43

Hyannis tobacco mixture as insecticide, . . . . . . 483

Hydrochloric acid on eggs, . . . . . . . . . . 413

Hydrocyanic acid gas, eggs treated with, . . . . . . 410

Hydrogen arsenide, eggs treated with, . . . . . . 412

sulphide, eggs treated with, . . . . . . . . 412 
Hylan, J. P., on assembling of gypsy moth, . . . . . $\quad 345$

on leaf area of trees, . . . . . . . . . . 495

Hyla pickeringii, . . . . . . . . . . . 404

Hymenoptera attacking the gypsy moth, . . . . . 375

Hymenopterous parasites destroyed by flycatchers, . . $220,241,376$

Hyphantria cunea, . . . . . . . . . . 402

Hypogymna dispar, . . . . . . . . . . 255

I.

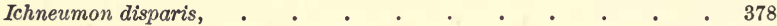

grandis, hibernation of, . $\quad . \quad$. $\quad . \quad$. 377

Ichneumons captured by birds, . . . . . . $220,241,376$

Icterus galbula. See Baltimore oriole.

Imago of gypsy moth. See Female moth; male moth.

Implements used in searching for eggs, . $\quad . \quad$. $\quad . \quad$. 125

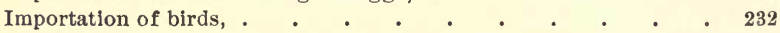

of Engiish sparrow, . . . . . . . . 233, 234

of gypsy moth, form of, . . . . . . . . 4

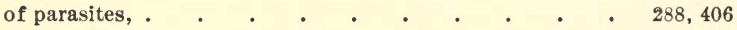

Imported insects, damage from, . . . . . . . . 270

In-and-in breeding, $\quad . \quad+\quad \cdot \quad \cdot \quad \cdot \quad \cdot \quad \cdot \quad \cdot 368$

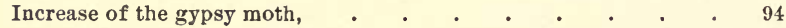

conditions favoring rapid, . . . . . . . . . 95

due in some measure to sparrows, . . . . . . 235

influences that retarded, . . . . . . . . . .

normal rate of, in isolated colonies, . . . . . . 95

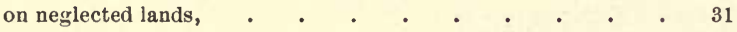

ratio of, . $\quad . \quad+\quad . \quad+\quad . \quad . \quad . \quad . \quad .95$

retarded by climate, . . . . . . . . . 5

retarded by isolation, . . . . . . . . . 6

weather favorable for the, . . . . . . . . 84

Indigo bird attacking gypsy moth, . . . . . . 207,219

Infestation, centres of, $\quad . \quad+\quad \cdot \quad \cdot \quad \cdot \quad \cdot \quad \cdot \quad \cdot 104$

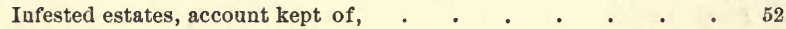

locallties, birds frequenting, . . . . . . . 223

localities designated on maps, . . . . . . . . . . . . 50,52

region appointed to inspectors, . $\quad . \quad$. $\quad . \quad . \quad . \quad . \quad 49$

region, colonies found in 1891 outside of, . $\quad$. $\quad . \quad$. 70

region, condition $\ln 1891$, $\quad . \quad$. $\quad . \quad . \quad . \quad . \quad . \quad .53$

region, description of, . . . . . . . . 100, 101

region, extent of, . $\quad . \quad+\quad . \quad+\quad . \quad$. 53,108

region, how inspected, . . . . . . . . . 196

region, inspection of belt around, . . . . . . . 108

region of 1891 , moth rarely found outside of, . . . . 61

region, proportion of population in, . . . . . . 101

region, rallroads running through, . . . . . . 101

region visited by Agricultural committee, . . . . . 36

region visited by entomologists, . $\quad . \quad . \quad . \quad . \quad .69,79$

towns, proportionate numbers of the gypsy moth in, . . . 99 
Infested woodlands, $\quad$ • . . . . . . . . . . 116

woodlands, known area of, . $\quad . \quad$. $\quad . \quad$. 87

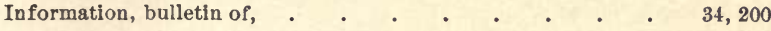

of the public, measures for, . $\quad . \quad . \quad . \quad$. $\quad$ - $31,198,200$

Injuries by gypsy moth in Old Worid, . . . . . . 273

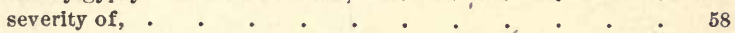

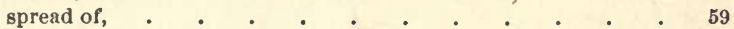

to man and animals from spraying (Appendix F), . . . 161

to woodland by the gypsy moth, . $\quad . \quad$. $\quad 85,88,273-284$

Ink, printers' used in destroying the gypsy moth, . . . . . 34

Insectary, description of, - . . . . . . . 406

Insecticides, contact, - $\quad . \quad+\quad \cdot \quad \cdot \quad \cdot \quad \cdot 57,58,163,485$

danger from arsenical (Appendix F).

experiments with, .

for destroying caterpilars, • • • • • • • •

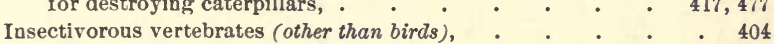

Insect lime. See Raupenleim.

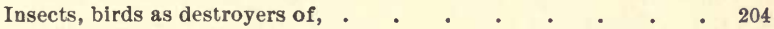

imported, danger from, . . . . . . . . 270

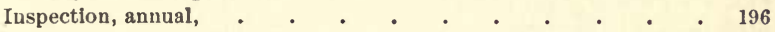

force insufficient for, $. \quad . \quad . \quad . \quad . \quad . \quad .79,81$

of belt around infested region, . . . . . . . . 106

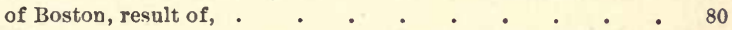

of outside territory, . $\quad . \quad$. $\quad . \quad$. $\quad . \quad 110,111$

of outside towns, result of, . . . . . . . . . . . . . . . 55,70

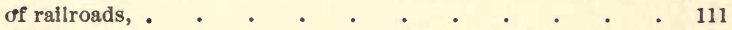

of wooded region, . $\quad . \quad$. $\quad . \quad . \quad . \quad .66,87$

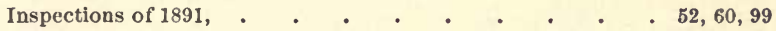

Inspectors, observatlons reported by, . $\quad$ - . $\quad$. $\quad$ - 51

town-sections allotted to, . . . . . . . 50

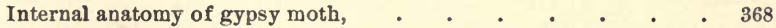

Introduction of English sparrow, $\quad . \quad+\quad . \quad+\quad . \quad$ - $\quad$ 233, 234

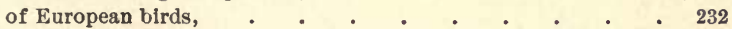

of European parasites, . $\quad . \quad$. . . . . 288,406

of gypsy moth into America by Leopold Trouvelot, . . . 3

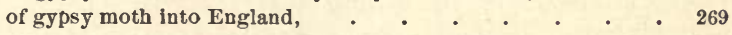

of gypsy moth, recorded by Professor Fernald, . . . . 3

Investigating committee, appointment of, urged by gypsy moth committee, . $. \quad . \quad . \quad . \quad . \quad .68,77$

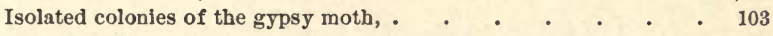

injury from, . $\quad$ - . . . . . . . . 95

normal rate of increase in, . . . . . . . . . 95

Italy, ravages of the gypsy moth in, $\quad . \quad+\quad . \quad . \quad$ - $\quad$ - 279

\section{J.}

Jäger, Dr., on diseases of nun moth, .

Japan, occurrence of gypsy moth in, . . . . . . . 267

Japanese gypsy moth, size of, • . . . . . . . 338

Jay, blue, attacking the gypsy moth, . . . . . . 6, 207, 225

attracted by meat,. $\quad . \quad$. . . . . . . . 229 
Jay, blue, destroying predaceous insects,

distributing the gypsy moth, . . . . . . . 236

feeding habits of, . . . . . . . . . 210,231

Joly, M. N., on ravages of the gypsy moth, . . . . $\quad 276$

Jones, F. H., preparation of soap powder emulsion by, . . . 163

\section{K.}

Kazan, ravages of the gypsy moth in, . . . . . 281, 283

Kearly, George, on increase of insects following destruction of

birds, . . . . . . . . . . . 205

on scarcity of gypsy moth in England, . . . . . $\quad$. 269

Kelly, Mrs. Daniel, statement of, . . . . . . . 22

Keppen, Theodore, note on cuckoo, . $\quad$. $\quad$ • . . . 208

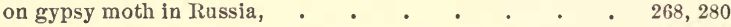

Kerosene emulsion, use of, . . . . . . . . 163,485

for destroying caterpillars, . $\quad$ • $\quad$ • $\quad$ • . . . 126

for destroying eggs, . . . . . . . . . . . 416

Kharkov, ravages of gypsy moth in, . . . . . . 281

Kiev, ravages of the gypsy moth in, . . . . . . . 281

King birds attacking the gypsy moth, . . . . 207, 226, 227

Kinglet attracted by meat, . . . . . . . . 229

Kirby, Catalogue Lepidoptera Heterocera, . . . . 255

Kirkland, A. H., cages for breeding beetles, . . . . $\quad 384$

observations on wood pewee, . . . . . . . 220

on assembling of gypsy moth, . . . . . . . 345

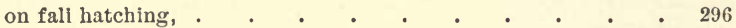

on food selection by larvæ, . . . . . . . . 485

on garden toad, . . . . . . . . . . 404

on internal anatomy of gypsy moth, . . . . . . 368

on predaceous Hemiptera, . • • • • . . . 392

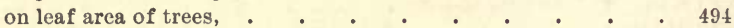

Kirsanov, ravages of gypsy moth in, . . . . . . $\quad$ • 282

Kishenev, ravages of gypsy moth in, . . . . . . $\quad 280$

Klausen, experiments of, with wadding bands, . $\quad$ • . . $\quad$. 286

Knapsack pump, . . . . . . . . . . . . 149

Knives, cleaning, . • . • • • • • • • • • 126

Köllar, Vincent, on egg killing, . • • • • • • • 118

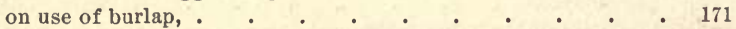

Kornauth, Wachtl and, on diseases of nun moth, . . . $\quad 405$

Kulagin, N., on injuries of gypsy moth in Russia, . . . $\quad 280$

\section{L.}

Labodsky on bands for trees, . . . . . . . . 285

Lacy, Sylvester, statement of, . . . . . . . . 17

Larches attacked by gypsy moth, . . . . . . . 277

Larch saw-fly, damage from, . . . . . . . . 270

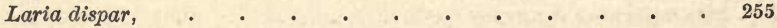

Larvæ of gypsy moth. See Caterpillars of gypsy moth. 
Law for protection of birds, need of enforcement of,

Lead, arsenate of. See Arsenate of lead.

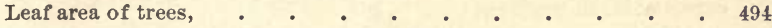

Least flycatcher attacking the gypsy moth, . . . . . 207

Leaves, how injured by arsenical poisons, . . . . . . 494

Legislature, petition for extermination of gypsy moth presented to, 36

Length of life of imago, . • • • • • • . . 343,362

larvæ without food, . $\quad . \quad$. . . . . 278,325

Lepidoptera attacked by predaceous bugs, . . . . . . 393

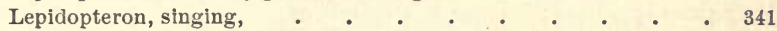

Lettuce, quantity eaten by gypsy moth, . . . . . . 315

Lexington, area of woodland infested in, . . . . . . 87

Light, caterpillars attracted to, . • . . . . . . 310

Limbs, large, removal of, . . . . . . . . . 184

Lime, insect. See Raupenleim.

Limenitis ursula, .

Lindens attacked by gypsy moth,

Lines of travel, relation of distribution to,

Lintner, Dr. J. A., Infested reglon visited by, . report of (Appendix D),

Liparis dispar,

monacha, damage by,

use of raupenleim against, . . . . . 132

Literature on gypsy moth, . . . . . . . . 257-267

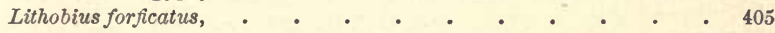

Livonia, occurrence of gypsy moth in, . . . . . 267, 268

Local extermination, success of, . • • . • . . 247

Localities, infested, birds frequenting, . . . . . . 223

Locusts destroyed by birds, $\quad$. . . . . . . . 205

Lodi on vitality of caterpillars, . $\quad . \quad$. . . . . . 327

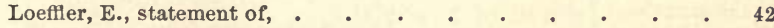

London purple, . . . . . . . . . 140,417,477

Leech, J. H., on Japanese gypsy moth, . 338

Lycosa sp. attacking the gypsy moth, . . . . . . 405

Lymantria monacha, ærostatic hairs of, . . . . . . 301

disease of, . . . . . . . . . . . 405

M.

Macharcea serriventris, . . . . . . . . . . . 392

Machines for burning eggs, . . . . . . . . 119 raupenleim, . $\quad \cdot \quad \cdot \quad \cdot \quad \cdot \quad \cdot \quad \cdot \quad \cdot \quad \cdot \quad \cdot \quad \cdot 131$ spraying, ..$\quad \cdot \quad \cdot \quad \cdot \quad \cdot \quad \cdot \quad \cdot \quad \cdot \quad \cdot{ }^{149-156}$

Majorca, island of, occurrence of gypsy moth in, . . . . 267

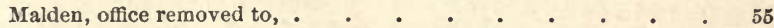
petition presented by clty officials of, . . . . . . 36 trees defoliated by gypsy moth in, . . . . . . 57

Male gypsy moth, anatomy of, . • . . . . . 339

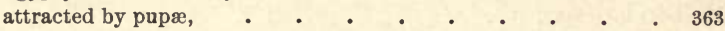


Male gypsy moth, birds feeding on, . . . . . . 228-240

description of, . . . . . . . . . . 336

digestive system of, . . . . . . . . . 371 .

distance over which female attracts, . . . . . 240,351

experiments in trapplng, . . . . . . . 69,357

flight of, . . . . . . . . . . 344,345

length of life of, . . . . . . . . . . 343

mating of, - . + . . . . . . . . 342

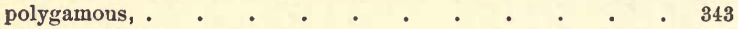

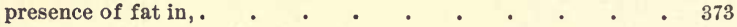

reproductive system of, $\quad . \quad . \quad . \quad . \quad . \quad . \quad . \quad 373$

Malpighian vessels of gypsy moth, structure of, . . . $\quad 370$

Man, distribution of the gypsy moth by, . . . . . 99, 100-103

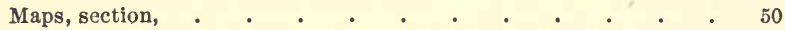

Market gardeners, distribution of moth by, . . . . $\quad$. 109

Marptusa familiaris, . . . . . . . . . . 405

Martin, Dr. Pearl, appointed commissioner, . $\quad$ - $\quad$ • $\quad$. 38

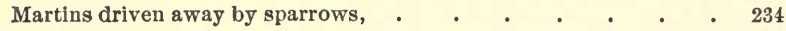

Maryland yellow-throated warbler attacking the gypsy moth, . . 208

Massachusetts Agricultural College, students of, as assistants, $\quad$. 46

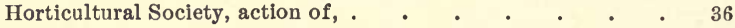

Mating of gypsy moth, . . . . . . . . 342

Maynard, C. J., note on bird digestion, . . . . . $\quad 204$

Maynard, Prof. S. T., recommendation concerning painting trees, . 178

Mayo, Mrs. Thomas F., statement of, . . . . . 15, 22, 24

McCarty, Miss R. A., statement of, . . . . . . . 19, 25

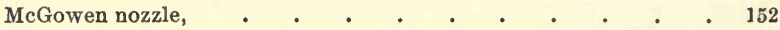

McKee, George W., bark shave invented by, . • • • . 190

McLaughlin, Wm., statement of, . . . . . . . 44

Medford, brick shipments from,. . . . . . . . 110

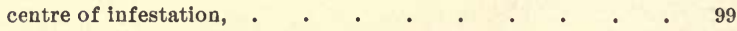

colonies of gypsy moth discovered in woods of, . . . . $\quad$. 85

description of section 8 (Appendix C).

distribution of caterpillars from, . . . . . . . 112

gypsy moth fought by municipal authorities of, . . . . 33

measures taken to destroy the pest in, . $\quad$. $\quad . \quad$. $\quad .34$

"Mercury," description by J. O. Goodwin of movements of caterpillars in, . . . . . . . . . 13

residence of Trouvelot in, $\quad . \quad$. $\quad . \quad . \quad . \quad . \quad . \quad 4$

selectmen of, petition for extermination of gypsy moth presented to Legislature by, . . . . . . . 36

statement of citizens as to escape of gypsymoth, . . . 4

trees defoliated by gypsy moth in, . . . . . ' 57

woodland burned in, . . . . . . . . . 166

Meeting of Board of Agrlculture, special, . $\quad$. $\quad . \quad$. $\quad 49$

opponents to spraying, . . . . . . . . . . 56

Meigenia bisignata, . . . . . . . . . . 392

Melrose, outbreak of the gypsy moth $1 n$, . . . . . 58

Men, examination and tralning of, . . . . . . $.68,85$

largest force of, . . . . . . . . . . 85

Menecles insertus, . . . . . . . . . . . 393 
Mephitis mephitica,

PAGE

Method of pruning,

of rearing predaceous insects,

of testing insecticides, .

pursued in outside inspecting,

384,394

418

60

164

284

in Europe,

most useful to the farmer,

194

Metropolitan Park Commission, gypsy moth committee hold meet-

ing with,.

location of territory controlled by the, $\quad . \quad+\quad . \quad$.

reservation, moths found in the,

"Mercury," Medford, description of movements of caterpillars in, . 13

Merrill, Mrs. E. E, statement of, . . . • . . . 42

Merula migratoria, . . . . . . . . . . . 216

Mesochorus, species parasitic on gypsy moth in Europe, . . $\quad 378$

Microgaster species, parasitic, on gypsy moth in Europe, . . $\quad$. 377

value of certain species in Europe, . . . . . . 288

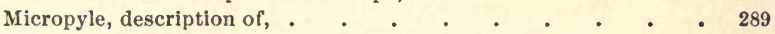

Middlesex Fells, colonies of gypsy moth found in the, - . 86

condition of, . $\quad . \quad$. $\quad . \quad . \quad . \quad . \quad . \quad . \quad . \quad 87$

Migration of the gypsy moth in search of food, . $\quad . \quad$. 97

Milk inspectors, information furnished by, . . . . 107

peddlers, distribution of gypsy moth by, . $\quad$. $\quad$. 109

Miller, J. C., statement of, . . . . . . . . . 13,42

Minott, C. W., experiments by, . . . . . . . 418

observations on feeding habits, . . . . . . . 311

observations on vitality of larvæ, . . . . . . $\quad$ • 299

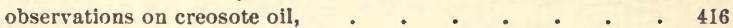

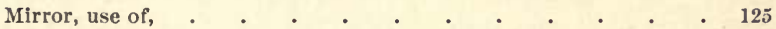

Mites attacking eggs, . $\quad . \quad$. $\quad . \quad . \quad . \quad . \quad . \quad 404$

Mixter, C. S., statement of, . . . . . . . . . 41

Molting of the gypsy moth, . . . . . . . 308

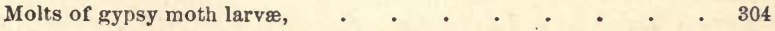

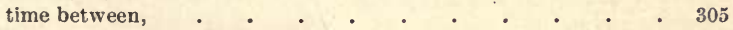

Mongoose, Importation into Jamaica, . . • • • 233

Monteiro, Dr. A. A. C., on egg-killing, . . . . . 118

Morton, Hon. J. Sterling, matter of appropriation presented to, $\quad 83$

Moscow, occurrence of gypsy moth in, . . . . . 268, 283

Mosher, F. H , experiments by, . • . . . . . 418

observations on blue-jay, . . . . . . . . . 214

observations on crow, . . . . . . . . . 217

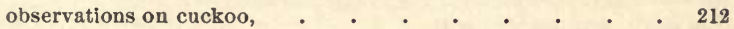

observations on flight of female, . . . . . . . 344

observations on hairy woodpecker, . . . . . . 221

observations on tree frog, . . . . . . . . 404

observations on vitality of larvæ, . $\quad$ - . . . . $\quad$. 299

Moth, gypsy. See Gypsy moth.

gypsy, female. See Female gypsy moth.

gypsy, male. See Male gypsy moth.

traps, 
Moth, tussock, increase due to sparrows, . . . . $\quad$. 235

Moulton, F. C., analyses by, . . . . . . . . 474

experiments by, . . . . . . . . . 142,407

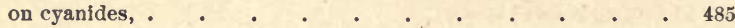

Myiarchus crinitus, . . . . . . . . . 207

\section{N.}

Names of gypsy moth, . . . . . . . . 255, 256

Naphtha burner for destroying caterpillars, . . . . 122,126

Nason, Prof. F. L., inventor of dendrolene, . . . . . 135

Nasonov, Dr. N., on egg-killing, . . . . . . . 118

on methods of destroying the gypsy moth, . . . . . 284

on ravages of gypsy moth in Poland, . . . . . . 283

Native birds driven away by sparrows, . . . . . . 234

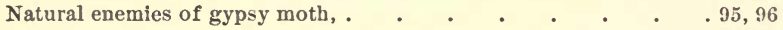

birds, • . • . • • • • • • . . 203

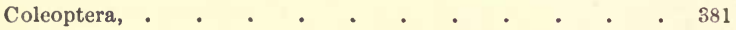

Diptera, . $\quad . \quad+\quad . \quad . \quad . \quad . \quad . \quad . \quad . \quad .385$

Hemiptera, . . . . . • • • . . . 392

Hymenoptera, . $. \quad . \quad . \quad . \quad . \quad . \quad . \quad .375$

spiders, . . . . . . . . . . . . . 404

vertebrates, . . . . . . . . . . . . 404

selection, effect on gypsy moth in England, . . . . 273

selection, influence on colors of gypsy moth, . . . . $\quad$. 272

selection, influence on flight of males, . $\quad . \quad 3 \quad . \quad . \quad 345$

Neitner, gypsy moth found in Ceylon by, . • • • • . 267

Nematus erichsonii, lamage from, . • . • • • • 270

ribesii, damage from, . $\quad . \quad$. $\quad . \quad$. $\quad 270$

Nervous system of gypsy moth, . . . . . . . . 373

Neville, T. J., statement of, . . . . . . . . 23

Nicholson, C., on extermination of the gypsy moth in England, $\quad$. 270

Nitric acid for destroying eggs, . . . . . . . . . 123

Nitrogen dioxlde for destroying eggs, . . . . . . 413

Noctua-c-nigrum, . . . . . . . . . . 400-402

Nolken on distribution of gypsy moth, . $\quad$. $\quad . \quad$. $\quad . \quad 268$

Norcross, J. Henry, efforts of, to secure an appropriation, . $\quad$. 36

Nothrus sp. attacking gypsy moth, . . . . . . . 404

Nozzle, cyclone, for burning, . . . . . • . $\quad$. 120

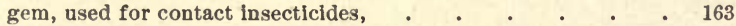

Nozzles for spraying, . . . . . . . $147,149,150,154$

Number of caterpillars from single egg-clusters, . . . $\quad$. 297

Nun moth, erostatic hairs of, . . . . . . . 301

damage by (see Lymantria (Liparis) monacha), . . . . 130

Nursery stock, where shipped, . . . . . . . 108

Nuthatch attracted by meat, . . . . . . . . 229

feeding hablts of, . . . . . . . . . . . 231

white-breasted, attacking the gypsy moth, . . . . . 208

Nymphaa odorata, . • . . . . . . . 317 
O.

Oak attacked by gypsy moth in Europe,

leaf, area of, .

Obstacles to extermination,

Ochsenheimer, "Schmett. v. Europa,"

Ocneria dispar, . . . . . . . . . . 255

act to provlde against depredations by, . . . . . 47

See Gypsy moth.

Ocneria rubca, peculiar structure on fore wings of, . . . . 342 studies on, . . . . . . . . . . . . 256

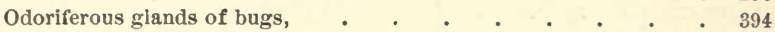

Oil, creosote, for destroying eggs, . $\quad$ • . . . $\quad$ • $63,123,410$

hose, . . . . . . . . . . . . 120

paraffine gas, used for burning, . . . . . . . 120

paraffine gas, used on eggs, . $\quad . \quad+\quad . \quad . \quad . \quad . \quad . \quad 4417$

rape, with tar for banding trees, . $\quad . \quad$. $\quad . \quad . \quad .285$

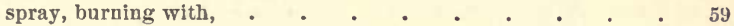

Old World, injuries of gypsy moth in, . . . . . 273

Orchards attacked by gypsy moth, . . . . . . 274

extermination of moth in, . . . . . . . . 248

Orenboorg, ravages of gypsy moth at, . . . . . $\quad 280$

Organization of committee, $\quad$. $\quad . \quad . \quad . \quad . \quad . \quad . \quad .38,49$

of field force, $\quad . \quad+\quad . \quad . \quad . \quad . \quad . \quad . \quad .50$

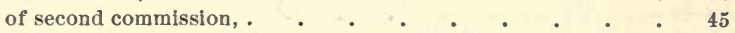

Orgyia definita, influence of environment on, . $\quad$. $\quad$. $\quad 273$

leucostigma, . . . . . . . . . . . 402

compared with gypsy moth, . • . . . . . . 272

destroyed by spraying, . . . . . . . . . 140

increase due to English sparrows, $\quad$. $\quad$. $\quad . \quad 235$

Oriole, Baltimore, attacking the gypsy moth, - . $6,213,225,227,237$

Osborn, Prof. Herbert, identification of mites, . . . . . 404

Outbreaks of the gypsy moth checked by birds, . . . . 205

of the gypsy moth in 1889, . . . . . . . . 10

Oven bird attacking the gypsy moth, . . . . . . 208, 219

Oviposition of gypsy moth, . . . . . . . . . 363

Ovipositor of gypsy moth, . $\quad$ • . . . . . . . 342

P.

Packard, Dr. A. S., infested region visited by, . $\quad$ - $\quad$. $\quad$. 69 report of (Appendix D).

Paint and creosote tube, . . . . . . . . . 124 for use in marking trees, . . . . . . . 51,124 ,

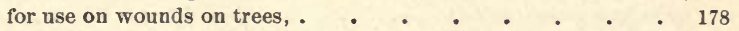
town section bounds marked with, . . . . . . 50

Paleacrita vernata, . . . . . . . . . . 402

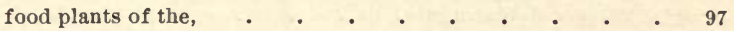

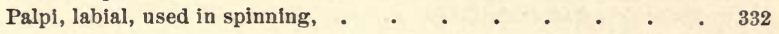

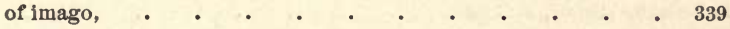


Panzer on ravages of gypsy moth,

Paraffine gas oil for burning, .

gas oll on eggs, . . .

Parasitized pupæ, per cent. of, . . . . . . . . . . 336

Parasites of gypsy moth, . . . . . . . . . 375

ald given by, in Europe, . . . . . . . . 284

breeding, on many hosts, . . . . . . . . 377

destroyed by birds, . . . . . . . . $220,241,376$

dipterous, . . . . . . . . . . . . 385

hymenopterous, . . . . . . . . . . $\quad$. 375

importation of, . . . . . . . . . . . 406

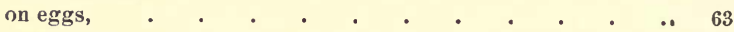

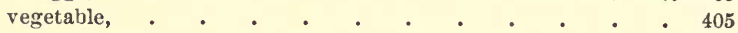

Parexorista sussurans, . . . . . . . . . . 392

Paris green, . $\quad$. $\quad$. $39,56,58,59,80,137,138,417,419,473$

analyses of, . . . . . . . . . . . 492

Paris green and lime, analyses of, . . . . . . . 492

comparative effects of, . $\quad . \quad$. $\quad . \quad$. $\quad . \quad$. $\quad . \quad .473$

experiments with,. $\quad . \quad+\quad . \quad+\quad . \quad . \quad . \quad . \quad .436$

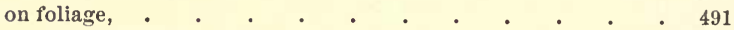

Parasitigena segregata, . . . . . . . . . $\quad$ • 392

Park, Franklin, Boston, colony of gypsy moths found in, . . $\quad 70$

reservation, Metropolitan, moths found in, . . . $\quad$. 86

Parks, possible danger to, . . . . . . . . . 87

Parthenogenesis, . . . . . . . . . . . 365

Parus atricapillus. See Chickadee.

major, . . . . . . . . • • . 233

Passerina cyanea,. . . . . . . . . . . . . $\quad .207$

Pearce, W. J., on parthenogenesls, . . . . . . . $\quad$ • 367

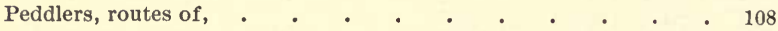

Pedestrians, distribution of the gypsy moth by, . . . 103

Pekin, gypsy moth occurring at, . . . . . . 268

Penza, ravages of the gypsy moth in, . . . . . . 281

Pergande, Theo., identification of ants by, . . . . . 381

Perillus circumcinctus, . . . . . . . . . . 393

Perkins, Dr. G. H., Infested region visited by, . $\quad . \quad$ • $\quad . \quad$. 79

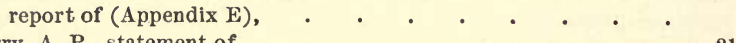

Perry, A. P., statement of, . $\quad$. . . . . . . . 21

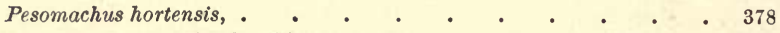

Petition by city officials of Malden, . . . . . . . . 36

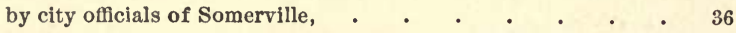

by Essex County Agricultural Soclety, . • • . . 36

by executive committee of the State Board of Agriculture, $\quad .36,78$

by Massachusetts Horticultural Soclety, . . . . . 36

by selectmen of Arlington, . . . . . . . . . . 36

by selectmen of Everett, . . . . . . . . . 36

by selectmen of Stoneham, . . . . . . . . 36

by selectmen of Wakefield, . . . . . . . . . 36

by selectmen of Winchester, . . . . . . . . 36

by State Board of Agriculture, . . . . . . . 36

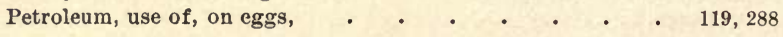


Pewee, wood, attacking the gypsy moth, .

Phalana (Bombyx) dispar, .

Phalangium dorsatum,

Phenol on eggs,

Phidippus galathea,

Phidippus tripunctatus, .

Phloeothrips, .

Phœbe attacking the gypsy moth,

207,227

220,376

- 255

- 404

123,414

405

404

404

207,227

Phora incisuralis, .

scalaris,

setacea,

Phorocera,

Phorocera concinnata, .

Phosphoric acid deposits in caterpillar,

Pierce, G. T., statement of,

Pierce, Richard, statement of,

Pierce, W. A., at conference on gypsy moth (Appendix A),

Pieris rapa, damage from,

Pimpla flavicans, .

instigator,

pedalis, .

tenuicornis,

Pines attacked by the gypsy moth,

attacked by the gypsy moth in Europe,

Pipilo erythrophthalmus,

Piranga erythromelas, .

Pitch, trees banded with,

Plants attacked by the gypsy moth;

in Europe,

not attacked by the gypsy moth, .

Plaster of Paris, use of, on trees,

Platynus limbatus,

Plummer, Mrs. A. H., statement of, :

Podisus cynicus,

serieventris,

early stages of,

Poisoned larvæ, analyses of,

Poland, ravages of the gypsy moth in forests of,

Police regulations, enforcement of,

Polistes pallipes, .

Poltava, ravages of the gypsy moth in,

Poiygamy of the gypsy moth,

Pomerania, insect outbreak in, . .

$21,29,43$

45

270

378

378

375,377

375

86,277

282

207

207

$58,70,316,318,323$

325

323

188

384

$29,31,42$

392

393

396

474

283

$.54,55$

378

281

343

205

317

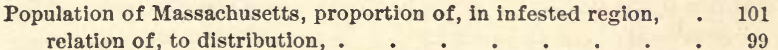

Porchinsky, Dr. J., on means of distributing the gypsy moth, . $\quad 286$

on ravages of the gypsy moth in the Crimea, . . . . 279

Porthetra dispar, . . . . . . . . . . . 255

systematic position of (see Gypsy moth), . . . . . 256 
Post offices, frames placed in,

Potassic cyanide on eggs, . . . . . . . . . 413

Potato beetle killed by arsenate of lead, . . . . . . 144

Pratt, Augustus, elected a member of the committee, ..$\quad$. 76

Predaceous Coleoptera, . . . . . . . . . 381

Diptera,. $\quad . \quad . \quad . \quad . \quad . \quad . \quad . \quad . \quad . \quad . \quad .392$

Hemiptera, • . • • • • • . . . 392

Hemiptera attacked by crows, . . . . . . 394

Hemiptera, how reared, . . . . . . . . 394

Hymenoptera, . . . . . . . . . . 378

insects, aid given by, . $\quad . \quad$. $\quad . \quad$. . . . 284

insects destroyed by birds, . . . . . . . . 241

insects, Dr. Altum on importation of, . $\quad . \quad$. $\quad . \quad$. $\quad .288$

Press, State, assistance given by, . . . . . . . $\quad$. 199

Primary distribution of the gypsy moth, . . . . . 104

Printens' ink used in protecting trees from gypsy moth, . . . 34

Process of emerging, . . . . . . . . . . . 336

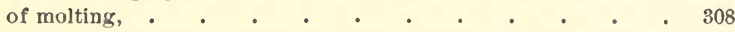

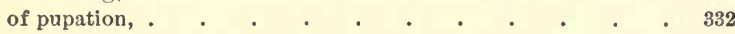

Progress of extermination, . $\quad . \quad$. $\quad . \quad . \quad . \quad . \quad . \quad .244$

Protection of birds, law for, . . . . . . . . . 206, 242

Protoparce celeus, granules in, . . . . . . . . $\quad$. 370

Pruning, effects of improper, . . . . . . . . 175

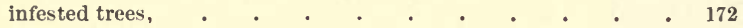

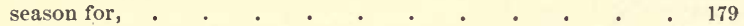

Preyssler, on ravages of the gypsy moth, . . . . . 275

Pteromalus boucheanus, . . . . . . . . . 377

halidayanus, . . . . . . . . . 377

pini, . . . . . . . . . . . . . $\quad . \quad 377$

Ptinus brunneus, . . . . . . . . . . . 385

Pumps, Gould, . . . . . . . . . . 150

how repaired, $\quad . \quad+\quad . \quad+\quad . \quad \cdot \quad \cdot \quad \cdot 156$

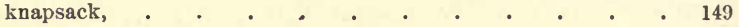

Pupæ of the gypsy moth, arsenic found in, . . . . $\quad$. 476

assembling by, . $. \quad . \quad . \quad . \quad . \quad . \quad . \quad . \quad .363$

attacked by parasites, . $. \quad . \quad . \quad . \quad . \quad . \quad . \quad 376$

birds feeding on, . $\quad . \quad$. $\quad . \quad$ • $\quad . \quad 7,208,228$

comparison of number of, destroyed annually, . $\quad$. $\quad .93$

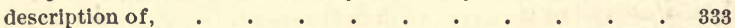

destruction of, $\quad . \quad . \quad . \quad . \quad . \quad . \quad .58,59,194$

emerging of imago from, . . . . . . . . . 336

parasites reared on, . . . . . . . . . 386

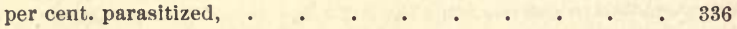

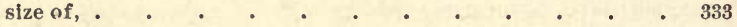

time spent in, . . . . . . . . . . 333

Pupation in the field, . . . . . . . . . . 335

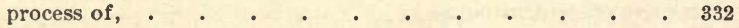

Purple grackle attacking the gypsy moth, . . . . . 207

Pyroligneous acid on eggs, . . . . . . . . . 416

Pyrophila pyramidoides, . . . . . . . . . 402

Pyrrharctia isabella, . . . . . . . . . . 377 
Q.

Quercus pedunculata attacked by gypsy moth, PAGE rubra, leaf area of,. . . . . . . . . 495

Quiscalus quiscula, . . . . . . . . . . . 207

R.

Railroad sidings, inspection of, . . . . . . . . . 111

trains obstructed by gypsy moth, . . . . . . . 280

Railroads running through the infested district, . . . 101,102

Rana silvatica,

Ransom, Miss M. M., statement of, . . . . . . 20, 27, 29

Ratzeburg on ravages of the gypsy moth, . . . . . $\quad 277$

Raupenleim bands, . . . . . . . . . 129-135

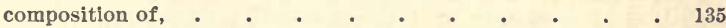

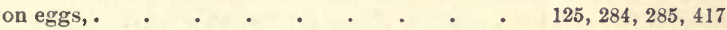

trees banded with, . . . . . . . . $64,69,136$

Ravages of the gypsy moth in Massachusetts, . . . . . 7-44

of the gypsy moth in Old World, . . . . . . . 273

Rawson, W. W., appointed commissioner,. $\quad$ - . . . . 38

Reaumer on birds destroying the gypsy moth, . . . . 232

Red-eyed vireo attacking gypsy moth, . . . . . 207, 216

Redstart, American, attacking the gypsy moth,. . 208, 219, 227

Reduction of infested area,. . . . . . . . . 245

Region, infested. See Infested region.

Regulations concerning the gypsy moth (Appendix B).

Reid, H. N., experiments by, . . . . . . . . 418

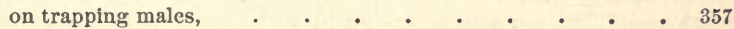

Reply of State Board to order of Representative W. J. D. Bullock, 73

Reports of inspectors,. . . . . . . . . . . $\quad .51,52$

of State Board of Agriculture, extracts from, $\quad 65-67,78,81,82$

of visiting entomologists (Appendix E), . . . . .

Reproductive powers of gypsy moth, . . . . . . . 245

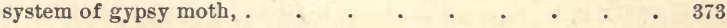

Respiratory system of gypsy motb, . • • • • • • : 372

Restriction of distribution of gypsy moth,. . . . . . 114

Retractile tubercles of gypsy moth larva, . . . . . 302

secretion from, . $\quad . \quad+\quad \cdot \quad \cdot \quad \cdot \quad \cdot \quad 304$

Rhynchagrotis alternata, . . • • . . . . 400,402

Riazan, ravages of gypsy moth in, . . . . . . 281

Richardson, D. M., statement of, . . . . . . $.12,27$

Riegel, on ravages of gypsy moth, . . . . . . $\quad$ - 277

Riley, Prof. C. V., at conference on gypsy moth (Appendix A), . 45

infested district visited by, . . . . . . . . 56

on assembling In the bombycidæ, . . . . . . 357

on insectivorous birds, . . . . . . . . . 207

on occurrence of gypsy moth in America, . . . . . 3

Rimrod, C. J., on ravages of gypsy moth, . • . . . . 275

Ritzems-Boz, Dr. J., on gypsy moth In Holland, • • . 268, 283

Road commissioners of Medford, meeting of, . • . . . 33 
Roads, destruction of eggs along,

Robert, M., on tree scraping, . . . . . . . . 191

Robin, American, attacking the gypsy moth, . . . 208, 216, 227 destroying predaceous insects, . . . . . . . 241

destruction of silk worms by, . . . . . . . . 6

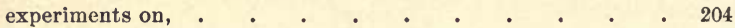

Rogers, J. H., statement of, . . . . . . . . 17

Romanoff on distribution of gypsy moth, . $\quad$. $\quad$. $\quad$. 268

Rose-breasted grosbeak attacking the gypsy moth, . . . 207, 219

Routes of transportation, study of the, . . . . . . 106

Rowe, C. H., on predaceous beetles, . . . . . $381,382,385$

Rubbish, destruction of, . . . . . . . . . . . 193

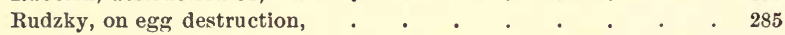

Rules and regulations concerning the gypsy moth (Appendix B), .

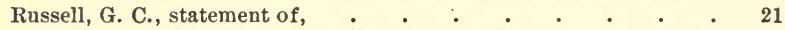

Russell, Gov. Wm. E., removal of salaried commission by, . $\quad$ - 45

Russell, Mrs. E. M., statement of, . . . . . . . 21

Russia, occurrence of gypsy moth in,. . . . . . . . 268 ravages of gypsy moth in, . . . . . . . 279,280

Ryder, Mrs. P. N., statement of, . . . . . . . 43

\section{S.}

Salisbury on occurrence of gypsy moth in England, . $\quad$ • $\quad$ - 268

Samara, ravages of gypsy moth in, . . . . . . . 281

Samuels, E. A., record of destruction of silkworms by birds, . $\quad 6$

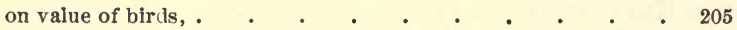

Sanderson, L. B., notes on wood thrush, . . . . . . $\quad$. 236

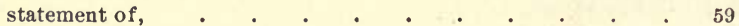

Sap, clrculation of, in trees, . . . . . . . . . $\quad$. 175

Saratov, ravages of gypsy moth in, . . . . . . 281,282

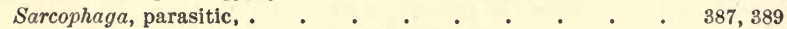

Sarcophaga affinis, . . . . . . . . . . . 392

Sargent, Dr. C. S., translation of Des Cars' “Tree Pruning” by, . 179

Sargent, F. W., elected member of the committee, . $\quad$ - $\quad 76$

Saugus, gypsy moth found in, . . . . . . . $53,86,87$

Saxony, ravages of gypsy moth in, . . . . . . 274

Sayornis phobe. See Phœbe.

Scales of gypsy moth wings, form of, . . . . . 341,342

Scariet tanager attacking the gypsy moth, . • • • . 207,227

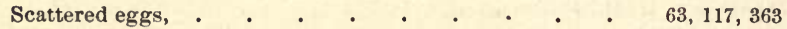

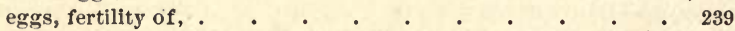

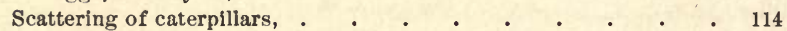

Schrffer, J. C., on ravages of gypsy moth in Saxony, . . $\quad$. 274

Scheffer, M., on use of burlap, . . . . . . . . 171

Scheuerien, Dr., on disease of nun moth, . . . . . . 405

Schmidberger on egg-killing, . . . . . . . . 117

Schrader, F. C., experiments by, . . . . . . 360,418

Schrank "Fauna Boica," . . . . . . . . . 255

Scolytidæ, attacking trees, . . . . . . . . 190 
Scolytus destructor attacking trees in England,

Scraping of eggs from trees, method of, discarded, . . . . 63

of eggs from trees, recommended by Europeans, . . $\quad 292$

of trees, . . . . . . . . . . . . . . 189

of trees, value of, . $\quad . \quad+\quad . \quad . \quad . \quad . \quad . \quad . \quad .172$

Scudder, Samuel, at conference on gypsy moth (Appendix A), $\quad 45$

Season for pruning, • • • • • • • • • • 179

larval, distribution in, . $\quad . \quad$. $\quad . \quad . \quad . \quad . \quad .110$

Second brood of the gypsy moth, . . . . . . 86,295

"Section" books, record of infested estates kept in, . . . 52

Section 8, Medford, description of (Appendix C).

Sections, towns divided into, . . . . . . . . . . . . 49

Seitz, raupenleim machine, . . . . . . . . . . 133

Seopru, Georg, on ravages of gypsy moth in the Crimea, . . . 280

Sessions, Hon. Wm. R., appointed member of committee, . . 49, 76

at conference on gypsy moth (Appendix A).

chosen chairman of committee, . . . . . . . 49

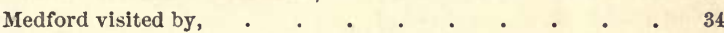

member of committee sent to Washington, . $\quad$. $\quad . \quad$. 83

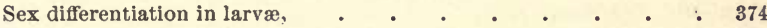

Sexual dimorphism of gypsy moth, . . . . . . . 272

Shade trees, how sprayed, . . . . . . . . . 158

Shaler, Prof. N. S., appointed member of committee, . . $\quad$. 49

assistance given by, . . . . . . . 72

at conference on gypsy moth (Appendix A), . . . . 45

interview with Mr. Trouvelot, . . . . . . . 4

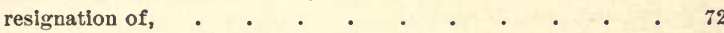

Shaw, H. J., moth trap invented by, . . . . . . $\quad 360$

observations on red-eyed vireo, . . . . . . . . 221

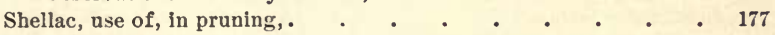

Sherman, J., statement of, . • . • • • . • 20

Sherman, Walter, statement of, . $\quad . \quad . \quad . \quad . \quad . \quad .20,26$

Shipov, ravages of gypsy moth in, . . . . . . 282

Sialia sialis. See Blue bird.

Siberia, occurrence of the gypsy moth in, . • . . 267, 268, 280

Sidings, railroad, inspection of, . . . . . . . . 111

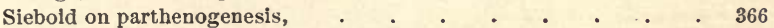

Silk, amount spun by gypsy moth caterpillars, . . . . . 331

glands of caterpillars, . . . . . . . . 370

Silkworms destroyed by birds, . . . . . . . . . 6

Silpha quadripunctata, . . . . . . . . . . 287

Simbeersk, ravages of gypsy moth in, . . . . . 281,283

Sinea diadema, . . . . . . . . • . . 405

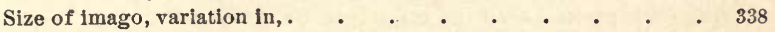

Skunk attacking the gypsy moth, . . . . . . . 404

Smith, Prof. J. B., infested region visited by, . . . . . $\quad$. 69

on insectivorous birds, . . . . . . . . 207

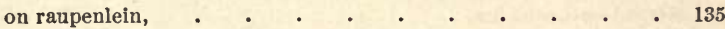

on systematic position of dispar, . . . . . . . 256

report of (Appendix D).

Smith, J. W., data furnished by, concerning wind, . . . . 350 
Snowdon, W. H., statement of, .

PAGE

Soap powders, use of, as contact insecticide,

$13,18,25,30$

Soda, arsenate of, experiments with, .

163,485

(a)

Somerville, petition presented by city officials of, . . . . 36

Sorauer, Dr. Paul, on tree pruning, . $\quad$. _ . . . $\quad$. 181

South, Richard, on extermination of gypsy moth in England, . . 269

Spain, occurrence of gypsy moth in, . . . . . . . 268

Sparrow, chipping, feeding on gypsy moth caterpillars, 207, 215, 226, 227

English, attacking the gypsy moth, . . . . . . 208

English, feeding on gypsy moth eggs, . . . . . . 231, 239

English, introduction of, . . . . . . . 233, 234

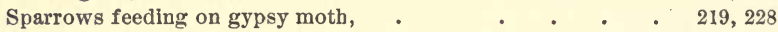

Speyer on distribution of gypsy moth, . . . . . . 267

Sphinx drupiferarum, . . . . . . . . . . .383

Spiders attacking gypsy moth, . . . . . . . 404, 405

"Spiegel," destruction of, . . . . . . . . . . 284

Spines on wings of gypsy moth, . $\quad . \quad$. $\quad . \quad . \quad . \quad .341$

Spinney, Mrs. F. T., statement of, · . . . . 12, 18, 29, 32

Spinning habits of caterpillars, . . . . . 102, 278, 330, 332

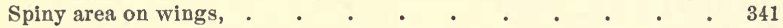

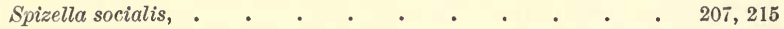

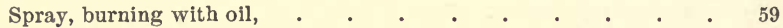

Spraying against gypsy moth, . . . . . . . . 157

apparatus, . . . . . . . . . . $145-156$

benefit to fruit crops from, . . . . . . . . 60

burlapping substituted for, . . . . . . . . 64

caterpillars distributed by, . . . . . . . . 113

caterpillars killed by, . . . . . . . . $57,58,64$

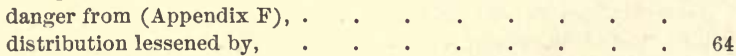

poisons for use in, $\quad$. $\quad . \quad$. $\quad . \quad$. $\quad .55,417,477$

not effectual as an exterminative method, . $\quad$ - . . 56

number of moths destroyed by, . . . . . . . . 92

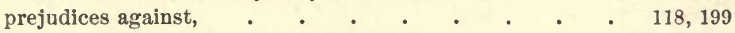

recommended by entomologists (Appendix A), . . . . 45,55

rules concerning (Appendix B).

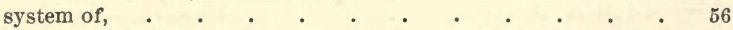

time of, . . . . . . . . . . . . 156,157

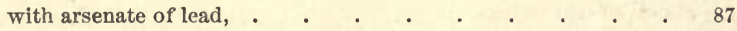

with arsenate of lead, effectiveness of, . $\quad . \quad$. $\quad . \quad . \quad .80$

with arsenical insecticides, failure of, as a means of extermina-

tíon, . . . . . . . . . . . 62

with contact insecticides, . . . . . . . . . $\quad . \quad 57$

with Paris green. See Paris green.

with Paris green, opposition to, . . . . . . . 56

outflits, . . . . . . . . . 55,140

Spread of gypsy moth, comparison with that of canker worm, $\quad 97$

efforts to prevent the, . . . . . . . . . 79

in twenty years, . . . . . . . . . . . 5

in woods, . $\quad . \quad+\quad . \quad . \quad+\quad . \quad+\quad . \quad+115$

slow, . . . . . . . . . . . 245 
Squirrels, eggs scattered by,

Starling attacking nun moth in Europe, . . . . $\quad$ 208, 209

State Board of Agriculture. See Board of Agriculture.

Statements of citizens concerning the gypsy moth (Appendix G), 7, 8-10, $11-13,14-32,33,40-44,59$

Station, experiment, erection of, 87,406

Staudinger on distribution of gypsy moth, . $\quad . \quad . \quad . \quad 267$

Steatoda borealis, . . . . . . . . . . . 405

Stepbens, "Illustrations of British Entomology," • • • . 255

on occurrence of gypsy moth in England, . $\quad$ • $\quad . \quad 2 \quad . \quad 269$

Stephenson, Dr. F. B., translation of Russian works on gypsy moth

by, . . . . . . . . . . . . 268

Stetson, John, statement of, . . . . . . . . . 10

Stetson, S. S., elected a member of the gypsy moth committee, . 84

Stockholm, occurrence of gypsy moth at, . . . . . . 267

Stomach examination of cuckoo, . . . . . . . 212

examination of toad, '. . . . . . . . . 405

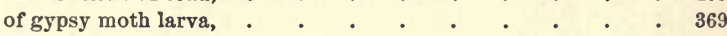

Stoneham, petition presented by selectmen of, . $\quad . \quad$. $\quad . \quad$. 36

Stone wails, comparison of yearly work on, $\quad$. $\quad . \quad$. 93

St. Petersburg, non-occurrence of gypsy moth at, . • . 268

Streams, caterpiliars distributed by, . . . . . . . . 98

Studies on systematic position of dispar, . . . . . . . $\quad$. 256

Study of the methods and routes of transportation, . . . . 106

Sulpho-naphthol, . . . • • • • • • . 4484

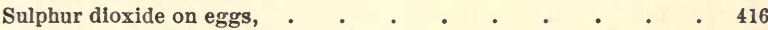

Summer pruning,. . . . . . . . . . . . . 184

Swallows, house, driven away by sparrows, . . . . 234

Swampscott, outbreak of the gypsy moth in, . . . . . 58

Sweden, occurrence of gypsy moth in, . . . . . . 267

Swill-takers, distribution of the moth by, . . . . . . 109

Swinton on sound producing insects, . . . . . . . . 341

Syrphus sp. attacking the gypsy moth, . . . . . . 405

Systematic position of dispar, . . . . . . . . 256

\section{T.}

Tachina, European parasites of gypsy moth, . . . . 392

Tachinids captured by birds, . . . • . • . • 241

parasitic, . . . . . . . . . . . 387

Tambov, ravages of the gypsy moth in, . . . . . 281

Tanager, scarlet, attacking the gypsy moth, . . . . 207, 227

Tangl, Dr., on disease of nun moth, . . . . . . . 405

Tar and rape oil bands, . . . . . . . . . 285

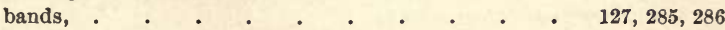

coal, use of, in tree pruning, . . . . . . $177,182,186$

used on eggs, . . . . . . . . . . . 125,414

Tarred burlap, use of, on trees, . . . . . . . . 188

paper, trees banded with, . $\quad$. $\quad$. $\quad$. . . 28

Taylor, Wm., statement of,. $\quad$. $\quad . \quad$. $\quad . \quad 8,19,25,28,31$ 
Teaming from infested region, .

Telea polyphemus,.

Tent caterpillars attacked by warblers

caterpillars destroyed by Baltimore oriole, .

caterpillars destroyed by spraying,

caterpillars killed by arsenate of lead,

Terns as insect destroyers, .

Territory infested. See Infested region.

Thaxter, Dr., on vegetable parasites, .

Thelymorpha vertiginosa,

Theronia melanocephala,

destroyed by wood pewee,

habits of,

Thomixus sp. attacking the gypsy moth,

Thrush, brown, feeding on the gypsy moth,

wood, feeding on the gypsy moth,

Tideman on ravages of the gypsy moth in Kazan,

Time between molts,

in pupa stage,

of feeding,

of hatcling,

record of men's,

required for emerging,

spent in laying,

spent in mating,

spent in spinning, .

Tin, use of, on trees,

Tiresias serra,

Titmouse attacking the gypsy moth in Europe, .

attracted by meat,

great, attacking other birds (see chickadee),

Tolype velleda,

Torches, kerosene, for burning caterpillars, . . . . . 39

Tortricids, British, dark color of, . . . . . . $\quad 271$

Tortrix fumiferana attacked by Pimpla pedalis, . . . $\quad 377$

Tower, W. L., notes on caterpillars, . . . . . . 169, 329

on predaceous Hymenoptera, . . . . . . 379

Towhee bunting, feeding on gypsy moth imagoes, . . . 225,227

Towns and cities from which false alarms have been' received, . 201

divided into sections, . . . . . . . . 50

efforts concentrated in outlying, . . . . . . . 53

infested, citizens from, present at hearings, . . . . 84

infested, proportionate numbers of gypsy moths in, . $\quad$. 99

inner, increase of the moths in, . . . . . . . . 92

inspected beyond infested area, . . . . . . . . 198

necessity of inspecting apparently cleared, . . . . . 80

worst infested, destruction of eggs in, . . . . . 69

Traffic, danger from, . . . . . . . . 109

distribution of the gypsy moth by, . . . . . . 102 
Traffic, ratio of distribution by, PAGE study of, . . . . . . . . . . . 109

Transportation, a study of the methods and routes of, . . . 106 by freight, . • . • • • • • • • . 110

Trapping of male moths, results of, . . . . . . 80,357

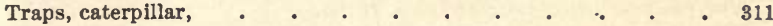
moth, . . . . . . . . . • . 358,360

Travel, danger from, to Boston, . . . . . . . . 107 direction of, from infested centre, . . . . . . 107 lines of, . . . . . . . . . . . 108

Travelling of young larvæ, . $\quad . \quad$. $\quad . \quad . \quad . \quad . \quad . \quad 310$

Treadwell, Professor, experiments on robins, . . . . . 204

Tree creepers attracted to meat, . . . . . . . . 229

Tree ink, trees banded with, . . . . . . . . 64, 128

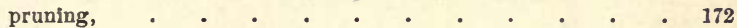

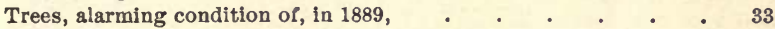

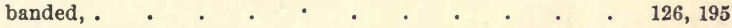
banded with burlap, $\quad . \quad$. $\quad . \quad . \quad . \quad . \quad . \quad .69,85,167$ banded with raupenleim, . . . . . . . . 64

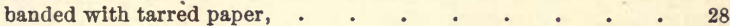
banded with tree ink, . . . . . . . . . . 64 comparison of yearly work on, . . . . . . . . . 92,93 defoliated by the gypsy moth, . . . . . . $.57,85$ destroyed by the gypsy moth, . . . . . . 23,70,274 hollow, treatment of, . . . . . . . . 63,187

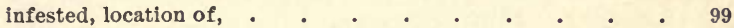
infested, marked with white paint, . . . . . . $\quad .51$ leaf area of, . . . . . . . . . . . . 494 per cent. of pupæ in, . . . . . . . . . 335

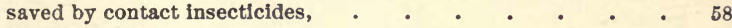

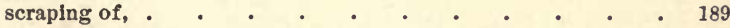

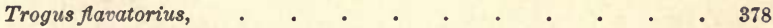

Trombidium bulbipes, . $. \quad . \quad . \quad . \quad . \quad . \quad . \quad . \quad .404$

Trouvelot, Leopold, interview with Prof. N. S. Shaler, . . . 4 introduction of the gypsy moth into America by, . . . 3 residence in Medford, . . . . . . . . . 4

Tube, paint and creosote, . $\quad . \quad$. $\quad . \quad$. . . 124

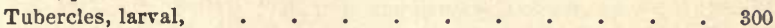
retractile, . . . . . . . . . . 303, 304

Tubeuf, Dr., on disease of nun moth, . . . . . . . 405 Turpentine for destroying eggs, . . . . . . . . . 123,416 Tussock moth destroyed by spraying, . . . . . . 140 increase of, due to sparrows, . . . . . . . . 235

Tutt, J. W., on the extermination of the gypsy moth in England, . 270

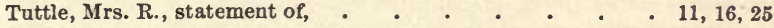
Tyrannus tyrannus, . . . . . . . . . 207 


\section{U.}

Uhler, Prof. P. R., description of Podisus serieventris, . . 399

determination of Hemiptera by, . . . . . . 400

Unfertllized females, eggs laid by, . . . . . $\quad 290,365,367$

United States Senate, resolve passed by the, . $\quad$. $\quad$. $\quad . \quad$. 83

Urates, presence of, in malpighian vessels of larvæ, . . . . $\quad$. 370

Useful birds, . • . • • • • • • • . 210

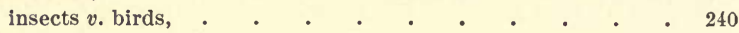

Utah, cricket ravages in, . . . . . . . . . 206

V.

Value of egg-eating birds, . . . . . . . . . 229

Vanessa antiopa, . . . . . . . . . . . 400,402

Variation in size of imago, . $\quad . \quad$. $\quad . \quad . \quad . \quad . \quad . \quad .338$

Vegetable parasites, . $\quad . \quad . \quad . \quad . \quad . \quad . \quad . \quad .288,405$

Vehicles inspected by police, . . . . . . . . 54

transportation of the gypsy moth by, . . . $\quad 39,102,103,107$

Vertebrates, insectivorous, . . . . . . . . . 404

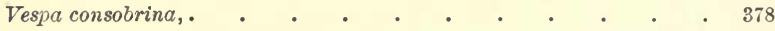

germanica,. $. \quad . \quad . \quad . \quad . \quad . \quad . \quad . \quad . \quad .378$

maculata, . . . . . . . . . . . 378

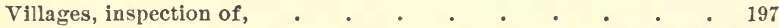

Vireo, red-eyed, attacking gypsy moth caterpillars, . . 207,216, 225

white-eyed, attacking the gypsy moth, . . . . . 208

yellow-throated, attacking the gypsy moth, . . $\quad 208,217,227$

Vitality of dipterous larvæ, . . . . . . . . . . . . . 386

of gypsy moth eggs, . . . . . . . . . 279,291

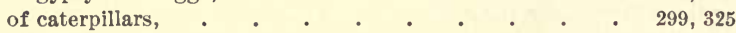

of predaceous bugs, . . . . . . . . . . . 393

Volsk, ravages of the gypsy moth in, . . . . . . . $\quad 282$

Voronezh, ravages of the gypsy moth in, . . . . . 281

\section{W.}

Wachtl and Kornauth on disease of nun moth, . . . . 405

Wadding bands, Klausen's experiments with, . . . . $\quad$ - 286

Wakefleld, petition presented by selectmen of, . . . . . 36

Walker, J. J., on the distributlon of the gypsy moth, . . $\quad$ - 268

Wallace, Mrs. B., statement of, . . . . . . . . 44

Walls, stone, comparison of yearly work on, . $\quad$. $\quad$ • $\quad$. 93

Warbler, black and white, attacking the gypsy moth, . . 208,225

black-throated green, attacking the gypsy moth, . . . 208

chestnut-sided, attacking the gypsy moth, . . . • . 208

creeping, feeding on the gypsy moth, . . . . . . 227

Maryland yellow-throated, attacking the gypsy moth, . 208

yellow, attacking the gypsy moth, . . . . . 208, 227

Ward, A. H., suggestions on insecticides by, . . . . . 142

Ware, E. C., directions concerning care of spraying machines, . 155 
Warsaw, occurrence of the gypsy moth in,

Wasps, predaceous,

Water birds as insect destroyers,

distribution of the gypsy moth by,

Wax, grafting, use in pruning trees, .

Weather, effect of, on the moth, .

egg destruction hindered by the, .

influence on assembling,

Webster, Prof. F. M., spraying $v$. bees,

Weed, Prof. Clarence M., infested reglon visited by,

on feeding habits of the gypsy moth, report of (Appendix D).

Weijnbergh on parthenogenesis,

Weir, J. Jenner, on the extermination of the gypsy moth in England,

Wellington, Dr. Chas., on Paris green and llme,

Wellington, J. E., statement of, .

270

491

Weston, S. F., statement of, ${ }^{-} \cdot{ }^{-} 30,43$

W • • • • • • • • • • •

Whale-oil soap, use of, . . . . . . . . 163,485

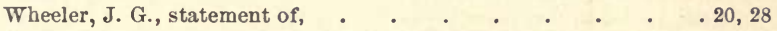

White-breasted nuthatch attacking the gypsy moth, . . . 208

White-eyed vireo attacking the gypsy moth, . . . . 208

Wiggin, Mayor, at conference on gypsy moth (Appendix A), . $\quad 45$

Wild, Miss Helen T., statement of, . . . . . . . 13, 21

Wilkes on occurrence of the gypsy moth in England, . . $\quad 268$

Williston, Dr. S. W., determination of dipterous parasites by, . 387

Winchester, outbreaks of the gypsy moth in, . . . . 58 petition of selectmen, . . . . . . . . . . 36

Wind, distribution of caterpillars by, . . . . . 9 98,301 influence of, on assembling, . . . . . . . . . . 346

Wingelmuller, C., on flying of female, . . . . . . 344

Wings, atrophy of female Orgyia, . . . . . . 273

effects of shellac on, . $\quad . \quad$. $\quad . \quad . \quad . \quad . \quad . \quad 351$

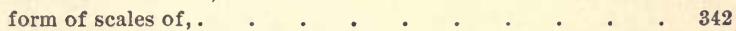

markings of, . . . . . . . . . . . . 337

not necessary to mating, . . . . . . . 356

sound producing apparatus on, . . . . . . . 341

spiny area of, . . . . . . . . . 341

"Winning" colony, pupation in, . . . . . . . . 335 second brood at, . . . . . . . . . 295

Winter oaks attacked by the gypsy moth, . . . . . 282 pruning, . . . . . . . . . . . 181

Woburn, area of infested woodland in, . $\quad . \quad$. $\quad . \quad 87$ woodland burned at, . . . . . . . . . 165

Wodzicki, Count, gypsy moth ravages on estate of, . . . 232

Wood, C. E., observations by, on the yellow-throated vireo, . 217,222

Wood, E. W., elected chairman of committee, . . . . $\quad 76$

Wooded region, inspection of, • • • • • • • • • 66

Woodland, area of, infested, . $\quad . \quad . \quad . \quad . \quad . \quad . \quad 87$

birds in infested, . $\quad . \quad . \quad . \quad . \quad . \quad . \quad . \quad 223$

burning of, . . . . . . . . . . . 165

colonies found in, . $\quad . \quad$. . . . . . . . 70 
Woodland, area of, defoliated by the gypsy moth, extermination of the gypsy moth in, . . . . . . 248 injury done to, by the gypsy moth, . . . . . $\quad$. 88

Woodpeckers attacking the gypsy moth, . . . . . . 207 attracted by meat,. . . . . . . . . . 229 eggs scattered by,. $\quad$. $\quad . \quad$. . . . . . 230,231 feeding habits of, . . . . . . . . . . . 210

Wood pewee attacking parasites, . . . . . . 220,376 attacking the gypsy moth, . . . . . . . 207

Woods, explanation of colonles in, . $\quad . \quad$. $\quad . \quad$. 107

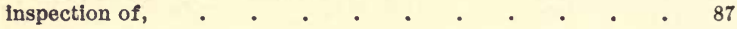

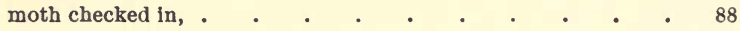
result of search of, $\quad$. $\quad$ - . . . . . 80

Wood thrush attacking the gypsy moth, . - . . . 208 distributing gypsy moth caterpillars, . . • . . . 236

Work, cost of, increased by delayed appropriations, . . . . 78 delayed by snow storms, $\quad . \quad$. $\quad . \quad . \quad . \quad .63,85$

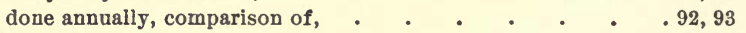
field, advice of Professor Fernald concerning, . • . . 57

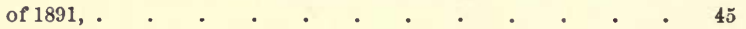

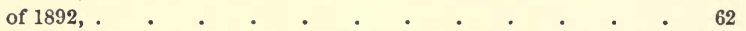

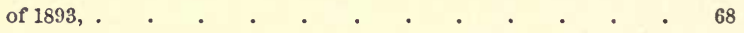

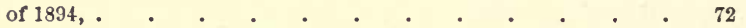

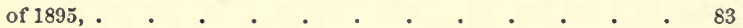

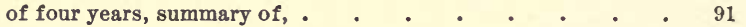

World's Columbian exposition, exhiblt at, . . . . . 200

Wounds from pruning, how healed, . . . . . . $\quad 177$

Wren, house, attacking the gypsy moth, . . . . • 208, 227

driven away by sparrows, . . . . . . . . 234

European, destroying eggs of the gypsy moth, . • . . 232

Wright, Walter, note ou liberation of English sparrows, . • • 234

\section{Y.}

Yaroschev on ravages of the gypsy moth, . . . . . 282

Yellow-billed cuckoo destroying the gypsy moth, . . . 207, 212

Yellow-throated vireo attacking gypsy moth caterpillars, . $\quad$ 208, 217, 227

Yellow warbler attacking the gypsy moth, . • • • • . 208

\section{Z.}

Zinc, arsenate of, experiments with, . . . . . . . 480

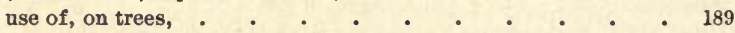

Zmiev, ravages of the gypsy moth in,. $\quad$. $\quad . \quad+\quad . \quad+\quad . \quad 282$ 





$$
\begin{aligned}
& S B \\
& 945 \\
& G_{9} F_{6}
\end{aligned}
$$<smiles>C1=CCC=C1</smiles>

$$
60^{g^{p^{\beta^{\beta}}}} .
$$











THE LIBRARY

UNIVERSITY OF CALIFORNIA

Santa Barbara

THIS BOOK IS DUE ON THE LAST DATE STAMPED BELOW.

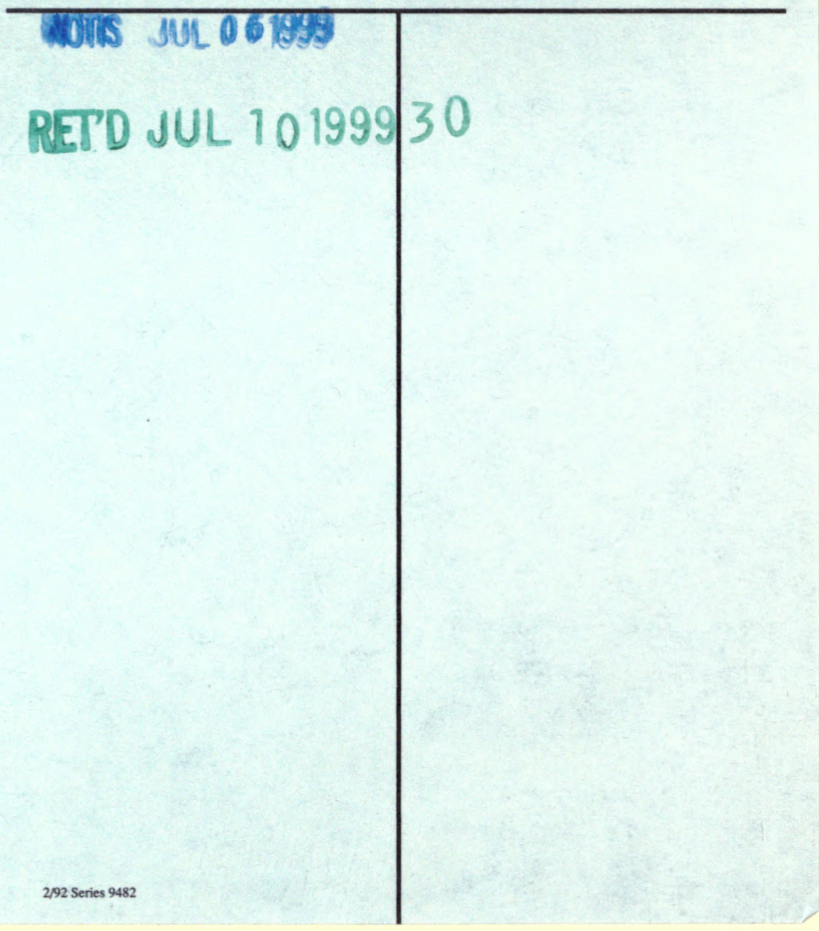




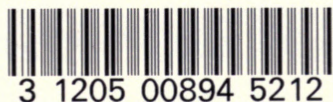

UC SOUTHERN REGIONAL LIBRARY FACILITY

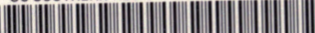

AA $000990659 \quad 5$ 
